\title{
La protection des transports de marchandises par mer en droit Ivoirien
}

Citation for published version (APA):

Firmin Aka, Y. (2021). La protection des transports de marchandises par mer en droit Ivoirien: sécurité de la marchandise et sûreté de la navigation. [, Maastricht University]. ProefschriftMaken Maastricht. https://doi.org/10.26481/dis.20210202yf

Document status and date:

Published: 01/01/2021

DOI:

10.26481/dis.20210202yf

Document Version:

Publisher's PDF, also known as Version of record

\section{Please check the document version of this publication:}

- A submitted manuscript is the version of the article upon submission and before peer-review. There can be important differences between the submitted version and the official published version of record.

People interested in the research are advised to contact the author for the final version of the publication, or visit the DOI to the publisher's website.

- The final author version and the galley proof are versions of the publication after peer review.

- The final published version features the final layout of the paper including the volume, issue and page numbers.

Link to publication

\footnotetext{
General rights rights.

- You may freely distribute the URL identifying the publication in the public portal. please follow below link for the End User Agreement:

www.umlib.nl/taverne-license

Take down policy

If you believe that this document breaches copyright please contact us at:

repository@maastrichtuniversity.nl

providing details and we will investigate your claim.
}

Copyright and moral rights for the publications made accessible in the public portal are retained by the authors and/or other copyright owners and it is a condition of accessing publications that users recognise and abide by the legal requirements associated with these

- Users may download and print one copy of any publication from the public portal for the purpose of private study or research.

- You may not further distribute the material or use it for any profit-making activity or commercial gain

If the publication is distributed under the terms of Article $25 \mathrm{fa}$ of the Dutch Copyright Act, indicated by the "Taverne" license above, 


\section{LA PROTECTION DES TRANSPORTS DE MARCHANDISES PAR MER EN DROIT IVOIRIEN : \\ sécurité de la marchandise et sûreté de la navigation}

AKA YAPO FIRMIN 


\section{Colophon}

(C) copyright Aka Yapo Firmin, Maastricht 2021

Printing: ProefschriftMaken || www.proefschriftmaken.nl

ISBN 9789464231090

All rights reserved. No part of this publication may be reproduced, stored in a retrieval system or transmitted, in any form or by any means, electronic, mechanical, photocopying, recording or otherwise, without prior permission of the author or the copyright-owning journals for previous published chapters. 
La protection des transports de marchandises par mer en droit ivoirien : sécurité de la marchandise et sûreté de la navigation

\section{DISSERTATION}

to obtain the degree of Doctor at the Maastricht University, on the authority of the Rector Magnificus,

Prof.dr. Rianne M. Letschert

in accordance with the decision of the Board of Deans, to be defended in public

on Tuesday, 2 February 2021, at 13.00 hours

by

Yapo Firmin AKA 


\section{Supervisor(s):}

Prof. dr. Michael G. Faure

Co-supervisor:

Dr. Jean-Claude Dakouri

\section{Assessment Committee:}

Prof. Mr. Gerrit van Maanen (chair)

Dr. Marta Santos Silva

Prof. dr. Steven van Garsse, University of Hasselt

Prof. dr. Wouter Verheyen, University of Antwerp 
La faculté de droit de l'université de Maastricht n'entend donner aucune approbation ni improbation aux opinions émises dans la présente thèse. Ces opinions doivent être considérées comme propres à leur auteur. 



\section{REMERCIEMENTS}

Je voudrais d'abord adresser mes sincères remerciements à l'ensemble des membres du jury, notamment à son Président et à tous les Suffragants pour leur contribution à l'amélioration de cette thèse.

Ensuite, au Professeur Michael G. FAURE, je voudrais exprimer ma profonde gratitude et mon entière admiration pour sa disponibilité, sa rigueur scientifique et ses encouragements permanents.

Au Docteur Yves Didier TIEBLEY et Docteur Jean Claude DAKOURI, tous deux enseignants à l'Université Houphouët Boigny d'Abidjan, merci du fond du cœur pour votre implication décisive à l'élaboration de cette thèse et votre appui à tous égards.

Je ne saurais oublier votre suivi régulier, vos observations pertinentes, vos conseils avisés et surtout vos nombreuses marques d'amitié qui m'ont sérieusement ému.

Je remercie enfin tous mes parents et amis qui, de près ou de loin, m'ont aidé, soutenu et contribué à la réalisation de cette œuvre.

A mon épouse et mes enfants, merci de votre soutien sans faille.

A mes Géniteurs : $\quad$ Reposez en paix.

Au Juge feu Adama BAMBA : Ta mémoire est à jamais honorée.

"Lorsque la calvitie arrive dans le village, à défaut de tête d'anciens pour l'accueillir, elle se pose sur la tête des jeunes».

Dicton Bété 


\section{LISTE DES PRINCIPALES ABREVIATIONS}

ADM : $\quad$ Armes de destruction massive.

AIDD : $\quad$ Association ivoirienne pour le développement du droit.

AIEA : $\quad$ Agence internationale de l'énergie atomique.

AIP : $\quad$ Agence ivoirienne de presse.

$\mathrm{Al}: \quad$ alinéa.

ALPC : $\quad$ Armes légères de petit calibre.

ARSTM : Académie régionale des sciences et techniques de la mer.

Art.: $\quad$ Article.

BIC : $\quad$ Bureau international pour la conteneurisation.

BTL : $\quad$ Bulletin des transports et de la logistique.

BIT : $\quad$ Bureau international du travail.

BT : $\quad$ Bulletin des transports.

CA : $\quad$ Cour d'appel.

CAA : $\quad$ Cour d'appel d'Abidjan.

Cass. Com : Cour de cassation chambre commerciale.

C. civ. : $\quad$ Code civil.

CDACI : $\quad$ Centre de droit des affaires et du commerce international.

CE : $\quad$ Conseil de l'Europe.

CEDEAO : Communauté économique des Etats de l'Afrique de l'ouest.

CEEAC : Communauté économique des États de l'Afrique centrale.

CEM-CI : $\quad$ Compagnie des experts maritimes de Côte d'Ivoire.

CESIM : $\quad$ Centre d'études de sécurité internationale et de maîtrise des Armements (France).

Cf. : $\quad$ Se référer à.

CIMA : $\quad$ Conférence interafricaine des marchés d'assurances.

Code IMDG : Code destiné à la réglementation du transport des marchandises dangereuses.

Code ISM : Code international de gestion de la sécurité.

Code ISPS : Code international pour la sûreté des navires et des installations Portuaires, en Anglais : "International Ship and Port Security Facility".

COGSA : $\quad$ Convention of Goods by Sea Act.

CSCJ : $\quad$ Cour suprême Chambre judiciaire.

D. : $\quad$ Recueil Dalloz.

CGG : $\quad$ Commission du Golfe de Guinée.

CIC : $\quad$ Centre Interrégional de Coordination.

CJCE : $\quad$ Cour de justice de la communauté européenne.

CMB : $\quad$ Convention de Montego Bay.

CMEAOC : Conférence maritime des Etats de l'Afrique de l'ouest et du centre.

CMMC : Centres multinationaux maritimes de coordination.

CMNI : $\quad$ Contrat de transport de marchandises en navigation intérieure.

CNRS : $\quad$ Centre national de la recherche scientifique.

CNUCED : Conférence des nations unies sur le commerce et le développement (en Anglais UNCTAD).

CNUDCI : Commission des nations unies pour le développement, le commerce et l'industrie. 
CRESMAC : Centre régional de sécurité maritime de l'Afrique centrale.

CRESMAO : Centre régional de sécurité maritime de l'Afrique de l'Ouest.

CSC : $\quad$ Convention internationale sur la sécurité des conteneurs

CSCJ : $\quad$ Cour suprême chambre judiciaire.

DGAMP : Direction générale des affaires maritimes et portuaires.

D.M.F. : $\quad$ Droit maritime français.

DTS : $\quad$ Droit de Tirage Spécial.

EMSA : $\quad$ Agence européenne pour la sécurité maritime en Anglais :

"European Maritime Security Agency».

EVP : $\quad$ Equivalent vingt pieds.

FCFA : $\quad$ Franc de la communauté financière africaine.

FCL : $\quad$ Conteneur chargé complet en Anglais : "Full container load».

FMI : $\quad$ Fonds Monétaire International.

Gaz. Pal : Gazette du Palais.

GRIP : $\quad$ Groupe de Recherche et d'Information sur la Paix et la Sécurité.

GSP : $\quad$ Groupe de Sécurité portuaire.

In : $\quad$ Dans.

In fine: $\quad$ A la fin.

Infra : Ci-dessous.

ITO : $\quad$ Sigle Anglais : "International Terminal Operators »

Incoterms : Ensemble de règles standardisées pour l'interprétation des termes utilisés dans les contrats de vente internationaux en Anglais : "International Commercial Terms".

JCP : Juris-classeur périodique.

JEICP : Juristes et Economistes Internationaux Contre la Pauvreté

JMM : $\quad$ Journal de la Marine Marchande.

JORCI : Journal officiel de la République de Côte d'Ivoire.

JORF : Journal officiel de la République française.

LCL : " "Less than container load", lot de marchandises occupant un volume moindre que celui offert par le conteneur utilisé.

LGDJ : $\quad$ Librairie générale de droit et de jurisprudence.

MARPOL Convention internationale de 1973 pour la prévention de la

73/78 : $\quad$ pollution par les navires modifiée par le protocole de 1978.

MSC : $\quad$ Comité de la sécurité maritime.

NIMASA : Agence nigériane chargée de la sûreté et de l'administration.

OHADA : Organisation pour l'harmonisation en Afrique du droit des affaires

OIT : $\quad$ Organisation internationale du travail.

OMAOC : Organisation maritime de l'Afrique de l'ouest et du centre.

OMCI : $\quad$ Organisation maritime consultative internationale.

OMD : $\quad$ Organisation mondiale des douanes.

OMI : $\quad$ Organisation maritime internationale.

ONU : $\quad$ Organisation des nations unies.

Op. cit. : Dans l'ouvrage précité.

PAA : $\quad$ Port autonome d'Abidjan.

Pêche INN : Pêche illicite, non déclarée et non réglementée.

PNUE : $\quad$ Programme des nations unies pour l'environnement.

PNUD : $\quad$ Programme des nations unies pour le développement. 
ReCAAP : $\quad$ Sigle Anglais : "Regional Cooperation Agreement on

Combating Piracy and Armed Robbery".

RID : $\quad$ Revue ivoirienne de droit.

SETV : $\quad$ Société d'exploitation du terminal de Vridi.

SOLAS : $\quad$ Convention pour la sauvegarde de la vie humaine en mer.

STCW : Convention internationale sur la formation des gens de mer et de délivrance des brevets et de veille.

SUA Convention pour la répression d'actes illicites contre la sécurité de la navigation maritime de 1988.

Supra : Ci-dessus.

T. com : $\quad$ Tribunal de commerce.

UCAO : $\quad$ Université catholique de l'Afrique de l'ouest.

UE : $\quad$ Union européenne

UEMOA : Union économique et monétaire ouest africaine.

UNCLOS : Convention des Nations Unies sur le droit de la mer en Anglais : "United Nations Convention on the Law Of the Seas".

WWW : $\quad$ world wide web.

ZEE : $\quad$ Zones économiques exclusives. 


\section{SOMMAIRE}

\section{Première Partie : L'EXISTENCE D'UNE LEGISLATION CENSEE PROTEGER LES TRANSPORTS DE MARCHANDISES PAR MER...43}

Titre 1 : Un cadre législatif consacré aux transports de marchandises par mer .46

Chapitre $1:$ Les normes législatives internationales et nationales de protection de la marchandise.

Chapitre 2 : Les normes législatives de lutte contre les infractions liées au trafic maritime.

Titre 2 : Une analyse critique du cadre législatif des transports de marchandises par mer.

Chapitre $1:$ Les approximations des normes de protection de la marchandise : genèse et limites.

Chapitre 2 : Les insuffisances de la lutte contre l'insécurité au regard de la persistance des infractions maritimes.

Deuxième Partie : LES PERSPECTIVES D'UNE AMELIORATION DE LA LEGISLATION EXISTANTE EN VUE DE SON EFFICACITE....196

Titre 1 : L'analyse du cadre législatif des transports de marchandises par mer en droit comparé.

Chapitre 1 : L'analyse des normes de protection de la marchandise en droits nationaux étrangers.

Chapitre 2 : L'analyse des normes de lutte contre l'insécurité maritime en droit européen

Titre 2 : L'amélioration des normes de protection de la marchandise et de lutte contre l'insécurité maritime à la lumière du droit étranger.

Chapitre $1:$ L'amélioration des normes pour la protection de la marchandise et la sécurité de la navigation maritime.

Chapitre 2 : Le renforcement de la lutte contre l'insécurité et des recommandations pour son amélioration dans le golfe de Guinée .268 


\section{INTRODUCTION}

1- "Dans le contexte de croissance de la production et des échanges, en raison des nombreux atouts qu'il présente, le trafic maritime assuré par une flotte de quelques trente-huit mille (38 000) navires battant pavillon de cent cinquante (150) Etats, s'est accru considérablement depuis les années 70, passant d'un milliard à plus de cinq milliards de tonnes de marchandises transportées "1.

2- La réflexion qui précède illustre aussi bien l'importance du trafic maritime dans les échanges internationaux que sa croissance rapide à partir des années 70. L'importance du trafic maritime, principal support du commerce international, n'est plus à démontrer car : « De nos jours, avec la mondialisation et le principe du libre échange, le transport maritime occupe une place de choix dans les échanges internationaux. En effet, $90 \%$ des marchandises sont transportées par voie maritime $»^{2}$. D'ailleurs, le doyen Rodière relevait le lien très étroit entre les échanges internationaux et le transport maritime en précisant que : "La plupart et les plus importantes des expéditions par mer correspondent à des ventes: le chargeur envoyant à son acheteur de la marchandise qu’il lui a vendue $»^{3}$. Cela explique bien la configuration du commerce international qui est marqué depuis la deuxième guerre mondiale par une corrélation étroite entre la croissance des échanges internationaux et le développement des transports maritimes ${ }^{4}$.

\footnotetext{
${ }^{1}$ SRITASTAVA (S.P), "Stratégie pour la protection du milieu marin ", manuel OMI, Grande Bretagne, juillet 1988, pp. 1-3, in DAKOURI (Jean-Claude), Le droit maritime international et le transport des Hydrocarbures, Thèse en droit privé , Maastricht, 2011, p. 13.

2 EHOULA COSY (Prince), Le transport maritime et le développement des infrastructures en Afrique, CNAM- Institut national du transport international et des ports, Opérateur multimodal des transports, 2013, p. 1.

${ }^{3}$ RODIERE (René), Traité général de droit maritime, tome 2, Dalloz, 1968, p. 22.

${ }^{4}$ Selon les statistiques, plus de 8,7 milliards de tonnes de marchandises ont emprunté ainsi la mer en 2011, assurant $90 \%$ du trafic mondial. Il y a donc une forte connexité entre vente et transport maritime international. http://fr.wikipedia.org (vu en ligne le 20 décembre 2013).
} 
3- Le droit des transports maritimes est une discipline à la charnière du droit public ${ }^{5}$ et du droit privé qui intéresse également le droit international ${ }^{6}$. Il a ainsi permis de développer et d'intensifier le commerce international. La suprématie des transports maritimes a été incontestablement instaurée dans le transport des marchandises. Car sur les longues distances, le transport maritime paraît plus économique et parfois le seul disponible. Aussi devonsnous retenir que les critères de choix des entreprises exportatrices sont fonction de la disponibilité du mode de transport, du coût du transport, de la capacité et la fiabilité du transport, du délai de livraison, de la sécurité du transport etc. En décembre 2009, une étude réalisée par l’Organisation des Nations Unies sur le transport maritime a montré que, malgré la crise économique récente, les échanges mondiaux utilisent de plus en plus la voie maritime ${ }^{7}$.

4- Selon une autre étude, le débit des échanges par conteneurs a connu une augmentation significative ${ }^{8}$. Alors, n'y a-t-il pas un lien entre l'augmentation des échanges par conteneurs et l'accroissement considérable du trafic maritime depuis les années $70^{9}$ ? Cette dernière question vient à point nommé car au 19ème siècle, la recherche d'un système d'emballage sûr et standardisé pour des marchandises transportées par voies navigables a constitué un souci des marchands, des chargeurs et des transporteurs. Trouver la formule d'un emballage susceptible de permettre l'acheminement de manière fiable d'une marchandise à travers tout le circuit du transport maritime et sans rupture de charge, a été une préoccupation majeure des professionnels et usagers du transport maritime ${ }^{10}$. C'est pourquoi il importe de consacrer dans ce

\footnotetext{
${ }^{5}$ L'Etat ne peut se désintéresser du développement de sa marine marchande ni des relations établies par la mer. Les nécessités du commerce d'importation et d'exportation, le désir d'une influence internationale par des relations régulières conduit l'Etat à encourager la marine marchande par différents moyens.

${ }^{6}$ Le caractère international du droit des transports maritimes se matérialise notamment par les nombreuses conventions internationales qui régissent la matière.

${ }^{7}$ CNUCED, Rapport du Groupe de travail, 8 décembre 2009, p. 4. http://www.unctad.org.

8 VINCENT (V.), «Etude sur les Transports Maritimes 2010», CNUCED, UNCTAD/RMT/2010, Rapport du secrétariat, 2010, p. 21.

9 Voir supra, p. 10.

${ }^{10}$ Voir PINEUS (K.), "Les conteneurs et les transports combinés ", DMF 1967, p. 395.
} 
développement introductif quelques précisions sur l'essor de l'usage du conteneur pour le conditionnement des marchandises.

5- La conteneurisation est devenue incontournable dans tous les modes de transport de marchandises. L'utilisation de l'acier et la standardisation des dimensions du conteneur ont favorisé sa généralisation à partir des années 1970. Son utilisation s'est étendue à tous les modes de transport et il en existe aujourd'hui différents types en fonction de leur utilisation : conteneur standard, conteneur réfrigéré, conteneur citerne ${ }^{11}$. L'unité de mesure permettant de quantifier le transport de conteneurs quelle que soit leur taille est l'équivalent vingt pieds $(\mathrm{EVP})^{12}$.

6- En effet, l'avènement du conteneur constitue pour les opérateurs du secteur des transports maritimes l'unique moyen de répondre au souci d'un emballage résistant et standardisé, conçu pour transporter la marchandise de bout en bout sans rupture de charge. Le conteneur se présente alors comme le moyen de mieux protéger la marchandise ${ }^{13}$. Il devient le matériel idéal de transport qui garantit la marchandise contre les casses, les pertes, les vols et les avaries.

7- Par ailleurs, le conteneur répond à une autre préoccupation essentielle des armateurs qui est le gain du temps. En effet, depuis les années 70, les armateurs étaient animés par le souci de gagner du temps en limitant la durée d'escale des navires à quai. Les opérations de manutention du conteneur, réalisées grâce à un équipement moderne et approprié, offraient un chargement

\footnotetext{
${ }^{11} \mathrm{Http}$ : // géo confluences. Ens-lyon.fr/glossaire/conteneur conteneurisation. Consulté en juillet 2017.

12 EVP : Equivalent vingt pieds pour les conteneurs; c'est l'unité de base utilisée pour déterminer la capacité de chargement de conteneurs dans un navire porte-conteneurs ou mixte. Voir Lamy transport, tome 2, 2010, p. 992.

13 TOURRET (P.), "La révolution du conteneur ", ISEMAR, note de synthèse $\mathrm{n}^{\circ} 49$, novembre 2002 , p. 3.
} 
et un déchargement assez rapides des marchandises mises en conteneurs, permettant de gagner réellement du temps ${ }^{14}$.

8- L'avènement du conteneur a affecté les structures traditionnelles du transport maritime autant sur la mer que sur la terre. Sur la mer, l'on trouve la présence de nouvelles générations de navires porte-conteneurs qui s’imposent par leur taille et leur capacité. En réponse, sur la terre, naissent des terminaux à conteneurs avec leurs installations et équipements portuaires dotés de technologies modernes sans précédentes ${ }^{15}$. On assiste alors à une véritable mutation voire une révolution dans ce secteur d'activités grâce au conteneur. Au demeurant, l'élément le plus remarquable qui accompagne cette mutation est sans doute la standardisation des équipements des terminaux à conteneurs et des navires porte-conteneurs.

9- Le conteneur est conçu pour sécuriser la marchandise transportée et faciliter les opérations de manutention tels que le chargement, le déchargement, l'acconage, etc. Cependant la question se pose de savoir si, en raison du transport de bout en bout sans rupture de charge qu'elle permet de réaliser, la conteneurisation ne se présente pas comme un moyen propice aux trafics illicites?

10- Enfin, l'on se pose la question de savoir si le transport par conteneurs ne représente pas une source d'insécurité dès lors que des armes de toutes natures, des marchandises dangereuses et même des déchets industriels peuvent être camouflés dans des conteneurs pour être acheminés d'un lieu à un autre.

11- Pour une meilleure appréhension de cette étude, notre développement introductif s'articulera autour de deux points essentiels. Ceux-ci permettront de présenter successivement le cadre général de l'étude (Section 1) et des considérations d'ordre méthodologiques (Section 2).

\footnotetext{
${ }^{14}$ BILLARD (J.), Porte-conteneurs, la révolution des transports maritimes, édition ETAI, 2003, p. 29.

${ }^{15}$ TERRASIER (N.), « La manutention portuaire de conteneurs en France : vers la consolidation? ", ISEMAR, note de synthèse ${ }^{\circ} 28$, octobre 2000 , p. 2.
} 


\section{Section 1 : Présentation du cadre général de l'étude}

12- Le port est un outil de développement pour tout pays qui le possède. Les ports ivoiriens (le Port Autonome d'Abidjan (PAA) et le Port Autonome de San Pedro (PASP)) sont des outils indispensables pour le développement de la Côte d'Ivoire, voire celui des pays de l'hinterland comme le Burkina Faso, le Mali et le Niger. Conformément à leurs différents statuts, les ports ivoiriens ont pour objet : l'exploitation et l'entretien des installations portuaires ; la réalisation de toutes les opérations d'exploitation rattachées aux activités portuaires notamment remorquage, acconage, entreposage, manutention, ... ; la réalisation des travaux de construction, d'extension, d'amélioration, de renouvellement, de reconstruction et de dragage, etc. ${ }^{16}$

13- La présentation du cadre général de notre étude portera sur l'évolution du trafic de marchandises en Côte d'Ivoire (\$1) et sur les enjeux et le cadre juridique régissant le transport de marchandises (\$2).

\section{$\S 1$ : Evolution du trafic de marchandises en Côte d'Ivoire}

14- Il est vrai que notre thème porte sur le transport de marchandises en général. Mais compte tenu du fait que la conteneurisation est un mode de transport relativement nouveau, il conviendra de situer son contexte dans ce développement introductif. La conteneurisation a connu son véritable essor en Côte d'Ivoire grâce aux installations et équipements modernes dont le terminal à conteneurs du Port autonome d'Abidjan s'est doté17. Le transport de

\footnotetext{
${ }^{16}$ Voir Décret n 2001-143 du 14 mars 2001 portant approbation des Statuts du Port autonome d'Abidjan (P.A.A.) et reclassification des immobilisations concédées, JORCI du 26 avril 2001, p. 314 ; voir également les Statuts du Port autonome d'Abidjan, art. 4. Voir aussi le décret $\mathrm{n}^{\circ} 95$ 818 du 29 septembre 1995 portant transformation du Port autonome de San-Pedro en société d'Etat.

17 "Le terminal à conteneurs de Vridi est doté des installations et équipements ci-après ${ }^{17}: 1000$ mètres linéaire de quai; 11,50 mètres de tirant d'eau ; 5 postes à quai ; 34 hectares de superficie pour le parc à conteneurs; des portiques de quai d'une capacité de 40 à 60 tonnes; des portiques de parc d'une capacité de 40 tonnes; des grues de quai d'une capacité de 100 tonnes; des tracteurs RORO d'une capacité de 40 tonnes; 1 système de gestion du parc à conteneurs assisté par GPS etc. ». http : //www. portabidjan.ci/fr/conteneur/terminal., Consulté en mars 2016.
} 
marchandises par conteneurs a débuté dans ce pays dans les années 7018, la genèse du trafic de conteneurs en Côte d'Ivoire (A) mais aujourd'hui quel est l'état des lieux relatif à ce trafic $(\mathbf{B})$ ?

\section{A- La genèse du trafic par conteneurs en Côte d'ivoire}

15- Malgré l'environnement défavorable, le conteneur a fait son apparition sur les côtes africaines, notamment en Afrique de l'Ouest et du Centre au début des années 7019. A l'instar des autres ports de la sous-région, le Port autonome d'Abidjan était à l'origine conçu de façon classique par un groupe de quais sans affectations particulières. Face au besoin de modernisation, ce port s'est adapté de manière progressive et planifiée en tenant compte du niveau du trafic de marchandises conteneurisées, des tendances futures en matière de trafic et de changement technologiques et logistiques, et des moyens financiers dont il pouvait disposer. La progression du trafic de marchandises conteneurisées au Port autonome d'Abidjan a d'ailleurs motivé en 1976 l'étude d'un véritable terminal à conteneurs dont les travaux, démarrés en 1977, se sont achevés en $1981^{20}$.

16- Selon le rapport d'un atelier sur la compétitivité du Port autonome d'Abidjan ${ }^{21}$, le Terminal à conteneurs de Vridi comprend 5 postes à quai destinés à l'accueil des navires porte-conteneurs dont un poste équipé d'une rampe $\boldsymbol{R O} / \mathbf{R O}^{22}$. La gestion du terminal à conteneurs est confiée à une structure privée spécialisée appelée la Société d’Exploitation du Terminal de Vridi (SETV).

\footnotetext{
${ }^{18}$ Voir ALLAH, Les ports africains face au développement de la conteneurisation, Association de Gestion des Ports de l'Afrique de l'Ouest et du Centre, Exposé, 5èmes Journées Portuaires Africaines de Lagos (Nigeria), octobre 1989, p. 7.

19 ALLAH, Les ports africains face au développement de la conteneurisation, Association de Gestion des Ports de l'Afrique de l'Ouest et du Centre, Exposé, 5èmes Journées Portuaires Africaines de Lagos (Nigeria), octobre 1989, p. 2.

${ }^{20}$ Voir ALLAH, «Les ports africains face au développement de la conteneurisation », op. cit., p. 8.

${ }^{21}$ Voir Atelier Grand-Bassam, thème : " Compétitivité du Port Autonome d'Abidjan, "Enjeux et Perspectives" ", Rapport, mai 2007, p. 36.

${ }^{22}$ Lamy transport, tome 2, 2010, p. 1014. Le terme RO/RO est l'abréviation de roll on/roll off qui signifie en français transroulage. C'est une technique de transport combiné dans le cadre de laquelle un véhicule routier en charge embarque à bord d'un navire de mer spécialement conçu, où il est placé en cale ou sur le pont.
} 
17- S'agissant du Port autonome de San Pedro, un port en eau profonde, il dispose d'un chenal d'accès dragué à -13,5 m, $650 \mathrm{~m}$ de long et de $150 \mathrm{~m}$ de large, d'un terminal à conteneurs de 5 hectares et d'un terminal polyvalent de 4 hectares. Au niveau des performances, le temps d'attente en rade extérieure n'excède pas 48 heures. Quatre grues mobiles sont en opération sur les porteconteneurs pour assurer la manutention. L'accroissement du trafic annuel de marchandises sur la période de 2011 à 2014 est de $163 \%{ }^{23}$. Ce trafic est conteneurisé à 40\% environ, soit plus de 50000 EVP (équivalent vingt pieds) ${ }^{24}$.

18- L'introduction du trafic conteneurisé en Côte d'Ivoire a donc coïncidé avec la construction des installations provisoires du Terminal à conteneurs de Vridi. Il convient de faire l'état des lieux de ce trafic par conteneurs.

\section{B- L'état des lieux du trafic conteneurisé}

19- Le conteneur a été conçu et lancé aux Etats-Unis dans les années 1950 et il a atteint l'Europe une décennie plus tard. Selon un auteur le conteneur fut inventé en 1956 par Malcom Mclean, un transporteur routier américain qui trouvait que le transbordement en vrac des marchandises était trop long. Il charge d'abord directement le camion dans le bateau, puis perfectionne cette idée. Il ne tarde pas à remarquer que son idée d'origine ne règle pas tous les problèmes de place perdue. Si le camion reste à quai, les remorques sont embarquées avec leur châssis, ce qui rend difficile l'exploitation rationnelle de l'espace à bord du navire. La solution est vite trouvée : il suffit de retirer le châssis pour n'embarquer que la partie supérieure de la remorque, soit la " boîte " elle-même! Idée simple mais lumineuse, et que personne avant lui n'a eue. Son invention restera confinée à la côte-est des États-Unis pendant $10 \mathrm{ans}$, puis franchira l'Atlantique en 1966 et connaîtra ensuite une croissance fulgurante ${ }^{25}$. Cette invention est à l'origine du conteneur moderne qui a

\footnotetext{
${ }^{23}$ Voir Guide promotionnel du Port de San Pedro, 1ère édition 2015, p. 12.

${ }^{24}$ Voir Livre blanc de la relance et du développement des activités du port de San Pedro, 04 décembre 2007, p. 17.

${ }^{25}$ CARCELLER (Julie), « Malcom Mclean », http://fr.wikipedia.org/Malcom_Mclean, juillet 2007, consulté le 22 mars 2018.
} 
révolutionné le transport et le commerce international au cours de la seconde moitié du XXème siècle.

20- Mais le conteneur est arrivé bien plus tard sur les côtes africaines à cause de certains obstacles imputés à la spécificité des pays africains. On a d'abord indiqué que les productions des pays africains, notamment les matières premières, n'étaient pas adaptées à la conteneurisation. On a ensuite évoqué un déséquilibre entre les exportations et les importations africaines. Ce qui entraînerait un retour à vide onéreux des conteneurs ${ }^{26}$. Enfin, on a présenté les insuffisances des installations et équipements portuaires comme un obstacle majeur voire insurmontable. En dépit de ces difficultés présumées, le conteneur a fait son apparition sur les côtes africaines notamment en Afrique de l'ouest et du centre.

21- Depuis lors, le trafic conteneurisé ne cesse de connaître en Côte d'Ivoire une expansion soutenue en modernisant la manutention portuaire ${ }^{27}$ et en surmontant progressivement les obstacles. Le trafic conteneurisé s'appuie sur une politique d'équipement et d'aménagement des installations portuaires qui existaient déjà28. A propos de l'expansion du trafic de marchandises conteneurisées, Monsieur Prince Ehoula Cosy précisait que le Terminal de Vridi présente les caractéristiques suivantes : mille (1 000) mètres de longueur totale des quais avec un tirant d'eau de douze (12) mètres, un parc à conteneurs de trente (30) hectares. Ce parc est assorti des équipements ci-après : six (6)

${ }^{2626}$ Voir ALLAH, « Les ports africains face au développement de la conteneurisation », op. cit., p. 2.

27 Voir Cahier d'activités 2006 du Port autonome d'Abidjan. Au niveau de la manutention portuaire, le conteneur est à la base de nombre d'innovations technologiques. La manutention des conteneurs ne peut se faire de manière traditionnelle comme cela se faisait autrefois. Car le poids brut d'un conteneur peut aller jusqu'à vingt-quatre tonnes. Des équipements adéquats sont donc nécessaires. On distingue les équipements de parc et les équipements " bord à quai ». Ces derniers permettent d'embarquer ou de débarquer les conteneurs : il s'agit de portiques et de grues. Tandis que les équipements de parc assurent le déplacement des conteneurs au sein des terminaux avant leur embarquement ou après leur débarquement. Parmi les équipements de parc, on trouve les " cavaliers ", les chariots élévateurs de type " challenger " avec " spreader " fixe ou télescopique et des grues de parc aux chariots élévateurs à fourches destinés au transport des conteneurs vides.

${ }^{28}$ Voir ALLAH, «Les ports africains face au développement de la conteneurisation », op. cit., p. 10. 
portiques de quai, trois (3) grues mobiles, seize (16) portiques de parc, etc. Le parc a une capacité de stockage de conteneurs pleins de vingt mille (20000) Equivalents Vingt Pieds avec un volume annuel du trafic conteneur se chiffrant à six-cent dix mille (610 000) EVP. Au niveau des services, des opérations de chargement et de déchargement en continu s'effectuent 24 heures sur 24 et 365 jours par an. L'accostage se fait 24 heures sur 24 et pendant les 7 jours de la semaine ${ }^{29}$.

22- En ce qui concerne les autres marchandises notamment les marchandises conventionnelles et les marchandises en vrac que nous aurons à définir, elles ne présentent pas de contextes historiques particuliers. Après cet aperçu sur l'évolution du trafic conteneurisé en Côte d'Ivoire notamment au terminal de Vridi, la question se pose de savoir quels sont les enjeux présentés par le trafic maritime et aussi quel est son cadre juridique.

\section{$\S 2$ : Enjeux du trafic maritime et aperçu de son cadre juridique}

23- Nous entendons par enjeux du trafic maritime, les avantages et inconvénients liés audit trafic. Nous essayerons d’indiquer les avantages sociaux et économiques que procure le trafic par conteneurs aux professionnels et usagers ${ }^{30} \mathrm{du}$ secteur maritime. Nous évoquerons aussi les problèmes sérieux de trafics illicites et de sécurité que pose le transport maritime en général. Ainsi, les enjeux socio-économiques du trafic conteneurisé et les problèmes de sécurité maritime (A) seront suivis par un aperçu du cadre juridique applicable au transport maritime $(\mathbf{B})$.

\section{A- Les enjeux socio-économiques du trafic conteneurisé et les problèmes de sécurité maritime.}

24- Dans le secteur du transport maritime, depuis plus d'une trentaine d'années, l'usage des conteneurs est de plus en plus incontournable pour

${ }^{29}$ EHOULA COSY (Prince), Le transport maritime et le développement des infrastructures en Afrique, CNAM- Institut national du transport international et des ports, Opérateur multimodal des transports 2013, p. 22.

${ }^{30}$ Voir COULIBALY (Climanlo Jérôme), Les intermédiaires du transport maritime international de marchandises en droit ivoirien, Thèse de droit privé, Université de Nice, 1987, n² 22, pp. 13 et 14. L'auteur entend par usagers du transport maritime le destinataire et le chargeur. 
l'acheminement des marchandises ${ }^{31}$. La question se pose alors de savoir qu'estce que l'usager gagne ou perd en choisissant de transporter sa marchandise au moyen du conteneur. En effet, la conteneurisation offre trois avantages décisifs aux professionnels et usagers à savoir : une très forte productivité lors des manutentions portuaires, des économies d'échelle permises par la taille croissante des navires et l'inter modalité qui consiste à transporter la marchandise de porte à porte à l'intérieur du même conteneur sans rupture de charge ${ }^{32}$. En outre, le conteneur procure de nombreux autres avantages ${ }^{33}$ qui, sans doute, justifient son utilisation massive dans tous les modes de transport.

25- Toutefois, des auteurs indiquent que le système de circulation des biens via les conteneurs maritimes est efficace, mais également vulnérable aux intrusions et au détournement. Les pertes liées au vol subies par le commerce de conteneurs semblent être de l'ordre de 20 milliards de dollars par an au niveau mondial, auxquelles s'ajoutent encore plusieurs milliards sous forme d'impôts non perçus. Ce manque de sécurité patent accroît la menace que des conteneurs soient utilisés par des terroristes, notamment pour fournir des Armes de Destruction massive (ADM) ${ }^{34}$. Il en résulte que le trafic par conteneurs pose de réels problèmes de sécurité que la présente étude tentera d'aborder.

\footnotetext{
${ }^{31} \mathrm{http}$ // géoconfluences. Ens-lyon.fr/glossaire/conteneur-conteneurisation.

$32 \mathrm{http} / / /$ géoconfluences. Ens-lyon.fr/glossaire/conteneur-conteneurisation.

${ }^{33}$ Voir NOËL (Benoît), Transport maritime : le développement de la conteneurisation, Mémoire, Ecole Supérieure des Transports, 2003, pp. 22 et s. selon l'auteur, les avantages de la conteneurisation sont nombreux : La rapidité : Pour le client comme pour l'armateur, les pertes de temps par rupture de charge peuvent être réduites au minimum. D'autre part, il y a une simplification de formalités douanières, le conteneur constituant une unité documentaire. Il sera rempli (empoté) sous surveillance douanière et scellé. L'économie : Le transport de conteneurs fait bon marché : l'armateur gagne du temps pour emballer (économie de matériel, gain de temps. Pour l'armateur, l'économie se situe au niveau du rendement du navire. Le client aura une marchandise (et donc des capitaux) immobilisée moins longtemps. L'assurance est moins chère. La souplesse : La vitesse est uniforme : depuis le moment où la marchandise est empotée, elle voyage jusqu'à ce qu'elle en sorte d'où une souplesse de stockage. La sécurité : Le conteneur va protéger la marchandise contre les intempéries, même pendant la manutention. Il diminue les vols, les détériorations et les pertes. Contre l'incendie, les cales sont en général protégées par un système d'extinction au $\mathrm{C} 02$ associé à une analyse de l'atmosphère ".

34 Voir SITT (Bernard) et HAUTECOUVERTURE (Benjamin) "Sécurité des conteneurs", l'International Experts Group on Global Security (IEGGS), Rapport, janvier 2005, p. 668. www.ndu.edu/ctnsp/DefTech/DTP9\%20Container\%20.
} 


\section{B- Un aperçu du cadre juridique applicable au transport maritime}

26- Les textes juridiques qui régissent le transport maritime aussi bien conteneurisé que conventionnel peuvent être classés en deux groupes. Il y a d'abord les conventions internationales (A) ensuite les textes adoptés par le législateur ivoirien (B).

\section{1- Les conventions internationales}

27- Le transport maritime de marchandises est régi en Côte d'Ivoire par un certain nombre de conventions internationales. Pour l'essentiel, citons la Convention de Bruxelles, pour l'unification de certaines règles en matière de connaissement ${ }^{35}$, signée le 25 août 1924 et entrée en vigueur le 2 juin 1931, amendée par les protocoles de 1968 et 1979. La convention originelle est désignée par "Règles de la Haye " et la version amendée par les protocoles de 1968 et 1979 désignée par: "Règles de la Haye Visby». Ensuite, il y a la Convention de Hambourg ${ }^{36}$ ou "Règles de Hambourg " ${ }^{37}$. Il y a aussi la convention SOLAS "Safety of Life At Sea" du 1er novembre 1974, pour la sauvegarde de la vie humaine en mer ${ }^{38}$ qui a été amendée par son protocole de 197839. Il y a également le Code ISPS : Code international pour la sûreté des navires et des installations portuaires de $2003^{40}$. Il y a enfin la dernière en date,

\footnotetext{
35 Voir aussi BLAISE (J-B.) et MOURGEON (J.), Lois et décrets de Côte d'Ivoire, Librairies techniques, 1970, p. 428 ; voir aussi la loi n 61-211 du 12 Juin 1961 autorisant le Président de la République à ratifier la Convention de Bruxelles de 1924.

${ }^{36}$ La Convention de Hambourg n'a pas été ratifiée par la Côte d'Ivoire certes, mais nous la citons parce qu'elle fait partie du droit maritime international sur lequel nous nous appuyons dans cette étude pour rechercher les améliorations du droit maritime ivoirien.

${ }^{37}$ Adopté le 31 mars 1978, la "Convention des Nations unies sur le transport de marchandises par mer ", est plus connue sous le nom de "Règles de Hambourg", du nom de la ville où elle a été signée. Elle est entrée en application le $1^{\text {er }}$ novembre 1992 entre les pays l'ayant ratifiée. Voir Lamy transport, tome 2, édition 2010, $\mathrm{n}^{\circ}$ 534, p. 266.

38 Voir JORCI du 20 août 1987, p. 306.

39 JORCI du 20 août 1987, p. 306.

40 L'OMI a institué en 2003 un code international portant sécurité des navires et des installations portuaires, baptisé code ISPS. Ce code est aujourd'hui obligatoire dans la quasitotalité des ports et appliqué au Port autonome d'Abidjan. Voir Décision n² 233/PPA du 26 avril 2005, portant création d'un comité de pilotage des actions relatives au code ISPS, prise par le Directeur Général du Port Autonome d'Abidjan.
} 
la Convention de Rotterdam ${ }^{41}$ de 2009 connue sous le nom de Règles de Rotterdam.

28- Il faut par ailleurs ajouter la Convention internationale sur la simplification et l'harmonisation des régimes douaniers (amendée) de Kyoto en février 2006 ${ }^{42}$. La Convention internationale d'assistance mutuelle administrative en matière douanière de Bruxelles en juin $2003^{43}$. La Convention internationale sur l'assistance d'avril 1989 à Londres ${ }^{44}$. La Convention international d'assistance mutuelle administrative en vue de prévenir, de rechercher et de réprimer les infractions douanières de Nairobi en juin 197745 . La Convention sur les règles d'avarie commune, du 1er juin 2004 appelée Règles d'York et d'Anvers. La Convention relative au régime douanier des conteneurs utilisés en transport international dans le cadre d'un pool du 21 janvier 1994 à Genève. La Convention internationale sur la sécurité des conteneurs (CSC) du 2 décembre 1972 à Genève ${ }^{46}$.

\section{2- Les textes adoptés par le législateur ivoirien}

29- Seuls les textes qui intéressent directement le transport maritime de marchandises en Côte d'Ivoire et les instruments juridiques relatifs à la prévention et à la lutte contre l'insécurité maritime et portuaire seront présentés ${ }^{47}$. Ceux-ci peuvent être regroupés en textes législatifs (1) et en textes règlementaires $(\mathbf{2})$.

\footnotetext{
${ }^{41}$ Voir Agence ivoirienne de presse (AIP) du 24 septembre 2012. "Adoptée par l'Assemblée générale des Nations Unies, le 11 décembre 2008 et officiellement ouverte à la signature des Etats membres à Rotterdam, le 23 septembre 2009, la convention des Nations Unies sur le contrat de transport international de marchandises par mer, dénommée "règles de Rotterdam" " a vu le jour. Précisons que : "Le texte a été ratifié par 21 Etats, représentant 25\% du commerce mondial. Parmi les pays signataires, figurent les USA, la France, la Grèce, le Danemark, ainsi que 11 Etats africains dont neuf côtiers, notamment le Congo, le Gabon, le Ghana, la Guinée, le Nigeria, le Sénégal, le Togo, le Cameroun, le Madagascar, le Mali et le Niger ». Voir également en ce sens TAKOUE (Sylvain), Commerce maritime mondial : La Côte d'Ivoire doit-elle signer la convention de Rotterdam? Le Nouveau Réveil, 25 septembre 2012.

$42 \mathrm{http}: / / \mathrm{www}$. wcoomd.org/fr/.

${ }^{43} \mathrm{http} / / / \mathrm{www} . \mathrm{wcoomd}$.org/fr/ ISO.

${ }^{44} \mathrm{http}: / / \mathrm{www} . \mathrm{wcoomd}$.org/fr/.

$45 \mathrm{http} / / / \mathrm{www}$. wcoomd.org/fr/.

${ }^{46}$ Ces quatre dernières conventions sont en ligne, http://www.logistiqueconseil.org.

${ }^{47}$ La liste n'est donc pas exhaustive.
} 


\section{a- Les textes législatifs}

30- Les textes législatifs visés se déclinent en lois portant ratification des conventions internationales et en lois qui sont de portée proprement nationale. S’agissant des premières, nous avons la loi nº 61-211 du 12 Juin 1961 autorisant le Président de la République à ratifier la Convention de Bruxelles de 1924 ; la loi 75-497 du 10 juillet 1975 portant approbation de la Convention relative à un code de conduite des conférences maritimes signé à Genève le 6 avril 1974. On peut citer également la loi n 87-764 du 28 juillet 1987 autorisant le Président de la République à ratifier la Convention des Nations Unies sur les conditions d'immatriculation des navires ${ }^{48}$; la Loi n $87-767$ du 28 juillet 1987 relative à la ratification de la Convention internationale de 1974 pour la sauvegarde de la vie humaine en mer (SOLAS 74) et son protocole de $1978^{49}$

31- S’agissant des lois proprement nationales, nous avons la Loi $\mathrm{n}^{\circ} 61$ 349 du 9 novembre 1961 relative à l'Institution d'un Code de la Marine marchande telle que modifiée par la loi n $62-254$ du 31 juillet 1962 ; la loi 77 926 du 17 novembre 977 portant délimitation des zones maritimes placées sous la juridiction nationale de la République de Côte d'Ivoire ; la Loi n 97 - 519 du 4 septembre 1997, portant définition et organisation des sociétés d'Etats ${ }^{50}$.

\section{b- Les textes réglementaires : décrets et arrêtés}

32- Au titre des décrets, citons par ordre chronologique le décret $\mathrm{n}^{\circ} 75$ 509 du 18 juillet 1975 portant ratification de la convention relative à un code de conduite des Conférences maritimes signé à Genève (Suisse), le 6 avril 1974 ; le décret $\mathrm{n}^{\circ}$ 81-142 du 19 février 1981 portant tarification des services des auxiliaires du transport maritime ${ }^{51}$. Il y a le décret $n^{\circ} 87-765$ du 28 février 1987 portant ratification de la Convention des Nations Unies sur les conditions d'immatriculation des navires; le décret 87-768 du 28 juillet 1987 portant ratification de la Convention internationale de 1974 pour la sauvegarde de la

\footnotetext{
${ }^{48}$ Voir JORCI du jeudi 20 août 1987, p. 305.

49 JORCI du jeudi 20 août 1987, p. 305.

${ }^{50}$ Voir JORCI du 2 octobre 1997.

51 Voir JORCI n 17 du jeudi 23 avril 1981, p. 181.
} 
vie humaine en mer (SOLAS 74) ; le décret 87-769 du 28 juillet 1987 portant publication de la Convention internationale de 1974 pour la sauvegarde de la vie humaine en mer (SOLAS 74) et son protocole de 1978. On peut ajouter le décret $\mathrm{n}^{\circ}$ 95-818 du 29 septembre 1995 portant transformation du Port autonome de San-Pedro en société d'Etat; le décret nº 99- 318 du 21 avril 1999 portant réglementation de police du port autonome d'Abidjan ; le décret $\mathrm{n}^{\circ} 96-$ 213 du 9 mars 1996 relatif aux opérations d'affrètement et de frètement de navires en Côte d'Ivoire. On a le décret n 97 - 614 du 16 octobre 1997 relatif à l'exercice des professions de manutentionnaire portuaire et de consignataire maritime dans les Ports Ivoiriens; le décret n 2001-143 du 14 mars 2001 portant approbation des statuts du Port autonome d'Abidjan et reclassification des immobilisations concédées ; le décret n² 2012-628 du 6 juillet 2012 portant création du Tribunal de Commerce d'Abidjan et fixant son ressort territorial.

33- Au titre des arrêtés, citons : l'Arrêté n 2191 du 1er janvier 1992 du Ministère de la défense ; l'Arrêté n 02191/MD/DAALP/ OR du 3 juin 1992 portant création du Groupe de Sécurité portuaire (GSP) ; l'Arrêté n 214/MS du 17 mai 1995 portant statut du commissariat de police spéciale du port autonome d'Abidjan; l'Arrêté nº 0082 du 5 mai 1999 portant règlement d'exploitation du Port Autonome d'Abidjan ;

34- A travers les développements qui précèdent, nous entendons éclairer sur l'évolution du trafic de marchandises au Port autonome d'Abidjan, notamment les enjeux de l'utilisation du conteneur, les textes juridiques constituant le droit applicable aux transports maritimes de marchandises, etc. Dans cette même optique, il convient de préciser les considérations d'ordre méthodologique que nous avons adoptées dans le cadre de l'étude.

\section{Section 2 : Considérations d'ordre méthodologique}

35- Les transports de marchandises par mer soulèvent une certaine problématique. Ces questions ne peuvent être clarifiées qu'à la lumière des définitions préalables des concepts clés du sujet (\$1) et les différents problèmes liés aux transports de marchandises $(\$ 2)$. 


\section{$\S 1$ : Approche définitionnelle des concepts clés du sujet}

36- Notre sujet d'étude qui s'intitule: «La protection des transports de marchandises par mer en droit ivoirien: sécurité de la marchandise et sûreté de la navigation ", correspond dans notre approche à la sécurité et à la sûreté maritimes. Il contient des concepts clés qui méritent d'être précisés à savoir la sécurité et la sûreté maritimes, le transport maritime et le type de marchandises. Par ailleurs, le transport maritime est par essence une activité transnationale. Le droit des transports maritimes est par conséquent un droit essentiellement international. Ainsi, l'utilisation du terme "en droit ivoirien" qui apparaît dans la thématique de l'étude au lieu du terme "droit international" mérite d'être clarifiée. En effet, le choix du terme "en droit ivoirien" traduit le fait qu'il s'agit de l'application du droit régissant les transports maritimes internationaux, mais sous la juridiction ivoirienne ${ }^{52}$.

37- Nous procèderons respectivement par la définition du transport maritime et du contrat (A) qui le régit, de la protection des transports maritimes (B) et enfin des marchandises concernées (C).

\section{A- Le transport maritime et le contrat de transport maritime}

38- Le transport désigne l'action de porter d'un lieu à un autre. Le transport maritime se définit comme un déplacement, à caractère commercial, de marchandises ou de passagers par mer au moyen d'un navire. Toutefois, notre sujet d'étude n'a retenu que le transport de marchandises. Au demeurant, le caractère maritime du transport soulève une question de forme concernant les documents requis. Selon Monsieur Patrick NICOLEAU, pour qu'un transport soit qualifié de transport maritime il faut qu'il soit constaté formellement par un document appelé connaissement ${ }^{53}$. Selon Monsieur Jean-Claude Dakouri, la

\footnotetext{
52 Il convient de préciser également que les sources de ce droit sont pour l'essentiel des conventions internationales.

53 Cf: NICOLEAU (Patrick), Lexique de droit privé, Paris, Ellipses, 1996, p. 90. Le connaissement se définit comme " un acte de reconnaissance fourni par le capitaine d'un navire comme quoi il a effectivement reçu à son bord les marchandises qui y sont mentionnées. Il est signé par le capitaine, éventuellement par un agent de l'armateur et contresigné par le chargeur ". Voir également l'article 3 al. 3 de la Convention de Bruxelles du 25 août 1924.
} 
Convention de Bruxelles de 1924 " écarte de son champ d'application non seulement les affrètements, mais aussi les transports par mer qui ne seraient pas constatés par connaissement $» 54$.

39- S'agissant du contrat de transport maritime, le doyen Rodière le définit comme : "le contrat par lequel un transporteur s'oblige à déplacer par mer sur une relation définie une marchandise définie moyennant le paiement d'un fret déterminé »55. Conformément à la Convention de Rotterdam, le terme contrat de transport "désigne le contrat par lequel un transporteur s'engage, moyennant paiement d'un fret, à déplacer des marchandises d'un lieu à un autre. Le contrat prévoit le transport par mer et peut prévoir, en outre, le transport par d'autres modes »56. Le Code maritime ivoirien de 2017 définit, en son article 684, le contrat de transport maritime comme tout contrat par lequel le transporteur s'engage, contre paiement d'un fret, à transporter des marchandises par mer d'un port à un autre. Dans le principe, il s'agit pour le transporteur maritime de s'engager à déplacer, par voie maritime, la marchandise que lui remet le chargeur et de la livrer à son ayant droit, à destination.

40- Par ailleurs, on constate que le déplacement de la marchandise par mer peut être également réalisé au moyen d'un contrat d'affrètement avec comme finalité le déplacement de marchandises. En effet, le contrat d'affrètement maritime se définit comme : Un contrat par lequel un fréteur s'engage, moyennant rémunération, à mettre un navire [ou un espace du navire] à la disposition d'un affréteur $"{ }^{57}$. Concrètement, l'affréteur loue le navire ou un espace du navire en vue d'assurer le déplacement de la marchandise. Mais le contrat de transport et le contrat d'affrètement se distinguent l'un de l'autre. "Dans le contrat de transport, il y a remise de la marchandise pour un transport: le transporteur se voit remettre de la marchandise pour l'acheminer. Dans le contrat d'affrètement, il y a remise d'un navire [ou un espace du navire] pour en

${ }^{54}$ DAKOURI (Jean-Claude), Le droit maritime international et le transport des hydrocarbures, Thèse en droit privé, Maastricht, 2011, op. cit., pp. 17 et s.

${ }^{55}$ RODIERE (R.), Traité général de droit maritime, tome 2, DALLOZ, Paris, 1968, op. cit., p. 11.

${ }^{56}$ Convention de Rotterdam de 2010, article premier, $\S 1$.

${ }^{57}$ Lamy transport, tome 2, édition 2010, p. 983. 
user. L'affréteur se voit remettre un navire [ou un espace de navire] pour en jouir $\grave{a}$ sa guise ${ }^{58}$.

41- La distinction a un enjeu car les deux contrats sont soumis à des régimes juridiques distincts. Les règles propres à l'affrètement sont supplétives de la volonté des parties tandis que le transport ne peut échapper à son statut légal : les règles du transport maritime sont d'ordre impératif ${ }^{59}$. Le professeur Daniel Veaux ${ }^{\mathbf{6 0}}$ considère que le contrat d'affrètement s'est distingué du contrat de transport stricto sensu en suivant l'évolution du commerce maritime. De sorte que de nos jours, la charte-partie soit l'instrument qui contienne le contrat d'affrètement et que le connaissement soit le seul document à même de prouver le contrat de transport maritime.

\section{B- La protection des transports de marchandises : la sécurité et la sûreté maritimes :}

42- Nous entendons par protection des transports de marchandises par mer toutes les mesures prises pour assurer la sécurité et la sûreté de la navigation maritime. La sécurité maritime se distingue de la sûreté maritime. La sécurité maritime a trait à la sécurité de la navigation, des personnes et des biens en mer ainsi qu'à la lutte contre la pollution marine. Elle se résume à la prévention et à la lutte contre les risques, accidents et sinistres dans les eaux maritimes, à bord des navires de commerce, de pêche et de plaisance, y compris les plates-formes off-shore. La sûreté maritime désigne la prévention et la lutte contre les incidents de sûreté que sont les vols à main armée, l'immigration clandestine, les trafics de substances illicites, la piraterie, le terrorisme et les autres actes illicites intentionnels ou de malveillance à l'encontre du navire, son

\footnotetext{
58 Lamy transport, tome 2, édition 2010, n 925, p. 456.

59 Voir Convention de Bruxelles originelle, art. 3, § 8. "Toute clause, convention ou accord dans un contrat de transport exonérant le transporteur ou le navire de responsabilité pour perte ou dommage concernant des marchandises, provenant de négligence, faute ou manquement aux devoirs ou obligations édictés dans cet article, ou atténuant cette responsabilité autrement que ne le prescrit la présente convention, sera nul, non avenu, et sans effet. Une clause cédant le bénéfice de l'assurance au transporteur ou toute clause semblable sera considérée comme exonérant le transporteur de sa responsabilité».

60 Cf : VEAUX (Daniel.), « Droit maritime », RID 1976 / 3-4, pp. 43 et s.
} 
équipage, ses passagers, sa cargaison ou des installations maritimes ou portuaires. En somme la sécurité maritime lutte contre les risques, accidents, sinistres et pollutions en mer tandis que la sûreté maritime lutte contre les actes illicites intentionnels ou de malveillance en mer ${ }^{61}$.

43- Dans le cadre de la protection des transports, il faut ajouter aux mesures de sécurité et de sûreté maritimes, les mesures prises en vue de la réparation des dommages subis par la marchandise au cas où ceux-ci survenaient. En clair, la protection de la marchandise consiste également à prendre les mesures à même de prévenir tous dommages pouvant survenir à la marchandise transportée et le cas échéant, les mesures capables d'offrir une meilleure réparation à la marchandise perdue ou avariée.

\section{C- Les marchandises concernées par l'étude}

44- Il est question de définir les différents types de marchandises et identifier celles qui sont concernées par la présente étude. Mais avant, des précisions sur le connaissement méritent d'être apportées. Une marchandise est dite sous connaissement lorsque ledit document l'accompagne. L'article $684 \mathrm{du}$ Code maritime ivoirien de 2017 définit le connaissement comme tout document faisant preuve d'un contrat de transport par mer et constatant la prise en charge ou la mise à bord des marchandises du chargeur par le transporteur ainsi que l'engagement de celui-ci de délivrer la marchandise au destinataire contre remise de ce document. Ainsi, le connaissement joue un triple rôle. En effet, il est un reçu des marchandises prises en charge par le transporteur. En outre, il est un titre faisant preuve du contrat de transport et enfin un titre représentatif des marchandises ${ }^{62}$. En tant que reçu, le connaissement vaut présomption, sauf preuve contraire, de la réception par le transporteur des marchandises telles qu'elles y sont décrites et permet au destinataire d'en prendre livraison. Et revêtu de la valeur de preuve du contrat de transport, le connaissement constitue un document qui constate ledit contrat et détermine les obligations

\footnotetext{
61. http://www.affmar.ci/motdg.php.

62 Lamy transport, tome 2, édition 2010, nº 605 à 607 p. 318.
} 
respectives des parties ${ }^{63}$. Et ce, en dépit du caractère consensuel du contrat de transport ${ }^{64}$. Enfin, en sa qualité de titre représentatif des marchandises le connaissement "représente » la marchandise c'est-à-dire qu'il a la même valeur que la marchandise ${ }^{65}$. C'est de là que résulte son caractère de titre négociable et librement transmissible.

45- Au demeurant, une marchandise est dite conteneurisée lorsqu'elle est transportée au moyen d'un conteneur. En réalité le terme marchandise conteneurisée ne pose guère de difficulté de compréhension. C'est en revanche celui de conteneur ${ }^{66}$ qui est sujet à différentes définitions. Pour certains, le conteneur est : "... un engin de transport de caractère permanent, et de ce fait assez résistant pour permettre un usage répété, spécialement conçu pour faciliter le transport des marchandises sans rupture de charge par un ou plusieurs modes de transport, conçu pour être assujetti et/ou manipulé facilement, des accessoires ayant été prévus à cet effet "67. Selon le Bureau International des Conteneurs (BIC), le conteneur est un " récipient conçu pour contenir des marchandises en vrac ou légèrement emballées spécialement en vue de leur transport sans manipulations intermédiaires, ni de rupture de charge, par un moyen de locomotion quelconque ou de combinaison de plusieurs d'entre eux ${ }^{68}$. Au vu de

\footnotetext{
${ }^{63}$ Lamy transport, tome 2, édition 2010, n 606, p. 318.

${ }^{64}$ Lamy transport, tome 2, édition 2010, $n^{\circ}$ 604-a, p. 318. Ayant un caractère consensuel, le contrat de transport résulte de l'accord de volonté des parties indépendamment de l'écrit (le connaissement) qui le matérialise.

${ }^{65}$ Lamy transport, tome 2, Edition 2010, $\mathrm{n}^{\circ}$ 607, p. 319. "Cette fonction, historiquement plus récente que les précédentes, a été rendue nécessaire par le développement du commerce maritime aux siècles derniers. L'accélération des échanges entre partenaires commerciaux se heurtait, en effet, à la relative lenteur des transports maritimes : il fallait trouver un moyen de vendre les marchandises en cours de transport sans attendre leur arrivée au port de destination. Les praticiens ont alors imaginé de transférer, à l'acheteur, des droits attachés aux marchandises et, notamment, le droit d'en prendre livraison au port d'arrivée, en adossant tout simplement le connaissement au profit de cet acheteur ".

${ }^{66}$ Le terme " conteneur " est un néologisme provenant de la francisation du mot anglais "container" dans le vocabulaire juridique grâce à une circulaire française en date du 15 septembre 1977. Voir JORF, 24 sept. 1977, NCP 6077.

${ }^{67}$ Voir Convention pour la Sécurité des Conteneurs (CSC), 02 décembre 1972 à Genève, art. 2. 68 Voir WAROT (J.), « L'avènement du container dans le trafic maritime », DMF 1951, p. 263.
} 
ces définitions, on constate que le conteneur est considéré tantôt comme un engin de transport, tantôt comme un emballage.

46- Sans porter de jugement de valeur sur ces définitions du conteneur, nous retenons que quelle que soit la définition qu'on peut lui donner ${ }^{69}$, toute marchandise qu'il contient est dite marchandise conteneurisée et en cette qualité elle est donc concernée par la présente étude. Toutefois, la question se pose de savoir quel est le sort des marchandises reconnues dangereuses se définissant comme des matières susceptibles, de par leur nature, de mettre en danger la sécurité des personnes et des biens et/ou de nuire à l'environnement lors de leur transport qui fait d'ailleurs l'objet de réglementations internationales et nationales spécifiques ${ }^{70}$. Sont-elles concernées par cette étude ? De notre point de vue, dès lors que ces marchandises dites dangereuses sont soumises à une réglementation spéciale ${ }^{71}$, elles ne peuvent pas être concernées par la présente étude.

${ }^{69} \mathrm{Du}$ point de vue juridique la qualité d'emballage n'a pas été reconnue au conteneur dès le départ. Il en était ainsi dans une décision rendue par un tribunal belge (voir Droit européen des transports 1986, p. 348) où le conteneur devrait être considéré comme un emballage lorsque les marchandises y sont placées par l'expéditeur et comme un engin de transport lorsque c'est le transporteur qui prend l'initiative d'y regrouper des colis. Ainsi le régime applicable aux conteneurs diffèrerait selon qu'il a été empoté par l'expéditeur ou par le transporteur. Ce régime instable et déroutante amène à s'interroger sur la véritable nature juridique du conteneur; estil un emballage ou un engin de transport? Du point de vue de la pratique, le conteneur a été présenté à son avènement comme : "Une forme relativement nouvelle d'emballage dont l'usage assurerait l'arrivée des colis en toute sécurité et au moindre frais en offrant par ailleurs une garantie contre casse, vol et avaries sans limitation". Voir K PINEUS, Les conteneurs et transports combinés, DMF 1967, p. 395. Selon l'auteur, la pratique entend donc par conteneur un emballage étanche, solide, inviolable et facile à manipuler. La résistance et l'inviolabilité sont les points forts du conteneur. Mais le conteneur n'est pas un simple emballage ; comparé aux autres types d'emballage, il s'en distingue par son coût et par sa pérennité. Mais le débat sur la qualité d'emballage ou engin de transport du conteneur importe peu aujourd'hui. Voir dans ce sens M. TILCHE, Conteneurs : engin de transport ou emballage? BTL 1991, 496.

${ }^{70}$ Pour les marchandises autres que les marchandises conteneurisées, voir www.logistiqueconseil. org/articles/transport-routier/type-transport-marchandises.htm.

${ }^{71}$ Voir Avant-propos des Recommandations relatives au transport de marchandises dangereuses de 2009. La règlementation du transport des marchandises dangereuses comprend: des Recommandations et un Règlement type. Les recommandations sont adressées aux gouvernements et aux organisations internationales intéressées par la sécurité du transport des marchandises dangereuses. Un règlement type y est annexé pour faciliter son intégration directe dans toutes les règlementations nationales et internationales. 
47- Par ailleurs, qu'entend-on par marchandise conventionnelle ? Lorsque la marchandise n'est pas mise en conteneurs elle est dite conventionnelle. En effet, ce terme désigne : "L'ensemble des marchandises transportées à nu ou avec des emballages légers, sans conditionnement particulier autre que des emballages ponctuels..."72. La marchandise conventionnelle est également concernée par la présente étude. Car ce type de marchandise est régi par la législation du transport sous connaissement.

48- Enfin, s'agissant des marchandises en vrac, elles se définissent comme des marchandises non emballées et ne comportant pas d'éléments individualisables. On distingue du vrac solide tel que le blé, du vrac liquide tel que le pétrole et du vrac gaz. Mais tenant compte du fait que les vraquiers de pétrole et certainement ceux de gaz sont soumis à une règlementation spéciale notamment en matière de protection de l'environnement $\operatorname{marin}^{73}$, de chargement et de déchargement, etc., il y a lieu de les exclure de la présente étude. Quant aux transports de vrac tels que le blé, le vin, ... qui pourraient s'effectuer sous connaissement, ils sont concernés par la présente étude.

49- A la lumière des définitions des concepts clés du sujet, il convient de cerner son contour et ses implications. Ce faisant, nous allons examiner les difficultés liés au transport de marchandises par mer tout en envisageant une hypothèse de travail.

\section{$\S 2$ : Difficultés du transport de marchandises par mer et hypothèse de travail}

50- Aujourd'hui, force est de constater que la conteneurisation est prisée par rapport au trafic conventionnel. Selon un auteur, "Le conteneur, du fait de ses exigences techniques, de son caractère intermodal et de son recours à un

\footnotetext{
${ }^{72}$ www.logistiqueconseil.org/articles/transport-routier/type-transport-marchandises.htm.

73 Voir DAKOURI (Jean-Claude), Le droit maritime international et le transport des Hydrocarbures, Thèse, Maastricht, 2011, op. cit., pp. 11 et 12. Le phénomène de marée noire qui résulte souvent du transport des hydrocarbures lui vaut une règlementation spéciale.
} 
navire spécialisé, transforme le paysage portuaire et le fonctionnement des ports traditionnels de l'après Seconde Guerre mondiale» ${ }^{74}$.

51- Une telle transformation du paysage portuaire et du fonctionnement des ports traditionnels peut-elle survenir sans effets secondaires ? La réponse est sans doute négative. C'est pourquoi, nous estimons nécessaire de passer en revue les différents problèmes qui résultent du trafic maritime en général et du transport conteneurisé en particulier (A) afin d'envisager une hypothèse et une méthodologie de travail (B) qui soient capables d'indiquer une orientation à l'étude.

\section{A- Problèmes liés au trafic maritime, problème de recherche et intérêt de l'étude}

52- Des problèmes liés au trafic maritime et en particulier à l'utilisation des conteneurs restent posés (1) ; nous indiquerons celui qui paraît englober les autres, le problème de recherche (2); et enfin l'intérêt de la présente étude (3).

\section{1- Les problèmes liés au trafic maritime}

53- La Convention de Bruxelles de 1924 pose problème à travers le sectionnement juridique du contrat de transport ${ }^{75}$ qu'elle a prévu. En effet, ce sectionnement du contrat de transport peut exposer la marchandise à une incertitude juridique lorsqu'elle se trouve dans les phases pré et post maritimes ${ }^{76}$. De quelle protection peut donc bénéficier la marchandise transportée en ces phases non maritimes?

54- On notera par la suite les problèmes relatifs à la fourniture du conteneur et à sa nature juridique (a), à la vérification des déclarations du

\footnotetext{
${ }^{74}$ DAMIEN (M. M.), Transport et logistique fluviaux, Edition Dunod, 2009, p. 110.

${ }^{75} \mathrm{~A}$ propos de sectionnement juridique du contrat de transport maritime, voir RIPERT (G.), « Le sectionnement du transport maritime ", DMF 1950, 471 ; CASSAN (L), " La phase maritime du transport de marchandises par mer », DMF 1963, 690 ; LAFAGE (G.H.), « Le régime juridique applicable aux opérations ante et post palan du contrat de transport maritime ", L’informateur de Sète, 14 août $1961, \mathrm{n}^{\circ}$ VIII.

${ }^{76}$ La question est d'autant plus préoccupante que sous l'empire du sectionnement juridique du contrat de transport, la marchandise n'est prise en charge par le transporteur que pendant la phase maritime qui s'étend strictement « de palan à palan : du chargement au déchargement ".
} 
chargeur relatives à la marchandise conteneurisée (b), et enfin à la piraterie et à la criminalité maritime (c).

\section{a- La fourniture du conteneur et sa nature juridique}

55- Selon les statistiques, cinquante pour cent (50\%) des conteneurs appartiennent aux transporteurs maritimes ou armateurs et les cinquante autres pour cent (50\%) sont la propriété d'opérateurs de transport77 qui les mettent à la disposition de toute personne intéressée en vue de leur location. La fourniture du conteneur par un tiers présente sans doute deux cas de figure : soit le chargeur loue un conteneur qu'il confie au transporteur; ou bien le transporteur loue un conteneur qu'il met à la disposition du chargeur qui a contracté avec lui ${ }^{78}$.

56- Des auteurs font remarquer que : «Les problèmes posés par la mise à disposition des conteneurs dans le cadre d'un transport maritime sont récurrents et diversifiés [...]. On pense notamment à la restitution des conteneurs et à son régime juridique. On pense aussi aux responsabilités encourues liées à la fourniture de conteneurs ${ }^{79}$. La préoccupation ici est de préciser quelles sont les règles de droit applicables à chaque cas.

57- Par ailleurs, la nature juridique conférée au conteneur a donné lieu à une controverse. Selon certaines conventions, le conteneur est un engin de transport $^{80}$ tandis que d'autres auteurs le considèrent comme un emballage ${ }^{81}$.

\footnotetext{
$77 \mathrm{http} / / /$ unctad.org/fr/Pages/Statistics.aspx.

78 HELAL (R.), "Conteneur maritime", Capitaine Au Long Cours. GROUP-CNAN/NORD EUROPE, Juillet 2013, p. 4.

${ }^{79}$ BONASIES (P.) et DELEBECQUE (P.), « Le Droit Maritime Français », La Revue Maritime, juin 2012, Hors-série $n^{\circ} 16$, pp. 77 et 109.

${ }^{80}$ Voir Convention pour la Sécurité des Conteneurs (CSC), 02 décembre 1972 à Genève, art. 2 ; voir aussi Convention douanière relative aux conteneurs, décembre 1972, Genève, op. cit., art. 1 ; voir également Convention de Rotterdam du 23 septembre 2009, op. cit., art. 1er paragraphe 26.

${ }^{81}$ WAROT (J.), "L'avènement du container dans le trafic maritime ", DMF 1951, op. cit., p. 263.
} 
Quant à la jurisprudence française, elle a considéré le conteneur comme un simple emballage ${ }^{82}$.

58- L’issue de cette controverse était d'une importance capitale. Car le régime de responsabilité des dommages aux marchandises dus à la conteneurisation en dépendait étroitement. Ainsi, lorsque le conteneur était considéré comme engin de transport le transporteur était responsable des dommages qu'il cause et en tant qu'emballage, c'est le chargeur qui en était responsable 83 .

59- Mais aujourd'hui, l'on s'interroge sur l'intérêt de ce débat d'antan relatif à la nature juridique du conteneur par rapport à la question de la responsabilité liée à la conteneurisation. Car les dommages dus à la conteneurisation sont désormais soumis à un régime juridique qui se distingue nettement de celui qui était fonction de la nature juridique du conteneur. Aujourd'hui, la responsabilité des dommages à la marchandise dus à la conteneurisation incombe soit au loueur qui a fourni un conteneur en mauvais état soit au professionnel qui a effectué un empotage défectueux ${ }^{84}$.

\section{b- La vérification des déclarations du chargeur relatives à la marchandise conteneurisée}

60- Lorsque le conteneur est empoté par le chargeur, il le présente au transporteur déjà plombé. Pour diverses raisons ${ }^{85}$, le transporteur s'abstient de procéder à la vérification de la marchandise mise en conteneur après la scellée.

\footnotetext{
82 Tribunal de commerce Bordeaux, 18 août 1982, BT. 1982, p. 125 ; Cass. com. 16 novembre 1983 n 79. 17. 031, BT. 1984, p. 385 ; Lyon, 11 mai 1978, BT. 1978, p. 317.

${ }^{83}$ Mais cette nature juridique est aujourd'hui sans effet sur le régime de responsabilité lié à la défaillance du conteneur ou de son empotage. Voir Cass. Com. 13 juin 1935 n $^{\circ} 93-14861$. Paris 30 sept. 1992. n91/815 ; Aix-en-Provence, 31 mai 1990. BT. 1950, p. 663 ; Rouen 2 déc. 1982, BT. 1983 p. 210 ; Cass. Com. 27 mars 1973 n²272, BT 1973, p. 240 ; CA Lyon, 11 mai 1978, BT. 1978 p. 317 ; CA Aix-en-Provence, $2^{\text {ème }}$ ch. 24 fév. 1994 inédit.

84 Voir Aix-en-Provence, 31 mai 1990. BT. 1950, p. 663 ; Rouen 2 déc. 1982, BT. 1983 p. 210 ; Cass. Com. 27 mars 1973 n²272, BT 1973, p. 240 ; CA Lyon, 11 mai 1978, BT. 1978 p. 317.

${ }^{85} \mathrm{La}$ réalité est que pour des raisons technique et économique, le transporteur se fie aux déclarations du chargeur. En effet, techniquement le transporteur ne peut rompre les plombs du conteneur et économiquement quel serait le coût de l'ouverture d'un conteneur plombé, de son dépotage, de la vérification des déclarations du chargeur relatives à la marchandise et enfin de son empotage à nouveau?
} 
Cette difficulté a été bien perçue par le doyen Rodière qui l'avait soulignée en ces termes: "Le "container" n'est qu'un objet nouveau proposé au contrat de transport. On dira qu'il n'a vraiment de valeur que s'il n'est plus ouvert une fois clos. Soit, mais cela ne va pas contraindre les transporteurs maritimes à acheter "chat en poche", ici à prendre pour véridiques les affirmations du [groupeur], ... déclarant que le cadre présenté contient tant de colis ou telle et telle choses. Un compromis devra s'établir entre, d'une part, les nécessités économiques et commerciales et, d'autre part, cette vérité de bon sens que le transporteur ne peut pas accepter les yeux fermés les déclarations de ses clients ${ }^{86}$.

61- La vérification des déclarations du chargeur pose alors un réel problème de sécurité comme le note l'Organisation mondiale des douanes (OMD) en ces termes: "les scellés manuels ou mécaniques de haute sécurité peuvent jouer un rôle significatif dans un programme complet de sécurité des conteneurs. Mais il est important de reconnaître que celle-ci débute avec le remplissage du conteneur et que les scellés ne prouvent pas ou ne garantissent pas la régularité $d u$ chargement» ${ }^{87}$. Il est clair que l'insécurité du trafic conteneurisé commence, à n'en point douter, par l'empotage du conteneur.

62- Alors, se pose d'une part l'épineuse question de savoir comment prévenir l'empotage de produits prohibés telles que les drogues, les armes de toutes natures (à feu ou chimiques), les déchets industriels etc. D'autre part, la préoccupation est de savoir comment éviter qu'un transport de marchandises dangereuses ne se mue irrégulièrement en un transport ordinaire de marchandises conteneurisées ${ }^{88}$. En d'autres termes, comment faire respecter la réglementation du trafic de produits dangereux aux usagers du transport maritime?

\footnotetext{
${ }^{86}$ RODIERE (René), Traité général de droit maritime, tome 2, DALLOZ, Paris 1968, $\mathrm{n}^{\circ} 513$, p. 147 et 148.

${ }^{87}$ Administrative Committee for the Customs Convention on Containers, Amendment proposals by contracting parties, Bruxelles, 1er oct. 2004, Doc. PB0007E1 Annexe 1.

${ }^{88}$ En effet, le transport des marchandises jugées dangereuses est soumis à une réglementation spéciale différente de celle qui régit le transport de marchandises conteneurisées et conventionnelles non jugées dangereuses.
} 


\section{c- La piraterie et la criminalité maritime}

63- La piraterie et la criminalité maritimes sont les deux principales sources de l'insécurité maritime. Selon Messieurs Bernard SITT et Benjamin Hautecouverture, la sécurité repose de plus en plus sur la capacité des Etats à prendre en main les menaces non militaires émanant d'acteurs non étatiques. Parmi celles-ci, l'une des principales résulte de l'étendue et de la vulnérabilité du trafic maritime des conteneurs ${ }^{89}$. En effet, le transport conteneurisé constitue une réelle menace pour la sécurité maritime. Par ailleurs, nous nous accordons avec Robert Sabrina pour dire que la sécurité maritime protège les personnes, les biens et préserve le milieu marin ${ }^{90}$.

64- Force est de constater que la recrudescence de la piraterie en particulier et la criminalité maritime en général compromettent assez gravement la sécurité de la navigation, entamant ainsi la protection des biens et des personnes visée par la législation des transports maritimes. La piraterie est définie comme un crime consistant, pour toute personne se trouvant à bord d'un aéronef en vol, d'un navire en mer ou de toute autre moyen de transport collectif, à s'en emparer ou à en exercer le contrôle par violence ou menace de violence $^{91}$. Toutefois, le droit international consacre le terme de piraterie aux crimes commis en haute mer, lieu qui ne relève de la juridiction d'aucun Etat. Dès lors, le terme approprié aux crimes commis dans les eaux territoriales d'un Etat, en vertu de la Résolution A. 922 (22) de l'Organisation Maritime Internationale, est celui de "vols à main armée ». La piraterie constitue une

\footnotetext{
89 Voir SITT (Bernard) et HAUTECOUVERTURE (Benjamin) "Sécurité des conteneurs", International Experts Group on Global Security (IEGGS), Rapport, janvier 2005, p. 668. www.ndu.edu/ctnsp/DefTech/DTP9\%20Container\%20 Security.pdf.

${ }^{90}$ Voir SABRINA (Robert), L'Erika : responsabilité pour un désastre écologique, Paris, éd. Pedon, octobre 2003, pp. 8-9; in DAKOURI (Jean-Claude), Le droit maritime international et le transport des Hydrocarbures, Thèse, Maastricht, 2011, note ${ }^{\circ} 25$, p. 17.

${ }^{91}$ Cf : GUILLIEN (Raymond) et VINCENT (Jean), Lexique des termes juridiques, DALLOZ,

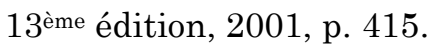


menace réelle car les itinéraires des porte-conteneurs, d'Asie en Europe, sont les plus exposés à ce fléau dans le monde ${ }^{92}$.

65- L'insécurité sur les côtes ivoiriennes devient aussi grandissante comme en témoignent le détournement du pétrolier français GASCOGNE battant pavillon luxembourgeois ${ }^{93}$ dans les eaux ivoiriennes la nuit du 2 au 3 février 2013, celui du tanker «ORFEAS» dans le courant d'octobre $2012^{94}$ au large de San-Pedro et la prise du pétrolier «ITRI» battant pavillon panaméen par les pirates le 16 janvier 2013 au large d'Abidjan, pour ne citer que ceux-ci. Des cargaisons entières de navires sont ainsi vidées par des pirates ${ }^{95}$. « $A$ l'évidence, la piraterie dans les eaux ivoiriennes est en pleine poussée. La Côte d'Ivoire n'a pas pu contrarier la montée en puissance des pirates qui menacent sérieusement le trafic dans les différents ports du pays" affirmait un expert maritime 96 .

66- Dès lors, des mesures de sécurité s'avèrent nécessaires. D’où l'opportunité qui se présente dans cette étude, d'examiner les instruments de

\footnotetext{
92 Voir «Les mutations de la marine marchande et la conteneurisation ». http//www.museemarine-fr/sites/delfault/.

${ }^{93}$ Le pétrolier français avait à son bord 17 membres d'équipage, dont sept Togolais, quatre Béninois, deux Ivoiriens, deux ${ }^{22}$ Sénégalais, un Chinois et un Sud-Coréen. Ensuite, les pirates bien armés se sont dirigés vers l'est où le navire a été localisé au large du Nigeria trois jours plus tard, mais délesté d'une partie de sa cargaison. Selon les responsables du navire, les 17 membres d'équipage sont sains et saufs, mais deux d'entre eux ont été légèrement blessés et ont reçu les premiers soins à bord. Le navire était attendu dans la soirée du mercredi 6 février au port de Lomé, au Togo._Dès l'annonce de la disparition du navire, le Bénin qui est voisin du Nigeria, a mis en alerte ses forces navales, avec des patrouilleurs qui ont multiplié des opérations de surveillance tandis que les équipements radar de la base navale balayaient les côtes béninoises pour identifier des déplacements suspects sur la mer. Voir http://www.connectionivoirienne.net/82215/la-cote-divoire-face-a-la-piraterie-maritime.

${ }^{94}$ Le 6 octobre 2012 a eu lieu au large de San-Pedro dans le sud-ouest de la Côte d'Ivoire, une attaque contre le tanker Orfeas, immatriculé aux Bahamas et appartenant à la compagnie grecque 'Grace Management'. Une partie de la cargaison d'environ 30.000 tonnes d'essence avait été emportée par les pirates. Voir http://www.connectionivoirienne.net/82215/la-cote-divoireface-a-la-piraterie-maritime, consulté avril 2016.

${ }^{95} \mathrm{http} / / / \mathrm{www} . c o n n e c t i o n i v o i r i e n n e . n e t / 82215 /$ la-cote-divoire-face-a-la-piraterie-maritime, consulté en mai 2017.

96 Voir OKANZA (Kouamé Ambroise), Expert en économie maritime basé à Abidjan. Voir http://www.connectionivoirienne.net/82215/la-cote-divoire-face-a-la-piraterie-maritime, consulté en janvier 2016.
} 
prévention, de répression et de lutte permanente contre la piraterie en mer en particulier et l'insécurité maritime et portuaire en général. Au regard des différents problèmes relatifs aux transports de marchandises par mer et à la protection des personnes et des biens, il convient de nous interroger sur la problématique réelle qui induit et sous-tend notre étude.

\section{2- La problématique de recherche}

67- La législation des transports maritimes de marchandises suscite un certain nombre d’interrogations au nombre desquelles nous retiendrons les plus pertinentes. Le problème essentiel qui sous-tend notre recherche est de savoir si en droit ivoirien, les normes qui régissent la navigation maritime protègent efficacement les transports de marchandises par mer. Les normes de lutte contre l'insécurité de la navigation maritime contribuent-elles à éradiquer la piraterie et la criminalité dans le golfe de Guinée ? En d'autres termes, les normes de sécurité et de prévention des dommages à la marchandise ne comportent-elles pas de limites qui réduisent leur efficacité ? A la lumière des législations étrangères, existe-il des perspectives d'amélioration de la législation ivoirienne pour rehausser l'efficacité de la protection de la marchandise et celle de la sûreté de la navigation maritime?

\section{3- L'intérêt de l'étude}

68- Notre étude présente des intérêts d'ordres scientifique et pratique. Au niveau scientifique, nous ferons une analyse globale des normes juridiques applicables au trafic de marchandises par mer en Côte d'Ivoire et à la lutte contre les trafics illicites et l'insécurité maritime. A travers nos réflexions, nous entendons contribuer à l'amélioration du droit ivoirien des transports de marchandises par mer.

69- $\mathrm{Au}$ niveau pratique, notre étude vise à rassurer les opérateurs du secteur des transports de marchandises par mer en Côte d'Ivoire. A ce titre, elle 
peut profiter aux acteurs des transports maritimes. En outre, l'étude tient également compte des intérêts des compagnies d'assurance ${ }^{97}$ et des banquiers ${ }^{98}$.

70- Par ailleurs, l'étude intéresse également nos administrations qui ont en charge la sécurité des personnes et des biens ainsi que la protection de notre économie, notamment l'administration des Affaires Maritimes et Portuaires et l'administration des Douanes. Ces services administratifs peuvent y recourir notamment en ce qui concerne les recommandations relatives à la lutte contre les trafics illicites et la criminalité maritime.

\section{B- Hypothèse de travail, approche méthodologique et annonce du plan}

71- Préalablement aux différents développements proprement dits, il convient de dresser une hypothèse de travail (1), donner l'approche méthodologique (2) et enfin annoncer le plan de l'étude (3).

\section{1- Hypothèse de travail}

72- Nos recherches sont fondées sur deux hypothèses de travail. D’abord, il est indéniable que des normes régissant la navigation maritime, en vue de réglementer les transports de marchandises par mer, existent. Cependant, il est possible de déceler des limites quant-à leur efficacité. En effet, la législation est censée protéger les intérêts des transports maritimes. Mais il apparaît que des dommages subis par la cargaison et les attaques contre la navigation maritime persistent. Aussi, des infractions maritimes et des trafics illicites sont toujours constatés à l'occasion des transactions maritimes.

73- A travers un examen critique des instruments juridiques adoptés pour la protection de la marchandise et la lutte contre l'insécurité de la navigation

\footnotetext{
${ }^{97}$ L'assurance maritime est indispensable au transport de marchandises par mer.

98 Notons que les banquiers sont beaucoup impliqués dans le commerce international et corrélativement dans le transport maritime international de marchandises à travers les crédits documentaires qu'ils octroient à leurs clients. En effet, Le crédit documentaire qui est un outil fondamental du commerce international se définit comme un : "Contrat par lequel une banque, conformément aux instructions d'un acheteur, s'engage à régler au vendeur le prix d'une marchandise contre remise de certains documents" ; en particulier le connaissement. Voir Lamy transport, tome 2, édition 2010, p. 985.
} 
maritime, nous rechercherons leurs éventuelles limites tant au plan international que national ivoirien.

74- En outre, il est possible que des normes nationales de certains pays étrangers notamment le Canada ${ }^{99}$, la France ${ }^{100}, \ldots$ et des normes régionales européennes ${ }^{101}$ présentent des avancées en matière de sécurité de la marchandise et de lutte contre l'insécurité maritime. C'est pourquoi, nous analyserons les droits canadien, belge et français. Dans le même ordre d’idée, nous analyserons le droit communautaire européen consacré à la sûreté de la navigation maritime. Sur la base des avancées des normes étrangères issues de ces analyses en droit comparé, nous envisagerons les perspectives d'amélioration des normes de lutte contre l'insécurité maritime en droit ivoirien. Ce faisant, nous entendons recourir à une méthodologie précise en vue de mener à bien nos développements.

\section{2- Approche méthodologique}

75- Pour répondre à la problématique que sous-tend le thème de notre étude, nous avons fait le choix de deux méthodes : l'une est dialectique et l'autre comparative. La méthode dialectique va nous permettre de mettre en exergue le contraste existant entre une législation à vocation protectrice des transports de marchandises par mer et des défis sécuritaires.

76- Au niveau de la méthode comparative, nous aurons recours au droit comparé. Ce recours se justifie par notre volonté de nous inspirer des solutions issues d'autres pays et à l'échelle internationale en matière de protection des transports de marchandises par mer. Ces expériences vont nous permettre de faire des recommandations en vue de rehausser l'efficacité de la protection de la marchandise et celle de la lutte contre l'insécurité maritime qui entrave les

\footnotetext{
99 Voir loi canadienne de 1993, art. 7-2 et art. 111-1.

100 Voir loi française $n^{\circ} 66-420$ du 18 juin 1966, arts. 15, 16 et 27.

101 Voir par exemple l'Accord de l'Union Européenne relatif aux trafics illicites par mer adopté à Strasbourg le 31 janvier 1995 et le Règlement n 725/2004 du 31 mars 2004 relatif à l'amélioration de la sûreté des navires et des installations portuaires en application du Code ISPS adopté par le Parlement et le Conseil de l'Europe
} 
transports maritimes au plan international et à l'échelle nationale ivoirienne en particulier.

77- Dans cette optique nous visons à encourager des mesures de coopération opérationnelle et d'entraide judiciaire entre la Côte d'Ivoire et les Etats de la sous-région ouest-africaine à la lumière de la stratégie de lutte contre l'insécurité maritime dans l’Union européenne.

\section{3-Annonce du plan}

78- En guise de réponse à notre problématique, le plan de nos développements comportera deux axes. En effet, les normes régissant la navigation maritime censées protéger les transports de marchandises par mer existent en droit ivoirien (Partie I) certes, mais elles comportent des limites. Ces limites rendent nécessaire l'amélioration de la législation existante en vue du rehaussement de son efficacité. (Partie II). 
PREMIERE PARTIE : L'EXITENCE D'UNE LEGISLATION CENSEE PROTEGER LES TRANSPORTS DE MARCHANDISES PAR MER EN DROIT IVOIRIEN 
80- La question se pose de savoir s'il existe une règlementation propre au trafic conteneurisé. Cette préoccupation a été soulevée par le doyen Rodière qui a aussitôt pris position en ces termes : "Mais la question, toute autre, est de savoir si cette technique [la conteneurisation] appelle une législation du transport qui leur soit particulière et la réponse doit être rigoureusement négative sauf sur un point. Croire le contraire relève de l'hérésie juridique consistant à croire que la nature concrète des choses doit peser toujours sur le statut des contrats dont elles sont l'objet, à croire que la vente ou le transport d'un kilo de bananes ou de 100 tonnes de ciment doivent s’inscrire dans des cadres juridiques différents »102.

81- Il ressort de la position de l'auteur que le transport maritime conteneurisé n'appelle pas une législation spéciale. La législation qui régit le transport de marchandises par mer est donc habilitée à s'appliquer au transport maritime conteneurisé. En d'autres termes, la législation régissant le transport conventionnel est également applicable au transport conteneurisé.

82- Au niveau de ce premier axe de notre étude, il est question d'indiquer d'abord le contenu de la législation du transport de marchandises par mer avant de préciser le but recherché. La règlementation des transports maritimes a pour principal objectif de définir les normes juridiques devant régir ce mode de transport. Cependant, les rédacteurs de ces différents textes juridiques en question, conscients des dangers qui jalonnent ce mode de transport, ont visé un second objectif à savoir la protection des intérêts des acteurs du transport maritime.

83- Comment le législateur maritime ${ }^{103}$ protège-t-il les intérêts des usagers et des acteurs du transport maritime? En la matière nous distinguons

102 RODIERE (R), Traité général de droit maritime, tome 2, DALLOZ, Paris 1968, n 513, p. 148. ${ }_{103} \mathrm{Au}$ sens large du terme le législateur maritime désigne « tout organe pouvant édicter des règles juridiques générales (normes de droit), que ce soit le gouvernement ou le Parlement». Voir GUILLIEN (Raymond) et VINCENT (Jean), Lexique des termes juridiques, DALLOZ, 13ème édition, 2001, p. 620. A ces deux entités (Parlement et gouvernement), viennent s'ajouter les Etats et les organisations internationales. Puisque la législation maritime concerne non seulement les textes nationaux (lois, décrets arrêtés,... pris soit par le Parlement soit par le gouvernement) mais aussi les conventions internationales adoptées par les Etats et les organisations internationales. Le terme convention au sens générique vise tous les accords 
deux types de protection à savoir la protection des parties au contrat de transport et la protection contre les agissements des tiers ${ }^{104}$. Ces deux types de protection sont censés constituer la législation des transports maritimes de marchandises. Par ailleurs, la question se pose de savoir si cette législation protège efficacement les intérêts des transports maritimes. Pour répondre correctement à cette préoccupation, il convient au préalable de faire une analyse critique dudit cadre juridique aux fins d'en déterminer ses forces et faibles.

84- Ainsi, dans ce premier axe de l'étude qui porte sur la législation censée protéger les intérêts des transports maritimes, nous montrerons d'une part, qu'il existe effectivement un cadre législatif relatif aux transports de marchandises par mer (Titre 1) en droit ivoirien. D'autre part, nous ferons une analyse critique de celui-ci (Titre 2).

internationaux tout comme le mot traité qui est défini par la convention de vienne de 1969 sur le droit des traités entre Etats en son art. 2 comme étant un " accord international conclu par écrit entre Etat et régi par le droit international, qu'il soit consigné dans un instrument unique ou dans deux ou plusieurs instruments connexes, et qu'elle soit sa dénomination particulière. ${ }^{104}$ Par agissements des tiers, entendons les infractions contre la sureté maritime telles que la piraterie en mer, la criminalité maritime, le trafic de drogue et stupéfiants, le trafic illicite d'armes, la pollution maritime etc. 
TITRE 1 : UN CADRE LEGISLATIF CONSACRE AUX TRANSPORTS DE MARCHANDISES PAR MER 
85- La protection des transports de marchandises par mer porte sur les intérêts des parties au contrat de transport et sur les agissements des tiers contre la sûreté de la navigation maritime. Les instruments juridiques de protection de la marchandise peuvent se situer en amont de l'opération de transport 105 ou en aval de ladite opération ${ }^{106}$. L'approche préventive de la protection consiste à mettre en place des mécanismes juridiques permettant d'éviter que des dommages surviennent à la marchandise. En ce qui concerne l'approche curative, elle consiste à prévoir des mécanismes juridiques permettant de réparer les éventuels dommages subis par la marchandise au cours de son expédition.

86- S'agissant de la protection contre les agissements des tiers, la conteneurisation 107 est susceptible de devenir un moyen propice aux trafics illicites. Par conséquent, elle peut se muer en un facteur d’insécurité pour le transport maritime. Dès lors, en plus de la criminalité maritime et la piraterie $^{108}$, des armes de toutes natures, des marchandises dangereuses et même des déchets industriels peuvent être camouflés dans des conteneurs pour être acheminés à différents endroits et servir à des fins illicites. La conteneurisation ouvre la voie aux trafics illicites, car sous la couverture de la scellée, les délinquants arrivent à faire circuler les marchandises prohibées.

87- Face aux agissements des tiers contre les intérêts du transport de marchandises par mer, des normes juridiques ont été prévues, tant au niveau international qu'au niveau national ivoirien, pour prévenir et réprimer, le cas échéant, les infractions qui y sont liées.

\footnotetext{
105 C'est l'approche préventive de la protection.

${ }^{106} \mathrm{Il}$ s'agit d'une approche curative de la protection appelée encore la réparation des dommages subis par la marchandise.

${ }^{107}$ La conteneurisation confère une sorte d'anonymat à la marchandise transportée. Voir supra $\mathrm{n}^{\circ} 9$ et 10, p. 4 et $\mathrm{n}^{\circ} 62$, p. 25.

108 Voir BRONER (Romain), La répression de la piraterie maritime et ses enjeux juridiques, Mémoire, Université Panthéon-Assas - paris II, Année 2009/2010, p. 18. L’auteur indique que matériellement, l'acte de piraterie est le même que celui du brigandage (ou criminalité maritime), seul le lieu de commission de l'infraction varie. La piraterie se déroule en haute mer ou dans les zones qui ne relèvent de la juridiction d'aucun État et dispose de son propre régime juridique, alors que le brigandage a lieu dans la mer territoriale d'un État.
} 
88- Eu égard aux objectifs visés par la protection des transports de marchandises à savoir la sécurité et la sûreté de la navigation maritime et celle de la marchandise transportée, les différentes conventions régissant le transport maritime ne peuvent se renfermer dans des cloisonnements hermétiques entre elles. Pour les besoins d'organisation des différents développements de notre étude, nous avons regroupé d'un côté les instruments de protection de la marchandise contre les dommages et de l'autre côté les instruments de lutte contre l'insécurité maritime.

89- Le cadre législatif consacré aux transports maritimes permettra de montrer que le législateur ivoirien a prévu des normes juridiques pour la protection de la marchandise transportée (Chapitre 1) et des normes juridiques pour la lutte contre l’insécurité maritime (Chapitre 2) 


\section{CHAPITRE 1: LES NORMES INTERNATIONALES ET NATIONALES DE PROTECTION DE LA MARCHANDISE}

90- Par l'expression "protection de la marchandise ", il faut entendre la prévention du dommage à la marchandise et, le cas échéant, la réparation d'éventuels dommages subis par la marchandise. Selon le dictionnaire le Grand Robert, prévenir c'est empêcher par des précautions un mal, un abus. Prévenir c'est aussi éviter une chose considérée comme gênante en prenant les devants ${ }^{109}$. La prévention des dommages consiste donc à sauvegarder l'intégrité physique de la marchandise pendant son expédition. En ce qui concerne la réparation des dommages subis par la marchandise, elle consiste à prévoir des normes juridiques permettant de situer la responsabilité des acteurs du transport en vue de l'indemnisation des préjudices subis.

91- Le transport maritime étant par nature international110, les mesures de protection de la marchandise doivent, par souci d'efficacité, être prises dans un cadre interétatique concerté. Cela peut se constater par le fait que la Côte d'Ivoire est membre en la matière de deux organisations communautaires régionale et internationale. Il s'agit respectivement de l'Organisation Maritime de l'Afrique de l'Ouest et du Centre111 (OMAOC) et de l'Organisation Maritime Internationale112 (OMI). L'OMI est une institution spécialisée de l'Organisation

\footnotetext{
${ }^{109}$ Robert/SEJER, 2005, www, lerobert.com, consulté le 27 septembre 2017.

110 Cette nature internationale découle de ce que la mer à l'inverse des frontières terrestres qui divisent les systèmes juridiques et les peuples, a toujours été un trait d'union entre les cultures juridiques, un lieu de rencontre entre les hommes.

${ }^{111}$ L'Organisation Maritime de l'Afrique de l'Ouest et du Centre OMAOC créée en mai 1975 à travers la Charte d'Abidjan, était connue à l'origine sous la dénomination de CMEAOC/TM. Depuis 1999, l'OMAOC a pour missions de : promouvoir des services de transport maritime rentables, la sécurité et la sûreté maritime, la circulation de l'information, le renforcement des capacités des acteurs du transport maritime, le financement durable de l'industrie des transports maritimes et la facilitation du transport en transit vers les Etats membres sans littoral. https://www.iho.int/mtg-docs/rchc/EAtHC.

112 Voir Convention du 6 mars 1948 portant création de l'Organisation Maritime Consultative Internationale OMCI, art. 1. "L'OMCI est devenue aujourd'hui l'OMI: Organisation Maritime Internationale en vertu des amendements à la convention portant création de l'organisation et entrée en vigueur le 22 mai 1982. L'OMI se présente comme l'institution spécialisée des Nations
} 
des Nations Unies ${ }^{113}$ qui n'est compétente que pour des questions de sécurité et de coopération technique à l'exclusion des questions économiques qui sont attribuées à la CNUCED ${ }^{114}$. La Convention du 6 mars 1948 portant création de l'Organisation Maritime Consultative Internationale (OMCI) dispose que la mission de l'OMI est d'instituer un système de collaboration entre les gouvernements dans le domaine de la réglementation et des usages gouvernementaux ayant trait aux questions techniques de toutes sortes qui intéressent la navigation commerciale. Aussi, elle doit encourager et faciliter l'adoption générale de normes aussi élevées que possible en ce qui concerne la sécurité maritime, l'efficacité de la navigation, la prévention de la pollution et traiter des questions administratives et juridiques liées aux objectifs énoncés dans le présent article 115 .

92- Quels sont les instruments juridiques prévus par le législateur pour garantir la protection de la marchandise au cours de son transport maritime? A travers les dispositions pertinentes des différents instruments juridiques, seront examinées successivement le système de protection de la marchandise selon les normes internationales (Section 1) et selon les normes ivoiriennes (Section 2).

Unies dont l'activité est entièrement consacrée aux questions de la sécurité maritime. Elle regroupe aujourd'hui 168 États membres".

113 BOUDONG (Nathalie), La piraterie maritime moderne, Mémoire, UNIVERSITE PAUL CEZANNE III, Droit maritime et des transports, Année universitaire 2008/2009. pp. 48 et 50. Selon l'auteur, l'OMI a son siège au Royaume-Uni, 166 Etats en sont membres et deux en sont associés. Une Assemblée se réunit tous les deux ans, et un Conseil, organe décisionnel, est composé de 40 gouvernements élus par L'Assemblée. Quatre comités principaux coexistent au sein de l'OMI : le Comité de la sécurité maritime (MSC), le Comité de la protection du milieu marin, le Comité juridique, et le Comité de la coopération technique. Il existe par ailleurs un Comité de la simplification des formalités.

114 Voir ASSONITIS (Géorges), "Règlementation internationale dans les transports maritimes dans le cadre de la CNUCED ", Puf, Paris, 1991, pp. 5 et s.

$115 \mathrm{Cf}$ : Convention du 6 mars 1948 portant création de l'Organisation Maritime Consultative Internationale (OMCI), art. 1 amendé. 


\section{Section 1: La protection de la marchandise selon les normes internationales}

93- Selon un auteur, "Les espaces maritimes sont un élément central de l'histoire humaine. Dès l'antiquité, la plupart des civilisations se sont basées sur une composante maritime essentielle à leur développement, comme la civilisation grecque ou encore l'empire phénicien. Comme l'énonce Raleigh, la maîtrise des mers est indissociable de toute activité économique, de commerce, et donc de prospérité. De cette richesse, de cette prospérité découlent à la fois la puissance et le rayonnement d'une civilisation $" 116$.

94- Ce constat de Monsieur Romain BRONER met en évidence la nécessité de sécuriser les espaces marins eu égard aux enjeux qu'ils présentent117. En effet, de nombreux dangers sont liés à la navigation maritime ${ }^{118}$. Des cargaisons entières de navires sont non seulement exposées aux éventuels dommages mais aussi sont l'objet de convoitise des pirates de mer et autres criminels. A cela s'ajoutent les trafics illicites résultant du transport de certaines marchandises mises en conteneurs. C'est pourquoi, le législateur maritime international a prévu des normes juridiques en vue de sécuriser les transports de marchandises par mer.

95- La protection des transports maritimes revêt plusieurs aspects. Il s'agit essentiellement de la sécurité et de la sûreté de la navigation maritime. La protection des transports maritimes touche également la sauvegarde de la

\footnotetext{
116 BRONER (Romain), La répression de la piraterie maritime et ses enjeux juridiques, Mémoire de Master de recherche, Université Panthéon-Assas - Paris II. Année universitaire 2009 - 2010, p. 7 .

117 Voir BEALL (Jacques), "La politique européenne de transport maritime au regard des enjeux de développement durable et des engagements climat ", JORF du 11 mai 2017, Rapport, op. cit., p. 26. L'auteur précise que concrètement, l'Organisation a pour mission d'élaborer des normes internationales d'une part dans le domaine de la sécurité et de la sureté maritimes, d'autre part dans le domaine de la protection de l'environnement. Elle conçoit également des instruments de " droit souple " et facilite la mise en œuvre des conventions adoptées pour une application uniforme et universelle. Il est important de noter que l'OMI traite marginalement des questions de droit social.

118 Nous pensons notamment aux catastrophes naturelles en mer, aux difficultés liées à la réparation des dommages subis par la marchandise, aux trafics illicites, à la piraterie et à la criminalité maritime.
} 
vie humaine en mer contenue dans la Convention SOLAS ${ }^{119}$. La présente analyse portera sur les mesures d'avant la survenance des périls maritimes ( $\$$ 1) ensuite sur les solutions suite à la survenance des périls maritimes (\$2).

\section{$\S 1$ : Les mesures d'avant la survenance des périls maritimes}

96- Dans l'optique de prévention des dommages à la marchandise, les Etats membres de l'OMI ont adopté diverses conventions. Nous analyserons notamment la Convention de Montego Bay de 1982 et la Convention sur les normes de formation du personnel naviguant, de délivrance de brevets et de veille de 1978 (A), ensuite la Convention internationale sur la sécurité des conteneurs (CSC) de 1972 et le Code ISPS de $2002^{120}$ (B).

\section{A- Les normes prévues par la Convention de Montego Bay de 1982 et la Convention sur les normes de formation du personnel naviguant, de délivrance de brevets et de veille de 1978}

97- En ce qui concerne la prévention des dommages à la marchandise, seront examinées les normes prévues par la Convention de Montego Bay $(\mathrm{CMB})^{121}$ (1) et la Convention sur les normes de formation du personnel naviguant, de délivrance de brevets et de veille de 1978 (2)

\section{1- Les normes prévues par la Convention de Montego Bay de 1982}

98- En vue de sécuriser la navigation et assurer une protection efficace de la marchandise transportée par mer, la Convention de Montego Bay (CMB) a procédé à un sectionnement juridique de l'espace marin ${ }^{122}$ à savoir la mer

\footnotetext{
119 LUCCHINI (L) et VOECKEL (M), "Droit de la mer. La mer et son droit. Les espaces maritimes", Pedon Paris, tome 1, 1996, op. cit., p. 315. L'auteur indique que la Convention SOLAS de 1974 lie 128 Etats représentant 98,3\% du tonnage mondial. Mais dans cette étude, nous n'avons pas évoqué la Convention internationale pour la sauvegarde de la vie humaine en mer SOLAS, conclue à Londres le 1er novembre 1974, destinée à remplacer la Convention internationale de 1960 pour la sauvegarde de la vie humaine en mer, afin de tenir compte des faits nouveaux intervenus depuis sa conclusion. La raison est toute simple : cette convention ne traite pas de la sécurité de la marchandise.

${ }^{120}$ Le code ISPS est le code international pour la sûreté des navires et des installations portuaires.

${ }^{121}$ La CMB est encore appelée Convention UNCLOS (United Nations Convention on the Law Of the Seas), Convention des Nations Unies sur le Droit de la Mer.

122 Voir le préambule de la Convention de Montego Bay : «Les Etats parties, ..., conscients que les problèmes des espaces marins sont étroitement liés entre eux et doivent être envisagés dans
} 
territoriale ${ }^{123}$, la mer contiguë, la zone économique exclusive et la haute mer. L'Etat côtier exerce sa souveraineté sur la mer territoriale sous réserve du libre passage inoffensive des navires étrangers. Sur la zone contigüe, l'Etat côtier exerce certains droits justifiés par sa protection douanière, fiscale, sanitaire ou militaire. L'Etat côtier reçoit en exclusivité tous les droits de nature proprement économique pouvant s'exercer dans la zone économique exclusive. Enfin, en haute mer ou zone internationale les droits de l'Etat du pavillon ${ }^{124}$ s'appliquent aux navires. Où qu'il se trouve, le navire est soit sous la compétence d'un Etat côtier soit sous l'autorité de l'Etat du pavillon ${ }^{125}$. Alors sa sécurité peut être assurée $^{126}$. On abordera les normes régissant la compétence de l'Etat côtier (a) et celles régissant l'autorité de l'Etat du pavillon en haute mer (b).

leur ensemble, reconnaissant qu'il est souhaitable d'établir, au moyen de la Convention, compte dûment tenu de la souveraineté de tous les Etats, un ordre juridique pour les mers et les océans qui facilite les communications internationales et favorise les utilisations pacifiques des mers et des océans, l'utilisation équitable et efficace de leurs ressources, la conservation de leurs ressources biologiques et l'étude, la protection et la préservation du milieu marin, considérant que la réalisation de ces objectifs contribuera à la mise en place d'un ordre économique international juste et équitable dans lequel il serait tenu compte des intérêts et besoins de l'humanité tout entière et, en particulier, des intérêts et besoins spécifiques des pays en développement, qu'ils soient côtiers ou sans littoral, ... ».

${ }^{123}$ Voir Convention de Montego Bay, art. 2: "Régime juridique de la mer territoriale et de l'espace aérien surjacent, ainsi que du fond de cette mer et de son sous-sol.

1. La souveraineté de l'Etat côtier s'étend, au-delà de son territoire et de ses eaux intérieures ...

2. Cette souveraineté s'étend à l'espace aérien au-dessus de la mer territoriale, ainsi qu'au ...

3. La souveraineté sur la mer territoriale s'exerce dans les conditions prévues par les ...".

124 Voir BEALL (Jacques), « La politique européenne de transport maritime au regard des enjeux de développement durable et des engagements climat ", JORF, 11 mai 2017, Rapport, op. cit., p. 108,. L'auteur définit l'État du pavillon comme le pays auprès duquel le navire est immatriculé et qui est responsable du respect des réglementations nationale et internationale, relevant notamment des conventions de l'OMI et des conventions européennes (si l'État est membre de l'UE) relatives à la sécurité, la sureté, à la dimension sociale et à l'environnement.

${ }^{125}$ Pour toutes ces précisions, voir GUINCHARD (Serge) et VINCENT (Jean), Lexique des termes

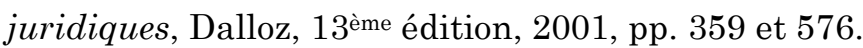

${ }^{126}$ Voir GALLETTI (Florence), "Le droit de la mer, régulateur des crises pour le contrôle des espaces et des ressources : quel poids pour des États en développement ?" Mondes en Développement, Vol. 39-2011/2-n¹54, pp. 123 et s. Selon l'auteur, les espaces, depuis la bande côtière, adjacents aux côtes des États et prolongés au plus loin jusqu'à la haute mer, cristallisent les velléités concurrentes d'États voisins ou éloignés les uns des autres, anciens ou nouveaux, émergents ou dominants, tous souverains sur leur territoire terrestre et entendant bénéficier d'une projection de cette souveraineté sur des espaces marins convoités comme "territoires maritimes", vus par les gouvernements comme le prolongement du territoire national terrestre. Au plan juridique, cette perception n'est pas tout à fait exacte. Si les espaces proches de la côte 


\section{a- Les normes régissant la compétence de l'Etat côtier}

99- Selon la Convention de Monte Bay, Lorsque les côtes de deux Etats sont adjacentes ou se font face, ni l'un ni l'autre de ces Etats n'est en droit, sauf accord contraire entre eux, d'étendre sa mer territoriale au-delà de la ligne médiane dont tous les points sont équidistants des points les plus proches des lignes de base à partir desquelles est mesurée la largeur de la mer territoriale de chacun des deux Etats. Cette disposition ne s'applique cependant pas dans le cas où, en raison de l'existence de titres historiques ou d'autres circonstances spéciales, il est nécessaire de délimiter autrement la mer territoriale des deux Etats $^{127}$.

100- Quel est le régime juridique de la mer territoriale? La souveraineté de l'Etat côtier s'étend, au-delà de son territoire et de ses eaux intérieures et, dans le cas d'un Etat archipel, de ses eaux archipélagiques, à une zone de mer adjacente désignée sous le nom de mer territoriale. Aussi, cette souveraineté s'étend à l'espace aérien au-dessus de la mer territoriale, ainsi qu'au fond de cette mer et à son sous-sol. Enfin, la souveraineté sur la mer territoriale s'exerce dans les conditions prévues par les dispositions de la Convention et les autres règles du droit international ${ }^{128}$.

102- Toutefois, l'article 17 prévoit que sous réserve de la Convention, les navires de tous les Etats, côtiers ou sans littoral, jouissent du droit de passage inoffensif ${ }^{129}$ dans la mer territoriale.

créent des droits de souveraineté très forts pour l'État côtier, cette souveraineté se dégrade avec l'avancée vers le large, pour se transformer en droits dits "de juridiction", moins complets, qui disparaissent, pour la plupart, une fois la haute mer atteinte ; ...

127 Voir Convention de Montego Bay de 1982, art. 15.

128 Convention de Montego Bay, art. 2.

129, Idem, art. 19 al. 1 : «Le passage est inoffensif aussi longtemps qu'il ne porte pas atteinte à la paix, au bon ordre ou à la sécurité de l'Etat côtier. Il doit s'effectuer en conformité avec les dispositions de la Convention et les autres règles du droit international ". Et l'article 18 dispose : "1. On entend par "passage" le fait de naviguer dans la mer territoriale aux fins de:

a) la traverser sans entrer dans les eaux intérieures ni faire escale dans une rade ou une installation portuaire située en dehors des eaux intérieures; ou

b) se rendre dans les eaux intérieures ou les quitter, ou faire escale dans une telle rade ou installation portuaire ou la quitter. 
101- Dans la zone contigüe, l'Etat côtier peut exercer le contrôle nécessaire en vue de, non seulement prévenir les infractions à ses lois et règlements douaniers, fiscaux, sanitaires ou d’immigration sur son territoire ou dans sa mer territoriale, mais aussi réprimer les infractions à ces mêmes lois et règlements commises sur son territoire ou dans sa mer territoriale ${ }^{130}$. La mer contiguë est donc sous juridiction de l'Etat côtier.

102- La zone économique exclusive est une zone située au-delà de la mer territoriale et adjacente à celle-ci, elle est soumise au régime juridique particulier établi par la présente partie ${ }^{131}$, en vertu duquel les droits et la juridiction de l'Etat côtier et les droits et libertés des autres Etats sont gouvernés par les dispositions pertinentes de la Convention ${ }^{132}$.

103- Dans la zone économique exclusive, l'Etat côtier exerce ses droits et s'acquitte de ses obligations en vertu de la Convention ${ }^{133}$. Il tient dûment compte des droits et des obligations des autres Etats et agit d'une manière compatible avec la Convention. Toutefois, dans la zone économique exclusive, tous les Etats, qu'ils soient côtiers ou sans littoral, jouissent, dans les conditions prévues par les dispositions pertinentes de la Convention, des libertés de navigation ${ }^{134}$.

104- Dans les cas où la Convention n'attribue de droits ou de juridiction, à l'intérieur de la zone économique exclusive, ni à l'Etat côtier ni à d'autres Etats et où il y a conflit entre les intérêts de l'Etat côtier et ceux d'un ou de plusieurs autres Etats, ce conflit devrait être résolu sur la base de l'équité et eu égard à toutes les circonstances pertinentes ${ }^{135}$. Et ce, compte tenu de l'importance que

2. Le passage doit être continu et rapide. Toutefois, le passage comprend l'arrêt et le mouillage, mais seulement s'ils constituent des incidents ordinaires de navigation ou s'imposent par suite d'un cas de force majeure ou de détresse ou dans le but de porter secours à des personnes, des navires ou des aéronefs en danger ou en détresse".

${ }^{130}$ Conformément à l'article 33 de la Convention de Montego Bay.

${ }^{131}$ Il s'agit de la partie IV de la Convention de Montego Bay.

132 Voir Convention de Montego Bay, art. 55.

${ }^{133}$ Idem, art. 56, al. 2.

${ }^{134}$ Convention de Montego Bay, art. 18, al. 1.

135 Convention de Montego Bay, art. 59. 
des intérêts en cause présentent pour les différentes parties et pour la communauté internationale dans son ensemble.

105- Nous devons conclure que dans la zone économique exclusive, l'Etat côtier comme tous les autres Etats exercent leur juridiction dans les conditions prévues par la convention. Nous convenons avec Florence GALLETTI que le droit de la mer est un moyen de formuler et de régler les conflits entre les Etats $^{136}$. Toutefois, les normes issues de la Convention de Montego Bay permettent de répartir le droit de poursuite judiciaire et de répression pénale des infractions relatives à la navigation maritime entre l'Etat côtier, l'Etat du pavillon du navire et l'Etat dont les victimes ou les auteurs de l'infraction sont ressortissants, etc.

\section{b- Les normes régissant l'autorité de l'Etat du pavillon en haute mer}

106- On entendait par haute mer toutes les parties de la mer n'appartenant pas à la mer territoriale ou aux eaux intérieures d'un Etat donné137. Aujourd'hui, la notion a évolué. L'article 86 de la Convention de Montego Bay définit la haute mer comme toutes les parties de la mer qui ne sont comprises ni dans la zone économique exclusive, la mer territoriale ou les eaux intérieures d'un Etat, ni dans les eaux archipélagiques d'un Etat archipel. La haute mer appelée encore zone internationale est donc l'espace maritime situé

\footnotetext{
${ }^{136}$ GALLETTI (Florence), « Le droit de la mer, régulateur des crises pour le contrôle des espaces et des ressources : quel poids pour des États en développement? ", op. cit., pp. 125 et s. Selon l'auteur, le droit international "de la mer" a eu pour vocation de réguler les conflits interétatiques de la manière suivante. Il est un moyen de formuler le conflit. Marqué par un caractère coutumier (cas du droit se formant d'après le comportement des États sur l'espace maritime), il a pris, ces cinquante dernières années, un caractère supplémentaire. En effet, de plus en plus écrit et codifié dans des accords internationaux, il a un but : mieux définir, clarifier et sécuriser les droits étatistes respectifs sur des espaces marins de plus en plus délimités, et sur la haute mer, marquée par la liberté (de circulation, de pêche, de prédation, de pose de câbles, de recherche scientifique). La Convention des Nations unies sur le droit de la mer est l'exemple de l'effort portant sur le passé et l'avenir. Elle a " codifié du droit international existant et esquissé le projet d'un droit international nouveau " (Boutros-Ghali, 2000, 10). Par des définitions, et une série de situations objets de recommandations et de droits, elle permet la mise en forme juridique des prétentions des États s'opposant.

137 Voir Convention de Genève de 1958, art. 1. Cette définition de la haute mer a évolué conformément à l'article 86 de la Convention de Montego Bay de 1982. Il convient d'indiquer que la Convention de Genève de 1958 n'a pas été ratifiée par la Côte d'Ivoire.
} 
au-delà des juridictions nationales et échappant à la souveraineté des Etats ${ }^{138}$. Elle est alors régie par la partie VII de la Convention de Montego Bay.

107- "Tout Etat, qu’il soit côtier ou sans littoral, a le droit de faire naviguer en haute mer des navires battant son pavillon "139. Les conditions juridiques de navigation des navires sont fixées par l'article 92 de la Convention qui dispose que les navires naviguent sous le pavillon d'un seul Etat et sont soumis, sauf dans les cas exceptionnels expressément prévus par des traités internationaux ou par la Convention, à sa juridiction exclusive en haute mer. Aucun changement de pavillon ne peut intervenir au cours d'un voyage ou d'une escale, sauf en cas de transfert réel de la propriété ou de changement d'immatriculation.

108- L'Etat du pavillon exerce effectivement sa juridiction et son contrôle dans les domaines administratif, technique et social sur les navires battant son pavillon au regard de son droit interne ${ }^{140}$. Il prend toutes mesures nécessaires pour assurer la sécurité de la navigation en mer.

109- La liberté de la haute mer ${ }^{141}$ est affirmée par l'article 87 de la Convention de Montego Bay qui dispose en son alinéa 1 que la haute mer est ouverte à tous les Etats, qu'ils soient côtiers ou sans littoral. La liberté de la haute mer comporte entre autres : la liberté de survol ; la liberté de poser des câbles et des pipelines sous-marins, sous réserve de la partie VI ; la liberté de

\footnotetext{
138 Voir GUILLIEN (Raymond) et VINCENT (Jean), Lexique des termes juridiques, DALLOZ,

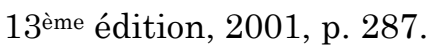

${ }^{139}$ La Convention de Montego Bay prévoit en son article 90, la liberté de navigation sur la haute mer pour tout navire à condition qu'il batte pavillon d'un seul Etat. Ainsi, le navire est sous juridiction de l'Etat du pavillon.

140 Convention de Montego Bay, art. 94.

${ }^{141}$ Voir BRONER (Romain), La répression de la piraterie maritime et ses enjeux juridiques, Mémoire, 2009/2010, Université panthéon-Assas - Paris II. p. 8. L'auteur indique que cette affirmation juridique de la liberté de la mer faisait suite à une affaire de piraterie. En effet, un navire de la Compagnie Hollandaise des Indes Orientales avait capturé, dans le détroit de Malacca, un navire de commerce portugais en 1603. Le Portugal ayant dénoncé cet acte de piraterie et réclamé la restitution de la cargaison, la Compagnie chercha à prouver le bien-fondé de cette prise. Grotius se fonda alors sur la légitime défense contre un pays, le Portugal, qui prétendait avoir un contrôle exclusif des mers en Asie pour assurer son commerce. C'est en arguant de la liberté des mers, et de la liberté de commerce, que Grotius fonde le principe de libre circulation maritime.
} 
construire des îles artificielles et autres installations autorisées par le droit international, sous réserve de la partie VI ; la liberté de la pêche, sous réserve des conditions énoncées à la section 2 ; la liberté de la recherche scientifique, sous réserve des parties VI et XIII ${ }^{142}$.

110- Par ailleurs, les navires naviguent sous le pavillon d'un seul Etat et se trouvent soumis, sauf dans les cas exceptionnels expressément prévus par les traités internationaux, à sa juridiction exclusive en haute mer ${ }^{143}$. Chaque Etat exerce ces libertés en tenant dûment compte de l'intérêt que présente l'exercice de la liberté de la haute mer pour les autres Etats, ainsi que des droits reconnus par la Convention concernant les activités menées dans la Zone ${ }^{144}$. L'article 89 prévoit l'illégitimité des revendications de souveraineté sur la haute mer en disposant notamment qu'aucun Etat ne peut légitimement prétendre soumettre une partie quelconque de la haute mer à sa souveraineté ${ }^{145}$.

\section{2- La Convention sur les normes de formation du personnel naviguant, de délivrance de brevets et de veille STCW de 1978}

111- La sécurité du trafic maritime implique également la compétence et la qualification de l'équipage. Cet aspect sécuritaire portant sur le travail du personnel à bord du navire, ne peut échapper à l'emprise de l'Organisation Internationale du Travail (OIT). L'adoption des règles relatives au personnel de navigation relève donc à la fois de l'OMI et de l'OIT. La convention STCW de $1978^{146}$ prescrit les conditions d'obtention des différents brevets pour les

\footnotetext{
142 Convention de Montego Bay, art. 87-1.

${ }^{143}$ Cette disposition est bien affirmée par l'article 92 de la Convention de Montego Bay sur le droit de la mer.

${ }^{144}$ Convention de Montego Bay, art. 87-2.

${ }^{145}$ Idem, art. 89. Illégitimité des revendications de souveraineté sur la haute mer.

146 Voir BLAVEC (André), « Les conventions STCW et STCW-F », in La Revue Maritime $N^{\circ} 467$, janvier 2004, p. 1. Selon l'auteur, La convention STCW 78 (Convention on Standards of Training, Certification and Watchkeeping for Seafarers) fut le premier instrument prévu pour établir des normes professionnelles minimales concernant les gens de mer. Cette convention n'est pas applicable aux navires de guerre et autres navires gouvernementaux à finalité non-commerciale, aux navires de pêche et aux yachts de plaisance ne se livrant à aucun trafic commercial. L'intérêt majeur de la convention STCW de 78 fut de prescrire des normes minimales auxquelles chacun des pays membres se devait de souscrire. Pour certains pays émergeants, la mise en place de ces normes, assez peu contraignantes, leur a permis de relever le niveau de leur formation et de se
} 
membres de l'équipage et aussi les normes régissant le service de pont, le service de machine et le service radio. Mais le caractère non contraignant de certaines dispositions de ladite convention a fait l'objet de vives critiques ${ }^{\mathbf{1 4 7}}$ qui ont abouti à l'amendement de 1995. Quelles sont les normes de sécurité prévues par la convention (a) et quelles sont les conditions de délivrance des brevets aux membres de l'équipage (b) ?

\section{a- Les normes de sécurité prévues par la Convention STCW}

112- La Convention "s'applique aux gens de mer servant à bord des navires de mer qui sont autorisés à battre le pavillon d'un Etat partie, à l'exception de ceux qui servent à bord: des navires de guerre, navires de guerre auxiliaires ou autres navires appartenant à un Etat ou exploités par cet Etat tant que celui-ci les utilise exclusivement à des fins gouvernementales et non commerciales; des navires de pêche; des yachts de plaisance ... ${ }^{148}$. Les navires de pêche n'étaient donc pas concernés par la convention STCW de 1978. C'est pourquoi, consciente de cette lacune, l'OMI en liaison avec le BIT a, du 26 juin au 7 juillet 1995, organisé une conférence qui a adopté la convention STCW - F, Standards of Training, Certification and Watchkeeping for Fishing vessel personnel qui est destinée aux navires de pêche ${ }^{149}$.

113- Par ailleurs, les Etats parties s'engagent à promulguer toutes lois et tous décrets, ordres et règlements et à prendre toutes autres mesures nécessaires pour donner à la Convention son plein et entier effet, afin de garantir que, du point de vue de la sauvegarde de la vie humaine et des biens

situer dans un cadre internationalement défini. L'entrée en vigueur de cette convention 78 était conditionnée par la signature d'au moins 25 pays représentant $50 \%$ du tonnage mondial. Le niveau des signatures fut atteint le 27 avril 1983 et la convention STCW 78 entra en vigueur le 28 avril 1984.

${ }^{147}$ Voir Reflets, OMI, « La nouvelle convention STCW », janvier 1996, pp. 2 et s.

148 Voir la Convention sur les normes de formation du personnel naviguant STCW de 1978, art. 3.

${ }^{149}$ Voir BLAVEC (André), "Les conventions STCW et STCW-F ", La Revue Maritime $N^{\circ} 467$, janvier 2004, op. cit., pp. 3 et 4. L'auteur ajoute in fine que tous les personnels des navires de pêche doivent avoir reçu une formation de base en matière de sécurité : techniques personnelles de survie incluant brassières de sauvetage et combinaisons d'immersion ; prévention et lutte contre le feu; premiers secours (secourisme) ; prévention contre les pollutions marines ; prévention contre les accidents à bord». 
en mer ainsi que de la protection du milieu marin, les gens de mer à bord des navires ont les qualifications et l'aptitude correspondant à leurs fonctions ${ }^{150}$.

114- Les navires, à l'exception de ceux exclus par l'article 3, sont soumis dans les ports d'un Etat partie à des contrôles effectués par des fonctionnaires dûment autorisés par cet Etat, afin de vérifier que tous les gens de mer servant à bord qui sont tenus d'être titulaires d'un brevet au titre de la Convention sont détenteurs dudit brevet ou d'une dispense appropriée ${ }^{151}$. Au cours du contrôle par l'État du port (Port State Control - PSC), " les responsabilités et obligations des compagnies sont renforcées par des dispositions qui instaurent des inspecteurs de l'État du port chargés entre autres de vérifier les qualifications et les compétences des gens de mer. Les inspecteurs sont habilités à contrôler : que les marins sont titulaires des certificats requis ou de dispenses ; que des visas sont délivrés dans le cas de marins de nationalité différente de celle du pavillon ; que le nombre de marins est en rapport avec la liste type d'équipage imposée par l'État du pavillon ${ }^{152}$.

115- Au titre du contrôle ${ }^{153}$, en cas de constatation de carences, le fonctionnaire chargé du contrôle en informe immédiatement par écrit le capitaine du navire et le consul ou, en son absence, le représentant diplomatique le plus proche ou l'autorité maritime de l'Etat dont le navire est autorisé à battre le pavillon afin que des mesures appropriées soient prises ${ }^{154}$. Cette notification fait état de façon détaillée des carences qui ont été constatées et des raisons pour lesquelles l'Etat partie considère que ces carences présentent un danger pour les personnes, les biens ou l'environnement. Toutefois, le contrôle de la qualification des gens de mer se fait de sorte que les navires battant le pavillon d'un Etat non contractant ne bénéficient pas d'un traitement plus favorable que celui réservé aux navires battant pavillon d'un Etat partie ${ }^{155}$.

\footnotetext{
${ }^{150}$ Convention STCW, art. 1-2.

${ }^{151}$ Convention STCW, art. 10.

152 BLAVEC (André), Les conventions STCW et STCW-F, op. cit., p. 3.

${ }^{153} \mathrm{Il}$ s'agit des contrôles prévus par l'alinéa 1 de l'article 10 de la Convention STCW.

${ }^{154}$ Convention STCW, art. 10, al. 2.

155 Voir l'article 10, alinéa 5 de la Convention STCW.
} 


\section{b- Les conditions de délivrance des Brevets aux membres de l'équipage}

116- L'alinéa 1 de l'article 6 de la Convention sur les normes de formation des gens de mer dispose que: "Des brevets sont délivrés aux candidats aux fonctions de capitaine, d'officier, de matelot ou de mécanicien qui, à la satisfaction de l'Administration, remplissent les conditions requises en matière de service, d'âge, d'aptitude de physique, de formation, de qualifications et d'examens conformément aux dispositions appropriées de l'Annexe de la Convention". Les brevets de capitaine et d'officier délivrés conformément aux dispositions de la Convention sont visés, par l'Administration qui les délivre, de la manière prescrite à la règle I/2 de l'Annexe. Si la langue utilisée n'est pas l'anglais, une traduction dans cette langue doit être jointe ${ }^{156}$.

117- L'Etat partie peut conserver ou adopter d'autres méthodes d'instruction et d'entraînement, y compris celles qui comportent un service en mer et une organisation de bord spécialement adaptés aux progrès techniques et à des types particuliers de navires et de services. Mais à condition que le niveau du service en mer, des connaissances et de l'efficacité atteint en matière de navigation et de maniement technique du navire et de la cargaison assure un degré de sécurité en mer et ait des effets, en ce qui concerne la prévention de la pollution, au moins équivalents à ceux des prescriptions de la Convention ${ }^{157}$.

118- Enfin, en matière de formation des gens de mer, la Convention STCW prévoit la coopération technique entre les Etats parties. Ceux-ci doivent, en consultation avec l'Organisation et avec son appui, promouvoir l'aide à apporter aux Parties qui demandent une assistance technique. Soit pour former du personnel administratif et technique, soit pour créer des établissements pour la formation des gens de mer. Il peut également s'agir de mettre au point des programmes de formation appropriés, comprenant une formation pratique à

\footnotetext{
156 Convention STCW, art. 6, al. 2.

157 Voir Convention sur les normes de formation des gens de mer (SOLAS), art. 9, al. 1.
} 
bord de navires de mer ou de faciliter l'adoption d'autres mesures et dispositions susceptibles d'améliorer les qualifications des gens de mer ${ }^{158}$.

\section{B- Les normes prévues par le Code international pour la sûreté des navires et des installations portuaires de 2002 et la Convention internationale sur la sécurité des conteneurs de 1972}

119- Il s'agit de montrer comment le Code international pour la sûreté des navires et des installations portuaires de 2002 (1) assure la sûreté de la navigation maritime et des installations portuaires et comment la Convention internationale sur la sécurité des conteneurs de 1972 (2) protège le trafic des conteneurs.

\section{1- Les normes prévues par le Code international pour la sûreté des navires et des installations portuaires « Code ISPS " de 2002}

120 Face à l'insécurité aéroportuaire au sens notamment des évènements du 11 septembre 2001 aux Etats-Unis ${ }^{159}$, l'initiative a été prise de renforcer la sécurité maritime et portuaire à l'échelle internationale. Ainsi, le Code international pour la sureté des navires et des installations portuaires, International Ship and Port Security Facility dit code ISPS a été créé. Il s'agit d'un ensemble de normes adoptées en décembre 2002 par la Conférence Diplomatique de l'Organisation Maritime Internationale ${ }^{160}$. Son but est: "...d'établir un cadre international dans lequel les Gouvernements contractants, les organismes publics, les administrations locales et les secteurs maritime et portuaire puissent coopérer pour détecter et évaluer les menaces pour la sûreté et pour prendre des mesures de sauvegarde contre des incidents de sûreté touchant des navires ou des installations portuaires participant au commerce international;...»161. La Conférence des Gouvernements contractants à la Convention internationale de 1974 pour la sauvegarde de la vie humaine en mer, tenue à Londres du 9 au 13 décembre 2002, a modifié le chapitre XI existant de la Convention SOLAS, qui est devenu le chapitre XI-1, et elle a adopté un

\footnotetext{
158 Convention STCW, art. 11, al. 1.

159 Il s'agit des attentats terroristes des tours jumelles du World Trade Center à New York.

160 Avant-propos du code ISPS, paragraphe 1.

${ }^{161}$ Code ISPS, paragraphe 2.
} 
nouveau chapitre XI-2 sur les mesures spéciales pour renforcer la sûreté maritime ${ }^{162}$. On examinera le contenu des plans de sûreté (a) et les différents agents de sûreté et leur rôle (b).

\section{a- Les plans de sûreté définis par le code ISPS}

121- Le code ISPS définit un plan de sûreté pour chaque installation portuaire, chaque navire et chaque compagnie maritime. Le plan de sûreté doit être approuvé par l'administration. Mais compte tenu du fait que le plan de sûreté de la compagnie maritime a pour but de coordonner les plans de sûreté des différents navires de la compagnie, nous aborderons dans ce paragraphe le plan de sûreté de l'installation portuaire et le plan de sûreté du navire à l'exclusion du plan de sûreté de la compagnie maritime.

122- Le code ISPS dispose: "qu'un plan de sûreté de l’installation portuaire doit être élaboré et tenu à jour, sur la base d'une évaluation de la sûreté de l'installation portuaire pour chaque installation portuaire et doit être adapté à l'interface navire/port... "163. Conformément à cette disposition, chaque port élabore le plan de sûreté de son installation portuaire et le fait approuver par son gouvernement. Le plan de sûreté doit comprendre, entre autres, "les mesures visant à empêcher l'introduction, dans l’installation portuaire ou à bord du navire, d'armes, de substances dangereuses et d'engins destinés à être utilisés contre des personnes, des navires ou des ports et dont la présence n'est pas autorisée " 164 . Cette même disposition prévoit que le plan doit également contenir des procédures pour faire face à une menace contre la sûreté ou une atteinte à la sûreté y compris des dispositions pour maintenir les opérations essentielles de l'installation portuaire ou de l'interface navire/port. " Le plan de sécurité de l'installation portuaire peut aussi être combiné avec le plan de sécurité

\footnotetext{
162 Voir le paragraphe 1 de l'avant-propos du Code international pour la sûreté des navires et des installations portuaires. Ce code est appelé dans la règle XI-2/1 de la Convention SOLAS, telle que modifiée, ou encore, en abrégé, Code ISPS.

163 Voir le point 16-1 du code ISPS.

${ }^{164}$ Code ISPS point 16-3. $§ 1$.
} 
$d u$ port ou tout autre plan d'urgence portuaire ou faire partie de tels plans » ${ }^{165}$. Quid du plan de sûreté du navire?

123- Le point 9-1 du code ISPS prévoit un plan de sûreté à bord de chaque navire qui doit également être approuvé par l'administration. Ce plan doit prévoir des dispositions pour les différents niveaux de sûreté définis par le code. Le plan de sûreté du navire porte sur: "les mesures visant à empêcher l'introduction à bord, des armes, des substances dangereuses et d'engins destinés à être utilisés contre les personnes, les navires ou les ports et dont la présence à bord n'est pas autorisée »166. Au demeurant, le plan de sûreté du navire doit comporter des procédures permettant de faire face à toute menace contre la sûreté du navire ou toute atteinte à la sûreté, y compris des dispositions pour maintenir les opérations essentielles du navire ou de l'interface navire/port.

\section{b- Les différents agents de sûreté et leur rôle}

124- Pour assurer le fonctionnement et l'animation permanente des plans de sûreté à bord du navire et au sein du port, le code ISPS a prévu trois agents de sûreté : l'agent de sûreté du navire, l'agent de sûreté de l'installation portuaire et l'agent de sûreté de la compagnie maritime.

125- Le point 12.1 du code ISPS dispose : «qu'un agent de sûreté du navire doit être désigné à bord de chaque navire ". L'agent de sûreté a pour tâche et responsabilité d'assurer et superviser la mise en œuvre du plan de sécurité du navire. Conformément au point 12-2 du code, l'agent de sûreté du navire coordonne les mesures de sûreté de la manutention des cargaisons et des provisions de bord avec les autres membres du personnel de bord et avec les agents de sûreté pertinents des installations portuaires. Il a également pour rôle de sensibiliser le personnel de bord pour une prise de conscience accrue de la sûreté et de la vigilance à bord du navire.

\footnotetext{
165 Code ISPS, point 16-5, op. cit.

166 Code ISPS, point 9 , al. $4 \S 1$, op. cit.
} 
126- Un agent de sûreté est désigné pour chaque installation portuaire ou pour plusieurs installations portuaires ${ }^{167}$. Cet agent de sûreté a pour mission de mener une étude de sûreté initiale de l'installation portuaire en vue d'élaborer et mettre en œuvre le plan de sûreté de l'installation portuaire. Il est chargé : "d’accroître la prise de conscience de la sûreté et la vigilance du personnel de l'installation portuaire. Il a aussi pour mission de coordonner les actions sécuritaires avec l'agent de sécurité de la compagnie et l'agent de sécurité du navire pour assurer la sécurité des installations portuaires, des personnels, des navires et leurs cargaisons ${ }^{\mathbf{1 6 8}}$.

127- Il est également prévu la désignation d'un agent de sûreté au sein de chaque compagnie maritime. Cet agent de sûreté a pour tâches et responsabilités, entre autres, de veiller à l'application du plan de sûreté dans chaque navire. Il doit aussi : "veiller à l'efficacité de la communication et de la coopération entre l'agent de sûreté du navire et les agents de sûreté pertinents des installations portuaires ${ }^{\mathbf{1 6 9}}$. Il est tenu de coordonner les exigences en matière de sûreté pour éviter toute atteinte à la sûreté des installations portuaires, des navires et leur personnel de bord, ainsi que leurs cargaisons et les provisions de bord. A présent, portons le regard sur les normes prévues par la Convention relative à la sécurité des conteneurs.

\section{2- La Convention internationale sur la sécurité des conteneurs (CSC) de 1972}

128- Ayant décidé d'officialiser les règles de construction des conteneurs destinées à garantir la sécurité de leur manutention, de leur gerbage et de leur transport dans des conditions normales d'exploitation ${ }^{170}$, les parties contractantes ont, à cet effet, prescrit des normes définissant les conditions de sécurité des conteneurs. La réunion de ces conditions sécuritaires donne droit à

\footnotetext{
${ }^{167}$ Le point $17.1 \mathrm{du}$ code ISPS prévoit la désignation d'un agent de sûreté pour chaque installation portuaire ou pour plusieurs installations portuaires.

168 Voir point 17.1 du code ISPS.

169 Voir point 11.2.10 du code ISPS, op. cit., p. 18.

170 Voir le préambule de la Convention internationale sur la sécurité des conteneurs (CSC) de 1972.
} 
un agrément ${ }^{171}$ en vue de l'utilisation des conteneurs qui doit être délivré par l'Administration ${ }^{172}$ ainsi que les conditions de son approbation et de son contrôle.

129- Le principe de l'agrément s'applique à tous les conteneurs qu'ils soient neufs ou existants utilisés pour un transport international, à l'exception des conteneurs spécialement conçus pour le transport aérien ${ }^{173}$. L'alinéa 2 de l'article 3 de la Convention dispose que tout conteneur neuf doit être agréé conformément aux dispositions de l'Annexe I applicables aux essais d'agrément par type ou aux essais d'agrément individuel. Quant à l'alinéa 3 du même article, il précise que tout conteneur existant doit être agréé conformément aux dispositions pertinentes régissant l'agrément des conteneurs existants énoncées dans l'Annexe I, dans les cinq ans qui suivent la date d'entrée en vigueur de celle-ci.

130- Conformément à l'alinéa 3 de l'article 4 de la Convention, la demande d'agrément peut être adressée à l'Administration de toute Partie Contractante. A cet effet, la Convention CSC dispose en son article 4, alinéa 1 : "Pour mettre en œuvre les dispositions de l'Annexe I, chaque Administration doit instaurer une procédure efficace d'essais, d'inspection et d'agrément des conteneurs, conformément aux critères établis dans la présente Convention; elle peut toutefois confier ces essais, inspection et agrément à des organisations dûment autorisées par elle».

131- L’agrément accordé aux termes de la Convention CSC sous la responsabilité d'une partie contractante doit être approuvé par les autres parties contractantes pour tout ce qui concerne les objectifs de ladite convention.

\footnotetext{
${ }^{171}$ Convention CSC, art. 2, al. 5. L'agrément désigne la décision par laquelle une Administration juge qu'un type de construction ou un conteneur offre les garanties de sécurité prévues dans la présente Convention.

172 Convention CSC, art. 2, al. 3. L'Administration désigne le Gouvernement de la Partie Contractante sous l'autorité de laquelle les conteneurs sont agréés.

${ }^{173}$ Convention CSC, art. 3, al. 1.
} 
Il doit être considéré par les autres parties contractantes comme ayant la même valeur que l'agrément accordé par elles ${ }^{174}$.

132- Tout conteneur ayant été agréé en vertu de l'article 3 est soumis, sur le territoire des Parties Contractantes, au contrôle des fonctionnaires dûment autorisés par ces Parties ${ }^{175}$. Lorsqu'il apparaît que le conteneur ne satisfait plus aux prescriptions en matière de sécurité par suite d'un défaut qui aurait pu exister au moment de son agrément, l'Administration responsable de cet agrément en sera informée par la Partie Contractante qui a décelé le défaut ${ }^{176}$.

133- Par ailleurs, des marchandises peuvent subir des dommages en dépit des mesures à caractère préventif. D'où la nécessité d'analyser les normes curatives des dommages survenus à la cargaison.

\section{$\S 2$ : Les solutions suite à la survenance des périls maritimes}

134- Les normes curatives des dommages peuvent être envisagées à travers trois instruments juridiques à savoir la Convention de Bruxelles de 1924 dite Règles de La Haye ${ }^{177}$ et ses Protocoles modificatifs (A), la Convention de Hambourg de 1978 (B) et enfin la Convention de Rotterdam de 2009 (C).

\section{A- Les normes prévues par la Convention de Bruxelles de 1924 et ses Protocoles modificatifs}

135- La Convention de Bruxelles du 25 août 1924 pour l'unification de certaines règles en matière de connaissement, modifiée par les Protocoles du 23 février 1968 et du 21 décembre 1979178, définit les normes permettant de situer

\footnotetext{
174 Voir Convention CSC, art. 5, al. 1.

175 Convention CSC, art. 6, al. 1.

176 Idem, art. 6, al. 2.

177 Des auteurs français estiment qu'il est impropre de donner le nom de « Règles de La Haye à la Convention de 1924 ». Voir. RODIÈRE (René), Traité général de droit maritime, op. cit., $\mathrm{n}^{\circ}$ 736 note 1, p. 365 ; voir aussi REMOND-GOUILLOUD (M), Droit maritime, Paris, Pedone, 1988, $\mathrm{n}^{\circ} 510$, p. 293. L'argument que ces auteurs avancent est que la Convention de 1924 n'a aucun lien avec la ville de La Haye, notamment parce qu'elle n'y a pas vu le jour.

178 La Convention de Bruxelles de 1924 parfois improprement désignée par l'expression de "Règles de la Haye » est entrée en vigueur le 2 juin 1931. Elle a été ratifiée par l'Etat de Côte d'Ivoire le 15 décembre 1961. Son protocole modificatif de 1968, également désigné par les Règles
} 
la responsabilité des acteurs du transport maritime en cas de dommages survenus à la marchandise. Ainsi, le transporteur est soumis à des obligations et responsabilités. "Sous réserve des dispositions de l'article 6, le transporteur, dans tous les contrats de transport des marchandises par mer, sera quant au chargement, à la manutention, à l'arrimage, au transport, à la garde/aux soins et au déchargement des dites marchandises, soumis aux responsabilités et obligations, comme il bénéficiera des droits et exonérations ci-dessous énoncés » 179 .

136- En effet, le "transport de marchandises" se définit comme le temps écoulé depuis le chargement des marchandises à bord du navire jusqu'à leur déchargement $\mathrm{du}$ navire au port de destination ${ }^{180}$. Par ailleurs, "Le transporteur, sous réserve des dispositions de l'article 4, procédera de façon appropriée et soigneuse au chargement, à la manutention, à l'arrimage, au transport, à la garde, aux soins et au déchargement des marchandises transportées ${ }^{181}$. A la lecture combinée des articles 1-e), 2, et 3-2, on déduit que le transporteur est responsable des marchandises depuis le début de leur chargement à bord du navire jusqu'à leur déchargement. Il convient donc de mettre en exergue, d'une part, les obligations et responsabilités du transporteur (1) et, d'autre part, ses droits et exonérations (2).

\section{1- Obligations et responsabilités du transporteur}

137- Au titre des obligations en charge, "le transporteur sera tenu avant et au début du voyage d'exercer une diligence raisonnable pour a) Mettre le navire en état de navigabilité ; b) Convenablement armer, équiper et approvisionner le navire; c) Approprier et mettre en bon état les cales, chambres froides et frigorifiques, et toutes autres parties du navire où des marchandises sont

de Visby, est entré en application le 23 juin 1977. Voir Lamy transport, tome II, édition 2010, n 531 et 532 p. 265.

179 Convention de Bruxelles, art. 2.

180 Idem, art. 1-e. Cette disposition introduit ainsi ce qu'il est convenu d'appeler le sectionnement légal du contrat de transport maritime.

181 Voir Convention de Bruxelles de 1924, art. 3-2. 
chargées, pour leur réception, transport et conservation »182. L'article 3 prévoit en son alinéa 3 qu'après avoir reçu et pris en charge les marchandises, le transporteur ou le capitaine ou agent du transporteur devra, sur demande du chargeur, délivrer au chargeur un connaissement ${ }^{183}$. L'alinéa 4 du même article 3 précise : "qu’un tel connaissement vaudra présomption, sauf preuve contraire, de la réception par le transporteur des marchandises telles qu'elles y sont décrites, conformément au paragraphe 3, a), b) et c). (Protocole de 1968) Toutefois, la preuve contraire n'est pas admise lorsque le connaissement a été transféré à un tiers porteur de bonne foi ".

138- Enfin, toute clause, convention ou accord dans un contrat de transport exonérant le transporteur ou le navire de responsabilité par perte ou dommage concernant des marchandises provenant de négligences, faute ou manquement aux devoirs ou obligations édictées dans cet article ou atténuant cette responsabilité autrement que ne le prescrit la présente convention sera nulle non avenue et sans effet. Il en va de même pour toute clause cédant le bénéfice de l'assurance au transporteur ou toute clause semblable qui sera considérée comme exonérant le transporteur de sa responsabilité184.

\section{2- Droits et exonérations du transporteur}

139- En l'absence de réclamation de l'ayant droit à la marchandise, la livraison faite par le transporteur est réputée conforme et le libère. A moins qu'un avis de pertes ou dommages et de la nature générale de ces pertes ou

\footnotetext{
182 Voir Convention de Bruxelles amendée par les Protocoles modificatifs de 1968 et de 1979, art. 3 , al. 1.

183 Pour le contenu du connaissement voir Convention de Bruxelles, art. 3, in fine : «...un connaissement portant entre autres choses : a) Les marques principales à l'identification des marchandises telles qu'elles sont fournies par écrit par le chargeur avant que le chargement de ces marchandises ne commence, pourvu que ces marques soient imprimées ou apposées clairement de toute autre façon sur les marchandises non emballées ou sur les caisses ou emballages dans lesquelles les marchandises sont contenues, de telle sorte qu'elles devraient normalement rester visibles jusqu'à la fin du voyage; b) Ou le nombre de colis, ou de pièces, ou la qualité ou le poids, suivant les cas, tels qu'ils sont fournis par écrit par le chargeur; c) L'état et le conditionnement apparent des marchandises".

184 Voir RODIERE (René), Traité général de droit maritime, Tome 2. Dalloz. Paris 1968, n 743, p. 376. Voir également la Convention de Bruxelles de 1924, art. 3 al. 8. Signalons que selon le doyen Rodière, cette Convention est rédigée dans un style surchargé d'inutiles lourdeurs, pâteux, encombré d'incidentes.
} 
dommages ne soit donné par écrit au transporteur ou à son agent au port de déchargement, avant ou au moment de l'enlèvement ou la livraison des marchandises, cet enlèvement constituera, jusqu'à preuve du contraire, une présomption que les marchandises ont été délivrées par le transporteur, telles qu'elles sont décrites au connaissement ${ }^{185}$. Si les pertes ou dommages ne sont pas apparents, l'avis doit être donné dans les trois jours de la délivrance. Les réserves écrites sont inutiles si l'état de la marchandise a été contradictoirement constaté au moment de la réception ${ }^{186}$.

140- Le Protocole modificatif de 1968 prévoit que sous réserve des dispositions du paragraphe 6 bis, le transporteur et le navire seront en tout cas déchargés de toute responsabilité, à moins qu'une action ne soit intentée dans l'année de leur délivrance ou de la date à laquelle elles eussent dû être délivrées. Ce délai peut toutefois être prolongé par un accord conclu entre les parties postérieurement à l'événement qui a donné lieu à l'action ${ }^{187}$.

141- Conformément aux Règles de la Haye, le transporteur bénéficie des exonérations prévues. En effet, ni le transporteur ni le navire ne seront responsables des pertes ou dommages provenant ou résultant de l'état d'innavigabilité. A moins que cet état d'innavigabilité ne soit imputable à un manque de diligence raisonnable de la part du transporteur à mettre le navire en état de navigabilité ou à assurer au navire un armement, équipement ou approvisionnement convenables ou à approprier et mettre en bon état les cales, chambres froides et frigorifiques et toutes autres parties du navire où des marchandises sont chargées de façon qu'elles soient aptes à la réception au transport et à la préservation des marchandises ${ }^{188}$. Ni le transporteur ni le navire ne seront responsables pour perte ou dommage résultant ou provenant

\footnotetext{
185 Convention de Bruxelles, art. 3, al. 6.

186 Convention de Bruxelles, art. 3, al. 6, paragraphes 2 et 3.

187 Voir Convention de Bruxelles, art. 3, al. 6. Protocole de 1968.

188 Idem, art. 4-1.
} 
des cas exceptés prévus par une liste exhaustive à l'alinéa 2 de l'article 4 de la Convention 189 .

142- Les exonérations et limitations prévues par la Convention sont applicables à toute action en réparation de pertes ou dommages à des marchandises contre le transporteur faisant l'objet d'un contrat de transport, que l'action soit fondée sur la responsabilité contractuelle ou sur une responsabilité extracontractuelle ${ }^{190}$. Ces exonérations appelées cas exceptés ne sont pas des causes absolues d'irresponsabilité du transporteur. Les cas exceptés deviennent inopérants face à la preuve contraire. Concrètement, " le demandeur enrayera la libération du transporteur soit par la preuve de l'absence de due diligence ou de la faute du transporteur, soit par la preuve que l'événement invoqué comme cas excepté n'en est pas un "191. En outre, lorsqu'une action est intentée contre un préposé du transporteur, ce préposé pourra se prévaloir des exonérations et des limitations de responsabilité que le transporteur peut

189 Voir les détails des cas exceptés, Convention de Bruxelles amendée par les Protocoles modificatifs de 1968 et de 1979, art. 4, al. 2. "Ni le transporteur ni le navire ne seront responsables pour perte ou dommage résultant ou provenant :

a) Des actes, négligence ou défaut du capitaine, marin, pilote, ou des préposés du transporteur dans la navigation ou dans l'administration du navire; b) D'un incendie, à moins qu'il ne soit causé par le fait ou la faute du transporteur; c) Des périls, dangers ou accidents de la mer ou d'autres eaux navigables ; d) D'un "acte de Dieu" ; e) De faits de guerre ; f) Du fait d'ennemis publics ; g) D'un arrêt ou contrainte de prince, autorités ou peuple, ou d'une autorité judiciaire ; h) D'une restriction de quarantaine ; i) D'un acte ou d'une omission du chargeur ou propriétaire des marchandises, de son agent ou représentant; j) De grèves ou lock-out ou d'arrêts ou entraves apportés au travail, pour quelque cause que ce soit, partiellement ou complètement ; $k$ ) D'émeutes ou de troubles civils ; I) D'un sauvetage ou tentative de sauvetage de vies ou de biens en mer ; $m$ ) De la freinte en volume ou en poids ou de toute autre perte ou dommage résultant de vice caché, nature spéciale ou vice propre de la marchandise ; n) D'une insuffisance d'emballage ; o) D'une insuffisance ou imperfection de marques ; p) De vices cachés échappant à une diligence raisonnable ; q) De toute autre cause ne provenant pas du fait ou de la faute du transporteur ou du fait ou de la faute des agents ou préposés du transporteur, mais le fardeau de la preuve incombera à la personne réclamant le bénéfice de cette exception et il lui appartiendra de montrer que ni la faute personnelle, ni le fait du transporteur n'ont contribué à la perte ou au dommage". 190 Convention de Bruxelles amendée par les Protocoles modificatifs de 1968 et de 1979, art. 4 bis 1.

191 Voir FETZE KAMDEM (Innocent), La responsabilité du transporteur maritime au niveau international : un échec d'uniformisation juridique, Mémoire, Université Laval Québec, Canada, Décembre 1999, p. 110. 
invoquer en vertu de la Convention ${ }^{192}$. Cependant, bien que la Convention de Bruxelles fût ratifiée par un grand nombre d'États, les difficultés d'application et d'interprétation de ses dispositions ont mis en doute son efficacité ${ }^{193}$, ce qui a conduit à l'adoption d'un nouveau texte : les Règles de Hambourg.

\section{B- Les normes prescrites par les Règles de Hambourg de 1978}

143- La Convention des Nations unies sur le transport de marchandises par mer, dite Convention ou Règles de Hambourg, adoptée le 31 mars 1978194, est entrée en application le $1^{\text {er }}$ novembre 1992 entre les pays qui l'ont ratifiée ${ }^{195}$. Elle exprime, selon Innocent Fetze Kamdem, un profond désir de combler les lacunes constatées dans les différentes versions de la Convention de

192 Convention de Bruxelles amendée par les Protocoles modificatifs de 1968 et de 1979, art. 4 bis 2 .

${ }_{193} \mathrm{ADIL}$ (Hind), Le régime juridique international de la responsabilité du transporteur maritime de marchandises sous connaissement : un échec ? Thèse, Université de Montréal, décembre 2009, p. 24-26. Selon l'auteur, il en était ainsi de l'affaire SS Mancaster Castle. Brièvement, la Chambre des Lords refusa dans l'espèce l'exonération du transporteur pour la faute de ses contractants indépendants, quant à l'obligation de navigabilité, et lui ordonna la réparation des dommages, d'où le mécontentement des transporteurs britanniques. Les transporteurs estimèrent pour la première fois que la Convention présentait des défauts, sans compter l'insatisfaction des chargeurs qui aspiraient au changement. Ces différents facteurs ont progressivement mené à la révision de la Convention de Bruxelles. Fut ainsi ratifié en 1968 le Protocole de Visby, ... Les modifications apportées se résument comme suit : - .... La deuxième modification du Protocole de Visby de 1979, ..., concerne les droits de tirage spéciaux (DTS) en tant qu'unité de compte de la limitation légale. Malgré les changements apportés, les Protocoles de La Haye-Visby déçoivent les attentes des organisations des pays des chargeurs provenant essentiellement de pays en voie de développement. Les solutions prévues par ces protocoles ne peuvent résoudre que partiellement les problèmes à régler, puisque les amendements préservent le régime de base de la Convention de Bruxelles. La position des chargeurs persista devant les abus observés dans les opérations de transport par les armateurs.

${ }^{194}$ Pour un aperçu des débats et discussions de la Conférence tenue à Hambourg sous l'égide des Nations Unies du 6 au 31 mars 1978, voir LEGENDRE (C.), "La Convention des Nations Unies sur le transport de marchandises par mer», (1978) 30 D.M.F. note 6,387- 395.

Voir également SWEENEY (J.C.), " Les Règles de Hambourg, point de vue d'un juriste anglosaxon ", (1979) 31 D.M.F. 323, 335 ; voir aussi W. TETLEY, "The Hamburg Rules : A Commentary ", L.M.C.L.Q. 1, 1979, pp.1-5 ; voir également RODIÈRE (R.), " La responsabilité du transporteur maritime suivant les Règles de Hambourg 1978 (le point de vue d'un juriste latin) ", 30 D.M.F. 1978, pp. 451 et 464.

195 Voir Lamy transport, tome 2. Edition 2010. N 534, p. 266. 
Bruxelles ${ }^{196}$. Nous analyserons, d'une part, la durée de la responsabilité du transporteur (1) et, d'autre part, le fondement de cette responsabilité (2).

\section{1- La durée de la responsabilité du transporteur}

144- Conformément à la Convention de Hambourg ${ }^{197}$, la responsabilité du transporteur, en ce qui concerne les marchandises, couvre la période pendant laquelle les marchandises sont sous sa garde au port de chargement, durant le transport et au port de déchargement. L'alinéa 2 du même article précise les conditions dans lesquels les marchandises doivent être réputées comme étant sous la garde du transporteur maritime ${ }^{198}$. Par ailleurs, les dispositions de la Convention ne s'appliquent pas aux contrats d'affrètement. Toutefois, lorsqu'un connaissement est émis en vertu d'un contrat d'affrètement, ledit connaissement est soumis aux dispositions de la Convention pour autant qu'il régisse les relations entre le transporteur et le porteur du connaissement, si ce dernier n'est pas l'affréteur199. Après la durée de la responsabilité du transporteur qu'en est-il de son fondement?

${ }^{196}$ Cf : FETZE KAMDEM (Innocent), « La responsabilité du transporteur maritime au niveau international: un échec d'uniformisation juridique", Mémoire, Université Laval Québec, Canada, Décembre 1999, op. cit., p. 13. À titre d'illustration, l'auteur indique que les articles 10 et 11 des Règles de Hambourg posent de nouvelles règles tenant respectivement à la responsabilité du transporteur substitué et à celle du transporteur ayant pris part à un transport successif. C'est aussi le cas des articles 21 et 22 qui énoncent tour à tour des règles salutaires de compétence et d'arbitrage.

197 Convention de Hambourg, art. 4-1.

198 Convention de Hambourg, art. 4, al. 2 : "Aux fins du paragraphe 1 du présent article, les marchandises sont réputées être sous la garde du transporteur :

a) à partir du moment où celui-ci les prend en charge des mains :

i) du chargeur ou d'une personne agissant pour son compte; ou

ii) d'une autorité ou autre tiers auquel les marchandises doivent être remises pour expédition, conformément aux lois et règlements applicables au port de chargement;

b) jusqu'au moment où il effectue la livraison:

i) en remettant les marchandises au destinataire; ou

ii) dans les cas où le destinataire ne reçoit pas les marchandises du transporteur, en les mettant à la disposition du destinataire conformément au contrat au contrat ou aux lois ou aux usages du commerce considéré applicables au port de déchargement; ou

iii) en remettant les marchandises à une autorité ou autre tiers auquel elles doivent être remises conformément aux lois et règlements applicables au port de déchargement".

199 Règles de Hambourg, art. 2, al. 3. 


\section{2- Le fondement de la responsabilité du transporteur}

145- Pour la Convention de Hambourg200 la responsabilité du transporteur est fondée sur une présomption de faute. En effet, "Le transporteur est responsable du préjudice résultant des pertes ou dommages subis par les marchandises ainsi que du retard à la livraison, si l'événement qui a causé la perte, le dommage ou le retard a eu lieu pendant que les marchandises étaient sous sa garde au sens de l'article 4, à moins qu'il ne prouve que lui-même, ses préposés ou mandataires ont pris toutes les mesures qui pouvaient raisonnablement être exigées pour éviter l'événement et ses conséquences »201. Sur la base de cette disposition, la preuve de l'absence de faute du transporteur le libère de toute responsabilité.

146- Toutefois, en cas d'incendie la preuve de l'absence de faute devient inefficace lorsque le demandeur prouve que l'incendie est imputable au transporteur. En effet, le transporteur est responsable des pertes ou dommages aux marchandises ou du retard à la livraison causés par l'incendie, si le demandeur prouve que l'incendie résulte d'une faute ou d'une négligence du transporteur, de ses préposés ou mandataires ${ }^{202}$. Le transporteur est également responsable des pertes, dommages ou retard à la livraison dont le demandeur prouve qu'ils résultent de la faute ou de la négligence du transporteur, de ses préposés ou mandataires en ce qui concerne les mesures qui pouvaient raisonnablement être exigées pour éteindre l'incendie et éviter ou atténuer ses conséquences.

147- Il convient de relever que les Règles de Hambourg élèvent le retard de livraison de la marchandise au rang des faits dommageables engageant la

\footnotetext{
200 Pour une étude approfondie de convention de Hambourg, voir AUCHTER (Gérard), La convention sur le transport de marchandises par mer, (Règles de Hambourg 1978), Droit Européen des transports, 1979 , vol. XIV, ${ }^{\circ} 1,2$ et 3, pp. 3 et s et 215 et s ; BONASSIES (Pierre), "Les Règles de Hambourg une avancée certaine, mais modeste", JMM 1988. 1341 et s ; MAKOUTA, "La protection du chargeur à travers la convention du 25 aout 1924 et les Règles de Hambourg ", JMM, 1988, pp. 821 et s, cité par RODIERE (René) et DU PONTAVICE (Emmanuel), Droit Maritime, Précis Dalloz, 12 ème édition, p. 385 nº 394.

201 Convention de Hambourg, art. 5, al. 1.

202 Voir Convention des Nations unies sur le transport de marchandises par mer, art. 5, al. 4-a.
} 
responsabilité du transporteur maritime ${ }^{203}$. Il y a retard à la livraison lorsque les marchandises n'ont pas été livrées au port de déchargement prévu par le contrat de transport par mer, dans le délai expressément convenu ou, à défaut d'un tel accord, dans le délai qu'il serait raisonnable d'exiger d'un transporteur diligent compte tenu des circonstances de fait ${ }^{204}$. Tout comme les Règles de La Haye, les Règles de Hambourg ont un caractère impératif accentué 205 en ce sens que " toute stipulation figurant dans un contrat de transport par mer [...] est nulle pour autant qu'elle déroge directement ou indirectement aux dispositions [contenues dans lesdites Règles]» ${ }^{206}$.

148- Qu'en est-il, à présent, de la Convention des Nations Unies sur le contrat de transport international de marchandises effectué entièrement ou partiellement par mer.

\section{C- Les normes prévues par la Convention de Rotterdam de 2009}

149- La Convention des Nations Unies sur le contrat de transport international de marchandises effectué entièrement ou partiellement par mer, connue sous le nom de Règles de Rotterdam, est ouverte à la signature des Etats le 23 septembre 2009 à Rotterdam ${ }^{207}$. C'est donc la dernière convention en date relative à la réparation des dommages subis par la marchandise. Les Etats sont désormais appelés à s'engager dans la procédure de ratification. La convention

\footnotetext{
${ }^{203}$ Règles de Hambourg, art. 5, al. 1.

${ }^{204}$ Règles de Hambourg, art. 5, al. 2.

${ }^{205}$ Ce caractère impératif est accentué en ce sens que, contrairement à la Convention de Bruxelles, les Règles de Hambourg y attachent une sanction. En effet, lorsqu'une stipulation contractuelle contrevient à l'une de ses dispositions et cause un préjudice au destinataire par sa seule nullité, celui-ci a droit à l'application de l'une des sanctions prévues à l'article 23-4: " 4 . Lorsque l'ayant droit aux marchandises a subi un préjudice résultant d'une stipulation nulle en vertu du présent article ou de l'omission de la mention visée au paragraphe 3 du présent article, le transporteur est tenu de payer à l'ayant droit aux marchandises, conformément à la présente Convention, l'éventuel complément de réparation dû afin d'obtenir la réparation de toute perte, dommage ou retard subi par les marchandises. En outre, le transporteur est tenu de rembourser les frais encourus par l'ayant droit dans le but d'exercer son droit, sous réserve que les frais encourus dans la procédure au cours de laquelle la disposition ci-dessus est invoquée soient déterminés conformément à la loi de l'Etat où la procédure a été engagée ".

${ }^{206}$ Convention de Hambourg, art. 23-1.

207 Voir Lamy transport, tome 2, édition 2010, n 535, p. 266.
} 
doit entrer en vigueur un an après la ratification d'au moins vingt et un Etats ${ }^{208}$. On abordera d'abord la durée de la responsabilité du transporteur (1) prévue par les dispositions de la Convention et ensuite le contenu de cette responsabilité (2)?

\section{1- Durée de la responsabilité du transporteur maritime}

150- Le transporteur est responsable des marchandises depuis leur réception par une partie exécutante ${ }^{209}$ ou lui-même en vue de leur transport jusqu'à leur livraison ${ }^{210}$. Pour déterminer la durée de la responsabilité du transporteur, les parties peuvent convenir du moment et du lieu de la réception et de la livraison. Cependant, toute clause d'un contrat de transport est réputée non écrite dans la mesure où elle prévoit : que la réception des marchandises est postérieure au moment où débute leur chargement initial conformément au contrat; ou que la livraison des marchandises est antérieure au moment où s'achève leur déchargement final conformément au contrat 211.

\section{2- Obligations et contenu de la responsabilité du transporteur}

151- Le transporteur, dans les conditions prévues par la Convention et conformément aux clauses du contrat de transport, déplace les marchandises jusqu'au lieu de destination et les livre au destinataire ${ }^{212}$. Par ailleurs, le transporteur, pendant la durée de sa responsabilité telle qu'elle est définie, procède de façon appropriée et soigneuse à la réception, au chargement, à la

\footnotetext{
${ }^{208}$ Lamy transport, tome 2, édition 2010, $\mathrm{n}^{\circ} 535$, p. 266.

${ }^{209}$ Convention de Rotterdam art. 1, al. 7 : "Le terme "partie exécutante maritime" désigne une partie exécutante dans la mesure où elle s'acquitte ou s'engage à s'acquitter de l'une quelconque des obligations du transporteur pendant la période comprise entre l'arrivée des marchandises au port de chargement d'un navire et leur départ du port de déchargement d'un navire. La qualité de "partie exécutante maritime" ne peut être reconnue à un transporteur intérieur que si celui-ci fournit ou s'engage à fournir ses services exclusivement dans une zone portuaire».

210 Voir Convention des Nations Unies sur le contrat de transport international de marchandises effectué entièrement ou partiellement par mer, signée à Rotterdam en 2009, art.12, al. 1 : «Le transporteur est responsable des marchandises en vertu de la présente convention depuis leur réception par une partie exécutante ou lui-même en vue de leur transport jusqu'à leur livraison". Avec la Convention de Bruxelles l'exécution du transport commence à partir du chargement de la marchandise à bord du navire tandis qu'avec la Convention de Rotterdam elle commence à partir de la réception de la marchandise par le transporteur ou par une partie exécutante.

211 Convention des Nations Unies de 2009, art. 11, al. 3.

${ }^{212}$ Convention de Rotterdam, art. 11, al. 3. art. 11.
} 
manutention, à l'arrimage, au transport, à la garde, aux soins, au déchargement et à la livraison des marchandises ${ }^{213}$. Aussi, le transporteur est tenu avant, au début et pendant le voyage par mer d'exercer une diligence raisonnable dont le contenu est détaillé à l'article $14^{214}$ de la Convention.

152- Le transporteur est responsable de la perte, du dommage ou du retard de livraison subis par les marchandises, si le destinataire prouve que cette perte, ce dommage ou ce retard, ou l'événement ou la circonstance qui l'a causé ou y a contribué, s'est produit pendant la durée de sa responsabilité telle que celle-ci est définie par l'article 12 en son alinéa $1^{215}$. C'est pourquoi, le professeur Philippe DELEBECQUE affirme que ce système repose sur une présomption de responsabilité ${ }^{216}$. En effet, dès lors que le dommage survient pendant la période de prise en charge de la marchandise, la responsabilité du transporteur est présumée.

153- En revanche, le transporteur est déchargé de tout ou partie de sa responsabilité s'il prouve que la cause ou l'une des causes de la perte, du dommage ou du retard n'est pas imputable à sa faute ou à la faute de l'une quelconque des personnes mentionnées à l'article $18^{217}$. Aussi, le transporteur est-il déchargé de toute ou partie de sa responsabilité si, au lieu de prouver l'absence de faute, il prouve qu'un ou plusieurs des événements ou circonstances énumérées à l'alinéa 3 de l'article 17 ont causé la perte, le dommage ou le retard ou y ont contribué.

${ }^{213}$ Convention de Rotterdam, art. 13, al. 1.

${ }^{214}$ A titre d'obligations particulières applicables au voyage par mer, l'article 14 dispose que le transporteur est tenu avant, au début et pendant le voyage par mer d'exercer une diligence raisonnable pour :

a) Mettre et maintenir le navire en état de navigabilité ;

b) Convenablement armer, équiper et approvisionner le navire et le maintenir ainsi armé, équipé et approvisionné tout au long du voyage ; et

c) Approprier et mettre en bon état les cales et toutes les autres parties du navire où les marchandises sont transportées, ainsi que les conteneurs fournis par lui dans ou sur lesquels les marchandises sont transportées, et les maintenir appropriés et en bon état pour la réception, le transport et la conservation des marchandises.

215 Voir Convention de Rotterdam de 2009, art 17, al. 1.

216 Voir dans ce sens, DELEBECQUE (Philippe), "L'évolution du transport maritime ", DMF 2009, p. 16.

${ }^{217}$ Convention de Rotterdam de 2009, art. 17, al. 2. 
154- Cependant, toute disposition écartant ou limitant la responsabilité du transporteur s'applique dans une action judiciaire ou arbitrale, qu'elle soit fondée sur la responsabilité contractuelle ou délictuelle ou autrement, engagée contre les acteurs du transport pour une perte, un dommage ou un retard de livraison subi par les marchandises faisant l'objet d'un contrat de transport, ou pour manquement à toute autre obligation prévue par la Convention ${ }^{218}$.

155- S'agissant du délai pour agir, il est portée à deux $a^{219}$ et conformément à l'article 63, ce délai n'est susceptible d'être ni interrompu ni suspendu. Toutefois, la personne à qui une réclamation est adressée peut à tout moment pendant le cours du délai, proroger celui-ci par une déclaration adressée à l'ayant droit. Le délai peut être de nouveau prorogé par une ou plusieurs autres déclarations. Au total, les Règles de Rotterdam laissent apparaître, de notre point de vue, un défaut d'équilibre entre les opérateurs du commerce maritime 220 .

\footnotetext{
218 Voir Règles de Rotterdam, art 4, al. 1.

219 Règles de Rotterdam, art. 62: "1. Aucune action judiciaire ou arbitrale relative à des réclamations ou des litiges découlant d'un manquement à une obligation prévue dans la présente Convention ne peut être engagée après l'expiration d'un délai de deux ans.

2. Le délai visé au paragraphe 1 du présent article court à partir du jour où les marchandises ont été livrées par le transporteur ou, lorsqu'elles n'ont pas été livrées ou ne l'ont été que partiellement, à partir du dernier jour où elles auraient dû être livrées. Le jour indiqué comme point de départ du délai n'est pas compris dans la computation.

3. Nonobstant l'expiration du délai visé au paragraphe 1 du présent article, une partie peut invoquer un droit et l'opposer à l'autre partie comme moyen de défense ou de compensation". 220 Voir GUERRA (Frank Nectali Miranda), Le conflit de lois en droit des transports de marchandises par mer, Thèse de Droit Privé, Université de Bourgogne, juillet 2013, pp. 103 et s. L'auteur indique que les Règles de Rotterdam peut-être ne seront pas largement ratifiées comme les Règles de Hambourg. Elles reflètent l'absence d'un cadre suffisant pour la protection du juste rapport entre les opérateurs du commerce maritime. Les Etats représentés ont essayé de faire un compromis sur certains aspects : la limite de responsabilité du transporteur, les contrats de volume et la compétence. Bien sûr, la position adoptée, par les Etats a été influencée par les opérateurs du commerce maritime : les chargeurs, les transporteurs, les transitaires, les exportateurs, lors des sessions du Groupe de travail III (Droit des transports) de la CNUDCI. Néanmoins, ces aspects pour d'autres Etats font obstacle à la ratification des Règles de Rotterdam. Leurs raisons de réticence révèlent, en général, un défaut d'équilibre dans les Règles de Rotterdam.
} 
156- A travers diverses conventions internationales ${ }^{221}$ nous avons étudié les normes à caractère préventif et curatif lorsque le cas échéant, des dommages surviennent à la marchandise. Ces normes constituent la protection de la marchandise à l'échelle internationale. A cette étude, il convient d'ajouter celle des normes de protection des transports maritimes en droit national ivoirien.

\section{Section 2: La protection de la marchandise selon les normes maritimes ivoiriennes}

157- Il sera étudié les normes de prévention et de réparation des dommages subis par la marchandise (\$1) qui seront complétées par les normes de l'assurance maritime $(\boldsymbol{\$} \mathbf{2})$.

\section{$\S 1$ : Les normes de prévention et de réparation des dommages à la marchandise}

158- Les normes de prévention des dommages à la marchandise sont prévues par voie réglementaire (A) tandis que la réparation des dommages à la marchandise est prévue par voie législative, le Code maritime ivoirien (B).

\section{A- La prévention des dommages dans les ports ivoiriens}

159- Il y a le décret $n^{\circ} 99-318$ du 21 avril 1999 portant règlement de police du Port autonome d'Abidjan (1) et l'arrêté $\mathrm{n}^{\circ} 0082$ du 05 mai 1999 portant règlement d'exploitation dudit port (2). Au port de San Pedro, nous donnerons quelques indications sur la prévention des dommages (3)

\section{1- Les normes prévues par le décret de 1999 portant règlement de police du Port autonome d'Abidjan}

160- D'emblée, il convient d'indiquer que conformément à l'article 6, « Le commandant du port d'Abidjan est, sous les ordres immédiats du Directeur général du Port autonome d'Abidjan, responsable de l'ordre public dans les limites de la circonscription du port d'Abidjan. Il exerce à cet effet une action

\footnotetext{
${ }^{221}$ Notamment la Convention de Montego Bay de 1982, la Convention sur la sécurité des conteneurs CSC de 1972, la Convention sur les normes de formation des gens de mer STCW de 1978, la Convention sur le transport de marchandises dangereuses.
} 
générale sur tous les services publics en ce qui concerne les affaires qui intéressent directement l'ordre public».

161- En ce qui concerne l'accès au port et aux navires, selon l'article 57, le libre accès sur les voies, les quais et les terre-pleins à l'intérieur de l'enceinte douanière du port d'Abidjan est interdit au public. Toute personne doit être munie d'un titre d'accès délivré par le commandant du port d'Abidjan pour pouvoir pénétrer et circuler à l'intérieur de l'enceinte douanière ${ }^{222}$. Il en est de même pour tout véhicule et ses occupants ${ }^{223}$. Au demeurant, "Tout accès à l'intérieur de l'enceinte douanière se fait exclusivement par les portes prévues à cet effet. Tout autre accès, notamment par les portes réservées aux chemins de fer et par les plans d'eau, est interdit ${ }^{224}$.

162- Par ailleurs il est interdit aux navires d'entrer, de sortir ou de faire mouvement à l'intérieur du plan d'eau défini à l'article 1 du décret sans la présence d'un pilote à bord. Toutefois, il y a des exceptions qui sont accordées à certains navires ${ }^{225}$.

163- Pour lutter contre les incendies, l'article 99 dispose qu'il est interdit d'allumer du feu à l'intérieur de l'enceinte douanière ; de procéder à des travaux sur le port d'Abidjan nécessitant d'une façon générale des précautions contre les incendies. Quant à l'article 100, il interdit de fumer dans les cales des navires ; de faire du feu nu à bord des navires désarmés ; de fumer et de faire du feu à l'intérieur des magasins-cales et sous les hangars.

164- Par ailleurs, en ce qui concerne le cas particulier des matières radioactives, l'accès au port d'Abidjan de tout navire transportant des matières radioactives est subordonné à une autorisation du Directeur Général du port à

${ }^{222}$ Décret $\mathrm{n}^{\circ}$ 99-318 du 21 avril 1999 portant règlement de police du Port autonome d'Abidjan, art. 59 .

${ }^{223}$ Idem, art. 60.

${ }^{224}$ Décret n 99-318 du 21 avril 1999 portant règlement de police du Port autonome d'Abidjan, art. 58 .

${ }^{225}$ A propos, voir Décret $n^{\circ}$ 99-318 du 21 avril 1999 portant règlement de police du Port autonome d'Abidjan, art. 17. 
qui notification est faite de certains renseignements au moins 5 jours avant l'arrivée du navire ${ }^{226}$.

\section{2- Les normes prévues par l'arrêté nº 0082 du 05 mai 1999 portant règlement d'exploitation du port autonome d'Abidjan}

165- L'article 2 de l'arrêté $n^{\circ} 0082$ dispose que le pilotage est obligatoire à l'entrée, à la sortie et pour tout déplacement dans les limites définies à l'article $3^{227}$ pour tout navire. Toutefois, certains navires sont dispensés de cette obligation de pilotage obligatoire. Il s'agit des navires de guerre ivoiriens ; des navires de guerre des pays du Conseil de l'Entente ou des navires appartenant à des Etats auxquels des droits équivalents ont été reconnus ; des navires de moins de 150 tonneaux de jauge nette; des navires affectés exclusivement à l'amélioration, à l'entretien, à la surveillance du port d'Abidjan et de ses accès, quel que soit leur tonnage ; et des engins de servitude du port d'Abidjan d'une manière générale.

\section{3- La prévention des dommages au Port autonome de San Pedro}

166- S'agissant de la sécurité au sein du Port autonome de San Pedro, selon le Guide promotionnel dudit port, les installations portuaires sont conformes au code ISPS. En outre, l'Autorité Portuaire s'est engagée dans la démarche d'obtention de la norme ISO 28000 qui concerne le management de la chaîne d'approvisionnement pour mieux maîtriser les risques de sûreté et notamment les risques de vol, de terrorisme, de piraterie et de fraude. Sur la place portuaire il existe : un Groupement de Sapeurs-pompiers du port ; une Gendarmerie composée du Groupe de Sécurité Portuaire (GSP) et d'une brigade ${ }^{228}$.

\section{B- Les normes prévues en cas de dommages à la marchandise}

167- Le législateur ivoirien vient de doter les transports maritimes d'une nouvelle loi à savoir le Code maritime. En effet, la loi n 2017-442 du 30 juin

\footnotetext{
${ }^{226}$ A propos de ces renseignements, voir Décret n 99-318 du 21 avril 1999 portant règlement de police du Port autonome d'Abidjan, art. 121.

${ }^{227}$ L'article 3 de l'Arrêté 0082 du 5 mai 1999 définit les zones de pilotage obligatoire.

228 Voir Guide promotionnel du port de San Pedro, 1ère édition, septembre 2015, p. 18.
} 
2017 portant Code maritime est entrée en vigueur le 13 novembre $2018^{229}$, date de sa publication au Journal Officiel de la République de Côte d'Ivoire (JORCI) ${ }^{230}$. L'article $708 \mathrm{du}$ Code maritime ivoirien dispose que la responsabilité du transporteur en ce qui concerne les marchandises couvre la période pendant laquelle les marchandises sont sous sa garde au port de chargement, durant le transport et au port de déchargement. En outre, l'article 708 précise l'expression de «marchandises sous la garde du transporteur ${ }^{231}$. Celle-ci se définit comme la période qui part de la prise en charge de la marchandise à sa livraison. L’article 709 prévoit une présomption de responsabilité à la charge du transporteur durant toute la période où les marchandises sont sous la garde de celui-ci. En effet, le transporteur est responsable du préjudice résultant des pertes ou dommages subis par les marchandises ainsi que du retard à la livraison, si ces pertes, dommages ou retards sont survenus pendant que les marchandises étaient sous sa garde au sens de l'article 708 de la loi ${ }^{232}$.

168- En plus des normes édictées pour la prévention et la réparation des dommages à la marchandise, le destinataire et le chargeur sont tenus de prendre des dispositions nécessaires pour pallier les risques de dommages le cas échéant. C'est tout l'intérêt de la souscription d'une police d'assurance maritime.

${ }^{229}$ Voir Journal Officiel de la République de Côte d'Ivoire du mardi 13 novembre 2018, pp. 129208.

${ }^{230}$ Loi n 2017-442 du 30 juin 2017 portant code maritime, art. 1115 : «La présente loi sera publiée au Journal officiel de la République de Côte d'Ivoire et exécutée comme loi de l'Etat". ${ }^{231}$ Code maritime, art. 708: «... Les marchandises sont réputées être sous la garde du transporteur à partir du moment où celui-ci les prend en charge des mains soit du chargeur ou d'une personne agissant pour son compte, soit d'une autorité ou autre tiers auquel les marchandises doivent être remises pour l'expédition, conformément aux lois et règlements applicables au port de chargement.

De même, les marchandises sont réputées être sous la garde du transporteur jusqu'au moment où il effectue la livraison soit en remettant les marchandises au destinataire, soit dans les cas où le destinataire ne reçoit pas les marchandises du transporteur, en les mettant à la disposition du destinataire conformément au contrat ou aux lois ou aux usages du commerce applicables au port de déchargement".

${ }^{232}$ Loi n 2017-442 du 30 juin 2017 portant code maritime, art. 709. 


\section{§ 2 : L'incontournable système de l'assurance maritime}

169- Malgré les diverses conventions destinées à prévenir les dommages il arrive que la marchandise subisse des dommages. En dépit de la présomption de la responsabilité du transporteur prévue par les conventions destinées à réparer les dommages ${ }^{233}$ et le Code maritime en son article 708 , il arrive des fois où lesdits dommages ne soient pas réparés, ou à tout le moins pas entièrement réparés. Les marchandises acheminées par voie maritime dans le cadre des échanges internationaux sont soumises à des risques particuliers tels que les pertes, les vols, les casses, la mouille et bien d'autres. A ceux-ci s'ajoutent les risques liés aux diverses opérations effectuées par des intermédiaires du transport maritime notamment les opérations de manutention portuaire, de chargement et déchargement des marchandises etc.

170- En outre, la limitation de responsabilité du transporteur maritime est un instrument d'équilibre qui a pour but de répartir entre les exploitants de l'industrie maritime l'ensemble des risques inhérents à toute entreprise maritime ${ }^{234}$. Pour se mettre à l'abri de pertes non remboursables, de dommages non réparables, de risques d'insolvabilité du transporteur maritime et des délais souvent très longs de règlement, l'assurance des marchandises doit toujours être envisagée lors de la négociation du contrat commercial. La nature de l'incoterms $\underline{235}$ choisi détermine en général laquelle des deux parties ${ }^{236}$ aura la responsabilité d'assurer la marchandise au cours du transport. Toutefois, le destinataire a tout intérêt à prendre une couverture d'assurance pour la marchandise au cours de son transport maritime. L'assurance sur facultés offre

\footnotetext{
${ }^{233}$ Voir Convention de Bruxelles, art. 4-2 et Convention de Rotterdam, art. 17-1.

234 FETZE KAMDEM (Innocent), "La responsabilité du transporteur maritime au niveau international: un échec d'uniformisation juridique", Les Cahiers de Droit, vol. 41, n 4 , décembre 2000, p. 700.

${ }^{235}$ Voir Lamy transport, tome 2, édition 2010, p. 999. Incoterms : Abréviation de : International Commercial TERMS : Ensemble de règles standardisés pour l'interprétation des termes utilisés dans les contrats de vente internationaux. Publiés par la Chambre de commerce international et révisés périodiquement, les Incoterms déterminent les obligations réciproques du vendeur et de l'acheteur et précisent les conditions notamment de délivrance de la marchandise, le moment du transfert des risques et la répartition des frais.

${ }^{236} \mathrm{Il}$ s'agit de l'exportateur ou l'importateur, en d'autres termes du chargeur ou du destinataire de la marchandise.
} 
une protection appropriée ${ }^{237}$ de la marchandise. En effet, des impératifs économiques et sécuritaires ont fait de l'assurance maritime sur facultés une obligation incontournable 238 .

171- L'assurance des facultés à l'importation revêt un caractère obligatoire dans la mesure où les législations nationales le prévoient. Elle est alors régie par les dispositions spécifiques de ces législations ${ }^{239}$. Toutefois, les dispositions $\mathrm{du}$ présent code relatives au paiement des primes lui sont applicables ${ }^{240}$. En Côte d'Ivoire les assurances maritimes étaient régies, pour ce qui concerne l'assurance sur corps de navire par les clauses types de la CNUCED de 1989. Aujourd'hui, le nouveau Code maritime intègre en son livre IX, une large réglementation sur les assurances maritimes, en posant les principes généraux, les différentes règles en matière de conclusion de contrat d'assurances, d'obligations des parties et de règlement d'indemnités en cas de sinistre $^{241}$. Ainsi, la domiciliation de l'assurance sur facultés à l'importation est rendue obligatoire en Côte d'Ivoire par l'ordonnance $\mathrm{n}^{\circ} 2007-478$ du 16 mai $2007^{242}$.

172- Pour ce qui concerne cette étude, on s'intéressera à l'assurance des marchandises transportées par mer qui se définit comme le " contrat par lequel un souscripteur se fait promettre par un assureur une protection en cas de

\footnotetext{
237 NGAMKAN, (G). "Quelques conseils juridiques et politiques aux chargeurs et réceptionnaires africains afin de leur permettre de tirer le meilleur parti de leurs activités commerciales ", Juridis périodique, n² 28, oct-nov-déc. 96, pp. 83-93.

${ }^{238}$ FAIVRE (Y. Lambert) et LEVENEUR (Laurent), Droit des assurances, 12e éd précis Dalloz, 2005 ; voir aussi KENGUEP, (E), Analyse critique des règles de responsabilité du transporteur maritime de marchandises : contribution à la recherche de la solution au problème de l'équilibre contractuel, thèse 3ème cycle, Université de Yaoundé II, 2002, p. 315.

239 Voir Code CIMA, art. 278.

${ }^{240}$ Voir Annexe au Traité instituant la Conférence Interafricaine des Marchés d'Assurances (CIMA) du 10 juillet 1992, notamment le Règlement n 0001/CIMA/PCMA/PCE/2012 du 5 avril 2012.

${ }^{241}$ BILE (Vincent), "Regard Critique sur le Nouveau Code Maritime Ivoirien », Neptunus, e. revue Université de Nantes, vol. 24, 2018/3, p. 3.

${ }^{242}$ En effet, la loi $\mathrm{n}^{\circ}$ 86-485 du 1er juillet 1986 qui rend obligatoire la domiciliation locale de l'assurance des facultés à l'importation a été abrogée par l'ordonnance n97-444 du 08 août 1997. Celle-ci est également abrogée par l'ordonnance ${ }^{\circ}$ 2007-478 du 16 mai 2007 qui est en définitif intégrée au nouveau Code maritime.
} 
réalisation d'un risque moyennant le paiement d'un prix appelé prime ou cotisation "243. Quant au nouveau Code maritime ivoirien, il précise que : "Toute convention par laquelle le souscripteur, moyennant le paiement d'une prime se fait promettre par l'assureur, pour lui ou pour un tiers, une indemnisation en cas de sinistre relatif à un intérêt économique maritime, est un contrat d'assurance maritime soumis à la présente loi"244. Nous examinerons, d'une part, le domaine d'application et l'étendue de l'assurance (A) et, d'autre part, le temps, le lieu de l'assurance et la valeur assurée (B).

\section{A- Domaine d'application et étendue de l'assurance sur facultés}

173- Chargeurs et transporteurs, pour la couverture des risques de leurs affaires, font de l'assurance une des formalités incontournables dans leur gestion ${ }^{245}$. A cet effet, selon l'arrêté interministériel n 13 du 11 janvier 2018, "Les entreprises agrées à faire les opérations d'assurance de biens et marchandises de toute nature à l’importation doivent délivrer des certificats d'assurance électroniques via la plate-forme de Guichet Unique du Commerce Extérieur (GUCI) conformément au modèle joint en annexe »246. Dans une première approche, on examinera successivement le domaine d'application de l'assurance sur facultés (1) et l'examen de son étendue (2).

\section{1- Le domaine d'application de l'assurance sur facultés}

174- Selon le doyen René Rodière, pendant de longs siècles l'assurance n'a existé que dans le domaine maritime. Si aujourd'hui, elle s'est étendue à toutes les activités des hommes, elle ne règne nulle part comme sur la mer. La branche

\footnotetext{
${ }^{243}$ LAMBERT-FAIVRE (Yvonne), Droit des assurances, précis Dalloz, 2e éd. 1977, p. 39.

${ }^{244}$ Loi no $^{\circ}$ 2017-442 du 30 juin 2017 portant Code maritime, art. 903.

245 Voir FETZE KAMDEM (Innocent), « La responsabilité du transporteur maritime au niveau international : un échec d'uniformisation juridique ", op. cit., p. 700. Selon l'auteur, le chargeur fait appel aux assureurs traditionnels en vue de souscrire une assurance-faculté couvrant les marchandises, tandis que le transporteur désireux de couvrir les risques encourus par le navire, s'adresse généralement à des mutuelles mieux connues sous l'appellation "Protection and Indemnity clubs "(P\&I Clubs). Ce sont ces assureurs et P\&I Clubs qui, moyennant une contrepartie financière, supportent l'essentiel des risques marins.

${ }^{246}$ Voir l'article 1 de l'Arrêté interministériel n 013 MEF/SEPMBPE du 11 janvier 2018 portant modification de l'arrêté $n^{\circ}$ 849/MEF/DGTCP/DA du 10 novembre fixant le modèle de certificat pour l'assurance des biens et marchandises de toute nature à l'importation.
} 
transports des compagnies d'assurances qui opèrent dans tous les domaines accuse couramment des rentrées de primes quatre fois plus élevés dans le domaine maritime que pour l'ensemble des autres modes de transport (routier, ferroviaires, fluviaux et aériens) ${ }^{247}$. L'assurance sur facultés s'applique, dans les limites du voyage assuré, aux marchandises transportées ou prises en charge par le transporteur maritime, conformément aux usages reconnus du commerce.

175- L'assurance sur facultés s'applique uniquement si le navire transporteur détient le certificat de gestion de la sécurité ("safety management certificate"), et si la Compagnie possède l'attestation de conformité ("document of compliance"). Ces documents sont prescrits par la Convention SOLAS de 1974 instituant le "Code international de gestion de la sécurité", dit "Code ISM". Toutefois, lorsque le navire transporteur et la Compagnie ne détiennent pas les documents précités, la situation du navire au regard de la réglementation du Code ISM ne sera pas opposable, soit à l'assuré, soit au porteur des documents d'assurance, s'il établit qu'il ne pouvait pas, dans la pratique habituelle des affaires, connaître cette situation ${ }^{248}$.

\section{2- L'étendue de l'assurance sur facultés}

176- En matière d'assurance sur facultés, les risques commencent à courir à partir du moment où les marchandises quittent la terre pour être embarquées à bord du navire dans lequel elles doivent être transportées, ou pour être mises à bord d'une allège ou de tout autre engin flottant qui doit les amener à bord du navire transporteur. Les marchandises restent assurées pendant les périodes de séjour sur les allèges ou autres engins flottants, sur terre-plein ou en magasincale, au port de destination jusqu'à leur transfert en dépôt douane réel ou sur place $^{249}$. Si le navire sur lequel les marchandises sont transportées, devient innavigable en cours de voyage, et que les intérêts transportés doivent être

${ }^{247}$ RODIERE (René), Droit maritime, Dalloz, 5 ème édition, n519, pp. 423 et 424.

248 Voir Police française d'assurance maritime sur facultés (marchandises) du $1^{\text {er }}$ juillet 2009, art. 3. Mais il faut indiquer que les clauses de la police française d'assurance sont indicatives, les parties pouvant convenir de conditions d'assurance différentes. Aussi, pour toute clause comportant une exclusion, les parties peuvent convenir que l'assurance couvrira les risques visés par l'exclusion de garantie, soit par une extension de garantie, soit par un contrat distinct. ${ }^{249}$ Loi n $^{\circ}$ 2017-442 du 30 juin 2017 portant Code maritime, art. 949. 
transportés sur un autre navire, l'assurance couvre également les frais de transbordement, d'entreposage et de garde ainsi que le fret supplémentaire dû, jusqu'à concurrence de la valeur assurée ${ }^{250}$.

177- Cependant, le nouveau Code maritime exclut de la couverture d'assurance plusieurs dommages notamment la freinte de route ; le vice propre, le défaut ou l'insuffisance d'emballage des marchandises assurées ; le mauvais arrimage des marchandises, s'il a été réalisé sous la responsabilité de l'assuré, du chargeur ou de leurs préposés. ${ }^{251}$. Notre étude n'omet pas de prendre en compte les caractéristiques de l'assurance telles que le temps et le lieu de l'assurance ainsi que la valeur assurée.

\section{B- Les caractéristiques de l'assurance sur facultés}

178- Au sens de notre analyse, les caractéristiques de l'assurance sur facultés correspondent au temps et au lieu de la couverture d'assurance (1) ainsi qu'aux intérêts assurables (2).

\section{1- Temps et lieu de la couverture d'assurance}

179- Pour être couverts par l'assurance, les dommages doivent non seulement avoir été produits dans des conditions de temps mais aussi aux lieux prévus par la police d'assurance. Si le voyage comprend à la fois des trajets maritimes et des trajets en eaux intérieures, ou par la voie terrestre ou aérienne, les dispositions relatives aux assurances maritimes sont applicables à l'ensemble du voyage ${ }^{252}$. En effet, selon le Code maritime ivoirien, les expéditions de marchandises sous police flottante sont couvertes à partir du moment où elles sont exposées aux risques garantis. Elles sont également couvertes lorsqu'il s'agit des expéditions prévues à l'alinéa $1^{\mathrm{er}}$ de l'article précédent, et à condition que la déclaration d'aliment ait été faite à l'assureur dans les délais prévus dans la police ; à compter du jour de la déclaration faite par l'assuré, dans le cas des expéditions prévues à l'alinéa $1^{\mathrm{er}}$ de l'article

\footnotetext{
250 Idem, art. 950.

251 Voir Code maritime ivoirien, art. 956.

${ }^{252}$ Loi n $^{\circ} 2017-442$ du 30 juin 2017 portant Code maritime, art. 947.
} 
précédent ${ }^{253}$. En outre, conformément à l'alinéa $1^{\text {er }}$ de l'article 953 , en cas de police flottante, l'assuré est tenu de déclarer à l'assureur toutes les expéditions effectuées par voie maritime. L’assurance maritime couvre les risques pendant toute la durée de responsabilité du transporteur ${ }^{254}$.

180- La police d'assurance est parfaitement valable dès lors que le souscripteur n'avait pas connaissance du sinistre déjà survenu, au moment où il a donné l'ordre d'assurer la marchandise. C'est ce qui ressort d'une espèce où le naufrage du navire était survenu avant la date à laquelle l'ordre d'assurer la marchandise a été donné. Les juges de la Cour Suprême ont décidé que l'assuré soit indemnisé. Les faits de la cause sont les suivants : le naufrage du navire, à bord duquel la marchandise a été chargée, est survenu le 19 novembre 1997. Le 20 novembre 1997, l'assuré a donné l'ordre d'assurer la marchandise. Le 21 novembre 1997, l'assuré recevait l'information que le naufrage du navire a entraîné la perte de la marchandise. L’assureur refuse d'indemniser l'assuré en arguant que : "seul un risque aléatoire peut faire l'objet d'une assurance et qu'un bien quelconque déjà frappé d'un sinistre ne peut valablement faire l'objet d'une couverture $»^{255}$.

181- La prétention de l'assureur a été suivie par la Cour d'appel d'Abidjan. Cependant, la Cour Suprême cassa l'arrêt de la Cour d'appel au motif que : «La Cour d'appel en n’ayant pas cherché à établir si [l'assuré] savait que la marchandise qu'elle faisait assurer était inexistante n'a pas donné de motifs suffisants à sa décision »256 et que : "La police d'assurance est parfaitement valable dès lors que le souscripteur n’avait pas connaissance du sinistre déjà survenu, au moment où il a donné l'ordre d'assurance. En ne cherchant pas à

\footnotetext{
253 Idem, art. 954.

254 Voir Loi n² 2017-442 du 30 juin 2017 portant Code maritime, art. 708 : "La responsabilité du transporteur en ce qui concerne les marchandises couvre la période pendant laquelle les marchandises sont sous sa garde au port de chargement, durant le transport et au port de déchargement". Voir aussi Convention des Nations Unies sur le contrat de transport international de marchandises effectué entièrement ou partiellement par mer, art. 12 -1 : "Le transporteur est responsable des marchandises en vertu de la présente Convention depuis leur réception par une partie exécutante ou lui-même en vue de leur transport jusqu'à leur livraison ". 255 Voir Cour d'appel d'Abidjan, arrêt n 595 du 12 mai 2000. Arrêt inédit. 256 Cour Suprême Ch. Jud., arrêt n 507 du 13 juin 2002.
} 
établir si le souscripteur savait que la marchandise qu'elle faisait assurer était inexistante, la Cour d'Appel n'a pas donné de motifs suffisants à sa décision, qui encourt la cassation ${ }^{257}$. Sur évocation ${ }^{258}$, la Cour suprême condamna l'assureur à payer l'indemnité d'assurance à son assuré. Dans cette affaire, l'assureur a été débouté de sa prétention parce qu'il a été incapable de prouver que l'assuré avait connaissance du naufrage du navire avant de donner l'ordre d'assurer la marchandise.

182- Les marchandises sont assurées, soit par une police n'ayant d'effets que pour un voyage, soit par une police appelée police flottante ${ }^{259}$. Lorsqu'un contrat d'assurance de marchandises est conclu sous forme de police flottante, l'assuré est tenu de déclarer à l'assureur toutes les expéditions effectuées par voie maritime, en exécution de contrats d'achat ou de vente mettant à sa charge l'obligation d'assurer, ou toutes les expéditions faites pour le compte de tiers ayant laissé à l'assuré le soin de pourvoir à l'assurance, si l'assuré est intéressé à ces expéditions comme commissionnaire, consignataire ou en toute autre qualité. L'assureur est tenu de les accepter en aliment dans le cadre de la police $^{260}$. Le Code maritime dispose que l'importance des avaries aux marchandises est déterminée par comparaison de leur valeur en état d'avarie avec la valeur qu'elles auraient eue à l'état sain, à la même époque et au même lieu. Le taux de dépréciation ainsi obtenu est appliqué à la valeur assurée de la marchandise ${ }^{261}$.

\footnotetext{
${ }^{257}$ Cour Suprême Ch. Jud., arrêt n 507 du 13 juin 2002.

258 A propos du terme "évocation ", voir N'DRI (Kouacou François), Le juge ivoirien et la preuve dans le contentieux administratif, Thèse Université Felix HOUPHOUËT-BOIGNY d'Abidjan, mai 2013, p. 356. L'auteur montre que l'effet dévolutif de l'appel suppose que le juge de première instance avait statué sur le fond et qu'il y a lieu à reprise de toute l'affaire. Au contraire, l'évocation suppose qu'aucun jugement n'a été rendu sur le fond, alors qu'il aura dû l'être, ou s'il en a été rendu un, que cela a été fait dans d'irrégulières conditions. Sur le principe de l'évocation. Voir aussi DRAGO (Roland), "L'évolution dans la procédure administrative ", RDP 1957, pp. 453-473.

${ }^{259}$ Loi n $^{\circ} 2017-442$ du 30 juin 2017 portant Code maritime, art. 948.

${ }^{260}$ Loi n ${ }^{\circ}$ 2017-442 du 30 juin 2017 portant Code maritime, art. 953.

${ }^{261}$ Code maritime, art. 957.
} 


\section{2- Les intérêts assurables}

183- Tout intérêt légitime, y compris le profit espéré, peut faire l'objet d'une assurance. Tous les navires ou engins de navigation immatriculés en Côte d'Ivoire ainsi que toutes les importations de biens et marchandises à des fins directement ou indirectement commerciales ou industrielles sont soumis à l'obligation d'assurance. Constituent des intérêts assurables : le navire, le loyer dû pour l'affrètement du navire, la cargaison, le fret, le prix du passage, le profit espéré sur les marchandises, la contribution en avaries communes, la responsabilité civile encourue par l'armateur ou l'affréteur ${ }^{262}$.

184- Le but visé par les différentes conventions internationales relatives au trafic maritime est de prévenir en amont le dommage à la marchandise. Toutefois, en cas de dysfonctionnement des mécanismes de prévention, ayant causé des dommages à la marchandise, le destinataire a recours aux normes prévues pour leur réparation. Par ailleurs, le cadre juridique du transport de marchandises par mer est la réunion des normes de protection de la marchandise et des normes de sécurité maritime. A présent, la question se pose de savoir ce qu'il en est des normes de lutte contre l'insécurité maritime?

262 Code maritime, art. 903. 


\section{CHAPITRE 2 : LES NORMES LEGISLATIVES DE LUTTE CONTRE LES INFRACTIONS LIEES AU TRAFIC MARITIME}

185- L'étude des normes de prévention et de répression des infractions liées au trafic maritime de marchandises consiste à présenter au préalable l'état de quelques-unes de ces infractions susceptibles d'être commises sous la forme du trafic d'êtres humains et de la piraterie maritime.

186- Selon les Nations unies et le Conseil de l'Europe, la traite des êtres humains serait la troisième forme de trafic la plus rémunératrice dans le monde après le trafic de drogue et la contrefaçon. Ladite traite générerait un profit de 32 milliards de dollars par an ${ }^{263}$. La traite des êtres humains est une forme de criminalité internationale organisée assimilable à de l'esclavage moderne qui rapporte des milliards de dollars 264 .

187- Selon Monsieur Romain Broner, "La piraterie découle du commerce en mer en cela que dès quỉl a été possible de transporter des marchandises par la voie maritime, le long des côtes, il s'est trouvé des aventuriers pour tenter de s'enrichir en s'emparant de ces marchandises, en rançonnant leurs passagers, en exigeant un droit de passage. Cette pratique a perduré par-delà les âges, depuis l'Antiquité jusqu'à l'époque moderne. Dans notre monde contemporain, la piraterie est toujours présente $»^{265}$.

188- Depuis 1998, la piraterie maritime est revenue au-devant de la scène sur les deux côtes de l'Afrique comme ce fut le cas en Asie du Sud Est avec ses différentes facettes ${ }^{266}$. Spécialement depuis la chute des Tribunaux islamiques

\footnotetext{
${ }^{263}$ Voir https://www.diplomatie.gouv.fr/fr/.

${ }^{264}$ Voir https://www.interpol.int/fr/crime-areas/trafficking-in-human-beings/.

${ }^{265}$ BRONER (Romain), La répression de la piraterie maritime et ses enjeux juridiques, Mémoire de Master de Recherche, Sécurité et Défense, Université Panthéon-Assas-paris II, Année universitaire 2009/ 2010, p. 5 .

266 Voir BRONER (Romain), La répression de la piraterie maritime et ses enjeux juridiques, Mémoire de Master Recherche, Sécurité et Défense, Université Panthéon-Assas-paris II, Année universitaire 2009/ 2010, op. cit., p. 77. L'auteur, citant Éric FRECON, indique que trois types de piraterie ou de vols à main armée cohabitent dans la zone d'Asie du Sud-Est. Une petite piraterie qui s'assimile à de la petite délinquance locale, du fait de pêcheurs désargentés,
} 
en décembre 2006, la corne de l'Afrique et la côte s'étendant sur la Somalie, le Somaliland, les Seychelles et le Yémen ont vu éclore une nouvelle génération de pirates capables de déstabiliser le commerce mondial. En réaction, les pays d'Europe se sont mobilisés pour déployer, dans la zone touchée, une flotte militaire relativement offensive dans la mesure où les bâtiments peuvent aborder des navires pirates, procéder à des arrestations ou escorter des bâtiments en danger ${ }^{267}$.

189- Seront envisagées l'étude des normes de lutte adoptées à l'échelle internationale contre les infractions liées au trafic maritime (Section 1) et celles adoptées à l'échelle nationale ivoirienne (Section 2).

\section{Section 1 : Les normes de lutte de dimension internationale}

190- Les normes de prévention et de répression des infractions liées au trafic de marchandises sont mises en place, à l'échelle internationale, à travers les différentes conventions adoptées par l'OMI268. Ces conventions incriminent et luttent contre divers actes. Il s'agit de la lutte contre les trafics illicites de drogues et d'armes $(\boldsymbol{\$} \mathbf{1})$, la lutte contre le transport des polluants et le trafic d'êtres humains $(\boldsymbol{\$}$ 2) et la lutte contre l'insécurité de la navigation maritime (\$ 3).

\section{$\S 1$ : La lutte contre les trafics de drogues et les trafics d'armes}

191- Pour lutter contre les trafics de drogues et d'armes qui se passent couramment dans le secteur maritime, des normes juridiques ont été prévues

\footnotetext{
notamment dans l'île de Batam ; une piraterie organisée, qui fait intervenir des gangs de pirates plus structurés, avec la présence d'un ou plusieurs parrains locaux qui financent et organisent les attaques de cargos ; et enfin une piraterie internationale, qui a très probablement des liens avec les milieux mafieux d'Asie du Sud-Est, que ce soit à Hong-Kong, en Chine, à Taiwan, Singapour, Jakarta... Cette dernière concerne des actes de détournement de navire et de revente de sa cargaison, voire parfois de maquillage de navire.

267 Voir LECLERCQ (J.F.), "Communication à l'audience solennelle de rentrée de la Cour de cassation de Belgique ", $1^{\text {er }}$ septembre 2010, pp. 2-3.

268 A propos de l'OMI, nous rappelons que: de l'Organisation Maritime Consultative Internationale (OMCI) en 1948, on est passé à l'Organisation Maritime Internationale qui se présente comme l'institution spécialisée des Nations Unies dont l'activité est entièrement consacrée aux questions de la sécurité maritime. Voir supra pp. 37-38.
} 
au niveau international pour prévenir mais aussi réprimer ces infractions, le cas échéant ${ }^{269}$. Nous examinerons les normes prévues par la Convention des Nations Unies contre le trafic illicite de stupéfiants et de substances psychotropes de 1988 (A) puis les normes prévues par le traité des Nations Unies sur le commerce des armes (B).

\section{A- Les normes de la Convention des Nations Unies contre le trafic illicite de stupéfiants et de substances psychotropes de 1988}

192- Les concepts de drogue, substance psychotrope, stupéfiant et toxique se chevauchent quant à leurs significations avec cependant un sens bien différencié pour chacun d'entre $\mathrm{eux}^{270}$. Le trafic illicite de drogue en mer s’intensifie dans le golfe de Guinée comme en témoignent les recherches menées par Madame Marina Madel YAPO271.

193- Des Etats sont profondément préoccupées par l'ampleur et l'augmentation de la production, de la demande et du trafic illicites de stupéfiants et de substances psychotropes, qui constituent une menace grave

269 Voir BORÉ EVENO (Valérie), « Le cadre juridique international de la lutte contre le trafic maritime de stupéfiants. Quelles compétences pour les Etats? "Université de Nantes. Centre de Droit Maritime et Océanique, EA n 1165 , juin 2017, p. 17. L'auteur indique que Le 15 avril 2015, un voilier naviguant sous faux pavillon américain est intercepté par les douanes françaises, à $200 \mathrm{~km}$ au large des côtes martiniquaises. A son bord, plus de deux tonnes de cocaïne sont découvertes : l'une des plus importantes saisies jamais réalisées. Quatre mois plus tard, le 29 août 2015, c'est un autre voilier, battant pavillon des Pays-Bas et suspecté de convoyer plus d'une tonne de cocaïne, qui prend feu dans le Golfe de Gascogne, comme par hasard à l'approche d'un patrouilleur de haute mer. Ces évènements rappellent, s'il en était besoin, que la lutte contre le trafic maritime de stupéfiants est toujours d'actualité, bien qu'elle puisse paraître ces derniers temps médiatiquement occultée par un autre trafic malheureusement tout aussi rentable et particulièrement odieux : celui des migrants. L'accroissement du commerce mondial à travers cet extraordinaire espace de liberté que constituent les océans profite en effet à tous, y compris à ceux qui détournent cette liberté pour mener à bien leurs activités illicites.

270 Mais la distinction n'a pas d'effet dans cette étude.

${ }^{271}$ YAPO (Marina Madel), La lutte contre la criminalité maritime dans le golfe de guinée : cas de la Côte d'Ivoire et du Nigeria. Etude, Décembre 2013, p. 7. Selon l'auteur, les sonnettes d'alarme ont été tirées en ce qui concerne le volume de cocaïne transitant dans la région (environs 50 tonnes par an). L'Afrique de l'Ouest, qui n'a jamais été confrontée à des problèmes de drogue par le passé, est devenue une plaque tournante du trafic de cocaïne. Les ports et les aéroports internationaux sont utilisés par ces réseaux criminels pour les trafics de drogue de l'Asie (héroïne et substances psychotropes), l'Amérique latine (cocaïne), Afrique du Nord (résine de cannabis) et Europe (substances psychotropes). 
pour la santé et le bien-être des individus. Leurs autorités sont également conscientes que le trafic illicite est la source de gains financiers et de fortunes importantes qui permettent aux organisations criminelles transnationales de pénétrer, contaminer et corrompre les structures de l'Etat, les activités commerciales et financières légitimes et la société à tous les niveaux "272. C'est pourquoi, ils ont adopté la Convention des Nations Unies contre le trafic illicite de stupéfiants et de substances psychotropes. Nous examinerons les dispositions relatives à l'infraction pénale et à la compétence juridictionnelle (1) et les dispositions relatives à l'extradition et à l'entraide judiciaire(2).

\section{1- L’infraction et la compétence juridictionnelle}

194- Chaque Etat Partie adopte les mesures nécessaires pour conférer le caractère d'infractions pénales conformément à son droit interne. Lorsque qu'il constate que l'acte a été commis intentionnellement à la production, à la fabrication, à l'extraction, à la préparation, à l'offre, à la mise en vente, à la distribution, à la vente, à la livraison à quelque condition que ce soit, au courtage, à l'expédition, à l'expédition en transit, au transport, à l'importation ou à l'exportation de tout stupéfiant ou de toute substance psychotrope. Et cela en violation des dispositions de la Convention de 1961, telle que modifiée ou de la Convention de 1971273. Des mesures nécessaires doivent être prises par chaque Etat Partie afin de conférer le caractère d'infraction pénale aux faits illicites décrits par les dispositions de la Convention. En ce qui concerne précisément le trafic par mer, les parties coopèrent en vue d'y mettre fin ${ }^{274}$.

\footnotetext{
272 Voir le Préambule de la Convention des Nations Unies contre le trafic illicite de stupéfiants et de substances psychotropes de 1988.

${ }^{273} \mathrm{Cf}$ : Convention des Nations Unies contre le trafic illicite de stupéfiants et de substances psychotropes, art. 3-1.

${ }^{274}$ Cf : Convention des Nations Unies contre le trafic illicite de stupéfiants et de substances psychotropes, art. $17:$ : 1. Les Parties coopèrent dans toute la mesure possible en vue de mettre fin au trafic illicite par mer, en conformité avec le droit international de la mer.

2. Une Partie qui a des motifs raisonnables de soupçonner qu'un navire battant son pavillon ou n'arborant aucun pavillon ou ne portant aucune immatriculation se livre au trafic illicite peut demander aux autres Parties de l'aider à mettre fin à cette utilisation. Les Parties ainsi requises fournissent cette assistance dans la limite des moyens dont elles disposent.

3. Une Partie qui a des motifs raisonnables de soupçonner qu'un navire exerçant la liberté de navigation conformément au droit international et battant le pavillon ou portant une immatriculation d'une autre Partie se livre au trafic illicite peut le notifier à l'Etat du pavillon, demander confirmation de l'immatriculation et, si celle-ci est confirmée, demander l'autorisation à cet Etat de prendre les mesures appropriées à l'égard de ce navire.
} 
195- En matière de compétence juridictionnelle, chaque Etat partie adopte les mesures nécessaires pour établir sa compétence en ce qui concerne les infractions qu'elle a établies conformément au paragraphe 1 de l'article 3 lorsque l'infraction a été commise sur son territoire ; ou lorsque l'infraction a été commise à bord d'un navire battant son pavillon ou d'un aéronef immatriculé conformément à sa législation au moment où l'infraction a été commise ${ }^{275}$.

\section{2- L'extradition et l'entraide judiciaire}

196- En ce qui concerne l'extradition des délinquants, l'article 6 dispose en son paragraphe 1 que sont extradés, les auteurs des infractions établies par les Etats parties conformément au paragraphe 1 de l'article 3 . Chacune des infractions auxquelles s'applique le présent article est de plein droit incluse dans tout traité d'extradition en vigueur entre les Etats parties en tant qu'infraction dont l'auteur peut être extradé. Les Etats parties s'engagent à inclure ces infractions en tant qu'infractions dont l'auteur peut être extradé dans tout traité d'extradition qu'elles concluront ${ }^{276}$.

197- Enfin, en matière d'entraide judiciaire selon la Convention ${ }^{277}$, les Etats parties s'accordent mutuellement l'entraide judiciaire la plus étendue pour toutes enquêtes, poursuites pénales et procédures judiciaires concernant les infractions établies conformément au paragraphe 1 de l'article 3.

198- Après les normes prévues pour lutter contre le trafic illicite de stupéfiants et de substances psychotropes, il convient de porter le regard sur la lutte contre le commerce des armes.

4. Conformément aux dispositions du paragraphe 3 ou aux traités en vigueur entre elles ou à tous autres accords ou arrangements conclus par ailleurs entre ces Parties, l'Etat du pavillon peut notamment autoriser l'Etat requérant à: a) Arraisonner le navire; b) Visiter le navire; c) Si des preuves de participation à un trafic illicite sont découvertes, prendre les mesures appropriées à l'égard du navire, des personnes qui se trouvent à bord et de la cargaison ...».

275 Voir Convention des Nations Unies contre le trafic illicite de stupéfiants et de substances psychotropes, art. 4-1.

${ }^{276}$ Idem, art. 6-2.

277 Convention des Nations Unies contre le trafic illicite de stupéfiants et de substances psychotropes, art. 7-1. 


\section{B- Les normes prévues par le traité des Nations Unies sur le commerce des armes de 2013}

199- Avant de préciser ces normes juridiques de lutte contre le commerce des armes (2), il serait judicieux de situer, de prime à bord, le contexte de ladite lutte (1).

\section{1- Le contexte de la lutte contre le trafic illicite d'armes}

200- Le Conseil de sécurité réaffirme que la prolifération des armes nucléaires, chimiques et biologiques et de leurs vecteurs constitue une menace pour la paix et la sécurité internationales. Demeurant gravement préoccupé par la menace du terrorisme et le risque de voir des acteurs non étatiques se procurer, mettre au point ou utiliser des armes nucléaires, chimiques ou biologiques et leurs vecteurs, ou en faire le trafic, y compris en tirant parti, à cette fin, des avancées rapides de la science, de la technologie et du commerce international, le Conseil de sécurité décide de rester saisi de la question du commerce des armes ${ }^{278}$. En outre, il est essentiel que la communauté internationale, y compris le Conseil de sécurité, travaille à l'élaboration d'un cadre juridique complet visant à l'interdiction des armes nucléaires et de leurs vecteurs.

201- S'agissant notamment de ces armes nucléaires, en 2004 le Conseil de sécurité des Nations Unies a pris la résolution 1540, visant à empêcher les acteurs non étatiques ${ }^{279}$ de mettre au point, d'acquérir ou d'utiliser des armes de destruction massive (nucléaires, biologiques et chimiques). Mais hélas, cette résolution 1540 de 2004 qualifiée de résolution pionnière, n'est pas mise en œuvre. Quant à la résolution 2325 de 2016 adoptée à l'unanimité de ses 15 membres, le Conseil de sécurité des Nations Unies demande aux États membres qui ne l'ont pas encore fait de présenter leur premier rapport sur les mesures prises ou qu'ils comptent prendre pour empêcher que des acteurs non étatiques se retrouvent en possession de ce type d'armes.

\footnotetext{
278 Voir le texte du projet de résolution des Nations Unies (S/2016/1052).

$279 \mathrm{Il}$ s'agit en particulier des terroristes.
} 
202- Par ailleurs, les armes légères sont aussi meurtrières que les armes de destruction massive. Kofi Annan, ex-Secrétaire général de l’ONU déclarait que : «Les armes légères font infiniment plus de victimes que les autres types d'armes. La plupart des années, le nombre de morts attribuable à ces armes dépasse largement celui des victimes des bombes atomiques d'Hiroshima et de Nagasaki. De fait, au regard des carnages qu'elles provoquent, elles pourraient être assimilées à des armes de destruction massive "280. Ces armes légères tuent une personne toutes les deux minutes dans le monde, dans les pays déchirés par les conflits civils et dans les cas d'homicides liés à la délinquance ou aux drogues ${ }^{281}$.

203- Le commerce illicite des armes légères et leurs munitions est un fléau mondial qui cause des ravages partout. Des rebelles attaquent des civils ou des Casques bleus. Des barons de la drogue tuent aveuglément des responsables de l'application des lois ou toute autre personne qui entrave leurs activités illicites. Des bandits détournent des convois d'aide humanitaire. Sur tous les continents, les armes légères non contrôlées posent un problème durable ${ }^{282}$. La question se pose de savoir comment empêcher les armes de tomber entre les mauvaises mains. Au niveau de la CEDEAO, existe une Convention de lutte contre le trafic illicite des armes ${ }^{283}$. Les fusils d'assaut et

280 Voir http://www.un.org/smallarms 2006/, consulté en avril 2016.

${ }^{281}$ Idem.

282 Voir Commission nationale de lutte contre la prolifération des armes légères du Mali. New York, Rapport, juin 2014. http://www.poa-iss.org/bms5. Le rapport indique partout dans le monde, les armes légères sont présentes, passent de main en main, changent d'utilisateurs et de propriétaires. La circulation de ces armes est une menace contre la puissance et l'autorité des Etats et pour la sécurité des populations, particulièrement dans les pays en voie de développement. Elles sont, dans de nombreux cas, une cause d'instabilité des Etats, surtout si elles sont détenues par des groupes rebelles au sein desquelles les utilisateurs sont très peu formés au maniement des armes et utilisent abusivement les armes pour tuer, violer ou pour détruire. La problématique des armes légères constitue l'un des plus grands défis du continent africain.

283 BERGHEZAN (Georges), "Côte d'Ivoire et Mali, au Cour des trafics d'armes en Afrique de l'ouest». Rapport 2013/1 du Groupe de Recherche et d'Information sur la Paix et la Sécurité (GRIP), p. 9. Le rapport indique que les Etats de l'Afrique de l'Ouest, excepté la Mauritanie, sont soumis à la Convention «sur les armes légères et de petit calibre, leurs munitions et autres matériels connexes ", qu'ils ont adoptée le 14 juin 2006 et qui est entrée en vigueur le 29 septembre 2009. Depuis cette date, les Etats qui l'ont ratifiée, sont légalement contraints de l'appliquer, en particulier son article 3.1 qui interdit « le transfert des armes légères et de petit calibre ainsi que (des) équipements servant à leur fabrication sur/vers et à partir de leur territoire ». Aussi, son article 3.2 interdit " sans exception, tout transfert d'armes légères et de 
autres armes légères et de petit calibre sont les armes de prédilection des combattants engagés dans de nombreux conflits internes dans le monde. Ces armes sont fabriquées suivant des spécifications militaires, pour être les plus meurtrières possible. Lorsqu'elles sont fabriquées et écoulées de manière illicite, ces armes tombent souvent entre les mains de criminels organisés, des trafiquants de drogues, des chefs de guerre et autres délinquants.

\section{2- Les normes juridiques de lutte contre le trafic illicite d'armes}

204- Au vu de ce qui précède, les Nations Unies, à travers le traité sur le commerce des armes, visent à instituer des normes communes les plus strictes possibles aux fins de réglementer ou d'améliorer la réglementation du commerce international d'armes classiques, de prévenir et éliminer le commerce illicite d'armes classiques et empêcher le détournement de ces armes ${ }^{284}$. En effet, le traité s'applique à toutes les armes classiques relevant des catégories suivantes : chars de combat; véhicules blindés de combat; systèmes d'artillerie de gros calibre ; avions de combat ; hélicoptères de combat ; navires de guerre ; missiles et lanceurs de missiles ; armes légères et armes de petit calibre ${ }^{285}$.

205- Quant au paragraphe 2 du même article 2 , il précise que les activités de commerce international s'entendent dans le traité : l'exportation, l'importation, le transit, le transbordement et le courtage des armes. Toutefois, le transport international par tout État Partie ou pour son compte d'armes classiques destinées à son usage, pour autant que ces armes restent sa propriété, ne s'applique pas au Traité286.

206- L'article 5 dispose en son paragraphe 2 que chaque État partie institue et tient à jour un régime de contrôle national, notamment une liste nationale de contrôle, afin de mettre en œuvre les dispositions du traité. Au

\footnotetext{
petit calibre à des acteurs non étatiques, si ce transfert n'est pas autorisé par l'Etat Membre importateur. Relevons encore que cette convention a eu comme origine un Moratoire sur l'importation, l'exportation et la fabrication des armes légères adopté par la CEDEAO en 1998 et reconduit en 2001. Cependant, ce moratoire reposait sur une base volontaire, alors que la Convention est légalement contraignante.

284 Traité des Nations Unies sur le commerce des armes de 2013, art. 1.

285 Idem, art. 2-1.

286 Traité des Nations Unies sur le commerce des armes de 2013, art. 2-3.
} 
demeurant, chaque État partie communique, en vertu de son droit interne, sa liste nationale de contrôle au secrétariat qui la porte à la connaissance des autres États parties. Les États Parties sont encouragés à rendre publique leur liste de contrôle ${ }^{287}$.

207-Aussi, l'État partie désigne les autorités nationales compétentes afin de disposer d'un régime de contrôle national efficace et transparent ayant pour vocation de réglementer les transferts d'armes classiques visés par l'article 2 paragraphe 1 et des biens visés par les articles 3 et 4. L'Etat partie désigne un ou plusieurs points de contact nationaux chargés de l'échange d'informations relatives à la mise en œuvre du traité et fournit au secrétariat, créé en application de l'article 18, toute information concernant son ou ses points de contact nationaux et tient ces informations à jour ${ }^{288}$.

208- Enfin, l'État partie ne doit autoriser aucun transfert d'armes classiques visées par l'article 2 paragraphe 1 ou de biens visés par les articles 3 ou 4 qui violerait ses obligations résultant de mesures prises par le Conseil de sécurité de l'Organisation des Nations Unies agissant en vertu du Chapitre VII de la Charte des Nations Unies, en particulier les embargos sur les armes ${ }^{289}$.

209- L'analyse des normes de lutte contre le trafic de drogues et le trafic d'armes prenant fin, quid des luttes contre le transport des polluants et le trafic d'êtres humains?

\section{$\S 2$ : La lutte contre le transport des polluants, de marchandises et de déchets dangereux et le trafic d'êtres humains}

210- Parmi les marchandises transportées il y en a qui peuvent s'avérer dangereuses. A ce titre, elles nécessitent une réglementation particulière susceptible de protéger non seulement l'environnement marin mais aussi les personnes impliquées dans le transport maritime ${ }^{290}$. Aussi, les ressources

\footnotetext{
287 Traité des Nations Unies sur le commerce des armes de 2013, art. 5-4.

288 Idem, art. $5, \S 5$ et 6 .

289 Traité des Nations Unies sur le commerce des armes de 2013, art. 6-1.

290 DE BONTE POERI (Priscille), Les lacunes du droit relatif au mouvement transfrontière des déchets dangereux : illustration à l'aide de l'affaire Probo Koala en Côte d'Ivoire, Mémoire,
} 
halieutiques, quant-à elles, ont besoin d'être sauvegardées. Par ailleurs, plus de deux siècles après l'abolition de l'esclavage ${ }^{291}$, les êtres humains continuent de faire l'objet de trafics. Alors, de quels moyens juridiques dispose-t-on pour protéger ces ressources halieutiques, lutter contre la pollution marine et contre le trafic des êtres humains? Au niveau sous régional, la Convention de Bamako sur l'interdiction d'importer en Afrique des déchets dangereux et sur le contrôle des mouvements transfrontières et la gestion des déchets dangereux a été adoptée le 30 janvier 1991.

211- Par ailleurs, on examinera les normes de la Convention MARPOL 73/78 et celles des Nations Unies sur la conservation et la gestion des stocks de poissons (A). Ensuite, les normes de la Convention de Bâle sur le contrôle des mouvements transfrontières de déchets dangereux et de leur élimination et la Convention de Bamako de 1991 (B). Enfin, on aura les normes du Protocole contre le trafic illicite de migrants par terre, air et mer de la Convention de Palerme de $2000^{292}(\mathbf{C})$.

\section{A- Les normes prévues par la Convention MARPOL 73/78 et les conventions relatives à la conservation et à la gestion des stocks de poissons}

212- Le transport maritime s'effectuant grâce aux navires, il y a nécessairement des risques de pollution de l'environnement en général et du milieu marin en particulier. La protection $\mathrm{du}$ milieu marin vise

Université de Montréal, juin 2015, p. 23. Selon l'auteur, la gestion des déchets issus des navires ne constitue pas un souci majeur pour les États du Nord. Généralement, ces derniers considèrent les États du Sud, comme des lieux propices à toute évacuation de déchets industriels. Quant aux États du Sud, les activités menées par les navires en haute mer ne semblent avoir créé aucune réaction politique au point d'éradiquer ce phénomène. Certes, l'existence des conventions encadrant la gestion des déchets montre une quelconque volonté étatique100. En effet, dans le but de sensibiliser les États Nord-Sud, des conventions ont vu le jour par le biais du Programme des Nations unies pour l'environnement (PNUE).

${ }^{291}$ De quelques dates relatives à l'esclavage dans le monde.

En 1808 : Interdiction de la traite par le Congrès des Etats Unis d'Amérique ;

En 1833 : Abolition de l'esclavage dans les colonies britanniques ;

En 1848: Abolition de l'esclavage dans les colonies françaises ;

En 1860 : Abolition de l'esclavage dans les colonies hollandaises. In

https://www.universalis.fr/encyclopedie/abolition, consulté en octobre 2017.

292 Voir https://fr.wikipedia.org/wiki/traite, consulté en octobre 2017. 
fondamentalement la conservation et la gestion rationnelle des ressources halieutiques. C'est dans ce sens que vont notamment la Convention MARPOL 73/78 pour la prévention de la pollution par les navires (1) et les normes des conventions relatives à la conservation et à la gestion des stocks de poissons de 1995 (2).

\section{1- Les normes de la Convention MARPOL 73/78 pour la prévention de la pollution par les navires}

213- Il est évident que les déversements délibérés, par négligence ou accidentels, d'hydrocarbures et autres substances nuisibles par les navires constituent une source grave de pollutions. Aussi, est-il nécessaire de mettre fin à la pollution intentionnelle du milieu marin par les hydrocarbures et autres substances nuisibles et de réduire au maximum les rejets accidentels de ce type de substances. Cette nécessité résulte de la prise de conscience des Etats que le meilleur moyen de réaliser cet objectif est d'établir des règles de portée universelle qui ne se limitent pas à la pollution par les hydrocarbures ${ }^{293}$. Ainsi, les parties contractantes ont-elles signé la Convention MARPOL pour la prévention de la pollution par les navires le 02 novembre $1973^{294}$.

214- Quel est le champ d'application de la convention (a), comment se font les inspections de navires, la délivrance de certificats ou l'apposition de visas (b) enfin quelles sont les dispositions pertinentes de lutte contre la pollution par les hydrocarbures (c) ? Telles sont quelques questions qui nécessitent des réponses précises.

\section{a- Champ d'application de la convention}

215- La Convention MARPOL 73/78 s'applique aux navires autorisés à battre le pavillon d'un Etat Partie à la Convention et aux navires qui ne sont pas autorisés à battre le pavillon d'un Etat Partie mais qui sont exploités sous l'Autorité d'un tel Etat ${ }^{295}$. Sauf disposition expresse contraire, toute référence à

${ }^{293}$ Voir le préambule de la Convention internationale de 1973 pour la prévention de la pollution par les navires.

294 Voir le préambule de l'Annexe I révisée de la Convention MARPOL 73/78. En effet, elle a été amendée par le Protocole de 1978.

295 Voir Convention MARPOL 73/78 pour la prévention de la pollution par les navires, art. 3-1. 
la Convention constitue en même temps une référence à ses Protocoles et aux Annexes ${ }^{296}$.

216- Toutefois, la Convention ne s'applique ni aux navires de guerre ou navires de guerre auxiliaires ni aux autres navires appartenant à un Etat ou exploités par cet Etat tant que celui-ci les utilise exclusivement à des fins gouvernementales et non commerciales ${ }^{297}$. Chaque Partie doit s'assurer, en prenant des mesures appropriées qui ne compromettent pas les opérations ou la capacité opérationnelle des navires de ce type lui appartenant ou exploités par elle, que ceux-ci agissent d'une manière compatible avec la Convention, pour autant que cela soit raisonnable dans la pratique.

\section{b- Inspections des navires, délivrance de certificats et apposition de visas}

217- A ce niveau, un certificat international de prévention de la pollution par les hydrocarbures doit être délivré, après une visite initiale ou une visite de renouvellement effectuée conformément aux dispositions de la règle 6 de ladite annexe, à tout pétrolier d'une jauge brute égale ou supérieure à 150 et à tout autre navire d'une jauge brute égale ou supérieure à 400. Et ce, lorsque ces pétroliers et navires effectuent des voyages à destination de ports ou de terminaux au large relevant de la juridiction d'autres Parties à la présente Convention ${ }^{298}$. Ce certificat doit être délivré, ou un visa doit y être apposé, selon qu'il convient, soit par l'Autorité, soit par une personne ou un organisme dûment autorisé par elle. Et que dans tous les cas, l'Autorité assume l'entière responsabilité du certificat 299 .

218- En ce qui concerne le modèle du certificat, la Règle 9 dispose que le certificat international de prévention de la pollution par les hydrocarbures doit être établi conformément au modèle qui figure à l'appendice II de la présente

\footnotetext{
${ }^{296}$ Amendements à l'annexe du Protocole de 1978 relatif à la Convention internationale de 1973 pour la prévention de la pollution par les navires, art. $1, \S 2$ (Annexe 1 révisée de MARPOL $73 / 78)$.

297 Convention MARPOL 73/78, art. 3-3.

298 Selon la Règle 7-1 de l'annexe 1 révisée de MARPOL 73/78.

299 Voir Convention MARPOL 73/78dem, Règle 7-2.
} 
Annexe 300 et être rédigé au moins en anglais, en espagnol ou en français. Si la langue officielle de l'État qui le délivre est utilisée également, celle-ci doit prévaloir en cas de différend ou de désaccord. Quant à sa durée et à sa validité, le certificat international de prévention de la pollution par les hydrocarbures doit être délivré pour une période dont la durée est fixée par l'Autorité, sans que cette durée puisse dépasser cinq ans ${ }^{301}$. Après la prévention de la pollution par les navires, l'on peut bien s'interroger sur la protection des ressources halieutiques?

\section{c- Dispositions de lutte contre la pollution par hydrocarbures}

219- Il s'agit d'abord de la Règle 30 qui prescrit les installations de pompage, de tuyautages et de rejet ${ }^{302}$; ensuite la Règle 31 prévoit un dispositif de surveillance continue et de contrôle des rejets d'hydrocarbures. Aussi, il y a un détecteur d'interface hydrocarbures/eau qui doit être installé ${ }^{303}$. le lavage au pétrole brut, le contrôle des rejets d'hydrocarbures, un plan d'urgence de bord contre la pollution par les hydrocarbures sont également prévus ${ }^{304}$. La Règle 38 exige des installations de réception hors d'une zone spéciale et des installations de réception à l'intérieur des zones spéciales. Des prescriptions spéciales sont applicables aux plates-formes fixes ou flottantes ${ }^{305}$. Des règles générales relatives à la sécurité et à la protection du milieu marin et enfin les prescriptions spéciales relatives à l'utilisation ou au transport d'hydrocarbures dans la zone de l'Antarctique sont également prévues ${ }^{306}$.

\footnotetext{
${ }^{300} \mathrm{Il}$ s'agit de l'annexe 1 révisée de la Convention MARPOL 73/78.

301 Voir Convention MARPOL 73/78, Règle 10, paragraphes 1 et s.

302 Voir la Règle 30 de l'annexe 1 révisée de MARPOL 73/78: "À bord de tout pétrolier, un collecteur de rejet pouvant être relié aux installations de réception pour l'évacuation des eaux de ballast polluées ou des eaux contenant des hydrocarbures doit aboutir au pont découvert sur les deux bords du navire" ".

${ }^{303}$ Convention MARPOL 73/78, Règle 32.

304 Voir respectivement les Règles n 33, 34 et 37 de la Convention MARPOL 73/78.

305 Convention MARPOL 73/78, Règle 39.

306 Voir Convention MARPOL 73/78, Règles 41 et 43.
} 
220- Toute violation des dispositions de la Convention ${ }^{307}$ est sanctionnée par la législation de l'Autorité dont dépend le navire en cause, quel que soit l'endroit où l'infraction se produit. Si l'Autorité est informée d'une telle infraction et est convaincue qu'il existe des preuves suffisantes pour lui permettre d'engager des poursuites pour l'infraction présumée, elle engage ces poursuites le plus tôt possible conformément à sa législation. Aussi, toute violation des dispositions de la Convention commise dans la juridiction d'une Partie à la Convention est sanctionnée par la législation de cette Partie ${ }^{308}$. Et chaque fois qu'une telle infraction se produit, la Partie doit : soit engager des poursuites conformément à sa législation, soit fournir à l'Autorité dont dépend le navire les preuves qui peuvent être en sa possession pour démontrer qu'il y a eu infraction.

\section{2- Les normes des Convention relatives à la conservation et à la gestion des stocks de poissons}

221- Examinons successivement les dispositions pertinentes de l'Accord des Nations Unies sur la conservation et la gestion des stocks de poissons de 1995 (a) et celles de la Convention relative à la conservation et à la gestion des stocks de poissons grands migrateurs dans le Pacifique occidental et central (b).

\footnotetext{
307 Il s'agit des règles prévues par l'annexe 1 révisée de MARPOL 73/78 pour les visites et délivrance des certificats. Concernant les visites, la Règle 6 en son paragraphe 1 dispose que tout pétrolier d'une jauge brute égale ou supérieure à 150 , ainsi que tout autre navire d'une jauge brute égale ou supérieure à 400 , doit être soumis aux visites spécifiées ci-après. S'agissant de la délivrance du certificat ou de l'apposition d'un visa, conformément à la Règle 7 de l'annexe 1 révisée de MARPOL 73/78, un certificat international de prévention de la pollution par les hydrocarbures doit être délivré aux pétroliers. Notamment à tout pétrolier d'une jauge brute égale ou supérieure à 150 et à tout autre navire d'une jauge brute égale ou supérieure à 400 effectuant des voyages à destination de ports ou de terminaux au large relevant de la juridiction d'autres Parties à la présente Convention. Et ce, après une visite initiale ou une visite de renouvellement effectuée conformément aux dispositions de la règle 6 de la présente Annexe, Ce certificat doit être délivré, ou un visa doit y être apposé, selon qu'il convient, soit par l'Autorité, soit par une personne ou un organisme dûment autorisé par elle. Dans tous les cas, l'Autorité assume l'entière responsabilité du certificat ".

308 Convention MARPOL 73/78, art. 4-1 et 2.
} 


\section{a- L'Accord des Nations Unies sur la conservation et la gestion des stocks de poissons de 1995}

222- En vue de l'application de La Convention des Nations Unies sur le droit de la mer du 10 décembre 1982 relatives à la conservation et à la gestion des stocks de poissons dont les déplacements s'effectuent tant à l'intérieur qu'audelà de zones économiques exclusives (stocks chevauchants) et des stocks de poissons grands migrateurs, l'accord signé à New York le 04 août 1995 par la Conférence des Nations Unies ${ }^{309}$ est entré en vigueur le 11 décembre $2001^{310}$. On parlera des obligations et pouvoirs de police de l'Etat du pavillon (1) et des pouvoirs de police des Etats autres que celui du pavillon (2).

\section{1)- Obligations et pouvoirs de police de l'Etat du pavillon}

223- Les articles 18, 19 et 20 de l'Accord prévoient les mesures à prendre par l'Etat du pavillon, l'habilitant à contrôler les activités des navires de pêche battant pavillon en haute mer et à réagir en cas d'infraction aux mesures de conservation et de gestion ${ }^{311}$. S'agissant du contrôle des navires de pêche en haute mer par l'Etat du pavillon, le moyen d'assurer un meilleur contrôle des navires de pêche est de soumettre leurs activités à des licences et autorisations de pêche à délivrer par l'Etat du pavillon. Il appartient aux autorités de pêche de l'Etat du pavillon d'assortir ces licences de clauses restrictives, assurant à cet Etat la possibilité de s'acquitter des responsabilités lui incombant en vertu de l'accord. Les Etats parties doivent tenir « un registre national des navires de pêche autorisés à pêcher en haute mer ${ }^{312}$.

224- Des obligations sont définies et mises à la charge de l'Etat du pavillon pour mener les enquêtes ${ }^{313}$ tandis que les autres Etats ont le devoir de

\footnotetext{
309 Voir https://treaties.un.org/doc/traeties/1995/08/.

310 Conformément au paragraphe 1 de son article 40.

311 Voir MOMTAZ (Djamchid), "L'Accord relatif à la conservation et à la gestion des stocks de poissons chevauchants et grands migrateurs", Editions du CNRS Paris. Droit de la mer, Bulletin $n^{\circ} 45$, Division des affaires maritimes et du droit de la mer, Nations Unies, 2002, p. 688. 312 Voir art. 18-3 de l'Accord des Nations Unies sur la conservation et la gestion des stocks de poissons de 1995.

${ }^{313} \mathrm{Cf}$ : Convention de Montego Bay, art. 19.
} 
coopérer à cette fin ${ }^{314}$. Si l'Etat du pavillon est convaincu de disposer des preuves suffisantes de l'infraction, il doit engager les poursuites judiciaires sans tarder. En ce qui concernant les sanctions l'Accord a prévu la suspension ou le retrait de l'autorisation d'exercer les fonctions de capitane ou d'officier à bord des navires.

\section{2)- Les pouvoirs de police des Etats autres que celui du pavillon}

225- "La compétence exclusive d'un Etat sur les navires battant son pavillon en haute mer n'est pas immuable »315. Ainsi, conformément à l'article 21 de l'Accord, dans tout le secteur de la haute mer couvert par un organisme de pêche, tout Etat partie membre de cet organisme peut, par l'intermédiaire de ses inspecteurs, arraisonner et inspecter les navires de pêche battant le pavillon d'un autre Etat partie. Dans ces conditions, les procédures à suivre seront établies par l'organisme compétent, à défaut, les procédures de base prévues par l'article 22 seront observées. Enfin, l'article 8 de l'Accord prévoit une coopération utile entre les Etats pêchant en haute mer.

\section{b- Convention relative à la conservation et à la gestion des stocks de poissons grands migrateurs dans le Pacifique occidental et central}

226- Conscients de la nécessité de coopérer en vue d'assurer la conservation des stocks de poissons grands migrateurs et de promouvoir l'exploitation optimale de ces espèces sur l'ensemble de leurs parcours migratoires, les Etats parties ont signé le 5 septembre 2000 la Convention ayant pour but d'assurer, par une gestion efficace, la conservation à long terme et l'exploitation durable des stocks de poissons grands migrateurs dans l'océan pacifique occidental et central. La Convention est entrée en vigueur le 19 juin $2004^{316}$.

\footnotetext{
314 Voir l'article 20 de la Convention de Montego Bay.

315 Voir A/Conf./164/28 p. 4 ; in MOMTAZ (Djamchid), « L'Accord relatif à la conservation et à la gestion des stocks de poissons chevauchants et grands migrateurs ", op. cit., p. 689.

${ }^{316}$ Division des affaires maritimes et du droit de la mer, Nations Unies, Bulletin nº 45,2002 , pp. 61-85.
} 
227- En vue d'assurer la conservation et la gestion de l'ensemble des stocks de poissons grands migrateurs dans la zone de la Convention, les membres de la Commission ${ }^{317}$ prennent des mesures pour assurer la durabilité des stocks de poissons grands migrateurs dans la zone de la Convention. Ils veillent à ce que ces mesures soient fondées sur les observations scientifiques les plus fiables dont ils disposent et soient de nature à maintenir ou à rétablir les stocks à des niveaux qui assurent le rendement constant maximum, eu égard aux facteurs économiques et écologiques pertinents. A ces facteurs, s'ajoutent les besoins particuliers des États en développement dans la zone de la Convention, notamment les petits États insulaires en développement, et compte tenu des procédés de pêche, de l'interdépendance des stocks et des normes minimales internationales généralement recommandées aux niveaux sous régional, régional ou mondial ${ }^{318}$.

228- Les membres de la Commission prennent des mesures pour réduire au minimum les déchets, les rejets, les captures par des apparaux perdus ou abandonnés, la pollution provenant de bateaux de pêche, la prise de poissons et d'animaux des espèces non visées ainsi que les répercussions subies par les espèces associées ou dépendantes, en particulier les espèces menacées d'extinction ${ }^{319}$. Il en est de même pour la promotion de la mise au point et de l'utilisation d'engins et de techniques de pêche sélectifs, sans danger pour l'environnement et d'un bon rapport coût-efficacité.

229- Les mesures ci-dessus indiquées visent à protéger les stocks de poissons dans le Pacifique. Mais il y en a d'autres qui tendent à réglementer les mouvements transfrontières des déchets dangereux.

\footnotetext{
317 Voir Convention relative à la conservation et à la gestion des stocks de poissons grands migrateurs, art. 1-c : "On entend par "Commission" la Commission pour la conservation et la gestion des stocks de poissons grands migrateurs dans l'océan Pacifique occidental et central, dont la présente Convention porte création".

318 Voir Convention relative à la conservation et à la gestion des stocks de poissons grands migrateurs dans le Pacifique occidental et central, art. 5-b.

319 Conformément au paragraphe e) de l'article 5 de la Convention.
} 


\section{B- Les normes de la Convention de Bâle sur les mouvements transfrontières des déchets dangereux de 1989 et la Convention de Bamako de 1991}

230- Les Etats étaient convaincus que des mesures nécessaires pour faire en sorte que la gestion des déchets dangereux, y compris leurs mouvements transfrontières et leur élimination, doivent être compatibles avec la protection de la santé humaine et de l'environnement ${ }^{320}$. Ainsi, ont-ils conclu, le 22 mars 1989 à Bâle, la Convention sur le contrôle des mouvements transfrontières de déchets dangereux dite Convention de Bâle. Par ailleurs en référence à celleci $^{321}$, les Etats africains ont adopté à Bamako (Mali), le 10 janvier 1991, la Convention de Bamako sur l'interdiction d'importer en Afrique des déchets dangereux et sur le contrôle des mouvements transfrontières et la gestion des déchets dangereux produits en Afrique. En effet, l'article 4 de la Convention de Bamako dispose que toutes les parties prennent les mesures juridiques, administratives et autres appropriées sur les territoires relevant de leur juridiction en vue d'interdire l'importation en Afrique de tous les déchets dangereux, pour quelque raison que ce soit, en provenance de parties non contractantes. Leur importation est déclarée illicite et passible de sanctions pénales $^{322}$. Toutefois, tenant compte du fait que la Convention de Bamako se réfère aux dispositions de la Convention de Bâle ${ }^{323}$, nous avons alors mis l'accent sur celle-ci à ce niveau de notre analyse.

231- Ainsi, le champ d'application de la Convention de Bâle est constitué par les " déchets dangereux » et "d'autres déchets ». Les déchets dangereux sont définis par l'article 1 en son alinéa $1^{324}$ tandis que l'alinéa 2 du même article 1

\footnotetext{
320 Voir le Préambule de la Convention.

${ }^{321}$ Voir Convention de Bamako, point 11 du Préambule.

${ }^{322} \mathrm{Cf}$ : Convention de Bamako, art. 4-1.

${ }^{323}$ Voir Convention de Bamako, point 11 du Préambule : "Tenant compte de la Déclaration de la Conférence des Nations Unies sur l'environnement (Stockholm, 1972), ..., des dispositions pertinentes de la Convention de Bale de 1989 sur le contrôle des mouvements transfrontières de déchets dangereux et de leur élimination qui autorisent la conclusion d'accords régionaux qui peuvent contenir des dispositions équivalentes ou plus strictes que ses propres dispositions, des ...".

${ }^{324}$ Convention de Bâle de 1989, art. 1-1 : "Les déchets ci-après, qui font l'objet de mouvements transfrontières, seront considérés comme des "déchets dangereux" aux fins de la présente
} 
dispose que seront considérés comme «d'autres déchets» les déchets qui appartiennent à l'une des catégories figurant à l'annexe II et faisant l'objet de mouvements transfrontières.

232- Sont exclus du champ d'application de la Convention les déchets qui, en raison de leur radioactivité, sont soumis à d'autres systèmes de contrôle internationaux, y compris des instruments internationaux, s'appliquant spécifiquement aux matières radioactives; les déchets provenant de l'exploitation normale d'un navire et dont le rejet fait l'objet d'un autre instrument international ${ }^{325}$. Seront analysées, les dispositions portant sur les obligations générales des parties (1) et les mouvements transfrontières de déchets dangereux et d'autres déchets entre les parties (2).

\section{1- Les obligations générales des parties}

233- Les obligations générales des parties sont définies à l'article 4 de la Convention. En effet, les Etats parties interdisent ou ne permettent pas l'exportation de déchets dangereux et d'autres déchets dans les Etats Parties qui ont interdit l'importation de tels déchets, lorsque cette interdiction a été notifiée conformément aux dispositions de la Convention ${ }^{326}$. Les Etats Parties interdisent ou ne permettent pas l'exportation de déchets dangereux et d'autres déchets si l'Etat d'importation ne donne pas par écrit son accord spécifique pour l'importation de ces déchets, dans le cas où cet Etat d'importation n'a pas interdit l'importation de ces déchets ${ }^{327}$.

234- Conformément au paragraphe 2-b) de l'article 4, chaque Etat partie doit assurer la mise en place d'installations adéquates d'élimination qui devront, dans la mesure du possible, être situées à l'intérieur du pays, en vue d'une gestion écologiquement rationnelle des déchets dangereux et d'autres déchets

Convention: a) les déchets qui appartiennent à l'une des catégories figurant à l'annexe I, à moins qu'ils ne possèdent aucune des caractéristiques indiquées à l'annexe III, et b) les déchets auxquels les dispositions de l'al. a) ne s'appliquent pas, mais qui sont définis ou considérés comme dangereux par la législation interne de la Partie d'exportation, d'importation ou de transit" ".

325 Convention de Bâle de 1989, art. 1, al. 3 et 4.

326 Voir art. 4-1-b de la Convention de Bâle de 1989.

${ }^{327}$ Convention de Bâle de 1989, art. 4-1-c. 
en quelque lieu qu'ils soient éliminés. Chaque Etat partie doit également veiller à ce que les personnes qui s'occupent de la gestion des déchets dangereux ou d'autres déchets à l'intérieur du pays prennent les mesures nécessaires pour prévenir la pollution résultant de cette gestion et, si une telle pollution se produit, pour en réduire au minimum les conséquences pour la santé humaine et l'environnement ${ }^{328}$. D'autres paragraphes de l'article 4 précisent des dispositions à prendre par les Etats parties en matière de coopération et de poursuite contre les violations de la Convention.

235- En tout état de cause, le trafic illicite de déchets dangereux ou d'autres déchets est considéré comme une infraction pénale par les Parties ${ }^{329}$. Cependant, lorsque les déchets dangereux (toxiques) ont été déversés sur la ville d'Abidjan en 2006 par le navire PROBO KOALA affrété par la société TRAFIGURA ${ }^{330}$, faisant des milliers de victimes, les auteurs d'une telle infraction n’ont pas été pénalement poursuivis en Côte d'Ivoire. Outre sa responsabilité civile, la société TRAFIGURA, en raison de son adresse fiscale aux Pays-Bas, a été jugée par les tribunaux néerlandais pour son infraction, ainsi que l'un de ses dirigeants et le capitaine du navire, au regard de l'article 18 du règlement de l'Union Européenne. En outre, Amsterdam Port Service (APS) et son directeur ont également été poursuivis pour avoir enfreint à la loi néerlandaise relative à la gestion de l'environnement ${ }^{331}$. La société TRAFIGURA fut condamnée à une amende d'un million d'euros et une peine d'emprisonnement de onze mois avec sursis en raison de cinq mois pour le capitaine du navire et six mois pour l'un des dirigeants. En revanche, la société

\footnotetext{
328 Voir art. 4-2-c de la Convention de Bâle de 1989.

329 Voir Convention de Bâle de 1989, art. 4-3.

${ }^{330}$ La société TRAFIGURA qui a affrété le navire PROBO KOALA, dispose de son centre opérationnel à Londres (Royaume-Uni), son adresse fiscale à Amsterdam (Pays-Bas) et son siège social à Lucerne (Suisse). Elle mentionnait que le navire avait pour activité le transport de l'hydroxyde de sodium en plus des hydrocarbures.

331 Voir DE BONTE POERI (Priscille), Les lacunes du droit relatif au mouvement transfrontière des déchets dangereux : illustration à l'aide de l'affaire Probo Koala en Côte d'Ivoire, Mémoire Université de Montréal, juin 2015, p. 88.
} 
Amsterdam Port Service (APS) n'a pas été pénalement condamnée au motif que la négligence qui lui est reprochée n'est pas passible de sanction pénale ${ }^{332}$.

\section{2- Les mouvements transfrontières de déchets dangereux et d'autres déchets entre Etats parties}

236- Ces mouvements doivent s'effectuer dans une transparence totale et avec le consentement mutuel des parties concernées. Ainsi, l'article 6 dispose en son paragraphe 1 que: "L'Etat d'exportation informe par écrit, l'autorité compétente des Etats concernés de tout mouvement transfrontière de déchets dangereux ou d'autres déchets envisagé, ou exige du producteur ou de l'exportateur qu'il le fasse. Ces notifications doivent contenir les déclarations et renseignements spécifiés à l'annexe $V$-A, rédigés dans une langue acceptable pour l'Etat d'importation. Une seule notification est envoyée à chacun des Etats concernés ». L'Etat d'importation doit accuser par écrit réception de la notification à celui qui l'a donnée en consentant au mouvement avec ou sans réserve, ou en refusant l'autorisation de procéder au mouvement, ou en demandant un complément d'information. Une copie de la réponse définitive de l'Etat d'importation est envoyée aux autorités compétentes des Etats concernés qui sont parties ${ }^{333}$.

237- Après les normes de la Convention de Bâle de 1989 sur les mouvements transfrontières de déchets dangereux et de leur élimination, la lutte contre le trafic des êtres humains se présente avec ses différentes facettes.

\section{C- La lutte contre le trafic des êtres humains : le Protocole contre le trafic illicite de migrants par terre, mer et air}

238- A propos du fléau du trafic d'êtres humains, Monsieur Kofi Anam, s'exprimait en ces termes : "Je crois que la traite des personnes, en particulier des femmes et des enfants que l'on force à travailler, que l'on exploite, y compris sexuellement, est l'une des pires violations des droits de l'homme à laquelle les

\footnotetext{
332 DE BONTE POERI (Priscille), Les lacunes du droit relatif au mouvement transfrontière des déchets dangereux : illustration à l'aide de l'affaire Probo Koala en Côte d'Ivoire, Mémoire, op. cit., p. 89.

333 Voir Convention de Bâle de 1989, art. 6-2.
} 
Nations Unies sont maintenant confrontées. Elle est généralisée, et elle s'aggrave. Elle a ses racines dans la situation économique et sociale des pays d'où viennent les victimes, elle est facilitée par les pratiques discriminatoires à l'égard des femmes et portée par l’indifférence cruelle à la souffrance humaine de ceux qui exploitent les services fournis sous la contrainte par les victimes. Le sort de ces personnes les plus vulnérables de notre planète est un affront à la dignité humaine et un défi lancé à chaque État, chaque peuple et chaque communauté »334. Ces propos illustrent la gravité de la traite des êtres humains qui persiste et continue de prendre de l'ampleur. D'après les statistiques de l'ONU et du Conseil de l'Europe, chaque année, 2,5 millions de personnes, essentiellement des femmes et des enfants, tomberaient sous l'emprise des trafiquants. La découverte fin aout 2015 en Autriche d'un camion rempli de 71 cadavres de migrants avait rendu compte de la réalité de la situation de nombreux migrants tentant d'entrer en Europe $\underline{335}$. Cependant, à l'échelle internationale un protocole a été signé ${ }^{336}$.

239- Le Protocole contre le trafic illicite de migrants par terre, air et mer, adopté par la résolution 55/25 de l'Assemblée générale, est entré en vigueur le 28 janvier 2004. En effet, ce protocole qui traite de la question du trafic de migrants par des groupes criminels organisés, souvent au péril des migrants et contre une somme d'argent élevée, a pour objet de prévenir et combattre le trafic de migrants, promouvoir la coopération entre les Etats parties, protéger les droits des migrants faisant l'objet d'un trafic et éviter leur exploitation. Ce Protocole donne une définition consensuelle du trafic de migrants à savoir que "L'expression "trafic illicite de migrants" désigne le fait d'assurer, afin d'en tirer,

\footnotetext{
334 Voir Convention des Nations Unies contre la criminalité transnationale organisée, Palerme (Italie), décembre 2000, avant-propos rédigé par Kofi A. ANNAN, § 6.

$335 \mathrm{Cf}:$ https://fr.wikipedia.org/wiki/traite, Consulté en décembre 2016.

336 Voir le Protocole visant à prévenir, réprimer et punir la traite des personnes, en particulier des femmes et des enfants, additionnel à la Convention des Nations Unies contre la criminalité transnationale organisée. Le paragraphe 1 du préambule prévoit qu'une action efficace visant à prévenir et combattre la traite des personnes, exige de la part des pays d'origine, de transit et de destination une approche globale et internationale comprenant des mesures destinées à prévenir une telle traite, à punir les trafiquants et à protéger les victimes de cette traite, des États ont signé le Protocole visant à prévenir, réprimer et punir la traite des personnes.
} 
directement ou indirectement, un avantage financier ou un autre avantage matériel, l'entrée illégale dans un État Partie d'une personne qui n'est ni un ressortissant ni un résident permanent de cet État ${ }^{337 .}$

240- En vue de respecter ce Protocole sur le trafic de migrants son article 6 exige des Etats parties qu'ils incriminent le trafic de migrants, la production de faux papiers et le fait de permettre le séjour illégal des personnes sur le territoire ${ }^{338}$. Aussi, il est demandé aux Etats parties de conférer le caractère de circonstances aggravantes au fait de mettre en danger ou de risquer de mettre en danger la vie ou la sécurité des migrants concernés et au traitement inhumain ou dégradant de ces migrants ${ }^{339}$. L'alinéa 2 de l'article 6 renforce le dispositif de protection des migrants en prévoyant que chaque État partie adopte également les mesures législatives et autres nécessaires pour conférer le caractère d'infraction pénale au trafic de migrants.

241- Définissant son champ d'application, l'article 4 dispose que le Protocole s'applique à la prévention, aux enquêtes et aux poursuites concernant les infractions établies conformément à son article 6 , lorsque ces infractions sont de nature transnationale et qu'un groupe criminel organisé y est impliqué, ainsi qu'à la protection des droits des personnes qui ont été victimes de telles infractions.

242- Pour réussir leur mission de protection des migrants, les États parties coopèrent dans toute la mesure possible en vue de prévenir et réprimer le trafic illicite de migrants par mer, conformément au droit international de la

\footnotetext{
337 Voir art. 3-a) du Protocole contre le trafic illicite de migrants par terre, air et mer, additionnel à la convention des Nations Unies contre la criminalité transnationale organisée.

338 Voir article 6-1 du Protocole : "Chaque État Partie adopte les mesures législatives et autres nécessaires pour conférer le caractère d'infraction pénale, lorsque les actes ont été commis intentionnellement et pour en tirer, directement ou indirectement, un avantage financier ou autre avantage matériel: ..." ".

339 Voir art. 6-3 du Protocole : "Chaque État Partie adopte les mesures législatives et autres nécessaires pour conférer le caractère de circonstance aggravante des infractions établies conformément aux alinéas a), b) i) et c) du paragraphe 1 du présent article et, sous réserve des concepts fondamentaux de son système juridique, des infractions établies conformément aux alinéas b) et c) du paragraphe 2 du présent article :...".
} 
mer $^{340}$. Et en cas de soupçons de trafic illicite de migrants, des mesures spécifiques définies par les dispositions de l'article $8 \mathrm{du}$ Protocole $^{341}$ en ses différents paragraphes favorisent l'arraisonnement du navire, la visite du navire et toutes autres sanctions appropriées à l'égard du navire. Concernant les mesures aux frontières, sans préjudice des engagements internationaux relatifs à la libre circulation des personnes, les États parties renforcent, dans la mesure du possible, les contrôles aux frontières nécessaires pour prévenir et détecter le trafic illicite de migrants ${ }^{342}$.

243- En vue de renforcer la protection des migrants, ceux-ci sont déchargés de toute responsabilité pénale. En effet, «Les migrants ne deviennent pas passibles de poursuites pénales en vertu du présent Protocole du fait qu’ils ont été l'objet des actes énoncés à son article $6 »^{343}$. A ce niveau, il convient de nous interroger sur l'esprit de cette disposition. Telle que formulée, la disposition exonère les migrants de toute responsabilité pénale même en cas d'agissements de leur part. La question se pose donc de savoir si l'objectif de protection des migrants doit primer sur l'objectif de lutte contre le trafic illicite de migrants. De notre point de vue il n'y a pas de divergence entre ces deux objectifs car lutter contre le trafic de migrants revient à protéger les migrants. Toutefois, dans le but de dissuader les potentiels candidats à la migration clandestine, on pourrait envisager d’incriminer la complicité des migrants. Mais en réalité, les migrants sont les victimes des trafiquants d'esclaves. Alors incriminer la complicité des migrants, au fond, reviendrait à réprimer les victimes d'un acte illicite. Une telle option n'aura aucun sens et n'est donc pas souhaitable.

244- Pour clore la question du trafic des migrants notons, à juste titre, que la Convention de Montego Bay interdit le transport d'esclaves en ces termes : "Tout Etat prend des mesures efficaces pour prévenir et réprimer le

\footnotetext{
${ }^{340}$ Voir art. 7 du Protocole.

${ }^{341}$ Voir art. 8 du Protocole : mesures contre le trafic illicite de migrants par mer.

${ }^{342}$ Voir le Protocole, art. 11-1.

343 Voir l'article 5 du Protocole.
} 
transport d'esclaves par les navires autorisés à battre son pavillon et pour prévenir l'usurpation de son pavillon à cette fin. Tout esclave qui se réfugie sur un navire, quel que soit son pavillon, est libre ipso facto ${ }^{344}$.

245- Les luttes contre les trafics illicites de drogues, d'armes, de déchets dangereux et d'êtres humains ne sont pas les seuls défis de sûreté à relever dans les transports maritimes. Il y a aussi les défis de la sûreté de la navigation maritime qu'il faut aborder.

\section{$\S 3$ : La lutte contre la criminalité maritime et la piraterie en mer}

246- La répression des actes illicites contre la sécurité maritime s'étend sur les zones de souveraineté et de juridiction nationales et sur la haute mer. Les infractions commises dans les zones de souveraineté et sous juridiction nationales sont qualifiées de "criminalité maritime organisée" 345 tandis que celles commises en haute mer sont qualifiées de "piraterie maritime" 346 . Selon Romain Broner, la piraterie se distingue de la criminalité. "Matériellement, l'acte est le même, ses éléments constitutifs sont identiques ; seul le lieu de commission de l'infraction varie. [...] tandis que la piraterie se déroule en haute mer ou dans les zones qui ne relèvent de la juridiction d'aucun État et dispose de son propre régime juridique, caractérisé notamment par le principe de juridiction universelle, le brigandage [criminalité maritime] a lieu quant à lui dans la mer territoriale d'un État. Seul celui-ci est alors, selon le droit international public, compétent pour poursuivre et juger les auteurs de l'infraction, selon sa législation nationale. Aucun autre État n'a alors le droit ni d'arrêter les responsables, ni de les traduire en justice, sans l'autorisation de l'État en question ${ }^{347}$. La piraterie

\footnotetext{
${ }^{344}$ Convention de Montego Bay, art. 99.

345 Voir Convention des Nations Unies contre la criminalité transnationale organisée, signée à Palerme (Italie) en décembre 2000, art. 2-a) : "L'expression "groupe criminel organisé" désigne un groupe structuré de trois personnes ou plus existant depuis un certain temps et agissant de concert dans le but de commettre une ou plusieurs infractions graves ou infractions établies conformément à la présente Convention, pour en tirer, directement ou indirectement, un avantage financier ou un autre avantage matériel ".

346 BRONER (Romain), La répression de la piraterie maritime et ses enjeux juridiques, Mémoire de Master 2, Université Panthéon-Assas - paris II, Année 2009/ 2010, p. 18.

347 BRONER (Romain), La répression de la piraterie maritime et ses enjeux juridiques, Mémoire de Master 2, op. cit., p. 18.
} 
se distingue également du terrorisme ${ }^{348}$. Les Conventions destinées à lutter contre la criminalité martine (A) seront analysées avant la Partie VII de la Convention de Montego Bay relative à la haute mer (B).

\section{A- Les Conventions destinées à lutter contre la criminalité maritime}

247- Sous les auspices des Nations Unies, deux instruments juridiques ont été produits pour lutter contre la criminalité maritime. Il s'agit de la Convention des Nations Unies contre la criminalité transnationale organisée (1) en outre du Protocole pour la répression d'actes illicites contre la sécurité des plates-formes fixes situées sur le plateau continental (2).

\section{1- La Convention des Nations Unies contre la criminalité transnationale organisée}

248- La Convention des Nations Unies contre la criminalité transnationale organisée, dite Convention de Palerme, adoptée par la résolution 55/25 de l'Assemblée générale, le 15 novembre 2000, est le principal instrument de la lutte contre la criminalité transnationale organisée. Elle est complétée par trois Protocoles qui visent des activités et manifestations spécifiques de la criminalité organisée ${ }^{349}$. Ainsi, tenant compte du fait qu'il n'y a aucun instrument universel qui porte sur tous les aspects du trafic illicite de migrants et d'autres questions connexes ${ }^{350}$, le Protocole contre le trafic illicite de migrants

\footnotetext{
${ }^{348}$ Idem BRONER (Romain), La répression de la piraterie maritime et ses enjeux juridiques, Mémoire, op. cit., p. 18. Selon l'auteur, la piraterie n'est pas du terrorisme. Tant les moyens mis en œuvre que les buts sont différents. Les attaques du navire américain USS Cole, en mouillage à Aden, le 12 octobre 2000, et du pétrolier français Limburg le 22 septembre 2002, sont les deux seuls cas de terrorisme maritime dans la région. (Voir Alain Gascon, "La piraterie dans le golfe d'Aden : les puissances désarmées ? ", Hérodote 2009/3, n¹34, pp. 120-121). Les entreprises terroristes visent à provoquer la terreur par des actes impressionnants, meurtriers et/ou avec une grande portée médiatique. A l'inverse, le pirate agit dans un but de lucre purement privé : c'est un bandit des mers. Il cherche seulement à s'enrichir en prenant le contrôle de navires, de leur cargaison et éventuellement de leurs passagers, pour en tirer un profit substantiel.

349 Voir la Convention des Nations contre la criminalité transnationale organisée et les Protocoles s'y rapportant.

${ }^{350}$ Voir le Préambule du Protocole contre le trafic illicite de migrants par terre, air et mer.
} 
par terre, air et mer a pu voir le jour. Les Etats sont tenus d'être Parties à la Convention de Palerme avant d'être Parties à ses Protocoles additionnels ${ }^{351}$.

249- La Convention a pour objet de promouvoir la coopération afin de prévenir et de combattre plus efficacement la criminalité transnationale organisée 352 . Elle définit le "groupe criminel organisé" comme un groupe structuré de trois personnes ou plus existant depuis un certain temps et agissant de concert dans le but de commettre une ou plusieurs infractions graves ou infractions établies conformément à la Convention, pour en tirer, directement ou indirectement, un avantage financier ou un autre avantage matériel. En outre le "groupe structuré" définit un groupe qui ne s'est pas constitué au hasard pour commettre immédiatement une infraction et qui n'a pas nécessairement de rôles formellement définis pour ses membres, de continuité dans sa composition ou de structure élaborée ${ }^{353}$. On examinera l'incrimination des faits (a) l'entraide judiciaire et l'extradition des présumés délinquants en matière de poursuite (b).

\section{a- Les actes à incriminer}

250- La Convention recommande à chaque État Partie d'adopter les mesures législatives et autres nécessaires pour conférer le caractère d'infraction pénale, lorsque certains actes sont intentionnellement commis. Il s'agit du fait de s'entendre avec une ou plusieurs personnes en vue de commettre une infraction grave à une fin liée directement ou indirectement à l'obtention d'un avantage financier ou autre avantage matériel ; ou de la participation active d'une personne aux activités criminelles d'un groupe criminel organisé 354 . Au regard de cette disposition, transparaît l'éternelle difficulté des conventions internationales de traduire des comportements délictueux en infractions

351 L'article premier du Protocole prévoit que celui-ci complète la Convention contre la criminalité transnationale organisée, qu'il est interprété conjointement avec la Convention et que les dispositions de la Convention s'appliquent mutatis mutandis au Protocole.

352 Convention des Nations Unies contre la criminalité transnationale organisée, art. 1.

${ }^{353} \mathrm{Cf}$ : Convention des Nations Unies contre la criminalité transnationale organisée, art. 2-§ a et $\mathrm{c}$.

${ }^{354}$ Convention des Nations Unies contre la criminalité transnationale organisée, art. 5-1. Le paragraphe 2 de l'article 5 ajoute que la connaissance, l'intention, le but, la motivation ou l'entente visés au paragraphe 1 de cet article peuvent être déduits de circonstances factuelles objectives. 
pénales. Elles renvoient, en général, la définition des infractions pénales à l'échelle nationale de chaque Etat Partie. A propos d'incrimination de faits, un auteur fait remarquer que: "En termes de criminalisation, la loi française spécifie toutes les infractions qu'elle incrimine notamment, le détournement de navire, la participation à la préparation de l'acte et le détournement de navire en bande organisée. Ces infractions et les peines correspondantes sont déterminées dans le code criminel, amendées et applicables pour tout acte commis dans les eaux intérieures, territoriales et les zones maritimes visées par la loi. Une telle incrimination permet aisément de réprimer les actes, car fournie de façon précise toutes les informations relatives aux infractions, les peines et la zone géographique d'application de la loi » ${ }^{355}$. Il n'en est rien en droit ivoirien.

\section{b- La répression : l'entraide judiciaire et l'extradition des suspects}

251- Les États Parties s'accordent mutuellement l'entraide judiciaire la plus large possible lors des enquêtes, poursuites et procédures judiciaires concernant les infractions visées par la Convention, comme prévu à l'article 3. Aussi, ils s'accordent réciproquement une entraide similaire lorsque l'État Partie requérant a des motifs raisonnables de soupçonner que l'infraction visée est de nature transnationale, y compris quand les victimes, les témoins, le produit, les instruments ou les éléments de preuve de ces infractions se trouvent dans l'État Partie requis et qu'un groupe criminel organisé y est impliquééc6. En outre, l'entraide judiciaire la plus large possible est accordée, autant que les lois, traités, accords et arrangements pertinents de l'État Partie requis le permettent, lors des enquêtes, poursuites et procédures judiciaires concernant des infractions dont une personne morale peut être tenue responsable dans l'État Partie requérant, conformément à la Convention ${ }^{357}$.

\footnotetext{
355 YAPO (Marina Madel), La lutte contre la criminalité maritime dans le golfe de guinée : cas de la Côte d'Ivoire et du Nigeria. Etude, Programme de Bourses de Recherche, Nations UniesFondation Nippone du Japon 2012-2013, Décembre 2013, p. 42.

${ }^{356}$ Convention des Nations Unies contre la criminalité transnationale organisée, art. 16, al. 1. ${ }^{357}$ Convention des Nations Unies contre la criminalité transnationale organisée, art. 16, al. 1.
} 
252- En ce qui concerne l'extradition, la Convention s'applique aux infractions visées ${ }^{358}$ ou bien dans les cas où un groupe criminel organisé est impliqué dans une infraction et que la personne faisant l'objet de la demande d'extradition se trouve sur le territoire de l'État Partie requis, à condition que l'infraction pour laquelle l'extradition est demandée soit punissable par le droit interne de l'État Partie requérant et de l'État Partie requis. Chacune des infractions auxquelles s'applique la Convention est de plein droit incluse dans tout traité d'extradition en vigueur entre les États Parties en tant qu'infraction dont l'auteur peut être extradé. Si un État Partie subordonne l'extradition à l'existence d'un traité, lorsqu'il reçoit une demande d'extradition d'un État Partie avec lequel il n'a pas conclu pareil traité, il peut considérer la présente Convention comme la base légale de l'extradition pour les infractions auxquelles le présent article s'applique ${ }^{359}$. Cette dernière disposition, qui évite l'existence de traité bilatéral d'extradition, est de nature à faciliter l'extradition entre les Etats Parties à la Convention.

\section{2- Le Protocole pour la répression d'actes illicites contre la sécurité des plates-formes fixes situées sur le plateau continental 360}

253- Sous réserve des dispositions de l'article 2, la Convention s'applique si le navire navigue ou si, d'après son plan de route, il doit naviguer dans des eaux, à travers des eaux ou en provenance d'eaux situées au-delà de la limite extérieure de la mer territoriale d'un seul Etat, ou des limites latérales de sa mer territoriale avec les Etats adjacents. Dans les cas où la Convention n'est pas

\footnotetext{
358 Voir Convention pour la répression d'actes illicites contre la sécurité de la navigation maritime conclue à Rome en 1988, art. 16-1.

${ }^{359}$ Convention contre la criminalité transnationale organisée, art. 16- al. 3 et 4 .

360 Relevons qu'un protocole relatif à la Convention pour la répression d'actes illicites contre la sécurité de la navigation maritime a été conclu à Londres le 14 octobre 2005. Mais ce protocole, visant notamment la répression d'actes terroristes, ne saurait s'appliquer en matière de lutte contre la piraterie et la criminalité maritimes. Car le terroriste et le pirate ont des objectifs différents. Pendant que le premier vise un but politique, le second vise un but purement lucratif : se faire de l'argent.
} 
applicable, ses dispositions sont toutefois applicables si l'auteur ou l'auteur présumé de l’infraction est découvert sur le territoire d'un Etat partie ${ }^{361}$.

254- Dans sa définition de l'infraction, la convention met l'accent sur l'usage de la violence et de la force ${ }^{362}$. La tentative de commettre, l'incitation à commettre et la menace de commettre l'une quelconque des infractions définies au paragraphe 1 de l'article 3 sont incriminées ${ }^{363}$.

255- Aussi, tout Etat partie prend les mesures nécessaires pour établir sa compétence aux fins de connaître des infractions prévues à l'article 3 quand l'infraction est commise à l'encontre ou à bord d'un navire battant, au moment de la perpétration de l'infraction, le pavillon de cet Etat; ou sur le territoire de cet Etat, y compris sa mer territorial ; ou par un ressortissant de cet Etat ${ }^{364}$.

256- Par ailleurs, s'il estime que les circonstances le justifient et conformément à sa législation, tout Etat partie sur le territoire duquel se trouve l'auteur ou l'auteur présumé de l'infraction assure la détention de cette personne ou prend toutes autres mesures nécessaires pour assurer sa présence pendant

361 Voir Convention pour la répression d'actes illicites contre la sécurité de la navigation maritime conclue à Rome en 1988, art. 4.

362 Protocole pour la répression d'actes illicites contre la sécurité des plates-formes fixes situées sur le plateau continental, art. 3-1: "Commet une infraction pénale toute personne qui, illicitement et intentionnellement :

a) s'empare d'un navire ou en exerce le contrôle par violence ou menace de violence; ou

b) accomplit un acte de violence à l'encontre d'une personne se trouvant à bord d'un navire, si cet acte est de nature à compromettre la sécurité de la navigation du navire; ou

c) détruit un navire ou cause à un navire ou à sa cargaison des dommages qui sont de nature à compromettre la sécurité de la navigation du navire; ou

d) place ou fait placer sur un navire, par quelque moyen que ce soit, un dispositif ou une substance propre à détruire le navire ou à causer au navire ou à sa cargaison des dommages qui compromettent ou sont de nature à compromettre la sécurité de la navigation du navire; ou

e) détruit ou endommage gravement des installations ou services de navigation maritime ou en perturbe gravement le fonctionnement, si l'un de ces actes est de nature à compromettre la sécurité de la navigation d'un navire; ou

f) communique une information qu'elle sait être fausse et, de ce fait, compromet la sécurité de la navigation d'un navire; ou

g) blesse ou tue toute personne, lorsque ces faits présentent un lien de connexité avec l'une des infractions prévues aux al. a) à f), que celle-ci ait été commise ou tentée".

363 Voir Convention pour la répression d'actes illicites contre la sécurité de la navigation maritime conclue à Rome en 1988, art. 3-2.

${ }^{364}$ Idem, art. 6-1. 
le délai nécessaire à l'engagement de poursuites pénales ou d'une procédure d'extradition ${ }^{365}$.

257- Toute personne contre laquelle une procédure est engagée en raison d'une des infractions prévues à l'article 3 jouit de la garantie d'un traitement équitable à tous les stades de la procédure, y compris la jouissance de tous les droits et garanties prévus pour une telle procédure par les lois de l'Etat sur le territoire duquel elle se trouve ${ }^{366}$. Il faut ajouter que la Convention, à travers son article 9 , maintient les règles du droit international concernant l'exercice de la compétence des Etats en matière d'enquête ou d'exécution à bord des navires qui ne battent pas leur pavillon. Enfin, les articles 12 et 13 définissent les conditions de coopération et d'entraide judiciaire entre les Etats parties. Au demeurant, quid de la lutte contre la piraterie?

\section{B- Les normes issues de la Partie VII de la Convention de Montego Bay $(\mathrm{CMB})$ relative à la haute mer : la lutte contre la piraterie}

258- De nos jours, les marins des navires de commerce ne sont ni équipés, ni formés pour repousser une attaque armée. Même si des formations en matière de la prévention et de l'intervention sont réalisées pour les équipages transitant dans des zones à risques, et même si des équipements sont apportés aux navires, il n'appartient pas au marin de faire face à la violence d'une attaque pirate ${ }^{367}$. La piraterie maritime est une activité criminelle dont l'origine se perd dans les

\footnotetext{
365 Convention pour la répression d'actes illicites contre la sécurité de la navigation maritime conclue à Rome en 1988, art. 7-1.

366 Voir Convention pour la répression d'actes illicites contre la sécurité de la navigation maritime conclue à Rome en 1988, art. 10-2.

367 BOUDONG (Nathalie), La piraterie maritime moderne, Mémoire UNIVERSITE PAUL CEZANNE III, Droit maritime et des transports, Année universitaire 2008/2009, p. 6. L'auteur soutient que les pirates ne se limitent plus à l'heure actuelle à piller les marchandises et les effets personnels contenus sur les navires. Après avoir pris le contrôle du navire, ils réclament désormais des rançons pour son relâchement. Certains pirates vont même jusqu'à tuer tout l'équipage pour revendre la marchandise et se servir du navire détourné pour faire transiter en toute impunité une marchandise qui sera détournée à nouveau, et ainsi de suite, en modifiant à chaque fois l'immatriculation grâce à des pavillons de complaisance attribués sans aucun contrôle. Les transporteurs, seuls face à leurs décisions, se retrouvent désemparés, et finissent souvent par accorder les rançons demandées après les avoir négociées. Il semble incompréhensible à l'heure actuelle de constater le désarroi de ceux qui ont pour rôle de rendre les échanges mondiaux possibles du fait d'une poignée d'hommes armés.
} 
histoires les plus anciennes ${ }^{368}$. Conformément à la Convention de Montego Bay la piraterie maritime se définit comme: tout acte illicite de violence ou de détention ou toute déprédation commis par l'équipage ou des passagers d'un navire privé, agissant à des fins privées, et dirigé contre un autre navire ou contre des personnes ou des biens à leur bord, en haute mer, contre un navire, des personnes ou des biens, dans un lieu ne relevant de la juridiction d'aucun Etat. Il en est de même de tout acte de participation volontaire à l'utilisation d'un navire, lorsque son auteur a connaissance de faits dont il découle que ce navire est un navire pirate. Enfin, tout acte ayant pour but d'inciter à commettre les actes ci-dessus définis, ou commis dans l'intention de les faciliter ${ }^{369}$.

259- Face à la piraterie maritime et ses enjeux ${ }^{370}$, tous les Etats coopèrent dans toute la mesure du possible à la répression de la piraterie en haute mer ou en tout autre lieu ne relevant de la juridiction d'aucun Etat ${ }^{371}$. En outre, tout Etat peut, en haute mer ou en tout autre lieu ne relevant de la juridiction d'aucun Etat, saisir un navire pirate ou assimilé ${ }^{372}$, ou un navire capturé à la suite d'un acte de piraterie et aux mains de pirates, et appréhender les

368 THOUVENIN (Jean-Marc), «Piraterie maritime : quel droit, pour quelle juridiction, Notes de cours ", p. 1 à 7 . Selon l'auteur, on raconte qu'après la mort de Sylla (-78 avant Jésus-Christ), César revenant d'exil, fut capturé par des pirates, qui n'exigèrent qu'une rançon de 20 talents. César leur fit savoir qu'il valait plus du double, ce qu'il leur fit payer, mais promit, lorsqu'il les quitta, de les crucifier. II tint parole. Une dizaine d'année plus tard, (-67 avant J-C) le Sénat de Rome confia les pouvoirs les plus étendus à Pompée pour qu'il mette enfin un terme à la piraterie en méditerranée. Le succès de Pompée fut fulgurant; il éradiqua méthodiquement la piraterie en méditerranée en quelques mois de campagne.

369 Voir Convention de Montego Bay, art. 101.

370 Voir BOUDONG (Nathalie), La piraterie maritime moderne, Mémoire Droit maritime et des transports, op. cit., p. 15. L'auteur, expliquant la réaction des acteurs qui subissent les effets de la piraterie écrit ceci : "La situation force les premiers intéressés à prendre des décisions rapides. Les armateurs ne souhaitent plus voir leurs navires détournés et faisant l'objet de grosses rançons, ni des hommes d'équipage blessés, traumatisés voire tués, retenus dans des conditions difficiles durant des jours. Les assureurs ne veulent pas régler indéfiniment des risques d'une valeur trop grande pour être couverts par des primes qui deviennent trop basses. Les Etats ne veulent pas voir leurs ressortissants croisant dans des paysages paradisiaques en voilier pris en otage ou tués, pour quelques dollars. Les Etats côtiers berceaux des pirates ne veulent pas voir les autorités d'autres Etats, ou internationales pénétrer sur leur territoire pour en quelque sorte s’immiscer dans la gestion du pays".

371 Voir Convention de Montego Bay, art. 100.

372 Convention de Montego Bay, art. 102 : «Les actes de piraterie, tels qu'ils sont définis à l'article 101, perpétrés par un navire de guerre, un navire d'Etat dont l'équipage mutiné s'est rendu maître sont assimilés à des actes commis par un navire privé». 
personnes et saisir les biens se trouvant à bord. Les tribunaux de l'Etat qui a opéré la saisie peuvent se prononcer sur les peines à infliger, ainsi que sur les mesures à prendre en ce qui concerne le navire, ou les biens, réserve faite des tiers de bonne foi ${ }^{373}$. Cependant, l'incrimination des actes de piraterie pose la question de l'adaptation du droit international aux dispositifs nationaux en matière de répression ${ }^{374}$.

260- Toutefois, la saisie pour raison de piraterie est réservée aux navires habilités à l'effectuer. Seuls les navires de guerre ou militaires, ou les autres navires qui portent des marques extérieures indiquant clairement qu'ils sont affectés à un service public et qui sont autorisés à cet effet, peuvent effectuer une saisie pour cause de piraterie $^{375}$, car les pirates sont aujourd'hui suréquipés ${ }^{376}$.

261- En ce qui concerne le droit de visite ${ }^{377}$, sauf dans les cas où l'intervention procède de pouvoirs conférés par traité, un navire de guerre qui

${ }^{373}$ Convention de Montego Bay, art. 105.

${ }^{374}$ LEFEBVRE-CHALAIN (Hélène) et LEBOEUF (Cédric), La piraterie maritime, Université de Nantes, Compte-rendu des Journées Méditerranéennes de décembre 2009. Vol. 16, 2010/2, p. 4. http://www.droit.univ-nantes.fr/labos/cdmo/centre-droit-maritime-

oceanique/cdmo/cdmo/cdmo.php, consulté le 15 février 2016. Selon les auteurs, le terme de répression utilisé par la Convention de Montego Bay (CMB) peut être selon Serge Segura largement interprété. L'article 101 définit de manière relativement précise les comportements répréhensibles. La Convention pour la répression d'actes illicites contre la sécurité de la navigation maritime de 1988 dite encore convention SUA n'apporte pas de réelle solution sur ce point car son application aux actes de piraterie n'est pas généralement acceptée. Les problèmes liés à la répression sont l'application de la CMB compte tenu des incertitudes liées au pavillon des navires pirates, le rassemblement des preuves et le jugement des pirates devant la multiplication des arrestations.

375 Convention de Montego Bay, art. 107.

376 Voir dans ce sens BOUDONG (Nathalie), La piraterie maritime moderne, Mémoire, op. cit., p. 13. L'auteur indique que les hommes qui sont entrés dans l'illégalité en pratiquant des attaques contre des pêcheurs, des navires de commerce ou des plaisanciers ne sont pas ces hommes qui naviguent au gré des mers, vivant d'alcool et de danses, dans l'attente de rencontrer la fortune. Les pirates modernes sont suréquipés, et leurs " chefs " assurent la pérennité de la piraterie en gérant les attaques comme s'il s'agissait d'une entreprise.

377 A propos de droit de visite, voir Convention de Montego Bay de 1982, art. 110 : «1. Sauf dans les cas où l'intervention procède de pouvoirs conférés par traité, un navire de guerre qui croise en haute mer un navire étranger, autre qu'un navire jouissant de l'immunité prévue aux articles 95 et 96, ne peut l'arraisonner que s'il a de sérieuses raisons de soupçonner que ce navire: a) se livre à la piraterie; b) se livre au transport d'esclaves; c) sert à des émissions non autorisées, l'Etat du pavillon du navire de guerre ayant juridiction en vertu de l'art. 109; d) est sans nationalité; ou e) 
croise en haute mer un navire étranger, autre qu'un navire jouissant de l'immunité prévue aux articles 95 et 96, ne peut l'arraisonner que s'il a de sérieuses raisons de soupçonner que ce navire se livre à la piraterie; se livre au transport d'esclaves; etc. ${ }^{378}$.

262- Par ailleurs, l'examen des normes de prévention et de répression des infractions à l'échelle internationale ne doit pas nous perdre de vue la lutte contre les infractions à l'échelle nationale ivoirienne.

\section{Section 2: La prévention et la répression des infractions à l'échelle nationale ivoirienne}

263- La question se pose de savoir comment la législation ivoirienne prévoit la lutte contre les infractions liées au transport maritime. Force est de reconnaître qu'il n'existe pas en droit ivoirien de mesures propres consacrées à la lutte contre des trafics illicites tels que le trafic des êtres humains et le trafic des armes. Nous examinerons les normes destinées à lutter contre la criminalité maritime $(\S 1)$ et celles destinées à la protection de l'environnement marin $(\S 2)$ auxquelles se limitent, à notre connaissance, les normes maritimes ivoiriennes en ce qui concerne la lutte contre les infractions liées au trafic maritime.

\section{$\S 1$ : La lutte contre la criminalité liée au transport maritime}

264- Historiquement, avant le Code maritime de 2017, c'est le code ivoirien de la marine marchande qui punit la piraterie. Bien qu'elle ne l'ait pas définie le Code ivoirien de la marine marchande réprimait la piraterie. Il ne distingue pas la criminalité maritime de la piraterie maritime ${ }^{379}$. Les actes réprimés sont ceux commis aussi bien dans les zones sous juridiction nationale que dans la zone non soumise à une juridiction nationale.

\footnotetext{
a en réalité la même nationalité que le navire de guerre, bien qu’il batte pavillon étranger ou refuse d'arborer son pavillon...".

378 Voir Convention de Montego Bay de 1982, art. 110.

379 Voir ci-dessus $n^{\circ} 246$, pp.112 et 113 . La piraterie concerne les infractions perpétrées dans une zone maritime non soumise à une juridiction nationale tandis que les actes commis dans les zones soumises à compétence nationales sont connus sous l'appellation de criminalité ou brigandage maritime.
} 
265-Ainsi, est poursuivi et jugé comme pirate, tout individu faisant partie de l'équipage d'un navire ivoirien lequel commet à main armée des actes de déprédation ou de violation, soit envers des navires ivoiriens ou des navires d'une puissance avec laquelle la Côte d'Ivoire n'est pas en état de guerre, soit envers les équipages ou chargements de ces navires. Il en est de même pour tout individu faisant partie de l'équipage d'un navire étranger, hors l'état de guerre et sans être pourvu de lettres de marque et de commissions régulières, commet lesdits actes envers les navires ivoiriens, leurs équipages ou chargements ${ }^{380}$. Sont applicables en la matière les dispositions du Code pénal (A) et celles du Code maritime (B).

\section{A- Les normes issues du Code Pénal ivoirien}

266- Des dispositions du code pénal ivoirien s'appliquent en matière de criminalité maritime et de piraterie. L'infraction maritime et la piraterie s'opèrent au moyen de l'emploi de la violence de leurs auteurs contre les victimes. Ces actes illicites de violence sont réprimés par le code pénal ivoirien. En effet, selon le code pénal quiconque, volontairement, porte des coups ou fait des blessures ou commet toute autre violence ou voie de fait est puni ${ }^{381}$. Le code pénal punit également d'un emprisonnement de cinq à dix ans et d'une amende de 500.000 à 5.000 .000 de francs, quiconque, sans ordre des autorités constituées et hors les cas où la loi ordonne de saisir les auteurs d'infractions, arrête, détient ou séquestre une ou plusieurs personnes. La tentative est punissable ${ }^{382}$.

\footnotetext{
${ }^{380}$ Voir Code de la marine marchande, art. 229.

381 Voir les détails dans la loi n 81-640 du 31 juillet 1981 instituant le code pénal, art. 345 : "Quiconque, volontairement, porte des coups ou fait des blessures ou commet toute autre violence ou voie de fait est puni :

$\left.1^{\circ}\right)$ de l'emprisonnement de cinq à vingt ans, lorsque les coups portés et les blessures faites, même sans intention de donner la mort, l'ont pourtant occasionnée ;

$\left.2^{\circ}\right) d^{\prime}$ 'un emprisonnement de cinq à dix ans et d'une amende de 50.000 à 500.000 francs lorsque les violences ont occasionné une mutilation amputation ou privation de l'usage d'un membre, la cécité ou la perte d'un œil ou toute autre infirmité permanente ;

$\left.3^{\circ}\right)$ d'un emprisonnement d'un à cinq ans et d'une amende de 20.000 à 200.000 francs lorsqu'il en est résulté une maladie ou incapacité totale de travail personnel pendant plus de dix jours ; $\left.4^{\circ}\right) d^{\prime} u n$ emprisonnement de six jours à un an et d'une amende de 10.000 à 100.000 francs lorsqu'il n'en est résulté aucune maladie ou incapacité de travail de l'espèce mentionnée à l'alinéa précédent".

${ }^{382}$ Loi n $81-640$ du 31 juillet 1981 instituant le code pénal, art. 373.
} 
267- Les normes du code pénal en matière de lutte contre la piraterie et la criminalité maritime en Côte d'Ivoire sont sommaires et nécessitent donc d'être appuyées par celles du Code maritime.

\section{B- Le Code maritime de 2017}

268- Le nouveau Code maritime élargit son champ répressif des atteintes à la navigation maritime par la création de diverses infractions consignées dans son livre XI. La poursuite et la répression des actes illégaux sont confiées aux autorités compétentes ivoiriennes ${ }^{383}$. Les infractions aux dispositions du Code maritime sont constatées par les agents des affaires maritimes, les officiers et officiers mariniers et commandants de bâtiments de la marine nationale, les officiers de police judiciaire, les fonctionnaires et agents auxquels sont attribuées des fonctions de police judiciaire. Le procureur de la République peut engager des poursuites indépendamment de la procédure de la saisine conformément à la procédure de droit commun ${ }^{384}$. En application des conventions internationales auxquelles la Côte d'Ivoire est partie, les personnes mentionnées à l'article 987 disposent d'un droit de poursuite en haute mer des auteurs des faits de piraterie ${ }^{385}$.

\section{$\S 2$ : La protection de l'environnement marin : les normes de la loi $\mathbf{n}^{\circ} \mathbf{9 6}$ - 766 du 3 octobre 1996 portant Code de l'Environnement}

269- Face aux problèmes environnementaux de plus en plus importants, à la fin des années 80, les autorités ivoiriennes ont senti la nécessité de préserver l'environnement et les ressources naturelles en vue d'une économie durable. Cette situation complexe dont les solutions ne sont pas évidentes à court terme et qui avait un caractère mondial apparaissait comme une opportunité pour le gouvernement de trouver des solutions solidaires et partagées. Dès lors, le respect des engagements pris au niveau international devient une obligation mais également le moyen de trouver des solutions au

\footnotetext{
383 Voir Loi n 2017-442 du 30 juin 2017 portant code maritime, art. 1018 : «Les juridictions ivoiriennes sont compétentes pour connaître des faits de piraterie tels que prévus et réprimés par les articles 1008 à 1016 même lorsqu'ils sont commis en haute mer...".

${ }^{384}$ Loi n 2017-442 du 30 juin 2017 portant code maritime, art. 987.

${ }^{385}$ Idem. Code maritime, art. 1018 in fine.
} 
niveau local. Dans ce sens, on note également que les décideurs publics adhèrent totalement à la politique du développement durable. Vue l'ampleur et le caractère transversal du problème et des solutions à adresser, ceux-ci avaient pleine conscience de la nécessité d'une implication de tous les acteurs ${ }^{386}$. C'est dans ce contexte que la loi ivoirienne intervient pour régir la protection de l'environnement ${ }^{387}$ en termes de prévention de la pollution de l'environnement marin (A) et de répression de la pollution de l'environnement marin (B).

\section{A- Les normes de prévention de la pollution de l'environnement marin}

270- La loi du 3 octobre 1996 portant code de l'environnement en Côte d'Ivoire s'applique aux différents milieux naturels notamment : le sol et le soussol, les ressources en eau, l'air, la diversité biologique, les paysages, etc. ${ }^{388}$. Nous entendons par environnement marin, les zones maritimes comprenant : les eaux archipélagiques, la mer territoriale, la zone économique exclusive, le plateau continental ainsi que le rivage de la mer, les fonds marins et le sous-sol correspondant. Nous ne relèverons que les dispositions relatives à la protection

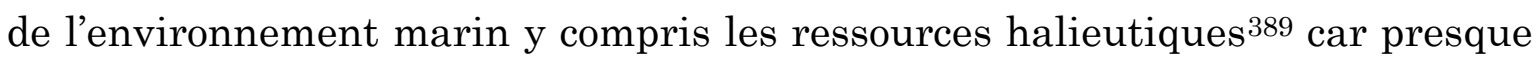
la surexploitation des ressources halieutiques étant décriée partout et en particulier sur le littoral atlantique africain ${ }^{390}$.

271- D'abord, il est interdit de rejeter dans les zones maritimes et lagunaires, toutes substances susceptibles de détruire la faune et la flore; de

\footnotetext{
386 Voir Rapport national du développement durable en Côte d'Ivoire dans la perspective de Rio+20, pp. 23 et 24 .

387 Selon la Loi n $96-766$ du 3 octobre 1996 portant Code de l'Environnement, l'environnement est l'ensemble des éléments physiques, chimiques, biologiques et des facteurs socioéconomiques, moraux et intellectuels susceptibles d'avoir un effet direct ou indirect, immédiat ou à terme sur le développement du milieu, des êtres vivants et des activités humaines.

${ }^{388} \mathrm{Cf}$ : Loi n ${ }^{\circ}$ 96-766 du 3 octobre 1996, art. 1.

389 Selon le Courrier, "Certes, l'importance de la pêche varie considérablement selon les pays : seules sont particulièrement poissonneuses les zones où a lieu la remontée d'eaux froides chargées d'éléments nutritifs pour le plancton comme celles allant des côtes sénégalaises aux côtes libériennes (surtout en févriers-mars et juillet-août), du Gabon au Congo (en juillet-août et févriermars), du Ghana à la Côte-d'Ivoire, de la région du cours du Congo sur une distance d'environ $450 \mathrm{~km}$ ". Voir Le Courrier n²41 janvier-février 1971.

390 BARDONNET (C. Daniel) et CARROZ (Jean), « Les autres États de l'Afrique de l'Ouest et le droit international des pêches maritimes ", AFDI, 1973 pp. 837, 858. Voir aussi en ce sens, CERES Revue de la FAO, n c 112, volume 19, nº 41986.
} 
constituer un danger pour la santé des êtres vivants; de porter atteinte à la valeur esthétique et touristique de la lagune, de la mer et du littoral ${ }^{391}$. Il est également interdit de rejeter dans les eaux maritimes et lagunaires des eaux usées, à moins de les avoir préalablement traitées conformément aux normes en vigueur, des déchets de toutes sortes non préalablement traités et nuisibles ${ }^{392}$.

272- Le déversement, l'écoulement, le rejet ou le dépôt de toutes natures susceptibles de provoquer ou d'accroître la pollution des eaux continentales, lagunaires et maritimes dans les limites territoriales sont également interdits $^{393}$. Enfin, la loi du 3 octobre $1996^{394}$ précitée reprend certaines dispositions des conventions internationales ratifiées par la Côte d'Ivoire notamment la Convention de Bâle sur le contrôle des mouvements transfrontières de déchets dangereux et de leur élimination ${ }^{395}$. A cet égard, sont interdits l'importation non autorisée de déchets sur le territoire national ; les dépôts de déchets sur le domaine public maritime; l'immersion, l'incinération ou l'élimination par quelque procédé que ce soit, des déchets dans les eaux continentales, lagunaires et maritimes, sous juridiction ivoirienne.

273- Sont également interdits les déversements, les immersions et incinérations dans les eaux maritimes sous juridiction ivoirienne de substances de toutes natures susceptibles: de porter atteinte à la santé publique et aux ressources maritimes biologiques; de nuire aux activités maritimes y compris la navigation et la pêche ; d'altérer la qualité des eaux maritimes et de dégrader les valeurs d'agréments et le potentiel touristique de la mer et du littorale ${ }^{396}$.

274- Toutes ces normes ci-dessus évoquées sont de nature à prévenir la pollution de l'environnement 397 notamment des eaux et de la mer sous

\footnotetext{
391 Voir Loi n $96-766$ du 3 octobre 1996 portant Code de l'Environnement, art. 76. 392, Loi n ${ }^{\circ}$ 96-766 du 3 octobre 1996 art. 77.

${ }^{393}$ Loi n ${ }^{\circ} 96-766$ du 3 octobre 1996, art. 79.

${ }^{394} \mathrm{Cf}$ : Loi du 3 octobre 1996 portant code de l'environnement en Côte d'Ivoire, art. 81.

395 Voir Convention de Bâle de 1989, art. 4.

396 Convention de Bâle de 1989, art. 80.

397 Cf : Rapport national du développement durable en Côte d'Ivoire dans la perspective de Rio+20, op. cit., p 7. «Les Nations Unies ont, depuis le début des années 70, engagé la réflexion et pris des résolutions sur la nécessité d'intégrer les préoccupations environnementales et sociales dans tout processus de croissance et de développement. En effet, en 1972, la Conférence des
} 
juridiction nationale. D'autres dispositions du même code sont consacrées à la répression des actes de pollution.

\section{B- Les normes de répression de la pollution de l'environnement marin}

275- Lorsque les actes de pollution de l'environnement marin sont perpétrés, leurs auteurs sont réprimés par des peines d'emprisonnement et/ou d'amende. Ainsi, quiconque effectue des rejets interdits ou, sans autorisation, des rejets soumis à autorisation préalable ainsi que défini aux articles 74 à 86 du code de l'environnement, est passible d'une amende ${ }^{398}$.

276- L'article 97 punit d'une amende et/ou d'un emprisonnement de deux mois à deux ans, toute personne ayant pollué les eaux continentales par des déversements, écoulements, rejets et dépôts de substances de toute nature susceptible de provoquer ou d'accroître la pollution des eaux continentales et/ou des eaux maritimes dans les limites territoriales ${ }^{399}$.

277- Conformément à l'article 98, est puni d'une amende et/ou d'un emprisonnement, quiconque, procède à des déversements, immersion et incinération dans les eaux maritimes sous juridiction ivoirienne, des substances de toutes natures susceptibles de porter atteinte à la santé publique et aux ressources maritimes biologiques ; de nuire aux activités maritimes y compris la navigation et la pêche ; d'altérer la qualité des eaux maritimes ; de dégrader les valeurs d'agrément et le potentiel touristique de la mer et du littoral. Aussi, la même disposition permet in fine à l'administration maritime d'arraisonner

\footnotetext{
Nations Unies sur l'environnement Humain, dite de "Stockholm", a placé les questions écologiques au rang des préoccupations internationales et a marqué le début d'un dialogue entre pays industrialisés et pays en développement concernant le lien entre la croissance économique, la pollution de l'environnement (l'air, l'eau, les sols) et le bien-être des peuples dans le monde entier".

${ }^{398}$ Loi $\mathrm{n}^{\circ}$ 96-766 du 3 octobre 1996, art. 96. Cette disposition est certainement applicable aux personnes morales eu égard aux montants très élevés prévus les amendes et à l'absence de réclusion criminelle des auteurs de l'infraction.

399 Nous pensons que cette disposition est destinée à s'appliquer aux personnes physiques, vu les montants de l'amende " 2000000 de francs à 50000000 de francs " et la possibilité de l'emprisonnement de l'auteur de l'infraction.
} 
tout navire surpris en flagrant délit de déversement de contaminants, y compris les hydrocarbures en mer.

278- La dépose des déchets dans le domaine public maritime national ; l'importation sans autorisation des déchets sur le territoire national ; l'immersion, l'incinération ou l'élimination par quelque procédé que ce soit des déchets dans les eaux et la promotion de toute entreprise procédant des dépôts sauvages sont également réprimés ${ }^{400}$.

279- La règlementation relative à l'environnement est intégrée au nouveau Code maritime comme le souligne Monsieur Vincent Bilé. En effet, par le passé, la protection de l'environnement marin et fluvio-lagunaire était régie par des textes de portée générale. Il s’agit notamment de la loi n96-766 du 3 octobre 1996 portant Code de l'environnement, ... , la loi n²014-390 du 20 juin 2014 d'orientation sur le développement durable et le décret n97-678 du 3 décembre 1997 portant protection de l'environnement marin et lagunaire contre la pollution, lequel a internalisé les différentes conventions internationales sur l'environnement marin. Le Code maritime a consacré à la protection de l'environnement marin et fluvio-lagunaire son livre VI, en mettant à jour l'ensemble des règlementations y afférentes $»^{401}$.

400 Voir loi n 96-766 du 3 octobre 1996, art. 99 et 100.

${ }^{401}$ BILE (Vincent), « Regard Critique sur le Nouveau Code Maritime Ivoirien », op. cit., pp. 2 et 3. 


\section{Conclusion du titre 1}

280- Le premier titre de notre travail a consisté à mettre en évidence les mécanismes de protection des transports maritimes. Cette protection se ressent à deux niveaux. D'une part, assurer à la marchandise son intégrité physique lors de l'expédition maritime et d'autre part, mettre la navigation maritime à l'abri des périls et des attaques humaines.

281- L'aspect protection de la marchandise a amené le législateur à adopter des normes juridiques permettant de prévenir les dommages à la marchandise et surtout de les réparer, le cas échéant. C'est dire que nonobstant l'existence de normes de prévention des dommages, il arrive que la marchandise subisse des avaries et pertes au cours du transport. Aussi, il convient de relever qu'en dépit de l'insécurité qu'il présente en favorisant divers trafics illicites, le conteneur constitue en soi une protection efficace de la marchandise au cours de son transport. Les conditions de sécurité du conteneur notamment la manutention, le gerbage et le transport sont définies par la Convention internationale sur la sécurité des conteneurs de 1972 et soumises à la délivrance d'un agrément ${ }^{402}$ qui constitue un gage de sécurité pour l'utilisation du conteneur. Aussi, pour renforcer les normes prévues pour la réparation des dommages, le destinataire est tenu de souscrire une assurance maritime ${ }^{403}$ de la marchandise. Il se pose alors le problème de l'efficacité des normes de prévention des dommages à la marchandise tout comme le problème de l'efficacité des normes de réparation des dommages.

282- En ce qui concerne la lutte contre les infractions maritimes, il existe, d'une part, des normes destinées à lutter contre les trafics illicites notamment le trafic des drogues et stupéfiants, le trafic des armes, le trafic des déchets dangereux, la pollution de l'environnement marin et, d'autre part, des normes

\footnotetext{
402 Convention internationale sur la sécurité des conteneurs, art. 2, al. 5.

${ }^{403}$ A propos de la nécessité de l'assurance voir supra ${ }^{\circ} 180$ et 181, pp. 77 et s. En effet, compte tenu de la lenteur de la procédure judiciaire, la limitation de la responsabilité du transporteur maritime, la possibilité d'une faillite de celui-ci et des nombreux cas exceptés légaux, la souscription à une assurance sur facultés paraît indispensable au destinataire de la marchandise.
} 
destinées à lutter contre la criminalité et la piraterie maritimes. A l'échelle nationale ivoirienne et à l'échelle internationale, ces normes ont pour vocation de prévenir les différentes infractions qu'elles définissent et le cas échéant, de réprimer leurs auteurs.

283-A présent, notre préoccupation est de rechercher $\boldsymbol{a}$ posteriori, à quel point cette législation des transports maritimes est efficace relativement à la protection de la marchandise et à la lutte contre l'insécurité. La quête d'une réponse à cette préoccupation majeure commande une analyse qui mette la législation protectrice des transports maritimes à l'épreuve de son exécution effective. C'est donc un regard critique de la législation des transports de marchandises par mer qu'il nous faut envisager. 
TITRE 2: UNE ANALYSE CRITIQUE DU CADRE LEGISLATIF DES TRANSPORTS DE MARCHANDISES PAR MER 
284- A travers le premier titre de notre étude nous avons montré comment la législation protège le transport maritime. Il s'agit d'abord de la protection de la marchandise conteneurisée ou conventionnelle contre les dommages et ensuite de la lutte contre l'insécurité maritime. Mais cette démonstration théorique ne nous renseigne pas sur l'efficacité de la législation du transport maritime à protéger la marchandise contre les dommages ni sur sa capacité à résorber ou, à tout le moins, à réduire l'insécurité dans le transport maritime.

285- L'activité de transport maritime a toujours présenté un caractère éminemment international et est ainsi voué à un développement dans une dimension dépassant les Etats. Acheminer des marchandises d'un port à un autre sans dommage est l'objet du contrat de transport maritime. Pour atteindre ce but, le contrat et les usages du milieu mettent des obligations à la charge des différentes parties. La spécificité des risques et l'importance de la cargaison transportée imposent des mesures de sécurité.

286- Les différentes conventions internationales en vigueur, qui régissent la matière, organisent de façon plus ou moins précise les rôles du chargeur et du transporteur, parties principales du contrat de transport. En raison de la valeur de la cargaison et de son importance pour l'économie internationale, l'objectif de la protection est double : d'abord éviter que les marchandises soient endommagées et ensuite, en cas d'échec de cette prévention, engager la responsabilité des parties ${ }^{404}$. A cet objectif double, s'ajoute celui de la sécurité et la sûreté maritimes. C'est pourquoi, pour la suite de nos développements, la préoccupation majeure reste à savoir si la législation en vigueur protège efficacement les transports maritimes. Pour prendre la mesure de l'efficacité de la législation des transports de marchandises par mer, il y a lieu d'interroger la pratique desdits transports à travers la jurisprudence et la doctrine ${ }^{405}$.

404 Voir Rabah HELAL, "Protection des marchandises en transport maritime ». Capitaine Au Long Cours / ISM at. GROUP - CNAN / NORD EUROPE, 15 juil. 2013, https://fr.slideshare.Net/rabahparadise2/protection-des marchandises-transport-maritime, consulté en mars 2016. 405 Nous pensons que c'est principalement à travers les décisions des juridictions et accessoirement les commentaires des théoriciens et des praticiens du droit des transports 
287- En effet, l'appréciation de l'efficacité de la protection de la marchandise transportée mérite d'examiner les approximations des normes de protection de la marchandise à travers leur genèse et leurs limites (Chapitre 1) et de rechercher les insuffisances de la lutte contre l'insécurité au regard de la prolifération des infractions maritimes (Chapitre 2).

maritimes que nous pourrons observer l'efficacité ou la non-efficacité de la législation du transport maritime. 


\section{CHAPITRE 1 : LES APPROXIMATIONS DES NORMES DE PROTECTION DE LA MARCHANDISE : GENESE ET LIMITES}

288- Les normes relatives à la réparation des dommages méritent un examen plus approfondi afin d'apprécier leur efficacité. A l'échelle nationale ivoirienne, l'arrêté nº 0082 du 05 mai 1999 portant règlement d'exploitation du port autonome d'Abidjan n'intervient pas dans la réparation des dommages. La réparation des dommages subis par la marchandise, à l'échelle internationale, est réglée par les conventions internationales notamment la Convention de Bruxelles de 1924 et ses protocoles modificatifs, la Convention de Hambourg de 1978 et enfin la Convention de Rotterdam de 2009 sur le contrat de transport international de marchandises effectué entièrement ou partiellement par mer.

289- Selon Monsieur Innocent Fetze Kamdem, la mise en œuvre nationale des conventions internationales se fait tantôt par leur incorporation dans les législations nationales, tantôt par leur interprétation à l'aide des lois de portée interne. Le premier procédé s'entend de l'insertion avec ou sans modification de la convention dans le texte de loi d'un pays, parfois à l'instigation de la convention elle-même. Le second procédé de mise en œuvre nationale consiste à interpréter la Convention en faisant usage des méthodes d'interprétation des lois nationales sans égard à son caractère international ${ }^{406}$. La Convention de Hambourg n'a pas été ratifiée par la Côte d'Ivoire ${ }^{407}$, la Convention de Rotterdam non plus. Seule la Convention de Bruxelles de $1924^{408}$ était

406 FETZE KAMDEM (Innocent), La responsabilité du transporteur maritime au niveau international : un échec d'uniformisation juridique, Mémoire, Université Laval Québec, Canada, Décembre 1999, p. 15.

407 Voir BIGOT (Mamadou), Présentation et état de ratification des principales conventions maritimes pour les Etats de la CMEAOC, Août 1991, p. 165.

${ }^{408}$ La loi n 61-211 du 12 juin 1961 autorise le président de la République de Côte d'Ivoire à ratifier la convention internationale signée à Bruxelles le 25 août 1924, relative à la responsabilité du transporteur maritime. (Voir J.O. 1961, 902). Et la convention a été intégrée dans la législation ivoirienne par le décret $\mathrm{n}^{\circ}$ 69-158 du 14 avril 1969 portant ratification de la convention internationale pour l'unification de certaines règles en matière de connaissement (Voir J.O. 1969, 570 ; avec le texte de la convention). 
d'application directe en matière de réparation des dommages subis par la marchandise en droit ivoirien avant le Code maritime de 2017.

290- On examinera la genèse des règles de protection de la marchandise en droit ivoirien (Section 1) et les limites découlant de l'application des normes de réparation des dommages par le juge ivoirien (Section 2)?

\section{Section 1 : La genèse des règles de protection de la marchandise en droit ivoirien}

291- Selon Monsieur Gurvan Branellec, à travers les clauses "Paramout" 409 les Règles de la Haye peuvent être mises en application par un procédé contractuel ${ }^{410}$. Ainsi, avant le Code maritime, en matière de responsabilité du transporteur, la législation ivoirienne se réduisait à la Convention de Bruxelles. Conformément à son article 1-e, la marchandise n'est prise en charge par le transporteur que pendant la phase maritime du transport qui s'étend "de palan à palan" : c'est-à-dire du chargement au déchargement 411 de la marchandise. La prise en charge sous palan n'est rien d'autre que la prise en charge "de palan à palan". La prise en charge sous palan (ou livraison sous palan) est une : "Clause par laquelle le transporteur maritime stipule qu'il ne

\footnotetext{
${ }^{409}$ Lamy transport, tome 2, Edition 2010, p. 980. "La clause "Paramout" (ou clause souveraine) est une clause aux termes de laquelle les parties déterminent par avance la loi ou la convention applicable à leur contrat de transport".

410 BRANELLEC (Gurvan), La coexistence des règles applicables au contrat de transport international de marchandises par mer : contribution à l'étude de l'uniformité du droit, Thèse, Université de Bretagne Occidentale, Ecole doctorale des Sciences de la Mer, juin 2007, n 625 pp. 355 et 356. Selon l'auteur, cette clause peut ainsi participer à une certaine uniformisation du droit applicable aux transports internationaux de marchandises. Il est important de noter que les dispositions d'une Convention internationale peuvent être mises en œuvre par d'autres procédés, sans passer par la méthode classique en droit international public qui est celle de la ratification par les Etats. La Convention de Bruxelles est souvent mise en œuvre par un procédé contractuel : l'insertion dans la plupart des connaissements d'une clause Paramount renvoyant à la Convention de Bruxelles. Il est ainsi déjà possible de voir que les opérateurs peuvent jouer un rôle dans la mise en œuvre de la législation internationale en matière de transport maritime de marchandises.

${ }^{411}$ Du chargement au déchargement, seul le transporteur jouit de la qualité de donneur d'ordre. Voir N'TOH (Lath Suzanne), Le déchargement des marchandises transportées par mer, Thèse de Droit privé, Aix-Marseille III 2005, n 344 p. 96. Dans l'espèce citée par l'auteur (Cass. Com. 2 oct. 1990, DMF 1994, p. 504 ; BTL 1991, 340), la Cour précise que le transporteur " était le seul donneur d'ordre pour les opérations de chargement et de déchargement qui lui incombaient impérativement".
} 
prendra pas la marchandise en charge avant qu'elle ne soit déposée à quai, prête à être saisie pour être hissée à bord, et que la livraison sera effectuée dès que la marchandise aura été, à l'arrivée, déposée à quai immédiatement après le déchargement ${ }^{412}$.

292- Selon l'analyse de la doctrine ${ }^{413}$, cette disposition instituant la prise en charge de la marchandise sous palan crée un sectionnement juridique au sein du contrat de transport de marchandises par mer. En effet, elle écarte la phase pré maritime et la phase post maritimes 414 des obligations du transporteur maritime. En conséquence de cause ces deux phases non maritimes ne peuvent relever du régime de responsabilité applicable au transporteur. Dès lors la question se pose de savoir quel régime juridique régit les phases pré et post maritimes ${ }^{415}$.

293- On présentera l'évolution des règles successives, de la clause de prise en charge sous palan antérieurement au Code maritime $(\boldsymbol{\$} \mathbf{1})$ à la prise en charge de la réception à la livraison avec l'avènement du Code maritime (\$ 2).

\section{§ 1: L'admission de la clause de prise en charge sous palan antérieurement au Code maritime}

294- En application de l'article premier alinéa e de la Convention de Bruxelles de 1924, les transporteurs maritimes inséraient généralement une clause de prise en charge de la marchandise de palan à palan. Dans ces

${ }^{412}$ Lamy Transport, tome 2, édition 2010, p. 1011.

${ }^{413}$ Cf : LAFAGE (G.H), Régime juridique applicable aux opérations "ante" et "post" palan du contrat de transport maritime, Extrait de l'Informateur, Sète, 1961, n VIII, in RODIERE (René), Traité général de droit maritime, tome 2, Dalloz. Paris, 1968, pp. 231 et 232 ; voir aussi RIPERT (Georges), "Le sectionnement du transport maritime", DMF 1950, 471 ; CASSAN (L), "La phase maritime du transport de marchandises par mer ", DMF 1963, 690.

${ }^{414}$ La phase pré-maritime s'entend de la réception de la marchandise par le transporteur jusqu'au début de son chargement à bord du navire tandis que la phase post-maritime s'entend de la fin du débarquement de la marchandise du navire jusqu'à sa livraison au destinataire.

415 Voir DE JUGLART (Michel), «Sectionnement ou unité du contrat de transport maritime? Les arrêts du 17 mai 1960 », DMF 1960, 451. La Cour de Cassation a indiqué que les opérations qui suivent le déchargement de la marchandise jusqu'à sa livraison au destinataire font parties du transport maritime et ne constituent, en principe, pas des opérations de transport terrestre. L'auteur estimant que la marchandise étant sous le hangar du transporteur, celui-ci en assume la responsable; et le régime de cette responsabilité doit être celui du transporteur maritime. 
conditions leur responsabilité commence depuis le chargement de la marchandise et prend fin au déchargement, c'est la responsabilité de palan à palan du transporteur ${ }^{416}$ (A). En dehors de cette période, c'est la liberté contractuelle entre les parties qui régit les phases pré et post maritimes (B).

\section{A- La responsabilité de" palan à palan" du transporteur maritime}

295- Les articles 1-c et 2 de la Convention de Bruxelles de 1924 prescrivent une présomption de responsabilité à la charge du transporteur maritime ${ }^{417}$. Cette responsabilité présumée commence au chargement de la marchandise à bord du navire pour s'achever au déchargement. Toutefois, une nuance reste à faire entre marchandise conteneurisée et marchandise conventionnelle ${ }^{418}$. La marchandise conventionnelle subit la clause de livraison sous palan sans difficulté. Quant aux marchandises conteneurisées, il faut encore distinguer le conteneur plein "FCL" 419 du conteneur de groupage "LCL" 420 . Tels que les conteneurs sont définis, la clause de livraison sous palan ${ }^{421}$ peut valablement s'appliquer au conteneur plein. En revanche elle est manifestement incompatible avec le conteneur de groupage ${ }^{422}$.

\footnotetext{
${ }^{416}$ Voir RODIERE (René), Traité général de droit maritime, tome 2, Dalloz. Paris, 1968, ${ }^{\circ} 585$, p. 227. Les opérations antérieures à toute prise en charge par le transporteur échappent à sa responsabilité puisque le contrat de transport n'a pas encore commencé. Les opérations postérieures à la livraison de la marchandise échappent également à la responsabilité du transporteur puisque le contrat de transport est achevé et que sa responsabilité contractuelle ne peut plus être engagée.

${ }^{417}$ A la lecture combinée des articles 1-c et 2 de la Convention de Bruxelles, on se rend compte qu'il est prévu à la charge du transporteur maritime un régime de responsabilité de plein droit qui s'étend sur toute la période de prise en charge de la marchandise.

${ }^{418}$ La marchandise est dite conventionnelle lorsqu'elle n'est pas mise en conteneur.

${ }^{419}$ La mention "FCL » portée sur le conteneur signifie que les marchandises appartiennent à un seul destinataire. Dans ce cas, le dégroupage du conteneur n'est pas nécessaire pour la livraison des marchandises.

${ }^{420}$ La mention "LCL" signifie que les marchandises appartiennent à plusieurs destinataires et cela nécessite que les opérations de dépotage et de dégroupage soient effectuées par le transporteur.

${ }^{421}$ La clause de livraison sous palan n'est rien d'autre que la clause de prise en charge sous palan ou encore clause de responsabilité " de palan à palan ".

${ }^{422}$ Voir N'TOH (Lath Suzanne), Le déchargement des marchandises transportées par mer, Thèse de Droit privé, Aix-Marseille III, 2005, n 274, pp. 75 et 76. Selon l'auteur, la clause de livraison sous palan est incompatible avec la mention "LCL". En effet, matériellement comme juridiquement, la livraison des différents colis du conteneur ne peut pas intervenir à quai ; ceuxci devant être nécessairement individualisés. Cette indentification n'est réalisable qu'après le
} 
296- En effet, le conteneur de groupage réunit plusieurs envois ${ }^{423}$. A la livraison, le transporteur est tenu responsable de plein droit pour toute perte ou avarie constatées de commun accord ${ }^{424}$. Il n'est totalement libéré de toute responsabilité que trois jours après la délivrance de la marchandise en cas de dommages non apparents ou de marchandises conteneurisées ${ }^{425}$. En effet, lorsque le transporteur a reçu les marchandises dans un conteneur scellé, il ne peut vraisemblablement vérifier si l'emballage est adéquat ou non. En conséquence, il est absous s'il prouve que les dommages sont dus à l'insuffisance d'emballage soit dans le cas du conteneur, soit par rapport à chacun des articles empotés dans celui-ci. En revanche, le transporteur engage pleinement sa responsabilité s'il a lui-même chargé les marchandises dans le conteneur ${ }^{426}$

\section{B- La liberté contractuelle régissant les phases pré et post maritimes}

297- La question se pose de savoir quel est le régime de responsabilité applicable aux dommages survenus aux marchandises pendant les phases non maritimes du transport exclues de la phase purement maritime ${ }^{427}$ ? En pratique, les transporteurs se fondent sur l'article 1-e des Règles de la Haye pour imposer aux chargeurs une clause les exonérant de leur responsabilité sur les

\footnotetext{
dépotage du conteneur dans les magasins du transporteur ou de son agent. Il s'ensuit que le connaissement couvrant un tel transport ne peut pas stipuler en même temps une clause de livraison sous palan. En effet, la pratique de livraison sous palan cesse dès que le conteneur porte la mention « LCL».

${ }^{423}$ L'envoi est défini par les contrats types de transports comme la "Quantité de marchandise mise effectivement, au même moment, à la disposition d'un transporteur ou d'un commissionnaire de transport dont le transport est demandé par un même expéditeur pour un même destinataire d'un lieu de chargement unique à un lieu de déchargement unique et faisant l'objet d'un même contrat de transport". Autrement dit, à chaque envoi correspond un contrat de transport d'où un connaissement. Voir Lamy transport, 1997, tome II, op. cit., n 1464. p. 873.

${ }^{424}$ RODIERE (René), Traité général de droit maritime, tome 2, op. cit., n 610, pp. 249 et 250. L'auteur relève la règle selon laquelle : "Un plaideur ne se forge pas lui-même et seul les éléments qui étayeront ses prétentions et qu'aucune preuve n'est meilleure que celle qui émane de l'adversaire ". En effet, aucune difficulté ne se présente lorsque le transporteur maritime luimême constate ou reconnaît les dommages allégués par le réceptionnaire de la marchandise : c'est le sens du caractère contradictoire de la constatation des dommages.

${ }^{425} \mathrm{Cf}$ : Convention de Bruxelles de 1924 art. 3-6.

${ }^{426}$ Voir FETZE KAMDEM (Innocent), La responsabilité du transporteur maritime au niveau international : un échec d'uniformisation juridique, Mémoire, Université Laval Québec Canada, Décembre 1999, p. 107.

427 Voir Convention de Bruxelles de 1924, art. 1, al. e.
} 
périodes avant le chargement et après le déchargement. Les destinataires sont obligés de supporter entièrement le risque de pertes ou de dommages aux marchandises, pendant ces périodes dites non maritimes, bien que les marchandises se trouvent sous le contrôle des transporteurs. En effet, l'interprétation stricte de l'article 1-e des Règles de la Haye exclut les opérations de pré acheminement et de post acheminement du régime de responsabilité présumée du transporteur maritime ${ }^{428}$.

298- Par ailleurs, aucune disposition de la Convention de Bruxelles ne défend à un transporteur ou à un chargeur d'insérer dans un contrat des stipulations, conditions, réserves ou exonérations relatives aux obligations et responsabilités du transporteur ou du navire pour la perte ou les dommages survenant aux marchandises, ou concernant leur garde, soin et manutention, antérieurement au chargement et postérieurement au déchargement du navire sur lequel les marchandises sont transportées par mer ${ }^{429}$. Au terme d'une lecture combinée des deux dispositions (articles 1-e et 7), il ressort que les parties au contrat de transport maritime fixent librement le régime de responsabilité pour régir les phases pré et post maritimes du contrat de transport.

299- En application de la convention des parties dans une espèce ${ }^{430}$, la Cour d'appel d'Abidjan a retenu la responsabilité de la partie chargée d'accomplir les opérations pré maritimes. Le pourvoi en cassation ${ }^{431}$ formé par cette partie reprochait à la Cour d'avoir estimé d'une part qu'elle s'est comportée

\footnotetext{
${ }^{428}$ Pour une analyse complète des phases du transport et des personnes qui y sont impliquées ainsi que des opérations qui ont lieu pendant ces périodes, voir Rapport du Secrétaire général de l'ONU, "Responsabilité du transporteur maritime en ce qui concerne les marchandises transportées : Connaissements ", doc. A/CN.9/63 et Add. 1, Annuaire de la CNUDCI, 1972, vol. III, pp. 287-290, "Les connaissements », Rapport du Secrétariat de la CNUCED, op. cit., pp. 3638 ; voir aussi RODIERE (René), Traité général du droit maritime, op. cit., vol. II, p. 589.

${ }^{429}$ Voir Règles de la Haye, art. 7. Dès lors que la volonté des parties s'exprime strictement sur les phases non maritimes, la Convention de Bruxelles limite considérablement la liberté contractuelle en matière de transport maritime. Voir plus généralement à cet égard RAMBERG (J.), «Freedom of Contract in Maritime Law ", (1993) L.C.M.L.Q., pp. 178 et s.

${ }^{430}$ Voir Cour d'Appel d'Abidjan, arrêt n 929 du 30 juillet 2004.

${ }^{431}$ Cour d'Appel d'Abidjan, arrêt n 929 du 30 juillet 2004.
} 
comme un commissionnaire de transport maritime et d'autre part qu'elle a commis une faute contractuelle.

300- Cependant, la Cour Suprême a rejeté ce pourvoi au motif que «la Cour d'Appel a d'abord relevé que la partie [SDV-CI servant d'intermédiaire de transport] était chargée des opérations de Transit et d'embarquement des containers, mais également de trouver un transporteur maritime et un navire disponible ${ }^{432}$. La Cour suprême a poursuivi sa motivation en précisant que : " la Cour [d'appel] a ensuite estimé que les containers n'ayant pas été embarqués, la [partie], qui en avait la charge, ne s'est pas comportée en bon père de famille et a commis une faute contractuelle ${ }^{433}$. De cette espèce, nous déduisons que les juridictions inférieures ${ }^{434}$ et la juridiction de droit ont fait une bonne application de la règle de la convention des parties sur la phase pré maritime.

301- Mais encore, faut-il que ce régime de responsabilité librement fixé soit connu et accepté de toutes les parties intéressées au contrat de transport pour être opposable car, selon la Cour suprême de Côte d'Ivoire, « ... aucune force probante ne peut être accordée à un acte, entre les parties, qui ne comporte pas les signatures expressément ou tacitement reconnues de ces parties à l'acte ». ${ }^{435}$. Sur le fondement de ce principe, tout connaissement dans lequel est insérée une clause pour régir les phases non maritimes du transport doit être signé par le

\footnotetext{
${ }^{432}$ Cour Suprême, Chambre Judiciaire, arrêt nº : 609/06 du 09 novembre 2006, inédit. ${ }^{433}$ Idem.

${ }^{434}$ Voir Cour suprême Chambre Judiciaire, arrêt n 609/06 du 09 novembre 2006. "Attendu selon les énonciations de l'arrêt confirmatif attaqué, que ... ». La Cour d'appel a donc confirmé le jugement de Première instance.

435 Voir Cour suprême, arrêt n ${ }^{\circ} 306 / 03$ du 5 juin 2003. Dans cette espèce, le connaissement émis par le transporteur comportait une clause attributive de juridiction qui n'a pas été signée par le chargeur. La Cour suprême précise à cet effet, que « ... pour déclarer les juridictions ivoiriennes incompétentes, la Cour d'appel énonce qu'aux termes de l'article 24 du connaissement le Tribunal compétent est celui d'ANVERS, lieu où le transporteur maritime a son siège, à l'exclusion de tous autres tribunaux, et que "peu importe si le chargeur, [...] a signé ou non le connaissement émis en vue du transport dont l'exécution est la cause du litige" ". La Cour poursuit sa motivation en indiquant que: "Attendu cependant qu'en se bornant à affirmer, sans le justifier, que peu importait que le chargeur ait signé ou non signé le connaissement, alors qu'aucune force probante ne peut être accordée à un acte, entre les parties, qui ne comporte pas les signatures expressément ou tacitement reconnues de ces parties à l'acte, la Cour d'appel a manqué de donner une base légale à sa décision".
} 
chargeur ${ }^{436}$. A défaut de la signature du chargeur sur le connaissement une telle clause insérée au connaissement par les soins du transporteur ne saurait être valablement opposable aux parties ${ }^{437}$.

302- Toutefois, lorsque le transporteur ne prend pas de réserves à la réception de la marchandise de nature à signaler son état défectueux, celle-ci est présumée lui ayant été remise en bon état. Dans ces conditions, le transporteur est tenu responsable des dommages sans pouvoir mettre en jeu la convention des parties sur la phase pré maritime du transport au cas où elle existait. Ainsi, l'arrêt n ${ }^{\circ} 349$ du 08 mars 2002 rendu par la Cour d'Appel d'Abidjan, en statuant que " ni le transporteur maritime, ni l'acconier ne peuvent être responsables des avaries résultant d'une condensation dont ils ne sont pas à l'origine, dans la mesure où il s'agit de marchandise conteneurisée ", a été cassé à juste titre.

303- A la réception de la marchandise le transporteur n'a pris aucune réserve. Dans cette espèce la Chambre judiciaire de la Cour Suprême, sur évocation, a retenu la responsabilité du transporteur au motif: "qu’il est constant comme résultant de l'expertise que les avaries subies par les marchandises en cause sont consécutives à des effets de condensation qui se sont développés au cours du transport; que le transporteur maritime n'ayant émis aucune réserve à l'embarquement desdites marchandises, il y a lieu de retenir sa responsabilité $;. . . »^{438}$. Le manque de réserve du transporteur sur le récépissé de dépôt a entraîné une présomption de réception de la marchandise en bon état, telle que décrite au connaissement ${ }^{439}$, de sorte à empêcher la convention des parties de jouer.

304- Au regard de ce qui précède, retenons que face à une clause de prise en charge sous palan les phases non maritimes du contrat de transport

\footnotetext{
${ }^{436}$ C'est l'établissement de la preuve que la convention des parties est connue et acceptée de toutes les parties.

${ }^{437}$ Les parties qui probablement l'ignoraient à la formation du contrat de transport.

438 Cour Suprême, Chambre Judiciaire, arrêt n 301/06 du 01 juin 2006.

439 Voir également Cass. Com. 17 janvier 1995, BTL 1995, p. 384.
} 
échappent au domaine de responsabilité présumée du transporteur ${ }^{440}$. Le destinataire de la marchandise endommagée doit d'abord rechercher la convention des parties régissant les phases non maritimes afin d'engager la responsabilité de l'auteur des dommages. Le même contrat soumet les acteurs du transport à un double régime de responsabilité à savoir : un régime de responsabilité présumée sur la phase maritime "de palan à palan" et la convention des parties, ou à défaut, un régime de responsabilité de droit commun sur les phases pré et post maritimes. Ce dernier régime n'assure pas une protection assez efficace de la marchandise dès lors qu'il est difficile au destinataire d'identifier le responsable du dommage, faire la preuve de sa faute et établir le lien de causalité. L'instabilité de ce double régime de responsabilité ne semble pas protéger efficacement la marchandise ${ }^{441}$, d'où le renforcement de la législation maritime par l'adoption d'un nouveau Code maritime.

\section{$\S 2$ : La règle de la prise en charge de la marchandise prévue par le Code maritime}

305- Le Code maritime traite les transports de marchandises par mer à travers les dispositions contenues dans le titre II de son livre VII. Ainsi, la question du sectionnement juridique du contrat de transport 442 qui était de rigueur dans la Convention de Bruxelles de 1924 trouve une solution ${ }^{443}$ à travers

\footnotetext{
${ }^{440}$ BONASSIES (P.), SCAPEL (Christian), Traité de droit maritime, Ed. L.G.D.J., 2006, p. 721, in ASSONGBA (Cossi Hervé), Le transport maritime de marchandises conteneurisées, Thèse, Université Lille 2, Faculté des sciences juridiques, politiques et sociales, Novembre 2014, p. 141. Selon les auteurs, le transporteur maritime supporte aujourd'hui une responsabilité de plein droit (dénommée aussi "présomption de responsabilité") dès lors que la marchandise à lui confiée subit des pertes ou avaries

${ }^{441}$ Nous pensons que le régime de responsabilité à double vitesse n'est pas un gage de stabilité de la protection de la marchandise en ce sens que les périodes pré et post maritimes du transport ne sont pas couvertes par la responsabilité présumée du transporteur. Ainsi, étendre la responsabilité présumée du transporteur sur les phases non maritimes serait souhaitable.

442 Voir Règles de La Haye, art. 1-e). Cette disposition écarte la responsabilité du transporteur au cours des opérations pré et post maritimes du transport.

${ }^{443}$ Voir BILE (Vincent), « Regard Critique sur le Nouveau Code Maritime Ivoirien ",

Neptunus, e. revue Université de Nantes, vol. 24, 2018/3, op. cit., p. 2. Selon l'auteur, s'agissant du transport maritime, le Code innove essentiellement en trois points. Il consacre l'unité du contrat de transport, en mettant fin à son sectionnement tel que résultant de la convention de Bruxelles du 25 août 1924 relative à l'unification de certaines règles en matière de connaissement et de la loi du 02 avril 1936 relative aux transports des marchandises par mer.
} 
les dispositions des articles 688444, 708 et 709 du Code maritime. Avec celui-ci le transporteur encourt une responsabilité présumée (A) dont la durée s'étend de la prise en charge de la marchandise à sa livraison au destinataire (B).

\section{A- La responsabilité présumée du transporteur maritime}

306- Dans sa quête de renforcement des normes de protection de la marchandise, le législateur ivoirien vient de doter les transports maritimes d'un texte nouveau : le Code maritime. En effet, conformément à son article $1115^{445}$, la loi n 2017-442 du 30 juin 2017 portant Code maritime est entrée en vigueur le 13 novembre $2018^{446}$, date de sa publication au Journal Officiel de la République de Côte d'Ivoire (JORCI). Ainsi, s’inspirant certainement de l'article 16 de la loi française ci-dessous citée, le législateur ivoirien a pris en compte les obligations et responsabilité du transporteur au cours des phases pré et post maritimes dans la loi nouvelle. Le transporteur est chargé désormais d'un régime de responsabilité présumée dite encore responsabilité objective ou responsabilité automatique partant de la réception de la marchandise à sa livraison. Quelle est sa signification (1) et quelle est sa portée (2) ?

\section{1- La signification du principe de la responsabilité présumée du transporteur}

307- L'article 709 du Code maritime dispose que le transporteur est responsable du préjudice résultant des pertes ou dommages subis par les

\footnotetext{
${ }^{444}$ Code maritime, art. 688 : "Les dispositions du présent chapitre sont applicables à tous les contrats de transport de marchandise par mer qui ne sont pas soumis à une convention internationale à laquelle la Côte d'Ivoire est partie, et en tous les cas aux opérations de transport et aux clauses des contrats de transport qui sont hors du champ d'une telle convention, dès lors que:-le port de chargement ou de déchargement prévu dans le contrat de transport par mer est situé en Côte d'Ivoire ; -l'un des ports à option de déchargement est le port de déchargement effectif et que ce port est situé en Côte d'Ivoire; -le connaissement ou autre document faisant preuve du contrat de transport par mer est émis en Côte d'Ivoire ou prévoit que les dispositions de la présente loi régissent le contrat". Cette disposition permet d'étendre la durée de la responsabilité du transporteur aux opérations pré et post maritimes.

${ }^{445}$ Loi n 2017-442 du 30 juin 2017 portant code maritime, art. 1115 : "La présente loi sera publiée au Journal officiel de la République de Côte d'Ivoire et exécutée comme loi de l'Etat". ${ }^{446}$ Voir Journal Officiel de la République de Côte d'Ivoire du mardi 13 novembre 2018, pp. 129208.
} 
marchandises ainsi que du retard à la livraison ${ }^{447}$, si ces pertes, dommages ou retards sont survenus pendant que les marchandises étaient sous sa garde, conformément à l'article 708. Ce régime de responsabilité présumée signifie que le destinataire de la marchandise engage la responsabilité du transporteur sans avoir besoin d'établir la cause du dommage ni rechercher son auteur. A la livraison, lorsque la marchandise subit un dommage la responsabilité du transporteur est automatiquement engagée. C'est ainsi que la Cour Suprême a jugé que le consignataire ne peut être responsable des engagements du transporteur vis-à-vis du destinataire ${ }^{448}$. Dans cette espèce, le transporteur maritime tentait d'échapper à sa responsabilité comme le précise l'arrêt : le refus des armateurs de prendre en charge le manquant constaté, compte tenu, selon eux, des clauses du connaissement ${ }^{449}$. La Cour a répondu en ces termes : "Aucun contrat de transport n'ayant existé entre le propriétaire des marchandises et le consignataire représentant et mandataire de l'armateur, ledit mandataire ne pouvait être tenu pour responsable de la non-exécution ou de l'exécution partielle des engagements souscrits par le transporteur au profit du propriétaire de la marchandise transportée en l'absence d'une faute personnelle commise par le consignataire ${ }^{450}$.

\section{2- La portée du principe de la responsabilité de plein droit}

308- Le principe de la responsabilité de plein droit du transporteur maritime a un caractère impératif et ne souffre aucune dérogation. L'article 688 du Code maritime empêche le transporteur de contourner le régime de responsabilité impératif prévu à sa charge ${ }^{451}$. Toutefois, la responsabilité de plein droit du transporteur ne s'applique pas à tous les dommages. Elle s'applique exclusivement aux avaries, pertes et retards subis par la

\footnotetext{
${ }^{447}$ Selon l'article $710 \mathrm{du}$ Code maritime, il y a retard de livraison lorsque les marchandises n'ont pas été livrées au port de débarquement prévu par le contrat de transport dans le délai expressément convenu ou dans celui qu'il serait raisonnable d'exiger d'un transporteur diligent compte tenu des circonstances de fait.

448 En l'espèce la responsabilité du consignataire est écartée parce qu'il n'a pas commis de faute car en cas de faute commise, il serait soumis à l'action récursoire du transporteur.

${ }^{449}$ Cour Suprême Chambre judiciaire. Arrêt n 257/2003 du 15 mai 2003.

450 Idem.

${ }^{451}$ Voir Code maritime, arts. 708 et 709.
} 
marchandise. A contrario, tout autre préjudice subi par le destinataire, qui n'a pas de lien directe avec le transport, est donc exclu du principe de la responsabilité présumée.

309- Dans le régime de la responsabilité présumée l'absence de faute ne libère pas le transporteur. C'est ainsi que lorsqu'il n'a pas commis de faute et que l'origine $\mathrm{du}$ dommage reste inconnue, le transporteur verra sa responsabilité engagée; il est alors responsable du dommage d'origine indéterminée ${ }^{452}$.

310- Au regard de ce qui précède, retenons que la responsabilité du transporteur telle que définie par les articles 708 et 709 du Code maritime est une responsabilité présumée à caractère impératif qui tient compte des fautes commises par les intermédiaires requis par le transporteur et aussi les dommages d'origine inconnue. Le principe de la responsabilité présumée du transporteur maritime facilite la tâche du destinataire quant à la recherche de l'auteur des dommages subis par la marchandise de sa réception par le transporteur à sa livraison. De ce point de vue la responsabilité de plein droit du transporteur offre une protection assez efficace de la marchandise ${ }^{453}$.

311- Néanmoins, sur le fondement de l'article $711 \mathrm{du}$ Code maritime le législateur ivoirien donne la latitude au transporteur de s'exonérer en établissant, le cas échéant, la cause du dommage au moyen de la preuve d'un des cas exceptés prévus par cette même disposition.

312- La présomption de la responsabilité du transporteur est une protection sûre de la marchandise transportée, encore faut-il qu'elle couvre toutes les phases du transport maritime.

\section{B- La durée de la présomption de la responsabilité du transporteur}

313- L'article 708 du Code maritime présume la responsabilité du transporteur depuis la prise en charge de la marchandise à sa livraison c'est-à-

\footnotetext{
452 Voir Cour d'appel de Paris 27 novembre 2006.

${ }^{453}$ Cette efficacité ne peut s'observer que sur le plan de la détermination de l'auteur des dommages et ne saurait nous situer sur l'efficacité de la réparation que nous aborderons dans les prochains développements.
} 
dire au cours des phases maritime et non maritime, pendant les moments où la marchandise est sous sa garde. L'article 708 du Code maritime dispose que: "La responsabilité du transporteur en ce qui concerne les marchandises couvre la période pendant laquelle les marchandises sont sous sa garde au port de chargement, durant le transport et au port de déchargement ". Après avoir défini la période de responsabilité du transporteur comme étant la période pendant laquelle la marchandise est sous sa garde, l'article 708 précise la notion de " marchandises sous la garde du transporteur "454 comme étant la période qui part de la prise en charge de la marchandise à sa livraison à l'instar de l'article 15 de la loi française précitée ${ }^{455}$. Dans le nouveau Code maritime ivoirien, elle s'étend de la réception de la marchandise par le transporteur au port d'embarquement à sa livraison au destinataire au port de débarquement.

314- Toutefois, s'agissant de marchandises conteneurisées, le transporteur ne se libère pas de sa responsabilité le jour de la livraison du conteneur car les dommages subis par les marchandises mises en conteneurs étant réputés dommages non apparents. En effet, en cas de dommages non apparents le Code maritime de 2017 en son article 724 a prévu que le destinataire de la marchandise dispose d'un délai de huit (8) jours pour adresser par écrit l'avis de perte ou d'avarie au transporteur. Cette dernière disposition est beaucoup plus favorable au destinataire qui par le passé ne disposait que de

\footnotetext{
454 Code maritime, art. 708: "... Les marchandises sont réputées être sous la garde du transporteur à partir du moment où celui-ci les prend en charge des mains soit du chargeur ou d'une personne agissant pour son compte, soit d'une autorité ou autre tiers auquel les marchandises doivent être remises pour l'expédition, conformément aux lois et règlements applicables au port de chargement.

De même, les marchandises sont réputées être sous la garde du transporteur jusqu'au moment où il effectue la livraison soit en remettant les marchandises au destinataire, soit dans les cas où le destinataire ne reçoit pas les marchandises du transporteur, en les mettant à la disposition du destinataire conformément au contrat ou aux lois ou aux usages du commerce applicables au port de déchargement $"$.

${ }^{455}$ Loi française $\mathrm{n}^{\circ}$ 66-420 du 18 juin 1966, art. 15: «... Les dispositions du présent titre s'appliquent depuis la prise en charge jusqu'à la livraison ".
} 
trois jours pour adresser son avis de perte ou d'avarie au transporteur en cas de dommage non apparent 456 .

315- En somme, cette réforme de la durée de la responsabilité du transporteur opérée par le Code maritime ivoirien, apparait comme une avancée majeure au profit du chargeur et du destinataire car elle renforce la protection de la marchandise. Toutefois, des limites se dégagent des conditions d'application des normes de réparation des dommages subis par la marchandise à son arrivée à destination.

\section{Section 2 : Les limites découlant des conditions d'application des normes de réparation des dommages}

316- En cas de dommages constatés à l'arrivée de la marchandise, le chargeur ou le destinataire ont la possibilité d'engager une action en responsabilité contre le transporteur et les intermédiaires du transport pour mauvaise exécution du contrat de transport 457 . Le corollaire de la responsabilité, il faut bien s'en douter, est la réparation financière des dommages en d'autres termes l'indemnisation du préjudice subi. Cependant, en matière de transport maritime les normes législatives de réparation des dommages subis par la marchandise comportent deux caractéristiques essentielles. Il y a, d'une part, la limitation de la responsabilité du transporteur ${ }^{458}$ et, d'autre part, les moyens pour combattre la présomption de sa responsabilité encore connus sous le terme de cas exceptés. La limitation de la responsabilité est incompatible au principe

\footnotetext{
${ }^{456}$ Voir Convention de Bruxelles art. 3-6 : «... A moins qu'un avis de pertes ou dommages et de la nature générale de ces pertes ou dommages ne soit donnée par écrit au transporteur ou à son agent au port de déchargement, avant ou au moment de l'enlèvement des marchandises, et de leur remise sous la garde de la personne ayant droit à la délivrance ... Si les pertes ou dommages ne sont pas apparents, l'avis doit être donné dans les trois jours de la délivrance".

${ }^{457}$ Le vendeur de la marchandise est hors de cause en ce sens qu'il s'agit de l'exécution du contrat de transport. En plus, à la réception de la marchandise le transporteur a la possibilité de prendre des réserves contre le vendeur.

458 A propos de réparation de dommage, Boris Starck écrivait que : "L’indemnité a pour mesure le préjudice. Elle ne peut lui être ni supérieure, ni inférieure». (Voir Boris Starck, Droit civil. Obligations, $1971, \mathrm{n}^{\circ} 950$ et s. p. 324 et s). L'auteur met en relief la nécessité de faire coïncider le montant des dommages et intérêts à la valeur du préjudice subi, de sorte que la réparation du dommage soit juste : c'est la traduction du principe de la réparation intégrale du dommage subi.
} 
de la réparation. Les cas exceptés exonèrent le transporteur d'une responsabilité présumée. Ces caractéristiques des normes de réparation des dommages causés à la marchandise ne limitent-elles pas l'efficacité de la réparation ?

317- Pour répondre à cette préoccupation, examinons d'abord la limitation ou le plafonnement de la responsabilité et les conditions défavorables de sa mise en œuvre ( $\$ \mathbf{1})$ ensuite les cas exceptés qui semblent constituer un obstacle à la réparation des dommages $(\mathbf{\$} 2)$.

\section{$\S 1$ : La limitation de la responsabilité et les conditions défavorables de sa mise en œuvre au cours des procès}

318- Le Professeur René Rodière fait remarquer qu'en droit des transports maritimes, une réparation intégrale du préjudice subi par la marchandise rendrait excessivement coûteuses les primes d'assurance couvrant la responsabilité des armateurs ${ }^{459}$. En conséquence, la prime d'assurance rendrait le fret excessif. Alors, si le principe de la réparation intégrale était appliqué, il mettrait en péril l'activité des armateurs et par ricochet le commerce international serait menacé de disparition. Toutefois, l'idée selon laquelle une indemnisation intégrale mettrait en péril l'activité des armateurs est battue en brèche par le Professeur Vialard ${ }^{460}$ en matière de transport des hydrocarbures. Pour lui, l'argument est fallacieux car si tel était vraiment le cas, aucun armateur ne transporterait un seul baril de pétrole aux Etats Unis d'Amérique (USA) dans la mesure où les plafonds d'indemnisation y sont très élevés et que d'ailleurs certains Etats pratiquent la responsabilité illimitée c'est-à-dire la réparation intégrale ${ }^{461}$.

\footnotetext{
${ }^{459}$ RODIERE (René), Traité général de droit maritime, Dalloz. Paris, 1968, tome 2, op. cit., $\mathrm{n}^{\circ}$ 664, pp. 297 et s.

${ }^{460}$ Voir Professeur VIALARD «Faut-il réformer le régime de l'indemnisation des dommages de pollution par les hydrocarbures? ", DMF mai 2003, p. 435, in DAKOURI (Jean-Claude), Le droit maritime international et le transport des Hydrocarbures. Thèse de Droit privé, Maastricht, 2011, op. cit., p. 257.

${ }^{461}$ Le Professeur Michael FAURE rapporte qu'une étude menée en 2003 a identifié 16 États qui imposent la responsabilité illimitée en cas de marées noires. In DAKOURI (Jean-Claude), Le droit maritime international et le transport des Hydrocarbures, Thèse de Droit privé, Maastricht, 2011, op. cit., p. 257. Voir aussi en ce sens Etkin, D., A World wide Review of Maine Oil Spill Fines and Penalties, Environnemental Reseacsh Consulting, 2003, p. 22, cité par FAURE
} 
319- Pour des raisons historiques, la responsabilité du transporteur ne met pas à sa charge l'obligation corrélative de réparation intégrale du dommage subi par l'ayant droit à la marchandise. Il en est de même dans le transport de marchandises par route ${ }^{462}$. Ainsi, aux dépens du principe de la réparation in integrum lato sensu, la responsabilité du transporteur est, en principe, limitée ${ }^{463}$. La question se pose alors de savoir si le plafonnement de la responsabilité du transporteur ne constitue pas un obstacle à la réparation intégrale du préjudice subi (A). Aussi, se demande-t-on si les conditions de mise en œuvre de la responsabilité favorisent la protection de la marchandise (B).

\section{A- Le plafonnement de la responsabilité, défavorable à une réparation entière du préjudice}

320- On indiquera la signification du principe de plafonnement de la responsabilité (1) puis on examinera les conséquences d'un plafonnement modéré sur la réparation des dommages (2).

\section{1- Le plafonnement de la responsabilité, signification du principe et perte du bénéfice}

321- Que signifie ce principe (a) et à quel moment le transporteur maritime perd le bénéfice du plafonnement de sa responsabilité (b) ?

\section{a- La signification du principe du plafonnement de la responsabilité}

322- Conformément à l'article 713 du Code maritime, la responsabilité du transporteur pour le préjudice résultant des pertes ou dommages subis par les marchandises est limitée à un montant, fixé par la réglementation ou les usages en vigueur, calculé soit par colis ou autre unité de chargement, soit par

(Michael), «Responsabilité civile et réparation des pollutions marines, Leçon à tirer des déversements provenant des plateformes pétrolières ", Aménagement-Environnement, 2011/2, Kluwer, p. 8.

${ }^{462}$ BROU Kouakou (Mathurin), «Le nouveau droit des contrats de transport de marchandises par route dans l'espace OHADA ", Penant n 845, octobre-décembre 2003.

463 RIPERT (Georges), Droit maritime, "Crédit maritime - Fortune de mer - Transports maritimes ", Paris Éditions Rousseau et Cie, 4e édition, Tome 2, 1952, n 1229-1230, p. 140. Selon l'auteur, le plafonnement de la responsabilité est la "clé de voûte " du droit maritime, mais il indique par ailleurs qu'il est regrettable que son ratio legis semble aujourd'hui en porteà-faux. 
kilogramme de poids brut des marchandises perdues ou avariées, la limite la plus élevée étant applicable. Le Code maritime n'a pu fixer un montant plafond et son article 713 renvoie aux usages et réglementation en vigueur. En la matière on se réfère à la Convention de Bruxelles de 1924.

323- Le plafond de la responsabilité du transporteur retenu dans cette Convention, dans sa rédaction originelle, a été modifié par le protocole de 1979. En effet, "A moins que la nature et la valeur des marchandises n'aient été déclarées par le chargeur avant leur embarquement et que cette déclaration ait été insérée dans le connaissement, le transporteur, comme le navire ne seront en aucun cas responsables des pertes ou dommages des marchandises ou concernant celles-ci pour une somme supérieure à 666,67 unités de compte par colis ou unité, ou 2 unités de compte pas kilogramme de poids brut des marchandises perdues ou endommagées »464. Entendons par unité de compte le Droit de Tirage Spécial (DTS) $^{465}$ du Fonds Monétaire International (FMI). Selon Monsieur Innocent Fetze Kamdem, la conversion des DTS en monnaie nationale ne pose pas de problème particulier car, presque quotidiennement, le FMI établit la valeur de la monnaie de chacun de ses États membres à son adresse Internet ${ }^{466}$.

\footnotetext{
${ }^{464}$ Convention de Bruxelles de 1924, art.4, al.5, modifiée par le protocole de 1979.

${ }^{465}$ Voir plus généralement \&DR Suppléments Existing Reservesn. (septembre 1999) 28 IMF Survey Suppléments pp. 26 et 27. Le droit de tirage spécial (D.T.S.) créé en 1969 est l'unité de valeur utilisée par le Fonds Monétaire International (F.M.I.) et ses 182 pays membres (selon les données disponibles sur le site électronique. In httu://www.imf.ora/extema /nu/seclmcmdirlme.htm\# au 10 août 1999) pour assurer un certain équilibre monétaire entre la valeur des différentes monnaies nationales de façon à pondérer les hausses et les baisses de chacune des monnaies nationales. Même s'il ne circule pas comme monnaie d'échange, le D.T.S. représente depuis le 28 février 1999 la valeur commerciale moyenne des quatre monnaies nationales les plus fortes et les plus sollicitées dans le commerce mondial. Ces monnaies sont : le dollar américain (Etats-Unis), l'Euro (en remplacement du mark allemand et du franc français), le yen (Japon) et la livre Sterling (Grande-Bretagne). Idéalement, quand la valeur d'une ou de deux de ces quatre monnaies baisse, celle des autres devrait grimper de telle manière que les variations de l'une soient absorbées par les autres et qu'en bout de ligne le D.T.S. lui, ne fluctue pas, du moins pas beaucoup.

466 FETZE KAMDEM (Innocent), La responsabilité du transporteur maritime au niveau international : un échec d'uniformisation juridique, Mémoire, Université Laval Québec Canada, Décembre 1999, op. cit., p. 82. Pour une consultation des taux quotidiens, voir l'adresse Internet suivante : http://www.imf.org/external/np/tre/sdr/drates/0701.htm.
} 
324- Le colis équivaut à l'unité ${ }^{467}$. Pour le doyen Rodière " le colis est un élément de la cargaison, reconnu par des marques distinctives et porté sur le titre de transport ${ }^{468}$. Cette définition met le transporteur maritime en sécurité car elle précise à quoi il s'engage en prenant la marchandise en charge. Comme l'a si bien indiqué en substance la Cour de cassation ${ }^{469}$ : le colis est un élément de la cargaison qui a été spécifié c'est-à-dire physiquement individualisé et matérialisé en tant que tel au document de transport par conséquent, il est pris en charge à ce titre.

325- Mais s'agissant de la marchandise mise en conteneur la question se pose de savoir si elle représente un seul colis ou au contraire plusieurs colis individualisés à l'intérieur du conteneur. Après tâtonnement de la jurisprudence française ${ }^{470}$ et de la doctrine ${ }^{471}$, la Cour de cassation ${ }^{472}$ a décidé de prendre en compte le nombre de colis individualisés et pris en charge par le transporteur à travers le connaissement. En effet, "Lorsqu'un cadre, une palette ou tout engin similaire est utilisé pour grouper des marchandises, tout colis ou unité énuméré au connaissement comme étant inclus dans cet engin sera considéré comme un colis ou unité au sens de ce paragraphe. En dehors du cas prévu ci-dessus, cet engin sera considéré comme colis ou unité ${ }^{473}$.

326- Eu égard à cette disposition, le chargeur est tenu d'individualiser la marchandise mise en conteneur en divers colis identifiables. A défaut d'individualiser la marchandise mise en conteneur en divers colis sur le connaissement, en cas de dommages survenus, ladite marchandise est considérée comme un seul colis ${ }^{474}$. Lorsque la marchandise conteneurisée se

\footnotetext{
467 Voir les Règles de la Haye-Visby, art. 4, §5, nouveau.

468 Rodière, Traité général de droit maritime. op. cit., tome $2, \mathrm{n}^{\circ} 669$, pp. 301 et s.

469 Cass. com. 12 octobre 1964, DMF, 1965, p. 18 ; BT. 1965, p. 23.

470 CA. Montpellier, 26 mai 1965, DMF 1968, p. 239.

471 FRAIKIN (J.), Traité de la responsabilité du transporteur maritime, Paris, Librairie

générale de droit et de jurisprudence, 1957, n³06.

472 Cass. com. 12 octobre 1964.

473 Convention de Bruxelles, Protocole de 1979, art. 4, § 5, c.

474 Voir Rouen, 16 mars 1973, BT 1973, p. 288.
} 
présente en divers colis identifiables, le nombre de colis est pris en compte en plus du conteneur lui-même ${ }^{475}$.

327- Toutefois, relevons que la limitation de la responsabilité du transporteur maritime n'est pas d'application automatique. Elle est inapplicable à des hypothèses où le transporteur perd, en effet, le bénéfice de son usage.

\section{b- La perte du bénéfice du plafonnement de la responsabilité}

328- Le transporteur perd le bénéfice de la limitation de responsabilité soit par une déchéance soit par une déclaration de la valeur de la marchandise. La perte par déchéance se définit comme une perte inopinée, non voulue lors de la conclusion du contrat de transport maritime. Elle s'analyse comme une sanction: le transporteur ne peut bénéficier d'aucune limitation (aussi bien légale que contractuelle) de sa responsabilité lorsqu'il commet un dol ou une faute inexcusable $e^{476}$.

329- S'agissant de la perte de la limitation de responsabilité par déclaration de la valeur de la marchandise, l'article 713 du Code maritime dispose que la limite précitée est écartée lorsque celle fixée par la convention des parties est plus avantageuse pour l'ayant droit à la marchandise. On en trouve des illustrations dans la jurisprudence ivoirienne. Ainsi, dans l'arrêt $\mathrm{n}^{\circ}$ 270 du 10 mai 2001 rendu par la Cour suprême les juges ont décidé que : "Le connaissement comportant la liste et le nombre des pièces transportées, il n'y a pas de doute sur la valeur desdites marchandises, dès lors la Convention de Bruxelles de 1924 n'est pas applicable».

\footnotetext{
475 Cass. com. 29 janvier 1980, n77-14.923-BT 1980, p. 152.

476 Voir Code maritime, art. 716 : «Le transporteur, son préposée ou son mandataire, ne peut pas se prévaloir de la limitation de responsabilité, s'il est prouvé que la perte, le dommage ou le retard à la livraison résulte d'un acte ou d'une omission de l'auteur du dommage commis soit avec l'intention de provoquer cette perte, ce dommage ou ce retard, soit témérairement et sachant que cette perte, ce dommage ou ce retard en résulterait probablement ».
} 


\section{2- Le plafonnement modéré de la responsabilité, une limite à la réparation complète du préjudice}

330- Le plafonnement ou limitation de la responsabilité du transporteur est une règle dérogatoire au droit commun et une règle propre au droit maritime. La limitation de responsabilité est qualifiée par certains auteurs ${ }^{477}$ d'institution la plus originale du droit maritime. Pour le doyen Georges Ripert, l'un des principes fondamentaux du droit maritime est que «l'exploitation du navire ne peut être bien comprise que si l'on a sans cesse dans l'esprit cette idée que le propriétaire du navire n'est pas un débiteur ordinaire, ...., [et] ne peut être indéfiniment responsable» ${ }^{478}$. En matière de transport terrestre, un plafond légal de responsabilité est également fixé au-delà duquel le transporteur ne peut être tenu ${ }^{479}$.

331- Le principe de plafond de responsabilité a pour but de limiter la réparation due par le transporteur à un seuil au-delà duquel celui-ci n’assume plus de responsabilité. Conformément à l'article 713 du Code maritime qui renvoie à la règlementation en vigueur, ce plafond fixé à «666,67 unités de compte par colis ou unité, ou 2 unités de compte pas kilogramme de poids brut des marchandises perdues ou endommagées " 480 paraît assez modérée. L'application du principe de plafonnement de la responsabilité du transporteur entraîne des conséquences. La première est d'empêcher le destinataire d'obtenir une réparation intégrale des dommages subis par la marchandise et la seconde, est que l'indemnisation résultant de ce principe peut être largement inférieure au préjudice subi au point d'être dérisoire. Toutefois, il faut comprendre que

\footnotetext{
477 BONNASSIES (Pierre) et SCAPEL (Christian), Traité de droit maritime, Ed. L.G.D.J., 2006. 478 RIPERT (Georges), Droit maritime, Tome II, Ed. Rousseau, 1929.

479 Voir l'Acte uniforme de l'OHADA relatif aux contrats de transport de marchandises par route, art. 18, al. 1 et 2. "1. L'indemnité pour avarie ou pour perte totale ou partielle de la marchandise est calculée d'après la valeur de la marchandise et ne peut excéder 5000 Francs CFA par kilogramme de poids brut de la marchandise. Toutefois, lorsque l'expéditeur a fait à la lettre de voiture une déclaration de valeur ou une déclaration d'intérêt spécial à la livraison l'indemnité pour le préjudice subi ne peut excéder le montant indiqué dans la déclaration. 2. Dans le cas d'une déclaration d'intérêt spécial à la livraison, il peut être réclamé, indépendamment de l'indemnité prévue à l'alinéa 1 , et à concurrence du montant de l'intérêt spécial, une indemnité égale au dommage supplémentaire dont la preuve est apportée".

${ }^{480}$ Voir Convention de Bruxelles de 1924, art. 4, al. 5, modifiée par le protocole de 1979.
} 
cette limitation de la responsabilité est une nécessité pour l'équilibre des relations contractuelles entre le transporteur et le destinataire de la marchandise. En effet, le plafonnement de la responsabilité permet au transporteur de savoir à quoi il s'engage et en conséquence les frais de transport et les primes d'assurance sont raisonnablement fixés.

332- Le plafonnement modéré de la responsabilité du transporteur constitue une limite à la réparation complète du dommage subi par la marchandise. Cependant, le système traditionnel de la limitation de la responsabilité du transporteur précédemment décrit auquel semble s'attacher le législateur ivoirien mérite d'être relativisé. Et ce, au regard des avancées favorables aux propriétaires des marchandises que nous avons constatées au niveau du droit international et notamment en droit italien. En effet, l'article 62 de la Convention de Bruxelles de 1957 élargit la responsabilité de l'affréteur, sans distinction entre les temps d'affrètement, à l'armateur et à l'armateur gérant $^{481}$. En outre, en droit italien par la publicité de la qualité de l'armateur ${ }^{482}$, le problème de la responsabilité exclusive des propriétaires de navires a été résolu ${ }^{483}$. Les délais impartis au destinataire tant pour la prise de réserves à la réception de la marchandise que pour la prescription de l'action en responsabilité contre le transport sont également l'objet de préoccupation.

\section{B- La réclamation et l'action en responsabilité des dommages}

333- Lorsque la marchandise arrive à destination avec des avaries, des manquants, ou retards de livraison, le réceptionnaire doit prendre des réserves dans un délai précis pour servir de base au recours de l'ayant droit. Ce délai est imparti pour la prise de réserves à la livraison (1). Aussi, la loi maritime définit le délai au cours duquel le destinataire de la marchandise doit agir sous peine de forclusion, c'est le délai de prescription de l'action ou délai pour agir (2).

\footnotetext{
${ }^{481} \mathrm{Il}$ en est de même pour la convention on limitation of liability of maritime claims de 1976 (où l'affréteur est aussi cité sans distinguer entre les temps d'affrètement et la liste des bénéficiaires est encore élargie).

${ }^{482}$ Connu sous le nom de " Déclaration d'armateur».

483 Presses universitaires d'Aix-Marseille in books.openedition.org.
} 


\section{1- La réclamation de l'ayant droit à la marchandise}

334- Le réceptionnaire de la marchandise doit être diligent pour conserver les dommages. Cela consiste à émettre aussitôt des réserves utiles contre le transporteur. Le Code maritime ${ }^{484}$ dispose qu'en cas de perte ou de dommage aux marchandises le destinataire est tenu de donner par écrit au transporteur un avis de perte ou de dommage spécifiant la nature générale de cette perte ou de ce dommage. L'avis de perte ou de dommage est donné au transporteur au plus tard le premier jour ouvrable suivant le jour où les marchandises lui ont été remises, en cas de perte ou de dommage apparent. Lorsque la perte ou le dommage n'est pas apparent, le destinataire dispose d'un délai de huit jours consécutifs à compter de la date à laquelle les marchandises ont été remises pour adresser l'avis au transporteur. En l'absence d'un tel avis les marchandises sont présumées livrées conformes au document de transport ou en bon état. En cas d'acceptation de l'avis par le transporteur, la preuve des dommages subis est ainsi faite. Mais en cas de contestation du transporteur, une expertise contradictoire amiable ${ }^{485}$ constatera les dommages subis par la marchandise et identifiera leur cause. En cas de retard à la livraison, ce délai est de trente jours conformément à l'article 729 du Code maritime ${ }^{486}$.

335- En ce qui concerne les marchandises conteneurisées, la question se pose de savoir si les dommages qu'elles subissent sont réputés apparents ou non apparents. Le Code maritime ivoirien étant muet sur la question, il y a lieu de rechercher la solution dans la jurisprudence. Le dommage apparent est défini comme un dommage constatable par simple examen extérieur, tandis que le dommage non apparent est une avarie ou un manquant qu'un examen extérieur de l'emballage ou de la marchandise voyageant à nu ne permet pas de déceler,

\footnotetext{
484 Voir Code maritime, art. 724.

${ }^{485}$ Lamy transport, tome 2, édition 2010, op. cit., p. 992. L'expertise est amiable lorsqu'elle est pratiquée par un expert choisi d'un commun accord par les parties. Elle est judiciaire lorsqu'elle est ordonnée par le président du tribunal de commerce ou du tribunal d'instance sur requête de l'une quelconque des parties intéressées à la solution d'un litige relatif à l'exécution d'un contrat de transport.

486 Code maritime, art. 729 : «Aucune réparation n'est due pour le préjudice résultant du retard à la livraison à moins qu'un avis n'ait été donné par écrit au transporteur, ..., dans un délai de trente jours à compter de la date à laquelle les marchandises ont été livrées au destinataire".
} 
ni même de soupçonner ${ }^{487}$. Selon la jurisprudence française, le dommage est dit apparent lorsqu'à la livraison le réceptionnaire peut s'en rendre compte par un examen rapide à l'aide des sens dont chacun dispose ${ }^{488}$. En conséquence, il convient de retenir que le dommage subi par la marchandise logée en conteneur est réputé non apparent 489 , à moins que le conteneur présente des dommages apparents à la réception ${ }^{490}$. Car lorsque le conteneur présente des dommages apparents tels les trous dans le conteneur, on peut raisonnablement envisager que la marchandise qu'il contient a subi des dommages apparents.

336- Le réceptionnaire de la marchandise dispose d'un délai d'un jour ouvrable à compter de la date de la remise des marchandises pour adresser son avis au transporteur en cas de dommage apparent. Lorsque le dommage est non apparent, le délai pour adresser l'avis au transporteur est de huit jours consécutifs. Avec les marchandises de plus en plus conteneurisées ce délai de huit jours en cas de dommage non apparent semble assez protecteur. Le nouveau Code maritime ivoirien, en prévoyant un délai relativement long pour adresser l'avis au transporteur en cas de dommage non apparent, renforce ainsi la protection de la marchandise conteneurisée. En effet, lorsque la marchandise est conteneurisée, le destinataire nécessite plus de temps pour dépoter le conteneur et rechercher ledit dommage. En guise de comparaison la Convention de Rotterdam de 2009 prévoit un délai de sept jours ${ }^{491}$.

\footnotetext{
487 Voir Lamy transport, tome 2, édition 2010, op. cit., p. 989.

${ }^{488}$ CA Paris, 9 juillet 1959, DMF 1959, p. 680.

489 Voir en ce sens, T. com., Le Havre 27 déc. 1983, Cies ass. c/ Malasian International Shipping Corp.

490 Voir Cour suprême, arrêt n 356 du 07 juin 2001. La Cour motive son arrêt comme suit. « Mais attendu que les juges d'Appel pour retenir la seule responsabilité de [l'entreprise d'acconage et de manutention] ont énoncé que celle-ci est intervenue en tant qu'acconier manutentionnaire; qu'elle a omis d'émettre des réserves contre le transporteur maritime alors même que, l'expertise a établi l'existence d'avaries apparentes notamment des trous dans les containers; qu'en ne prenant pas de réserves en présence de dommages apparents elle a commis une négligence fautive suffisante à engager sa seule responsabilité ; qu'en statuant ainsi, ils ont par des motifs non contradictoires, légalement justifié leur décision; d'où il suit que ce moyen n'est pas fondé».

${ }^{491}$ Voir Convention de Rotterdam de 2009, art. 23. "1. Le transporteur est présumé, en l'absence de preuve contraire, avoir livré les marchandises telles que celles-ci sont décrites dans les données du contrat, à moins qu'un avis de perte ou de dommage subi par les marchandises indiquant la nature générale de la perte ou du dommage n'ait été donné au transporteur ou à la partie
} 
337- Les moyens de recours du destinataire étant conservés, encore fautil agir dans le délai légalement défini sous peine de forclusion de l'action en responsabilité contre le transport.

\section{2- Les règles relatives à l'action en responsabilité contre le transporteur}

338- Le délai dont dispose l'ayant droit à la marchandise pour intenter une action en responsabilité contre le transporteur est de deux ans ${ }^{492}$. La prescription biennale de l'action contre le transporteur est d'ordre public comme le précise l'article $730 \mathrm{du}$ Code maritime. Le délai de prescription court à partir du jour où le transporteur a livré les marchandises ou lorsque les marchandises n'ont pas été livrées, à partir du dernier jour où elles auraient dû l'être. Le jour indiqué comme point de départ du délai de prescription n'est pas compris dans le délai.

339- Toutefois, le point de départ de l'action du destinataire diffère selon qu'il s'agit soit de perte totale soit d'avaries ou manquants. En cas de perte totale, le point de départ de la prescription de l'action est compté du dernier jour où la marchandise aurait dû être livrée ${ }^{493}$ à son ayant droit ou son représentant. Ce jour est alors déterminé par présomption. Il s'agit précisément du jour où le navire a touché le port de destination ou au plus tard le jour où le déchargement a pris fin ${ }^{494}$.

340- En cas d'avaries ou de manquants constatés lors de la livraison, la prescription de l'action contre le transporteur court à partir du jour de la délivrance des marchandises ou une partie des marchandises ${ }^{495}$. C'est en effet, le jour où la détention des marchandises est transférée au destinataire et que celui-ci a été mis en mesure d'émettre par écrit son avis de perte ou de dommage

exécutante qui les a livrées, avant ou au moment de la livraison ou, si la perte ou le dommage n'est pas apparent, dans un délai de sept jours ouvrables au lieu de livraison à compter de la livraison".

492 Voir Code maritime de 2017, art. 730.

${ }^{493}$ Code maritime, art. 730.

${ }^{494}$ Voir CA Paris, 5 mai 1978, DMF 1978, p. 716.

${ }^{495} \mathrm{Cf}$ : Code maritime, art. 730. 
sur l'état des marchandises ${ }^{496}$. Par conséquent, le délai de prescription ne court pas du jour de la survenance du dommage ${ }^{497}$.

341- Le délai d'un an imparti au destinataire, par la Convention de Bruxelles de 1924, pour agir contre les intervenants au transport était jugé bref 498 . Très souvent, les destinataires de la marchandise avariée ou perdue se trouvaient forclos et perdaient de facto leur action contre les intervenants au transport maritime. C'est pourquoi, la Convention de Rotterdam de 2009, et aujourd'hui le Code maritime ivoirien, dans un souci de protection renforcée des intérêts du destinataire de la marchandise, ont porté ce délai jusqu'à deux années ${ }^{499}$.

342- Il ressort de cette analyse que le Code maritime ${ }^{500}$ accorde un délai d'un jour ouvrable (en cas de dommage apparent) et de huit jours consécutifs (en cas de dommage non apparent) au destinataire pour adresser son avis de perte ou de dommage au transporteur. En outre le Code maritime dispose que l'action $\mathrm{du}$ destinataire contre le transporteur se prescrit par deux ans ${ }^{501}$. Ces délais paraissent favorables à une réparation efficace des dommages subis par la marchandise. A présent, quid des cas d'exonération de responsabilité ou cas

496 Voir Code maritime, art. 724.

497 T. Com. Marseille, 17 nov. 1978. Rev. Scapel 1979, p. 7.

498 Pour remédier cela les Règles de Hambourg portent ce délai à deux ans. Voir art. 20-1 et 2. "1. Toute action relative au transport de marchandises par mer en vertu de la présente Convention est prescrite si une procédure judiciaire ou arbitrale n'a pas été introduite dans un délai de deux ans.

2. Le délai de prescription court à partir du jour où le transporteur a livré les marchandises ou une partie des marchandises, ou lorsque les marchandises n'ont pas été livrées, à partir du dernier jour où elles auraient dû l'être".

499 Voir Convention de Rotterdam, art. 62. "Durée du délai pour agir :

1. Aucune action judiciaire ou arbitrale relative à des réclamations ou des litiges découlant d'un manquement à une obligation prévue dans la présente Convention ne peut être engagée après l'expiration d'un délai de deux ans.

2. Le délai visé au paragraphe 1 du présent article court à partir du jour où les marchandises ont été livrées par le transporteur ou, lorsqu'elles n'ont pas été livrées ou ne l'ont été que partiellement, à partir du dernier jour où elles auraient dû être livrées. Le jour indiqué comme point de départ du délai n'est pas compris dans la computation.

3. Nonobstant l'expiration du délai visé au paragraphe 1 du présent article, une partie peut invoquer un droit et l'opposer à l'autre partie comme moyen de défense ou de compensation".

500 Code maritime, art. 724.

501 Code maritime, art. 730 . 
exceptés dont dispose le transporteur pour combattre la présomption de sa responsabilité ?

\section{$\S 2$ : Les cas exceptés justifiés, un obstacle à la réparation des dommages}

343- Selon un auteur, les cas exceptés sont des causes objectives de dommage auxquelles le législateur confère une vertu exonératoire ${ }^{502}$. Mais pour le doyen Rodière, ces cas légaux d'exonération de responsabilité sont inspirés du Harter Act de 1893, une loi fédérale américaine du nom de son initiateur Michael D. Harter. Cette loi fédérale américaine est marquée par deux principales caractéristiques : " $1^{\circ}$ la condition légale du transporteur est adoucie par rapport à la règle ancienne; $2^{\circ}$ elle ne peut pas l'être davantage par la convention des parties ${ }^{503}$. En effet, la règle ancienne ne retenait pas la catégorie des fautes nautiques comme cause d'exonération de la responsabilité du transporteur. Le Harter Act, en les retenant parmi les causes d'exonération de la responsabilité du transporteur, adoucit la condition de celui-ci. Ainsi, s'inspirant du Harter Act la responsabilité du transporteur, tout en restant présumée, a été équilibrée par les moyens de la combattre. Ces moyens sont les treize (13) cas d'exonération de sa responsabilité appelés cas exceptés ${ }^{504}$.

502 Voir SERIAUX, « La faute du transporteur », économica, 1998, n 9 et s.

${ }^{503}$ RODIÈRE (René), Traité général de droit maritime, tome II, Paris, Dalloz, 1968. n 577 , pp. 219 et $\mathrm{s}$.

504 Voir Code maritime, art. $711:$ « Le transporteur est responsable des pertes et dommages subis par la marchandise à moins qu'il ne prouve que ces pertes et dommages proviennent de l'une des causes suivantes :

- Innavigabilité du navire à condition que le transporteur apporte la preuve qu'il a satisfait à ses obligations ;

- Fait constituant un événement non imputable au transporteur, imprévisible et pour lequel le transporteur, ses préposés ou mandataires ont pris toutes les mesures raisonnables pour éviter les conséquences ;

- Faits de guerre ;

- Faits d'ennemis publics ;

- Arrêt ou contrainte de prince ;

- Restriction de quarantaine ;

- Incendie ;

- Faute du chargeur, notamment dans l'emballage, le conditionnement ou le marquage des marchandises ;

- Grèves, lock-out ou entrave apportée au travail ; 
344- Il sera question d'indiquer d'abord l'effet principal du cas excepté (A) et de montrer par la suite que les cas exceptés définis par le Code maritime ivoirien constituent un facteur d'incertitude à la réparation des dommages subis par la marchandise $(\mathbf{B})$.

\section{A- L'effet principal du cas excepté, l'exonération de la responsabilité du transporteur}

345- Seule la preuve d'un cas excepté est capable de faire tomber la présomption de responsabilité et libérer le transporteur maritime car « ...dans toute situation où il n'est pas prouvé que le dommage provient de l'une ou l'autre de ces causes où la responsabilité du transporteur est ainsi exceptée, celui-ci demeure responsable» ${ }^{505}$. C'est pourquoi, juges et arbitres exigent couramment du transporteur qui veut se prévaloir d'un cas excepté, de démontrer cumulativement sa "diligence raisonnable» et la réalité de l'événement qu'il invoque comme cause exonératoire ${ }^{506}$.

346- Les cas exceptés s'entendent comme les seules causes d'exonération de la responsabilité du transporteur maritime, leur effet principal est de détruire la présomption de responsabilité qui pèse sur celui-ci. Dès lors qu'il est prouvé que la cause du dommage est l'un des cas exceptés légalement prévus, de facto il n'y a plus lieu de présumer la responsabilité du transporteur. Le cas excepté fait donc obstacle à la présomption de la responsabilité.

347- En application du cas excepté lié à une cause extérieure au transporteur les juges ivoiriens ont décidé que "Ne sauraient être imputées ni au navire ni au transporteur maritime, les avaries qui ne trouvent pas leur cause

- Acte ou tentative de sauvetage de vie ou de biens en mer ou de déroutement à cette fin;

- Vice propre de la marchandise ou freinte de route ;

- Vice caché du navire échappant à un examen vigilant ;

- Périls dangers ou accident de mer".

Le chargeur ou le destinataire peut néanmoins, dans les cas ci-dessus faire la preuve que les pertes ou les dommages sont dus, en tout ou en partie, à une faute du transporteur, de ses préposés, ou mandataires".

${ }^{505}$ Voir BONASSIES (Pierre), « Le droit positif français en 1991 », DMF, 1992, vol. 44, pp. 4-7.

506 FETZE KAMDEM (Innocent), La responsabilité du transporteur maritime au niveau international : un échec d'uniformisation juridique, Mémoire, Université Laval Québec Canada, Décembre 1999, op. cit., pp. 101-102. 
dans le fait ou la faute du transporteur maritime, de ses préposés ou de ses agents. Il en est ainsi lorsque les avaries qui ont consisté en l'oxydation des fonds de boîte sont, selon les conclusions de l'expert, imputables à la mouille des palettes ou de leur contenu survenu avant ou au cours de leur empotage à l'origine suite à leur stationnement plus ou moins prolongé sous la pluie et sans que l'étanchéité du conteneur puisse être mise en cause ... "507. En l'espèce, les avaries étant liées à des événements extérieurs au transporteur, elles constituent pour lui un cas excepté exonératoire de sa responsabilité.

348- Le Code maritime de 2017 a prévu en son article 711, treize (13) cas exceptés. Dans un souci d'application uniforme de ses dispositions, le Code maritime dispose en son article 715 que les causes d'exonération de responsabilité bénéficient au transporteur quel que soit le fondement contractuel ou extracontractuel de l'action intentée contre lui pour pertes et dommages à la marchandise. En outre que son ou ses préposés et mandataires peuvent également s'en prévaloir pour la même action. Toutefois, il en est autrement en cas de dol ou de faute lourde. En effet, conformément à l'article 716 le dol et la faute lourde empêchent la cause exonératoire de responsabilité de jouer pleinement ${ }^{508}$.

349- Lorsque dans sa défense le transporteur maritime a établi un cas d'exonération de sa responsabilité et que le destinataire parvient à prouver une faute de celui-ci ou de ses préposés de nature à engager sa responsabilité, le moyen de défense du transporteur devient inopérant ${ }^{509}$. Cependant, il convient de préciser que dans certaines hypothèses où la faute du transporteur ou de ceux dont il répond est assortie d'un cas excepté, une exonération partielle de responsabilité lui est accordée ${ }^{510}$.

\footnotetext{
${ }^{507}$ Cour Suprême, arrêt n 466 du 9 octobre 2003. Inédit.

508 Voir Code maritime de 2017, art. 716.

509 Code maritime de 2017, art. 716 ; voir aussi CA Aix-en-Provence, 30 novembre 1977, Comaran Africa Line c/Cies d'ass. ; CA Aix-en-Provence, 27 juin 1986, DMF 1988, p. 243.

510 CA Paris, 5 ème Ch. A, 15 mai 1985, Armement Martin c/ divers.
} 


\section{B- Les cas exceptés, facteur d'incertitude de la réparation des dommages subis par la marchandise}

350- Lorsque le transporteur maritime fait la preuve d'un cas excepté, il s'exonère de la présomption de sa responsabilité. La probabilité de l'existence de cas exceptés pose problème. En effet, le transporteur s'exonère de sa responsabilité d'autant plus qu'il existe de cas exceptés. Vu l'effectif pléthorique de cas exceptés légalement définis (13 cas), la question se pose de savoir si un tel effectif ne rend pas incertaine l'indemnisation des préjudices. Le Code maritime a instauré un système de responsabilité automatique avec la possibilité d'exonération par la preuve de cas exceptés. Plus la liste des cas exceptés est brève, plus la responsabilité est objective. Le transporteur n'échappe à sa responsabilité que par ces cas définis au gré du législateur. Cependant, bien qu'aucune disposition du Code maritime ne l'exige, le destinataire a la possibilité de prouver que le dommage ne résulte pas du cas excepté invoqué par le transporteur ${ }^{511}$. Si le dommage est dû concurremment à un cas excepté et à une autre cause, le transporteur a la charge d'établir la part de dommage attribuable au cas libératoire et celle qui est imputable à l'autre cause sous peine de demeurer responsable pour le tout ${ }^{512}$.

351- Les cas exceptés regroupent toutes les hypothèses où la marchandise subit des dommages sans que son ayant droit puisse engager la responsabilité

\footnotetext{
${ }^{511}$ L'appréciation des cas exceptés est une question de fait généralement laissée à l'entière sagesse du juge ou de l'arbitre. Ainsi, juges et arbitres exigent couramment du transporteur qui se prévaut d'un cas excepté de démontrer cumulativement sa due diligence ou sa "diligence raisonnable " au moment où s'est produit l'événement qu'il invoque comme cas excepté, ainsi que son bien-fondé. En clair, le transporteur doit faire la preuve de sa due diligence avant de démontrer la réalité de l'un des cas exceptés. La décision rendue au Canada dans l'affaire Maxine Footwear Co. c. Can. Government Merchant Marine Ltd., illustre cette double exigence. Voir FETZE KAMDEM (Innocent), La responsabilité du transporteur maritime au niveau international : un échec d'uniformisation juridique, Mémoire, Université Laval Québec Canada, Décembre 1999, op. cit., p. 101.

512. Voir FETZE KAMDEM (Innocent), La responsabilité du transporteur maritime au niveau international : un échec d'uniformisation juridique, Mémoire, op. cit., p. 101. Un exemple en est fourni par l'article 5 (7) des Règles de Hambourg qui enjoint au transporteur traduit en justice de préciser d'abord les différentes causes qui ont contribué aux dommages subis par la marchandise et de faire ensuite la part de celles qui lui sont imputables et de celles qui ne le sont pas, codifiant ipso facto la Vallescura Rule élaborée par la Cour suprême des États-Unis dans l'affaire Schnell \& Co. v. S.S. Vallescura, 1934.
} 
du transporteur. Les cas exceptés empêchent le transporteur de réparer le dommage subi par la marchandise. En invoquant un cas excepté comme cause du dommage et en établissant la relation de cause à effet avec ledit dommage, le transporteur s'exonère de la présomption de sa responsabilité ou, à tout le moins, opère un renversement du fardeau de la preuve ${ }^{513}$. Dans ces conditions il revient au destinataire, ayant droit à la marchandise, de prouver que le transporteur a commis une faute qui est à l'origine du dommage. Selon Monsieur Innocent Fetze Kamdem : "Grosso modo, le demandeur enrayera la libération du transporteur soit par la preuve de l'absence de due diligence ou de la faute du transporteur, soit par la preuve que l'événement invoqué comme cas excepté n'en est pas un ${ }^{514}$.

352- En définitive, retenons que le cas excepté a pour effet principal de faire tomber la présomption de responsabilité qui pèse sur le transporteur. Il est vrai que ce régime de responsabilité, tel que conçu, vise à maintenir l'équilibre entre les intérêts du destinataire et ceux du transporteur. La présomption de la responsabilité favorise l'ayant droit à la marchandise tandis que les nombreux cas exceptés profitent au transporteur. Toutefois, la définition en extension qui consiste à énumérer tous les cas exceptés plausibles ${ }^{515}$ nous semble très favorable au transporteur. C'est pourquoi, une définition dans laquelle le cas excepté serait constitué de force majeure, aurait été plus équitable à notre sens. Ainsi, le transporteur serait chargé de faire la preuve du caractère imprévisible et insurmontable de l'événement ayant causé le dommage à la marchandise.

353- Enfin, les cas exceptés, de par leur effet exonératoire de responsabilité et leur nombre élevé516, semblent favoriser le transporteur et affaiblir la protection de la marchandise. On en tire la conséquence que les cas

\footnotetext{
513 DIALLO (Ibrahima Khalil), "Etude de l'acte uniforme relatif au contrat de transport de marchandises par route ", OHADATA D-05-08. Le bulletin du transport multimodal, juilletdécembre $2004, \mathrm{n}^{\circ} 2$ et 3 , p. 12 .

514 FETZE KAMDEM (Innocent), La responsabilité du transporteur maritime au niveau international : un échec d'uniformisation juridique, Mémoire, Université Laval Québec Canada, Décembre 1999, op. cit., p110.

515 L'article 711 du Code maritime définit 13 cas exceptés. 516 Idem.
} 
exceptés, bien qu'étant conçus pour équilibrer la présomption de responsabilité qui accable le transporteur, ont pour effet secondaire d'effriter l'efficacité de la protection de la marchandise.

354- L'analyse critique des normes de protection de la marchandise a révélé l'existence de limites ${ }^{517}$ et d'insuffisances ${ }^{518}$. Toutefois, vu la prolifération des infractions liées au trafic maritime, on est en droit de s'interroger sur l'efficacité de la lutte contre l'insécurité maritime.

517 A savoir que les cas exceptés affaiblissent la protection de la marchandise telle que définie par la législation maritime.

518 Voir FETZE KAMDEM (Innocent), La responsabilité du transporteur maritime au niveau international : un échec d'uniformisation juridique, Mémoire, Université Laval Québec Canada, Décembre 1999, op. cit., p. 118. L'auteur partage son inquiétude à travers sa conclusion. "En définitive, au niveau international, la responsabilité du transporteur de marchandises par mer est loin d'être soumise à un corps de règles unique. L'entreprise d'uniformisation commencée en 1924 a abouti à trois principaux textes : les Règles de La Have, les Règles de La Haye-Visby et les Règles de Hambourg. En conséquence, le montant de la réparation à laquelle sera condamné le transporteur et les circonstances de son exonération varient selon que l'un ou l'autre des trois régimes en lice est appliqué. Cette situation est pleinement exploitée par le transporteur ... Devant ce constat, l'uniformisation effective du régime de la responsabilité du transporteur maritime est devenue un vœu, pour ne pas dire un impératif, partagé aussi bien par les tribunaux que par la doctrine». 


\section{CHAPITRE 2: LES INSUFFISANCES DE LA LUTTE CONTRE L'INSECURITE AU REGARD DE LA PERSISTANCE DES INFRACTIONS MARITIMES}

355- Les instruments juridiques de lutte contre l’insécurité maritime sont perceptibles tant à l'échelle internationale que nationale. La question se pose de savoir quel est l'apport de ces nombreuses conventions internationales et textes nationaux en matière de sécurité maritime. Leur existence permet-elle de résorber les cas d'insécurité dans les transports maritimes ? La persistance de la piraterie ${ }^{519}$ et des infractions liées au trafic maritime semble poser également la question de l'efficacité des instruments de lutte contre l'insécurité maritime ${ }^{520}$. La recherche de réponse claire à ces préoccupations, conduit à l'analyse de la problématique liée aux instruments de prévention et de répression contre les infractions maritimes (Section 1) et à celle des causes de l'inefficacité de la répression des infractions maritimes en Côte d'Ivoire (Section 2).

\footnotetext{
519 YAPO (Marina Madel), La lutte contre la criminalité maritime dans le golfe de Guinée : cas de la Côte d'Ivoire et du Nigeria, Programme de Bourses de Recherche, Nations Unies-Fondation Nippone du Japon, Etude 2012-2013, Décembre 2013, p. 7. Selon l'auteur, sur les 58 attaques rapportées en 2012, 37 au moins ont été perpétrés avec des armes. En Côte d'Ivoire, 05 incidents ont été rapportés en 2012 contre 01 en 2011. Au dernier trimestre de 2012 un tanker Panamax a été détourné au large des côtes ivoiriennes par des pirates suspectés de nationalité nigériane. En raison de l'impuissance des autorités ivoiriennes face à ce détournement, ce navire s'est retrouvé au large des côtes du Nigeria dépouillé de toute sa cargaison. La montée de la piraterie maritime et des vols à main armée dans le Golfe de Guinée est à l'évidence une menace pour les économies des pays riverains, qui dépendent des activités portuaires pour leurs exportations ou leurs approvisionnements extérieurs.

${ }^{520}$ En matière de trafic illicite de drogue en mer, voir UNODC, 2008. Le trafic de drogue comme, menace à la sécurité en Afrique de l'Ouest et son impact sur la sécurité dans les Etats fragiles. Il est indiqué ceci : "Les sonnettes d'alarme ont été tirées en ce qui concerne le volume de cocaïne transitant dans la région (environs 50 tonnes par an). L'Afrique de l'Ouest, qui n'a jamais été confrontée à des problèmes de drogue par le passé, est devenue une plaque tournante du trafic de cocaïne. Les ports et les aéroports internationaux sont utilisés par ces réseaux criminels pour les trafics de drogue de l'Asie (héroïne et substances psychotropes), l'Amérique latine (cocaïne), l'Afrique du Nord (résine de cannabis) et l'Europe (substances psychotropes) ». Voir aussi l'affaire du "Probo Koala", in DE BONTE POERI (Priscille), « Les lacunes du droit relatif au mouvement transfrontière des déchets dangereux : illustration à l'aide de l'affaire Probo Koala en Côte d’Ivoire », Mémoire, Université de Montréal, juin 2015, pp. 87-88 et 135-136.
} 


\section{Section 1 : La problématique liée aux instruments de prévention et de lutte contre les infractions maritimes}

356- Il est indéniable que malgré l'existence d'une législation maritime ivoirienne et la pléthore de conventions internationales ${ }^{521}$ destinées à assurer la sécurité et la sûreté maritimes, la piraterie, la criminalité maritime et les trafics illicites par mer persistent. Ces instruments ci-dessus évoqués rencontrent-ils un dysfonctionnent dans leur application? Il convient de faire la lumière sur les insuffisances constatées et de faire des propositions tant au niveau des normes à l'échelle internationale (\$1) que des normes de dimension nationale ivoirienne (\$2).

\section{$\S 1$ : Cas des normes relatives à la sécurité maritime à l'échelle internationale}

357- Il s'agit de chercher à comprendre pourquoi face à cette pléthore d'instruments internationaux destinés à prévenir et réprimer les infractions maritimes, celles-ci continuent de proliférer. Le constat est que des instruments internationaux sont méconnus en droit ivoirien faute de ratification (A). En outre, il existe des défaillances dans la mise en œuvre des dispositions des conventions internationales $(\mathbf{B})$.

\section{A- Méconnaissance des instruments juridiques internationaux faute de leur ratification en droit ivoirien}

358- La législation destinée à lutter contre les infractions maritimes est abondante et constituée pour l'essentiel de conventions internationales qui ne sont pas directement applicables en Côte d'Ivoire. Encore, faut-il qu'elles soient d'abord ratifiée et ensuite intégrées dans l'ordonnancement juridique ivoirien à travers des mesures nationales d'application. Certaines conventions internationales prévues pour la lutte contre les différents trafics illicites et surtout contre la criminalité maritime ne sont pas encore ratifiées par la Côte d'Ivoire ${ }^{522}$, elles sont par conséquent inapplicables en droit ivoirien. En

\footnotetext{
${ }^{521} \mathrm{Il}$ s'agit de toutes les conventions internationales et des normes internes de lutte contre l'insécurité maritime.

${ }^{522}$ Il s'agit entre autres du traité des Nations Unies sur le commerce des armes de 2013 ; de l'Accord des Nations Unies sur la conservation et la gestion des stocks de poissons de 1995; de
} 
revanche, d'autres conventions protectrices des intérêts des transports maritimes sont déjà ratifiées ${ }^{523}$. La question est de savoir si elles ont été effectivement intégrées à la législation nationale ivoirienne.

359- S'agissant des conventions ratifiées par la Côte d'Ivoire ${ }^{524}$, à notre connaissance, elles n'ont pas été suivies de dispositions nationales propres en vue de leur application. En effet, plusieurs instruments ont été produits par les Nations Unies pour protéger le trafic maritime. Certains d'entre eux sont ratifiés par la Côte d'Ivoire et d'autres pas encore ${ }^{525}$. Mais les conventions ratifiées, par manque de dispositions nationales ne peuvent être appliquées. Dans ces conditions, l'on peut s'attendre à ce que les trafics illicites, la criminalité et la piraterie en mer continuent de prospérer dans le secteur des transports maritimes en Côte d'Ivoire.

\section{B- Mise en œuvre défaillante des normes internationales relatives à la répression des actes illicites}

360- Les infractions maritimes peuvent être distinguées. En effet, il y en a qui portent sur les trafics illicites et la protection de l'environnement marin. D'autres portent sur la piraterie et la criminalité en mer. Contre chaque groupe d'infractions existe au moins un instrument international de lutte. La préoccupation est de savoir si ces instruments internationaux, lorsqu'ils sont ratifiés ${ }^{526}$, peuvent s'appliquer directement dans les législations nationales des Etats parties.

\footnotetext{
la Convention de Palerme contre la criminalité transnationale organisée du 15 novembre 2000 ; de la Convention de Rome de 1988 pour la répression d'actes illicites contre la navigation maritime et ses Protocoles de 1988 et de 2005 ; et bien d'autres.

${ }^{523}$ Il s'agit de la Convention de Montego Bay sur le droit de la mer, ratifiée en 1984 ; la Convention des Nations Unies contre le trafic illicite de stupéfiants et de substances psychotropes de 1988, ratifiée le 25 novembre 1991. Il y a aussi le Protocole contre le trafic illicite de migrants par terre, air, mer auquel la Côte d'Ivoire a adhéré le 8 juin 2017.

524 Voir ci-dessus, ${ }^{\circ} 358$, p. 165.

525 Idem.

${ }^{526}$ Il faut cependant distinguer la signature d'une convention internationale de sa ratification. En effet, la signature d'un traité est une "formalité qui constate l'accord intervenu au terme de la négociation sur le texte d'un traité, mais qui, sauf exceptions, ne lie pas normalement l'Etat". Tandis que la ratification exprime le consentement de l'Etat à être lié par le traité. La ratification est donc une "Approbation d'un traité par les organes internes compétents pour
} 
361- En ce qui concerne le traité sur le commerce des armes du 3 juin 2013, son préambule réaffirme le droit souverain de tout État de réglementer et de contrôler les armes classiques exclusivement à l'intérieur de son territoire en vertu de son propre ordre légal ou constitutionnel. Le préambule réaffirme également le principe selon lequel: «La responsabilité de chaque État de réglementer, dans le respect de ses obligations internationales, le commerce international d'armes classiques et d'en prévenir le détournement et, au premier chef, celle d'instituer et d'appliquer un régime national de contrôle "527. En outre, pour l'exécution du traité, son article 14 dispose que: "Chaque État Partie adopte les mesures nécessaires pour faire appliquer les lois et règlements nationaux mettant en œuvre les dispositions du présent Traité ». Au regard de ce qui précède il est évident que les dispositions de ce traité ne peuvent être directement appliquées dans les Etats parties. Elles doivent nécessairement être transcrites dans les législations nationales.

362- S'agissant de la convention des nations unies contre le trafic illicite de stupéfiants et substances psychotropes du 19 décembre 1988, son objet est que : "Dans l'exécution de leurs obligations aux termes de la Convention, les Parties prennent les mesures nécessaires, y compris des mesures législatives et réglementaires compatibles avec les dispositions fondamentales de leurs systèmes législatifs internes respectifs »528. Pour la définition des infractions et des sanctions afférentes il est prévu que "Chaque Partie adopte les mesures nécessaires pour conférer le caractère d'infractions pénales conformément à son droit interne, lorsque l'acte a été commis intentionnellement "529. La priorité est enfin donnée à l'Etat partie de définir sa compétence juridictionnelle : "Chaque Partie adopte les mesures nécessaires pour établir sa compétence en ce qui concerne les infractions qu'elle a établies conformément au paragraphe 1 de

engager internationalement l'Etat... ». Pour toutes ces précisions Voir GUILLIEN (Raymond) et VINCENT (Jean), Lexique des termes juridiques, Dalloz, 13ème édition, pp. 511 et 459.

527 Voir Traité sur le commerce des armes du 3juin 2013. Principes énoncés dans le préambule.

528 Convention des nations unies contre le trafic illicite de stupéfiants et de substances psychotropes du19 décembre 1988, art. 2 .

529 Convention des nations unies contre le trafic illicite de stupéfiants et de substances psychotropes du19 décembre 1988, art. $3 \S 1$. 
l'article $3 »^{530}$. Ces différentes dispositions incitent les Etats à adopter des lois nationales en application desdites conventions pour lutter contre le trafic illicite de stupéfiants et de substances psychotropes.

363- La Convention des Nations unies contre la criminalité transnationale organisée dispose en son article 5 que: "Chaque État Partie adopte les mesures législatives et autres nécessaires pour conférer le caractère d’infraction pénale, lorsque commis intentionnellement, ...». Ensuite, dans le Protocole visant à prévenir, réprimer et punir la traite des personnes, en particulier des femmes et des enfants, il est prévu que : "Chaque État Partie adopte les mesures législatives et autres nécessaires pour conférer le caractère d'infraction pénale aux actes énoncés à l'article 3 du présent Protocole, lorsqu'ils ont été commis intentionnellement ${ }^{531}$. Le Protocole contre le trafic illicite de migrants par terre, mer et air renvoie également l'incrimination aux Etats parties $^{532}$. Enfin, la Convention de Montego Bay sur le droit de la mer de 1982, après avoir défini la piraterie en son article 101 sans l'assortir de sanctions pénales dispose que : "Tout Etat peut, en haute mer ou en tout autre lieu ne relevant de la juridiction d'aucun Etat, saisir un navire ou un aéronef pirate, [...]. Les tribunaux de l'Etat qui a opéré la saisie peuvent se prononcer sur les peines à infliger, ainsi que sur les mesures à prendre en ce qui concerne le navire, l'aéronef ou les biens, réserve faite des tiers de bonne foi "533. Ainsi, la définition et l'application des peines relèvent strictement du droit national.

364- Il ressort de cette analyse que les dispositions des conventions internationales ne sont pas conçues pour être directement appliquées dans les Etats parties pour lutter contre les infractions en mer. Cette inapplicabilité

530 Convention des nations unies contre le trafic illicite de stupéfiants et de substances psychotropes du19 décembre 1988, art. 4.

531 Protocole visant à prévenir, réprimer et punir la traite des personnes, en particulier des femmes et des enfants, art. 5 .

532 Protocole contre le trafic illicite de migrants par terre, mer et air, art. 6 : " Chaque État Partie adopte les mesures législatives et autres nécessaires pour conférer le caractère d’infraction pénale, lorsque les actes ont été commis intentionnellement et pour en tirer, directement ou indirectement, un avantage financier ou autre avantage matériel: a) Au trafic illicite de migrants ; b) Lorsque les actes ont été commis afin de permettre le trafic illicite de migrants ...".

${ }^{533}$ Voir Convention des Nations Unies sur le droit de la mer de décembre 1982, art. 105. 
directe des dispositions des conventions internationales dans les Etats parties se présente, à notre sens, comme un dysfonctionnement du mécanisme de protection des transports maritimes entraînant son inefficacité à l'échelle internationale.

365- Cependant, nous pensons que la non-ratification et la nonapplication des conventions internationales de protection des transports maritimes ne sauraient constituer une problématique. La question pertinente qu'il convient de se poser est celle de savoir si la Côte d'Ivoire dispose d'une législation nationale capable de sécuriser la navigation maritime.

\section{$\S 2$ : Cas des normes de dimension nationale ivoirienne relatives à la sécurité maritime}

366- Avant la Loi n 2017-442 du 30 juin 2017 portant Code maritime, la législation qui régissait la sécurité des transports maritimes était contenue dans des textes comportant des lacunes. Celles-ci peuvent être constatées au niveau des Codes de la marine marchande et pénal ivoiriens (A). Aujourd'hui, avec l'adoption du nouveau Code maritime ivoirien, l'on devrait sans risque de se tromper affirmer que ces lacunes ont trouvé des solutions (B).

\section{A- Les lacunes constatées dans la législation du transport avant le Code maritime}

367- En matière de lutte contre la piraterie et la criminalité en mer la législation nationale qui se réduisait au Code pénal ${ }^{534}$ et au Code de la marine marchande présentait des limites tant au niveau de l'incrimination qu'au niveau de la répression ${ }^{535}$. Le Code pénal ivoirien ne contient aucune disposition

\footnotetext{
${ }^{534}$ Le Code pénal (Edition 2019). Dernière mise à Jour : 17/02/2019. Le Code pénal ivoirien est constitué des textes ci-après : Loi n $81-640$ du 31 juillet 1981 instituant le code pénal, modifiée par les lois : $n^{\circ}$ 95-522 du 06 juillet $1995 ; n^{\circ} 96-764$ du 03 octobre $1996 ; n^{\circ} 97-398$ du 11 juillet 1997 ; n 98-756 du 23 décembre 1998 ; n²008-222 du 4 aout 2008 modifiant et complétant les dispositions du code pénal relatives à la répression du racisme, de la xénophobie, du tribalisme et des discriminations raciales et religieuses; $n^{\circ} 2015-134$ du 9 mars 2015. www.ivoirejuriste.com. Consulté en janvier 2019.

535 En matière de sécurité en général la répression suit l'incrimination. Le comportement punissable et la sanction afférente sont définis par le même texte à l'échelle nationale. Mais il en est autrement dans certaines conventions internationales qui, après avoir défini les comportements punissables, renvoient les Etats parties à leur législation nationale quant-aux
} 
relative aux infractions maritimes. Il renferme des dispositions portant sur le droit pénal général et des dispositions sur le droit pénal spécial. Ainsi la définition de la piraterie et sa répression sont ignorées par le Code pénal ivoirien. En ce qui concerne le Code de la marine marchande 536 de 1961, il ne consacre que quelques dispositions aux délits, crimes et poursuites relatives aux infractions maritimes à travers les chapitres 3 et 9 du titre VII. Curieusement, l'article $150 \mathrm{du}$ Code de la marine marchande qui prévoit comment sont recherchés et constatés les crimes et délits commis à bord des navires ne définit pas lesdits crimes et délits. Quant aux articles 231 à 233 du même Code de la marine marchande, ils définissent les conditions dans lesquelles les membres de l'équipage sont poursuivis et jugés comme pirates. Toutefois, aucune des dispositions dudit Code ne prévoit la définition de la piraterie encore moins celle de la criminalité maritime. Nous en déduisons que le Code de la marine marchande prévoit la répression de certains délits et crimes commis à bord des navires mais ne définit pas la piraterie et la criminalité maritime.

368- Par ailleurs, la Direction générale des affaires maritimes et portuaires (DGAMP) ${ }^{537}$ ne dispose pas d'organe en charge du suivi et du contrôle de l'application des normes de sûreté maritime. Cela contribue à l'inefficacité de la lutte contre la criminalité maritime. S'agissant de la circulation des armes légères et de petit calibre, la législation ivoirienne méritait d'être revue ${ }^{538}$. Dans

sanctions. Voir dans ce sens les articles 101 et 105 de la Convention de Montego Bay. Voir également l'article 5 de la Convention de Palerme ; l'article 5 du Protocole visant à prévenir, réprimer et punir la traite des personnes, en particulier des femmes et des enfants : voir enfin l'article 6 du Protocole contre le trafic illicite de migrants par terre, mer et air.

536 Voir la loi n 61-349 du 9 novembre 1961, relative à l'institution d'un code de la marine marchande en Côte d'Ivoire.

${ }^{537}$ La DGAMP n'existe que depuis 2004. Cependant, son histoire remonte à 1960. De 1960 à nos jours, l'Administration Maritime Ivoirienne a connu plusieurs mutations. D'abord, il y a eu la création de la Direction de la Marine Marchande rattachée au Ministère des Travaux Publiques et des Transports, par le décret nº0-353 du 02 novembre 1960. Puis, en 1977, cette administration a changé de tutelle en intégrant le secrétariat d'Etat à la Marine par le décret n77-567 du 10 août 1977 et placé sous l'autorité du Président de la République. Mais aujourd'hui conformément au décret $\mathrm{n}^{\circ} 2011-401$ du 16 novembre 2011 portant organisation du Ministère des Transports, la DGAMP a intégré ledit Ministère. Voir https //fr. wipedia. Org/wiki/marine nationale. Consulté le 17 juillet 2017.

${ }^{538}$ Cette législation est composée de la loi 81-640 du 31 juillet 1981 instituant le Code pénal ; la loi 98-749 du 23 décembre 1998 portant répression des infractions à la réglementation sur les 
cet ordre d'idées, Savannah De Tessières soutient que les textes comportent des lacunes et doivent être révisés afin de correspondre à l'effort d'harmonisation des législations de la sous-région selon les dispositions de la Convention de la CEDEAO sur les armes légères et de petit calibre, leurs munitions et autres matériels connexes ${ }^{539}$. Le Code maritime ivoirien de 2017 apporte des solutions aux difficultés relatées.

\section{B- Des solutions décelables dans le Code maritime ivoirien de 2017}

369- Le nouveau Code maritime ivoirien ${ }^{540}$ apparaît comme une avancée en matière de sécurité en ce sens qu'il contient des dispositions portant sur la sécurité du transport de marchandises par mer. En effet, la piraterie maritime y est définie et punie à travers l'article 1008. La piraterie maritime est entendue comme : " tout acte illicite de violence, de menace, de détention ou de déprédation commis par l'équipage ou des passagers d'un navire [...] et dirigé contre un autre ou aéronef ou contre des personnes ou les biens à leur bord, au-delà de la mer territoriale, ... L’infraction de piraterie prévue au présent article est punie, d'une peine de dix à vingt ans et d'une amende de 20000000 à 2000000000 Francs CFA. La tentative est punissable. ... ${ }^{541}$. En outre, les juridictions ivoiriennes de droit commun sont seules compétentes en matière de crimes et délits commis à bord des navires sous pavillon ivoirien ${ }^{542}$. En cas d'infraction commise dans les eaux territoriales ou portuaires ivoiriennes à bord des navires sous pavillon

\footnotetext{
armes, munitions et substances explosives; le décret 99-183 du 24 février 1999 portant réglementation des armes et des munitions. Il faut ajouter le décret 2009-154 du 30 avril 2009 portant création, organisation, attribution et fonctionnement de la Commission nationale de lutte contre la prolifération et la circulation illicite des ALPC. Enfin l'arrêté 148/MD/CAB du 2 février 2007 portant fixation des modalités d'utilisation des armes à feu et des grenades dans le cadre des activités de garde rapprochée et de transport de fonds

${ }^{539}$ DE TESSIERES (Savannah), " Enquête nationale sur les armes légères et de petit calibre en Côte d'Ivoire. Les défis du contrôle des armes et de la lutte contre la violence armée avant la crise post-électorale ». Rapport spécial avril 2012, p. 151. L'auteur indique que la législation ivoirienne comporte des lacunes malgré l'existence de plusieurs textes législatifs visant à réglementer la possession, l'utilisation, le transfert, la gestion et la production des ALPC et des munitions.

540 Voir Loi $\mathrm{n}^{\circ}$ 2017-442 du 30 juin 2017 portant Code maritime, entrée en vigueur le 13 novembre 2018 (Journal Officiel de la République de Côte d'Ivoire du 13 novembre 2018).

${ }^{541} \mathrm{Cf}$ : Loi n 2017-442 du 30 juin 2017 portant Code maritime, art. 1008.

542 Idem, art. 1041.
} 
étranger, les juridictions pénales sont compétentes pour connaître du jugement desdites infractions lorsque: l'intervention des autorités ivoiriennes a été réclamée; l'infraction a troublé l'ordre public; l'auteur ou la victime est ivoirien ${ }^{543}$. Dans les cas prévus à l'article 1043, l'autorité maritime informe le représentant diplomatique de l'Etat dont le navire bat pavillon des faits à la suite desquels les juridictions ivoiriennes ont eu à connaître des crimes ou délits commis à bord du navire ${ }^{544}$.

370- Les infractions contre la sécurité de la navigation maritime sont régies par le Code maritime. Celui-ci définit et réprime la piraterie et la criminalité en mer contrairement à la Convention de Montego Bay qui incrimine la piraterie mais ne la réprime pas. Car la CMB s'en remet aux Etats parties en vue d'une éventuelle répression de l'infraction maritime ${ }^{545}$. En effet, on entend par piraterie maritime tout acte illicite de violence, de menace, de détention ou de déprédation commis par l'équipage ou des passagers d'un navire ou d'un aéronef et dirigé contre un autre navire ou aéronef ou contre des personnes ou des biens à leur bord, au-delà de la mer territoriale ${ }^{546}$. Les juridictions de droit commun de Côte d'Ivoire sont seules compétentes en matière de crimes et délits commis à bord des navires sous pavillon ivoirien ${ }^{547}$. En cas d'infraction commise dans les eaux territoriales ou portuaires ivoiriennes à bord des navires sous pavillon d'un Etat étranger, les juridictions pénales sont compétentes pour connaître du jugement lorsque : l'intervention des autorités ivoiriennes a été réclamée; l'infraction a troublé l'ordre public; l'auteur ou la victime est ivoirien $^{548}$.

\footnotetext{
${ }^{543}$ Loi n $^{\circ}$ 2017-442 du 30 juin 2017 portant Code maritime, art. 1042.

${ }^{544} \mathrm{Cf}$ : Loi n ${ }^{\circ}$ 2017-442 du 30 juin 2017 portant Code maritime, art. 1043.

${ }^{545}$ La convention de Montego définit en son article 101 la piraterie et son article 105 renvoie aux Etats parties la définition des peines à infliger aux actes de piraterie : « ... Les tribunaux de l'Etat qui a opéré la saisie peuvent se prononcer sur les peines à infliger, ainsi que sur les mesures à prendre en ce qui concerne le navire, l'aéronef ou les biens, réserve faite des tiers de bonne foi $»$.

546 Voir Code maritime ivoirien de 2017, art. 1008.

547 Idem, art. 1041.

548 Code maritime de 2017, art. 1042.
} 
371- S'agissant de la protection de l'environnement marin, elle était organisée par le passé par plusieurs textes comme le souligne Monsieur Vincent Bilé549. Aujourd'hui, la protection de l'environnement marin et fluvio-lagunaire est régie par le livre VI du Code maritime. Ainsi, l'Etat de Côte d'Ivoire élabore forme et dans quelque condition que ce soit, à l'exception de ceux dont un plan de lutte contre la pollution marine dont l'organisation opérationnelle doit respecter les principes édictés par l'organisation maritime internationale ${ }^{550}$. Ainsi, est interdite l'immersion des déchets ou autres matières sous quelque forme et dans quelque condition que ce soit, à l'exception de ceux dont l'immersion est subornée à la délivrance d'un permis ${ }^{551}$. Et en cas de rejet par un navire étranger de substances nuisibles ou nocives dans les eaux sous juridiction ivoirienne, constaté par l'autorité maritime administrative, celle-ci fournit aux autorités de l'Etat dont le navire bat pavillon, la preuve de ce rejet afin de leur permettre de prendre des mesures appropriées, sans préjudice des poursuites qui peuvent être engagées par les autorités judiciaires compétentes en Côte d'Ivoire 552 .

372- En dépit des avancées constatées, force est de reconnaître que la législation maritime reste perfectible. C'est ainsi que nous partageons l'avis de Monsieur Vincent Bilé. L'auteur soutient que le nouveau Code maritime contient des innovations importantes adaptées aux besoins du commerce international, très pointilleux sur des questions de sécurité juridique et d'évolution technologique. Mais comme toute œuvre humaine, il n'échappe pas à l'imperfection étalant quelques limites ${ }^{553}$. Le Code maritime ivoirien apporte

\footnotetext{
549 Voir BILE (Vincent), " Regard Critique sur le Nouveau Code Maritime Ivoirien ", Neptunus, e. revue Université de Nantes, vol. 24, 2018/3, 2018, pp. 2 et 3. L'auteur cite ces textes : "la loi $n^{\circ}$ 96-766 du 3 octobre 1996 portant Code de l'environnement, l'ordonnance $n^{\circ} 2012-487$ du 7 juin 2012 portant Code des investissements, la loi $n^{\circ} 2014-390$ du 20 juin 2014 d'orientation sur le développement durable et le décret $n^{\circ} 97-678$ du 3 décembre 1997 portant protection de l'environnement marin et lagunaire contre la pollution, lequel a internalisé les différentes conventions internationales sur l'environnement marin ". www.cdmo.univ-nantes.fr".

${ }^{550} \mathrm{Cf}$ : Code maritime ivoirien de 2017, art. 583.

551 Idem, art. 621.

${ }_{552}$ Code maritime ivoirien de 2017, art. 585.

553 Voir BILE (Vincent), « Regard Critique sur le Nouveau Code Maritime Ivoirien ", Neptunus, e. revue Université de Nantes, vol. 24, 2018/3. op. cit., p. 1.
} 
une protection renforcée de l'environnement marin grâce à ses dispositions $1091^{554}$ et $1096^{555}$. Il abroge le code de la marine marchande de $1961^{556}$.

\section{Section 2 : Constat de l'inefficacité des normes nationales et sous régionales de lutte contre les infractions maritimes}

373- La persistance des infractions dans les transports maritimes amène à s'interroger sur l'efficacité des normes relatives à la répression desdites infractions. Pour ce faire, on examinera successivement les règles nationales ivoiriennes de répression des infractions maritimes $\left(\begin{array}{l}\mathbf{S} \\ \mathbf{1}\end{array}\right)$ et les normes à caractère sous régional en la matière $(\mathbf{\$} 2)$.

\section{$\S 1$ : Cas des règles nationales ivoiriennes relatives à la répression des infractions maritimes}

374- En Côte d'Ivoire les questions liées au transport maritime sont du ressort de la Direction générale des affaires maritimes et portuaires (DGAMP). En effet, la DGAMP est chargée de la conduite de la politique nationale en matière d'Affaires Maritimes et Portuaires et de la coordination des activités de Services placés sous son autorité557. Elle comprend cinq directions dont celle de la navigation, de la sécurité et de la garde côtière, de la sûreté, des affaires portuaires et du domaine. Ces directions jouent un rôle important en matière de police maritime, de sauvetage et surveillance du territoire maritime de la Côte d'Ivoire $»^{558}$.

375- A notre sens, les difficultés liées à la répression des infractions maritimes sont de deux ordres. Les unes se manifestent par une application non

\footnotetext{
${ }^{554}$ Loi n ${ }^{\circ}$ 2017-442 du 30 juin 2017 portant Code maritime, art. 1091 : "L'autorité maritime administrative peut immobiliser tout navire qui ne se conforme pas aux prescriptions des dispositions des conventions internationales en vigueur".

555 Code maritime ivoirien, art. 1096: "Est puni des amendes prévues au code de l'environnement, tout armateur, propriétaire ou capitaine de navire qui enfreint les prescriptions des dispositions en vigueur en matière de pollution marine et d'immersion des déchets en mer ". ${ }^{556}$ Loi n 2017-442 du 30 juin 2017 portant Code maritime, art. 1114: "Les dispositions antérieures contraires à la présente loi sont abrogées, notamment celles de la loi 61-349 du 09 novembre 1961 relative à l'institution d'un code de la marine marchande ».

${ }^{557}$ Décret n 2011-401 du 16/10/2011 portant organisation du Ministère des Transports, art. 1.

558 Voir Organisation et fonctionnement du ministère des transports. https//fr.wipedia.Org/wiki/marine nationale (cote d'ivoire).
} 
effective des instruments internationaux (A) et les autres par la faiblesse de l'équipement de la DGAMP en matériels de surveillance maritime (B).

\section{A- Une application non effective des instruments internationaux}

376- L'action de la DGAMP concerne notamment l'élaboration de la règlementation et la production des titres de sécurité et de sûreté559. Au plan international, la DGAMP participe à la coordination des actions de coopération maritime, à la gestion des accords maritimes bilatéraux et multilatéraux ${ }^{560}$ et à la coopération avec un certain nombre d'organisations maritimes représentées en Côte d'Ivoire ${ }^{561}$. Les activités de la Direction des Affaires Maritimes et Portuaires en la matière ont trait à la gestion administrative des gens de mer en ce qui concerne le recrutement, la formation, la délivrance de brevets et le suivi de carrière.

377- Par ailleurs, plusieurs objectifs ont été assignés à la Direction Générale des Affaires Maritimes et Portuaires. Il s'agit de la promotion du développement des activités de transport maritime, de consignation et de manutention portuaires. La DGAMP assure la sécurité de la navigation maritime; veille à l'application des normes de sûreté des navires, des installations portuaires et des plates-formes off-shore; coordonne et met en œuvre les activités de garde côtière au niveau régional; assure la police balnéaire ${ }^{562}$. S'agissant du troisième objectif qui consiste à veiller à l'application des normes de sureté des navires, encore faut-il préciser que ces normes sont

\footnotetext{
559 Voir la Résolution $n^{\circ}$ 4/2004/CM/UEMOA du 28/03/2008 relative à la sécurité et à la sûreté maritimes au sein de l'UEMOA; le Décret n 2011-401 du 16 novembre 2011 portant organisation du Ministère des Transports, art. 24 ; l'Arrêté n06/MINIMAR/CAB/SGM/DNAMN du 04 mai 1982, relative à la sécurité des plates-formes de forage et autres installations offshore ; l'Arrêté $n^{\circ}$ 46/MEMT/DGAMP du 14 mars 2005 portant organisation et attributions de la Direction Générale des Affaires Maritimes et Portuaires, arts. 8 à 12 et 15 .

560 Décret $n^{\circ}$ 2011-401 du 16 novembre 2011 portant organisation du Ministère des Transports art. 26 ; voir aussi l'arrêté $n^{\circ}$ 46/MEMT/DGAMP du 14 mars 2005 portant organisation et attributions de la Direction Générale des Affaires Maritimes et Portuaires, art. 16.

561 Il s'agit de l'Organisation Maritime Internationale (OMI) ; l'Organisation Maritime de l'Afrique de l'Ouest et du Centre (OMAOC) ; l'Académie Régionale des Sciences et Techniques de la Mer d'Abidjan (ARSTM) ; le Centre de coordination régionale de la Garde-côte de la zone II ; le Centre de coordination Régionale secondaire de recherche et de sauvetage.

562 Voir http://www.affmar.ci/motdg.php.
} 
celles prévues par les conventions internationales sur la sécurité des transports maritimes. Toutefois, la question se pose de savoir quelle est la capacité de la DGAMP à assurer efficacement l'application des normes relatives à la sécurité maritime.

378- Il apparaît que deux obstacles se dressent à l'application des normes de sécurité et de sûreté de la navigation maritime. D'abord, nous l'avons indiqué plus haut, certaines conventions internationales relatives à la sûreté des navires ne sont pas encore ratifiées par l'Etat ivoirien ${ }^{563}$. Dans ces conditions la DGAMP ne peut pas appliquer les normes de sécurité et de sûreté prévues par ces conventions.

379- Le deuxième obstacle se situe au niveau structurel et fonctionnel. La DGAMP présente une lacune à savoir le défaut d'organe de suivi et de contrôle de l'application des normes de sûreté maritime prévues par les conventions internationales et les lois nationales. A cela s'ajoute un dysfonctionnement dû au cloisonnement des différentes structures de l'Etat qui interviennent dans l'activité portuaire. Ainsi, dans l'affaire du déversement des déchets toxiques dans la ville d'Abidjan en Côte d'Ivoire dans la nuit du 19 au 20 août 2006, Priscille De Bonté Poeri a pu relever un dysfonctionnement résultant du défaut de communication inter structurelle ${ }^{564}$. Ce constat de l'auteur met en lumière les difficultés de la mise en œuvre du droit international à travers le droit national au regard du cadre législatif et institutionnel ivoirien. Dans ces

\footnotetext{
${ }^{563}$ Voir supra $\mathrm{n}^{\circ} 358, \mathrm{p} 164$.

${ }^{564} \mathrm{Cf}$ : DE BONTE POERI (Priscille), Les lacunes du droit relatif au mouvement transfrontière des déchets dangereux : illustration à l'aide de l'affaire Probo Koala en Côte d'Ivoire. Mémoire, Université de Montréal, juin 2015, p. 136. Selon l'auteur, ce dysfonctionnement est dû au cloisonnement des structures ayant chacune ses propres normes, surtout pour ce qui concerne les institutions. À ce niveau, il faut remarquer qu'il n'existe aucune interactivité entre les textes règlementaires, de sorte que chaque institution agit séparément. En outre, en dépit de la multiplicité des structures publiques et privées, il n'existe aucune structure chargée d'identifier l'importation illicite des déchets dangereux, mais aussi capable de différencier ces déchets des marchandises. Ce problème pose la question de formation technique et juridique des agents portuaires sur la notion de mouvements transfrontières des déchets dangereux. Ces difficultés sont la résultante des lacunes systémiques de ce cadre législatif et institutionnel qu'on observe à profusion dans l'affaire Probo koala.
} 
conditions il est assez difficile d'apprécier l'effectivité de l'application des normes prévues pour lutter contre l’insécurité maritime.

380- Au-delà de l'inapplication de certaines conventions internationales de lutte contre l'insécurité maritime, une question reste à clarifier, celle de savoir si la DGAMP est dotée d'un équipement adéquat capable de répondre à sa mission générale de répression des infractions maritimes et de garde-côtes.

\section{B- Une inefficacité liée au sous équipement en matériels de surveillance maritime et de garde-côte}

381- Un auteur a pu constater que l'opérationnalisation des engagements pris au niveau politique, entre les organismes et entre les États, pour combattre la piraterie et les actes criminels connexes dans le golfe de Guinée dépendra de l'établissement de capacités robustes de surveillance, d'intervention et de répression ${ }^{565}$. Dans cette optique le Ghana, le Nigéria et le Sénégal ont amélioré leurs moyens de surveillance des côtes avec l'aide de partenaires tels que les États-Unis et l'Union Européenne. Malheureusement, de nombreux pays de la sous-région dont la Côte d'Ivoire, en raison de leur sous équipement en moyens d'intervention, éprouvent encore des difficultés à détecter les navires. Ils ne disposent pas de système d'identification automatique (AIS). De même, la faiblesse des capacités locales de maintenance pour faciliter les communications et les patrouilles posent des problèmes pour de nombreux pays de la sous-région du golfe de Guinée ${ }^{566}$.

382- A propos de la marine nationale ivoirienne, Monsieur Serge-Nicolas N'ZI indiquait que la Côte d'Ivoire s'étend sur $515 \mathrm{~km}$ de côte maritime à surveiller entre le Ghana et le Libéria. Cependant, de quels moyens peut-elle

\footnotetext{
565 ADENIYI ADEJIMI, (Osinowo), "La lutte contre la piraterie dans le golfe de guinée ", Bulletin de la sécurité africaine ${ }^{\circ}$ 32, Centre d'Etudes Stratégiques de l'Afrique, 19 avril 2017, pp. 10 et s. in https://africacenter.org/fr/publication/lutte-contre-piraterie-golfe-guinee/.

566 VOGEL (Augustus), «Relever les défis de la sécurité maritime en Afrique grâce aux investissements en science et technologies», Bulletin de la sécurité africaine, No 10 (Washington, DC: National Defense University Press, février 2011), In ADENIYI ADEJIMI (Osinowo), «La lutte contre la piraterie dans le golfe de guinée ", Bulletin de la sécurité africaine $n^{\circ} 32$, Centre d'Etudes Stratégiques de l'Afrique, 19 avril 2017, p. 10.
} 
disposer ? L'auteur nous apprend que le pays ne dispose que de trois patrouilleurs, deux vedettes de protection de pêche, un bâtiment de débarquement sur plage, un chaland de transport de matériel avec un total d'environ 200 hommes à la base navale de LOCODJORO et à la base annexe de la marine ivoirienne dans la commune de Plateau ${ }^{567}$. En outre, il note la vétusté de ce matériel acheté par la Côte d'Ivoire dans les années 1970 (il y a 50 ans) dans le cadre de la coopération de la France avec ses ex-colonies en matière de défense et de sécurité.

383- Au regard de ce qui précède, la Côte d'Ivoire fait partie des pays du Golfe de Guinée dont le faible niveau d'équipement en matériels d'intervention rapide ne permet pas de lutter efficacement contre la piraterie et la criminalité maritimes. C'est également l'avis de certains responsables de la Direction Générale des Affaires Maritimes et Portuaires, chargés de la sécurité maritime, dans un entretien qu'ils nous ont accordé. Cependant, nous continuons de nous interroger sur le point de savoir si en la matière il existe des progrès en ce qui concerne les normes sous régionales.

\section{$\S 2$ : Cas des normes à caractère sous régional}

384- Il existe dans l'espace sous régional ouest africain, l'Organisation Maritime de l'Afrique de l'Ouest et du Centre (OMAOC). Elle regroupe les Etats côtiers situés sur la façade atlantique de l'Afrique ${ }^{568}$. A l'origine l'OMAOC était une simple association de gestion des ports de l'Afrique de l'Ouest et du Centre qui regroupait les ports des Etats précédemment visés. Mais eu égard à la nécessité de coopération en vue du développement des ports de la sous-région et aux besoins de sécurité de la navigation maritime, l'association s'est muée en organisation intergouvernementale dénommée OMAOC ${ }^{569}$. Quelles sont les

\footnotetext{
${ }^{567}$ NZI (Serge-Nicolas), « La Côte d'Ivoire face à la piraterie maritime », Lugano (Suisse), février 2013, p. 2, https://www.connectionivoirienne.net/82215/ Consulté en janvier 2016. 568 En effet, l'OMAOC compte 25 Etats membres dont 20 pays de la façade maritime de la Mauritanie à l'Angola et 5 pays sans littoral, à savoir la Centrafrique, le Burkina-Faso, le Mali, le Niger et le Tchad.

569 Voir www.adiac-congo.com/content/marine-marchande, Consulté en mars 2015. Marine marchande : l'OMAOC à la recherche de solutions en vue de remettre en lice l'Institution, p. 2.
} 
moyens juridiques de lutte contre la piraterie et la criminalité maritime dont elle est dotée et quelle est leur efficacité ?

385- Il convient d'examiner l'inefficacité des normes relatives à la répression des infractions maritimes à travers des limites opérationnelles auxquelles est confrontée l'OMAOC (A) dans sa stratégie de lutte contre la piraterie maritime. En outre, il est des obstacles liés à la répression de la piraterie. Ceux-ci se manifestent par le contraste entre le droit du pavillon de l'Etat et la compétence universelle des Etats (B).

\section{A- Les limites liées à la lutte opérationnelles de l'OMAOC}

386- Le golfe de Guinée connaît des difficultés propres à son espace continental qui rendent inefficace la répression de la criminalité et la piraterie en mer570. Les limites liées à la lutte opérationnelle de l'OMAOC découlent des insuffisances des moyens d'action de l'organisation (1). A notre sens, ces insuffisances contrastent avec les objectifs assignés à cette organisation sous régionale (2).

\footnotetext{
"Fille de la Conférence ministérielle des Etats de l'Afrique de l'ouest et du centre sur les transports maritimes (CEMAOC/TM), créée le 7 mai et basée à Abidjan (Côte-d'Ivoire), l'OMAOC (née le 6 août 1999) a pour but d'harmoniser les politiques et stratégies des Etats membres dans le domaine du transport maritime, des ports, de la sécurité de la navigation maritime et la protection de l'environnement marin".

570 Voir ADENIYI ADEJIMI (Osinowo), La lutte contre la piraterie dans le golfe de guinée, p. 9. Bulletin de la sécurité africaine $\mathrm{N}^{\circ} 32,19$ avril 2017, p.3. Centre d'Etudes Stratégiques de l'Afrique. In https://africacenter.org/fr/publication/lutte-contre-piraterie-golfe-guinee/. Pour l'auteur, bien que le golfe de Guinée soit idéal pour le transport maritime et la pêche, la facilité avec laquelle les voleurs peuvent disparaître le long des côtes après une attaque met en évidence un aspect moins favorable de la région : les limites de la surveillance, de la collecte de renseignements et de la police communautaire dans les zones littorales. En particulier, les conditions politiques et socioéconomiques dans les pays mêmes, surtout l'armée grandissante de jeunes chômeurs, sont des moteurs de la piraterie dans la région. Dans le delta du Niger, par exemple, le programme d'amnistie offert par le gouvernement aux anciens militants en 2009 a entraîné une réduction immédiate des attaques de navires. Leur résurgence en 2013 a été attribuée en partie aux difficultés du maintien de l'offre d'opportunités d'emploi rémunéré aux jeunes de plus en plus nombreux de cette région. Il incombe également aux autorités gouvernementales de mener des actions plus efficaces de répression des réseaux de pirates à terre.
} 


\section{1- L'insuffisance des moyens d'actions de l'OMAOC}

387- Une réunion de concertation s'est tenue du 27 au 28 février à Kinshasa, en République Démocratique du Congo. Celle-ci avait comme objectif la recherche des voies et moyens pour insuffler une dynamique nouvelle à l'organisation commune. Et ce, eu égard au constat des difficultés qu'elle éprouve à mettre en œuvre ses programmes. En effet, selon l'état des lieux fait, cet organisme traverse une situation très délicate qui gangrène, depuis quelque temps, ses ambitions. Ces difficultés peuvent avoir plusieurs raisons parmi lesquelles: des problèmes de contributions financières statutaires des Etats membres qui ont mis la trésorerie de l'organisation dans une situation critique. Cela a eu un impact négatif sur la réalisation de ses projets et programmes ${ }^{571}$. L'OMAOC est donc à la recherche des voies et moyens capables de redresser sa situation financière.

388- Cette situation a impacté gravement la mise en œuvre de plusieurs projets de l'OMAOC. En effet, les dispositions prises pour intégrer les activités de surveillance maritime et améliorer la collecte de l'information buttent sur l'insuffisance d'équipements et l'absence d'un système de financement à long terme visant à renforcer la sécurité maritime ${ }^{572}$. Nombreux sont les d'États membres de la Communauté des Etats de l'Afrique de l'Ouest (CEDEAO) et de la Communauté des Etats de l'Afrique Centrale (CEEAC) qui doivent encore prendre des mesures pour ériger en infraction les actes de piraterie et mettre en place des institutions judiciaires chargées de leur répression. Ceux-ci doivent également assurer la formation du personnel de la sécurité maritime ${ }^{573}$. En outre, la CEDEAO doit chercher à se doter d'un centre commun de coordination, sur le modèle européen du centre d'analyse et de surveillance maritime, afin d'améliorer sa capacité à collecter et à diffuser les données sur la sécurité

\footnotetext{
571 Voir https://www.adiac-congo.com/content/, Consulté en mars 2015. Marine marchande : l'OMAOC à la recherche de solutions en vue de remettre en lice l'institution, p. 1.

572 Voir LUNTUMBUE (Michel), "Insécurité maritime dans le golfe de Guinée : vers une stratégie régionale intégrée ?" Groupe de Recherche et d'Information sur la Paix et la sécurité (GRIP), décembre 2012, p. 11, http://www.grip.org/fr/node778.

${ }^{573}$ Idem LUNTUMBUE (Michel), "Insécurité maritime dans le golfe de Guinée : vers une stratégie régionale intégrée ?» GRIP Décembre 2012, op. cit., p. 11.
} 
maritime en Afrique de l'Ouest. Au total, le manque de financement des programmes et projets de l'OMAOC semble ne pas garantir la continuité et la durabilité de ses actions qui visent essentiellement la sécurité maritime dans le golfe de Guinée.

\section{2- Les objectifs assignés à l'OMAOC}

389- Des objectifs précis ont été assignés à l'OMAOC à divers niveaux. Il y a l'objectif de rentabilité des services de transport maritime et de transit, celui de la circulation de l'information, l'objectif de l'appui financier aux projets et programmes etc. Toutefois, notre intérêt porte sur les objectifs relatifs à la sûreté maritime, à la sécurité et à la protection de l'environnement. Ces objectifs ont été définis comme il suit :

- " le développement des capacités de l'Etat du pavillon et de l'Etat du Port pour le contrôle des navires en Afrique de l'Ouest et du Centre effectué en collaboration avec l'OMI;

- un réseau sous régional intégré de Garde-côtes capable de mettre en œuvre les conventions de l'OMI visant à assurer la sécurité des navires, des passagers et des marchandises dans les eaux territoriales de la sous-région contre la piraterie, les vols à main armée et autres actes illicites /terroristes à l'encontre du commerce maritime de même que contre la pollution marine et l'exploitation illégale des ressources des Etats membres de l'Organisation ;

- la mise en œuvre du Code International sur la Sûreté des navires et des Installations portuaires (Code ISPS); l'entretien et le renforcement de la coopération entre les académies maritimes de la sous-région etc. » ${ }^{574}$.

390- Malgré ces objectifs stratégiques poursuivis, l’insécurité continue de régner dans le golfe de Guinée que l'organisation intergouvernementale est censée protéger. En clair l'OMAOC rencontre des difficultés dans 
l'accomplissement de sa mission. Les moyens dont elle dispose semblent en constituer un facteur favorisant.

391- Enfin, au titre des causes de l’inefficacité des normes relatives à la répression des infractions maritimes en Côte d'Ivoire, semble figurer le contraste entre les droits de l'Etat du pavillon et la compétence universelle des Etats en matière de répression de la piraterie maritime.

\section{B- Droit du pavillon et compétence universelle, face à la répression de la piraterie}

392- Le droit du pavillon et la compétence universelle des Etats sont prévues respectivement par les articles 92 et 105 de la Convention de Montego Bay de 1982. En haute mer s'exerce la liberté de navigation dans les conditions prévues par les dispositions de la Convention et les autres règles du droit international. En outre la résolution 1816 des Nations Unies prévoit la coopération judiciaire ${ }^{575}$. Mais cette liberté de la haute mer est contrebalancée par l'obligation de coopérer à la répression de la piraterie. En effet, tous les Etats coopèrent dans toute la mesure du possible à la répression de la piraterie en haute mer ou en tout autre lieu ne relevant de la juridiction d'aucun Etat ${ }^{576}$. Par ailleurs, les navires naviguent sous le pavillon d'un seul Etat et sont soumis, sauf dans les cas exceptionnels expressément prévus par des traités internationaux ou par la Convention, à sa juridiction exclusive en haute mer ${ }^{577}$. Il s'ensuit qu'en matière de répression de la piraterie maritime, existe un

\footnotetext{
575 En effet, le paragraphe 11 de la Résolution 1816 des Nations Unies prévoit une large coopération judiciaire qui doit être mise en place pour permettre le jugement des auteurs d'actes de piraterie ou de vols à main armée en mer. Sont notamment visés les Etats du pavillon, les Etats des ports, les Etats côtiers, les Etats des auteurs ou des victimes d'actes de piraterie et enfin les Etats «tirant juridiction du droit international ou du droit interne».

576 Convention de Montego Bay, art 100.

577 Convention de Montego Bay, aux termes de l'article 92, les navires naviguent sous le pavillon d'un seul Etat et sont soumis à sa juridiction exclusive en haute mer. Aucun changement de pavillon ne peut intervenir au cours d'un voyage ou d'une escale, sauf en cas de transfert réel de la propriété ou de changement d'immatriculation. Lorsqu'un navire navigue sous les pavillons de plusieurs Etats, dont il fait usage à sa convenance, il ne peut se prévaloir, vis-à-vis de tout Etat tiers, d'aucune de ces nationalités. En conséquence il est assimilé à un navire sans nationalité.
} 
principe, celui de la compétence universelle (1) qui au demeurant contraste avec le droit du pavillon (2).

\section{1- Le principe de la compétence universelle en matière de piraterie}

393- La compétence universelle est apparue avec la piraterie maritime ${ }^{578}$. En l'absence de juridiction internationale compétente pour juger les actes de piraterie maritime, la répression incombe, conformément aux dispositions de la Convention de Montego Bay579, aux tribunaux nationaux. C'est pourquoi, la latitude est donnée à tout Etat, en haute mer ou en tout autre lieu ne relevant de la juridiction d'aucun Etat, de saisir un navire pirate, ou un navire capturé à la suite d'un acte de piraterie et aux mains de pirates, et d'appréhender les personnes et saisir les biens se trouvant à bord. Les tribunaux de l'Etat qui a opéré la saisie peuvent se prononcer sur les peines à infliger, ainsi que sur les mesures à prendre en ce qui concerne le navire ou les biens, réserve faite des tiers de bonne foi. Cette disposition recommande les navires publics autorisés de tout Etat à contrôler, visiter, arraisonner les navires suspects et capturer les pirates présumés, qui pourront être poursuivis devant les tribunaux de l'Etat qui a opéré la saisie ${ }^{580}$.

394- Toutefois, selon Monsieur Jean-Christophe Martin cette compétence universelle reconnue aux Etats en matière de piraterie maritime est facultative car le droit international ne fait pas obligation aux Etats de poursuivre les personnes suspectées de piraterie ni même d'adopter une législation nationale portant incrimination de la piraterie et étendant la compétence des tribunaux

\footnotetext{
578 Voir Revue international de droit pénal, $1^{\text {er }}$ et $2^{\text {ème }}$ trimestre 2008, p. 148. La compétence universelle est définie comme un "Titre complémentaire de compétence sur les crimes qui, commis à l'étranger, ne sont pas couverts par un autre titre de compétence à disposition de l'Etat". Cette définition est inspirée du projet de résolution soumis en 2007 à l'Association internationale de droit pénal. Selon le Dictionnaire de Droit International Public, "La compétence universelle est l'aptitude reconnue aux tribunaux de juger des faits commis à l'étranger quels que soient le lieu de l'infraction et la nationalité de l'auteur ou de la victime (...)». Cf : SALMON (J) et BRUYLANT (D), Dictionnaire de Droit International Public AUF, Bruxelles 2001, p. 212. 579 Voir Convention de Montego Bay, art. 105.

580 MARTIN (Jean-Christophe), "La répression des actes de piraterie maritime : développements de poursuites et détention des pirates somaliens ", Annuaire Français de Droit International, Editions CNRS, Paris LV1 2010, pp. 502 et s.
} 
internes ${ }^{581}$. A ce titre, la compétence universelle ne constitue pas une obligation pour les Etats. En outre, conformément au droit du pavillon ${ }^{582}$, les navires naviguent sous le pavillon d'un seul Etat et sont soumis, sauf dans les cas exceptionnels expressément prévus par des traités internationaux ou par la Convention, à sa juridiction exclusive en haute mer. Aucun changement de pavillon ne peut intervenir au cours d'un voyage ou d'une escale, sauf en cas de transfert réel de la propriété ou de changement d'immatriculation. Cette disposition soumet tout navire navigant en haute mer, ou en tout autre lieu ne relevant de la juridiction d'aucun Etat, à la juridiction exclusive de l'Etat du pavillon et empêche la manifestation de l'autorité de tout autre Etat ${ }^{583}$. Dès lors, la question se pose de savoir si le principe de la compétence universelle reconnue aux Etats en matière de piraterie maritime ne contredit pas celui de la juridiction exclusive attribuée à l'Etat du pavillon du navire en haute mer.

\section{2- Compétence universelle et droit du pavillon : promotion et frein à la poursuite des pirates}

395- La compétence universelle des Etats en matière de piraterie renferme l'obligation de coopérer à la répression de la piraterie prévue par la Convention de Montego Bay. Tous les Etats coopèrent dans toute la mesure du possible à la répression de la piraterie en haute mer ou en tout autre lieu ne relevant de la juridiction d'aucun Etat. L'article 100 contraint tout Etat, ayant suspecté un navire de piraterie, à le contrôler, le visiter, l'arraisonner et au besoin appréhender les pirates présumés et saisir les biens se trouvant à bord. A ce stade du début de la répression, les droits exclusifs de l'Etat du pavillon

581 Cf: MARTIN (Jean-Christophe), «La répression des actes de piraterie maritime : développements de poursuites et détention des pirates somaliens », op. cit., p. 503.

582 Voir Convention de Montego Bay, art. 92. Aux termes des dispositions de cet article, l'unicité de pavillon est exigée aux navires.

583 Voir BOUDONG (Nathalie), La piraterie maritime moderne, Mémoire, UNIVERSITE PAUL CEZANNE III. Droit maritime et des transports, Année universitaire 2008/2009, p. 20. Selon l'auteur, les eaux internationales, dans lesquelles par principe, le navire pirate ne devrait être soumis qu'aux autorités de l'Etat dont il bat pavillon, empêchent la manifestation d'une autorité autre que celle du pavillon sur le navire croisant en haute mer. L'intérêt de contourner ce principe provient du fait que les navires pirates n'ont pas toujours de pavillon, et lorsque c'est le cas, le pavillon est un pavillon de complaisance (flag of convenience), ou pavillon en libre immatriculation : (flag of open registry). Cette situation laisse deviner que l'Etat dont bat pavillon le navire pirate n'interviendra pas en cas d'acte malveillant. 
sont préservés car son absence justifie l'obligation de tout autre Etat d'appréhender les présumés pirates.

396- La difficulté de la répression survient à partir du moment où les présumés pirates appréhendés sont étrangers ou que le navire saisi bat pavillon d'un autre Etat. Dans ces conditions, la répression devient complexe en raison $\mathrm{du}$ fait que la compétence universelle entre en concours avec le droit de juridiction de l'Etat du pavillon car l'Etat qui a interpellé les pirates est tenu de donner une suite judiciaire ${ }^{584}$. On dit souvent qu'en vertu du principe de compétence universelle à l'égard de la piraterie, les juridictions de tous les Etats peuvent être compétentes, pour peu que leurs droits internes le prévoient 585 . Mais la réalité est toute autre comme précise Jean-Marc Thouvenin : "Ce n'est pas ce qu’indique l'article 105 de la Convention de Montego Bay. Elle ne dit pas que tout Etat peut juger des pirates, mais que les tribunaux de l'Etat qui a opéré la saisie peuvent les juger. Cela dit, il est clair que le droit coutumier reconnaît cette compétence juridictionnelle universelle à tous les Etats. Du reste, de nos jours, la difficulté ne réside pas dans un excès de revendications de compétences universelles à l'égard des pirates, mais dans leur raréfaction. Ceci résulte sans doute d'une part d'un clair souhait des Etats de ne pas exercer une telle compétence, ou encore, et assez souvent, d'un défaut de compétence des juridictions internes $» 586$.

584 Voir BRONER (Romain), La répression de la piraterie maritime et ses enjeux juridiques. Mémoire de Master de Recherche, Sécurité et Défense, Université Panthéon-Assas-paris II, Année universitaire 2009/2010, op. cit., pp. 81 et 82. Selon l'auteur, par suite judiciaire à l'interpellation, on entend tous les actes de procédure qui permettront de déterminer la culpabilité ou l'innocence des personnes transférées, les conditions du transfert, ainsi que les éventuelles conséquences pénales d'un procès. Sont donc inclus : l'instruction du dossier, la garde à vue et la détention provisoire, le déroulement du procès, et l'exécution de la peine éventuelle. La solution la plus adaptée serait la mise en place d'une juridiction spécialisée, quel que soit son niveau. Cependant, en l'état actuel des choses, c'est le traitement judiciaire par un État qui prévaut.

585 THOUVENIN (Jean-Marc), "Piraterie maritime : quel droit, pour quelle juridiction ", Notes de cours, 2012-2013, p. 7, http://lewebpedagogique.com/jmthouvenin/.

586 THOUVENIN (Jean-Marc), " Piraterie maritime : quel droit, pour quelle juridiction ", Notes de cours, op. cit., p. 7. 
397- La question du droit applicable soulève également des difficultés ${ }^{587}$. Faut-il appliquer le droit international ou les droits internes ? D’abord, au niveau du droit international il y a deux principales conventions qui répriment la piraterie à savoir la Convention de Montego Bay de 1982 et la Convention de Rome de 1988. Mais cette dernière convention n'est pas applicable en Côte d'Ivoire car non ratifiée par l'Etat ivoirien. Quant-à la Convention de Montego Bay, à travers son article 105, elle déroge au principe de la compétence de l'Etat du pavillon en haute mer et habilite tout Etat « [à], en haute mer ou en tout autre lieu ne relevant de la juridiction d'aucun Etat, saisir un navire pirate ou capturé par des pirates, et appréhender les personnes et saisir les biens se trouvant à bord». Mais au regard de l'article 104588, les pirates ainsi appréhendés conservent leur nationalité.

398- Toutefois, conformément à l'article 105 de la Convention de Montego Bay « Les tribunaux de l'Etat qui a opéré la saisie peuvent se prononcer sur les peines à infliger, ainsi que sur les mesures à prendre en ce qui concerne le navire, l'aéronef ou les biens, réserve faite des tiers de bonne foi». La question se pose alors de savoir sur la base de quel instrument juridique les tribunaux de l'Etat ayant appréhendé les présumés pirates doivent-ils s'appuyer pour se prononcer sur les peines à leur infliger. Le droit international ou la législation interne?

399- La piraterie est définie par l'article 101 de la $\mathrm{CMB}^{589}$. Mais, cette disposition n'érige pas en infraction pénale l'acte de piraterie ainsi défini en ce

${ }^{587}$ THOUVENIN (Jean-Marc), " Piraterie maritime : quel droit, pour quelle juridiction », Notes de cours 2012-2013, op. cit.. p. 4. http://lewebpedagogique.com/jmthouvenin/ . Selon l'auteur, certes, parmi les personnes poursuivies, certaines ont été lourdement condamnées. Mais le ratio de condamnations reste faible. La question qui se pose alors est de savoir comment faire en sorte que les pirates capturés soient effectivement jugés. Ceci soulève deux questions : pour garantir que les pirates soient réellement poursuivis, sur quel droit faut-il compter, et sur quelles juridictions?

588 Voir Convention de Montego Bay, art. 104 «Conservation ou perte de la nationalité d'un navire ou d'un aéronef pirate. Un navire ou aéronef devenu pirate peut conserver sa nationalité. La conservation ou la perte de la nationalité est régie par le droit interne de l'Etat qui l'a conférée».

589 Convention de Montego Bay, art. 101: "La piraterie est un acte illicite de violence, ou de détention, ou de déprédation, commis à des fins privées par l'équipage ou des passagers d'un navire privé, dirigé contre un autre navire ou contre des personnes à bord d'un autre navire, en haute mer ou dans un lieu ne relevant de la juridiction d'aucun Etat". 
sens qu'il ne prévoit aucune peine pour le sanctionner. Par ailleurs, selon l'arrêt du 3 juin 2008 rendu par la Cour de Justice de la Communauté Européenne (CJCE) dans l'affaire Intertanko : " la convention de Montego Bay ne met pas en place des règles destinées à s'appliquer directement et immédiatement aux particuliers et à conférer à ces derniers des droits ou des libertés susceptibles d'être invoqués à l'encontre des États, indépendamment de l'attitude de l'État du pavillon du navire ${ }^{590}$. Eu égard à cette jurisprudence, nous disons que les dispositions de la Convention de Montego Bay sont certes indispensables pour la lutte contre la piraterie en permettant à tout Etat d'appréhender des personnes suspectées de piraterie, mais elles ne suffisent pas à les réprimer en Côte d'Ivoire. A cette difficulté, il faut ajouter l'admission difficile, par les juridictions, de la preuve de la piraterie contre les suspects ${ }^{591}$. Les dispositions de la Convention de Montego Bay doivent donc être assorties d'une législation nationale appropriée ${ }^{592}$.

590 Voir Cour de Justice de la Communauté Européenne (CJCE), arrêt du 3 juin 2008, Intertanko. 591 Voir LE GOFF (Roland), La protection des navires soumis au risque de piraterie. Enseignements tirés de l'épisode de piraterie somalienne (2006 à 2013), Thèse de Droit public, Université de Nantes, décembre 2016, p. 282. L'auteur montre que dans le cas d'une attaque déjà prononcée ou en cours, la collecte des témoignages de marins sera essentielle. Dans le cas d'une intention de piraterie, le problème est d'une autre nature, probablement plus complexe, ... Certains outils sont communs en pareils cas, mais leur présence n'atteste pas toujours d'une volonté criminelle. Ainsi, la détention d'une arme en mer n'est pas en soi répréhensible, et elle est même assez commune dans certaines parties du monde. En océan Indien et en mer Rouge, il arrive parfois que les pêcheurs soient armés, voire qu'ils emploient leurs armes pour attirer l'attention des navires de commerce qui se dirigent vers leurs filets de pêche afin de les inciter à changer de cap. Dans ces conditions, comment établir avec certitude la volonté d'un équipage de se livrer à la piraterie ? L'absence de réponse claire à cette question a conduit de nombreuses marines à relâcher un nombre important de suspects de piraterie plutôt que de risquer un transfert en vue d'un procès à l'issue aléatoire, compte tenu de la maigreur des preuves. Les pirates somaliens étaient parfois des pêcheurs devenus opportunistes face à la proie facile qui se présentait à eux. Face à cette difficulté, plutôt qu'un jugement à l'issue incertaine et coûteuse en temps et en ressources, les forces chargées de la lutte contre la piraterie ont souvent privilégié une forme de justice expéditive visant à détruire les moyens susceptibles de permettre l'entreprise de piraterie, dès lors que le commandant de l'unité au contact avait acquis l'intime conviction de sa réalité.

592 Voir dans ce sens BRONER (Romain), La répression de la piraterie maritime et ses enjeux juridiques. Mémoire de Master Recherche, Sécurité et Défense, Université Panthéon-Assasparis II, Année universitaire 2009/ 2010, op. cit., p. 62. "Si la décision d'une répression juridique de la piraterie est prise, certaines garanties procédurales doivent être respectées. Le droit interne doit donc être adapté à l'emploi de moyens militaires en opération de police, et aux contingences qui en découlent. Pour que le processus répressif de la piraterie soit mené à son terme, il peut être 
400- Comme l'a si bien indiqué le Professeur Jean-Marc Thouvenin, « ... pour connaître le droit applicable à la piraterie, il faut se tourner vers les droits internes, chacun d'entre eux, pour y trouver, éventuellement, des outils de répression de la piraterie. Les droits internes ne sont pas tous enclins à les prévoir. Ils sont assez prompts à permettre la répression des actes commis dans leurs eaux territoriales ou, en haute mer, à l'égard des navires battant leur pavillon, ou encore à l'endroit de leurs ressortissants. Mais ils établissent plus rarement une incrimination, et des peines, pour les crimes de piraterie ${ }^{593}$. Ainsi, lorsque des pirates sont appréhendés en haute mer ou dans une zone soumise à aucune juridiction étatique, la Côte d'Ivoire a la possibilité de les juger ou de les remettre à l'Etat du pavillon. En effet, l'application d'un code de la marine marchande inadapté aux défis actuels de la criminalité maritime organisée et de la piraterie a constitué un frein à la répression des actes illicites contre la sécurité de la navigation maritime.

401- En matière de répression de la piraterie, la partie VII de la Convention de Montego Bay n'est pas d'application directe dans les Etats ${ }^{594}$. A

nécessaire de passer par la répression judiciaire, qui permet une incarcération et une peine. Pour cela, le recours aux Etats est absolument inévitable, les prérogatives pénales étant, de nature, régaliennes. Il faut donc déterminer une interface pénale efficace au niveau international, qui découle sur un traitement national efficace de la piraterie ».

593 THOUVENIN (Jean-Marc), " Piraterie maritime : quel droit, pour quelle juridiction », Notes de cours 2012-2013, op. cit., p. 5, http://lewebpedagogique.com/jmthouvenin/.

594 Voir BRONER (Romain), La répression de la piraterie maritime et ses enjeux juridiques. Mémoire de Master de Recherche, Sécurité et Défense, Université Panthéon-Assas-paris II, Année universitaire 2009/ 2010, op. cit., pp. 64-65. Selon l'auteur, la convention de Montego Bay n'est pas directement applicable en droit interne en ce qui concerne la piraterie, et particulièrement sa définition prévue à l'article 101. De plus, la piraterie n'y est pas qualifiée juridiquement en tant qu'infraction. A la lecture de la convention de Montego Bay, il est impossible de savoir si la piraterie doit être considérée comme un crime, comme un délit, voire comme une simple contravention. Du fait de son imprécision, il semble donc difficile de donner à la convention un caractère d'invocabilité directe. Ce caractère d'applicabilité directe et d'invocabilité directe d'un traité international en droit interne suppose la réunion de plusieurs conditions. Il faut qu'il crée des droits subjectifs dont les particuliers puissent se prévaloir, mais aussi que les dispositions concernées du traité soient suffisamment claires et précises pour ne pas nécessiter une transcription en droit interne. Ce caractère d'applicabilité directe a surtout été reconnu pour les conventions qui concernent la protection des droits de l'Homme, ou encore les conventions d'extradition entre différents Etats. En ce qui concerne la piraterie, la simple mention d'un fait illicite, et de la compétence de l'État de saisie ne suffisent probablement pas à conférer un effet direct en droit interne, quel que soit l'État de jugement. Par conséquent, la 
propos d'instruments juridiques internes adéquats des Etats face aux actes de piraterie, le professeur Jean-Marc Thouvenin révèle que certains ordres internes sont tellement démunis à cet égard qu'ils forcent leurs autorités qui capturent des pirates à renoncer à envisager leur poursuite et à les relâcher immédiatement, faute à la fois de disposer des outils juridiques suffisants et de trouver un Etat acceptant de se charger de leur jugement ${ }^{595}$. Comme en témoigne la législation danoise ${ }^{596}$.

402- Il ressort de notre analyse que le concours de juridictions offert par la compétence universelle des Etats et les droits de l'Etat du pavillon favorisent la répression de la piraterie. En revanche, on peut noter qu'en général les Etats sont dépourvus d'outils internes efficaces pour la répression de la piraterie. Il est donc temps que les Etats situés sur la façade du golfe de Guinée, dont la Côte d'Ivoire ${ }^{597}$, se dotent d'instruments juridiques internes capables d'assurer une répression efficace de la piraterie et de la criminalité en mer. C'est le prix à payer pour résorber totalement ou à tout le moins réduire le fléau de la piraterie et la criminalité qui mine la navigation dans le golfe de Guinée.

\footnotetext{
lutte contre la piraterie est considérée comme une prérogative qui demeure optionnelle : un État peut tout à fait choisir de ne pas réprimer un acte de piraterie. Juridiction universelle ne signifie pas juridiction obligatoire.

595 THOUVENIN (Jean-Marc), "Piraterie maritime : quel droit, pour quelle juridiction ", Notes de cours op. cit., p. 5, http://lewebpedagogique.com/jmthouvenin/.

596 Voir BOUDONG (Melle Nathalie), La piraterie maritime moderne, Mémoire, UNIVERSITE PAUL CEZANNE III. Droit maritime et des transports, Année universitaire 2008/2009, p. 61. "En 2008, alors que la force navale danoise avait capturé des pirates au large de la Somalie, ils furent relâchés faute de ne pouvoir être jugés au vu d'une législation danoise ne prévoyant pas une répression adéquate".

597 En ce qui concerne la Côte d'Ivoire, le législateur vient de doter les transports maritimes d'une nouvelle législation avec des dispositions pertinentes en vue de la répression de la piraterie et la criminalité maritimes. Voir la Loi n 2017-442 du 30 juin 2017 portant code maritime, art. 987 à 990.
} 


\section{Conclusion du titre 2}

403- Ce second titre a pour objet de rechercher a posteriori, avec quelle efficacité, la législation du transport maritime protège la marchandise et lutte contre l'insécurité du transport maritime. Il a fallu une analyse critique de la législation supposée protéger les intérêts du transport maritime. Cette analyse s'est appuyée sur la doctrine et les faits à travers la jurisprudence. Il en ressort deux constats. D'une part, les normes de protection de la marchandise connaissent des limites et, d'autre part, la lutte contre l'insécurité maritime présente des insuffisances.

404- Au titre des limites des normes de protection de la marchandise, nous avons identifié les conséquences de la prise en charge de la marchande de "palan à palan "598, la limitation de la responsabilité du transporteur maritime 599 et le nombre pléthorique de cas exceptés ${ }^{600}$. L'article premier paragraphe e) des Règles de la Haye a institué le sectionnement juridique du contrat de transport qui supprime toute protection efficace de la marchandise pendant les phases non maritimes ${ }^{601}$.

405- S'agissant de la clause de livraison sous palan, nous avions indiqué qu'elle était par le passé incompatible avec le conteneur LCL. Toutefois, grâce au nouveau Code maritime ivoirien cette difficulté relative au conteneur de groupage a disparu dès lors que son article 708 prescrit une responsabilité présumée du transporteur depuis la réception de la marchandise à sa livraison en écartant la responsabilité de palan à palan. Aussi, grâce à la conteneurisation, le destinataire dispose désormais d'un délai long de huit jours,

\footnotetext{
598 Convention de Bruxelles de 1924, art. 1-e. La liberté contractuelle qui régit les phases dites non maritimes du contrat de transport ne semble pas protéger assez efficacement la marchandise.

599 Convention de Bruxelles, Protocole de 1968, art. 4-5-a. Le plafonnement modéré de la responsabilité du transporteur constitue une limite à la réparation complète du dommage subi par la marchandise.

${ }^{600}$ Convention de Bruxelles de 1924, art. 4-2.

${ }^{601}$ En ce sens que la présomption de la responsabilité du transporteur maritime, qui constitue une véritable garantie de la protection de la marchandise, ne couvre pas les phases non maritimes du contrat de transport.
} 
conformément à l'article 724 du Code maritime, pour adresser son avis de perte ou d'avarie au transporteur car les dommages subis par les marchandises mises en conteneurs sont réputées dommages non apparents602. Avec une conteneurisation de plus en plus généralisée on constate que le nouveau Code maritime ivoirien, en ayant prévu un délai relativement long pour adresser l'avis de perte ou d'avarie au transporteur en cas de dommage non apparent, renforce la protection de la marchandise mise en conteneur. Par ailleurs, le plafonnement modéré de la responsabilité du transporteur constitue une limite à la réparation complète des dommages subis par la marchandise. Enfin, l'analyse a montré que les cas exceptés exonèrent le transporteur de la présomption de responsabilité et par conséquent affaiblissent la protection de la marchandise ${ }^{603}$.

406- En ce qui concerne les insuffisances de la lutte contre l'insécurité maritime, certaines conventions internationales ${ }^{604}$ n'ont pas été ratifiées. En outre, le code ivoirien de la marine marchande ne répondait pas aux défis de la criminalité et la piraterie en mer. La Côte d'Ivoire était donc dépourvue d'outils internes efficaces pour la répression de la piraterie. Aussi, force est de reconnaitre que le système de circulation des biens via les conteneurs maritimes est efficace, mais également vulnérable aux intrusions et au détournement 605 . Ainsi, bien que la vocation première du conteneur soit de protéger la marchandise, son usage est source de pratiques illicites difficiles à combattre. Ces insuffisances constatées rendaient inefficace la lutte contre les trafics illicites, la criminalité et la piraterie en mer.

407- En somme, nous avons montré à travers le titre 1 de la première partie comment la législation du transport maritime protège la marchandise

\footnotetext{
602 Voir supra $\mathrm{n}^{\circ} 335$, pp.153 et 154 .

${ }^{603}$ Supra $n^{\circ} 346$, pp. 158 et $\mathrm{s}$. Le cas excepté a pour effet de briser la présomption de la responsabilité du transporteur. L'effet exonératoire et l'effectif pléthorique qui caractérisent les cas exceptés contrastent avec les normes de réparation des dommages subis par la marchandise. 604 Notamment la Convention de Rome de 1988 pour la répression d'actes illicites contre la navigation maritime, le traité des Nations Unies sur le commerce des armes de 2013 et bien d'autres.

605 Supra $^{\circ} 25$, p. 19.
} 
contre les dommages et comment elle lutte contre l'insécurité du transport de marchandises. Le titre 2 soumet cette législation du transport à une analyse critique aux termes de laquelle des limites et insuffisances ont été relevées en ce qui concerne la protection de la marchandise et la lutte contre l'insécurité maritime. Nous en tirons la conséquence que la législation du transport protège la marchandise et lutte contre l'insécurité maritime avec peu d'efficacité et peu de rigueur. Ces limites et insuffisances tirées de la pratique des transports maritimes nous interpellent. Elles justifient en effet la nécessité d'envisager une amélioration de la législation existante en vue de son efficacité. 
DEUXIEME PARTIE : LES PERSPECTIVES D'UNE AMELIORATION DE LA LEGISLATION EXISTANTE EN VUE DE SON EFFICACITE 
408- Le constat est que les normes de protection de la marchandise et de lutte contre l'insécurité maritime présente des insuffisances. Dès lors, compte tenu des nouveaux défis de la sûreté maritime notamment la criminalité maritime organisée, la solution à proposer doit comporter un double aspect à savoir un aspect curatif et un aspect préventif. C'est pourquoi, nous envisageons une amélioration de la législation du transport qui renforce la protection de la marchandise et qui tienne compte des défis de la sécurité maritime.

409- La question essentielle qui se pose est de savoir sur quoi doit se fonder l'amélioration de la législation du transport maritime en Côte d'Ivoire ? A notre sens, il s'avère nécessaire d'aller au-delà de l'analyse critique qui précède.

410- L'analyse critique de la législation du transport maritime a conduit à deux observations majeures, à savoir l'inefficacité de la législation maritime à protéger la marchandise et l'inefficacité des stratégies de lutte contre l'insécurité maritime. A cet effet, il convient de nous inspirer des normes de protection de la marchandise et des stratégies de lutte contre l'insécurité maritime mises en œuvre dans des pays étrangers en vue d'améliorer la législation du transport maritime en Côte d'Ivoire.

411- Ainsi, conviendra-t-il d'examiner d'abord le cadre législatif des transports de marchandises en droit comparé (Titre 1) afin de proposer le contenu des solutions nécessaires à l'amélioration des normes de protection de la marchandise et de lutte contre l'insécurité maritime au regard du droit étranger (Titre 2). 
TITRE 1 : L'ANALYSE DU CADRE LEGISLATIF DES TRANSPORTS DE MARCHANDISES PAR MER EN DROIT COMPARE 
412- Pour illustrer les avancées des dispositifs mis en place en matière de protection de la marchandise et de sécurité maritime, les exemples de certains pays étrangers et celui de l'Union européenne seront analysés. A cet effet, un auteur a pu affirmer qu'héritière des mouvements de territorialisation et de régionalisation de la gouvernance des espaces et des activités maritimes, l'Union européenne s'est érigée, malgré le silence des traités constitutionnels, en nouvel échelon d'élaboration du droit de la sécurité maritime. Les enjeux humains, économiques et environnementaux de la problématique ont fait de son ordre juridique un théâtre privilégié de la confrontation entre les traditions libérales du monde maritime et le besoin d'une régulation par la puissance publique en vue de prévenir, limiter et indemniser les préjudices de toutes natures pouvant résulter d'un accident en mer606.

413- En matière de lutte contre l'insécurité maritime, selon Madame Céline Guilleux, l'Union Européenne a mis en place un dispositif juridique ${ }^{607}$. Des dispositifs de protection de la marchandise existent dans chaque pays. Nous pensons que l'analyse de tels dispositifs peut être utile à la protection de la marchandise et à la lutte contre l'insécurité maritime en Côte d'Ivoire.

414- En matière de sécurité maritime nous examinerons les solutions de l'Union Européenne. S'agissant de la protection de la marchandise, notre analyse s'intéressera aux règles en vigueur dans certains pays étrangers notamment le Canada pour son appartenance à la zone maritime nord-

\footnotetext{
${ }^{606}$ Voir LANGLAIS (Peter), Sécurité maritime et droit de l'Union européenne, Bruylant, Droit de l'Union européenne, mai 2018, voir le résumé de l'ouvrage.

https://www.lgdj.fr/auteurs/langlais.peter.html.

${ }^{607}$ Par ailleurs l'auteur observe que l'Europe fait face aujourd'hui à de nouvelles problématiques liées au développement des activités humaines en mer qui ont progressivement conduit à une transformation du droit de la mer et du droit maritime mais qui restent encore juridiquement peu encadrées. Il est donc question de repenser les concepts nés de l'histoire des activités maritimes et de la navigation et de s'interroger sur l'intervention des Etats en mer, en particulier dans leurs eaux territoriales et en haute mer. Les compromis trouvés en 1982 à travers la Convention de Montego Bay, vis-à-vis du droit de la mer, doivent être renforcés. Il s'agit d'étudier notamment les influences et ambitions maritimes internationales de l'Union européenne ; les défis migratoires et les trafics illicites en mer ; et enfin le rôle des agences maritimes européennes. Cf : GUILLEUX (Céline), « La dimension européenne de la sûreté et de la sécurité maritime», septembre 2017, pp. 1-2, https://calenda.org/416048.
} 
américaine, la Belgique et la France pour leur appartenance à la zone maritime européenne 608 .

415- Les développements relatifs au droit comparé porteront respectivement sur les normes de protection de la marchandise en droits nationaux de certains pays étrangers (Chapitre 1) et sur les normes de lutte contre l'insécurité maritime dans l'Union européenne (Chapitre 2).

608 A propos du choix de la France, il faut ajouter que le français est la langue officielle de la Côte d'Ivoire. En outre, des accords de partenariat sont signés entre des organismes des deux Etats aux plans universitaire et scientifique. La Côte d'Ivoire et la France procèdent ainsi à des transferts de technologies. Cf : TRAORE (Adama), "Aux origines de la domination française en Côte d'Ivoire : les traités de protectorat. La création de la colonie de Côte d'Ivoire en 1893 ». https://fr.wikipedia.org/wiki/Relations, consulté le 21 octobre 2018. 


\section{CHAPITRE 1 : L'ANALYSE DES NORMES DE PROTECTION DE LA MARCHANDISE EN DROITS NATIONAUX ETRANGERS}

416- La législation maritime française en matière de protection de la marchandise tient pour l'essentiel à la Convention de Bruxelles de 1924 et ses protocoles modificatifs de 1968 et 1979 et à certains textes de loi et de décret. On peut citer la loi $\mathrm{n}^{\circ} 66-420$ du 18 juin 1966 sur les contrats d'affrètements et de transport maritimes modifiée par la loi n 86-1292 du 23 décembre 1986 ; le décret $\mathrm{n}^{\circ}$ 66-1078 du 31 décembre 1966 sur les contrats d'affrètement et de transport maritimes modifié par le décret $\mathrm{n}^{\circ}$ 87-922 du 12 novembre 1987609 . Il faut enfin citer le décret n 67-268 du 23 mars 1967 complétant l'article 28 de la loi du 18 juin 1966. Dans le présent chapitre, nous ne nous intéresserons qu'aux droits nationaux régissant la responsabilité du transporteur maritime international respectivement en Belgique, au Canada et en France.

417- La Convention de Bruxelles (art. 1-e), en prévoyant la prise en charge de la marchandise sous palan, institue un sectionnement juridique du contrat de transport de marchandises. Ce sectionnement anéantit toute protection efficace de la marchandise pendant les phases dites non maritimes en ce sens que la présomption de la responsabilité du transporteur, gage d'une protection efficace de la marchandise, ne couvre pas les opérations de pré et post acheminements. L'expérience de ces pays étrangers en matière de protection des marchandises se présentera comme une solution.

418- Pour ce faire nous examinerons les normes régissant la responsabilité du transporteur maritime en droits belge et canadien (Section 1) et les normes régissant la responsabilité du transporteur maritime en droit français (Section 2).

609 Voir Lamy Transport, tome 2, édition 2010, ${ }^{\circ} 531$, p. 265 ; n 540 , pp. 280 et s.; $n^{\circ} 536$, p. 267. 


\section{Section 1 : Les normes régissant la responsabilité du transporteur maritime en droits belge et canadien}

419- En application de l'article 1-e de la Convention de Bruxelles de 1924, on constate que le régime de responsabilité du transporteur n'assurait pas une protection efficace de la marchandise au cours des opérations pré et post maritimes. En droit canadien ${ }^{610}$ et en droit belge ${ }^{611}$, des textes à l'échelle nationale semblent renforcer la protection de la marchandise au cours des opérations pré et post maritimes. L'analyse des mécanismes de protection de la marchandise dans ces pays devient opportune. En effet, le choix du droit belge et $\mathrm{du}$ droit canadien respectivement de tradition civiliste et de la "Common law" se justifie par l'idée qu'ils pourraient inspirer une amélioration du droit des transports de marchandises par mer en Côte d'Ivoire. La responsabilité du transporteur se trouve régie tantôt par les Règles de La Haye tantôt par les Règles de La Haye-Visby ou encore par les Règles de Hambourg. Tous ces textes traduisent certes une réelle volonté d'uniformiser le régime international de la responsabilité du transporteur, mais force est de constater qu'en fin de compte leur application simultanée dans les différents pays n'a pas permis d'atteindre la réelle harmonisation qui est recherchée ${ }^{612}$. Notre analyse se limitera aux régimes de responsabilité du transporteur maritime en droit belge $\left(\begin{array}{l}\$ \\ 1\end{array}\right)$ et en droit canadien $(\boldsymbol{\$} \mathbf{2})$.

\section{$\S$ 1: Le régime de responsabilité appliqué au transporteur maritime en droit belge}

420- A notre sens, l'approche du législateur belge est louable dès lors qu'il a fait le choix des normes à caractère supplétif et non impératif. Il convient d'indiquer avec Monsieur Eric Van Hooydonk que les dispositions légales obligatoires, qui sont tout compte fait relativement rares et qui résultent généralement de conventions internationales, telles que celles relatives au

\footnotetext{
610 Voir loi canadienne de 1993, art. 7-2 et art. 111-1.

611 Voir Convention de Budapest relative au contrat de transport de marchandises en navigation intérieure (CMNI).

612 FETZE KAMDEM (Innocent), La responsabilité du transporteur maritime au niveau international : un échec d'uniformisation juridique, op. cit., voir le résumé du Mémoire.
} 
transport sous connaissement, n'excluent aucunement l'application d'usages et de conditions contractuelles types, parce que ces instruments restent indispensables pour compléter les principes obligatoires. Ainsi, le régime de responsabilités des Règles de La Haye est applicable en combinaison avec les usages portuaires relatifs à la responsabilité du transporteur maritime au cours des phases non maritimes ${ }^{613}$. Lorsque le législateur prévoit un régime légal pour certaines formes de contrat et responsabilités en matière de navigation, il le fait généralement sur la base des dispositions de droits supplétifs auxquelles les parties peuvent librement déroger ${ }^{614}$.

421- Le législateur belge se montre généralement réticent en ce qui concerne la régulation des droits et obligations des parties dans le commerce maritime. En effet, Monsieur Eric Van Hooydonk fait observer qu'il n'existe aucun cadre légal spécifique pour un grand nombre de contrats. Le législateur se fie pour cela à l'expertise pratique et juridique particulière du secteur du transport maritime et portuaire, et au pouvoir autorégulateur qui en découle. À défaut d'un régime légal, ne fût-ce que supplétif, les parties au contrat, généralement des partenaires commerciaux et professionnels opérant sur un pied d'égalité économique, bénéficient d'une liberté contractuelle complète. Les organisations professionnelles jouent un rôle important lors de la rédaction des conditions générales et lors de la codification des usages 615 . On analysera le principe de responsabilité du transporteur maritime (A) et la responsabilité de celui-ci sur les phases non maritimes (B).

\section{A- Le principe de responsabilité du transporteur maritime}

422- Les normes qui régissent la responsabilité du transporteur sont contenues dans la Convention de Bruxelles de 1924 et ses protocoles modificatifs

\footnotetext{
613 VAN HOOYDONK (Eric), "Ébauche de code belge de la navigation (droit privé)", Commission de droit maritime, Anvers, Rapport, 2014, p. 28. Cette attitude du législateur belge semble contribuer à l'affaiblissement de la protection de la marchandise. www.droitmaritime.be. 614 VAN HOOYDONK (Eric), "Ébauche de code belge de la navigation (droit privé)", Commission de droit maritime, Anvers, Rapport, 2014, p. 28.

615 VAN HOOYDONK (Eric), " Ébauche de code belge de la navigation (droit privé) », p. 27. Nous en déduisons l'absence de volonté du législateur belge d'adopter un régime juridique impératif pour protéger la marchandise transportée.
} 
de 1968 et 1979 et la Convention de Budapest relative au contrat de transport de marchandises en navigation intérieure (CMNI)616. En effet, selon Madame Cécile Tournaye le CMNI, tout comme les conventions internationales, pose le principe de la responsabilité du transporteur sitôt que la marchandise est placée sous sa garde, à moins qu'il ne prouve que le préjudice résulte de "circonstances que le transporteur ne pouvait pas éviter et aux conséquences desquelles il ne pouvait pas obvier"617.

423- Mais toute la difficulté réside dans la détermination du moment où la marchandise est réputée placée sous la garde du transporteur. Le CMNI dispose que : "le transporteur est réputé responsable du dommage, de la perte ou du retard, sitôt que la marchandise est placée sous sa garde, c'est-à-dire entre le chargement et le déchargement ${ }^{618}$. Cette dernière précision est importante. On en déduit qu'en droit belge la responsabilité du transporteur est présumée et commence au moment du chargement de la marchandise à bord du navire et prend fin à son déchargement. Sur ce point, le CMNI n'a fait que reprendre le sectionnement juridique effectué par les Règles de la Haye. Au regard de ce type de responsabilité du transporteur qui est qualifié de "palan à palan", se pose l'épineuse question de savoir à qui incombe la responsabilité des dommages subis par la marchandise au cours des opérations qui précèdent le chargement et de celles qui suivent le déchargement.

\section{B- La responsabilité du transporteur sur les phases non maritimes}

424- Tel que défini par les Règles de la Haye et la CMNI, le régime de responsabilité du transporteur maritime écarte, de son champ d'application, les pertes ou dommages subis par la marchandise avant le chargement et après le déchargement. Dès lors, à notre sens, le législateur belge devrait produire des dispositions en appoint de celles du CMNI pour régir la responsabilité du

616 TOURNAYE (Cécile), « Commentaire du projet de code belge de la navigation, partie dédiée à la navigation intérieure, livre IV et VI ", ITB, octobre 2015, p. 43.

617 Voir Convention de Budapest relative au contrat de transport de marchandises en navigation intérieure CMNI, art. $23 \S 2$.

618 Voir TOURNAYE (Cécile), "Commentaire du projet de code belge de la navigation, partie dédiée à la navigation intérieure ", ITB, octobre 2015, p. 45. 
transporteur au cours des phases non maritimes du transport. Selon Madame Cécile Tournaye, la loi nationale belge couvre des aspects non réglementés par le CMNI ou complète certaines dispositions du CMNI sur le connaissement en particulier619. Ainsi, en ce qui concerne les pertes ou les dommages subis par la marchandise avant son chargement à bord du navire et après son déchargement, le CMNI est hors d'application alors que l'article 34 de la loi belge de 1936 dispose que le contrat de transport peut prévoir l'exonération de la responsabilité du batelier ${ }^{620}$.

425- Au regard de ce qui précède, il convient de retenir qu'en droit belge, le régime impératif de présomption de la responsabilité du transporteur maritime n'est pas applicable aux pertes et dommages subis par la marchandise avant le chargement et après le déchargement. La responsabilité pour ces pertes et dommages relève donc de la convention des parties au contrat de transport conformément à l'article 34 de la loi belge de 1936. En effet, la législation belge n’a pas pu étendre la responsabilité présumée du transporteur sur les phases pré et post maritimes du transport. Sur ce point, le régime de responsabilité du transporteur en droit belge est identique à celui qui est appliqué en droit ivoirien aux pertes et dommages subis par la marchandise avant le chargement et après le déchargement.

426- Cependant le législateur ivoirien aurait pu s'inspirer de l'exemple législatif belge à d'autres égards. Celui-ci consiste à faire le choix des normes à caractère supplétif au lieu de celles à caractère impératif comme c'est le cas présentement avec le Code maritime ivoirien de 2017. Car les normes à caractère supplétif offrent une liberté contractuelle en donnant la possibilité aux parties de déroger aux dispositions légales. Les parties peuvent dans certaines circonstances écarter l'application des dispositions légales au profit de clauses privées. Mais les normes supplétives ont tout de même un inconvénient. Elles

619 TOURNAYE (Cécile), « Commentaire du projet de code belge de la navigation, partie dédiée à la navigation intérieure ", ITB, octobre 2015, p. 45.

${ }^{620}$ TOURNAYE (Cécile), " Commentaire du projet de code belge de la navigation, partie dédiée à la navigation intérieure ", ITB, octobre 2015, pp. 50-51. 
offrent la latitude au transporteur de déroger à certaines dispositions impératives de la loi et imposer des clauses contractuelles abusives au chargeur si celui-ci est économiquement faible. A présent, il nous faut examiner un autre régime de responsabilité du transporteur maritime qui sans doute pourra nous être plus utile, nous visons celui du droit canadien.

\section{§ 2: Le régime de responsabilité appliqué au transporteur maritime en droit canadien}

427- Les Règles de La Haye Visby de 1968 ont été adoptées par le Canada en mai 1993 dans sa nouvelle loi relative au transport des marchandises par eau ${ }^{621}$. Conformément à son article $10^{622}$, les Règles de La Haye-Visby ne visent que le transport international de marchandises ${ }^{623}$. Il convient d'examiner le principe de la responsabilité du transporteur maritime (A) et la responsabilité qui pourrait incomber à celui-ci sur les phases non maritime (B).

\section{A- Le principe de la responsabilité du transporteur maritime}

428- La responsabilité est la sanction de l'inexécution ou de la mauvaise exécution de l'obligation du débiteur. Et le caractère de l'obligation à exécuter détermine la nature de la responsabilité civile. Ainsi à une obligation de moyens correspond une responsabilité pour faute et à une obligation de résultat correspond une responsabilité de plein droit ${ }^{624}$. L'article 111 paragraphe 1 de la loi de 1993 dispose que le transporteur doit faire preuve d'une diligence

${ }^{621}$ Le Canada est une fédération dans laquelle la Loi constitutionnelle de 1867 détermine la compétence respective des Parlements fédéral et provinciaux. En outre, alors que la tradition civiliste s'applique dans la province du Québec, la Common Law, quant à elle, reçoit application dans toutes les autres provinces et territoires. Voir en ce sens LEFEDVRE (Guy), "La responsabilité du transporteur maritime au Canada", Revue du notariat, vol. 101, $\mathrm{n}^{\circ} 2$, septembre 1999, pp. 281-298, https://doi.org/10.7202/1046264ar.

${ }_{622}$ Voir les Règles de la Haye-Visby, art. 10: «Les dispositions de la présente Convention s'appliqueront à tout connaissement relatif à un transport de marchandises entre ports relevant de deux États différents, quand: a) le connaissement est émis dans un État contractant, ou b) le transport a lieu au départ d'un port d'un État contractant, ou c) le connaissement prévoit que les dispositions des présentes règles ou de toute autre législation les appliquant ou leur donnant effet régiront le contrat, quelle que soit la nationalité du navire, du transporteur, du chargeur, du destinataire ou de toute autre personne intéressée ".

${ }^{623}$ Toutefois, l'article 7-2 de la Loi de 1993 soumet également le transport interne à ces règles. ${ }^{624}$ Voir Code civil ivoirien, art. 1382. 
raisonnable s'agissant de la navigabilité du navire. En outre le paragraphe $8 \mathrm{du}$ même article prévoit la nullité des clauses de non responsabilité ou des clauses atténuant la responsabilité du transporteur. Seules les exonérations légales appelées encore cas exceptés, prévues par la loi, sont susceptibles de libérer le transporteur ${ }^{625}$. Enfin, dans tous les modes de transport, l'obligation principale du transporteur est de livrer la marchandise telle qu'il l'a prise en charge. C'est une obligation de résultat qui fait peser sur le transporteur une responsabilité présumée ${ }^{626}$.

429- Mais conformément à l'article 1-e, les dispositions de la Convention de Bruxelles de 1924 s'appliquent impérativement durant le temps qui s'écoule depuis le chargement des marchandises à bord du navire jusqu'à leur déchargement du navire. Il en résulte qu'en droit canadien, la responsabilité qui incombe au transporteur maritime pour les dommages subis par la marchandise est présumée. Et celle-ci couvre la période qui part du début du chargement de la marchandise à bord du navire jusqu'au déchargement: appelée phase maritime du transport ou encore phase "de palan à palan". Les Règles de La Haye-Visby, actuellement en vigueur au Canada627, ne s'appliquent qu'à la phase purement maritime et non aux phases antérieure au chargement et postérieure au déchargement. Dès lors la question se pose de savoir quel régime juridique régit les dommages subis par la marchandise pendant les phases antérieure au chargement et postérieure au déchargement.

\section{B- La responsabilité du transporteur avant le chargement et après le déchargement}

430- Au regard de l'application de la Convention de Bruxelles exclusivement à la phase maritime du transport, la responsabilité du transporteur devrait écarter les phases pré et post maritimes de son champ d'application. En effet, selon Guy Lefebvre et Stéphane Rousseau, « ... les Règles de La Haye-Visby, [...], ne s'appliquent qu'à la phase purement maritime et non

\footnotetext{
${ }^{625}$ LEFEBVRE (Guy), "La responsabilité du transporteur maritime au canada », Revue du notariat. Volume 101, $\mathrm{n}^{\circ} 2$, septembre 1999, p. 290, https://doi.org/10.7202/1046264ar.

${ }^{626}$ Celle-ci est dite responsabilité automatique ou encore de plein droit.

627 Voir Règles de La Haye-Visby, art. 4-1 et s.
} 
pas à la phase antérieure au chargement et postérieure au déchargement. Compte tenu $d u$ sectionnement $d u$ transport, le transporteur et le chargeur pourront déterminer librement, dans leur contrat, le régime juridique applicable aux phases antérieures au chargement et postérieures au déchargement. Ils auront alors la possibilité de prévoir les conditions et exonérations relatives aux obligations et à la responsabilité du transporteur, pour les dommages qui surviendront pendant ces première et troisième phases ${ }^{628}$.

431- Toutefois, pour connaître la position du juge, il convient d'examiner la jurisprudence canadienne relative à la responsabilité des dommages survenus à la marchandise avant le chargement et après le déchargement. Ainsi, dans l'affaire ITO $^{629}$, la question du régime juridique applicable au cours des phases pré et post maritimes s'est posée. Les faits de la cause sont les suivants : un navire a transporté des calculatrices du Japon à Montréal, où le propriétaire devait en prendre livraison. À leur arrivée, les marchandises ont été réceptionnées et entreposées par une compagnie d'acconage et de manutention. Celle-ci avait convenu avec le transporteur de les décharger du navire et de les entreposer jusqu'à ce qu'elles soient délivrées à leur propriétaire. Pendant l'entreposage, plusieurs cartons contenant des calculatrices ont été volés. Une action en justice a été intentée devant la Cour fédérale du Canada par le propriétaire des marchandises contre le transporteur et l'entrepositaire ${ }^{630}$.

432- La solution à la question de la responsabilité des dommages survenus à la marchandise pendant son entreposage, période située entre le déchargement et la livraison, pourrait être d'un apport précieux. Dans cette affaire quel régime de responsabilité a été appliqué aux dommages survenus à la marchandise après son déchargement du navire? Selon Monsieur Guy Lefebvre, " [Le juge McIntyre] insiste plus particulièrement sur le fait qu'en 1934,

\footnotetext{
${ }^{628}$ LEFEBVRE (Guy) et ROUSSEAU (Stéphane), La vente documentaire internationale : la problématique de l'application de la Common law au Québec, Introduction au droit des affaires, Éditions Thémis, Collection CDACI, Montréal, 2006, pp. 221-222.

${ }^{629}$ ITO - International Terminal Operators Ltd. c. Miida Electronics Inc., [1986] 1 R.C.S. 752.

${ }^{630} \mathrm{Cf}$ : LEFEBVRE (Guy) et ROUSSEAU (Stéphane), La vente documentaire internationale : la problématique de l'application de la Common law au Québec, Introduction au droit des affaires, op. cit., pp. 221-222.
} 
les règles de droit maritime d'Angleterre ont été incorporées dans le droit canadien et, lorsque survenait une question de responsabilité contractuelle ou délictuelle, le tribunal d'amirauté appliquait les principes de Common law en matière de dépôt et de négligence. Au nom de l'uniformité du droit canadien, il rejette la thèse voulant que la Cour fédérale puisse appliquer accessoirement le droit provincial, soit, dans le cas qui nous occupe, le droit civil québécois "631. L'argumentation contraire qui soutient qu'il ne s'agit pas d'une question de droit maritime, mais plutôt d'une question de droit civil délictuel, nécessitant l'application du droit civil québécois, n’a pas prévalu. Par conséquent le droit maritime canadien, relevant de la compétence fédérale sur la navigation et la marine marchande, tel que prévu par le paragraphe 10 de l'article 91 de la Constitution, a été appliqué632.

433- En effet, Guy Lefebvre précisait que: "Compte tenu $d u$ sectionnement du transport, le transporteur et le chargeur pourront déterminer librement dans le contrat le régime juridique applicable aux phases antérieure au chargement et postérieure au déchargement: ils pourront prévoir les conditions et exonérations relatives aux obligations et responsabilité $d u$ transporteur, pour les dommages qui surviendront pendant ces première et troisième phases. Si aucune stipulation n'est prévue à cet effet, le transporteur maritime devrait être normalement soumis au droit commun du transport : la Common law fédérale»633. A notre sens la difficulté résulte du fait que la responsabilité des dommages survenus pendant les phases non maritimes du transport est susceptible d'être soumise au droit maritime ou au droit provincial. Le droit maritime ne protégeant pas assez la marchandise pendant ces phases non maritimes, les juges auraient dû privilégier l'application du droit provincial

\footnotetext{
${ }^{631}$ LEFEBVRE (Guy) et ROUSSEAU (Stéphane), La vente documentaire internationale : la problématique de l'application de la Common law au Québec, Introduction au droit des affaires, Éditions Thémis, op. cit., p. 224.

${ }^{632}$ Idem. LEFEBVRE (Guy) et ROUSSEAU (Stéphane), La vente documentaire internationale : la problématique de l'application de la Common law au Québec, Introduction au droit des affaires, op. cit., p. 224.

633 Voir LEFEBVRE (Guy), " La responsabilité du transporteur maritime au canada ", Revue du notariat. Volume 101, $\mathrm{n}^{\circ} 2$, septembre 1999, p. 287, https://doi.org/10.7202/1046264ar.
} 
en l'occurrence le droit civil québécois qui pourrait s'appuyer sur le dépôt et la négligence pour offrir une meilleure protection de la marchandise.

434- Dans ces conditions, il convient de retenir à juste titre qu'en droit maritime canadien, les dommages survenus à la marchandise, après son déchargement du navire, ne relèvent pas de la responsabilité présumée du transporteur mais plutôt de la convention des parties. Toutefois, ces phases dites non maritimes du transport auraient pu être soumises au droit provincial capable d'offrir une meilleure protection à la marchandise. Le législateur ivoirien a pu alors s'en inspirer pour adopter des dispositions internes, notamment l'article 708 du Code maritime 2017, afin de mieux protéger la marchandise au cours de ces phases non maritimes du transport. A présent il convient d'examiner le régime de responsabilité du transporteur appliqué dans un autre pays, la France.

\section{Section 2 : Les normes régissant la responsabilité du transporteur maritime en droit français}

435- Avant le code maritime, la marchandise n'était pas suffisamment protégée au cours des phases non maritimes du transport ${ }^{634}$ en droit ivoirien. En effet, la responsabilité présumée du transporteur, véritable garantie de la protection de la marchandise, ne couvrait pas les opérations pré et post maritimes du transport. Le législateur ivoirien devait alors combler cette lacune pour rehausser la protection de la marchandise en termes de réparation des dommages subis. Par ailleurs, le principe de responsabilité présumée du transporteur en droit français semble s'étendre aux phases pré et post maritimes par l'effet de l'article 16 de la loi nationale $\mathrm{n}^{\circ} 66-420 \mathrm{du} 18$ juin 1966, adoptée en appoint de la Convention de Bruxelles de 1924. Cela justifie l’opportunité, pour nous, d'analyser le droit français.

\footnotetext{
${ }^{634}$ L'article 1 paragraphe e) de la Convention de Bruxelles, en prévoyant la prise en charge de la marchandise sous palan, a institué un sectionnement juridique du contrat de transport maritime de marchandises qui a pour effet de supprimer toute protection efficace de la marchandise pendant les phases pré et post maritimes.
} 
436- Les normes régissant la responsabilité du transporteur maritime en droit français sont contenues dans le principe de la présomption de responsabilité $(\boldsymbol{\$} \mathbf{1})$ et dans la durée de la présomption de la responsabilité $(\boldsymbol{\$} \mathbf{2})$.

\section{$\S 1$ - Le principe de la présomption de responsabilité du transporteur}

437- Le principe de la présomption de responsabilité sera appréhendé tant au niveau de son contenu (A) qu'au niveau de sa portée (B).

\section{A- Le contenu du principe de la présomption de responsabilité}

438- Le droit maritime français est composé des dispositions de la Convention de Bruxelles et des dispositions de la loi nº 66-420 du 18 juin 1966635 . La Convention de Bruxelles de 1924 dispose en son article 3 que: « 1. Le transporteur sera tenu avant et au début du voyage d'exercer une diligence raisonnable pour: ... [Assurer la navigabilité de son bâtiment]. 2. Le transporteur, sous réserve des dispositions de l'article 4, procèdera de façon appropriée et soigneuse au chargement, à la manutention, à l'arrimage, au transport, à la garde, aux soins et au déchargement des marchandises transportées ». La loi n 66-420 du 18 juin 1966 dispose en son article 27 que : "Le transporteur est responsable des pertes ou dommages subis par la marchandise depuis la prise en charge jusqu'à la livraison, à moins qu’il ne prouve que ces pertes ou dommages proviennent : ... ». Les dispositions précitées de la convention et la loi font peser sur le transporteur maritime une présomption de responsabilité. Il en résulte que le transporteur est responsable de plein droit de toutes les pertes et avaries constatées au déchargement ou à la livraison de la marchandise ${ }^{636}$ même lorsque l'origine des dommages ne peut être déterminée ${ }^{637}$.

\footnotetext{
${ }^{635} \mathrm{Cf}$ : loi française $\mathrm{n}^{\circ}$ 66-420 du 18 juin 1966, art. 16.

${ }^{636}$ Cour d'appel Aix-en-Provence, 10 janvier 2001, Picc c/Cosco BTL 2001, p. 129 ; Cour d'appel de Paris, 27 novembre 2002, Palimar Shipping et a. c/Gan et a. Lamyline.

${ }^{637}$ Cour d'appel de Paris, 27 novembre 1996, Atlantic Container Line c/Réunion européenne, Lamyline.
} 
439- Concernant le domaine de cette présomption de responsabilité, contrairement à l'article 3 de la Convention de Bruxelles qui reste imprécis, l'article 27 de la loi de 1966 précise que le transporteur est responsable des pertes ou dommages subis par la marchandise. Il ne s'agit que de pertes et de dommages qu'a pu subir la marchandise au cours de son transport. Il en résulte, selon René Rodière, que : "les dommages éprouvés par [le destinataire] autrement que sous la forme de pertes et dommages subis par la marchandise ne sont pas couverts par cette présomption ; ce sera le cas des conséquences du retard autres que celles qui prennent la forme d'avarie; ce sera également le cas de toutes les autres formes de préjudice qui ne se matérialisent pas en atteintes à la marchandise elle-même ;... »638.

440- Dans ce régime de responsabilité présumée, l'absence de faute du transporteur est inopérante dans la mesure où elle ne suffit pas à dégager ledit transporteur de la présomption ${ }^{639}$. Seule la preuve de l'existence d'une cause exonératoire, définie par la loi ou par la Convention notamment le cas excepté, est susceptible de combattre la présomption ${ }^{640}$. Encore faut-il qu'il existe un lien de causalité entre la cause d'exonération et le dommage subi par la marchandise ${ }^{641}$.

441- Par ailleurs le principe de responsabilité de plein droit qui pèse sur le transporteur maritime mérite qu'on accorde une attention toute particulière à sa portée.

\footnotetext{
${ }^{638}$ RODIERE (René), Traité général de droit maritime, Dalloz. Paris, 1968, tome II, nº 612 pp. $251 \mathrm{et} \mathrm{s.} \mathrm{En} \mathrm{effet,} \mathrm{toutes} \mathrm{les} \mathrm{autres} \mathrm{formes} \mathrm{de} \mathrm{préjudice} \mathrm{qui} \mathrm{ne} \mathrm{se} \mathrm{matérialisent} \mathrm{pas} \mathrm{en} \mathrm{atteintes}$ à la marchandise elle-même ne sont pas soumises au régime de responsabilité du transporteur maritime.

${ }^{639}$ Cour d'appel Aix-en-Provence, 2 décembre 2003, n 00/07505, Navigation et transport et a. c/Damoskibsselskabet Af 1912 et a., Lamyline.

${ }_{640}$ Cass. Com., 15 juillet 1987, n 86-10.409, Lamyline; Cour d'appel de Paris, 9 juillet 1985. SNCDV c/Allianz et a., Lamyline.

${ }^{641}$ Cass. Com., 16 avril 1991, ${ }^{\circ}$ 89-17.956/G, BTL 1991, p. 591. Voir aussi Cour d'appel d'Aix-enProvence, 4 mai 2004, n ${ }^{\circ}$ 2002/307, The British and Foreign Ins. Cy et a. c/Cosco, lamyline. Dans cette espèce, les juges ont estimé que l'avarie subie par la marchandise est intervenue au cours du transport et n'avait donc pas de lien avec l'incendie survenu dans la salle des machines du navire.
} 


\section{B- La portée du principe de la présomption}

442- La présomption de responsabilité ou responsabilité de plein droit a pour effet de dispenser le destinataire de faire la preuve que le dommage subi par la marchandise est dû à la faute du transporteur. Mais cette dispense de preuve de la faute du transporteur peut être également obtenue par la simple présomption de faute ${ }^{642}$. Or la présomption de faute suppose qu'en faisant la preuve qu'il n'a pas commis de faute, le transporteur se libèrerait, pourtant tel n'est pas le cas. En effet, la Convention de Bruxelles et la loi de 1966 disposent que le transporteur est responsable des dommages subis par la marchandise à moins qu'il ne prouve que ceux-ci proviennent d'une cause d'exonération c'est-àdire de cas exceptés légalement prévus ${ }^{643}$. Comme l'a indiqué le doyen Rodière : " Notre présomption se situe dans la zone des présomptions de responsabilités faibles. En effet, le transporteur peut s'en libérer en démontrant que le dommage est dû à l'une des causes entrant dans une longue énumération et certaines de ces causes a priori n'excluent nullement la possibilité d'une faute de sa part "644.

443- Pour combattre la présomption de responsabilité qui pèse sur lui, le transporteur ne dispose que de la preuve d'un cas excepté. Seule une cause exonératoire dûment démontrée peut libérer le transporteur. Toutefois, face à une faute du transporteur dont la preuve est rapportée par l'ayant droit à la marchandise, la cause exonératoire ou le cas excepté cesse de jouer ${ }^{645}$. Une telle faute rend la cause exonératoire inopérante ${ }^{646}$. Dans cette hypothèse, et au vu des éléments du dossier, les juges peuvent soit retenir la responsabilité du transporteur pour les dommages subis par la marchandise ${ }^{647}$, soit procéder à un

\footnotetext{
${ }^{642}$ Car la présomption de faute dispense également le demandeur de rapporter la preuve de la faute.

643 Voir en ce sens la Loi n 66-420 du 18 juin 1966, art. 27 ; voir également la Convention de Bruxelles de 1924, art. 4, al. 2.

${ }^{644}$ RODIERE (René), Traité général de droit maritime, Dalloz. Paris, tome II, 1968, nº 613, p. 254.

${ }^{645}$ Idem, RODIERE (René), Traité général de droit maritime, n 614 , pp. 254 et s.

${ }^{646}$ Voir Cass. Com., 30 juin 2004, n 03-10.650, Lamyline.

${ }_{647}$ Cour d'appel de Rouen, 8 septembre 1988, DMF 1991, p. 360.
} 
partage de responsabilité648, soit enfin considérer que la faute invoquée n'est pas suffisamment établie ${ }^{649}$.

444- Après l'examen de son principe et de son étendue, la question se pose de savoir quelle est la durée de la présomption de responsabilité applicable au transporteur maritime.

\section{§ 2- La durée de la présomption de la responsabilité}

445- La durée de la présomption pose le problème du champ d'application dans le temps de la loi française de 1966 et la Convention de Bruxelles de 1924. La responsabilité du transporteur est présumée mais la durée de la présomption diffère selon qu'il s'agit de la Convention de Bruxelles ou de la loi française de 1966. Pour mieux appréhender la durée de la présomption examinons, d'une part, la présomption de responsabilité telle que prévue par la Convention de Bruxelles (A) et, d'autre part, la présomption de responsabilité telle que prévue par la loi française $(\mathbf{B})$.

\section{A- La présomption de responsabilité « de palan à palan " prévue par la Convention de Bruxelles}

446- L'article premier paragraphe e dispose que le: "'Transport de marchandise" couvre le temps écoulé depuis le chargement des marchandises à bord du navire jusqu'à leur déchargement du navire». Il en ressort que la présomption de responsabilité du transporteur naît au chargement de la marchandise pour prendre fin au déchargement ${ }^{650}$. C'est le sectionnement légal du contrat de transport qui écarte de son champ d'application les opérations terrestres pré et post maritimes pour ne régir que les opérations purement maritimes. Le chargement et le déchargement sont alors entendus de manière étroite par la jurisprudence. Le chargement ne comprend que la saisie des marchandises à quai à proximité du navire pour être hissée ou y être introduite.

\footnotetext{
${ }^{648}$ Cour d'appel Aix-en-Provence, 6 mai 2004, nº 00/19532, AGF et a. c/Cogema, Lamyline. ${ }^{649}$ Cour d'appel Aix-en-Provence, 11 mars 2004, n 00/14533, Multiranda Trading c/CMA-CGM, BTL 2004, p. 703 ; Cass. Com., 24 avril 2007, n 06-12.508, DMF 2007, p. 825.

650 Cour d'appel de Paris, 6 novembre 2003, Axa et a. c/Golden Union Shipping et a. Lamyline.
} 
Ainsi dans un arrêt de la Cour d'appel d'Aix-en-Provence ${ }^{651}$, les juges ont refusé de soumettre à la Convention de Bruxelles un portage à quai effectué à une certaine distance du navire. Il en est de même pour le déchargement qui prend fin à la dépose de la palanquée : d'où l'expression responsabilité présumée du transporteur « de palan à palan ».

447- Avec la Convention de Bruxelles le transporteur est présumé responsable des pertes et avaries subies par la marchandise dès le début de son chargement à bord jusqu'à la fin de son déchargement du navire à destination. La question se pose de savoir quel régime de responsabilité est applicable aux opérations précédant le chargement et celles qui sont postérieures au déchargement. Deux situations sont à distinguer. Lorsqu'une clause de prise en charge et de livraison sous palan est dûment insérée au connaissement, le transporteur est alors exonéré de toute responsabilité pour les opérations pré maritimes effectuées, dans cette hypothèse, pour le compte du chargeur. Dans ces conditions, le chargeur pourra engager la responsabilité de l'entrepreneur de manutention pour les pertes et avaries survenues à la marchandise 652 au cours de ces opérations pré maritimes. Et lorsque le transporteur, à travers une note de chargement délivrée au chargeur, a pris en charge les marchandises, les opérations non maritimes sortent alors du champ d'application de la Convention de Bruxelles pour être soumises de plein droit à l'application des articles 15 et $16^{653}$ de la loi française du 18 juin $1966^{654}$. Qu'en est-il à présent de la durée de la présomption de responsabilité prévue par la loi française?

651 Voir Cour d'appel Aix-en-Provence, 5 mai 1987, DMF 1988, p. 384.

${ }^{652} \mathrm{Cf}$ : Loi du 18 juin 1966, art. 52 : "L'entrepreneur de manutention opère pour le compte de celui qui aura requis ses services, et sa responsabilité n'est engagée qu'envers celui-ci qui seul a une action contre lui"; voir également art. 53: "Quel que soit celui pour le compte de qui l'entrepreneur manipule, reçoit ou garde la marchandise, sa responsabilité est engagée dans les conditions et limites fixées ci-dessous : ... ".

653 Voir ci-dessus n ${ }^{\circ}$ 494, les dispositions des articles 15 et 16 de la loi du 18 juin 1966.

654 Cour d'appel de Versailles, 29 avril 2003, $\mathrm{n}^{\circ}$ 2001-644, VG Emballage c/Saga trans, Lamyline ; Tribunal de commerce de Paris, 20 octobre 1977, DMF 1978, p. 352 ; Cour d'appel de Rouen, 9 septembre 3004, nº 02/02601, BTL 2005, p. 251, DMF 2005, p. 851. 


\section{B- La présomption de responsabilité « de la prise en charge à la livraison " prévue par la loi française de 1966}

448- La durée de la présomption de la responsabilité du transporteur est définie par les articles 15 et 16 de la loi n 66-420 du 18 juin 1966. Aux termes de l'article 15 in fine il est indiqué que les dispositions du présent titre s'appliquent depuis la prise en charge jusqu'à la livraison. Quant à l'article 16, il dispose que : "Le présent titre est applicable aux transports, effectués au départ et à destination d'un port français, qui ne sont pas soumis à une convention internationale à laquelle la France est partie, et en tout cas aux opérations de transport qui sont hors du champ d'application d'une telle convention. ... ».

449- Les termes utilisés dans cette dernière disposition, à savoir « ... en tout cas aux opérations de transport qui sont hors du champ d'application d'une telle convention ", permettent de déduire que l'esprit de ce texte est d'englober les opérations pré et post maritimes dans son champ d'application. Ce texte prend en compte les opérations non maritimes écartées du champ d'application de la Convention de Bruxelles à travers son article premier paragraphe e. Avec la loi française de 1966 la présomption de responsabilité commence dès que le transporteur ou son représentant qualifié prend en charge la marchandise ${ }^{655}$ et elle prend fin lorsque la marchandise est délivrée au réceptionnaire ou à son représentant qualifié 656 .

450- En matière de transport maritime international, la loi française vient donc compléter la Convention de Bruxelles. Ainsi, pour régir les phases non maritimes (auparavant soumises à la convention des parties) une disposition impérative s'applique en lieu et place de la disposition supplétive. En effet, l'article 1-e de la Convention rendait inefficace la protection de la marchandise en écartant les opérations non maritimes de son champ d'application. La loi française en s'appliquant « aux opérations de transport qui

\footnotetext{
655 Voir dans ce sens Cour d'appel Aix-en-Provence, 31 octobre 1991, BTL 1992, p. 478. Voir également Cour d'appel Aix-en-Provence, 5 mai 1987, DMF 1988, p. 384.

${ }^{656}$ Cour d'appel de Rouen, $2^{\text {ème }}$ chambre, 9 septembre 2004, $n^{\circ}$ 02/01434, Hual As c/Axa et a., BTL 2004, p. 669.
} 
sont hors du champ d'application de [la Convention de Bruxelles] "657, présume la responsabilité du transporteur depuis la prise en charge de la marchandise jusqu'à sa livraison. Par ce dispositif, la présomption couvre les opérations aussi bien maritimes que non maritimes. Une telle protection de la marchandise a fait défaut en droit ivoirien des transports de marchandises par mer.

451- Notre analyse en droit comparé a montré que le législateur ivoirien aurait pu s'inspirer de l'approche du législateur belge qui a fait l'option de prévoir des normes supplétives au lieu de normes impératives ${ }^{658}$. Certes les normes supplétives offrent une liberté contractuelle mais présentent un inconvénient: celui de permettre au transporteur d'insérer des clauses qui lui sont favorables. Quant au droit canadien les phases du transport dites non maritimes peuvent être soumises au droit provincial, capable d'offrir une meilleure protection à la marchandise. Le législateur ivoirien a pu donc s'en inspirer pour adopter des dispositions internes pour mieux protéger la marchandise au cours de ces phases non maritimes. S'agissant de l'analyse des normes de protection de la marchandise en droit français, elle montre que le transport maritime international est régi concurremment par la Convention de Bruxelles et la loi de 1966. Les opérations non maritimes écartées du champ d'application de la présomption de responsabilité par les Règles de la Haye, y sont intégrées par la loi de 1966. Ainsi, le transporteur est présumé responsable de la prise en charge de la marchandise à sa livraison. De ce point de vue, la marchandise bénéficie d'une protection assez efficace. Par ailleurs, il convient de s’interroger sur les normes de lutte contre l”insécurité maritime en droit de la communauté européenne.

\footnotetext{
657 Voir l'article 16 de la loi française n 66-420 du 18 juin 1966. 658 Voir supra p. 201.
} 


\section{CHAPITRE 2: L'ANALYSE DES NORMES DE LUTTE CONTRE L'INSECURITE MARITIME EN DROIT EUROPEEN}

452- L’Union européenne ne cesse de renforcer les normes de sécurité et de lutte contre l'insécurité maritime ${ }^{659}$. L'harmonisation progressive du droit de la sécurité maritime à l'échelle continentale européenne limite la compétition législative que les États membres sont susceptibles de se livrer dans l'usage de l'autorité du pavillon et de l'autorité du port, même si cette harmonisation se fait parfois au prix d'un alignement sur les pratiques internationales. Afin d'assurer l'effectivité de son action en la matière, l'Union Européenne organise le rapprochement des administrations maritimes nationales, dont la coopération opérationnelle est orchestrée par des agences décentralisées ${ }^{660}$. Selon Monsieur Peter Langlais « Pour surmonter les limites auxquelles se heurte nécessairement une approche continentale, l'Union européenne multiplie les partenariats internationaux et défend à présent une approche différenciée par bassin. La singularisation par rapport au droit international de référence demeure quant à elle stratégiquement limitée, alors que l'attractivité commerciale de l'Europe autoriserait une stratégie d'incitation économique plus audacieuse »661.

453- La politique de sécurité maritime est une partie intégrante de la politique du transport maritime. Elle renforce la protection du milieu marin et les régions côtières mais aussi celle des marchandises, des passagers et des membres d'équipage. A propos de milieu marin, nul n'ignore l'importance des

\footnotetext{
${ }^{659} \mathrm{Cf}$ : BEALL (Jacques), « La politique européenne de transport maritime au regard des enjeux de développement durable et des engagements climat", JORF, Avis du Conseil économique, social et environnemental, Rapport, 11 mai 2017, p. 23. "Le naufrage du Titanic en 1912 a été le déclencheur de la réflexion sur la sécurité maritime. Puis une succession de catastrophes (le Torrey Canyon en 1967, le Boehlen en 1976, l'Amoco Cadiz en 1978...) a permis la prise de conscience de l'impact du transport maritime sur l'environnement et donc sa nécessaire prise en compte dans les politiques de sécurité. Par la suite, ce sont les naufrages des navires pétroliers Erika (1999) et Prestige (2002) qui ont poussé l'UE à renforcer les normes de sécurité en vigueur dans le domaine du transport maritime" .

${ }^{660}$ LANGLAIS (Peter), Sécurité maritime et droit de l'Union européenne, Bruylant, Droit de l'Union européenne, mai 2018, voir le résumé, https://www.lgdj.fr/auteurs/langlais.peter.html. 661 Idem.
} 
espaces maritimes tels que le golfe de Guinée, le golfe d'Aden, la Méditerranée 662 et bien d'autres. Le transport maritime étant par essence de dimension mondiale, l'OMI a pour mission d'édicter des normes internationales uniformes ${ }^{663}$. L'Union Européenne se charge d'intégrer rapidement dans le droit communautaire ces conventions internationales pour garantir une application homogène dans tous ses États membres ${ }^{664}$; qu'il s'agisse de la formation des gens de mer, l'équipement de bord, la sécurité des navires de transport de passagers, le contrôle par l'État du port et les organismes habilités à effectuer l'inspection et la visite des navires etc. ${ }^{665}$.

454- Selon Madame Melle Nathalie Boudong, la politique européenne se fonde sur trois piliers qui peuvent viser chacun à sa manière la lutte contre la piraterie. Le premier pilier est celui des communautés ou du marché commun,

662 TANDONNET (Jean), " Sécurité et sûreté maritime en Méditerranée ", La Revue Maritime, $\mathrm{n}^{\circ} 483$, p. 32. L'auteur indique que la Méditerranée qui couvre moins de $1 \%$ de la surface totale des océans, concentre cependant $30 \%$ du trafic mondial. Nous estimons à environ 2000 le nombre de navires marchand croisant chaque jour en Méditerranée avec parmi eux près de 300 pétroliers. Ces navires peuvent faire peser un risque pour l'environnement dans cette mer si encombrée. Certains sont les vecteurs de trafics en tout genre ou se livrent à des pollutions volontaires. [...]. En mer, sans doute plus qu'ailleurs, un pays ne peut agir seul, aussi puissant soit-il.

663 Voir BEALL (Jacques), « La politique européenne de transport maritime au regard des enjeux de développement durable et des engagements climat", JORF, Avis du Conseil économique, social et environnemental. Rapport, 11 mai 2017, op. cit., p. 26. L'OMI est une organisation créatrice de normes mais elle n'a pas de compétence de contrôle de leur application et ne dispose pas de moyens en ce sens. Seuls les États parties aux conventions de l'OMI peuvent veiller au respect de ces normes internationales.

664 Voir DELFAUD (Pierre), La sécurité du transport et du trafic maritime de marchandises, RESEAU TRANSNATIONAL ATLANTIQUE DES PARTENAIRES ECONOMIQUES ET SOCIAUX, Rapport, Mai 2005, p. 18. Selon l'auteur, c'est à partir de 1992 que la politique commune de la sécurité maritime est devenue une ambition de l'Union européenne et que dans cette matière, la règle de l'unanimité qui constituait un frein à l'adoption de mesures significatives a alors cédé la place à celle de la majorité qualifiée. Dès lors, plusieurs règlements et directives afférents ont été adoptés. Il convient de rappeler que si les règlements communautaires doivent s'appliquer de façon homogène dans tous les États membres, les directives se bornent à fixer des objectifs communs et des délais uniformes d'application, les moyens d'intervention étant laissés à l'initiative des États. Ceci est source de notables disparités auxquelles s'ajoutent les retards constatés dans certains États membres entrainant l'ouverture de procédures -toujours très longues- de mise en demeure de la part de la Commission européenne.

665 Voir BEALL (Jacques), « La politique européenne de transport maritime au regard des enjeux de développement durable et des engagements climat", JORF, Avis du Conseil économique, social et environnemental, Rapport, op. cit., 11 mai 2017, pp. 22-23. 
dont les transports permettent l'existence. Le second est la coopération en matière de politique étrangère et de sécurité commune, pouvant lui aussi viser la piraterie, et le dernier est relatif à la coopération policière et judiciaire en matière pénale. Bien que ces piliers ne doivent concerner que la politique de l'Union, ils peuvent fonder la lutte active contre la piraterie ${ }^{666}$. L'étude de la stratégie européenne de lutte contre l'insécurité maritime consistera à examiner les instruments régionaux de lutte contre les trafics et les actes illicites en mer (Section 1) et la promotion de la coopération régionale en matière de lutte contre les actes illicites en mer au sein de l'Union (Section 2).

\section{Section 1 : L'adoption d'instruments régionaux de lutte contre les trafics et actes illicites en mer}

455- A travers la politique de sécurité et de défense commune (PSDC) de l'Union Européenne, une opération dénommée Atalante a été mise en œuvre au large des côtes somaliennes pour participer à la lutte contre la piraterie maritime dans cette zone. L’implication de l’Union Européenne dans la lutte contre la piraterie somalienne semble avoir contribué à une prise de conscience accrue des besoins d’intégration en matière de surveillance maritime ${ }^{667}$. Compte tenu de la nécessité de la protection de l'environnement et la biodiversité, nous consacrerons notre quête de stratégie de lutte contre les actes illicites en mer aux instruments de lutte contre les trafics illicites et la pêche illégale ( $\$ 1$ ) et aux instruments de lutte contre la piraterie et la criminalité maritimes $(\boldsymbol{\$} 2)$.

\section{$\S 1$ : Les instruments de lutte contre les trafics illicites}

456- L'OMI édicte des normes internationales uniformes et l'Union Européenne assure leur application homogène dans ses États membres ${ }^{668}$. A titre d'illustration, on présentera l'Accord relatif au trafic illicite par mer, en

\footnotetext{
666 BOUDONG (Melle Nathalie), La piraterie maritime moderne, Mémoire, UNIVERSITE PAUL CEZANNE III, Droit Maritime et des Transports, Année universitaire 2008/2009, p. 58.

667 Voir dans ce sens AUDEBAUD (Nicolas), La lutte internationale contre la piraterie somalienne : représentations et enjeux, Mémoire, Université Paris 1, Panthéon-Sorbonne, 2010, pp. 247 et $\mathrm{s}$.

668 BEALL (Jacques), « La politique européenne de transport maritime au regard des enjeux de développement durable et des engagements climat ", JORF, Avis du Conseil économique, social et environnemental. Rapport, 11 mai 2017, op. cit., pp. 22-23.
} 
application de l'article 17 de la Convention des Nations Unies contre le trafic illicite de stupéfiants et de substances psychotropes (A). Ensuite sera présenté le Règlement (CE) n 1005/2008 du Conseil de l'Europe du 29 septembre 2008 sur la pêche illicite, non déclarée et non réglementée (INN) (B).

\section{A- L'Accord de l'Union Européenne relatif aux trafics illicites par mer}

457- Le 31 janvier 1995 à Strasbourg, a été conclu au sein du Conseil de l'Europe l'Accord relatif au trafic illicite par mer afin de mettre en place un cadre légal de coopération multilatérale pour la lutte contre le trafic illicite de drogue par mer. Cet accord a pour objet de mettre en œuvre, à l'échelle régionale européenne, l'article 17 de la Convention des Nations Unies contre le trafic illicite de stupéfiants et de substances psychotropes conclue à Vienne en décembre 1988669. En effet, l'Accord vise en particulier les infractions prévues par la Convention de Vienne de 1988 en son article 3, paragraphe 1, et qui sont commises au-delà des eaux territoriales ${ }^{670}$. Le cadre de coopération

669 Voir Convention des Nations Unies contre le trafic illicite de stupéfiants et de substances psychotropes signée à Vienne en décembre 1988, art. 17. "1. Les Parties coopèrent dans toute la mesure possible en vue de mettre fin au trafic illicite par mer, en conformité avec le droit international de la mer.

2. Une Partie qui a des motifs raisonnables de soupçonner qu'un navire battant son pavillon ou ... Les Parties ainsi requises fournissent cette assistance dans la limite des moyens dont elles disposent.

3. Une Partie qui a des motifs raisonnables de soupçonner qu'un navire exerçant la liberté de navigation conformément au droit international et battant le pavillon ou portant une immatriculation d'une autre Partie se livre au trafic illicite peut le notifier à l'Etat du ...

4. Conformément aux dispositions du paragraphe 3 ou aux traités en vigueur entre elles ou à tous autres accords ou arrangements conclus par ailleurs entre ces Parties, l'Etat du pavillon peut notamment autoriser l'Etat requérant à :

a) Arraisonner le navire ; b) Visiter le navire ; c) Si des preuves de participation à un trafic illicite sont découvertes, prendre les mesures appropriées à l'égard du navire, des personnes qui se trouvent à bord et de la cargaison ...".

670 Idem, art. 3. : "1. Chaque Partie adopte les mesures nécessaires pour conférer le caractère d'infractions pénales conformément à son droit interne, lorsque l'acte a été commis intentionnellement :

a) i) A la production, à la fabrication, à l'extraction, à la préparation, à l'offre, à la mise en vente, à la distribution, à la vente, à la livraison à quelque condition que ce soit, au courtage, à l'expédition, à l'expédition en transit, au transport, à l'importation ou à l'exportation de tout stupéfiant ou de toute substance psychotrope ...;

ii) A la culture du pavot à opium, du cocaïer ou de la plante de cannabis aux fins de la production de stupéfiants en violation des dispositions de la Convention de 1961 et de la Convention ... ; 
multilatérale mis en place par l'Accord porte essentiellement sur les échanges d'informations relatives aux infractions ci-dessus visées.

458- En outre, l'Accord définit le cadre de la coopération en matière de compétence judiciaire, de demande d'assistance et d'autorisation et enfin en matière d'exercice des mesures de contrôle et de coercition. Conformément à l'article 3, tout Etat peut exercer la compétence judiciaire pour des infractions commises à bord des navires battant pavillon étranger ou des navires apatrides au-delà des eaux territoriales des Etats. Toutefois, une telle compétence judiciaire doit être définie au moment de la ratification ou de l'adhésion de l'Etat à l'Accord. Aux termes de l'article 3, l'Etat du pavillon conserve son droit de compétence préférentielle mais aussi la latitude de l'exercer ou d'y renoncer.

459- En ce qui concerne la demande d'assistance l'Etat du pavillon, qui a des raisons sérieuses de penser que son navire se livre à des infractions, peut demander l'intervention d'un Etat partie pour mettre fin à ces actes. Quant-à la demande d'autorisation, elle consiste pour un Etat partie qui soupçonne qu'un navire battant pavillon d'un autre Etat partie est en train de se livrer à des infractions, à requérir l'autorisation de cet Etat du pavillon pour intervenir ${ }^{671}$. Conformément à l'article 9 de l'Accord ${ }^{672}$ l'intervention consiste, pour l'Etat intervenant, à arraisonner le navire, l'escorter dans une zone maritime nationale, l'inspecter, mettre les preuves sous scellé et les transmettre à l'Etat du pavillon. Il importe de préciser que la demande d'assistance peut être fondée sur tout soupçon relatif aux infractions portant sur les actes illicites notamment le trafic d'êtres vivants, le trafic de drogue et stupéfiants, l'immigration clandestine, la pêche illégale etc. Par ailleurs, conformément à sa législation nationale, l'Etat intervenant procède à l'arrestation des auteurs et à

iii) A la détention ou à l'achat de tout stupéfiant ou de toute substance psychotrope aux fins de l'une des activités énumérées au sous-alinéa i ci-dessus ;

iv) ...;

v) A l'organisation, à la direction ou au financement de l'une des infractions énumérées aux sousalinéas $i$, ii, iii ou iv ci-dessus ; ...».

671 Voir l'Accord relatif au trafic illicite par mer, mettant en œuvre l'article 17 de la Convention des Nations Unies contre le trafic illicite de stupéfiants et de substances psychotropes, art. 4. 672 Idem, art. 9. 
l'immobilisation du navire. En effet, grâce aux dispositions de l'Accord, «les Etats membres ne pourront intervenir de façon efficace et rapide contre toute activité de trafic illicite de drogue opéré par les navires au-delà des eaux territoriales des Etats parties $» 673$.

\section{B- Le Règlement ${ }^{674}$ (CE) $\mathbf{n}^{\circ}$ 1005/2008 du Conseil sur la pêche illicite, non déclarée et non réglementée (INN)}

460- A première vue le lien de ce Règlement avec la sécurité de la navigation maritime n'apparaît guère. Cependant, la nécessité de la protection de la biodiversité justifie son analyse. En réalité, son application en matière de transport maritime permet de lutter contre l'insécurité en mer en mettant à nu les navires délinquants qui pourraient se cacher sous l'identité de navires de pêche. Le Règlement (CE) n 1005/2008 du 29 septembre 2008 est un instrument qui vise à éradiquer la pêche $\mathrm{INN}^{675}$ par un contrôle adéquat de la chaîne d'approvisionnement des produits de pêche importés sur le marché de l'Union Européenne ${ }^{676}$. Il s'applique aux navires qui se livrent à des activités en violation des mesures de conservation et de gestion dans les eaux sous juridiction des Etats membres, les eaux d'Etats tiers, en haute mer y compris

${ }^{673}$ Voir YAPO (Marina Madel), La lutte contre la criminalité maritime dans le golfe de guinée : cas de la Côte d'Ivoire et du Nigeria, Etude du Programme de Bourses de Recherche, Nations Unies-Fondation Nippone du Japon 2012-2013, Décembre 2013, p. 51, http:/www.un.org/depts/los/nippon/unnff.

674 Voir BEALL (Jacques), « La politique européenne de transport maritime au regard des enjeux de développement durable et des engagements climat ", JORF, Rapport, op. cit., 11 mai 2017, p. 109. Le Règlement est un acte juridique qui émane des institutions de l'Union Européenne, de portée générale et obligatoire. Tous les États membres doivent obligatoirement le mettre en œuvre dans toutes ses dispositions de manière immédiate et directe, sans qu'il soit nécessaire de le transposer dans le droit national, à la différence des directives.

675 Règlement (CE) n 1005/2008 du Conseil du 29 septembre 2008 sur la pêche illicite, non déclarée et non réglementée. L'article 2 dispose : "Aux fins du présent règlement, on entend par : 1) "pêche illicite, non déclarée et non réglementée » ou "pêche INN», les activités de pêche considérées comme illicites, non déclarées ou non réglementées ; 2) "pêche illicite ", les activités de pêche : a) menées par des navires de pêche nationaux ou étrangers dans les eaux maritimes sous juridiction d'un État, sans l'autorisation de celui-ci ou en violation de ses lois et règlements; ...».

676 YAPO (Marina Madel), « La lutte contre la criminalité maritime dans le golfe de guinée : cas de la Côte d'Ivoire et du Nigeria », op. cit., p. 52. 
les eaux ne relevant de la juridiction d'aucun Etat677. En vue de la réalisation de son objectif, il a prévu certaines mesures notamment : "la mise en place d'un régime de certificat de capture, le contrôle par l'état du port et enfin des sanctions ".

461- Le régime de certificat de capture répond à l'objectif de protection des ressources halieutiques. En effet, toute importation de produits de pêche des navires d'Etats tiers dans la Communauté Européenne n'est autorisée que si elle est assortie d'un certificat de capture validé par l'Etat du pavillon. De même, toute exportation de produits de pêche effectuée par les navires des Etats de la Communauté Européenne est subordonnée à la validation d'un certificat de capture par l'autorité compétente de l'Etat du pavillon membre ${ }^{678}$.

462- En ce qui concerne le contrôle de l'Etat du port, conformément à l'article 5, paragraphe 1 du Règlement, les débarquements et les transbordements des produits de pêche des navires des Etats tiers ne sont autorisés que dans des ports désignés exclusivement par chaque Etat membre. A cet effet, le capitaine est tenu de notifier l'arrivée de son navire dans le port au moins trois jours avant et communiquer toutes les informations requises portant sur le navire, les captures ${ }^{679}$ et autres. Par ailleurs, les navires de pêche soupçonnés avoir pratiqué la pêche illicite non déclarée et non réglementée (pêche INN) doivent faire l'objet d'une inspection systématique.

463- S’agissant des mesures de répression, le Règlement 1005/2008 a prévu un système harmonisé de sanctions administratives et pénales efficaces, proportionnées et dissuasives pour les infractions graves 680 . Ensuite, sont établies une liste de navires communautaires INN et une liste d'Etats tiers non

\footnotetext{
677 Pour les détails relatifs aux navires auxquels cet instrument est appliqué, voir le Règlement 1005/2008 du Conseil de l'Europe du 29 septembre 2008, notamment les articles 3 et 1 paragraphe 3 .

678 Voir Règlement 1005/2008 du Conseil de l'Europe du 29 septembre 2008, notamment les articles 12-2 et 15-1.

${ }^{679}$ Cf : Règlement 1005/2008 du Conseil de l'Europe du 29 septembre 2008, art. 6-1.

680 YAPO (Marina Madel), « La lutte contre la criminalité maritime dans le golfe de guinée : cas de la Côte d'Ivoire et du Nigeria ", Etude du Programme de Bourses de Recherche, Nations Unies-Fondation Nippone du Japon 2012-2013, Décembre 2013, p. 53.
} 
coopérants pour lesquels des sanctions sont également prévues ${ }^{681}$. A travers le Règlement 1005/2008 du Conseil de l'Europe du 29 septembre 2008, l'Union Européenne définit alors les bases d'une lutte efficace contre la pêche illégale. Par ricochet, cette lutte contre la pêche illégale bénéfice également à la lutte contre l'insécurité de la navigation maritime dès lors qu'elle peut permettre d'appréhender les auteurs de trafics illicites et de lutter contre la piraterie et la criminalité en mer.

\section{$\S 2$ : Les instruments de lutte contre la criminalité et la piraterie en mer}

464- Dans l'espace Union européenne, les instruments de lutte contre la piraterie et la criminalité maritimes sont nés avec l'adoption du Traité de Maastricht du 7 février 1992. En effet, selon Monsieur Pierre Delfaud, c'est à partir de 1992 que la politique commune de la sécurité maritime est devenue une ambition de l'Union européenne ${ }^{682}$. A cet effet, la Commission a diffusé, le 24 février 1993 la communication intitulée : "Pour une politique commune de la sécurité maritime de la sécurité maritime »683. Ainsi, pour renforcer la sécurité et la sûreté maritimes au regard de la montée de la criminalité dans les eaux européennes, divers instruments ont été récemment adoptés ${ }^{684}$ et des structures

681 Voir Règlement 1005/2008 du Conseil de l'Europe du 29 septembre 2008, arts. 37 et 38. ${ }^{682}$ Cf : DELFAUD (Pierre), La sécurité du transport et du trafic maritime de marchandises, RESEAU TRANSNATIONAL ATLANTIQUE DES PARTENAIRES ECONOMIQUES ET SOCIAUX, Rapport, Mai 2005, p. 18.

${ }^{683} \mathrm{Cf}$ : Commission de l'Union européenne, http://www.emsa.europa.eu archive, consulté le 16 août 2019.

${ }^{684}$ Après le naufrage de l'Erika en décembre 1999, plusieurs recommandations ont été formulées et regroupées sous l'appellation Paquet Erika I (21 mars 2000). Elles portent d'abord "sur le renforcement du contrôle des navires dans les ports européens, pour les navires à risque et un bannissement de certaines catégories de navires "règlement double coques 1 ». Ensuite, "sur un renforcement du contrôle des États sur les sociétés de classification et la définition des responsabilités de chacun. Et enfin, "sur des mesures "positives" pour la construction de bases de données et une meilleure circulation de l'information auprès des États, des organismes de certification et autres organismes concernés par la sécurité maritime ", http://www.emsa.europa.euarchive, consulté le 13 mai 2018. Voir également BEALL (Jacques), « La politique européenne de transport maritime au regard des enjeux de développement durable et des engagements climat ", JORF, Avis du Conseil économique, social et environnemental, Rapport, mai 2017, op. cit., p. 24. Il y a entre autres le paquet législatif, « Erika III ». En effet, adopté le 11 mars 2010, il interdit l'accès aux ports de l'UE aux navires " sous normés " et met en place une indemnisation accrue des victimes de catastrophes. Ainsi depuis 2011, les États du port doivent 
mises en place par la Communauté Européenne. Toutefois, à travers l'Acte relatif à l'Action Commune 2008/851/PESC du Conseil du 10 novembre 2008 pour une contribution à la dissuasion, à la prévention et à la répression des actes de piraterie et de vols à main armée au large des côtes de la Somalie, l’Union européenne apporte son assistance à d'autres zones maritimes notamment dans les eaux somaliennes. Dans le cadre de l'assistance apportée par la Communauté européenne, selon Madame Marina Madel Yapo, "l’Union Européenne s'est engagée à coopérer avec le Gouvernement de transition de la Somalie à la répression des actes de piraterie dans les eaux somaliennes et en haute mer. Les dispositions de l'Acte déterminent entre autres, le mandat des forces d'intervention européennes, les modalités de participation des Etats tiers aux opérations, les conditions de transfert des personnes appréhendées ainsi que les objets saisis en vue des poursuites judiciaires ${ }^{685}$.

465- Examinons à présent le Règlement du parlement européen et du Conseil du 31 mars 2004, relatif à l'amélioration de la sûreté des navires et des installations portuaires (A) et l'Action Commune 2008/851/PESC du Conseil du 10 novembre 2008 relative à l'opération militaire de l'UE pour une contribution à la lutte contre les actes illicites au large des côtes de la Somalie (B).

\section{A- Au niveau de l'amélioration de la sûreté des navires et des installations portuaires}

466- En vue de renforcer la sûreté des navires et des installations portuaires en Europe, le Parlement et le Conseil de l'Europe ont élaboré le Règlement $n^{\circ} 725 / 2004$ en application du Code ISPS. En effet, ledit règlement édicte des normes pour la mise en œuvre et le contrôle du Code ISPS au sein de la Communauté Européenne. Il recommande aux Etats membres de la

\footnotetext{
inspecter tous les navires faisant escale dans leurs ports ou mouillant au large, selon des critères de risques. Les navires régulièrement " sous normés " pourront être bannis définitivement des eaux européennes. Des audits de sécurité devront être réalisés sur l'ensemble des flottes des pays européens. "Erika III » contraint les plus gros navires à souscrire une assurance pour couvrir les dommages aux personnes en cas d'accident.

685 YAPO (Marina Madel), La lutte contre la criminalité maritime dans le golfe de guinée : cas de la Côte d'Ivoire et du Nigeria, Programme de Bourses de Recherche, Nations Unies-Fondation Nippone du Japon 2012-2013, Etude, op. cit., décembre 2013, p. 43.
} 
Communauté la transposition systématique des dispositions du Code ISPS dans leurs législations nationales. A cet effet, la France a adopté le décret n²004-290 du 26 mars 2004 portant publication des amendements à l'annexe de la convention internationale de 1974. Selon Monsieur Jacques Beall, "Le règlement $(C E) n^{\circ} 725 / 2004$ a été conçu pour garantir une interprétation et une mise en œuvre uniformes des décisions adoptées par l'OMI. La stratégie de sûreté maritime de l'Union a été lancée via l'adoption par le Conseil, le 24 juin 2014, d'un acte politique et stratégique permettant de faire face efficacement et de manière globale aux défis en matière de sureté maritime par le recours à tous les instruments pertinents, sur les plans international, européen et national »686.

467- En outre, le règlement $(\mathrm{CE}) \mathrm{n}^{\circ}$ 725/2004 recommande à chaque Etat membre de l'Union Européenne la nomination d'une autorité nationale compétente chargée de la coordination et du contrôle ${ }^{687}$ de l'application des mesures prescrites. Pour s'assurer de l'application effective des mesures mises en place, un comité technique a été créé et chargé de mener des inspections dans les points de contacts respectifs des Etats. Ces inspections sont sanctionnées par un rapport adressé aux Etats concernés, qui sont alors tenus d'apporter dans les trois mois qui suivent, les mesures correctives nécessaires en cas de défaillance constatées ${ }^{688}$. Conformément aux dispositions du Règlement, les Etats sont

686 Voir BEALL (Jacques), « La politique européenne de transport maritime au regard des enjeux de développement durable et des engagements climat", JORF, Avis du Conseil économique, social et environnemental, Rapport op. cit., 11 mai 2017, p. 24.

${ }^{687}$ BEALL (Jacques), « La politique européenne de transport maritime au regard des enjeux de développement durable et des engagements climat», op. cit., 11 mai 2017, p. 66. L'Union Européenne a mis en place un cadre réglementaire très complet et très exigeant avec pour objectif d'éliminer des eaux communautaires, les navires ne répondant pas aux normes de sécurité. Ce cadre est opérationnel depuis plusieurs années et a un effet fortement dissuasif pour les armateurs et chargeurs peu regardants du fait de la probabilité élevée de contrôle et des risques d'immobilisation ou de détention des navires. Ainsi plus de 15000 contrôles sont effectués chaque année en Europe, le pourcentage de détention de navires étant passé de 5,4\% à $3,3 \%$ entre 2006 et 2014 et restant stable depuis. Le nombre total de navires de transport international est de plus de 50000 unités. La France pour sa part contrôle annuellement environ 1200 navires, sauf en 2016 ou on a observé une baisse de fréquentation, pour plus de 5600 escales effectuées par les navires.

${ }^{688}$ Règlement (CE) n 725/2004 du parlement Européen et du Conseil, arts. 9-4 et 9-6. 
tenus de prendre des sanctions efficaces et dissuasives à l'encontre de tout contrevenant 689 .

\section{B- Au niveau de la lutte contre les actes illicites au large des côtes de la Somalie}

468- En référence à son action de coordination militaire ${ }^{690}$, l’Union européenne a adopté un Acte ${ }^{691}$ portant sur l'action commune en Somalie du 10 novembre 2008 visant à coopérer avec le Gouvernement de transition de la Somalie en vue de la dissuasion, la prévention et la répression des actes de piraterie et de vols à main armée dans les eaux somaliennes et en haute mer ${ }^{692}$. Les dispositions de l'Acte déterminent le mandat des forces d'intervention européennes, les modalités de participation des Etats tiers aux opérations, les conditions de transfert des personnes appréhendées ainsi que les objets saisis en vue des poursuites judiciaires ${ }^{693}$. Conformément à l'article 6 de l'Acte du 10 novembre 2008, le mandat des forces consiste à la sécurisation des voies maritimes commerciales sous la coordination du Comité politique et de sécurité. Toutefois, bien qu'étant un Acte de l'Union Européenne, il est ouvert à la participation d'Etats tiers qui, à cet effet, doivent conclure au préalable un accord définissant les conditions de transfert des personnes appréhendées ${ }^{694}$. L'article 12, paragraphe 1 de l'Acte précise que le transfert s'opère sur la base

\footnotetext{
689 Pour toutes ces précisions, voir YAPO (Marina Madel), La lutte contre la criminalité maritime dans le golfe de guinée : cas de la Côte d'Ivoire et du Nigeria. Programme de Bourses de Recherche, Nations Unies-Fondation Nippone du Japon 2012-2013, Etude, op. cit., décembre 2013 , p. 43.

690 Voir Action commune 2008/749/PESC du Conseil du 19 septembre 2008 relative à l'action de coordination militaire de l'Union européenne à l'appui de la résolution 1816 (2008) du Conseil de sécurité des Nations unies (EU NAVCO) J.O. L 252 du 20.9.2008, p. 39-42.

${ }^{691}$ Suite aux résolutions 1814 (2008) et 1816 (2008) du Conseil de Sécurité des Nations Unies.

${ }^{692}$ Voir BRONER (Romain), La répression de la piraterie maritime et ses enjeux juridiques. Mémoire de Master Recherche, Sécurité et Défense, Université Panthéon-Assas-paris II, Année universitaire 2009/2010, p. 80. Selon l'auteur, on a pu parler de partage des responsabilités dans la lutte contre la piraterie : les marines occidentales apportent les capacités militaires et les Etats de la zone, dépourvus de moyens militaires, apportent une solution pénale.

${ }^{693} \mathrm{Cf}$ : YAPO (Marina Madel), La lutte contre la criminalité maritime dans le golfe de guinée : cas de la Côte d'Ivoire et du Nigeria, Programme de Bourses de Recherche, Nations UniesFondation Nippone du Japon 2012-2013, Etude, op. cit., décembre 2013, p. 43.

${ }^{694}$ Règlement (CE) n 725/2004 du parlement Européen et du Conseil, art. 10-3.
} 
de l'acceptation de la Somalie et conformément à l'article 105 de la Convention de Montego Bay ${ }^{695}$.

469- Les instruments régionaux de lutte contre les trafics et les actes illicites en mer adoptés par l'Union sont un aspect de la stratégie européenne de lutte contre l'insécurité maritime ${ }^{696}$. "L'implication de l'Union Européenne dans la lutte contre la piraterie somalienne semble avoir aussi participé à une prise de conscience accrue des besoins d'intégration en matière de surveillance maritime ${ }^{697}$. Monsieur Nicolas Audebaud justifie la mobilisation de la communauté internationale pour combattre la piraterie somalienne par des intérêts liés à des enjeux internes et à une volonté d'affirmer le rang international de chaque Etat impliqué dans ce dispositif. Il poursuit son analyse en indiquant que la prise en otage de nationaux demeure une question sensible pour les opinions publiques des sociétés et notamment des sociétés occidentales. Les gouvernements jouent leur crédibilité politique sur leur capacité à garantir la sécurité de leurs ressortissants et veulent aussi limiter au maximum le paiement de rançons pour éviter d'alimenter le système. De notre point de vue, l’Union européenne s'est davantage impliquée dans la piraterie en Somalie parce que celle-ci a un relent terroriste; ce qui n'est pas le cas de la piraterie dans le golfe de Guinée pour

${ }^{695}$ BRONER (Romain), La répression de la piraterie maritime et ses enjeux juridiques, Mémoire, Université Panthéon-Assas - paris II, Année 2009/ 2010, p. 52. Selon l'auteur, pour mieux coller à la fois aux exigences des résolutions du Conseil de Sécurité et aux possibilités offertes par celles-ci et par la Convention de Montego Bay, l'Union européenne a conclu des accords avec deux Etats pour la traduction en justice des pirates capturés : le Kenya et les Seychelles. Ces accords permettent aux forces navales présentes sur la zone qui agissent dans le cadre du mandat d'Atalanta de remettre les pirates à ces Etats, s'ils l'acceptent, afin d'être jugés. Le succès de l'opération Atalanta est indéniable, avec notamment depuis décembre 2008429 pirates arrêtés, dont 176 ont été remis à la justice, avec un taux de poursuite de l'ordre de $40 \%$. overblog.com/pages/_Bilan_des_operations_antipiraterie_Eunavfor_Atalanta_CTF_Otan_Russi Consulté le 26 avril 2010.

${ }^{696}$ AUDEBAUD (Nicolas), La lutte internationale contre la piraterie somalienne : représentations et enjeux, Mémoire de Master 2 de recherche, Université Paris 1 Panthéon-Sorbonne, 2010, pp. 251 et s. L'auteur indique que les acteurs européens de la lutte navale contre la piraterie somalienne présentent l'opération Atalante comme un succès en insistant sur le fait qu'il s'agit de la première opération de la Politique de Sécurité et de Défense Commune PSDC qui défende directement les intérêts des Européens.

${ }^{697}$ Idem, op. cit., pp. 249 et s. 
l'instant. Nicolas Audebaud n'a pas manqué de le souligner698. Cependant, le domaine d'intégration résiduel pour parachever la stratégie européenne de lutte contre l'insécurité maritime porte sur la coopération régionale au sein de l'Union en vue de la lutte contre les actes illicites en mer.

\section{Section 2 : Des exemples de coopération régionale en matière de lutte contre les actes illicites en mer}

470- Certaines zones maritimes se sont quasiment débarrassées de la piraterie, d'autres connaissent toujours, de manière endémique, certains actes de piraterie ou de brigandage ${ }^{699}$. La Commission Européenne est l'organe de l'Union Européenne dont le rôle est la promotion de l'intérêt général et la prise d'initiatives appropriées à cette fin. Elle propose des actes législatifs au Conseil qui est chargé de les étudier et les adopter en rapport avec le Parlement Européen ${ }^{700}$. La coopération au sein de l'Union européenne en vue de la lutte contre la piraterie et le vol à main armée s'étend tant bien au domaine opérationnel (\$ 1) qu’à celui de la prévention et de la répression $(\boldsymbol{\$} \mathbf{2})$.

\section{$\S 1$ : La coopération en matière de lutte opérationnelle}

471- En ce qui concerne la coopération en matière de lutte opérationnelle, on examinera différents moyens tels que l'Agence européenne pour la sécurité maritime (A) et le règlement 1625 de l’Union Européenne du 24 septembre 2016 (B).

\footnotetext{
${ }^{698}$ AUDEBAUD (Nicolas), La lutte internationale contre la piraterie somalienne : représentations et enjeux, op. cit., p. 112. "Ces programmes avaient d'abord pour but de renforcer le secteur de la sécurité au Somaliland et au Puntland. [...]. Les principaux [financiers] de ces programmes étaient le Programme des Nations Unies pour le Développement (PNUD), [...], l'Ethiopie, les Etats-Unis et le Royaume-Uni. L'origine de ces fonds tend à faire penser que l'objectif n'était pas tant de soutenir le secteur de la sécurité en Somalie que de financer par procuration l'intervention éthiopienne et la lutte antiterroriste des Américains pour empêcher l'établissement durable d'un gouvernement islamiste à Mogadiscio ".

699 BRONER (Romain), La répression de la piraterie maritime et ses enjeux juridiques, Mémoire de Master de Recherche, Sécurité et Défense, Université Panthéon-Assas-paris II, Année universitaire 2009/ 2010, op. cit., p. 10.

700 Voir Commission Européenne : http://ec.europa.eu/index_fr.htm.
} 


\section{A- Cas de l'Agence européenne pour la sécurité maritime}

472- En matière de lutte opérationnelle, la Commission de l’Union européenne est dotée, depuis 2002, de l'Agence européenne pour la sécurité maritime ${ }^{701}$. L'Agence a pour mission d'améliorer la sécurité et la sureté maritimes. L'EMSA fournit aux autorités maritimes des informations détaillées sur ce qui se passe en mer en temps réel pour les aider à mettre en œuvre efficacement les politiques maritimes à travers différents outils comme SafeSeaNet et CleanSeaNet ${ }^{702}$. Conformément à sa mission, "Elle fournit ainsi des services qui répondent à l'évolution des besoins des autorités maritimes dans toute l'Europe : la notification des navires, l'observation satellitaire, le système d'information maritime intégré, la lutte contre la pollution, le suivi et l'analyse des contrôles par l'État du port. Elle mène également de nombreux types de contrôles : elle inspecte les sociétés de classification reconnues par les pays de l'UE, évalue les systèmes d'éducation et de certification maritimes de pays non membres de l'UE, vérifie que les navires faisant escale dans les ports de l'UE sont correctement inspectés, évalue les systèmes nationaux de contrôle du trafic maritime. En outre, l'EMSA assure la cohérence des enquêtes sur les accidents maritimes dans toute l'UE. Elle mène également des tâches de nature opérationnelle comme la mise à disposition de navires en cas de marée noire importante au profit des États membres de l'UE et la détection de la pollution marine par satellite $» 703$.

473- En outre, selon le rapport de Monsieur Jacques Beall ci-dessus cité, l'Agence européenne de sécurité maritime traite un large éventail de questions liées à la sécurité et à la sureté maritimes d'un point de vue technique, scientifique ou réglementaire et possède dans son domaine, une expertise approfondie qui est reconnue aux niveaux européen mais aussi international.

\footnotetext{
${ }^{701}$ En abrégé EMSA ; qui signifie en Anglais European Maritime Security Agency.

702 Voir BEALL (Jacques), « La politique européenne de transport maritime au regard des enjeux de développement durable et des engagements climat », JORF, Rapport op. cit., 11 mai 2017, pp. 24-25.

${ }^{703}$ BEALL (Jacques), « La politique européenne de transport maritime au regard des enjeux de développement durable et des engagements climat», JORF, Rapport op. cit., 11 mai 2017, pp. $24-25$.
} 
L'Agence facilite la coopération technique entre les autorités des États membres et la Commission de l'Union Européenne et coordonne ses travaux et missions avec différentes agences européennes ${ }^{704}$. Il convient toutefois d'indiquer qu'il ressort du rapport précité que les moyens attribués à l'EMSA ne sont pas à la hauteur de ses missions.

474- Pour ce qui concerne le domaine des évaluations, selon Jacques Beall, l'Agence européenne pour la sécurité maritime a entrepris une analyse horizontale pour couvrir la mise en œuvre de la directive 2009/16/CE, avec des cycles de visite entre mars 2012 et avril 2016 dans 22 États membres et deux zones économiques européennes ${ }^{705}$. L'évaluation porte sur l'ensemble des dispositions de la directive ainsi que les procédures en vigueur du Mémorandum de Paris.

\section{B- Cas du Règlement 1625 de l'Union Européenne du 24 septembre 2016}

475- La politique de la sureté maritime est une réalité au sein de l’Union Européenne. En effet, à travers le Règlement 1625 adopté le 24 septembre 2016, l'Union européenne prévoit un système de coopération en matière de lutte opérationnelle contre l'insécurité maritime ${ }^{706}$. L'objectif de ce Règlement consiste, entre autres, à améliorer la coopération et la coordination entre les organismes nationaux et les agences qui assurent des fonctions de garde-côtes, en particulier dans les domaines de la surveillance opérationnelle et du partage des données. Cette coopération se manifeste par la collaboration entre les différents services spécialisés en matière de lutte contre l’insécurité maritime.

\footnotetext{
704 BEALL (Jacques), « La politique européenne de transport maritime au regard des enjeux de développement durable et des engagements climat", JORF, Rapport op. cit., 11 mai 2017, pp. 24-25.

${ }^{705}$ BEALL (Jacques), « La politique européenne de transport maritime au regard des enjeux de développement durable et des engagements climat», op. cit., p. 66.

706 Voir BEALL (Jacques), « La politique européenne de transport maritime au regard des enjeux de développement durable et des engagements climat ", JORF, Rapport op. cit., p. 68. Dans cette optique, M. Jacques Beall indiquait qu' : "Actuellement, plus de 300 autorités civiles et militaires des États membres assument des fonctions de garde-côtes dans un large éventail de domaines, tels que la sécurité et la sureté maritimes, les opérations de recherche et de sauvetage, le contrôle aux frontières, le contrôle des pêches, le contrôle douanier, l'application générale de la législation et la protection de l'environnement».
} 
A notre avis, l'accroissement des synergies entre les différents services des agences concernées, offre une opportunité aux autorités nationales en charge de la fonction de garde-côtes.

476- Le rapport fourni par Monsieur Jacques Beall indique bien qu'au niveau des Etats, cette fonction de garde-côtes peut être partagée entre de multiples agences avec une coordination parfois complexe ${ }^{707}$. L'auteur cite l'exemple de la France où une large part de la fonction de garde-côtes est assumée par la Marine Nationale, les Douanes et la Direction des Affaires maritimes. Quant-à Monsieur Romain BRONER, il indiquait que l'action concertée entre les Etats est au cœur de la suppression de la piraterie. A cet effet, deux types d'actions sont mises en œuvre: des actions de coordination entre différents Etats 708 et des actions de coopération plus poussées ${ }^{709}$. La coopération opérationnelle entre les Etats a tout son sens. Elle devient plus efficace lorsqu'elle s'achève par une coopération en matière de la répression des présumés pirates et bandits à main armée.

\section{§ 2 : La coopération en matière de lutte répressive contre la criminalité maritime}

477- Des exemples de coopération régionale en matière de répression des pirates de mer sont mis en œuvre dans d'autres zones maritimes notamment dans les eaux asiatiques. L’accord de coopération régionale sur la lutte contre la piraterie et les vols à main armée contre les navires en Anglais : Regional Cooperation Agreement on Combating Piracy and Armed Robbery (ReCAAP), signé le 11 novembre 2004 à Tokyo, et entré en vigueur le 4 septembre 2006, est

\footnotetext{
${ }^{707}$ BEALL (Jacques), « La politique européenne de transport maritime au regard des enjeux de développement durable et des engagements climat ", JORF, Rapport op. cit., 11 mai 2017, p. 69. 708 Cf : BRONER (Romain), La répression de la piraterie maritime et ses enjeux juridiques. Mémoire de Master de Recherche, Sécurité et Défense, Université Panthéon-Assas-Paris II, Année universitaire 2009/2010, op. cit., pp. 54 et 55. Pour l'auteur, les mécanismes de coordination, s'ils peuvent paraître les moins poussés, n'en demeurent pas moins indispensables pour avoir une vision d'ensemble du phénomène et permettre d'agir de manière coordonnée et donc, plus efficace.

${ }^{709}$ Idem, p. 56. L'auteur explique que les mécanismes de coopération, plus poussés, vont au-delà du simple partage d'information et de concertation sur la lutte contre la piraterie et qu'ils sont largement promus pour résorber la piraterie.
} 
destiné à combiner les efforts de toutes les parties dans la prévention et la lutte contre la piraterie dans la zone de l'Asie ${ }^{710}$. Au niveau de l'Union Européenne, la coopération régionale en vue de la répression de la piraterie consiste, d'une part, à l'observation d'une assistance mutuelle relative aux enquêtes, poursuites et procédures judiciaires (A) et, d'autre part, à l'établissement d'un point focal dans chaque Etat pour les émissions et les réceptions de demandes d'assistance (B).

\section{A- L'observation d'une assistance mutuelle relative aux enquêtes, poursuites et procédures judiciaires}

478- En leur qualité d'Etats parties à la Convention des Nations Unies contre la criminalité transnationale organisée de décembre 2000, les Etats membres de l'Union Européenne sont alors tenus d'observer les dispositions de la Convention de Palerme dont l'objet, conformément à son article premier, est la coopération afin de prévenir et de combattre plus efficacement la criminalité transnationale organisée. Ainsi, lesdites dispositions prévoient que «les États Parties s'accordent mutuellement l'entraide judiciaire la plus large possible lors des enquêtes, poursuites et procédures judiciaires concernant les infractions visées par la présente Convention, comme prévu à l'article $3 »{ }^{711}$. En outre, les Etats de l'Union Européenne s'accordent réciproquement une entraide similaire lorsque l'État partie requérant a des motifs raisonnables de soupçonner que l'infraction visée à l'alinéa $a$ ou $b$ du paragraphe 1 de l'article 3 est de nature transnationale, y compris quand les victimes, les témoins, le produit, les instruments ou les éléments de preuve de ces infractions se trouvent dans l'État partie requis et qu'un groupe criminel organisé y est impliqué712.

479- Aux termes de l'article 7 de la Convention des Nations Unies contre le trafic illicite de stupéfiants et de substances psychotropes de 1988, les parties s'accordent mutuellement l'entraide judiciaire la plus étendue pour toutes

\footnotetext{
${ }^{710}$ Pour les détails, voir BOUDONG (Melle Nathalie), La piraterie maritime moderne, Mémoire, UNIVERSITE PAUL CEZANNE III, Année universitaire 2008/2009, pp. 62-63.

711 Voir Convention des Nations Unies contre la criminalité transnationale organisée de décembre 2000, art. 18-1.

712 Idem.
} 
enquêtes, poursuites pénales et procédures judiciaires concernant les infractions établies conformément au paragraphe 1 de l'article 3. Aussi, l'entraide judiciaire qui est accordée peut être demandée aux fins de recueillir des témoignages ou des dépositions ; signifier des actes judiciaires; effectuer des perquisitions et des saisies; examiner des objets et visiter des lieux; fournir des informations et des pièces à conviction; fournir des originaux ou des copies certifiées conformes de documents et dossiers pertinents; identifier ou détecter des produits, des biens, des instruments ou d'autres choses afin de recueillir des éléments de preuve. Enfin, les Parties peuvent s'accorder entre elles toute autre forme d'entraide judiciaire autorisée par le droit interne de la Partie requise.

\section{B- L'établissement de point focal dans chaque Etat pour émissions et réceptions des demandes d'assistance}

480- L'entraide judiciaire prévue par l'article 7, paragraphe 1 de la Convention des Nations Unies contre le trafic illicite de stupéfiants et de substances psychotropes se concrétise à travers son article 17. Ainsi, en ce qui concerne la demande d'assistance, une partie qui a des motifs raisonnables de soupçonner qu'un navire battant son pavillon ou n'arborant aucun pavillon ou ne portant aucune immatriculation se livre au trafic illicite peut demander aux autres parties de l'aider à mettre fin à cette utilisation ${ }^{713}$. Et s'agissant de la demande d'autorisation, "Une Partie qui a des motifs raisonnables de soupçonner qu'un navire exerçant la liberté de navigation conformément au droit international et battant le pavillon ou portant une immatriculation d'une autre Partie se livre au trafic illicite peut le notifier à l'Etat du pavillon, demander confirmation de l'immatriculation et, si celle-ci est confirmée, demander l'autorisation à cet Etat de prendre les mesures appropriées à l'égard de ce navire $» 714$.

481- Les demandes d'assistance et les demandes d'autorisation ainsi formulées sont adressées à une autorité désignée en vue de leur traitement et de la suite à donner. Cette autorité désignée, dans chaque Etat partie à l'Accord

713 Convention des Nations Unies contre le trafic illicite de stupéfiants et de substances psychotropes, art. 17-2.

${ }^{714}$ Idem, art. 17-3. 
de l'Union Européenne de 1995 relatif au trafic illicite de drogue par mer, est encore appelée point focal de l'Etat ${ }^{715}$. A la lumière de la Convention des Nations Unies contre le trafic illicite de stupéfiants et de substances psychotropes, la coopération est la plus large possible ${ }^{716}$.

482- La coopération en matière de répression se poursuit dans la Communauté européenne à travers la création d'un centre d'analyse et de surveillance maritime. Selon Madame Marina Madel YAPO, "le centre d'analyse et de surveillance maritime de l'Atlantique a été d'un grand apport dans la lutte contre le trafic de drogue par mer dans la région de la méditerranée. Le rôle de collecte, d'analyse, d'échange d'informations, de surveillance et d'interception maritime ainsi que l'organisation interne mis en place au sein de ce centre, fait d'elle une véritable plateforme régionale de sûreté. La coordination des actions entre les services regroupés en son sein lui a permis, en moins de trois ans d'activités de réaliser des résultats satisfaisants. Ainsi, en 2008, 40 tonnes de cocaïnes ont été saisies et en 2009 une saisie de 65 tonnes de cocaïnes et 45 tonnes de cannabis a été enregistrée ${ }^{717}$. Enfin, il convient de relever que la coopération régionale se présente comme l'élément clef de la répression en droit communautaire en matière de lutte contre les actes illicites en mer.

\footnotetext{
715 Voir l'Accord de l'Union Européenne de 1995, relatif au trafic illicite de drogue par mer, art. 4 et 6.

716 Voir Convention art. 7-2.

717 YAPO (Marina Madel), «La lutte contre la criminalité maritime dans le golfe de guinée : cas de la Côte d'Ivoire et du Nigeria ", Programme de Bourses de Recherche, Nations UniesFondation Nippone du Japon 2012-2013, Etude, Décembre 2013, op. cit., p. 89. http:/www.un.org/depts/los/nippon/unnff.
} 


\section{Conclusion du titre 1}

483- Dans l'analyse du cadre législatif des transports de marchandises par mer en droit comparé, nous avons porté l'option sur les normes de protection de la marchandise en droits nationaux de pays étrangers et la stratégie de lutte contre l'insécurité maritime en droit communautaire européenne. En ce qui concerne les normes de protection de la marchandise en droits nationaux de pays étrangers, après la présentation des normes régissant la responsabilité du transporteur en droit belge et canadien, les normes de détermination de la responsabilité du transporteur en droit français ont été examinées. Cet examen a permis de constater qu'en droit français, la responsabilité du transporteur maritime est présumée ${ }^{718}$ comme c'est le cas en droit ivoirien. En revanche, la durée de cette responsabilité diffère selon qu'on est en droit français ou en droit ivoirien. En droit français, la responsabilité du transporteur est présumée depuis la prise en charge de la marchandise jusqu'à sa livraison au destinataire $^{719}$. Il en résulte que la présomption de responsabilité du transporteur couvre aussi bien les opérations purement maritimes que les opérations pré et post maritimes.

484- S'agissant de la stratégie de lutte contre l'insécurité maritime dans la communauté européenne, elle comporte deux axes essentiels. Le premier axe consiste à adopter des instruments juridiques à l'échelle régionale en vue de lutter contre les trafics illicites ${ }^{720}$, la pêche illégale et la criminalité et la piraterie en mer en tenant compte des conventions internationales déjà élaborées dans ces matières. Le second axe est relatif à la mise en œuvre d'une

\footnotetext{
718 Conformément à l'article 3 de la Convention de Bruxelles de 1924 et à article 27 de la loi du 18 juin 1966, le transporteur est responsable des pertes ou dommages subis par la marchandise depuis la prise en charge jusqu'à la livraison, à moins qu'il ne prouve que ces pertes ou dommages proviennent de cas d'exonération. Il pèse sur le transporteur maritime une présomption de responsabilité.

${ }^{719}$ L'article 16 de la loi française $n^{\circ}$ 66-420 du 18 juin 1966 en s'appliquant aux opérations de transport qui sont hors du champ d'application de la Convention de Bruxelles, présume la responsabilité du transporteur depuis la prise en charge de la marchandise jusqu'à sa livraison. Par ce dispositif, la présomption couvre les opérations aussi bien maritimes que non maritimes. ${ }^{720} \mathrm{Il}$ s'agit essentiellement du trafic illicite de stupéfiants et de substances psychotropes prévu par la Convention des Nations Unies conclue à Vienne en décembre 1988.
} 
coopération régionale afin de rendre efficace la lutte contre les infractions maritimes sus indiquées. Pour ce faire, la Communauté européenne a initié en son sein, d'une part, une coopération opérationnelle ${ }^{721}$ en vue de prévenir les actes illicites en mer et, d'autre part, elle observe une coopération en matière de répression des actes illicites déjà perpétrés ${ }^{722}$.

485- Au regard de l'état des lieux du cadre législatif des transports de marchandises, quelles recommandations proposons-nous aux fins non seulement d'améliorer la protection de la marchandise au cours de son transport mais également d'améliorer la sécurité et la sûreté de la navigation maritime?

${ }^{721}$ Voir supra $\mathrm{n}^{\circ} 475$ et 476 , pp. 228-220. On peut noter la mise en place de l'Agence européenne pour la sécurité maritime et l'adoption du règlement 1625 de l'Union Européenne du 24 septembre 2016 relatif à l'exercice des fonctions de garde-côtes.

${ }^{722}$ Voir supra $n^{\circ} 482$, p. 232. La coopération régionale à l'échelle de l'Union Européenne en vue de la répression de la piraterie consiste, entre autres, à l'observation d'une assistance mutuelle relative aux enquêtes, poursuites et procédures judiciaires. 
TITRE 2: LAMELIORATION DES NORMES DE PROTECTION DE LA MARCHANDISE ET DE LUTTE CONTRE L'INSECURITE MARITIME A LA LUMIERE DU DROIT ETRANGER 
486- Les développements qui précèdent ont montré qu'il existe en Côte d'Ivoire un cadre législatif consacré au transport maritime. Ce cadre législatif, passé au crible d'une analyse, a présenté deux insuffisances majeures à savoir son inefficacité à protéger la marchandise et à lutter contre l'insécurité maritime dans le golfe Guinée ${ }^{723}$. Dans notre quête de solutions à cette double inefficacité de la législation ivoirienne entravant le transport de marchandises par mer, nous avons jugé opportun d'inviter le législateur ivoirien à s'inspirer de l'expérience tirée du droit étranger. Pour ce faire, nous avons exposé les normes de protection de la marchandise mises en œuvre en droit belge, canadien et français et les normes de lutte contre l'insécurité maritime expérimentées en droit communautaire européen. Les résultats de notre réflexion feront l'objet de recommandations à l'adresse du législateur ivoirien et du législateur sous régional afin d'améliorer la lutte contre l'insécurité maritime dans le golfe de Guinée.

487- Toutefois, avant le 13 novembre 2018 date de publication de la loi $n^{\circ}$ 2017-442 du 30 juin 2017 portant Code maritime ${ }^{724}$ ivoirien, des efforts pour améliorer la protection de la marchandise et renforcer les normes de sécurité de la navigation maritime ont été réalisés. La quête de l'amélioration des normes de protection de la marchandise et de sécurité de la navigation maritime (Chapitre 1) et du renforcement de la lutte contre l'insécurité et les recommandations en vue de son amélioration dans le golfe de Guinée (Chapitre 2) seront l'objet de l'analyse qui va suivre.

${ }^{723}$ Voir supra $\mathrm{n}^{\circ} 407$, p. 191.

724 Voir Journal Officiel de la République de Côte d'Ivoire du mardi 13 novembre 2018, pp. 129208. 


\section{CHAPITRE 1 : L'AMELIORATION DES NORMES POUR LA PROTECTION DE LA MARCHANDISE ET LA SECURITE DE LA NAVIGATION MARITIME}

488- Pour l'amélioration de la législation des transports maritimes deux voies s'offraient au législateur ivoirien. En amont une amélioration du dispositif légal était indispensable et en aval le renforcement de la lutte contre l'insécurité maritime s'imposait. Il convient donc de rechercher, d'une part, les normes relatives à l'amélioration de la protection de la marchandise transportée (Section 1) et, d'autre part, celles relatives au renforcement de la sécurité maritime (Section 2).

\section{Section 1: La quête des normes relatives à l'amélioration de la protection de la marchandise}

489- S'agissant des normes de protection de la marchandise au cours du transport, il convient d'indiquer que notre analyse a révélé que la phase purement maritime du transport bénéficiait déjà d'une protection assez efficace de la marchandise ${ }^{725}$ avant même l'avènement du Code maritime ivoirien. Le besoin d'amélioration de la protection de la marchandise s'était donc fait sentir essentiellement au cours des phases non maritimes du transport à savoir les opérations antérieures au chargement et celles postérieures au déchargement. Dans ce contexte, des options se sont présentées pour son amélioration. Ainsi, il était possible soit, d'opter pour l'application de la Convention de Rotterdam de 2009 en droit positif ivoirien (\$1) soit, d'opter pour une réforme de la protection de la marchandise sur les phases non maritimes passant ainsi de la protection conventionnelle à une protection légale (\$2).

\footnotetext{
725 Voir supra n $^{\circ}$ 304, pp. 140-141. En effet, la législation maritime en vigueur en Côte d'Ivoire avant le Code maritime de 2017 assurait une protection assez efficace à la marchandise au cours de la phase purement maritime du transport. Ce sont donc les phases pré et post maritimes qui n'étaient pas couvertes par la présomption de responsabilité du transporteur et de ce fait, n'étaient pas efficacement protégées.
} 


\section{$\S 1$ : Possible amélioration de la protection de la marchandise par application de la Convention de Rotterdam en droit ivoirien}

490- La Convention internationale pour l'unification de certaines règles en matière de connaissement, signée à Bruxelles le 25 août 1924, et ses Protocoles, ainsi que la Convention des Nations Unies sur le transport de marchandises par mer, signée à Hambourg le 31 mars 1978, ont contribué dans une large mesure à l'harmonisation du droit des transports de marchandises par mer. Toutefois, conscients des évolutions technologiques et commerciales qui sont intervenues depuis l'adoption de ces conventions et de la nécessité de refondre et de moderniser celles-ci. ${ }^{726}$, des Etats ont autorisé la tenue d'une cérémonie d'ouverture à la signature d'une nouvelle convention le 23 septembre 2009 à Rotterdam (Pays-Bas).

491- Avant la signature de la Convention de Rotterdam en 2009, l'intention d'ériger une structure juridique internationale unique a plutôt abouti à une multitude de régimes juridiques qui se sont disputés le marché de la responsabilité du transporteur maritime de marchandises ${ }^{727}$.

492- C'est pourquoi, l'Assemblée générale des Nations Unies ${ }^{728}$ a adopté et autorisé à la signature la Convention sur le contrat de transport international

\footnotetext{
${ }^{726}$ Cf : Préambule de la Convention des Nations Unies sur le contrat de transport international de marchandises effectué entièrement ou partiellement par mer.

727 FETZE KAMDEM (Innocent), La responsabilité du transporteur maritime au niveau international : un échec d'uniformisation juridique, Mémoire, Université Laval Québec Canada, Décembre 1999, p. 7. Selon l'auteur, on compte aujourd'hui dans le monde quatre principaux régimes internationaux de la responsabilité du transporteur de marchandises par mer. Dans un ordre chronologique, ces régimes résultent des quatre textes conventionnels de 1924, 1968, 1978 et 1979. À nos yeux, d'autres régimes sont subsidiaires moins parce qu'ils s'appliquent à une échelle réduite que parce qu'au fond, ce sont les quatre premiers qui leur procurent leur substance en est ainsi d'un régime qui se distingue notamment par la nature particulière de son unité monétaire14 ou par les apports qu'il a reçus d'un législateur national lors de son adoption sous forme législative.

${ }^{728}$ Voir Résolution adoptée par l'Assemblée générale pour autoriser la tenue d'une cérémonie d'ouverture à la signature le 23 septembre 2009 à Rotterdam (Pays-Bas) de la Convention des Nations Unies sur le contrat de transport international de marchandises effectué entièrement ou partiellement par mer. Cette résolution précise ceci : "Constatant avec préoccupation que le droit existant ne prend pas suffisamment en compte les pratiques de transport modernes, notamment la conteneurisation, le transport de porte à porte et l'utilisation de documents de transport électroniques".
} 
de marchandises effectué entièrement ou partiellement par mer. On fera le point des avancées des dispositions de la Convention de Rotterdam (A) et on précisera ensuite les raisons de son inapplication en droit ivoirien (B).

\section{A- Les avancées des dispositions de la Convention de Rotterdam}

493- Rappelons que la mission des Règles de Rotterdam est d'instituer un régime juridique homogène du transport international de marchandises par mer qui prenne suffisamment en compte les pratiques de transport modernes. Notre préoccupation consiste à relever les dispositions des Règles de Rotterdam qui sont susceptibles de protéger efficacement la marchandise notamment au cours des opérations pré et post maritimes.

494- L'article 17 de la Convention de Rotterdam de 2009 dispose en son paragraphe 1 que : "Le transporteur est responsable de la perte, du dommage ou du retard de livraison subi par les marchandises, si l'ayant droit prouve que cette perte, ce dommage ou ce retard, ou l'événement ou la circonstance qui l'a causé ou y a contribué, s'est produit pendant la durée de sa responsabilité telle que celleci est définie au chapitre 4 [de la présente convention]". Cette disposition constitue $\boldsymbol{a}$ priori une réelle avancée dans le mécanisme de protection de la marchandise en ce sens qu'elle prend en compte les opérations pré et post maritimes du transport ainsi que le retard de livraison (1), en outre, elle étend la durée de la responsabilité du transporteur maritime (2).

\section{1- Une prise en compte des opérations pré et post maritimes du transport et du retard de livraison}

495- De prime à bord, relevons que le retard de livraison qui n'était pas couvert par la responsabilité présumée de palan à palan du transporteur en droit ivoirien (voir la Convention de Bruxelles), est désormais élevé au rang des dommages couverts par le principe de la présomption de responsabilité du transporteur à travers le paragraphe 1 de l'article 17 des Règles de Rotterdam de 2009. La prise en compte du retard de livraison est une amélioration de la protection de la marchandise. 
496- En outre, les rédacteurs de la Convention de Bruxelles de 1924, voulant résorber les abus antérieurs des transporteurs ${ }^{729}$ ont, à travers le paragraphe 2 de l'article 4, fondé la responsabilité du transporteur sur le principe de la présomption. Quant aux rédacteurs de la Convention de Rotterdam de 2009, à travers l'article 17730 , ils fondent la responsabilité du transporteur soit sur le principe de la présomption de responsabilité, soit sur le principe de la présomption de faute ou encore sur le principe de la faute prouvée. Toutefois, la différence majeure entre ces deux régimes juridiques se situe au niveau de leurs champs d'application respectifs. Les Règles de La Haye prescrivent à la charge du transporteur une présomption de responsabilité de sous palan à sous palan "tackle to tackle" " tandis que les Règles de Rotterdam prévoient pour le même transporteur une présomption de responsabilité pendant toute la période où il détient la marchandise c'est-à-dire depuis sa réception jusqu'à sa livraison à l'ayant droit.

497- Contrairement au sectionnement du transport prévu par la Convention de Bruxelles ${ }^{731}$, la Convention de Rotterdam, à travers son article

\footnotetext{
${ }^{729}$ Voir ASSONITIS (Georges), Réglementation internationale des transports maritimes dans le cadre de la CNUCED, Puf, Paris, 1991, pp. 201-242. Selon l'auteur, se fondant sur le principe de la liberté contractuelle qui est reconnu par le common law et les droits écrits, les armateurs ont cherché à insérer dans les connaissements des clauses visant non seulement les exceptions admises par le common law, mais aussi les autres risques de mer en vue d'échapper à leur responsabilité. L'usage ainsi fait de la liberté contractuelle a permis au transporteur de se dégager de presque toutes ses responsabilités même si la perte ou le dommage subi par les marchandises étaient dus à une faute ou négligence de sa part.

730 Voir Convention de Rotterdam, art. 17 : "1. Le transporteur est responsable de la perte, du dommage ou du retard de livraison subi par les marchandises, si l'ayant droit prouve que cette perte, ce dommage ou ce retard, ou l'événement ou la circonstance qui l'a causé ou y a contribué, s'est produit pendant la durée de sa responsabilité telle que celle-ci est définie au chapitre 4.

2. Le transporteur est déchargé de tout ou partie de sa responsabilité prévue au paragraphe 1 du présent article s'il prouve que la cause ou l'une des causes de la perte, du dommage ou du retard n'est pas imputable à sa faute ou à la faute de l'une quelconque des personnes mentionnées à l'article 18.

3. Le transporteur est aussi déchargé de tout ou partie de sa responsabilité prévue au paragraphe 1 du présent article si, au lieu de prouver l'absence de faute comme prévu au paragraphe 2 du présent article, il prouve qu'un ou plusieurs des événements ou circonstances ci-après ont causé la perte, le dommage ou le retard ou y ont contribué: ..."

${ }^{731}$ Voir RODIERE (René), Traité général de droit maritime, Dalloz. Paris, tome 2, op. cit., 1968, $\mathrm{n}^{\circ} 576$, pp. 217 et $\mathrm{s}$. Le transporteur est présumé responsable des dommages survenus à la marchandise de la prise en charge à la livraison car aucun sectionnement n'a été prévu.
} 
17, a prescrit l'unité du contrat de transport. Désormais, les opérations pré maritimes et post maritimes sont incluses dans les obligations du transporteur comme l'indique clairement le paragraphe 1 de son article 12.

\section{2- Une extension de la durée de responsabilité du transporteur maritime}

498- Conformément à l'article $12^{732}$ des Règles de Rotterdam, notamment en son paragraphe 1, le transporteur est présumé responsable des marchandises depuis leur réception par une partie exécutante ${ }^{733}$ ou lui-même en vue de leur transport jusqu'à livraison. Cette disposition réforme et innove fondamentalement la protection de la marchandise en ce sens que non seulement elle étend la responsabilité du transporteur depuis la réception de la marchandise jusqu'à sa livraison mais aussi et surtout, elle présume ladite responsabilité durant toute cette période. Il convient donc de retenir que les Règles de Rotterdam établissent à la charge du transporteur une présomption de sa responsabilité pour les pertes, les dommages ou les retards de livraison subis par les marchandises depuis leur réception jusqu'à leur livraison. L'inefficacité de la protection de la marchandise observée notamment au cours des opérations pré et post maritimes, en droit ivoirien ${ }^{734}$ avant l'adoption du

732 Convention de Rotterdam de 2009, art.12: "1. Le transporteur est responsable des marchandises en vertu de la présente Convention depuis leur réception par une partie exécutante ou lui-même en vue de leur transport jusqu'à leur livraison.

2. a) Si la loi ou la réglementation du lieu de réception exige que les marchandises soient remises à une autorité ou à un autre tiers auprès duquel il pourra les retirer, le transporteur est responsable des marchandises depuis leur retrait auprès de cette autorité ou de ce tiers.

b) Si la loi ou la réglementation du lieu de livraison exige qu'il remette les marchandises à une autorité ou à un autre tiers auprès duquel le destinataire pourra les retirer, le transporteur est responsable des marchandises jusqu'à leur remise à cette autorité ou à ce tiers.

3. Afin de déterminer la durée de la responsabilité du transporteur, les parties peuvent convenir du moment et du lieu de la réception et de la livraison. Cependant, ... ».

${ }^{733}$ Convention de Rotterdam de 2009, art. 1-7. "Le terme "partie exécutante maritime" désigne une partie exécutante dans la mesure où elle s'acquitte ou s'engage à s'acquitter de l'une quelconque des obligations du transporteur pendant la période comprise entre l'arrivée des marchandises au port de chargement d'un navire et leur départ du port de déchargement d'un navire. La qualité de "partie exécutante maritime" ne peut être reconnue à un transporteur intérieur que si celui-ci fournit ou s'engage à fournir ses services exclusivement dans une zone portuaire".

${ }^{734}$ En effet, le sectionnement juridique du contrat de transport institué par l'article 1 e de la Convention de Bruxelles de 1924 qui extrait les opérations pré et post maritimes de son champ 
Code maritime de 2017, aurait pu trouver une solution satisfaisante par l'application des articles 17 et 12 de la Convention de Rotterdam.

499- L'amélioration des normes de protection de la marchandise aurait pu être obtenue grâce à une sélection de toutes les dispositions de la Convention de Rotterdam susceptibles de renforcer la protection de la marchandise et à leur intégration dans l'ordonnancement juridique ivoirien à travers la voie législative ou règlementaire, ou encore par la ratification de ladite Convention. Mais qu'en est-il de son application en droit ivoirien?

\section{B- Les Règles de Rotterdam, une Convention non ratifiée par la Côte d'Ivoire}

500- L’Assemblée générale des Nations Unies, ayant constaté que le régime juridique $d u$ transport maritime international de marchandises manquait d'homogénéité et ne prenait pas suffisamment en compte les pratiques de transport modernes ${ }^{735}$, a estimé nécessaire d'adopter de nouvelles normes uniformes pour régir les contrats de transport maritime internationaux afin d'améliorer la certitude et l'efficacité juridiques.

501- Sans faire une analyse exhaustive des Règles de Rotterdam, on constate qu'elles prévoient de réelles avancées notamment en ce qui concerne son champ d'application; des sources, fondements et principes de la responsabilité du transporteur ; des causes d'exonération de responsabilité ; des limites de la responsabilité ; du délai pour agir contre le transporteur; des obligations et responsabilités du chargeur; la liberté contractuelle; la possibilité de déroger aux dispositions conventionnelles ${ }^{736}$; etc. Eu égard à ces nombreuses avancées, la ratification de cette Convention s'imposait.

\footnotetext{
d'application en les soumettant à la convention des parties ne protège pas efficacement la marchandise.

${ }^{735}$ Ces pratiques de transport modernes sont notamment la conteneurisation, le transport de porte à porte et l'utilisation de documents de transport électroniques.

${ }^{736}$ Voir en annexe 1 le Tableau comparatif des conventions de Bruxelles, de Hambourg et de Rotterdam.
} 
502- Entre autres objectifs ; le Code maritime de 2017, vise à 'étendre la responsabilité de plein droit du transport maritime. Celle-ci peut résulter des opérations pré et post maritimes ainsi que le prévoit l'article 12 de la Convention de Rotterdam de 2009. Mais sans doute selon un auteur, voulant mener une réforme portant sur les différents aspects du transport maritime, notamment la sûreté maritime, le législateur ivoirien a hésité de ratifier la Convention de Rotterdam de 2009737. Celui-ci a en fin de compte choisi la voie de la réforme en adoptant un nouveau code maritime afin d'améliorer l'ensemble de la législation régissant toutes les activités relatives aux transports maritimes en Côte d'Ivoire. Selon cet auteur, cette nouvelle loi a permis non seulement d'unifier dans un même corpus une règlementation applicable à divers domaines relevant à la fois du droit public et du droit privé, mais également, d'internaliser des conventions internationales et communautaires dont pour certaines, les délais de transposition étaient largement dépassés. L’article premier définit le champ d'application du nouveau Code maritime et situe le domaine vaste et varié concerné par la matière maritime. En effet, il s'applique aux activités civiles et marchandes se déroulant dans les eaux maritimes, les lagunes, les fleuves et plans d'eau en communication avec la mer et dans les ports, sous réserve de textes spécifiques et des conventions réglementant les activités portuaires.

\section{§ 2 : De la protection conventionnelle à la protection légale de la marchandise transportée}

503- Avant l'entrée en vigueur du Code maritime de 2017, les opérations antérieures au chargement et postérieures au déchargement étaient régies par la convention des parties ${ }^{738}$. Cette approche laissait apparaître des difficultés quant-à la protection de la marchandise (A). Ces défaillances sont corrigées au

\footnotetext{
${ }^{737}$ Voir en ce sens ; BILE (Vincent), " Regard Critique sur le Nouveau Code Maritime Ivoirien ", Neptunus, e.revue Université de Nantes, vol. 24, 2018/3, février 2019, p. 1.

738 Voir Convention de Bruxelles de 1924 art. 1-e). Mais en cas de doute, la responsabilité du transporteur est recherchée sur les phases pré et post maritimes. Voir dans ce sens Cours suprême arrêt n_301/06 du 01/06/2006. Dans cet arrêt, les juges ont présumé la responsabilité du transporteur: "Attendu que le transporteur maritime n'ayant émis aucune réserve à l'embarquement desdites marchandises, il y a lieu de retenir sa responsabilité ; Attendu que la part du dommage survenu à chaque étape ne pouvant être déterminée, il y a lieu de mettre à la charge du transporteur, l'intégralité du préjudice causé par son fait".
} 
moyen des solutions issues de la réforme du régime de la responsabilité du transporteur opérée dans le Code maritime ivoirien de 2017 (B).

\section{A-Aperçu des difficultés quant-à la protection de la marchandise avant le Code maritime}

504- Le transporteur maritime, en prenant en charge la marchandise pendant la phase purement maritime du transport dite phase "de palan à palan"739, exclut de sa responsabilité les opérations effectuées depuis la réception de la marchandise jusqu'à son embarquement et celles effectuées depuis la fin du déchargement jusqu'à la livraison. De facto l'exécution de ces opérations pré et post maritimes était régie par la convention intervenue entre le chargeur et le transporteur ${ }^{740}$. Aussi, un auteur s'est-il interrogé de savoir la durée de la responsabilité du transporteur ${ }^{741}$, en d'autres termes quelle est la période pendant laquelle le transporteur est responsable des pertes ou dommages causés à la marchandise?

505- L'article 7 des Règles de la Haye dispose que les parties sont libres de fixer le régime de responsabilité pour les périodes antérieure au chargement et postérieure au déchargement du navire sur lequel les marchandises sont transportées par mer ${ }^{742}$. Selon Monsieur Georges Assonitis, l'opinion dominante

${ }^{739}$ Convention de Bruxelles de 1924 (art. 1-e) : «le transport des marchandises couvre le temps écoulé depuis le chargement des marchandises à bord du navire jusqu'à leur déchargement du navire".

${ }^{740} \mathrm{Cf}$ : L'article premier paragraphe e de la Convention de Bruxelles, en prévoyant la prise en charge de la marchandise sous palan, supprime toute protection efficace de la marchandise pendant les phases non maritimes en ce sens que la responsabilité présumée du transporteur, qui constitue une véritable garantie de protection de la marchandise, ne couvre pas les phases non maritimes du contrat de transport.

${ }^{741}$ Voir ASSONITIS (Georges), Réglementation internationale des transports maritimes dans le cadre de la CNUCED, Puf, Paris, 1991, pp. 201-242. A propos des différentes phases du transport, l'auteur indique que pendant ces phases, les marchandises passent sous la garde et le contrôle de plusieurs personnes comme par exemple : les entreposeurs, les propriétaires de quais, les régies portuaires et les arrimeurs. Parfois, ces personnes agissent comme des préposés ou mandataires du transporteur ou du chargeur, parfois elles opèrent pour leur propre compte. ${ }_{742}$ Convention de Bruxelles de 1924, art. 7 : "Aucune disposition de la présente convention ne défend à un transporteur ou à un chargeur d'insérer dans un contrat des stipulations, conditions, réserves ou exonérations relatives aux obligations et responsabilités du transporteur ou du navire pour la perte ou les dommages survenant aux marchandises, ou concernant leur garde, soin et manutention, antérieurement au chargement et postérieurement au déchargement du navire sur lequel les marchandises sont transportées par mer. Aucune disposition de la présente convention 
en la matière est que le régime de responsabilité du transporteur est applicable de palan à palan ${ }^{743}$. L'auteur poursuit en indiquant qu'en pratique les transporteurs n'hésitent pas de se servir de l'article 7 de la Convention de Bruxelles de 1924 pour imposer aux chargeurs des clauses qui les exonèrent de leur responsabilité pour les périodes avant le chargement et après le déchargement. Les destinataires sont donc obligés de supporter entièrement les risques de perte ou de dommage aux marchandises pendant ces périodes.

506- Le transport de marchandises par conteneurs laisse toujours apparaître des difficultés notamment en ce qui concerne l'état et la nature des marchandises au moment de leur prise en charge et la détermination du moment précis de la libération du transporteur après la livraison. Concernant l'état et la nature de la marchandise nous avions indiqué que pour des raisons technique et économique, le transporteur s'abstenait de procéder à la vérification de la marchandise mise en conteneur par le chargeur après la scellée ${ }^{744}$. Ce qui a amené l'Organisation mondiale des douanes à reconnaître que la sécurisation du transport débute avec le remplissage du conteneur et que les scellés ne garantissent pas la régularité du chargement ${ }^{745}$. En outre, la non vérification des marchandises après la scellée des conteneurs a amené également le professeur René Rodière à envisager l'établissement d'un compromis entre les nécessités économiques et commerciales et le bon sens selon lequel le transporteur ne peut pas accepter les yeux fermés les déclarations de ses clients ${ }^{746}$. En tout état de cause la non-vérification des marchandises mises en conteneurs est préjudiciable à la sécurité maritime et au transporteur qui est

ne défend à un transporteur ou à un chargeur d'insérer dans un contrat des stipulations, conditions, réserves ou exonérations relatives aux obligations et responsabilités du transporteur ou du navire pour la perte ou les dommages survenant aux marchandises, ou concernant leur garde, soin et manutention, antérieurement au chargement et postérieurement au déchargement du navire sur lequel les marchandises sont transportées par mer $"$.

${ }_{743}$ Convention de Bruxelles de 1924, art. 7.

744 Voir supra $\mathrm{n}^{\circ} 60$ et $\mathrm{s}, \mathrm{pp} .33$ et 34 .

745 Voir "Administrative Committee for the Customs Convention on Containers, Amendment proposals by contracting parties", Bruxelles, 1er oct. 2004, Doc. PB0007E1, Annexe 1.

${ }^{746}$ RODIERE (René), Traité général de droit maritime, Dalloz, Paris, Tome 2, 1968, n 513, pp. $147-148$. 
par conséquent tenu de rapporter la preuve difficile que les dommages subis sont antérieurs à la prise en charge.

507- S'agissant de la détermination du moment précis de la libération du transporteur après la délivrance de la marchandise mise en conteneur, les dommages subis par celle-ci étant réputés non apparents ${ }^{747}$, ils devaient faire l'objet d'un avis de perte ou avarie adressé au transporteur dans un délai de trois jours conformément à l'article 3-6 des Règles de la Haye ${ }^{748}$. C'est au terme de ce délai que le transporteur pouvait se voir véritablement libéré.

508- L’article 1-e des Règles de la Haye, en établissant les rapports entre chargeur/destinataire et transporteur, affaiblit la protection de la marchandise pendant les périodes pré et post maritimes. En effet, l'exécution de ces phases non maritimes n'est pas régie par une législation capable de retenir, de manière stable et impérative, la responsabilité présumée du transporteur, seul gage d'une protection efficace de la marchandise. Tout ceci justifie une amélioration de la situation des chargeurs et destinataires à travers une réforme.

509- Par ailleurs, l'analyse des normes de protection de la marchandise en droit français a montré que le transport maritime international est régi concurremment par la Convention de Bruxelles et la loi de 1966. Les opérations non maritimes écartées du champ d'application de la présomption de responsabilité par les Règles de la Haye, y sont intégrées par l'article 16 de la loi française $n^{\circ}$ 66-420 du 18 juin 1966. Ainsi, le transporteur est présumé responsable de la prise en charge de la marchandise à sa livraison. La marchandise bénéficie alors d'une protection assez efficace en droit français. Cette approche du législateur français a dû inspirer son homologue ivoirien pour une réforme de la responsabilité du transporteur maritime.

\footnotetext{
747 Voir supra $\mathrm{n}^{\circ} 335$, p. 154.

748 Règles de la Haye, art. 3-6: "A moins qu'un avis de pertes ou dommages et de la nature générale de ces pertes ou dommages ne soit donnée par écrit au transporteur ..., cet enlèvement constituera jusqu'à preuve du contraire, une présomption que les marchandises ont été délivrées par le transporteur telles qu'elles sont décrites au connaissement. Si les pertes ou dommages ne sont pas apparents, l'avis doit être donné dans les trois jours de la délivrance".
} 


\section{B- Les solutions issues de la réforme du Code maritime de 2017}

510- L'article 708 du nouveau Code maritime ivoirien prévoit une responsabilité présumée à la charge du transporteur depuis la réception de la marchandise jusqu'à sa livraison au destinataire pour les pertes, dommages et retards de livraison subis ${ }^{749}$. Cette disposition est conforme à l'évolution actuelle $\mathrm{du}$ droit des transports maritimes internationaux de marchandises en l'occurrence la Convention de Rotterdam de 2009 et à certains droits nationaux européens notamment le droit maritime français. En effet, l'article 12, alinéa 1 de la Convention de Rotterdam de 2009 prévoit une responsabilité présumée du transporteur depuis la réception de la marchandise jusqu'à sa livraison. Il en a été de même de l'article 4 de la Convention de Hambourg de 1978750. Aussi, conformément à l'article 16 de la loi française $n^{\circ}$ 66-420 du 18 juin 1966 la responsabilité du transporteur reste présumée depuis la réception de la marchandise jusqu'à sa livraison ${ }^{751}$. Sans doute le législateur ivoirien s'est inspiré de ces dispositions de la loi française et des conventions précitées notamment la Convention de Rotterdam. Toutefois, le Code maritime de 2017 prévoit que le montant de l'indemnité est calculé en référence de la

\footnotetext{
749 Voir Code maritime ivoirien de 2017, art. 708 : « La responsabilité du transporteur en ce qui concerne les marchandises couvre la période pendant laquelle les marchandises sont sous sa garde au port de chargement, durant le transport et au port de déchargement.

Les marchandises sont réputées être sous la garde du transporteur à partir du moment où celuici les prend en charge des mains soit du chargeur ou d'une personne agissant pour son compte, soit d'une autorité ou autre tiers auquel les marchandises doivent être remises pour l'expédition, conformément aux lois et règlements applicables au port de chargement.

De même, les marchandises sont réputées être sous la garde du transporteur jusqu'au moment où il effectue la livraison soit en remettant les marchandises au destinataire, soit ... ".

750 Cf: Convention de Hambourg de 1978, art. 4: "1. Dans la présente Convention, la responsabilité du transporteur en ce qui concerne les marchandises couvre la période pendant laquelle les marchandises sont sous sa garde au port de chargement, durant le transport et au port de déchargement. 2. Aux fins du paragraphe 1 du présent article, les marchandises sont réputées être sous la garde du transporteur : a) A partir du moment où celui-ci les prend en charge des mains : i) Du chargeur ou d'une personne agissant pour son compte; ou ii) D'une autorité ou autre tiers auquel les marchandises doivent être remises pour expédition, ...; b) Jusqu'au moment où il en effectue la livraison: i) En remettant les marchandises au destinataire; ou ii) ..., en les mettant à la disposition du-destinataire conformément au contrat ou aux lois ou aux usages du commerce considéré applicables au port de déchargement; ou iii) En remettant les marchandises à une autorité ou autre tiers ..." .

${ }^{751}$ Voir les dispositions des articles 15 et 16 de la loi française $n^{\circ}$ 66-420 du 18 juin 1966.
} 
réglementation ou des usages en vigueur ${ }^{752}$ qui sont en réalité largement dépassés et obsolètes. A notre sens, le législateur maritime de 2017 aurait dû fixer de nouveaux plafonds de la responsabilité du transporteur.

511- Le législateur ivoirien aurait pu s'inspirer du principe de limitation de la responsabilité du transporteur tiré du droit comparé. En droit tunisien par exemple, selon Sarah Ben Fraj, le plafond de la responsabilité du transporteur est fixé à 400 dinars par colis ou par unité de fret de marchandise transportée ${ }^{753}$. Sans porter de jugement sur la valeur du taux légal en droit interne tunisien, un relèvement du plafond de responsabilité du transporteur s'imposait au législateur maritime ivoirien de 2017.

512- Par ailleurs, la question se pose de savoir quelle sera l'attitude du juge ivoirien confronté au choix de la règle applicable aux dommages survenus au cours des phases non maritimes pour un connaissement régi par la Convention de Bruxelles de 1924754. Doit-il appliquer les Règles de la Haye ou le Code maritime ivoirien? Les phases non maritimes étant régies par des dispositions supplétives de la Convention de Bruxelles ${ }^{755}$, en cas de conflit de loi, logiquement les dispositions du Code maritime, qui sont d'ordre impératif, l'emporteront sur celles, supplétives, de la Convention de Bruxelles au cours de ces phases dites non maritimes. Toutefois, au cours d'éventuels procès cette analyse est susceptible d'être combattue par le transporteur qui pourrait alors réclamer l'application stricte de l'article 1 e de la Convention de Bruxelles. Pour éviter d'éventuels conflits de loi, le législateur a dû insérer dans le Code

752 Loi n 2017-442 du 30 juin 2017 portant code maritime, art. 713.

753 Ben Fraj (Sarah), «La limitation de responsabilité du transporteur maritime de marchandises en droit Tunisien ", https: //metalaww.lead.org.tn, consulté le 22, août 2017. L'article 147 du Code de commerce maritime (CCM) modifié par le décret n 216 du 20/01/1990 dispose que «Quelle que soit la nature nationale ou internationale du transport, la responsabilité du transporteur ne peut en aucun cas, sauf en cas de dol, dépasser pour les pertes, avaries ou dommages subis par les marchandises, la somme de 400 dinars par colis ou par unité habituelle de fret de marchandise transportée, à moins que la nature et la valeur de ces marchandises n'aient été déclarées par le chargeur avant leur embarquement ou bien que le dommage ne soit dû au dol du transporteur ".

${ }^{754}$ C'est à dire un connaissement émis dans un Etat contractant.

755 Voir l'article 7 de Convention de Bruxelles de 1924. 
maritime, à l'instar de l'article 16 de la loi française de $1966^{756}$, l'article $688^{757}$ prévoyant expressément l'application des dispositions de l'article 708 du Code maritime à tout transport maritime effectué au départ ou à destination d'un port ivoirien, qu'il soit national ou international. Car n'étant pas d'application exclusive $^{758}$, les dispositions relatives au champ d'application dudit Code admettent l'application des conventions internationales. Mais nous estimons qu'à la lumière des difficultés d'application de cet article 708 du Code maritime qui se présenteront au juge ivoirien, le législateur pourrait apporter les amendements nécessaires.

513- Par ailleurs, conformément à son article $730^{759}$, le Code maritime prévoit un délai de deux ans pour la prescription de l'action contre le transporteur alors que les Règles de la Haye (art. 3, al. $6, \S 4$ ) ont prévu un délai d'un an. A ce propos, notons que le délai biennal (deux ans) semble mieux cadrer avec l'évolution actuelle du droit international des transports de marchandises

756 Loi française $\mathrm{n}^{\circ}$ 66-420 du 18 juin 1966, art. 16 : "Le présent titre est applicable aux transports, effectués au départ et à destination d'un port français, qui ne sont pas soumis à une convention internationale à laquelle la France est partie, et en tout cas aux opérations de transport qui sont hors du champ d'application d'une telle convention. ..."

757 Cf : Code maritime ivoirien de 2017, art. 688: "Les dispositions du présent chapitre sont applicables à tous les contrats de transport de marchandises par mer qui ne sont pas soumis à une convention internationale à lauelle la Côte d'Ivoire est partie, et en tous les cas aux opérations de transport et aux clauses des contrats de transport qui sont hors du champ d'application d'une d'une telle convention, dès lors que:

- le port de chargement ou de déchargement prévu dans le contrat de transport par mer est situé en Côte d'Ivoire ;

- l'un des ports à option de déchargement est le port déchargement effectif et que ce port est situé en Côte d'Ivoire ;

- le connaissement ou autre document de transport faisant preuve du contrat de transport par mer est émis en Côte d'Ivoire ou prévoit que les dispositions de la présente loi régissent le contrat".

758 Voir Code maritime, art. 1 : «Les dispositions de la présente loi sont applicables à toutes les activités maritimes civiles et marchandes se déroulant dans les eaux maritimes, les lagunes, fleuves et plans d'eau en communication avec la mer et dans les ports sous réserve des textes spécifiques et des conventions réglementant les activités portuaires".

$759 \mathrm{Cf}$ : Code maritime, art. 730 : «Toute action relative au transport se prescrit par deux ans. Le délai de prescription court à partir du jour où le transporteur a livré les marchandises ou une partie des marchandises ou lorsque les marchandises n'ont pas été livrées, à partir du dernier jour où elles auraient dû l'être». 
au regard de l'article 62 des Règles de Rotterdam ${ }^{760}$ et également de l'article 20 des Règles de Hambourg761. Mais un conflit de loi se profilerait à l'horizon. Car selon l'analyse de Vincent Bilé : "La question qui se pose alors est de savoir, lorsqu'une marchandise est couverte par un connaissement régi par la convention de Bruxelles du 25 août 1924, c'est à dire un connaissement émis dans un Etat contractant, quelle est la prescription qui s'appliquerait, alors surtout que la Côte d'Ivoire a ratifié ladite convention par la loi n61-211 du 12 juin 1961 qui n’a pas été abrogé par le nouveau Code maritime. Les juridictions ivoiriennes devraient-elles s'attendre à résoudre un problème de conflit de loi ? „762.

514- Toutefois, entrée en vigueur seulement en novembre 2018, il serait tendancieux de présager l'attitude du juge sur les questions de conflit de loi. Attendons donc de voir a posteriori l'efficacité et l'applicabilité des dispositions de la loi portant Code maritime. Pour notre part, nous pensons en effet, que c'est à travers une analyse des futures décisions qu'auront rendues les juridictions ivoiriennes ${ }^{763}$ que l'efficacité des dispositions du Code maritime pourra être valablement discutée. Enfin, concernant les possibilités d'exonération du transporteur, l'article 711 du nouveau Code maritime ivoirien ${ }^{764}$ n'a pas fait de progrès dès lors qu'il reprend, en substance, l'article 4 de la Convention de Bruxelles de 1924 qui avait prévu les nombreux cas d'exonération de

760 Règles de Rotterdam art. 62 : «1. Aucune action judiciaire ou arbitrale relative à des réclamations ou des litiges découlant d'un manquement à une obligation prévue dans la présente Convention ne peut être engagée après l'expiration d'un délai de deux ans. 2. Le délai visé, ... ".

${ }^{761}$ Règles de Hambourg, art. $20:$ : 1. Toute action relative au transport de marchandises par mer en vertu de la présente Convention est prescrite si une procédure judiciaire ou arbitrale n'a pas été introduite dans un délai de deux ans. 2. Le délai de prescription court à partir du jour où le transporteur a livré les marchandises ou une partie des marchandises, ou lorsque les marchandises n'ont pas été livrées, à partir du dernier jour où elles auraient dû l'être ... ".

762 Voir BILE (Vincent), « Regard Critique sur le Nouveau Code Maritime Ivoirien », Neptunus, e.revue Université de Nantes, vol. 24, 2018/3, 2018, p. 5.

${ }^{763}$ A présent, nous n'avons pas connaissance de décision rendue sur la question de conflit de loi entre la Convention de Bruxelles de 1924 et le Code maritime.

${ }^{764}$ Loi n 2017-442 du 30 juin 2017 portant code maritime, art. 711 : "Le transporteur est responsable des pertes et dommages subis par la marchandise, à moins qu'il ne prouve que ces pertes et dommages proviennent de l'une des causes suivantes: innavigabilité du navire à condition que le transporteur apporte la preuve qu'il a satisfait à ses obligations; fait constituant un événement non imputable au transporteur, imprévisible et pour lequel le transporteur, ses préposés ou mandataires ont pris toutes les mesures raisonnables pour éviter les conséquences ; faits de guerre ; faits d'ennemis publics ; arrêt ou contrainte de prince ; incendie ; [...;...]". 
responsabilité. Cela dit, qu'en est-il de l'amélioration des normes de sécurité de la navigation dans le golfe de Guinée?

\section{Section 2 : L'amélioration des normes de sécurité et de sûreté maritimes en droit ivoirien}

515- Avec l'application du code de la marine marchande de 1961 l'amélioration des normes de sécurité de la navigation s'était avérée nécessaire. Au demeurant, l'analyse de la législation des transports maritimes a montré que certaines normes présentaient des insuffisances rendant inefficaces la lutte contre les trafics illicites, la piraterie et la criminalité maritimes ${ }^{765}$. En outre, l'analyse du droit communautaire européen a montré que la stratégie de lutte contre l'insécurité maritime comporte deux axes essentiels. D'une part, des instruments juridiques sont adoptés pour lutter contre les actes illicites tels que les trafics de drogues et stupéfiants, la pêche illégale, la criminalité et la piraterie en mer. D’autre part, une coopération régionale est mise en œuvre pour rendre efficace la lutte contre les infractions maritimes. Le législateur ivoirien devrait sans doute s'en inspirer !

516- Eu égard à la position géographique du golfe de Guinée en tant qu'espace maritime commun aux Etats de la sous-région, l'amélioration des normes de sécurité dans cet espace maritime devrait revêtir une dimension nationale (\$ 1) mais également être organisée à l'échelle sous régionale (\$ 2$)$.

\section{$\S 1$ : Selon les réformes découlant du Code maritime}

517- Antérieurement au Code maritime, la législation de la sécurité en mer ne s'est pas intéressée à la prévention et à la lutte contre les différentes formes de la criminalité transnationale organisée ${ }^{766}$. Cette législation antérieure s'était alors révélée inefficace face aux défis actuels de la sûreté et de

\footnotetext{
765 Supra $n^{\circ} 406$, p. 190.

766 Supra $^{\circ}$ 367, pp. 168-169. La Convention de Palerme contre la criminalité transnationale organisée du 15 novembre 2000 et ses Protocoles visant des activités et manifestations spécifiques de la criminalité organisée définissent les formes actuelles de la criminalité transnationale organisée. Mais ladite convention est postérieure au code pénal ivoirien et au code de la marine marchande.
} 
la sécurité maritimes. En guise de solution, le législateur ivoirien a adopté la loi n 2017-442 du 30 juin 2017 portant Code maritime dont l'article 1114 abroge la législation antérieure ${ }^{767}$. Nous en examinerons les dispositions pertinentes relatives à la répression des infractions liées au trafic maritime (A) et apporterons des observations sur l'applicabilité desdites dispositions à l'échelle internationale (B).

\section{A- Les dispositions pertinentes du Code maritime relatives à la répression des atteintes à la sûreté de la navigation maritime}

518- Le nouveau Code maritime apporte des innovations importantes adaptées aux besoins du commerce international mais aussi et surtout des réformes sur des questions de sécurité maritime. Il élargit son champ répressif des atteintes à la navigation maritime par la création de diverses infractions consignées dans son livre XI. Selon Monsieur Vincent Bilé, «La nouvelle loi maritime vient, d'une part, combler l'absence de réglementation spécifique dans divers domaines, et d'autre part, rassembler dans le même corpus des réglementations éparses qui ont un lien direct avec la matière maritime »768.

519- Le législateur ivoirien confie ainsi la poursuite et la répression de la piraterie et autres actes illégaux aux autorités compétentes ivoiriennes. Les infractions aux dispositions de la présente loi sont constatées par les agents des affaires maritimes, les officiers et officiers mariniers et commandants de bâtiments de la marine nationale, les officiers de police judiciaire, les fonctionnaires et agents auxquels sont attribuées des fonctions de police judiciaire. Le procureur de la République peut engager des poursuites conformément à la procédure de droit commun ${ }^{769}$. En application des conventions internationales auxquelles la Côte d'Ivoire est partie, les personnes mentionnées à l'article 987 disposent d'un droit de poursuite en haute mer des

767 Loi n 2017-442 du 30 juin 2017 portant code maritime, art. 1114: "Les dispositions antérieures contraires à la présente loi sont abrogées, notamment celles de la loi 61-349 du 9 novembre 1961 relative à l'institution d'un code de la marine marchande".

768 Voir BILE (Vincent), « Regard Critique sur le Nouveau Code Maritime Ivoirien », Neptunus, e. revue Université de Nantes, vol. 24, 2018/3, 2018, p. 1.

${ }^{769} \mathrm{Cf}$ : Loi n $2017-442 \mathrm{du} 30$ juin 2017 portant code maritime, art. 987. 
auteurs des faits de piraterie. L'article 1018 dispose que : "Les juridictions ivoiriennes sont compétentes pour connaître des faits de piraterie tels que prévus et réprimés par les articles 1008 à 1016 même lorsqu'ils sont commis en haute mer...". On distinguera les dispositions portant sur les faits de piraterie et de trafics illicites en mer (1) de celles portant sur la pollution maritime(2).

\section{1- L'incrimination des actes de piraterie et de trafics illicites en mer par le Code maritime}

520- D’abord, le Code maritime entend par piraterie « tout acte illicite de violence, de menace, de détention ou de déprédation commis par l'équipage ou les passagers d'un navire ou d'un aéronef et dirigé contre un autre navire ou aéronef ou contre des personnes ou des biens à leur bord, au-delà de la mer territoriale [...] L’infraction de piraterie prévue au présent article est punie, d’une peine de dix à vingt ans et d'une amende de 20000000 à 200000000 Francs CFA. La tentative est punissable [...]. Les dispositions des articles 117 et 118 du code pénal relatives aux circonstances atténuantes ne sont pas applicables à l'infraction de piraterie » ${ }^{770}$. L'article 1010 élargit cette définition ${ }^{771}$.

521- En cas d'infraction commise dans les eaux territoriales ou portuaires ivoiriennes à bord des navires sous pavillon d'un Etat étranger, les juridictions pénales sont compétentes pour connaître du jugement desdites infractions lorsque : l'intervention des autorités ivoiriennes a été réclamée; l'infraction a troublé l'ordre public ; l'auteur ou la victime est ivoirien ${ }^{772}$. Dans les cas prévus à l'article 1042, l'autorité maritime est tenue d'informer immédiatement le consul ou le représentant diplomatique de l'Etat dont le navire bat pavillon des faits à la suite desquels les juridictions ivoiriennes ont eu à connaître des crimes

\footnotetext{
${ }^{770}$ Loi n $2017-442$ du 30 juin 2017 portant code maritime, art. 1008.

${ }^{771}$ Idem, art. 1010 : «Seront poursuivis et jugés conformément à l'alinéa 4 de l'article 1008 de la présente loi : 1. Tout individu faisant partie de l'équipage d'un navire ivoirien lequel commettrait à main armée des actes de déprédation ou de violence, soit envers des navires ivoiriens ou des navires étrangers, soit envers les équipages ou chargements de ces navires ;

2. tout individu faisant partie d'un navire étranger lequel, sans être muni d'une commission régulière, commettrait lesdits actes envers des navires ivoiriens, leurs équipages ou chargements ; 3. le capitaine et les officiers de tout navire qui auraient commis des actes d'hostilité sous un pavillon autre que celui de l'Etat dont ils auraient commission".

772 Voir Loi nº 2017-442 du 30 juin 2017 portant code maritime, art. 1042.
} 
et délits commis à bord du navire ${ }^{773}$. Le Code maritime réaffirme le droit de pavillon de l'Etat ivoirien en disposant à l'alinéa 1 de son article 1041 que : «Les juridictions de droit commun de Côte d'Ivoire sont seules compétentes en matière de crimes et délits commis à bord des navires sous pavillon ivoirien".

522- Aussi, la répression de la piraterie et la criminalité maritimes s'étend tant aux nationaux qu'aux étrangers. En effet, les dispositions relatives aux infractions contenues dans le livre XI du Code maritime sont applicables à toute personne, même étrangère, qui se trouve à bord d'un navire battant pavillon ivoirien ou non, lorsque l'infraction a été commise dans les eaux sous juridiction ivoirienne, sous réserve des dispositions de l'article 1018 en matière de piraterie ${ }^{774}$.

523- Aux termes de notre analyse, nous avions conclu qu'au regard des dispositions du code pénal ivoirien de 1981, de celles du code de la marine marchande de 1961 et de la partie VII de la Convention de Montego Bay relative à la répression de la piraterie, la législation pénale ivoirienne ne permettait pas une répression efficace des pirates et auteurs d'actes criminels en mer. Avec l'avènement du Code maritime il en va autrement. A travers le livre XI du Code maritime la Côte d'Ivoire s'est dotée désormais de dispositions homogènes permettant de poursuivre et réprimer les pirates et les auteurs de criminalité maritime. Cependant, leur efficacité ne pourra être appréciée qu'au regard de la pratique. Nous constatons que la sûreté et la sécurité maritimes ont été largement traitées par le Code maritime, il convient alors de s'interroger sur le traitement qui est fait de la pollution maritime.

\section{2- L'incrimination des actes de pollution maritime par la nouvelle législation}

524- Aux termes de l'article 583 du Code maritime, l'Etat de Côte d'Ivoire élabore un plan de lutte contre la pollution marine dont l'organisation opérationnelle doit respecter les principes édictés par l'Organisation Maritime

\footnotetext{
${ }^{773}$ Loi n 2017-442 du 30 juin 2017 portant Code maritime, art. 1042.

774 Idem, art. 988.
} 
Internationale en la matière. Le même article dispose in fine que toutes les entreprises recevant des hydrocarbures et des produits chimiques ont l'obligation de disposer d'un plan de lutte approuvé par l'autorité compétente en matière de lutte contre la pollution marine et sont soumises à l'obligation d'assurance. Selon Vincent Bilé, par le passé, la protection de l'environnement marin et fluvio-lagunaire était régie par des textes de portée générale, tels que la loi n96-766 du 3 octobre 1996 portant Code de l'environnement, l'ordonnance n²012-487 du 7 juin 2012 portant Code des investissements, la loi n²014-390 du 20 juin 2014 d'orientation sur le développement durable etc. Le Code maritime a consacré à la protection de l'environnement marin et fluviolagunaire son livre VI, en mettant à jour l'ensemble des règlementations $\mathrm{y}$ afférentes ${ }^{775}$.

525- Par ailleurs, le Code de l'Environnement interdit en son article 77 le rejet des déchets en mer en ces termes : "Il est interdit de rejeter dans les eaux maritimes et lagunaires des eaux usées, à moins de les avoir préalablement traitées conformément aux normes en vigueur et des déchets de toutes sortes non préalablement traités et nuisibles ». Et son article 98 prévoit une sanction pénale contre les actes de pollution maritime ${ }^{776}$. En revanche, pour une raison d'efficacité, en lieu et place d'une sanction pénale, la nouvelle législation prévoit la réparation desdits actes. En effet, l'article 593 du Code maritime dispose que : "Le propriétaire du navire au moment d'un événement ou si l'événement consiste en une succession de faits, au moment du premier de ces faits, est responsable de tout dommage par pollution causé par le navire et résultant de l'événement. Il en

\footnotetext{
775 BILE (Vincent), "Regard Critique sur le Nouveau Code Maritime Ivoirien », Neptunus, e. revue Université de Nantes, vol. 24, 2018/3, op. cit., 2018, p. 3.

776 Voir loi n 96-766 du 3 octobre 1996 portant Code de l'Environnement, art. 98: «Est puni d'une amende de 100000000 de francs à 1000000000 de francs et d'un emprisonnement de un à cinq ans ou de l'une des deux peines seulement sans préjudice des sanctions administratives en vigueur, quiconque, nonobstant les dispositions spéciales des conventions internationales, procède à des déversements, immersion et incinération dans les eaux maritimes sous juridiction ivoirienne, des substances de toutes natures susceptibles:

- de porter atteinte à la santé publique et aux ressources maritimes biologiques ;

- de nuire aux activités maritimes y compris la navigation et la pêche

- d'altérer la qualité des eaux maritimes ;

- de dégrader les valeurs d'agrément et le potentiel touristique de la mer et du littoral ...».
} 
est de même de l'affréteur en cas de contrat d'affrètement". Précisons que des cas d'exonération de la responsabilité du propriétaire du navire sont prévus à l'article 594 et suivants du Code maritime. Aussi, l'article 598 prévoit la limitation de la responsabilité du propriétaire de navire. Toutefois, il perd le bénéfice de cette limitation de sa responsabilité en cas d'agissement intentionnel de sa part ou en cas d'agissement avec conscience qu'un dommage en résulterait 777 .

\section{B- Les dispositions de lutte contre l'insécurité de la navigation maritime et le droit international}

526- Le nouveau Code maritime ivoirien contient maintes innovations qui sont adaptées aux besoins du transport de marchandises par mer. Les plus caractéristiques sont : la présomption de la responsabilité du transporteur sur toutes les phases du transport 778 ; la consécration du retard de livraison au titre des préjudices pouvant entrainer la responsabilité du transporteur ${ }^{779}$; le délai de prescription de l'action contre le transporteur qui est prolongé à deux ans conformément à l'article $730^{780}$; etc. Mais à présent, c'est l'élargissement du champ répressif des atteintes aux réglementations du transport maritime, à la sûreté et à la sécurité maritimes, par la création de diverses infractions consignées dans le livre XI qui nous préoccupe. A propos, la question se pose de savoir si ces dispositions relatives à la sécurité et à la sûreté maritimes sont compatibles au droit international.

527- Rappelons que la quasi-totalité des conventions internationales relatives à la sécurité et à la sûreté maritimes prévoient, pour leur application dans les Etats parties, des dispositions obligeant ceux-ci à prendre des mesures

\footnotetext{
777 Loi n ${ }^{\circ} 2017-442$ du 30 juin 2017 portant code maritime, art. 598 : « ..., Il ne peut limiter sa responsabilité s'il est prouvé que le dommage par pollution résulte de son fait ou de son omission personnelle, commis avec l'intention de provoquer un tel dommage, ou commis témérairement et avec conscience qu'un tel dommage en résulterait probablement".

778 Voir Loi n 2017-442 du 30 juin 2017 portant code maritime, art. 708.

${ }^{779}$ Ce n'est pas le cas dans les Règles de La Haye.

780 Voir Loi n 2017-442 du 30 juin 2017 portant code maritime, art. 730 : « Toute action relative au transport se prescrit par deux ans. Le délai de prescription court à partir du jour où le transporteur a livré les marchandises ou une partie des marchandises ou lorsque les marchandises n'ont pas été livrées, à partir du dernier jour où elles auraient dû l'être ".
} 
législatives et réglementaires compatibles avec leurs systèmes législatifs internes respectifs et à conférer surtout le caractère d'infraction pénale aux actes illicites visés ${ }^{781}$. Compte tenu de cette exigence récurrente des Conventions internationales de lutte contre l'insécurité maritime, l'adoption de dispositions répressives des actes illicites contenues dans le Code maritime était nécessaire pour se conformer au droit international.

528- Ainsi, en matière de piraterie, l'article 101 de la Convention de Montego Bay prévoit, à la charge des Etats parties, l'obligation de coopérer à la répression de la piraterie, tandis que l'article 105 dispose que « ... Les tribunaux de l'Etat qui a opéré la saisie peuvent se prononcer sur les peines à infliger, ainsi que sur les mesures à prendre en ce qui concerne le navire, ... ou les biens, réserve faite des tiers de bonne foi». En réponse à ces prescriptions du droit international, après avoir défini la piraterie et les peines y afférentes ${ }^{782}$, le Code maritime ivoirien prévoit la compétence des juridictions ivoiriennes pour la poursuite des faits de piraterie et octroie le droit de poursuite en haute mer aux autorités ivoiriennes. Aussi, en matière de criminalité maritime, l'article $988 \mathrm{du}$ Code maritime prévoit la poursuite de toute personne, même étrangère, ayant commis l'infraction dans les eaux sous juridiction ivoirienne.

529- Concernant la pollution maritime, la Convention internationale de 1973 pour la prévention de la pollution par les navires (Convention MARPOL) dispose que les actes de pollution soient sanctionnés de deux manières à savoir par les dispositions de la législation de l'Etat du pavillon, ou par celles de la

\footnotetext{
${ }^{781}$ Voir dans ce sens le Traité sur le commerce des armes du 3 juin 2013, art 14 et les principes énoncés dans son préambule. Voir également la Convention des nations unies contre le trafic illicite de stupéfiants et de substances psychotropes du 19 décembre 1988, art. 2 et art. $3 \S 1$. Il en est de même de la Convention des nations unies contre la criminalité transnationale organisée, art. 5. Voir le Protocole visant à prévenir, réprimer et punir la traite des personnes, en particulier des femmes et des enfants, art. 5. Voir le Protocole contre le trafic illicite de migrants par terre, mer et air, art. 6. Voir la Convention des Nations Unies sur le droit de la mer de décembre 1982, art. 105. Etc.

782 Voir Code maritime ivoirien, art. 1008 : "L’infraction de piraterie prévue au présent article est punie, d'une peine de dix à vingt ans et d'une amende de 20000000 à $200000000 \mathrm{~F}$. CFA».
} 
législation de l'Etat du port ${ }^{783}$. En réponse, le Code maritime ivoirien prévoit la compétence des juridictions ivoiriennes et l'application de la législation nationale pour la poursuite des actes de pollution maritime commis par les navires battant pavillon ivoirien ${ }^{784}$ ou commis dans les eaux sous juridiction ivoirienne ${ }^{785}$.

530- Au regard de ce qui précède, nous sommes en droit d'affirmer que les dispositions du Code maritime relatives à la lutte contre l'insécurité de la navigation maritime sont bien compatibles au droit international. Par ailleurs, les difficultés liées à la vérification pratique des marchandises mises en conteneurs à l'occasion du transport ne permettent pas d'éviter l'empotage des produits prohibés tels que la drogue, les armes à feu ou chimiques, les déchets industriels et autres. Cette difficulté semble survivre au nouveau Code maritime ivoirien qui est muet sur la nécessité de soumettre la marchandise empotée par le chargeur à un contrôle systématique du transporteur. Il convient alors d'indiquer que l'insécurité du transport conteneurisé commence au moment de l'empotage du conteneur. Enfin, le transport maritime ayant un caractère international, l'amélioration des normes de sécurité, pour son efficacité, doit tenir à deux niveaux, d'abord national puis sous régional en raison de la position géographique du golfe de Guinée dont la Côte d'Ivoire partage l'utilisation avec les Etats de la sous-région. Alors, après l'adoption des dispositions du Code maritime relatives à la sûreté de la navigation, que peut-il en être de la règlementation sous régionale relative à la sûreté maritime?

${ }^{783}$ Convention internationale de 1973 pour la prévention de la pollution par les navires de Londres, art. $4:$ : 1. Toute violation des dispositions de la présente Convention est sanctionnée par la législation de l'Autorité dont dépend le navire en cause, quel que soit l'endroit où l'infraction se produit. Si l'Autorité est informée d'une telle infraction et est convaincue qu'il existe des preuves suffisantes pour lui permettre d'engager des poursuites pour l'infraction présumée, elle engage ces poursuites le plus tôt possible conformément à sa législation.

2. Toute violation des dispositions de la présente Convention commise dans la juridiction d'une Partie à la Convention est sanctionnée par la législation de cette Partie [...]. 4. Les sanctions prévues par la législation des Parties en application du présent article doivent être, par leur rigueur, de nature à décourager les contrevenants éventuels, et d'une sévérité égale quel que soit l'endroit où l'infraction a été commise".

784 Voir Code maritime ivoirien, art. 584.

${ }^{785}$ Idem, art. 585. 


\section{§ 2: La nécessaire extension de la lutte contre l'insécurité maritime au plan sous régional}

531- En droit comparé, nous avons constaté l'institution au sein de l'Union européenne d'un certain nombre d'accords en vue de la lutte contre l'insécurité maritime par la coopération régionale ${ }^{786}$. Ces accords portent sur la lutte contre les trafics illicites et la pêche illégale et aussi sur la lutte contre la piraterie et la criminalité en mer. Sur inspiration de cette stratégie européenne les Etats de la sous-région du golfe de Guinée, pour réussir leur politique de sécurité et de sûreté maritimes, peuvent adopter un accord similaire. Cependant, à la différence de l'Union européenne qui dispose d'organes politiques propres ${ }^{787}$ notamment la Commission et le Parlement, les Etats de la sous-région du golfe de Guinée ne constituent pas une entité politique disposant d'organes propres. Néanmoins, déjà réunis au sein de l'OMAOC788, il est nécessaire que ces Etats riverains du golfe de Guinée concluent un accord en matière de lutte contre les trafics illicites et l'insécurité maritime ${ }^{789}$ (A) et l’intègrent dans les législations nationales $(\mathbf{B})$.

\section{A- La nécessaire conclusion d'un Accord de lutte contre l'insécurité maritime}

532- En référence à l'Accord relatif au trafic illicite par mer conclu par le Conseil de l'Europe pour mettre en place un cadre légal de lutte contre le trafic illicite de drogue et stupéfiants par mer, les Etats riverains du golfe de Guinée peuvent créer un cadre légal capable de prendre en compte les divers aspects de la sécurité et la sûreté maritimes. Mais la question se pose de savoir sous quelle

\footnotetext{
786 Supra n 477 , p. 229.

787 Voir Traité sur l'Union européenne, art. $13:$ : 1. L'Union dispose d'un cadre institutionnel visant à promouvoir ses valeurs, poursuivre ses objectifs, servir ses intérêts, ceux de ses citoyens, et ceux des États membres, ainsi qu'à assurer la cohérence, l'efficacité et la continuité de ses politiques et de ses actions. Les institutions de l'Union sont: le Parlement européen, le Conseil européen, le Conseil, la Commission européenne (ci-après dénommée "Commission »), la Cour de justice de l'Union européenne, la Banque centrale européenne, la Cour des comptes».

${ }^{788}$ L'OMAOC est l'Organisation Maritime de l'Afrique de l'Ouest et du Centre.

$789 \mathrm{Il}$ peut s'agir soit, d'un seul accord qui prenne les deux branches de l'insécurité maritime en compte à savoir les trafics illicites d'un côté et de l'autre côté la piraterie et la criminalité maritime soit, de deux accords portant chacun sur une branche de l'insécurité maritime.
} 
forme se présentera ce cadre légal : sous forme d'un acte uniforme d'application directe dans les Etats parties ou d'une convention régionale à faire appliquer dans les législations nationales ? L'option de la convention régionale paraît moins efficace car en matière de sûreté maritime, des conventions adoptées par les Nations Unies ont montré leurs limites quant à leur application dans les législations nationales. Un autre obstacle à surmonter pour rendre ce cadre légal ou Accord viable est la tendance du Nigéria à protéger ses ressortissants qui se livrent à la piraterie ${ }^{790}$. La solution à préconiser pour le surmonter est d'adopter des instruments de lutte contre l'insécurité dans le golfe de Guinée qui soient contraignants pour tous les Etats riverains.

533- C'est pourquoi nous recommandons l'élaboration d'un Accord sous la forme d'un Acte uniforme ${ }^{791}$ de l'Organisation pour l'Harmonisation en Afrique du Droit des Affaires (OHADA) 792 qui, une fois adopté, puisse s'appliquer directement et de façon identique dans l'ensemble des Etats parties suivant ainsi l'exemple des directives de l'Union européenne. Cet Accord aura pour objet de mettre en œuvre, à l'échelle sous régionale africaine, certaines dispositions des conventions des Nations Unies portant sur les différents trafics illicites, la piraterie et la criminalité maritimes. Il s'agit notamment de la Convention contre le trafic illicite de stupéfiants et de substances psychotropes de 1988 ; la Convention de Montego Bay en particulier la partie VII relative à la haute mer ;

\footnotetext{
790 Voir Fondation Méditerranéenne d'Etudes Stratégiques (FMES), «Le golfe de Guinée, recrudescence de la piraterie et du brigandage maritime", 29 Novembre 2019, p. 6, in franceorg/le-golfe-de-guinée-recrudescence-de-la-piraterie-et-du-brigandage-maritimes.

791 Voir Traité, OHADA, art. 1. L'acte uniforme est un acte qui, une fois adoptés, s'applique de façon identique dans l'ensemble des États membres.

792 "L'OHADA a été créée dans un contexte de crise économique aigüe et de chute drastique du niveau des investissements en Afrique, l'insécurité juridique et judiciaire étant alors identifiée comme cause majeure de défiance des investisseurs. Vétusté, disparité et inaccessibilité des règles régissant les opérations économiques généraient l'insécurité juridique se traduisant par une incertitude sur la règle en vigueur, tandis que le dénuement des tribunaux, l'insuffisance du personnel judiciaire, la formation déficitaire de celui-ci en droit économique, les lenteurs judiciaires et des problèmes de déontologie constituaient le ferment d'une insécurité judiciaire se traduisant par une certaine imprévisibilité des décisions de justice. Afin d'y remédier, l'OHADA a reçu pour mission de rationaliser l'environnement juridique des entreprises afin de garantir la sécurité juridique et judiciaire des activités économiques, dans la perspective de stimuler l'investissement et de créer un nouveau pôle de développement en Afrique". Voir https://fr.wiki.org/wiki/, consulté le 17 mars 2017.
} 
le traité des Nations Unies sur le commerce des armes de 2013 ; la Convention des Nations Unies contre la criminalité transnationale organisée et son Protocole contre le trafic illicite de migrants par terre, mer et air. Les dispositions relatives à la sûreté et à la sécurité maritimes contenues dans ces conventions doivent être internalisées ${ }^{793}$ à travers l'Accord des Etats riverains du golfe de Guinée. Cet Accord aura donc pour mission d'inclure des dispositions d'incrimination pénale ${ }^{794}$ mais essentiellement de prévoir directement les peines applicables ${ }^{795}$ comme dans le cadre d'une loi pénale nationale.

\section{B- L'application de l'Accord de lutte contre l'insécurité maritime dans les législations nationales}

534- D'abord, il convient de remarquer que la technique législative utilisée par L'OHADA se présente comme l'une des expériences d'intégration juridique les plus réussies. En effet, les Actes uniformes contiennent des règles de droit matériel qui, une fois adoptées, s'appliquent à l'identique dans l'ensemble des États membres et l'emportent sur toute législation interne contraire. Conformément à l'article $10 \mathrm{du}$ Traité OHADA, les Actes uniformes disposent donc d'un effet direct similaire aux règlements de l'UE. Ainsi, en s'inspirant de la technique législative de l'OHADA les Etats riverains du golfe de Guinée concluront l'Accord pour la lutte contre les trafics illicites et l'insécurité maritime. Cet accord, à l'instar des règlements de l'Union Européenne ${ }^{796}$, s'appliquera directement dans chaque Etat partie.

${ }^{793}$ L'expression "internaliser", que nous empruntons à Vincent Bilé signifie : intégrer des dispositions d'une convention internationale dans la législation nationale d'un Etat partie. Voir BILE (Vincent), « Regard Critique sur le Nouveau Code Maritime Ivoirien », Neptunus, e.revue Université de Nantes, vol. 24, 2018/3, op. cit., 2018, p. 1 : "Cette nouvelle loi, loin d'être une codification à droit constant, a permis non seulement d'unifier dans un même corpus une règlementation applicable à divers domaines relevant à la fois du droit public et du droit privé, mais également, d'internaliser des conventions internationales et communautaires dont pour certaines, les délais de transposition étaient largement dépassées".

${ }^{794}$ Cf: Traité OHADA, art. 5: «... Les actes uniformes peuvent inclure des dispositions d’incrimination pénale. Les Etats-Parties s'engagent à déterminer les sanctions pénales encourues".

${ }^{795}$ Cette dimension de l'Accord que nous recommandons met en évidence et justifie sa spécificité.

${ }^{796} \mathrm{La}$ base légale du Règlement européen ou communautaire est l'article 288 du Traité sur le fonctionnement de l'Union européenne qui dispose que pour exercer les compétences de l'Union, les institutions adoptent des règlements, des directives, des décisions, des recommandations et 
535- Certes, faut-il relever que l'Union Européenne et l'OHADA sont des formes d'intégration sous régionale constituées par des traités 797 permettant d'adopter pour la première des Règlements et pour la seconde des Actes uniformes tous d'application directe respectivement dans les Etats membres et les Etats parties. L'absence de traité constitutif des Etats riverains du golfe de Guinée en une organisation politique empêche l'adoption de Règlements ou d'Actes uniformes capables de s'appliquer directement dans ces Etats. Toutefois, pour les besoins de la cause, des dispositions de l'Accord, que nous recommandons, peuvent lui conférer un caractère d'application directe dans les Etats parties en faisant l'économie de son intégration dans chaque législation nationale. Ainsi, au lieu que les Etats parties internalisent 798 les dispositions de l'Accord, celles-ci s'auto intègreront dans les législations nationales. Cependant, compte tenu des prérogatives régaliennes de chaque Etat en matière de répression pénale ${ }^{799}$, il est impérieux qu'une disposition spéciale du futur Accord prescrive son application directe et immédiate dans tous les Etats parties.

536- On obtiendra ainsi un Accord de lutte contre l'insécurité maritime au sein des Etats riverains du golfe de Guinée. Cet Accord servira d'instrument

des avis. Le règlement a une portée générale. Il est obligatoire dans tous ses éléments et il est directement applicable dans tout État membre. La directive lie tout État membre destinataire quant au résultat à atteindre, tout en laissant aux instances nationales la compétence quant à la forme et aux moyens. La décision est obligatoire dans tous ses éléments. Lorsqu'elle désigne des destinataires, elle n'est obligatoire que pour ceux-ci. Les recommandations et les avis ne lient pas.

${ }^{797}$ Respectivement le Traité de Maastricht sur l'Union européenne du 7 février 1992 et le Traité de Port-Louis relatif à l'Organisation pour l'harmonisation du droit des affaires en Afrique (OHADA), du 17 octobre 1993 modifié par le Traité de Québec du 17 octobre 2008.

${ }^{798}$ Cette expression signifie : rendre les dispositions d'une convention internationale applicables en droit national. Voir FOLQUET (Léon), " La règlementation de l'UEMOA en matière de transport maritime ", Revue Africaine des Affaires Maritimes et des Transports, L'Harmattan, juillet 2013, p. 18, in BILE (Vincent), "Regard Critique sur le Nouveau Code Maritime Ivoirien ", Neptunus, e.revue, Université de Nantes, vol. 24, 2018/3, op. cit., p. 1.

799 Voir dans ce sens BRONER (Romain), La répression de la piraterie maritime et ses enjeux juridiques. Mémoire de Master Recherche, Sécurité et Défense, Université Panthéon-Assasparis II, Année universitaire 2009/ 2010, op. cit., p. 62. Selon l'auteur, pour que le processus répressif de la piraterie soit mené à son terme, il peut être nécessaire de passer par la répression judiciaire, qui permet une incarcération et une peine. Pour cela, le recours aux Etats est absolument inévitable, les prérogatives pénales étant, de nature, régaliennes. 
juridique de référence pour la poursuite et la répression de la piraterie dans le golfe de Guinée. 


\section{CHAPITRE 2 : LE RENFORCEMENT DE LA LUTTE CONTRE L'INSECURITE ET DES RECOMMANDATIONS POUR SON AMELIORATION DANS LE GOLFE DE GUINEE}

537- Assurer la sécurité et la sureté maritimes exige de grands moyens aux Etats mais aussi nécessite une étroite et indispensable collaboration entre eux. A propos, Monsieur Jean Tandonnet affirmait ceci : "Assurer la sécurité et la sureté des activités maritimes relève donc de systèmes d'informations, de capacités d'intervention et d'un cadre législatif et réglementaire complexe. La synergie interministérielle et la coopération internationale sont assurément deux facteurs d'efficacité dans la lutte commune contre les risques et les menaces en mer ou provenant de la mer. Les pays riverains de la Méditerranée, mer semi fermée aux activités maritimes multiples et denses, ont tout intérêt à coopérer dans ce domaine aussi sensible ${ }^{800}$.

538- Aussi, ressort-il de notre analyse en droit comparé que la stratégie de lutte contre les vols à main armée et la piraterie adoptée par l'Union européenne repose sur la lutte opérationnelle et la coopération dans la répression. Mais au regard des difficultés énormes qu'éprouve l'OMAOC à mettre en œuvre ses programmes, force est de reconnaître que cet organisme traverse une situation très délicate qui gangrène, depuis quelque temps, ses ambitions ${ }^{801}$. Les Etats riverains du golfe de Guinée ont donc décidé de renforcer leur coopération à travers une nouvelle approche de la stratégie de lutte contre l'insécurité maritime.

539- Notre préoccupation est d'analyser d'abord la quête de la stratégie de lutte contre l'insécurité maritime (Section 1) et terminer ensuite par des recommandations en vue d'améliorer la lutte contre l’insécurité dans le golfe de Guinée (Section 2).

800 Voir TANDONNET (Jean), "Sécurité et sûreté maritime en Méditerranée ", La Revue Maritime, ${ }^{\circ} 483,2008$, p. 37.

801 Voir supra ${ }^{\circ} 390$, pp. 180 et 181. 


\section{Section 1 : La quête de stratégie de lutte contre l'insécurité dans le golfe de Guinée}

540- La question se pose de savoir comment résoudre le problème de l'insécurité dans le golfe de Guinée. A l'instar de l'Union européenne, la coopération entre les Etats riverains du golfe de Guinée pour la lutte contre la piraterie et le vol à main armée prend en compte la dimension opérationnelle et la dimension répressive ${ }^{802}$. Comme le souligne Monsieur Vincent Groizeleau, le golfe de Guinée est une zone stratégique de plus de 6000 kilomètres de côtes qui voit transiter chaque année 140 millions de tonnes de marchandises, soit un quart du trafic maritime africain. C'est l'une des principales zones de production pétrolière de la planète et elle abrite d'importantes ressources halieutiques. Mais la région doit faire face à de nombreux problèmes sécuritaires qui sont autant de facteurs potentiels de déstabilisation. Ils vont des actes de brigandage et de piraterie jusqu'aux trafics en tous genres, drogues et armes notamment, en passant par les risques de pollution, la pêche illicite dans ces eaux très poissonneuses, ou encore les flux migratoires et les problèmes de surpeuplement des mégalopoles situées en bord de mer. ${ }^{803}$

541- Face à ces enjeux économiques importants, la sécurisation de la navigation dans le golfe de Guinée s'avère nécessaire. La stratégie recherchée consiste en une participation conjointe des structures sous régionales et des organes nationaux de lutte contre l'insécurité maritime (\$1). A cet effet, suivront des recommandations tendant à réprimer efficacement les auteurs d’infractions maritimes (§ 2).

\section{$\S 1$ : La collaboration entre les structures sous régionales et les organes nationaux de lutte contre l'insécurité maritime}

542- En juin 2013, les chefs d'état-major des marines de 17 Etats riverains du golfe de Guinée se sont engagés dans une importante action de

\footnotetext{
${ }^{802}$ Supra ${ }^{\circ} 475$ et $\mathrm{s}$, pp. 228 et 229.

803 GROIZELEAU (Vincent), " Golfe de Guinée : Les Africains prennent en main leur sécurité maritime », Le Fouladou, nouvel OPV mis en service en 2016 C OCEA, 2017, p. 1, www.meretmaritime.com, consulté le 17 septembre 2017.
} 
coopération initiée à Yaoundé, au Cameroun. Cette action de coopération s'est poursuivie plus tard comme le précise Monsieur Vincent Groizeleau. En effet, confirmé en 2016 lors du sommet de l'Union Africaine à Lomé (Togo), le processus de Yaoundé, qui vise à développer le travail commun et améliorer l'efficacité des Etats africains en matière de sûreté et de sécurité maritime, implique aussi au niveau politique les grandes organisations régionales, Communauté Economique des Etats d'Afrique de l'Ouest (CEDEAO), Communauté Économique des États de l'Afrique Centrale (CEEAC) et Commission du Golfe de Guinée (CGG). Issu d'une volonté politique commune de sécuriser cette zone maritime afin d'en assurer la prospérité, l'objectif du processus est, notamment, de mettre en œuvre une stratégie régionale de sûreté et de sécurité maritime, avec des actions concrètes destinées à lutter contre différentes menaces ${ }^{804}$.

543- Face aux défis de l'insécurité dans la zone et tenant compte de l'objectif de mise en œuvre d'une stratégie commune de sûreté et de sécurité maritimes, les Etats riverains du golfe de Guinée ont décidé de restructurer et d'accentuer la coopération en leur sein (A) en vue de l'organisation d'opérations conjointes de lutte contre l'insécurité maritime entre les structures sous régionales restructurées et les organes nationaux (B).

\section{A- La restructuration de la coopération entre les Etats riverains du golfe de Guinée}

544- Ayant constaté des dysfonctionnements au sein de l'OMAOC, la sous-région a donc décidé de se restructurer ${ }^{805}$. Ainsi, en septembre 2014, le Centre Interrégional de Coordination (CIC) a été installé à Yaoundé afin de veiller, au niveau stratégique, à mettre en œuvre les actions du processus. Cela

\footnotetext{
${ }^{804}$ GROIZELEAU (Vincent), « Golfe de Guinée : Les Africains prennent en main leur sécurité maritime », Le Fouladou, nouvel OPV mis en service en 2016 @ OCEA, 2017, p. 1.www.meretmaritime.com, consulté le 17 septembre 2017.

${ }^{805} \mathrm{~A}$ propos de dysfonctionnement de l'OMAOC, voir supra $\mathrm{n}^{\circ} 388$, p. 170 où il a été indiqué que « nombre d'États membres de la Communauté des Etats de l'Afrique de l'Ouest (CEDEAO) et de la Communauté des Etats de l'Afrique Centrale (CEEAC) doivent encore prendre des mesures pour ériger en infraction, les actes de piraterie et mettre en place des institutions judiciaires chargées de leur répression ".
} 
passe non seulement par la collaboration des armées (marines et garde-côtes en tête) mais aussi de nombreux autres acteurs ministériels concernés dans chaque pays par ces questions, avec à chaque fois une dimension internationale. Selon Monsieur Vincent Groizeleau, deux centres régionaux de sécurisation maritime, le Centre Régionale de Sécurité Maritime de l'Afrique Centrale (CRESMAC) à Pointe-Noire (Congo) pour l'Afrique centrale et le Centre Régionale de Sécurité Maritime de l'Afrique de l'Ouest (CRESMAO) à Abidjan (Côte d'Ivoire) pour l'Afrique de l'Ouest, ont été créés pour l'action opérationnelle. Chacun s'appuie sur des Centres Multinationaux Maritimes de Coordination (CMMC), soit trois pour le CRESMAO et deux pour le CRESMAC, et en dessous sur les centres opérationnels nationaux. A travers ces différentes structures et le maillage local qu'elles apportent, les pays riverains du golfe de Guinée développent des outils de surveillance et de suivi des activités en mer, accentuent les échanges d'informations et coopèrent pour mener des actions de sécurité maritime. Exceptées les eaux territoriales et les zones économiques du Nigéria, il devient par exemple beaucoup plus facile de repérer, suivre et éventuellement intercepter un bateau suspect, sans qu'il puisse jouer, comme c'était le cas auparavant, sur les délimitations des eaux territoriales et zones économiques exclusives (ZEE) ${ }^{806}$.

545- Toutefois, pour leur mise en œuvre et leur suivi, ces outils de coopération régionale (de coordination et d'échanges de renseignements) pour l'action en faveur de la sûreté et de la sécurité maritimes nécessitent d'importants investissements à consentir par les Etats concernés. Après la mise en place de ces nouvelles structures que sont le CRESMAC, le CRESMAO et les CMC pour surmonter l'état de léthargie et les dysfonctionnements de l'OMAOC dans le golfe de Guinée, nous suggérons des opérations conjointes à mener pour redynamiser la lutte contre l'insécurité dans cette zone maritime.

806 GROIZELEAU (Vincent), ), « Golfe de Guinée : Les Africains prennent en main leur sécurité maritime », Le Fouladou, nouvel OPV mis en service en 2016 @ OCEA, 2017, p. 2. 


\section{B- Les opérations conjointes structurelles de redynamisation}

546- Le golfe de Guinée est devenu une plaque tournante pour les approvisionnements mondiaux en énergie ${ }^{807}$. Des quantités considérables des différents produits pétroliers consommés en Europe, en Amérique du Nord et en Asie transitent par ses voies maritimes. Cependant, l'intensification de la piraterie et d'autres menaces maritimes transnationales a révélé la faiblesse de la connaissance du domaine maritime dans cette région du golfe de Guinée. En outre, la nature extrêmement fongible des menaces qui pèsent sur la sécurité maritime implique qu'un État ne peut pas s'attaquer de manière unilatérale au problème et qu'une coopération régionale cohérente s'impose en matière de sécurité 808 . Car bien qu’il y ait eu des progrès, un engagement politique plus ferme est nécessaire si l'on veut opérationnaliser les plans de coopération régionale en matière de sécurité maritime ${ }^{809}$.

547- Comme l'indique Monsieur Vincent Groizeleau, de nombreuses marines nationales sont en train de moderniser leurs flottes, s'équipant de patrouilleurs performants à même de surveiller et protéger les vastes étendues que représentent leurs ZEE. De nouvelles structures voient également le jour dans certains Etats comme le Bénin, qui a créé en 2016 l'équivalent d'une

807 Voir LUNTUMBUE (Michel), "Insécurité maritime dans le golfe de Guinée : vers une stratégie régionale intégrée ?» Groupe de Recherche et d'Information sur la Paix et la sécurité GRIP, décembre 2012, p. 1.

${ }^{808}$ LUNTUMBUE (Michel), "Insécurité maritime dans le golfe de Guinée : vers une stratégie régionale intégrée ?" Groupe de Recherche et d'Information sur la Paix et la sécurité GRIP, décembre 2012, p. 2. Selon l'auteur, l'enjeu pétrolier confère à la piraterie en golfe de Guinée une incontestable dimension internationale. La sous-région du golfe de Guinée fournit en effet près de $40 \%$ du pétrole consommé en Europe et $29 \%$ du pétrole consommé aux États-Unis 5. Toutefois, l'essor de la piraterie aux larges des côtes ouest-africaines reste d'abord une menace pour la stabilité politique et économique des pays de la sous-région, tant ceux situés sur le littoral, que ceux enclavés dans l'arrière-pays, qui dépendent également du commerce maritime pour leurs importations et leurs exportations. Au regard de l'ampleur du phénomène, aucun pays de la région ne semble en mesure de résoudre seul le problème de l'insécurité maritime. Un nombre croissant d'attaques se produisent en effet au-delà des limites des eaux territoriales des États, tandis que l'on constate une interpénétration entre la piraterie et d'autres formes de criminalité transnationale - trafic de stupéfiants, d'armes, traite des êtres humains, etc. - , qui touchent la sous-région.

809 Voir en ce sens ADENIYI ADEJIMI (Osinowo), « La lutte contre la piraterie dans le golfe de Guinée ", Bulletin de la sécurité africaine, Centre d'Etudes Stratégiques de l'Afrique, 19 avril 2017, p. 1, https://africacenter.org/wp-content/uploads/2016/06/. 
préfecture maritime française, avec une véritable organisation de l'action de l'Etat en mer et la mise en place d'une stratégie nationale de sécurité maritime ${ }^{810}$. L'exemple du Bénin doit inspirer les Etats de la sous-région notamment la Côte d'Ivoire qui gagnerait à créer une structure similaire à celle de la préfecture maritime française se chargeant, entre autres, des opérations d'intervention en mer, du suivi et du contrôle de l'application de la législation maritime.

548- Monsieur Adeniyi Adejimi Osinowo précise ceci : "En 2010, des améliorations dans la collaboration opérationnelle entre la Marine nigériane et la NIMASA ont entraîné de fortes réductions des attaques dans la zone du port de Lagos. Dans le cadre de cette collaboration, des navires à équipages mixtes effectuent des patrouilles de police et de répression de la piraterie appuyées par des moyens de surveillance électronique, en particulier dans les eaux territoriales et les approches des ports »811. Sur la base de cette expérience, nous suggérons qu'une coopération sous régionale opérationnelle soit organisée par l'Accord des Etats riverains du golfe de Guinée pour la lutte contre l'insécurité maritime ${ }^{812}$. Cet Accord prévoira un cadre des patrouilles conjointes organisées, d'une part, entre les Etats de la CEDEAO et le CRESMAO et, d'autre part, entre les Etats de la CEEAC et le CRESMAC ${ }^{813}$. Les patrouilles conjointes doivent être également mises en œuvre lorsque la sécurité de la navigation est menacée ou en cas de présence de navires suspects dans le golfe de Guinée. Par ailleurs, il importe de mentionner que les patrouilles conjointes, quelles qu'elles soient, sont habilitées à faire usage de la force contre les pirates ${ }^{814}$ et bandits à main

\footnotetext{
810 GROIZELEAU (Vincent), "Golfe de Guinée : Les Africains prennent en main leur sécurité maritime ", Le Fouladou, nouvel OPV mis en service en 2016 ( ) OCEA, 2017. p. 7.

811 Cf : ADENIYI ADEJIMI (Osinowo), "La lutte contre la piraterie dans le golfe de Guinée ", Bulletin de la sécurité africaine, Centre d'Etudes Stratégiques de l'Afrique, 19 avril 2017, n 32, p. 7, https://africacenter.org/wp-content/uploads/2016/06/.

812 Voir supra $\mathrm{n}^{\circ} 536$, pp 261 et $\mathrm{s}$.

813 Voir Annexe $n^{\circ} 3:$ Zones multinationales de coordination maritime en Afrique de l'Ouest et du Centre, p. XI. Source : International CRISIS GROUP, 2014.

814 Voir LEFEBRE-CHALAIN (Hélène) et LEBOEUF (Cédric), "La piraterie maritime", Université de Nantes, Centre de Droit Maritime et Océanique, Compte rendu, Journées Méditerranéennes Organisées Décembre 2009, p. 2. Selon les auteurs, l'usage de la force implique, au regard de la [Convention de Montego Bay (CMB)], le droit d'intervenir et le devoir
} 
armée dans les conditions prévues par le droit international notamment en prenant en compte les principes du respect de leurs droits.

549- La participation conjointe des structures sous régionales et des organes nationaux à la lutte contre l'insécurité maritime étant examinée, il ne reste plus qu'à faire des recommandations pour une répression efficace des auteurs d’infractions maritimes dans le golfe de Guinée.

\section{§ 2: Des recommandations pour une répression efficace des auteurs d'infractions maritimes à l'échelle sous régionale}

550- Les patrouilles conjointes ont pour but d'empêcher les agissements des pirates, des bandits à main armée et autres trafiquants illicites. Mais lorsque ces patrouilles conjointes et les autres dispositifs légaux mis en place n'ont pu empêcher les délinquants d'agir, il s'ensuit que des infractions sont perpétrées. Dès lors leurs auteurs doivent être réprimés. Pour son efficacité, la répression nécessite là encore une coopération sous régionale. A cet effet, seront prises des mesures susceptibles de contraindre le Nigéria à permettre la poursuite des pirates au-delà de ses limites territoriales. La répression doit porter, à notre sens, sur une uniformisation des procédures de poursuite, de conservation et de transmission des preuves des infractions (A) et sur des dispositions favorisant l'extradition rapide des personnes suspectées (B).

\section{A- Une uniformisation des peines, des procédures de poursuite, de conservation et de transmission des preuves des actes illicites}

551- La coopération régionale en vue de la répression de la piraterie dans l'Union européenne a consisté, entre autres actions, à observer une assistance mutuelle relative aux enquêtes, poursuites et procédures judiciaires ${ }^{815}$. A l'instar de la coopération communautaire, les Etats riverains du golfe de Guinée

\footnotetext{
de coopérer en vue d'enrayer la piraterie. Le professeur Lucchini rappelait les circonstances des négociations de la CMB et les articles 101 et suivants de la CMB. Selon lui, l'usage de la force dans le cadre du droit d'intervention implique une nécessaire distinction selon que l'intervention ait lieu en haute mer ou dans les eaux sous souveraineté. Et puisque les pirates sont nécessairement des Hommes, la question du recours à la force contre les pirates suppose que son cadre juridique prenne en compte les principes de respect de leurs droits universels. 815 Supra n 478 , p. 229-230.
} 
doivent uniformiser leurs procédures de poursuite, de conservation et de transmission des preuves de la piraterie et des autres actes illicites. Cela suppose au préalable une incrimination uniformisée de la piraterie et de la criminalité en mer assortie de sanctions pénales. Aussi, importe-il de distinguer la piraterie du terrorisme maritime pour une meilleure qualification des faits constitutifs de piraterie. Selon Monsieur Romain Broner, «... la piraterie n'est pas du terrorisme. Tant les moyens mis en œuvre que les buts sont différents. [...]. Les entreprises terroristes visent à provoquer la terreur par des actes impressionnants, meurtriers et/ou avec une grande portée médiatique. A l'inverse, le pirate agit dans un but de lucre purement privé : c'est un bandit des mers. Il cherche seulement à s'enrichir en prenant le contrôle de navires, de leur cargaison et éventuellement de leurs passagers, pour en tirer un profit substantiel» 816 .

552- Telle que définie par l'article 101 de la Convention de Montego Bay, la piraterie n'est pas assortie de sanctions pénales. A propos de peines applicables, l'article 105 de ladite Convention renvoie aux législations nationales ${ }^{817}$. En outre, s'agissant des peines applicables à la criminalité transnationale organisée, l'article 5 de la Convention de Palerme renvoie également aux législations nationales ${ }^{818}$. C'est pourquoi, nous pensons que des définitions de peines relatives à la piraterie et à la criminalité maritime doivent

\footnotetext{
816 Voir en ce sens BRONER (Romain), La répression de la piraterie maritime et ses enjeux juridiques, Mémoire de Master de Recherche, Sécurité et Défense, Université Panthéon-AssasParis II, Année universitaire 2009/2010, p. 18.

817 Convention de Montego Bay, art. 105 : "Tout Etat peut, en haute mer ou en tout autre lieu ne relevant de la juridiction d'aucun Etat, saisir un navire ou un aéronef pirate, ou un navire ou un aéronef capturé à la suite d'un acte de piraterie et aux mains de pirates, et appréhender les personnes et saisir les biens se trouvant à bord. Les tribunaux de l'Etat qui a opéré la saisie peuvent se prononcer sur les peines à infliger, ainsi que sur les mesures à prendre en ce qui concerne le navire, l'aéronef ou les biens, réserve faite des tiers de bonne foi ".

818 Convention des Nations Unies contre la criminalité transnationale organisée, art. $5:$ : 1. Chaque État Partie adopte les mesures législatives et autres nécessaires pour conférer le caractère d'infraction pénale, lorsque commis intentionnellement:

a) À l'un ou l'autre des actes suivants ou aux deux, en tant qu'infractions pénales distinctes de celles impliquant une tentative d'activité criminelle ou sa consommation: ... ;

b) Au fait d'organiser, de diriger, de faciliter, d'encourager ou de favoriser au moyen d'une aide ou de conseils la commission d'une infraction grave impliquant un groupe criminel organisé».
} 
être respectivement uniformisées dans un accord sous régional tenant compte des législations nationales et du droit international. Il en sera de même pour les procédures de poursuite, de conservation et de transmission des preuves en cas de piraterie ou de tout autre acte illicite perpétré en mer. Ainsi les peines rattachées à la piraterie, à la criminalité maritime et autres actes illicites et les procédures de poursuite pourront être prévues et uniformisées par l'Accord des Etats riverains du golfe de Guinée pour la lutte contre l'insécurité maritime ${ }^{819}$ que nous recommandons ci-dessus.

553- Par ailleurs, et c'est essentiel pour l'application dudit Accord, ses dispositions doivent prévoir un "droit de poursuite" pour les parties contractantes de sorte à rendre possible l'appréhension des personnes suspectées de piraterie ou de criminalité transnationale qui seraient en fuite dans les eaux territoriales des Etats riverains du golfe de Guinée, parties à l'Accord. Nous entendons par droit de poursuite la possibilité de poursuivre les navires suspects dans tout pays riverain du golfe de Guinée. Il est vrai qu'un tel droit de poursuite se heurte au principe de la souveraineté des Etats. Toutefois, il peut être justifié par la nécessité de dissuader et de réprimer les pirates et brigands à main armée qui opèrent dans cette zone. Ce droit de poursuite pourrait tirer son fondement de l'article 11 alinéa 2 de la Convention des Nations Unies contre la criminalité transnationale organisée de 2000820. En effet, si un tel droit de poursuite n'est pas prévu par l'Accord, certains Etats, notamment le Nigéria, peuvent se réfugier derrière leur souveraineté pour empêcher la poursuite d'éventuels pirates et brigands en fuite dans leurs eaux territoriales.

\footnotetext{
819 Supra n 533, pp. 260-261.

820 Voir Convention des Nations Unies contre la criminalité transnationale organisée de 2000, art. 11 al. 2: "Chaque État Partie s'efforce de faire en sorte que tout pouvoir judiciaire discrétionnaire conféré par son droit interne et afférent aux poursuites judiciaires engagées contre des individus pour des infractions visées par la présente Convention soit exercé de façon à optimiser l'efficacité des mesures de détection et de répression de ces infractions, compte dûment tenu de la nécessité d'exercer un effet dissuasif en ce qui concerne leur commission".
} 


\section{B- Une simplification de la procédure d'extradition des présumés pirates dans les Etats riverains du golfe de Guinée}

554- En matière de navigation maritime, le principe posé par le droit maritime est que le navire croisant en eaux internationales n'est soumis qu'à l'autorité de l'Etat de son pavillon. Toutefois, selon Madame Melle Nathalie Boudong, plusieurs raisons justifient la mise en place d'un régime dérogatoire d'intervention et de poursuite pour les actes de piraterie ${ }^{821}$. En effet, l'article 100 de la Convention de Montego Bay sur le droit de la mer a prévu le devoir de coopération des Etats en matière de répression de la piraterie. Ce devoir de coopération est complété par la compétence universelle des Etats établie par l'article 105 de la même convention. La compétence universelle confère ainsi à tout Etat le droit de poursuivre et de réprimer tout individu soupçonné d'avoir perpétré des actes de piraterie ${ }^{822}$. Selon Madame Melle Nathalie Boudong, « Il s'agit là du droit de juger pour sanctionner les auteurs d'un acte de piraterie. [Cela] permet de faire juger le pirate, pouvant être coupable de meurtre ou de violence sur des personnes à bord du navire attaqué, et permet aussi un jugement par les autorités de l'Etat dont sont ressortissantes les victimes de l'acte. Ce peut être le gage d'une meilleure justice, ou d'une peine qui sera effective, voire plus sévère » ${ }^{823}$. Cependant, la répression doit se faire dans le respect du droit international ${ }^{824}$ notamment la procédure d'extradition.

\footnotetext{
821 Tout d'abord, un navire battant un pavillon attribué par un Etat qui ne se soucie guère de ses devoirs en tant qu'Etat d'immatriculation, ou un pavillon attribué par un Etat ne disposant que de forces maritimes très limitées, voire un pavillon attribué par un pays de non droit ne risquent pas de faire appliquer une quelconque réglementation à bord de ces navires. Voir BOUDONG (Melle Nathalie), La piraterie maritime moderne, Mémoire de Master de recherche, UNIVERSITE PAUL CEZANNE III. Droit maritime et des transports, Année universitaire 2008/2009, op. cit., p. 27.

822 Convention de Montego Bay art. 105 in fine: "les tribunaux de l'Etat qui a opéré la saisie peuvent se prononcer sur les peines à infliger, ainsi que sur les mesures à prendre en ce qui concerne les navires...".

${ }^{823}$ BOUDONG (Melle Nathalie), La piraterie maritime moderne, Mémoire de Master de recherche, Droit maritime et des transports, UNIVERSITE PAUL CEZANNE III, Année universitaire 2008/2009, op. cit., p. 32 .

${ }^{824} \mathrm{Cf}$ : Convention de Montego Bay, art. 87 : «La haute mer est ouverte à tous les Etats, qu'ils soient côtiers ou sans littoral. La liberté de la haute mer s'exerce dans les conditions prévues par les dispositions de la Convention et les autres règles du droit international».
} 
555- L'extradition s'entend comme une procédure d'entraide répressive internationale par laquelle un Etat, appelé Etat requis, accepte de livrer un délinquant qui se trouve sur son territoire à un autre Etat, l'Etat requérant, pour que ce dernier puisse juger cet individu ou, s'il a déjà été condamné, pour lui faire subir sa peine ${ }^{825}$. Les principes de l'extradition doivent être respectés en matière de répression de la piraterie maritime. Par ailleurs, les Etats membres de la Communauté des Etats de l'Afrique de l'Ouest (CDEAO), déterminés à doter les tribunaux nationaux d'un instrument efficace qui permet l'arrestation, le jugement et l'exécution des peines des délinquants qui se seraient enfuis du territoire d'un Etat membre sur le territoire d'un autre ${ }^{826}$, ont conclu en leur sein une Convention d'extradition en 1994. Il importe de l'examiner et de s'inspirer de ses principes de base dans le cadre d'une application plus large entre les Etats riverains du golfe de Guinée.

556- Selon Monsieur Ismaël Mayela, la convention d'extradition de la CEDEAO met à la charge des Etats membres de la communauté l'obligation d'extrader lorsque les conditions ${ }^{827}$ qu'elle contient sont remplies ${ }^{828}$. Cependant, compte tenu de la particularité de l'acte de piraterie, les conditions à examiner seront celles qui sont relatives au lieu de commission de l'acte et au respect des droits des personnes suspectées de piraterie. En ce qui concerne le lieu de commission de l'acte, la Convention d'extradition de la CEDEAO dispose en son article 11 que: "l'Etat requis pourra refuser d'extrader l'individu réclamé en raison d'une infraction qui, selon sa législation a été commise en tout ou en partie sur son territoire ou en un lieu assimilé à son territoire. Lorsque l'infraction motivant la demande d'extradition aura été commise hors du territoire de l'Etat requérant l'Etat requis n'autorise pas la poursuite pour une infraction du même genre commise hors de son territoire, ou n'autorise pas l'extradition pour

\footnotetext{
825 Voir GUILLIEN (Raymond) et VINCENT (Jean), Lexique des termes juridiques, Dalloz, 13ème édition, 2001, p. 255.

${ }^{826}$ Convention d'extradition de la CEDEAO d'Abuja de 1994, voir le préambule.

$827 \mathrm{Au}$ titre des conditions voir notamment les articles $2 ; 3 ; 4 ; 5 ; 7$ et 10 de la Convention d'extradition de la CEDEAO précitée de 1994,

828 MAYELA (Ismaël), "L'obligation d'extrader des Etats membres de la CEDEAO ", www. village-justice.com/articles/obligations, consulté le 13 août 2018, p. 1.
} 
l'infraction faisant l'objet de la demande" Toutefois, le Nigéria a tendance à ignorer les dispositions de la Convention d'extradition de la CEDEAO et à privilégier les intérêts de ses propres ressortissants suspectés de piraterie dans le golfe de Guinée ${ }^{829}$. Il convient alors d'en tenir compte pour contraindre les Etats riverains du golfe de Guinée, notamment le Nigéria, à se soumettre aux normes de lutte contre l'insécurité maritime.

557- L'acte de piraterie s'exécutant en haute mer hors de toute juridiction étatique, seules la nationalité des pirates et celle des victimes ainsi que le pavillon du navire peuvent motiver une demande d'extradition de l'Etat requérant conformément au droit international. En effet, "Le principe de souveraineté étatique qui s'applique en haute mer, contenu dans l'article 19 de la convention sur la haute mer impliquerait que la responsabilité du pirate doit être engagée devant l'Etat dont il est ressortissant, ou celui dont bat pavillon le navire. Cependant, dans le cadre de la piraterie, il est nécessaire de permettre un jugement par les tribunaux de la partie victime de la piraterie par exemple, ou par tout Etat qui y voit un intérêt. Ainsi, au même titre que les crimes contre l'humanité, tout Etat qui le souhaite peut faire juger devant ses tribunaux les pirates que ses autorités ont arrêtés " ${ }^{830}$. C'est pourquoi, en vue de protéger les droits des parties ${ }^{831}$, la compétence universelle des Etats en matière de piraterie est assortie d'une obligation d'informer l'Etat dont les suspects sont

\footnotetext{
${ }^{829}$ Cf: Fondation Méditerranéenne d'Etudes Stratégiques (FMES), «Le golfe de Guinée, recrudescence de la piraterie et du brigandage maritime ", 29 Novembre 2019, in fmes-france org/le-golfe-de-guinée-recrudescence-de-la-piraterie-et-du-brigandage-maritimes, consulté en mars 2020.

830 BOUDONG (Melle Nathalie), La piraterie maritime moderne, Mémoire, Droit maritime et des transports, UNIVERSITE PAUL CEZANNE III, Année universitaire 2008/2009, op. cit., p. 32 .

${ }^{831}$ Convention pour la répression d'actes illicites contre la sécurité de la navigation maritime de Rome de 1988, art. $10:$ :2. Toute personne contre laquelle une procédure est engagée en raison d'une des infractions prévues à l'art. 3 jouit de la garantie d'un traitement équitable à tous les stades de la procédure, y compris la jouissance de tous les droits et garanties prévus pour une telle procédure par les lois de l'Etat sur le territoire duquel elle se trouve».
} 
ressortissants, l'Etat dont les victimes sont ressortissants ou encore l'Etat du pavillon du navire ${ }^{832}$.

558- L'obligation d'informer met à la charge de tout Etat ayant capturé des suspects de porter ces faits à la connaissance de l'Etat dont les pirates sont ressortissants, de l'Etat dont les victimes sont ressortissantes et de l'Etat du pavillon du navire ${ }^{833}$. De la sorte, les droits des pirates ${ }^{834}$, des victimes et de l'Etat du pavillon du navire sont préservés. Ainsi, conformément au droit international chacun de ces différents Etats peut formuler une demande d'extradition des suspects en vue de les juger. Toutefois, l'extradition ne sera pas accordée « si l'individu dont l'extradition est demandée a été ou serait soumis dans l'Etat requérant à des tortures et autres peines ou traitements cruels, inhumains ou dégradants. Il en sera de même lorsque l'individu n'a pas bénéficié ou est susceptible de ne pas bénéficier au cours des procédures pénales, des

832 Convention de Montego Bay, art. 94: «7. Chaque Etat ordonne l'ouverture d'une enquête, menée par ou devant une ou plusieurs personnes dûment qualifiées, sur tout accident de mer ou incident de navigation survenu en haute mer dans lequel est impliqué un navire battant son pavillon et qui a coûté la vie ou occasionné de graves blessures à des ressortissants d'un autre Etat, ou des dommages importants à des navires ou installations d'un autre Etat ou au milieu marin. L'Etat du pavillon et l'autre Etat coopèrent dans la conduite de toute enquête menée par ce dernier au sujet d'un accident de mer ou incident de navigation de ce genre".

${ }^{833}$ Convention de Montego Bay, art. 97 : «1. En cas d'abordage ou de tout autre incident de navigation maritime en haute mer qui engage la responsabilité pénale ou disciplinaire du capitaine ou de tout autre membre du personnel du navire, il ne peut être intenté de poursuites pénales ou disciplinaires que devant les autorités judiciaires ou administratives soit de l'Etat du pavillon, soit de l'Etat dont l'intéressé a la nationalité».

834 Voir MAHAMANE-OUMAROU (Rachid), Le respect des droits de l'homme dans la procédure d'extradition, Université catholique de l'Afrique de l'ouest UCAO, Mémoire 2012, p. 2. Selon l'auteur, entre les principes sus évoqués et l'approbation de la demande d'extradition, la marge de manœuvre des Etats est très réduite, car le respect des droits de l'homme demeure la plus grande préoccupation contemporaine. L'Etat requis, par les garanties qu'il aura obtenues du pays requérant, exercera un regard actif sur le traitement a posteriori réservé à l'extradé par ce dernier. D'une part pour le protéger d'abus et, d'autre part, pour lui assurer une protection juridictionnelle maximale. 
garanties minimales, prévues par l'article $7^{835}$ de la Charte africaine des droits de l'homme et des peuples $» 836$.

559- A notre sens, une réglementation spécifique sur l'extradition des pirates de mer s'avère nécessaire entre les Etats riverains du golfe de Guinée pour définir les principes et conditions de facilitation de la poursuite et de la répression desdits pirates tout en tenant compte de leurs droits fondamentaux ${ }^{837}$. Cette règlementation peut être incluse dans l'Accord des Etats riverains du golfe de Guinée proposé ci-dessus ${ }^{838}$. Aux recommandations faites en vue d'une répression efficace des auteurs d'infractions maritimes à l'échelle sous régionale, il faut ajouter celles qui sont nécessaires à l'amélioration de la lutte contre l’insécurité maritime.

\section{Section 2 : Des recommandations en vue de l'amélioration de la lutte contre l'insécurité maritime}

560- D'abord, l'une des causes de l'inefficacité de la lutte contre l'insécurité maritime est le défaut d'application aussi bien des conventions internationales que des lois nationales prévues à cette fin ${ }^{839}$. Un suivi de l'application des instruments de lutte contre les infractions maritimes s'avère donc nécessaire à l'échelle nationale ivoirienne. Une autre cause de l’inefficacité de la lutte contre l'insécurité maritime est, disons-le ouvertement, la passiveté de certains Etats face à la piraterie ou à tout le moins leur inaction face à l'insécurité maritime dans le golfe de Guinée. Seront donc examinés le suivi de l'application des instruments de lutte contre l'insécurité maritime à l'échelle

\footnotetext{
835 Charte africaine des droits de l'homme et des peuples art. $7:$ "1. Toute personne a droit à ce que sa cause soit entendue. Ce droit comprend: a. le droit de saisir les juridictions nationales compétentes de tout acte violant les droits fondamentaux qui lui sont reconnus et garantis par les conventions, les lois, règlements et coutumes en vigueur; $b$. le droit à la présomption d'innocence, jusqu'à ce que sa culpabilité soit établie par une juridiction compétente; c. le droit à la défense, $y$ compris celui de se faire assister par un défenseur de son choix; d. le droit d'être jugé dans un délai raisonnable par une juridiction impartiale. 2. ...».

${ }^{836}$ Voir Convention d'extradition de la CEDEAO de 1994, art. 5.

$837 \mathrm{Cf}$ : Charte africaine des droits de l'homme et des peuples, art. 7.

838 Voir supra $n^{\circ} 533$, pp. 260 et 261.

839 Voir supra $n^{\circ} 364$, p. 159 et $\mathrm{n}^{\circ} 367-368$, pp. 168-170.
} 
nationale (\$ 1) et des recommandations en vue d’impliquer tous les Etats riverains du golfe de Guinée dans la lutte contre l’insécurité maritime (\$2).

\section{$\S 1$ : Le suivi de l'application des instruments de lutte contre l'insécurité maritime à l'échelle nationale}

561- Doivent être suivis aussi bien les instruments de lutte contre l'insécurité maritime déjà existants que ceux qui seront édictés dans le futur. Ce suivi sera assuré, d'une part, par la Direction générale des affaires maritimes et portuaires (A) et, d'autre part, par les organes de répression des infractions liées au trafic maritime $(\mathbf{B})$.

\section{A- Un suivi de la lutte contre l'insécurité par la Direction générale des affaires maritimes et portuaires (DGAMP)}

562- L'une des insuffisances de la lutte contre l'insécurité maritime en Côte d'Ivoire est le manque d'organe de suivi et de contrôle de l'application des normes de sûreté maritime prévues par les conventions internationales et les lois nationales. La mise en place d'un organe de coordination nationale du suivi de l'application de la législation de lutte contre les actes illicites en mer (1) s'avère nécessaire. Par ailleurs, tenant compte des recommandations de Monsieur Romain Broner ${ }^{840}$, pour une lutte opérationnelle concertée contre les actes illicites en mer, une coopération s'impose entre la Coordination nationale de suivi de la l'application de la législation maritime et le CRESMAO (2).

\section{1- Mise en place d'une Coordination nationale de suivi de la législation de lutte contre l'insécurité maritime}

563- Au sein de la Direction générale des affaires maritimes et portuaires, doit être créé un organe en vue de la coordination nationale et du suivi de l'application de la législation maritime. Sa principale mission sera, en effet, la coordination du suivi de l'application de la législation relative à la sûreté et à la sécurité de la navigation maritime. C'est une mission transversale de

\footnotetext{
${ }^{840}$ BRONER (Romain), La répression de la piraterie maritime et ses enjeux juridiques. Mémoire, de Master de Recherche, Sécurité et Défense, Université Panthéon-Assas-paris II, Année universitaire 2009/ 2010, op. cit., p. 56. Selon l'auteur, les mécanismes de coopération, plus poussés, vont au-delà du simple partage d'information et de concertation sur la lutte contre la piraterie et qu'ils sont largement promus pour résorber la piraterie.
} 
coordination de toutes les structures qui ont en charge la sécurité maritime en vue de veiller à l'application de la législation prévue pour la sûreté et la sécurité maritimes. En conséquence, il doit être placé au-dessus des organes opérationnels pour exercer son pouvoir de contrôle sur ceux-ci.

564- La mise en place d'un tel organe au sein de la DGAMP a pour but de résoudre la question du défaut d'application de la législation relative à la lutte contre l'insécurité maritime soulevée lors de notre analyse critique ${ }^{841}$. Car il en est ressorti que le manque de structure de contrôle et de suivi constitue une cause de l'inapplication de la législation de lutte contre l'insécurité maritime. Toutefois, pour réussir sa mission la Coordination nationale de suivi de l'application de la législation maritime, à l'instar de ce qui se passe dans la zone de la Méditerranée ${ }^{842}$, doit être en coopération permanente avec les structures sous régionales notamment le Centre régional de sécurité maritime de l'Afrique de l'Ouest (CRESMAO).

\section{2- Coopération entre la Coordination nationale de suivi de la législation maritime et le CRESMAO}

565- A l'instar de l'Agence européenne pour la sécurité maritime EMSA dont la mission est d'améliorer la sécurité et la sureté maritimes, il a été mis en place le Centre Régionale de Sécurité Maritime de l'Afrique de l'Ouest CRESMAO à Abidjan (Côte d'Ivoire) au service des Etats de l'Afrique de l'Ouest pour l'action opérationnelle ${ }^{843}$. Il est soutenu par les centres opérationnels nationaux. Mais en plus de cet appui des centres opérationnels nationaux au CRESMAO, nous suggérons la mise en place d'une coopération étroite et

\footnotetext{
${ }^{841}$ Voir supra $\mathrm{n}^{\circ} 368$, p. 169.

842 Voir TANDONNET (Jean), "Sécurité et sûreté maritime en Méditerranée", La Revue Maritime $\mathrm{n}^{\circ} 483,2008$, p. 37. Selon l'auteur, assurer la sécurité et la sureté des activités maritimes relève donc de systèmes d'informations, de capacités d'intervention et d'un cadre législatif et réglementaire complexe. La synergie interministérielle et la coopération internationale sont assurément deux facteurs d'efficacité dans la lutte commune contre les risques et les menaces en mer ou provenant de la mer.

${ }^{843}$ Supra ${ }^{\circ} 544$, pp. 265-266.
} 
permanente entre le CRESMAO ${ }^{844}$ et la Coordination nationale du suivi de l'application de la législation de lutte contre l'insécurité maritime.

566- Il convient de préciser cependant que cette étroite coopération entre ces deux structures que nous suggérons n'est pas de nature à engager des actions concertées de lutte opérationnelle contre les actes illicites perpétrés en mer. Elle vise plutôt à veiller au suivi de la bonne application de la législation maritime internationale, régionale et nationale en Côte d'Ivoire. En effet, le diagnostic de l'insécurité maritime dans le golfe de Guinée ayant révélé l'existence d'une législation abondante en la matière mais hélas pas véritablement appliquée, un organe de coordination du suivi de l'application de ladite législation est vivement souhaité. Enfin, après la Direction générale des affaires maritimes et portuaire, nous suggérons que le suivi de la lutte contre l’insécurité maritime soit étendu aux organes de répression.

\section{B- Un suivi de la lutte contre l'insécurité maritime par les organes de répression}

567- Notons pour rappel que dans la région de la méditerranée, la coordination et le suivi des actions entre les services regroupés au sein du centre d'analyse et de surveillance maritime de l'Atlantique a permis de réaliser des

844 Voir CHEICKNA (D. Salif), "Sécurité maritime dans la CEDEAO, équipement du CRESMAO ", slifoudabou@fratmat.info, consulté le 7 mars 2018, p. 1. "Le directeur par intérim du CRESMAO, le Capitaine de Vaisseau-major, Konan Kouakou Boniface a expliqué les raisons qui ont conduit à la création dudit Centre. Il s'agit, à l'en croire, de sécuriser et de lutter contre les activités illégales dans le Golfe de Guinée. Et surtout de contribuer à une efficacité continue du CRESMAO dans son rôle de coordination des centres multinationaux maritimes de coordination (CMMC) des zones de sécurité maritime. "Dans ce processus, nous n'attendons que l'arrivée des cadres issus des autres Etats membres de la Communauté économique des Etats de l'Afrique de l'Ouest (CEDEAO) en vue de parachever la dimension régionale de ce centre à travers son personnel", a indiqué le directeur par intérim, le Capitaine de Vaisseau-major Konan Boniface [...]. Poursuivant, il a indiqué qu'au cours de la dernière décennie, il y a eu une augmentation significative des actes de piraterie et de vols à main armée en mer, particulièrement dans le Golfe de Guinée. Sans toutefois omettre la contrebande de drogues et d'armes, la traite des êtres humains, la pêche illégale et leurs liens possibles avec le terrorisme international qu'il a qualifié de "préoccupants"". 
résultats satisfaisants ${ }^{845}$. Pour le suivi de l'application de la législation de lutte contre l'insécurité maritime par les organes de répression, on examinera la question de l'opportunité ou non d'une juridiction spéciale pour connaître des infractions maritimes (1) et la mise en place d'une coopération entre les juridictions, la DGAMP et le CRESMAO (2).

\section{1- De l'opportunité ou non d'une juridiction spéciale pour connaître des infractions maritimes en haute mer}

568- En matière de criminalité maritime, conformément au droit international $^{846}$ la compétence juridictionnelle est attribuée principalement à l'Etat côtier sur l'espace maritime duquel l'acte est commis. A l'échelle européenne, selon Monsieur Jean Tandonnet, les pays riverains de la Méditerranée, mer semi fermée aux activités maritimes multiples et denses, ont tout intérêt à coopérer dans ce domaine aussi sensible. Mais sans un effort pour imaginer au plan européen une tutelle judiciaire aux opérations multinationales en mer, la multiplication couteuse des moyens continuera à être de mise ${ }^{847}$. La question se pose de savoir s'il est opportun de mettre en place au niveau de la sous-région du golfe de Guinée une juridiction spéciale pour connaître des actes illicites perpétrés en haute mer contre la sécurité de la navigation maritime.

569- A propos de juridiction spéciale réservée à la piraterie, Monsieur Romain Broner indiquait que la solution la plus adaptée serait certainement la mise en place d'une juridiction qui serait dédiée aux problématiques spécifiques de la piraterie. Ces spécificités découleraient à la fois de l'espace où elle se déroule, et de la qualité militaire de ses intervenants. Une telle juridiction pourrait prendre de nombreuses formes : chambre spécialisée au sein d'une juridiction nationale, mise en place d'une Cour régionale dédiée à la lutte contre

\footnotetext{
${ }^{845}$ Cf : YAPO (Marina Madel), La lutte contre la criminalité maritime dans le golfe de guinée : cas de la Côte d'Ivoire et du Nigeria, Programme de Bourses de Recherche, Nations UniesFondation Nippone du Japon, Etude 2012-2013, Décembre 2013, op. cit., p. 89.

846 Voir Convention pour la répression d'actes illicites contre la sécurité de la navigation maritime de Rome de 1988, art. 6.

847 Voir TANDONNET (Jean), "Sécurité et sûreté maritime en Méditerranée ", La Revue Maritime $\mathrm{n}^{\circ} 483,2008$, p. 37.
} 
la piraterie, création d'une Cour internationale de la piraterie, avec un statut juridique entièrement nouveau pour les pirates, ou encore rattachement à une Cour internationale déjà existante (Tribunal International du Droit de la Mer, situé à Hambourg, ou encore Cour Pénale Internationale, située à La Haye) ${ }^{848}$. Mais il faut signaler que le Tribunal international du droit de la mer n'est pas une juridiction pénale ${ }^{849}$.

570- Toutefois, quelques difficultés se présenteraient à chacune de ces propositions ci-dessus relatives à la juridiction spéciale. En effet, la mise en place d'une chambre spécialisée au sein d'une juridiction nationale pose le problème de la procédure pénale à adopter en son sein ${ }^{850}$. Quant-à la création d'une Cour régionale dédiée à la lutte contre la piraterie, elle nécessiterait une modification du protocole de cette Cour et probablement de l'accord qui a présidé à sa création. Enfin, l'idée d'une Cour internationale de la piraterie nécessite la négociation d'un accord international qui risque de prendre énormément de temps et faire l'objet de nombreuses tractations ${ }^{851}$. D'autres auteurs sont encore moins favorables à la répression de la piraterie par une juridiction internationale 852 .

848 BRONER (Romain), La répression de la piraterie maritime et ses enjeux juridiques, Mémoire de Master de Recherche, Sécurité et Défense, Université Panthéon-Assas-paris II, Année universitaire 2009/ 2010, op. cit., p. 82.

849 WOLFRUM (Rüdiger), "Importance du Tribunal international du droit de la mer pour Hambourg : profil, attentes et réalité", Übersee-Club, Hambourg, février 2008, p. 1. Selon l'auteur, il ne s'agit pas d'un Tribunal pénal et seul un tribunal pénal serait compétent pour juger des pirates; en revanche les domaines de compétence du Tribunal du droit de la mer concernent la pêche, la protection de l'environnement et l'exploitation économique des mers, pour autant qu'elles donnent lieu à des différends entre Etats; si l'on y réfléchit bien, le Tribunal du droit de la mer ne peut pas agir de sa propre initiative, mais a besoin que l'initiative émane d'Etats.

${ }^{850}$ En effet, une chambre spécialisée aura tendance à utiliser la procédure judiciaire de l'Etat d'accueil, ce qui risquerait de ne pas être accepté par les autres Etats.

851 Pour plus de précisions sur ces difficultés voir BRONER (Romain), La répression de la piraterie maritime et ses enjeux juridiques, Mémoire 2009/2010, op. cit., p. 83.

${ }^{852}$ Voir LEFEBVRE-CHALAIN (Hélène) et LEBOEUF (Cédric), "La piraterie maritime", Compte-rendu des Journées Méditerranéennes Organisées par le Centre de Droit Maritime et Océanique, Université de Nantes, Décembre 2009, p. 6, http://www.droit.univnantes.fr/labos/cdmo/centre-droit-maritime-oceanique/cdmo/cdmo/cdmo.php. Pour les auteurs, l'internationalisation de la fonction juridictionnelle s'appuie sur une autre logique. Et selon le Professeur Thouvenin, la piraterie n'est pas dans la liste des crimes nécessitant une répression 
571- La matière pénale relevant d'un domaine spécifique dans lequel la souveraineté nationale est la plus imprégnée, l'idée de la mise en place d'une juridiction spéciale à l'échelle sous régionale du golfe de Guinée pour connaître de la piraterie s'effrite au profit d'un traitement judiciaire par chaque Etat. Présentement, ce sont les juridictions nationales des Etats riverains du golfe de Guinée qui se chargent de la répression pénale de la piraterie tout en laissant la lutte opérationnelle contre ce fléau à leurs marines nationales respectives et aux centres régionaux de sécurité maritime tels que le CRESMAO, le CRESMAC etc. Mais selon Monsieur Romain Broner, le traitement judiciaire par des Etats locaux pose problème. Peu d'Etats se sont pour l'instant montrés favorables à une poursuite judiciaire des pirates par leurs juridictions ${ }^{853}$. En outre, les juridictions locales de droit commun sont de plus en plus engorgées dans les Etats africains. Ce sont, entre autres, quelques difficultés relatives au traitement de la piraterie par les juridictions nationales de droit commun de certains Etats africains. Enfin, quid de la coopération entre les structures nationales et sous régionales chargées de la répression de la piraterie dans le golfe de Guinée?

\section{2- La coopération entre les tribunaux, la DGAMP et le CRESMAO pour le suivi de la répression des actes illicites en mer}

572- D'abord, il convient de rappeler que la lutte contre la piraterie et la criminalité maritime se situe à un double niveau à savoir: une lutte opérationnelle et une répression judiciaire consistant à sanctionner les auteurs des actes commis. En Côte d'Ivoire la lutte opérationnelle est confiée à la

\footnotetext{
par les juridictions internationales car tout d'abord, elle n'est pas une menace à la sécurité internationale et ensuite, elle repose sur la compétence des juridictions nationales. Dans ce cadre, un tribunal international n'est pas la solution car il impose un important dispositif nécessitant d'importantes négociations quant au cadre légal d'instauration. Le jugement des pirates s'appuie certes sur une compétence universelle mais la répression reste délicate et décentralisée. Ainsi, le transfert de personnes impose la vigilance sur le respect des règles du procès équitable et notamment les principes de garanties de procédures. La communauté internationale doit dès lors se mobiliser sur la mise à niveau des conditions des juridictions et du droit applicable au plan national en vue du maintien des pirates dans leur région.

${ }^{853}$ BRONER (Romain), La répression de la piraterie maritime et ses enjeux juridiques, Mémoire de Master de Recherche, Sécurité et Défense, Université Panthéon-Assas-Paris II, Année universitaire 2009/ 2010, op. cit., p. 84.
} 
DGAMP et au CRESMAO dans le cadre régional ${ }^{854}$ tandis que la répression relève des tribunaux ivoiriens. Toutefois, pour réussir cette mission de lutte contre les actes illicites qui nuisent à la sûreté de la navigation maritime, une coopération entre le volet opérationnel et le volet répressif nous paraît nécessaire voire indispensable.

573- La coopération entre ces structures devrait porter sur l'entraide judiciaire la plus large possible lors des enquêtes, poursuites et procédures judiciaires concernant les infractions visées à l'article 3 de la Convention de Palerme ${ }^{855}$ et concernant la piraterie telle qu'elle est définie par la Convention de Montego Bay ${ }^{856}$. La coopération devrait porter également sur tous les actes de procédure qui permettent de déterminer la culpabilité ou l'innocence des suspects, ainsi que les éventuelles conséquences pénales d'un procès. Il s'agit donc des questions relatives à l'instruction du dossier ${ }^{857}$, à la garde à vue et à la détention provisoire, au déroulement du procès et à l'exécution de la peine qui aura été prononcée. Cette coopération pourrait être élargie à la future Coordination nationale de suivi de l'application de la législation maritime ${ }^{858}$.

574- La coopération a un double enjeu. D’abord au plan opérationnel entre la DGAMP et le CRESMAO les échanges d'informations relatives aux pirates et bandits à main armée, sur leurs mouvements et actions entreprises,

\footnotetext{
${ }^{854}$ NZI (Serge-Nicolas), " La Côte d'Ivoire face à la piraterie maritime », Lugano (Suisse), Février 2013 , p. 5. L'auteur soutient que dans le cadre de la coopération ouest africaine, il faut envisager une coordination avec des patrouilles conjointes pour surveiller les mouvements maritimes et, de partager des informations sur les navires suspects dans le golfe de Guinée. Cela nous éviterait le dégazage sauvage des navires étrangers au large pour souiller nos côtes en toute impunité. Et aussi de communiquer toutes les informations sur les mouvements de navires suspects. https://www.connectionivoirienne.net/author/laredaction, consulté le 25 février 2015.

855 Voir la Convention des Nations Unies contre la criminalité transnationale organisée de Palerme de 2000, art. 18-1.

${ }^{856}$ Convention de Montego Bay, art. 101 : «On entend par piraterie l'un quelconque des actes suivants: a) tout acte illicite de violence ou de détention ou toute déprédation commis par l'équipage ou des passagers d'un navire ou d'un aéronef privé, agissant à des fins privées, et dirigé : ..."

857 En effet, c'est à ce stade que la coopération devient indispensable car les organes opérationnels doivent fournir tous les renseignements nécessaires qu'ils détiennent sur les personnes prévenues aux organes juridictionnels pour une instruction complète du dossier. 858 Supra $^{\circ} 563$, p. 268.
} 
permettront une riposte non seulement concertée mais aussi plus prompte des organes opérationnels de lutte contre l’insécurité. Au plan de la répression, l'appui des organes opérationnels à l'organe juridictionnel constitue un gage de succès de la répression des criminels. En outre, l'intervention de la future Coordination nationale de suivi de l'application de la législation maritime dans cette coopération garantira une application effective de la législation en matière de répression des actes illicites perpétrés en mer.

\section{§ 2 : L'implication nécessaire de chaque Etat riverain du golfe de Guinée dans la lutte contre l'insécurité maritime}

575- L'efficacité des recommandations ci-dessus nécessite l'implication effective de chaque Etat riverain du golfe de Guinée dans la lutte contre l'insécurité maritime. La quête de l'efficacité doit nous conduire à examiner les spécificités de l'insécurité maritime dans le golfe de Guinée (A) en vue d’y adapter les instruments (B).

\section{A- Les spécificités de la piraterie et de la criminalité maritimes dans le golfe de Guinée}

576- Comme spécificités des violences perpétrées dans cette zone maritime, nous examinerons leurs causes et l'identité des criminels. Le golfe de Guinée est un espace où s'effectuent les transports de produits de toute nature. Ces activités hautement lucratives interviennent dans un contexte politique, économique et social complexe. Dans certains Etats riverains du Golfe de Guinée notamment au Nigéria, une étude a indiqué que la gouvernance est souvent gangrénée par la corruption et donc sans réelles retombées pour les populations ${ }^{859}$. D'où la naissance de la piraterie dans les années 70 , dans le delta du Niger, au sud-est du Nigeria, le cœur de l'exploitation pétrolière du pays. Dans ces régions, les populations ont vu, pendant des décennies, des centaines de millions de barils de brut passer par leur communauté vivant dans une pauvreté écrasante, sans aucun service d'Etat ou travail, pour enrichir les élites

\footnotetext{
859 Voir Fondation Méditerranéenne d'Etudes Stratégiques (FMES), « Le golfe de Guinée, recrudescence de la piraterie et du brigandage maritime », 29 novembre 2019, p. 3.
} 
et le reste du pays ${ }^{860}$. Les pirates sont originaires de ces régions marécageuses où les communautés vivaient traditionnellement de la pêche et connaissaient la mer, avant que le pétrole ne vienne polluer les eaux et tuer leur unique source de revenus.

577- Depuis de nombreuses années, les pirates nigérians sont responsables de l'immense majorité des attaques dans le golfe de Guinée ${ }^{861}$. Avec l'évolution du temps, les tactiques des groupes criminels changent. Il est désormais plus rentable de procéder aux enlèvements d'équipages contre rançon que de dérober le brut des pétroliers pour le revendre au marché noir. Toutefois, force est de constater que la piraterie génère une industrie florissante dans des pays où les perspectives de développement économique sont extrêmement réduites et où l'Etat est défaillant. "Cette activité génère tout un business : une opération nécessite des hommes armés, des vivres, du ravitaillement, des bateaux et une organisation à terre pour les otages. Les bénéfices sont conséquents et largement distribués dans les villages côtiers : chefs de village, responsables de l'administration locale, etc. ${ }^{862}$. En outre pour parvenir à leurs fins les pirates doivent disposer d'une base de repli. Confronté à une véritable explosion démographique, le Nigéria doit offrir aux jeunes générations des opportunités d'emplois en vue de désactiver les réseaux de piraterie qui menacent gravement la vie humaine et la sécurité maritime.

578- Cependant, face à l'insécurité dans le golfe de Guinée réputée causée essentiellement par les ressortissants du Nigéria, les officiels nigérians adoptent une attitude paradoxale. En effet, " la marine nigériane n'a d'ailleurs pas particulièrement intérêt à mettre fin à l’insécurité, puisque les compagnies internationales doivent payer ses services pour escorter ou faire des rondes sur les navires de marchandises. [...] Il y a un risque que ce ne soit pas très

\footnotetext{
860 Fondation Méditerranéenne d'Etudes Stratégiques (FMES), "Le golfe de Guinée, recrudescence de la piraterie et du brigandage maritime », 29 novembre 2019, p. 3.

861 https://fr.africanews.com/2019/11/09/golfe-de-guinee-le-combat-du-nigeria-contre-lapiraterie//.

862 Fondation Méditerranéenne d'Etudes Stratégiques (FMES), «Le golfe de Guinée, recrudescence de la piraterie et du brigandage maritime », 29 novembre 2019 , p. 3.
} 
encourageant pour lutter contre la piraterie. Ca ne serait pas très bon pour les affaires de l'armée " ${ }^{863}$. Cette attitude du Nigéria qui consiste à protéger ses propres ressortissants suspectés de piraterie ou, à tout le moins, à ne pas les poursuivre vise à compromettre l'efficacité de la lutte contre l'insécurité dans le golfe de Guinée. Il faut donc tenir compte de cette réalité dans la quête des instruments de lutte contre l'insécurité dans la zone.

\section{B- Les instruments de lutte à adapter aux spécificités de la piraterie dans le golfe de Guinée}

579- La quête d'instruments de lutte contre l'insécurité dans le golfe de Guinée doit tenir compte du fait que la majorité des pirates qui y opèrent sont des nigérians et qu'officieusement le Nigéria rechigne à les poursuivre. Comment surmonter cette difficulté afin de prendre des mesures qui permettent une lutte efficace contre la piraterie et le brigandage maritimes dans le golfe de Guinée? A notre sens, la meilleure stratégie d'approche est d'impliquer nécessairement les structures des Nations unies (1) pour l'adoption, sous son égide, d'instruments de lutte contre l'insécurité dans le golfe de Guinée, contraignants pour tous les Etats riverains (2).

\section{1- L'implication des organes des Nations Unies dans la recherche de solutions}

580- Au regard de l'ampleur de la piraterie dans la région du golfe de Guinée, aucun pays ne peut à lui seul résoudre le problème. Comme le souligne Monsieur Robert Dussey ${ }^{864}$, le défi majeur est donc de rechercher une solution globale au problème de l'insécurité, car la plupart des solutions antérieures apportées, soit dans le cadre des accords bilatéraux ou régionaux se sont révélées insuffisantes. Aussi, grâce aux diverses actions des Nations Unies, notamment la résolution 2018 du 31 octobre 2011 et la résolution 2039 du 29 février 2012, le golfe de Guinée est devenu actuellement une préoccupation

\footnotetext{
${ }^{863}$ https://fr.africanews.com/2019/11/09/golfe-de-guinee-le-combat-du-nigeria-contre-lapiraterie//.

864 Voir DUSSEY (Robert), « La piraterie maritime : quels enjeux pour le golfe de guinée ?", Editions Choiseul « Géo économie » 2014/1 n 68, pp. 171-176. https://www.cairn.info/revuegeoeconomie-2014-1-page-171.htm.
} 
internationale nécessitant une stratégie globale. Les efforts des organisations sous régionales CEDEAO, CEEAC et CGG ont permis de mettre sur pied un code de bonne conduite et un mémorandum d'entente sur la sécurité maritime dans le golfe de Guinée ${ }^{865}$. Mais cela reste insuffisant.

581- C'est pourquoi, conscientes des dangers pour l'économie mondiale, dès 2013 de nombreuses puissances internationales ont décidé d'appuyer les marines d'Afrique de l'Ouest. L'un des éléments clés de la lutte contre la piraterie est de renforcer le système judiciaire, et le Nigeria a voté un amendement dans ce sens, avec l'appui des Nations unies, pour créer une unité spéciale d'investigation dans le but d'augmenter le nombre de condamnations ${ }^{866}$. Il est clair que les Nations Unies, à travers le Conseil de sécurité et l'Organisation Maritime Internationale, sont capables d'amener les Etats du golfe de Guinée au respect strict des mesures de lutte contre l'insécurité maritime initiées sous leurs auspices.

\section{2- Des mesures de lutte contre l'insécurité dans le golfe de Guinée, prises sous l'égide des Nations Unies et contraignantes pour les Etats riverains}

582- Le laisser-faire des autorités nigérianes face aux pirates qui opèrent dans le golfe de Guinée conduit à une insécurité chronique dans la zone. La solution est d'autoriser les poursuites des personnes suspectées de piraterie audelà des limites maritimes de chaque Etat ainsi que le souligne l'étude menée récemment par la Fondation Méditerranéenne d'Etudes Stratégiques (FMES). Cette étude indique que l'augmentation des actes de piraterie et de brigandage maritime et la violence accrue de ces attaques sont de vrais défis sécuritaires. Le golfe de Guinée doit favoriser la mise en œuvre d'une gouvernance maritime efficace. Celle-ci ne pourra être garantie qu'avec l'adaptation des législations des différents pays côtiers, autorisant les poursuites au-delà des limites maritimes des États. Cette priorité a été réaffirmée lors du 3ème symposium sur la sécurité

865 DUSSEY (Robert), « La piraterie maritime : quels enjeux pour le golfe de guinée ?», Editions Choiseul « Géo économie " 2014/1 n 68, pp. 171-176.

$866 \mathrm{https} / / /$ fr.africanews.com/2019/11/09/golfe-de-guinee-le-combat-du-nigeria-contre-lapiraterie//. 
maritime dans le golfe de Guinée le 22 octobre 2018 ${ }^{867}$, notamment grâce au mécanisme à caractère sous régional dénommé Architecture de Yaoundé où sont regroupés les partenaires régionaux de lutte contre l'insécurité maritime.

583- En effet, l'Architecture de Yaoundé est le Centre interrégional de coordination (CIC) de Yaoundé. Il centralise les informations provenant des centres régionaux de l'Afrique centrale et de l'Afrique de l'Ouest et est chargé de l'harmonisation des textes d'application du droit maritime, notamment ceux relatifs à la lutte contre la piraterie ${ }^{868}$. La reconnaissance de la priorité qui consiste à adapter les législations des Etats côtiers afin d'autoriser les poursuites des pirates suspectés au-delà des limites maritimes des Etats est une avancée à exploiter. Dès lors, dans l'avenir les instruments de lutte contre l'insécurité dans le golfe de Guinée doivent contenir des dispositions précisant clairement cette priorité. Il en sera de même pour l'Accord que nous recommandons entre les Etats côtiers du golfe de Guinée ${ }^{869}$.

584- Au total, en vue de l'efficacité de la lutte contre la piraterie, les Etats côtiers du golfe de Guinée sont tenus de prendre un engagement formel et collectif pour autoriser les poursuites des personnes suspectées de piraterie audelà des limites maritimes de leurs Etats respectifs. Pour ce faire, il est nécessaire que les mesures de lutte contre l'insécurité dans le golfe de Guinée soient prises sous l'égide des Nations Unies à travers l'implication du Conseil de sécurité ou de l'OMI. L'implication du Conseil de sécurité ou des organismes onusiens constitue, à notre sens, un moyen de persuasion et de contrainte pour

867 Cf: Fondation Méditerranéenne d'Etudes Stratégiques (FMES), «Le golfe de Guinée, recrudescence de la piraterie et du brigandage maritime ", 29 novembre 2019, p. 6, in france org/le-golfe-de-guinée-recrudescence-de-la-piraterie-et-du-brigandage-maritimes. Consulté le 12 mars 2020. L'étude précise que ce symposium a réuni 20 chefs d'états-majors des marines et des garde-côtes du golfe de Guinée (ou leurs représentants), des délégations de haut niveau des principaux pays impliqués dans la zone (États-Unis, Brésil, Royaume-Uni, Portugal, Espagne, Italie, Allemagne, Belgique, Danemark, Canada, Maroc).

868 Fondation Méditerranéenne d'Etudes Stratégiques (FMES), "Le golfe de Guinée, recrudescence de la piraterie et du brigandage maritime "; précitée, p. 6, in france org/le-golfede-guinée-recrudescence-de-la-piraterie-et-du-brigandage-maritimes, consulté le 12 mars 2020. ${ }^{869}$ Voir supra ${ }^{\circ} 536$, p. 262. 
les Etats et donc un gage de l'application des instruments de lutte contre l'insécurité adoptés par lesdits Etats ${ }^{870 .}$

870 En ce sens que le Conseil de sécurité des Nations unies peut interpeller les Etats individuellement et même collectivement ou les rappeler à l'ordre en cas de non-respect de leurs engagements. 


\section{Conclusion du titre 2}

585- Ce titre est consacré aux solutions nécessaires à l'amélioration de la législation ivoirienne des transports de marchandises. Il examine la législation ivoirienne relative aux transports maritimes en Côte d'Ivoire en ce qui concerne l'amélioration et le renforcement des normes de protection de la marchandise et de sécurité de la navigation maritime, au regard des législations européennes et sous régionales africaines.

586- Dans le même temps, on constate que la législation concernée présente deux insuffisances, l'une porte sur la responsabilité du transporteur et l'autre sur la sécurité de la navigation maritime. En effet, en ce qui concerne la limitation de la responsabilité du transporteur, le Code maritime de 2017 renvoie à la règlementation ou aux usages en vigueur. Le législateur ivoirien aurait mieux fait de fixer de nouveaux plafonds de responsabilité en s'inspirant des harmonisations prévues par la Convention sur la limitation de la responsabilité des propriétaires de navires de mer conclue à Bruxelles le 10 octobre 1957. Celle-ci prévoit en son article 3-1 qu'en cas de dommages matériels, la responsabilité du propriétaire du navire est limitée à un montant de 1000 francs par tonneau de jauge du navire. Le législateur aurait pu s'inspirer également de la législation de certains pays comme l'Italie. En effet, des auteurs indiquent que selon l'article 423 du Code italien de la navigation, la compensation des dommages causés par le transporteur ne peut excéder 103,29 $€$ par unité de chargement à moins que l'expéditeur n'ait soumis une déclaration de valeur avant le chargement ${ }^{871}$. En somme, un chiffrage du plafond de la responsabilité du transporteur en monnaie nationale ivoirienne aurait été sans doute audacieux mais judicieux à notre sens.

587- S’agissant des normes de sécurité maritime, nous avions indiqué que la législation pénale ivoirienne antérieure au Code maritime de 2017 ne permettait pas une répression efficace des pirates et auteurs d'actes criminels

\footnotetext{
871 Voir Claudio Perrella et Adeliana Carpineta, Assurance transport et subrogation en Italie, LS-Lexjus Sinacta, décembre 2015, p. 20.
} 
en mer872. En outre, les conventions internationales relatives à la sécurité maritime prévoient, pour leur application dans les Etats parties, des dispositions obligeant ceux-ci à prendre des lois et règlements compatibles à leurs systèmes législatifs internes respectifs et à conférer le caractère pénale aux actes visés ${ }^{873}$. A travers les articles 1008 et 1018 du Code maritime, le législateur vient de doter la Côte d'Ivoire de dispositions homogènes permettant la poursuite et la répression des pirates et auteurs de criminalité maritime.

588- Pour renforcer la coopération sous régionale, la conclusion d'un accord sous forme de normes communautaires entre les Etats riverains du golfe de Guinée est nécessaire. Celui-ci aura pour objet de mettre en œuvre, à l'échelle sous régionale africaine, certaines dispositions des conventions des Nations Unies portant sur les différents trafics illicites, la piraterie et la criminalité maritimes. S'agissant du renforcement de la sécurité maritime, nous avons examiné la restructuration de la coopération entre les Etats riverains du golfe de Guinée en vue d'une participation opérationnelle conjointe des structures sous régionales et des organes nationaux pour une lutte plus efficace contre l'insécurité maritime. A cet effet, nous suggérons au sein de la Direction Générale des Affaires Maritimes et Portuaires, un organe de Coordination nationale pour le suivi de la lutte contre les actes illicites perpétrés en mer.

589- Concernant les recommandations, les Etats riverains du golfe de Guinée doivent uniformiser leurs procédures de poursuite et de conservation des preuves de la piraterie et des autres actes illicites. D'où la nécessité d'une incrimination uniformisée de la piraterie et de la criminalité en mer assortie de sanctions pénales également uniformisées. Enfin, en vue de rendre efficace la lutte contre les infractions maritimes, les Etats côtiers du golfe de Guinée sont tenus de prendre, sous l'égide des Nations unies, des engagements collectifs pour faciliter la poursuite des personnes suspectées de piraterie au-delà des limites maritimes de leurs Etats respectifs.

\footnotetext{
872 Supra $\mathrm{n}^{\circ} 367$, pp. 168-169.

${ }^{873}$ Supra n$^{\circ} 361$ à 363, pp. 166 à 167.
} 


\section{CONCLUSION GENERALE}

590- La problématique posée par notre sujet d'étude est de savoir s'il existe en Côte d'Ivoire une législation relative au transport de marchandises par mer capable d'offrir une protection efficace auxdites marchandises et d'assurer la sécurité et la sûreté de la navigation maritime. Au terme de l'étude, la préoccupation est de répondre à cette problématique sur le fondement des analyses faites.

591- En ce qui concerne la législation relative au transport maritime, son existence ne fait l'ombre d'aucun doute. En effet, il existe de toute évidence une législation en Côte d'Ivoire qui régit le transport des marchandises par mer. Elle est composée d'une part de normes destinées à la protection de la marchandise et d'autre part de normes consacrées à la lutte contre l'insécurité de la navigation maritime. La protection de la marchandise a consisté pour le législateur à adopter des normes juridiques permettant de prévenir les dommages à la marchandise et de les réparer au cas où ils surviennent. Aussi, en renforcement de la réparation des dommages prévue par la législation, le destinataire est tenu de souscrire une assurance maritime pour couvrir les risques de perte et de dommages à la marchandise ${ }^{874}$. S'agissant de la lutte contre l'insécurité maritime, le législateur a adopté des normes juridiques pour lutter contre les trafics illicites, la criminalité et la piraterie en mer tant à l'échelle nationale ivoirienne qu'à l'échelle internationale.

592- La question s'est ensuite posée de savoir si la législation protège la marchandise et lutte contre l'insécurité maritime avec efficacité. Nous avons alors soumis la législation supposée protéger les intérêts des transports maritimes à une analyse. S'appuyant sur les faits à travers la jurisprudence et sur la doctrine, l'analyse a permis de constater que les normes de protection de la marchandise connaissent des limites et que la lutte contre l'insécurité maritime comporte des insuffisances.

${ }^{874}$ Supra n 169-171, pp. 80-82. 
593- Au titre des limites des normes de protection de la marchandise, l'article premier paragraphe e) des Règles de la Haye avait institué une prise en charge de la marchandise "de palan à palan" qui supprime toute protection efficace de la marchandise pendant les phases non maritimes. Par ailleurs, le plafonnement modéré de la responsabilité du transporteur constitue un obstacle à la réparation intégrale des dommages subis par la marchandise. Enfin, les cas exceptés, en exonérant le transporteur maritime de sa responsabilité présumée, affaiblissent de facto la protection de la marchandise. Au titre des insuffisances de la lutte contre l'insécurité maritime, on a pu noter que le code ivoirien de la marine marchande ne répondait plus aux défis de la piraterie et la criminalité en mer du moment. La Côte d'Ivoire se trouvait ainsi dépourvue d'outils internes efficaces pour la répression des actes illicites en mer ${ }^{875}$.

594- Face à ces difficultés, il nous a paru nécessaire d'envisager des solutions susceptibles d'apporter une amélioration substantielle à la législation des transports de marchandises par mer. La question s'est donc posée de savoir sur quoi devait s'appuyer une telle amélioration. Nous avons alors analysé des normes de protection de la marchandise ainsi que des normes de lutte contre l'insécurité maritime mises en œuvre dans d'autres pays et à l'échelle régionale afin de nous en inspirer utilement.

595- Mais avant nos recommandations proprement dites, nous avons constaté un renforcement de la sécurité maritime dans le golfe de Guinée. En effet, les Etats riverains du golfe de Guinée ont restructuré leur coopération sous régionale pour une lutte plus efficace contre l'insécurité maritime. Cette restructuration s'opère à travers la coordination de patrouilles et le partage d'informations sur les navires suspects dans cette zone maritime ${ }^{876}$. A l'échelle nationale ivoirienne, nous suggérons le suivi de l'application de la législation destinée à la lutte contre les actes illicites perpétrés en mer. Cette mission sera assurée par la Coordination nationale du suivi de l'application de la législation

875 Supra $\mathrm{n}^{\circ} 367$, pp. 168-169.

876 Voir supra n 544 , pp. 265-266. 
pour la lutte contre les actes illicites en mer qui sera installée à la Direction générale des affaires maritimes et portuaires ${ }^{877}$.

596- En ce qui concerne le renforcement des normes de protection de la marchandise, une alternative s'offrait au législateur ivoirien. Soit, tenant compte des avancées notables relatives à la présomption de responsabilité du transporteur perçues dans la Convention de Rotterdam de 2009878, le législateur procédait à la ratification de cet instrument international pour le rendre applicable en Côte d'Ivoire. Toutefois, sur inspiration du droit maritime français (art. 16, loi n 66-420 du 18 juin 1966) et de la Convention de Rotterdam de 2009 (art. 12-1), le législateur ivoirien a pris un texte nouveau, en l'occurrence les articles 708 et 709 du Code maritime de 2017, pour régir les opérations pré et post maritimes. De la sorte, celles-ci sont présentement couvertes par la présomption de responsabilité du transporteur.

597- S'agissant de la lutte contre l'insécurité maritime à l'échelle nationale, les articles 1008 à 1018 et les articles 1041 à 1045 du Code maritime ivoirien créent les conditions d'une répression appropriée de la piraterie et des actes criminels en mer. A l'échelle régionale, en référence de l'accord relatif au trafic illicite par mer conclu par le Conseil de l'Europe, nous avons suggéré l'élaboration d'un accord des Etats riverains du golfe de Guinée pour la lutte contre l'insécurité maritime. Cet accord définira les infractions et les peines applicables. Sa spécificité sera de prévoir leur application directe et surtout contraignante 879 dans les Etats parties. A cette fin, nous avons proposé les auspices du Conseil de sécurité des Nations Unies et de l'OMI pour l'adoption dudit accord. L'enjeu est de briser la protection des personnes suspectées de piraterie dans le golfe de Guinée par les autorités nigérianes ${ }^{880}$.

598- Relativement à la conteneurisation, le Code maritime ivoirien de 2017 présente des avancées sur certaines questions mais fait de l’immobilisme

\footnotetext{
877 Supra ${ }^{\circ} 563$, p. 277.

878 Supra ${ }^{\circ} 498$, p. 241.

879 Pour vaincre la résistance du Nigéria à poursuivre ses propres ressortissants suspectés de piraterie. Voir dans ce sens supra n $^{\circ} 582-583$, pp. 278 et 279.

880 Supra ${ }^{\circ} 582$, p. 287.
} 
sur d'autres. Au titre des avancées, notons la disparition de l'incompatibilité de la livraison sous palan avec le conteneur LCL grâce aux articles 708 et $709 \mathrm{du}$ nouveau Code maritime qui ont supprimé ce type de livraison en étendant la responsabilité du transporteur sur les opérations pré et post maritimes ${ }^{881}$. En outre, à la faveur de la conteneurisation, le destinataire dispose désormais d'un délai de huit jours, conformément à l'article 724 du Code maritime, pour adresser son avis de perte ou d'avarie au transporteur. Car les dommages subis par les marchandises mises en conteneurs sont réputées dommages non apparents $^{882}$. La disposition de l'article 724 du Code maritime renforce donc la protection de la marchandise mise en conteneur.

599- Au titre de l'immobilisme du Code maritime par rapport à la conteneurisation, il a été indiqué que celle-ci se présentait comme un moyen propice aux trafics illicites et est par conséquent un facteur d'insécurité pour le transport maritime ${ }^{883}$. En outre, les difficultés liées à la vérification pratique des marchandises mises en conteneurs ${ }^{884}$ constituent une source d'insécurité dès lors que des armes, des marchandises prohibées, des déchets industriels peuvent être camouflés dans des conteneurs pour être acheminés. Le Code maritime ivoirien de 2017 n'a rien prévu pour obliger le transporteur à contrôler les déclarations du chargeur. Ces difficultés, n'ayant pas trouvé de solution dans le Code maritime de 2017, demeurent une préoccupation en matière de sûreté maritime.

600- Enfin, selon Monsieur Vincent Bilé, le nouveau Code maritime contient de réelles avancées. L’adoption de la loi n²017-442 du 30 juin 2017 portant nouveau Code maritime, dont la venue s'est longuement fait attendre, apporte une satisfaction générale dans le secteur des transports maritimes. C'est un Code innovant, en ce que non seulement, il comble l'absence de réglementation spécifique dans divers domaines, mais également rend conforme

\footnotetext{
881 Voir supra $n^{\circ} 405$, pp. 189-190.

882 Voir supra $n^{\circ} 335$, p. 154.

883 Supra n²5, pp. 19-20.

884 Supra n $60-62$, pp. 34-35.
} 
notre réglementation maritime à certains standards internationaux ${ }^{885}$. Toutefois, en dépit de ses nombreux apports, le nouveau Code maritime ivoirien suscite des incertitudes. Monsieur Vincent Bilé soutient qu'au regard des nombreuses insuffisances relevées à son niveau, le nouveau Code maritime ne satisfait pas aux attentes légitimes placées dans son avènement. Son application va-t-elle se confronter à des difficultés ? Il semble trop tôt pour y répondre. Il conviendrait donc de l'éprouver à la pratique afin de pouvoir tirer, dans les faits, toutes les leçons résultant de son étude. Un texte de loi n'étant pas statique, le législateur ivoirien pourrait par la suite apporter les ajustements nécessaires ${ }^{886}$.

601- Pour notre part, nous portons le regard essentiellement sur deux éléments à savoir le mécanisme de protection de la marchandise et le système de sûreté de la navigation prévus par le Code maritime ivoirien de 2017. S'agissant de la protection de la marchandise, les articles 708 et 709 du Code maritime ivoirien prévoient une responsabilité de plein droit du transporteur élargi sur toutes les phases du transport. Ce qui constitue a priori une réelle avancée du régime de réparation des dommages à la marchandise. Cependant, dans certains cas, l'auteur des dommages à la marchandise se révèle difficilement identifiable ${ }^{887}$. Monsieur Yacouba Cissé souligne à cet effet, une hostilité quasi générale des droits nationaux à l'égard de la clause "identity of carrier" 888 ou "demise clause". Il note par exemple qu'en droit américain, où la demise clause est considérée comme une fraude, est transporteur, selon les circonstances, le propriétaire du navire, l'affréteur, et par extension tous ceux qui ont pris part au transport de la marchandise sous le régime de la COGSA

\footnotetext{
885 Voir BILE (Vincent), « Regard Critique sur le Nouveau Code Maritime Ivoirien », Neptunus, e.revue Université de Nantes, vol. 24, 2018/3,2018, p. 6.

886 BILE (Vincent), « Regard Critique sur le Nouveau Code Maritime Ivoirien », op. cit., p. 6.

${ }^{887} \mathrm{Cf}$ : CISSE (Yacouba), L'identification du transporteur maritime à l'épreuve de la qualification juridique, Revue générale de droit, 2004, pp. 8 et 9.

888 La clause identity of carrier ou demise clause est une clause qui permet d'identifier l'auteur des dommages à la marchandise en cas de confusion entre les professionnels, acteurs du transport maritime.
} 
(Convention of Goods by Sea Act) ${ }^{889}$. En droit italien, selon certains auteurs ${ }^{890}$, l'identification du transporteur se fonde sur le contenu du connaissement. Aussi, l'en-tête du connaissement peut être utilisé à condition qu'il ne contredise pas la signature. Les "Identity of carrier clauses" sont généralement ignorées par les Cours italiennes. Toutefois, le droit anglais se montre favorable à la clause identity of carrier. La jurisprudence anglaise reconnaît la validité de la clause ${ }^{891}$. A l'échelle internationale, la Convention sur la limitation de la responsabilité des propriétaires de navires de 1957 étend la responsabilité des dommages à la marchandise à d'autres acteurs ${ }^{892}$.

602- Le constat est que le législateur ivoirien a manqué d'introduire dans le Code maritime de 2017, des dispositions pouvant permettre d'identifier clairement l'auteur des dommages subis par la marchandise ${ }^{893}$ en cas de confusion entre les acteurs du transport. Par ailleurs, le Code maritime est entré en vigueur le 13 novembre 2018 ${ }^{894}$. Ainsi, notre appréciation des dispositions relatives à la responsabilité du transporteur n'a pu être étayée par la

889 CISSE (Yacouba), L'identification du transporteur maritime à l'épreuve de la qualification juridique, op. cit., pp. 41 et 42 . En effet, la jurisprudence américaine a toujours considéré la demise clause comme étant une fraude, en violation de l'article 3(8) des règles de La Haye.

890 PERRELLA (Claudio) et CARPINETA (Adeliana), Assurance transport et subrogation en Italie, LS-Lexjus Sinacta, Décembre 2015, p. 18.

891 CISSE (Yacouba), L'identification du transporteur maritime à l'épreuve de la qualification juridique, op. cit., p. 35.

892 Convention internationale sur la limitation de la responsabilité des propriétaires de navires de mer, du 10 octobre 1957, Bruxelles, art. 6-2 "Sous réserve du par. (3) du présent article, les dispositions de cette Convention seront applicables à l'affréteur, à l'armateur, à l'armateurgérant, ainsi qu'aux capitaine, membres de l'équipage et autres préposés du propriétaire, de l'affréteur, de l'armateur, ou de l'armateur-gérant, agissant ...".

${ }^{893}$ Voir loi n 2017-442 du 30 juin 2017 portant Code maritime, art. 684 : «Au sens de la présente loi, on entend par transporteur, toute personne par laquelle ou au nom de laquelle un contrat de transport de marchandises par mer est conclu avec un chargeur; transporteur substitué, toute personne à laquelle l'exécution du transport de marchandises, ou d'une partie de ce transport, est confiée par le transporteur et doit s'entendre ou toute autre personne à laquelle cette exécution est confiée".

894 Certes, le Code maritime ivoirien a été adopté en 2017, mais il est entré en vigueur pratiquement vers fin 2018. Et eu égard à la non-retro activité de la loi, nous n'avons pas pu obtenir de décision de justice relative au code maritime au moment de la rédaction de notre thèse. 
jurisprudence ivoirienne, faute de décision de justice disponible au moment où s'achevait la rédaction de cette thèse.

603- En ce qui Concerne la sûreté de la navigation maritime, on note des avancées substantielles dans le nouveau Code maritime à travers certaines de ses dispositions qui renforcent la lutte contre l'insécurité maritime ${ }^{895}$. Cependant, on constate que la piraterie maritime continue de prospérer dans le golfe de Guinée augurant paradoxalement une possible inefficacité de la loi $\mathrm{n}^{\circ}$ 2017-442 du 30 juin 2017 portant Code maritime, en matière de lutte contre l'insécurité. Il est vrai que l'on ne peut apprécier $\boldsymbol{a}$ priori l'effectivité ${ }^{996}$ et l'efficacité897 d'un texte législatif. Néanmoins, nous avons bon espoir que l'application des dispositions du nouveau Code maritime consacrées à la lutte contre l'insécurité maritime ${ }^{898}$ et la mise en œuvre de nos suggestions pour le renforcement de la sûreté maritime, permettront une navigation sécurisée dans le golfe de Guinée. Toutefois, si dans l'application de ladite loi, la protection de la marchandise s'avère inefficace ou des formes d'insécurité maritime persistent, au vu de la réalité des faits, le législateur ivoirien aura la latitude de procéder aux amendements utiles.

Pour l'instant attendons de voir !

895 Voir les articles 1008 à 1018 et les articles 1041 à 1045 du Code maritime ivoirien. 896 Cf : CARBONIER (Jean), Flexible Droit, LGDJ. Paris, 3ème édition 1976, pp. 99 et s. In SARASSORO (Yacinthe), L'enfant naturel en droit Ivoirien, Les Nouvelles Editions Africaines, 1984, pp. 101 et s. Selon l'auteur, l'effectivité de la règle de droit renvoie à son usage par les justiciables. En effet, l'effectivité d'une loi s'apprécie par rapport à son utilisation par les justiciables ; en d'autres termes, c'est la volonté des usagers à recourir à la règle de droit.

897 Idem. L'efficacité d'un texte de loi renvoie à sa capacité à régler le ou (les) problèmes pour lesquels il est pris.

898 Voir Code maritime, arts. 1008, 1041 et 1042 


\section{RESUME}

Il existe une législation en droit ivoirien qui régit les transports de marchandises par mer. Celle-ci porte aussi bien sur la protection de la marchandise que sur la sûreté de la navigation. Mais compte tenu des limites qu'elle comporte, elle mérite d'être améliorée.

En effet, l'existence de la législation des transports maritimes découle des normes destinées à protéger la marchandise et à sécuriser la navigation maritime. Toutefois, les dommages subis par les marchandises et les attaques à main armée qui continuent de sévir dans le golfe de Guinée révèlent les limites de ladite législation.

De ce constat, il résulte la nécessité d'envisager des solutions pour améliorer la législation existante. Pour ce faire, le recours au droit comparé s'avère indispensable. Ainsi, l'expérience constatée en droit communautaire européen permet de suggérer aux Etats côtiers du golfe de Guinée, l'adoption d'un Accord de coopération sous régional pour lutter contre l'insécurité maritime.

Enfin, pour rehausser l'efficacité de la lutte contre l'insécurité dans les Etats côtiers du golfe de Guinée concernés, des engagements collectifs s'imposent pour faciliter la poursuite des pirates au-delà des limites maritimes desdits Etats. 


\section{SUMMARY}

There is legislation in Ivorian law governing the transport of goods by sea. It deals with the protection of goods and the safety of navigation. However, given the limits it contains, it deserves to be improved.

Indeed, the existence of maritime transport legislation stems from the standards designed to protect the goods and make maritime navigation safe. However, the damage suffered by goods and the armed attacks that continue to occur in the Gulf of Guinea reveal the limits of the said legislation.

From this observation, it follows the need to consider solutions to improve the existing legislation. To this end, the use of comparative law is indispensable. Thus, the experience observed in European Community law makes it possible to suggest to the coastal States of the Gulf of Guinea, the adoption of a sub-regional cooperation agreement to fight against maritime insecurity.

Finally, to enhance the effectiveness of the fight against insecurity in the Gulf of Guinea coastal States concerned, collective commitments are required to facilitate the pursuit of pirates beyond the maritime limits of these States. 


\section{IMPACT DE LA THESE}

Notre étude a un grand intérêt d'ordres scientifique et pratique. Au niveau scientifique, c'est la première fois qu'une thèse fait une analyse intégrale des normes juridiques applicables au transport maritime ainsi qu'à la lutte contre les trafics illicites et l'insécurité dans le transport maritime conteneurisé en Côte d'Ivoire. Concernant la protection de la marchandise, le législateur a adopté des normes juridiques permettant de prévenir les dommages à la marchandise et de les réparer le cas échéant. Aussi, en dépit de l'insécurité qu'il présente en favorisant divers trafics illicites, le conteneur protège efficacement la marchandise au cours de son transport. Aussi, pour renforcer les normes prévues pour la réparation des dommages, le destinataire est tenu de souscrire une assurance maritime au bénéfice de la marchandise.

S'agissant de la lutte contre les infractions maritimes, il existe des normes destinées à lutter contre les trafics illicites notamment le trafic des drogues et stupéfiants, le trafic des armes, le trafic des déchets dangereux, la pollution de l'environnement marin et, aussi des normes destinées à lutter contre la criminalité et la piraterie maritimes. A l'échelle nationale ivoirienne et à l'échelle internationale, ces normes ont pour vocation de prévenir les différentes infractions qu'elles définissent et dont elles répriment les auteurs.

Mais au terme de l'analyse critique de ces normes, des limites et insuffisances ont été relevées en ce qui concerne la protection de la marchandise et la lutte contre l'insécurité maritime. Ces limites justifient alors la nécessité d'une amélioration de la législation existante. A cet effet, il convenait de s'inspirer des avancées des normes de protection de la marchandise et des stratégies de lutte contre l'insécurité maritime mises en œuvre dans des pays étrangers.

Pour ce faire, nous avons mené une étude en droit comparé. Il en ressort que le nouveau droit des transports maritimes de marchandises en Côte d'Ivoire, à travers le code maritime ivoirien de 2017, connait de réelles avancées inspirées du droit étranger. En outre, s'appuyant sur les avancées du droit communautaire européen, nous avons fait des recommandations à l'adresse du législateur sous régional afin d'améliorer l'efficacité de la lutte contre l'insécurité maritime dans le golfe de Guinée.

Au regard de cette analyse exhaustive des normes relatives au transport et à la sécurité maritimes et des recommandations faites, l'étude constitue une réelle contribution scientifique au rehaussement de l'efficacité du droit maritime ivoirien des transports de marchandises en général et du trafic conteneurisé en particulier. 
Au niveau pratique, la thèse fait une analyse détaillée des instruments juridiques de lutte contre le trafic de drogue, le trafic d'armes, le transport des polluants et le trafic d'êtres humains ainsi que des instruments de lutte contre la criminalité et la piraterie maritimes. Il en est ressorti des limites constatées d'où la nécessité de renforcer la coopération sous régionale par la conclusion d'un accord entre les Etats riverains du golfe de Guinée en vue de rendre la lutte contre l'insécurité maritime sous régionale plus efficace.

En outre, il ressort également de cette étude que lesdits Etats doivent uniformiser leurs procédures d'incrimination de la piraterie et de la criminalité en mer qui doivent être assorties de sanctions pénales également uniformisées. Enfin, les Etats de la sous-région du golfe de Guinée doivent s'engager à faciliter la poursuite des personnes suspectées de piraterie au-delà des limites maritimes respectives de leurs différents Etats.

Vu l'importance de cette criminalité maritime dans le golfe de Guinée en général mais aussi dans les eaux sous juridiction ivoirienne en particulier; vu les indications concrètes en vue de l'amélioration des normes applicables à la lutte contre la criminalité maritime, il est indéniable que notre étude aura un impact pratique et social en Côte d'Ivoire mais aussi dans la sous-région.

En effet, l'analyse détaillée des normes régissant le transport de marchandises par mer vise à rassurer les intérêts des opérateurs du secteur des trafics maritimes en Côte d'Ivoire y compris ceux des compagnies d'assurance et des banquiers.

Par ailleurs, pour les besoins de sécurité des personnes et des biens en mer ainsi que pour le besoin de protection de l'économie nationale, cette thèse intéresse en particulier l'administration des Affaires Maritimes et Portuaires et l'administration des Douanes en Côte d'Ivoire.

Dans la sous-région, avec l'espoir que le législateur sous régional portera un intérêt particulier aux recommandations et suggestions faites, cette thèse vise l'efficacité d'une lutte plus efficace contre l'insécurité maritime dans le golfe de Guinée. 


\section{LISTE DES ANNEXES}

Annexe 1: Tableau comparatif des conventions de Bruxelles, Hambourg et Rotterdam.

Source : Synthèse du Séminaire sur les règles de ROTTERDAM, mars 2010 à Yaoundé.

Annexe 2 : Zones multinationales de coordination maritime en Afrique de l'Ouest et du Centre.

Source : International CRISIS GROUP 2014.

Annexe 3: Loi $n^{\circ}$ 2017-442 du 30 juin 2017 portant Code maritime. Extrait

JORCI du 13 novembre 2018. 
Annexe 1 : Tableau comparatif des conventions de Bruxelles, Hambourg et Rotterdam. (Source : Synthèse du Séminaire sur les règles de ROTTERDAM, mars 2010 à Yaoundé).

\begin{tabular}{|c|c|c|c|c|}
\hline \multicolumn{5}{|l|}{$\begin{array}{l}\text { Comparaiso } \\
\text { Rotterdam }\end{array}$} \\
\hline $\begin{array}{l}\text { Régimes } \\
\text { juridiques }\end{array}$ & $\begin{array}{l}\text { BRUXELLES } 1924 \\
\text { (Règles de la } \\
\text { HAYE) }\end{array}$ & \begin{tabular}{|l} 
BRUXELLES \\
modifiée 1968 \\
(Règle de la \\
HAYE-VISBY) et \\
1979 (Protocole \\
DTS)
\end{tabular} & $\begin{array}{l}\text { HAMBOURG } \\
1979\end{array}$ & ROTTERDAM 2009 \\
\hline $\begin{array}{l}\text { Champs } \\
\text { d'application }\end{array}$ & $\begin{array}{l}\text { * Transport } \\
\text { Maritime de } \\
\text { sous palan à } \\
\text { palan (tackle to } \\
\text { tackle) } \\
\\
\text { * Connaissement } \\
\text { ou tout autre } \\
\text { document } \\
\text { similaire formant } \\
\text { titre, émis dans } \\
\text { un état } \\
\text { contractant } \\
\text { (art.10) } \\
\text { *Exclusion des } \\
\text { animaux vivants } \\
\text { et des } \\
\text { marchandises en } \\
\text { pontée (art.1-c) }\end{array}$ & $\begin{array}{l}\text { * Transport } \\
\text { Maritime de sous } \\
\text { palan à palan } \\
\text { (tackle to tackle) } \\
\\
\text { * Connaissement } \\
\text { ou tout autre } \\
\text { document } \\
\text { similaire formant } \\
\text { titre, Emis dans } \\
\text { un état } \\
\text { contractant } \\
\text { * Port de } \\
\text { Chargement situé } \\
\text { dans un Etat } \\
\text { contractant } \\
\end{array}$ & $\begin{array}{l}\text { * Connaissement } \\
\text { émis dans un Etat } \\
\text { contractant } \\
\text { * Port à option } \\
\text { de déchargement } \\
\text { situé dans un } \\
\text { Etat contractant } \\
\text { si déchargement } \\
\text { effectif dans ce } \\
\text { port }\end{array}$ & $\begin{array}{l}\text { * Transport } \\
\text { Maritime et } \\
\text { Transport } \\
\text { Multimodal ayant } \\
\text { une phase maritime } \\
\text { : multimodal } \\
\text { transmaritime (door } \\
\text { to door) } \\
\text { * Lieu de réception } \\
\text { ou port de } \\
\text { chargement ou lieu } \\
\text { de livraison ou port } \\
\text { de déchargement } \\
\text { situé dans un Etat } \\
\text { contractant } \\
\text { * application à tous } \\
\text { types de document } \\
\text { de transport, y } \\
\text { compris les } \\
\text { documents } \\
\text { électroniques de } \\
\text { transport } \\
* \text { application aux } \\
\text { marchandises en } \\
\text { pontée }\end{array}$ \\
\hline
\end{tabular}




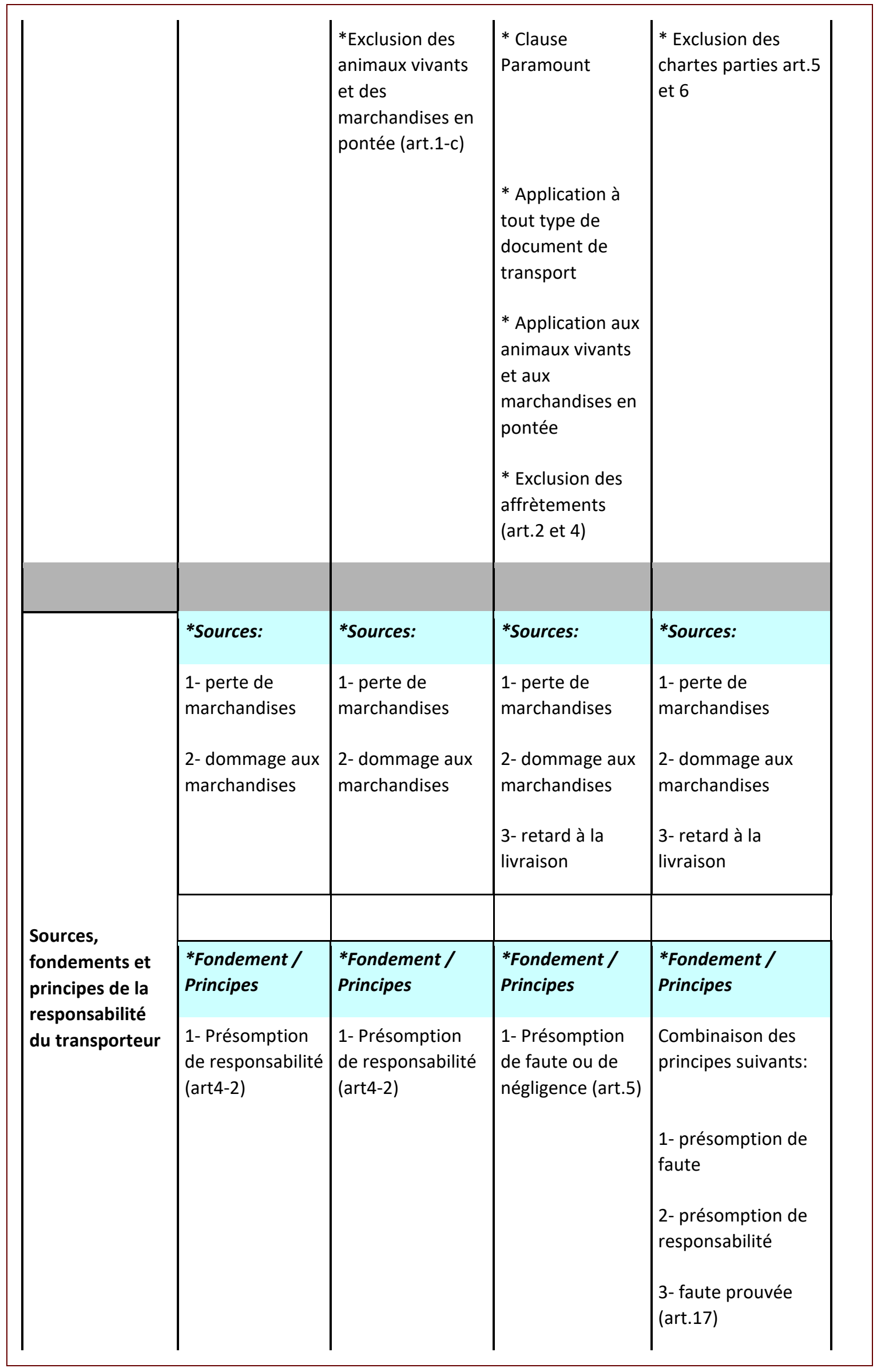




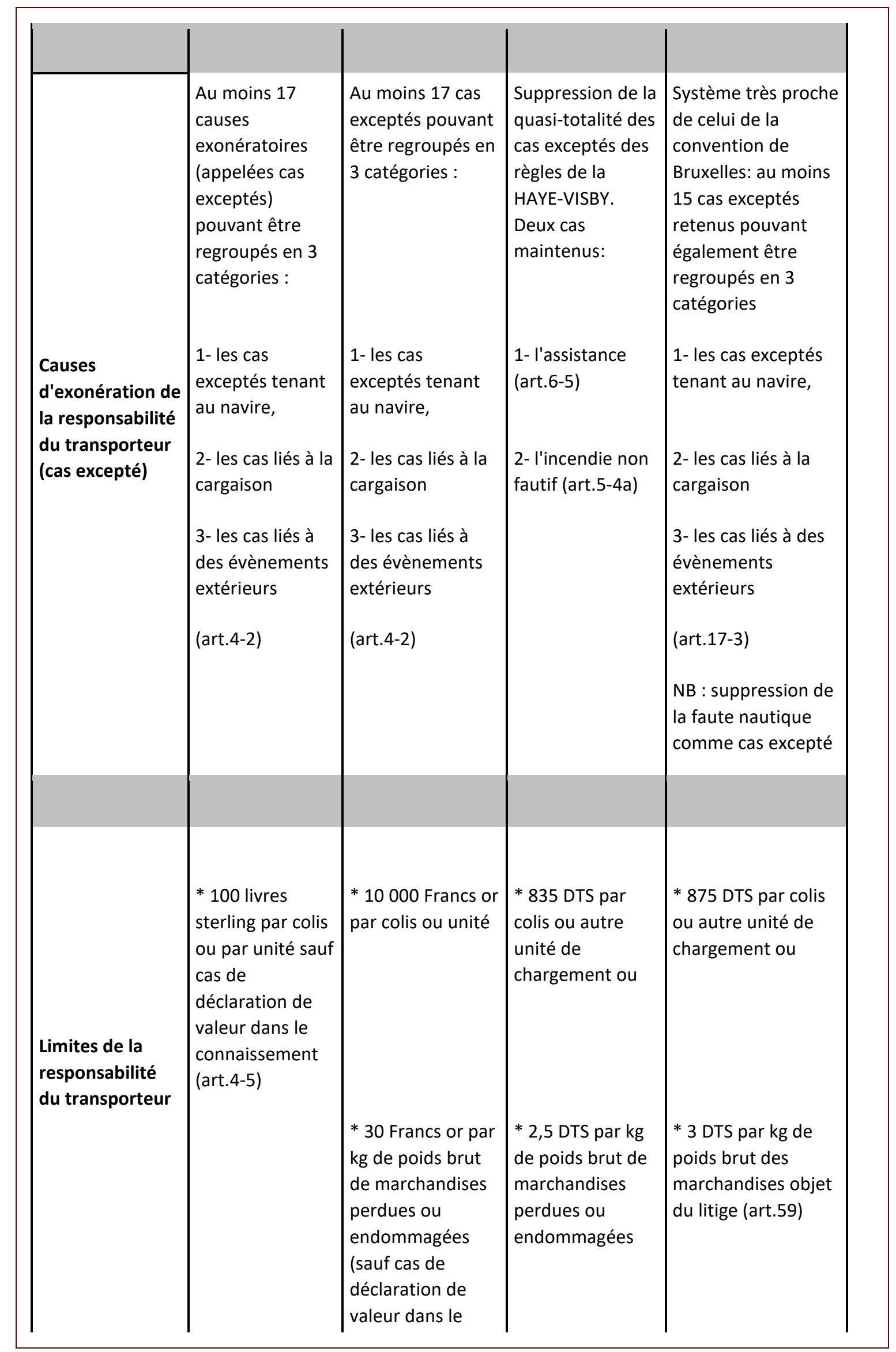




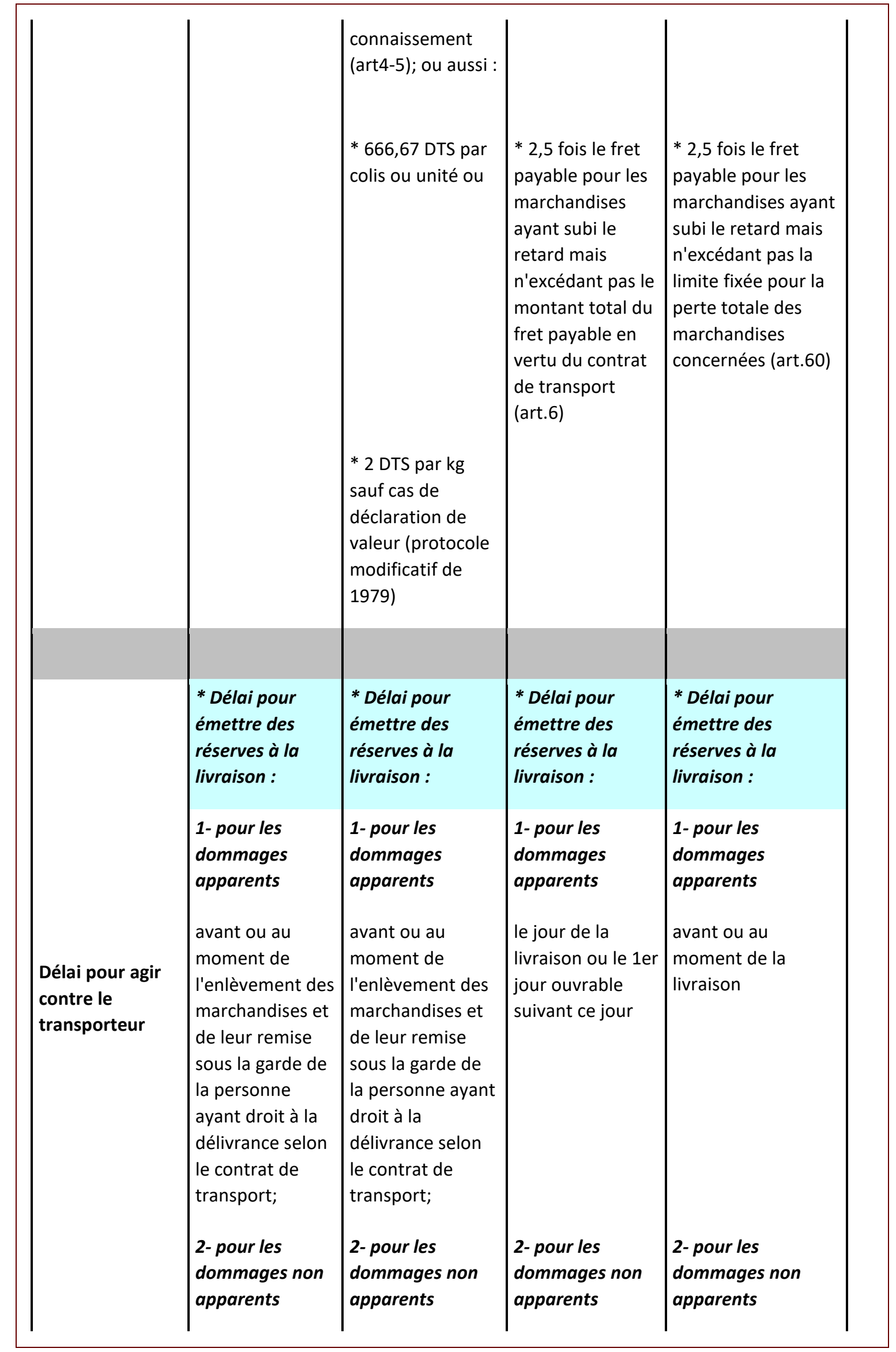




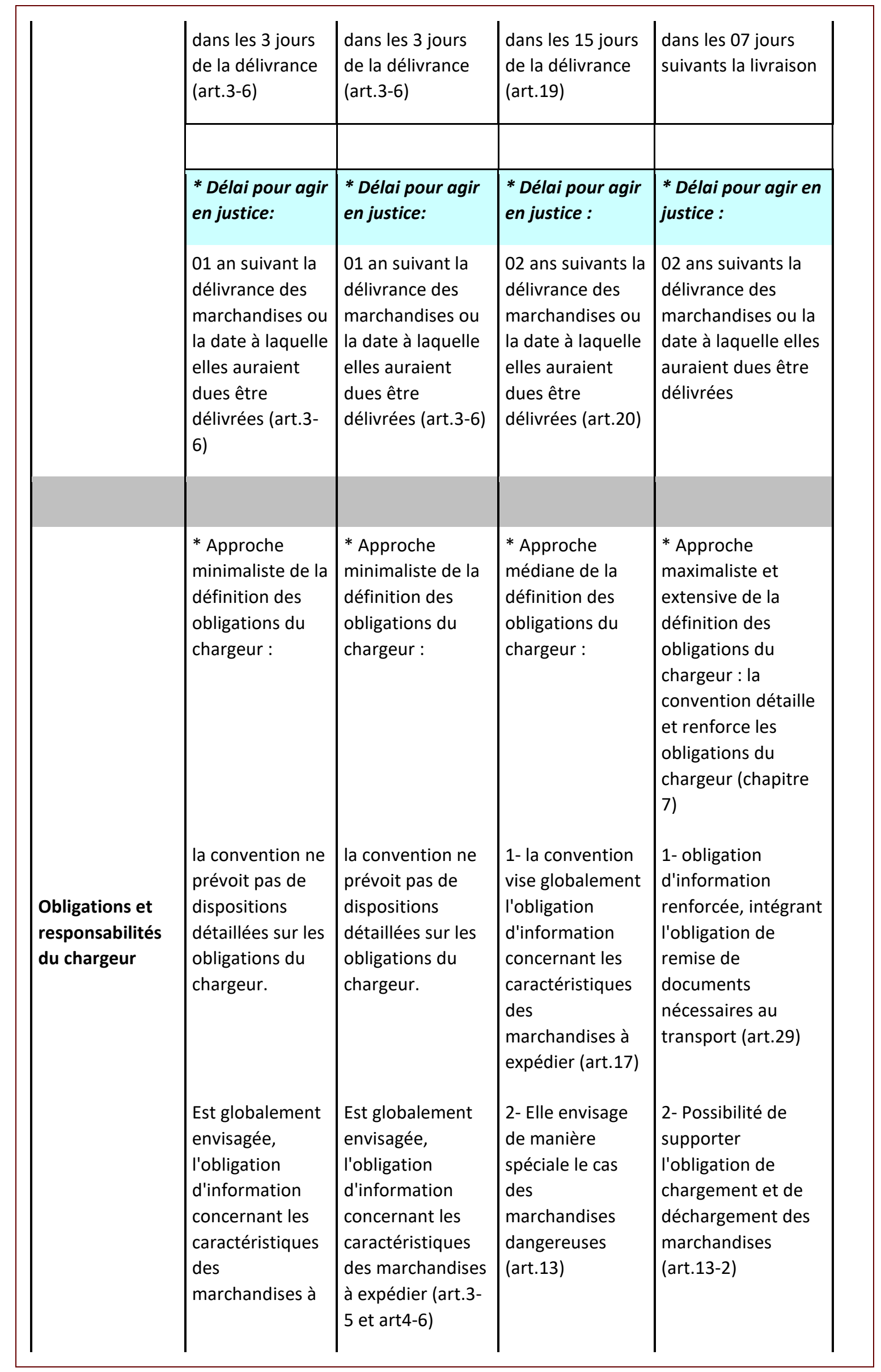




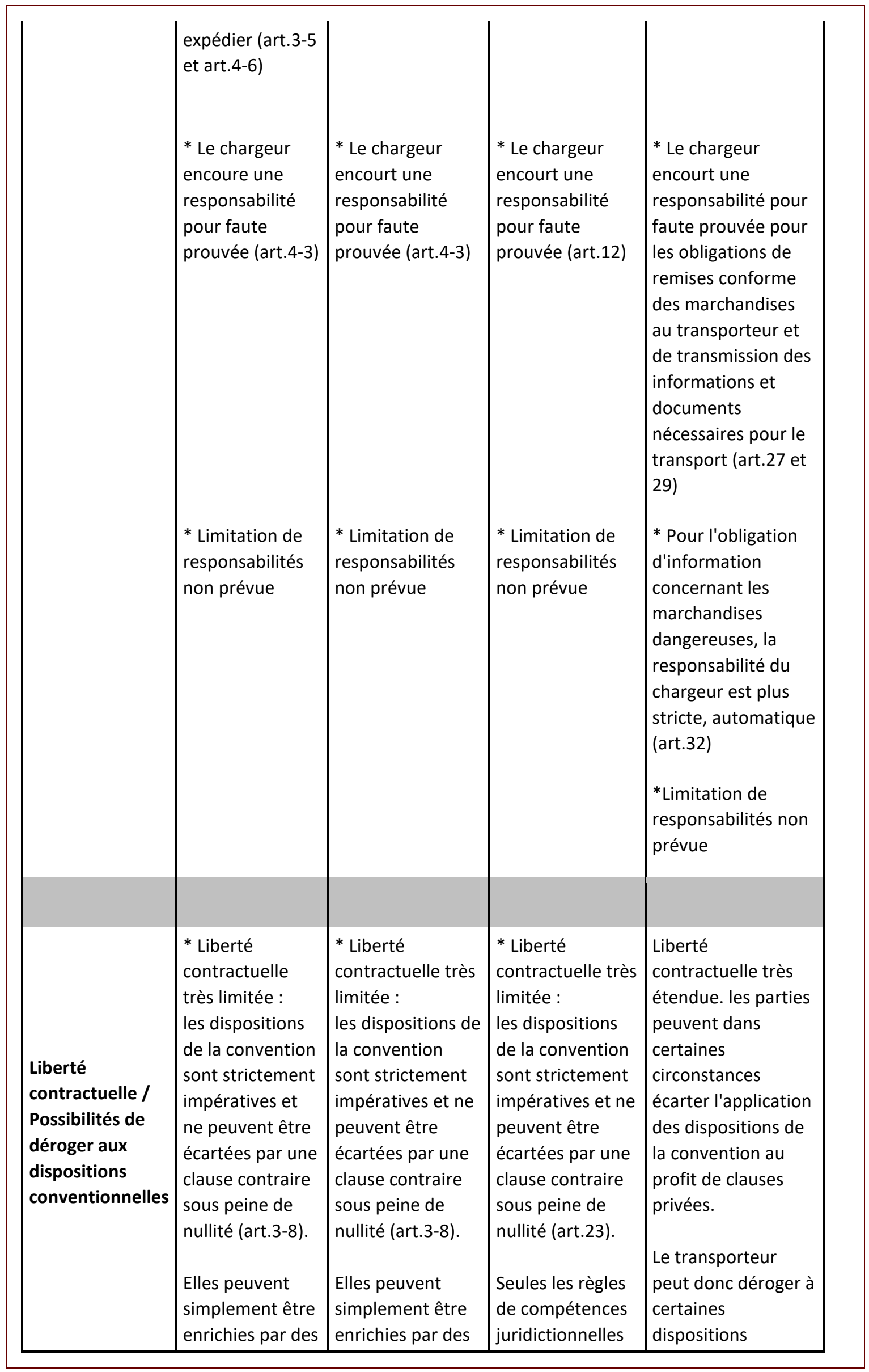




\begin{tabular}{|l|l|l|l|l|}
\hline $\begin{array}{l}\text { clauses } \\
\text { supplétives } \\
\text { (art.7) }\end{array}$ & $\begin{array}{l}\text { clauses } \\
\text { supplétives (art.7) }\end{array}$ & $\begin{array}{l}\text { et arbitrales } \\
\text { peuvent faire } \\
\text { l'objet d'une } \\
\text { clause contraire } \\
\text { après la } \\
\text { naissance d'un } \\
\text { litige (compromis } \\
\text { d'arbitrage ou de } \\
\text { juridiction), } \\
\text { art.21-5 et } \\
\text { art.22-6) }\end{array}$ & $\begin{array}{l}\text { impératives de la } \\
\text { convention et } \\
\text { imposer des clauses } \\
\text { contractuelles au } \\
\text { chargeur art.13-2 et } \\
\text { art.80 - contrats de } \\
\text { volume }\end{array}$ \\
\hline
\end{tabular}




\section{Annexe 2 : Zones multinationales de coordination maritime en Afrique de}

l'Ouest et du Centre. Source : International CRISIS GROUP (2014).

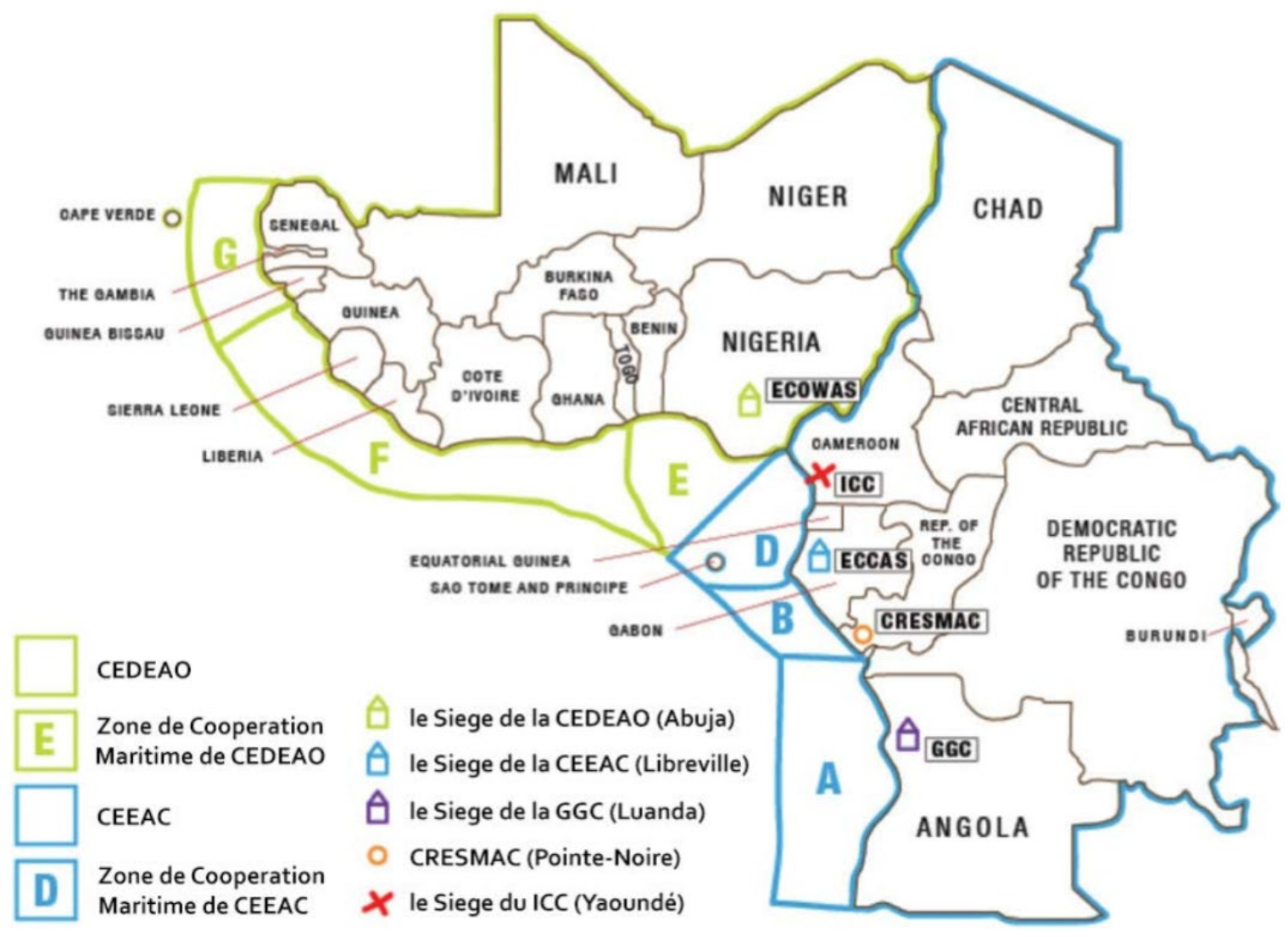




\section{Annexe 3 : Loi $\mathbf{n}^{\circ}$ 2017-442 du 30 juin 2017 portant Code maritime, publiée le 13 novembre 2018. Extrait.}

\section{Section III : La responsabilité du transporteur}

Article 708 : La responsabilité du transporteur en ce qui concerne les marchandises couvre la période pendant laquelle les marchandises sont sous sa garde au port de chargement, durant le transport et au port de déchargement.

Les marchandises sont réputées être sous la garde du transporteur à partir du moment oủ celui-ci les prend en charge des mains soit du chargeur ou d'une personne agissant pour son compte, soit d'une autorité ou autre tiers auquel les marchandises doivent être remises pour l'expédition, conformément aux lois et règlements applicables au port de chargement.

De même, les marchandises sont réputées être sous la garde du transporteur jusqưau moment oủ il effectue la livraison soit en remettant les marchandises au destinataire, soit dans les cas oủ le destinataire ne reçoit pas les marchandises du transporteur, en les mettant à la disposition du destinataire conformément au contrat ou aux lois ou aux usages du commerce applicables au port de déchargement.

Le terme de transporteur ou de destinataire s'entend ici également de leurs préposés ou mandataires respectifs.

Article 709: Le transporteur est responsable du prejudice résultant des pertes ou dommages subis par les marchandises ainsi que du retard à la livraison, si ces pertes, dommages ou retards sont survenus pendant que les marchandises étaient sous sa garde au sens de l'article 708 de la présente loi.

Article 710: II y a retard à la livraison lorsque les marchandises n'ont pas été livrées au port de déchargement prévu par le contrat de transport dans le délai expressément convenu ou dans celui qu'il serait raisonnable d'exiger d'un transporteur diligent compte tenu des circonstances de fait.

Article 711: Le transporteur est responsable des pertes et dommages subis par la marchandise, à moins qu'il ne prouve que ces pertes et dommages proviennent de l'une des causes suivantes:

- innavigabilité du navire à condition que le transporteur apporte la preuve qu'il a satisfait á ses Obligations :

- fait constituant un événement non imputable au transporteur, imprévisible et pour lequel le transporteur, ses préposés ou mandataires ont pris toutes les mesures raisonnables pour éviter les conséquences ;

- faits de guerre :

- fait d'ennemis publics :

- arrêt ou contrainte de prince :

- restriction de quarantaine ;

- incendie;

- fautes du chargeur, notamment dans l'emballage, le conditionnement ou le marquage des marchandises :

- grèves, lock-out ou entrave apportée au travail : 
- acte ou tentative de sauvetage de vie ou de biens en mer ou de déroutement à cette fin:

- vice propre de la marchandise ou freinte de route:

- vices cachés de navire échappant à un examen vigilant ;

- périls, dangers ou accidents de mer.

Le chargeur ou le destinataire peut néanmoins, dans les cas ci-dessus faire la preuve que les pertes ou les dommages sont dus, en tout ou en partie, à une faute du transporteur, de ses préposés, ou mandataires.

Article 712 : En cas de transport d'animaux vivants, le transporteur n'est pas responsable des pertes, dommages ou retards à la livraison qui tiennent aux risques particuliers inhérents à ce genre de transport. Si le transporteur établit quili s'est conformé aux instructions concernant les animaux qui lui ont été données par le chargeur et que, dans les circonstances de fait, la perte, le dommage ou le retard peut être imputé à ces risques particuliers, la perte, le dommage ou le retard est présumé avoir été ainsi causé, à moins qu'il ne soit prouvé que la perte, le dommage ou le retard résulte, en totalité ou en partie, d'une faute ou d'une négligence du transporteur, de ses préposés ou mandataires.

Article 713 : La responsabilité du transporteur pour le préjudice résultant des pertes ou dommages subis par les marchandises est limitée à un montant, fixé par la réglementation ou les usages en vigueur, calculé soit par colis ou autre unité de chargement, soit par kilogramme de poids brut des marchandises perdues ou avariées, la limite la plus élevée étant applicable.

La limite précitée est écartée lorsque celle fixée par la convention des parties est plus avantageuse pour l'ayant droit à la marchandise.

La responsabilité du transporteur en cas de retard à la livraison est limitée à une somme correspondant à deux fois et demie le fret payable pour les marchandises ayant subi le retard. Cette somme ne peut excéder le montant total du fret payable en vertu du contrat de transport de marchandises.

En aucun cas, le cumul des réparations dues par le transporteur ne peut dépasser la limite qui serait applicable en cas de perte totale des marchandises pour le transport desquelles la responsabilité du transporteur est engagée.

Article 714 : La limite la plus élevée est calculée selon les règles ci-après :

- lorsqu'un conteneur, une palette ou tout engin similaire est utilisé pour grouper des marchandises, il est considéré comme un colis ou unité de chargement et indiqué au connaissement émis, ou dans tout autre document faisant preuve du contrat de transport par mer. En dehors de ce cas, les marchandises contenues dans cet engin sont considérées comme une unité de chargement ;

- lorsque cet engin luí-même a été perdu ou endommagé, ledit engin est considéré, sil n'appartient pas au transporteur ou n'est pas fourni par lui, comme une unité distincte. 
Article 715 : Les exonérations et limitations de responsabilité prévues par les dispositions du présent chapitre sont applicables dans toute action contre le transporteur pour pertes ou dommages subis par les marchandises faisant lobjet du contrat de transport ou pour retard à la livraison, que laction soit fondée sur la responsabilité contractuelle, délictuelle ou quasi délictuelle.

Si laction prévue à l'alínéa précédent est dirigée contre un préposé ou un mandataire du transporteur, ce préposé ou mandataire, s'il prouve avoir agi dans l'exercice de ses fonctions, est habilité à se prévaloir des exonérations et des limitations de responsabilité que le transporteur peut invoquer en vertu des dispositions du présent chapitre.

Article 716 : Le transporteur, son préposé ou son mandataire, ne peut pas se prévaloir de la limitation de responsabilité, s'il est prouvé que la perte, le dommage ou le retard à la livraison résulte d'un acte ou d'une omission de l'auteur du dommage commis soit avec lintention de provoquer cette perte, ce dommage ou ce retard, soit témérairement et sachant que cette perte, ce dommage ou ce retard en résulterait probablement.

Article 717 : Le transporteur n'est autorisé à transporter les marchandises en pontée que si ce transport est effectué conformément à un accord avec le chargeur ou aux usages du commerce considéré ou s'il est exigé par la réglementation en vigueur.

Si le transporteur et le chargeur sont convenus que les marchandises seront transportées en pontée ou pourront l'être, le transporteur en fera mention au recto du connaissement ou sur tout autre document faisant preuve du contrat de transport. En l'absence d'une telle mention, le transporteur aura la charge d'établir qu'un accord pour le transport en pontée a été conclu mais il n'aura pas le droit d'opposer cet accord à un tiers porteur de bonne foi du connaissement.

Article 718: Lorsque les marchandises ont été transportées en pontée et que le transporteur ne peut pas invoquer un accord pour le transport en pontée, il ne peut se prévaloir des limitations prévues aux articles 713 et 714 pour les pertes, dommages ou retards à la livraison résultant uniquement du transport en pontée.

Article 719: Lorsque l'exécution du transport ou d'une partie du transport a été confiée à un transporteur substitué, que ce soit ou non dans l'exercice d'une faculté qui lui est reconnue dans le contrat de transport, le transporteur n'en demeure pas moins responsable de la totalité du transport, conformément aux dispositions du présent chapitre. Pour la partie du transport effectuée par le transporteur substitué, le transporteur est responsable des actes et omissions du transporteur substitué, et de ses préposés et mandataires agissant dans lexercice de leurs fonctions.

Le montant total des réparations dues par le transporteur, le transporteur substitué et leurs préposés et mandataires ne peut dépasser les limites de responsabilité prévues par le présent chapitre.

Article 720: Nonobstant les dispositions de l'article 719 alinéa 1, lorsqu'un contrat de transport par mer prévoit expressément qu'une partie spécifiée du transport auquel s'applique ledit contrat sera exécutée par une personne dénommée autre que le 
transporteur, il peut également y être stipulé que le transporteur n'est pas responsable de la perte, du dommage ou du retard à la livraison causé par un événement qui a eu lieu alors que les marchandises étaient sous la garde du transporteur substitué pendant cette partie du transport.

Néanmoins, toute stipulation limitant ou excluant cette responsabilité est sans effet si aucune procédure judiciaire ne peut être engagée contre le transporteur substitué. Le transporteur a la charge de prouver que la perte, le dommage ou le retard a la livraison a étè causé par ledit événement.

Article 721: Toutes les dispositions de la présente loi régissant la responsabilité du transporteur s'appliquent à la responsabilité du transporteur substitué pour les transports effectués par lui.

\section{Section IV : La responsabilité du chargeur}

Article 722: Le chargeur est responsable envers le transporteur, le transporteur substitué ou le navire, pour les préjudices ou dommages résultant de sa faute ou négligence ou de celles de ses préposés ou mandataires.

Les prèposés ou mandataires du chargeur sont responsables des dommages ou préjudices causés par leurs fautes ou négligences, au transporteur ou au transporteur substitué.

Article 723: Le chargeur est réputé avoir garanti au transporteur l'exactitude des indications relatives à la nature générale des marchandises, à leurs marques, leur nombre, leur quantité et leur poids, fournies par lui pour mention au connaissement. Le chargeur doit indemniser le transporteur du préjudice résultant de linexactitude de ces indications.

Le chargeur reste tenu par la garantie prévue à l'alinéa 1 même si le connaissement a été transmis à un tiers. Le droit du transporteur à cette indemnisation ne limite en aucune façon sa responsabilité en vertu du contrat de transport par mer envers toute personne autre que le chargeur.

\section{Section V : Les droits et actions}

Article 724: A moins que le destinataire ne donne par écrit au transporteur, à son représentant ou au consignataire du navire un avis de perte ou de dommage spécifiant la nature générale de cette perte ou de ce dommage au plus tard le premier jour ouvrable suivant le jour oủ les marchandises lui ont été remises, cette remise constitue une présomption, sauf preuve contraire, que les marchandises ont été livrées par le transporteur telles qu'elles sont décrites dans le document de transport ou, si aucun document de transport n'a été émis, qưelles ont été livrées en bon état. Cet avis peut être donné sur le document de livraison.

Lorsque la perte ou le dommage n'est pas apparent, les dispositions de l'alinéa précédent ne deviennent applicables que si l'avis n'est pas donné par écrit dans un délai de huit jours 
- le défaut de signalisation conforme d'une plate-forme en mer et le non-respect de la distance de sécurité pour les autres navires :

- la vitesse excessive devant les plages sans respect du balisage :

- le non-respect des régles de conduite d'un engin sportif à moteur :

- le défaut de déclaration d'une manifestation collective de plaisance :

- le défaut de mesure de sécurité dans un club sportif ou lors d'une manifestation autorisée ;

- le non-respect de la distance de sécurité autour d'un signal de plongeur qui remonte.

Article 1004: Est puni d'une amende de 500.000 à 2.000.000 Francs CFA, quiconque vend à un utilisateur des matériels de sécurité non conformes aux exigences des conventions internationales ou des règlements nationaux.

Dans ce cas, l'autorité maritime administrative peut, après avis des services concernés, demander au tribunal compétent d'ordonner la saisie et la destruction desdits matériels.

Article 1005 : En cas d'infraction aux règles de sécurité et de navigation, le navire est interdit d'appareiller par lautorité maritime administrative.

\section{Chapitre II : Les accidents de mer}

Article 1006: Les capitaines, pilotes, officiers de quart et mécaniciens sont pénalement responsables des infractions qu'ils commettent dans la conduite du navire.

Article 1007: Est puni d'une peine d'emprisonnement de trois à douze mois et d'une amende de 500.000 à 5.000 .000 de Francs CFA ou de lune de ces deux peines seulement, quiconque :

- s'abstient de déclarer une épave :

- soustrait frauduleusement ou détourne une épave.

\section{Chapitre III : La piraterie}

Article 1008: On entend par piraterie maritime tout acte illicite de violence, de menace, de détention ou de déprédation commis par l'équipage ou des passagers d'un navire ou d'un aéronef et dirigé contre un autre navire ou aéronef ou contre des personnes ou des biens à leur bord, au-delà de la mer territoriale.

Est également qualifié de piraterie maritime tout acte de participation volontaire à l'utilisation d'un navire ou d'un aéronef, lorsque son auteur a connaissance de faits dont il découle que ce navire ou cet aéronef est un navire ou aéronef pirate.

Tout acte ayant pour but d'inciter à commettre les actes définis aux alinéas 1 et 2 du présent article ou commis dans l'intention de les faciliter est également qualifié de piraterie maritime.

L'infraction de piraterie prévue au présent article est punie, d'une peine de dix à 
vingt ans et d'une amende de 20.000 .000 à 200.000 .000 Francs CFA.

La tentative est punissable.

S'il résulte des faits de piraterie des blessures ou des maladies, le maximum des peines prévues à l'alinéa $\mathbf{4}$ du présent article est appliqué.

S'il en résulte la mort d'une ou plusieurs personnes, la peine est l'emprisonnement à vie.

Les dispositions des articles 117 et 118 du code pénal relatives aux circonstances atténuantes ne sont pas applicables à l'infraction de piraterie.

Article 1009: Sera poursuivi et jugé conformément à l'alinéa 4 de l'article $1008 \mathrm{ci}$ dessus :

1. tout individu faisant partie de l'équipage d'un navire et naviguant sans être inscrit sur le rôle d'équipage, ou sans avoir été muni pour le voyage de passeport, de commissions ou d'autres actes constatant la légitimité de sa présence à bord :

2. tout capitaine d'un navire porteur de commission délivrée par deux ou plusieurs puissances ou Etats différents.

Article 1010: Seront poursuivis et jugés conformément à l'alinéa 4 de l'article 1008 de la présente loi :

1. tout individu faisant partie de r'équipage d'un navire ivoirien lequel commettrait à main armée des actes de déprédation ou de violence, soit envers des navires ivoiriens ou des navires étrangers, soit envers les équipages ou chargements de ces navires :

2. tout individu faisant partie d'un navire étranger lequel, sans être muni d'une commission régulière, commettrait lesdits actes envers des navires ivoiriens, leurs équipages ou chargements ;

3. le capitaine et les officiers de tout navire qui auraient commis des actes d'hostilité sous un pavillon autre que celui de l'Etat dont ils auraient commission.

Article 1011: Sera également poursuivi et jugé comme pirate tout ivoirien, qui, ayant obtenu, méme avec l'autorisation du Gouvernement, commission d'une puissance étrangère pour commander un navire armé, commettrait des actes dhostilité envers des navires ivoiriens ou d'Etats auxquels des droits équivalents ont été reconnus, leurs équipages ou leurs chargements.

Article 1012: Seront poursuivis et jugés comme pirates :

1. tout individu faisant partie de l'équipage d'un navire ivoirien qui, par fraude ou violence envers le capitaine, s'emparerait dudit navire :

2. tout individu faisant partie de l'équipage d'un navire ivoirien qui le livrerait à des pirates ou à lennemi. 
Article 1013: Dans le cas prévu par le paragraphe 1 de larticle 1009 ci-dessus, les pirates seront punis des peines suivantes:

- 20 ans d'emprisonnement, pour les capitaines, chefs et officiers :

- 10 ans d'emprisonnement, pour les autres hommes de l'équipage.

Tout individu coupable de Pinfraction prévue au paragraphe 2 du même article sera puni d'une peine de 20 ans d'emprisonnement.

Article 1014: Dans les cas prévus par les paragraphes 1 et 2 de l'article 1010 de la présente loi, s'il a été commis des dégradations et violences sans homicides ni blessures, les capitaines, chefs et officiers seront punis de lemprisonnement à vie et les autres hommes de l'équipage seront punis de la peine de 20 ans d'emprisonnement.

Si ces dégradations et violences ont été précédées, accompagnées et suivies d'homicides ou de blessures, lemprisonnement à vie sera indistinctement prononcé contre les officiers et les autres hommes de l'équipage.

L'infraction mentionnée au paragraphe 3 de larticle 1010 sera puni d'une peine d'emprisonnement à vie

Article 1015: Quiconque est reconnu coupable de linfraction prévue par larticle 1011 de la présente loi sera puni de la peine de l'emprisonnement à vie.

Article 1016: Dans le cas prévu au paragraphe 1 de larticle 1012 de la présente loi, la peine sera :

- l'emprisonnement à vie contre les chefs et les officiers :

- L'emprisonnement de 20 ans contre les hommes de l'équipage.

Si le fait a été précédé, accompagné ou suivi d'homicides ou de blessures, la peine de lemprisonnement à vie sera indistinctement prononcée contre tous les hommes d'équipage.

L'infraction prévue au paragraphe 2 du même article sera puni de la peine de l'emprisonnement à vie.

Article 1017: La vente des navires capturés pour cause de piraterie sera ordonnée par le tribunal compétent et le produit de ladite vente sera versé au fonds d'appui au développement du secteur maritime et portuaire.

Un décret déterminera les modalités d'application des dispositions du présent article.

Article 1018 : Les juridictions ivoiriennes sont compétentes pour connaitre des faits de piraterie tels que prévus et réprimés par les articles 1008 à 1016 même lorsqu'ils sont commis en haute mer.

En application des conventions internationales auxquelles la Côte d'lvoire est Partie, les personnes mentionnées à l'article 987 disposent d'un droit de poursuite en haute mer des auteurs des faits de piraterie. 


\section{INDICATION BIBLIOGRAPHIQUE}

I - OUVRAGES GENERAUX

II - OUVRAGES SPECIALISES, RAPPORTS, ETUDES

III- ARTICLES DE DOCTRINE

IV- THESES ET MEMOIRES

V- REVUES ET QUOTIDIENS

VI - CONVENTIONS, TRAITES, REGLEMENTS, DIRECTIVES

* CONVENTIONS ONUSIENNES

* CONVENTIONS AFRICAINES

* CONVENTIONS EUROPEENNES

VII - LOIS, DECRETS ET ARRETES

* nationaUX

* etrangers

VIII- REFERENCES JURISPRUDENTIELLES

* JURISPRUDENCE IVOIRIENNE

* JURISPRUDENCE FRANÇAISE

* JURISPRUDENCE EUROPEENNE

IX- SITE WEB 


\section{I -DUVRAGES GENERALX}

ASSONITIS (Georges), Règlementation internationale dans les transports maritimes dans le cadre de la CNUCED, Puf, Paris, 1991, 328 p.

BLAISE (J-B.) et MOURGEON (J.), Lois et décrets de Côte d'Ivoire, Librairies techniques, 1970, 938 p.

BONASSIES (Pierre) et SCAPEL (Christian), Traité de droit maritime, Ed. L.G.D.J., 2006, 960 p.

CARBONNIER (Jean), Flexible droit, LGDJ. Paris, 3ème édition, 1976, 338 p.

FORTEAU (Mathias) et THOUVENIN (Jean-Marc), Traité de droit international de la mer. Editions A. Pedone, $1322 \mathrm{p}$.

GUILLIEN (Raymond) et VINCENT (Jean), Lexique des termes juridiques, Dalloz, 13ème édition, 2001, 592 p.

GOUBEAUX (Gilles) et BIHR (Philippe), Les épreuves écrites en droit civil, Dalloz, Répertoire de droit civil, 1983, 304 p.

NICOLEAU (Patrick), Lexique de droit privé, Paris, Ellipses, 1996, p. 90.

REY (Alain), REY-DEBOVE (Josette), ROBERT (Paul), Le Robert. 2949 p.

RIPERT (Georges), Droit maritime, "Crédit maritime-Fortune de mer-

Transports maritimes", Éditions Rousseau et Cie, Paris, 4e édition, Tome 2, 1952, $963 \mathrm{p}$.

RODIERE (René), Traité général de droit maritime, Dalloz. Paris, 1968, Tome $2,472 \mathrm{p}$.

RODIÈRE (René) et DU PONTAVICE (Emmanuel), Droit Maritime, 12 ème édition, Précis Dalloz 1997, 612 p.

RODIERE (René), Traité général de droit maritime, Dalloz, 1970, Tome III, Acconage - Consignation - Transit - ... 453 p.

RODIERE (René), Droit maritime, 6è édition, Paris, Précis Dalloz 1977, 289 p.

SALMON (Jean) et BRUYLANT (D), Dictionnaire de Droit International Public AUF Bruxelles 2001, 1200 p.

SARASSORO (Hyacinthe), L'enfant naturel en droit Ivoirien. Les Nouvelles Editions Africaines, 1984, 111 p.

STARCK (Boris), Droit civil. Obligations, TARDY-QUERCY-AUVERGNE, 1971,819 p.

\section{II- DUVRAGES SPECIALISES, RAPPORTS, ETUDES}

ALLAH, Les ports africains face au développement de la conteneurisation, Association de Gestion des Ports de l'Afrique de l'Ouest et du Centre, Exposé, 5èmes Journées Portuaires Africaines de Lagos (Nigeria), octobre 1989, $12 \mathrm{p}$.

AUCHTER (Gérard), La convention des Nations unies sur le transport de marchandises par mer, (Règles de Hambourg 1978), Droit Européen des transports, vol. XIV. 1979, 470 p.

BERGHEZAN (Georges), Côte d'Ivoire et Mali, au Cour des trafics d'armes 
en Afrique de l'ouest, Groupe de Recherche et d'Information sur la Paix et la Sécurité (GRIP), Rapport 2013/1, 2013, 41 p.

BIGOT (Mamadou), Présentation et état de ratification des principales conventions maritimes pour les Etats de la CMEAOC, CNUCED, Projet RAF, Août 1991, 165 p.

BILLARD (J.), Porte-conteneurs, la révolution des transports maritimes, Edition ETAI, 2003, 248 p.

BONNASSIES (Pierre) et SCAPEL (Christian), Traité de droit maritime, Ed. L.G.D.J., 2006, 896 p.

DAMIEN (M. M.), Transport et logistique fluviaux, Edition Dunod, 2009, 359 p. DELEBECQUE (Philippe), Le droit maritime français à l'aube du XXIe siècle, Le droit privé français à la fin du XXe siècle, Editions Litec, Paris, 2001, 935 p.

DELFAUD (Pierre), La sécurité du transport et du trafic maritime de marchandises, RESEAU TRANSNATIONAL ATLANTIQUE DES PARTENAIRES ECONOMIQUES ET SOCIAUX, Rapport, Mai 2005, 94 p.

DE TESSIERES (Savannah), Enquête nationale sur les armes légères et de petit calibre en Côte d'Ivoire, Small Arms Survey, avril 2012.

EHOULA COSY (Prince), Le transport maritime et le développement des infrastructures en Afrique, CNAM- Institut national du transport international et des ports, Opérateur multimodal des transports, 2013, 32 p.

FAIVRE (Y. Lambert) et LEVENEUR (Laurent), Droit des assurances, Précis Dalloz, 12e édition, 2005, $122 \mathrm{p}$.

FRAIKIN, (G.), Traité de la responsabilité du transporteur maritime, Librairie générale de droit et de jurisprudence (LGDJ), Paris, 1957, 451 p.

KOFI A. ANNAN, Convention des Nations Unies contre la criminalité transnationale organisée et protocoles s'y rapportant, Palerme (Italie), décembre 2000, Préface, 90 p.

LAMBERT-FAIVRE (Yvonne), Droit des assurances, précis Dalloz, 2e édition, 1977, 686 p.

LANGLAIS (Peter), Sécurité maritime et droit de l'Union européenne, Bruylant, Droit de l'Union européenne, mai 2018, 956 p.

LECLERCQ (J.F.), Communication à l'audience solennelle de rentrée de la Cour de cassation de Belgique, $1^{\mathrm{er}}$ septembre 2010, 59 p.

LEFEBVRE-CHALAIN (Hélène) et LEBOEUF (Cédric), La piraterie maritime, Journées Méditerranéennes Organisées par le Centre de Droit Maritime et Océanique, Université de Nantes. Décembre 2009, 13 p.

LEFEBVRE (Guy) et ROUSSEAU (Stéphane), La vente documentaire internationale : la problématique de l'application de la Common law au Québec, Introduction au droit des affaires, Éditions Thémis, Collection : 
Centre de droit des affaires et du commerce international (CDACI), Montréal, 2006, 702 p.

LUCCHINI (L) et VOECKEL (M), Droit de la mer : La mer et son droit. Les espaces maritimes, Pedon, Paris, Tome 1,1996, 424 p.

PERRELLA (Claudio) et CARPINETA (Adeliana), Assurance transport et subrogation en Italie, LS-Lexjus Sinacta, Décembre 2015, p. 20.

REMOND-GOUILLOUD (Martine), Droit maritime, Pedon, Paris, 1988, 450 p.

SABRINA (Robert), L'Erika : responsabilité pour un désastre écologique, Ed. Pedon, Paris, Octobre 2003, 259 p.

THOUVENIN (Jean-Marc), Piraterie maritime : quel droit, pour quelle Juridiction, Notes de cours 2012-2013, 13 p.

YACOUBA (Cissé), L’identification du transporteur maritime à l'épreuve de la qualification juridique, Revue générale de droit, 2004, 46 p.

YAPO (Marina Madel), La lutte contre la criminalité maritime dans le golfe de guinée : cas de la Côte d'Ivoire et du Nigeria, Programme de Bourses de Recherche, Nations Unies-Fondation Nippone du Japon, Etude 20122013, Décembre 2013, 195 p.

\section{III- ARTICLES DE DOCTRINE}

ADENIYI ADEJIMI (Osinowo), " La lutte contre la piraterie dans le golfe de Guinée ", Bulletin de la sécurité africaine, Centre d'Etudes Stratégiques de l'Afrique, Avril 2017, n 32, pp. 10 et s.

BARDONNET (C. Daniel) et CARROZ (Jean), «Les autres États de l'Afrique de l'Ouest et le droit international des pêches maritimes ", AFDI, 1973, pp. 837-858.

BEALL (Jacques), " La politique européenne de transport maritime au regard des enjeux de développement durable et des engagements climat ", JORF, Mai 2017, Avis du Conseil économique, social et environnemental, pp. 22108.

BEN FRAJ (Sarah), « La limitation de responsabilité du transporteur maritime de marchandises en droit Tunisien ", https://metalaww.lead.org.tn, consulté le 22 août 2017.

BILE (Vincent), " Regard Critique sur le Nouveau Code Maritime Ivoirien ", Neptunus, e. revue Université de Nantes, vol. 24, 2018/3, 2018, pp. 1-6.

BLAVEC (André), "Les conventions STCW et STCW-F, la formation aux métiers de la mer ", La Revue Maritime, n 467, janvier 2004, pp. 3-4.

BONASSIES (Pierre), "Le droit positif français en 1991 », DMF, 1992, volume 44, pp. 4-7.

BONASSIES (Pierre), " Les Règles de Hambourg une avancée certaine, mais Modeste ", JMM 1988, pp. 1341 et s.

BONASIES (Pierre) et DELEBECQUE (Philippe), « Le Droit Maritime

Français ", Hors-série n²16, juin 2012, pp. 77-109.

BORÉ EVENO (Valérie), « Le cadre juridique international de la lutte contre 
le trafic maritime de stupéfiants. Quelles compétences pour les Etats?", Université de Nantes, Centre de Droit Maritime et Océanique, EA n ${ }^{\circ}$ 1165 , p. 17.

BROU Kouakou (Mathurin), « Le nouveau droit des contrats de transport de marchandises par route dans l'espace OHADA", Penant $n^{\circ} 845$, octobre-décembre 2003.

CARCELLER (Julie), « Malcom Mclean », juillet 2007, http://fr.wikipedia.org/Malcom_Mclean, consulté le 22 mars 2017.

CASSAN (L), "La phase maritime du transport de marchandises par mer ", DMF 1963, p. 690.

CHEICKNA (D. Salif), « Sécurité maritime dans la CEDEAO, équipement du CRESMAO », slifoudabou@fratmat.info, mars 2018, p. 1.

DE JUGLART (Michel), « Sectionnement ou unité du contrat de transport maritime? "Les arrêts du 17 mai 1960" ", DMF 1960, p. 451.

De JUGLART (Michel), Le particularisme du droit maritime, in Recueil Dalloz 1959, Chronique XXVII, pp.183-186.

DELEBECQUE (Philippe), «L'évolution du transport maritime », DMF 2009, p. 16.

DIALLO (Ibrahima Khalil), « Etude de l'acte uniforme relatif au contrat de transport de marchandises par route ", OHADATA D-05-08. Le bulletin du transport multimodal, juillet-décembre 2004, n 2 et 3, p. 12.

DOUMBOUYA (Sekou F.) et NANA (François), « Négociations commerciales et l'Assurance. Etude de cas de la CIMA ». JEICP Juristes et Economistes Internationaux Contre la Pauvreté, Mai 2009, p. 10.

DRAGO (Roland), «L'évolution dans la procédure administrative », RDP 1957, pp. 453-473.

DUSSEY (Robert), « La piraterie maritime : quels enjeux pour le golfe de Guinée ?», Editions Choiseul « Géo économie » 2014/1 nº 68, pp. 171-176.

FAURE (Michael), « Responsabilité civile et réparation des pollutions marines, Leçon à tirer des déversements provenant des plateformes pétrolières ", Aménagement-Environnement, 2011/2, Kluwer, p. 8.

FOLQUET (Léon), " La règlementation de l'UEMOA en matière de transport maritime ", Revue Africaine des Affaires Maritimes et des Transports, L'Harmattan, juillet 2013, p. 18.

GALLETTI (Florence), « Le droit de la mer, régulateur des crises pour le contrôle des espaces et des ressources : quel poids pour des États en développement? ", Mondes en développement, vol. 39-2011/2-n¹54, 2011, pp. 123 et $\mathrm{s}$.

GROIZELEAU (Vincent), « Golfe de Guinée : Les Africains prennent en main leur sécurité maritime », Le Fouladou, nouvel OPV (C OCEA, septembre 2017, pp. 1-7.

GUILLEUX (Céline), " La dimension européenne de la sûreté et de la sécurité maritime ", septembre 2017, pp. 1-2.

HELAL (Rabah), « Protection des marchandises, transport maritime », 
Capitaine Au Long Cours / ISM at. GROUP-CNAN/NORD EUROPE, Juillet 2013, pp. 3-4.

LAFAGE (G.H), "Régime juridique applicable aux opérations "ante" et "post" palan du contrat de transport maritime ", Extrait de l'Informateur, Sète, 1961, n VIII.

LEFEBVRE (Guy), " La responsabilité du transporteur maritime au Canada ", Revue du notariat, vol. 101, $\mathrm{n}^{\circ} 2$, septembre 1999, pp. 281-298.

LEGENDRE (C.), «La Convention des Nations Unies sur le transport de marchandises par mer», (1978) 30 D.M.F. note 6, pp. 387- 395.

LUNTUMBUE (Michel), "Insécurité maritime dans le golfe de Guinée : vers une stratégie régionale intégrée ? " Groupe de Recherche et d'Information sur la Paix et la sécurité GRIP, décembre 2012, pp. 1-11.

MAKOUTA (Moise), " La protection du chargeur à travers la convention du 25 aout 1924 et les Règles de Hambourg ", JMM, 1988, pp. 821 et s.

MARTIN (Jean-Christophe), « La répression des actes de piraterie maritime : développements de poursuites et détention des pirates somaliens". Annuaire Français de Droit International, Editions CNRS, Paris. LV1 2010, pp. 502-503.

MAYELA (Ismaël), « L'obligation d'extrader des Etats membres de la CEDEAO ». www.village-justice.com/articles/obligations, consulté le 13 août 2018, p. 1.

MOMTAZ (Djamchid), “ L’Accord relatif à la conservation et à la gestion des stocks de poissons chevauchants et grands migrateurs ", Annuaire français de droit international XLI-1995-Editions du CNRS Paris. Droit de la mer, Bulletin $n^{\circ} 45$, Division des affaires maritimes et du droit de la mer, Nations Unies, 2002, p. 688.

NGAMKAN (G). «Quelques conseils juridiques et politiques aux chargeurs et réceptionnaires africains afin de leur permettre de tirer le meilleur parti de leurs activités commerciales ". Juridis périodique $\mathrm{n}^{\circ} 28$, oct-nov-déc. 1996, pp. 83-93.

N'ZI (Serge-Nicolas), " La Côte d'Ivoire face à la piraterie maritime ", Lugano (Suisse), Février 2013, pp. 2-5.

OKANZA (Kouamé Ambroise), « La Côte d'Ivoire face à la piraterie maritime ». http://www.connectionivoirienne.net/82215/.

PINEUS (K.), "Les conteneurs et les transports combinés ", DMF, 1967, p. 395. RAMBERG (J.), "Freedom of Contract in Maritime Law ", L.C.M.L.Q., 1993. RIPERT (Georges), « Le sectionnement du transport maritime », DMF, 1950, p. 471.

RODIĖRE (René), " La responsabilité du transporteur maritime suivant les Règles de Hambourg 1978, (le point de vue d'un juriste latin) » D.M.F., 1978, 30, pp. 451-464.

SERIAUX (Alain), "La faute du transporteur », économica, 1998, nº 9 et s.

SITT (Bernard) et HAUTECOUVERTURE (Benjamin) « Sécurité des 
conteneurs", International Experts Group on Global Security (IEGGS), Rapport, janvier 2005, p. 668.

SRITASTAVA (S. P), "Stratégie pour la protection du milieu marin », Grande Bretagne, Manuel OMI, juillet 1988, pp. 1-3.

SWEENEY (J C), «Les Règles de Hambourg, point de vue d'un juriste anglosaxon ", D.M.F, (1979) 31, pp. 323-335.

TANDONNET (Jean), " Sécurité et sûreté maritime en Méditerranée ", $L a$ Revue Maritime n483, 2008, pp. 32-37.

TASSEL (Yves), " La clause Paramount face à la norme et face à elle-même ", Annuaire de droit maritime et océanique, vol. XXI, 2003, pp. 59-73.

TERRASIER (N.), «La manutention portuaire de conteneurs en France : vers la consolidation?», ISEMAR, Note de synthèse $\mathrm{n}^{\circ} 28$, octobre 2000 , p. 2.

TETLEY (W.), « The Hamburg Rules : A Commentary », L.M.C.L.Q., 1979, pp. $1-20$.

TILCHE (M.), « Conteneurs : engin de transport ou emballage »? BTL 1991, p. 496.

TOURRET (P.), " La révolution du conteneur ", ISEMAR, Note de synthèse $\mathrm{n}^{\circ}$ 49, novembre 2002 , pp. 1-4.

TOURNAYE (Cécile), « Commentaire du projet de code belge de la navigation, partie dédiée à la navigation intérieure, livre IV et VI ", octobre 2015, pp. 43-51.

TRAORE (Adama), « Aux origines de la domination française en Côte d'Ivoire : les traités de protectorat. La création de la colonie de Côte d'Ivoire en 1893 ", https://dyabukam.com/index.php/fr/savoir/histoire/item/, p. 34.

VAN HOOYDONK (Eric), " Ébauche de code belge de la navigation (droit privé) ", Commission de droit maritime, Anvers, Rapport, 2014, pp. 27-28.

VEAUX (Daniel.), « Droit maritime », RID 1976/3-4, pp. 43 et s.

VIALARD (Antoine), « Faut-il réformer le régime de l'indemnisation des dommages de pollution par les hydrocarbures "? DMF mai 2003, p. 435.

VINCENT (V.), « Etude sur les Transports Maritimes 2010 ». Rapport du secrétariat du CNUCED, UNCTAD/RMT/, 2010, p. 21.

VOGEL (Augustus), «Relever les défis de la sécurité maritime en Afrique grâce aux investissements en science et technologies ", Bulletin de la sécurité africaine, $\mathrm{n}^{\circ} 10$ Washington, DC: National Defense University Press. février 2011.

WAROT (J.), « L'avènement du container dans le trafic maritime ». DMF 1951, p. 263.

WOLFRUM (Rüdiger), « Importance du Tribunal international du droit de la mer pour Hambourg : profil, attentes et réalité", Übersee-Club, Hambourg, février 2008, p. 1. 


\section{IV- THESES ET MEMDIRES}

* THESES

ADIL (Hind), Le régime juridique international de la responsabilité du transporteur maritime de marchandises sous connaissement : un échec? Thèse, Université de Montréal, décembre 2009, 337 p.

ASSONGBA (Cossi Hervé), Le transport maritime de marchandises conteneurisées, Thèse, Université Lille 2, Faculté des sciences juridiques, politiques et sociales. Novembre 2014, 503 p.

BRANELLEC (Gurvan), La coexistence des règles applicables au contrat de transport international de marchandises par mer : contribution à l'étude de l'uniformité $d u$ droit, Thèse, Université de Bretagne Occidentale Ecole doctorale des Sciences de la Mer. juin 2007, 640 p.

COULIBALY (Climanlo Jérôme), Les intermédiaires du transport maritime international de marchandises en droit ivoirien, Thèse, Université de Nice, $1987,530 \mathrm{p}$.

DAKOURI (Jean-Claude), Le droit maritime international et le transport des hydrocarbures, Thèse de droit privé, Université de Maastricht, Année universitaire 2010/2011, 445 p.

FRAIKIN (G.), Le problème de la responsabilité du transporteur depuis la loi du 2 avril 1936, Thèse Paris, 1944.

GUERRA (Frank Nectali Miranda), Le conflit de lois en droit des transports de marchandises par mer, Thèse de Droit Privé, UNIVERSITE DE BOURGOGNE, juillet 2013, 355 p.

GUYON (Yves-Félix), Les transports régis par la loi du 2 avril 1936, thèse Paris 1957, 296 p.

ISMAILI (Syrine), Le facteur humain dans la mise en œuvre de la sécurité et de la sûreté maritimes: analyse de l'inscription de la Tunisie dans l'ordonnancement juridique international, Thèse de Droit public, Université de Lille 2, avril 2012, 502 p.

KENGUEP, (E), Analyse critique des règles de responsabilité du transporteur maritime de marchandises : contribution à la recherche de la solution au problème de l'équilibre contractuel, thèse 3ème cycle, Université de Yaoundé II, 2002, 315 p.

LE GOFF (Roland), La protection des navires soumis au risque de piraterie. Enseignements tirés de l'épisode de piraterie somalienne (2006 à 2013). Université de Nantes. Thèse de Droit public, décembre 2016, 483 p.

N'DRI (Kouacou François), Le juge ivoirien et la preuve dans le contentieux administratif, Thèse de droit public, Université Felix HOUPHOUËTBOIGNY d'Abidjan, mai 2013, 410 p.

N'TOH (Lath Suzanne), Le déchargement des marchandises transportées par mer, Thèse de Droit privé, Université Aix-Marseille III, 2005, 406 p.

TASSEL (Yves), Le statut juridique de l'entrepreneur de manutention dans la 
loi française du 18 juin 1966 et le décret du 31 décembre 1966, Thèse, Nantes 1973.

\section{* MEMOIRES}

ADIL (Hind), La responsabilité du transporteur maritime international de marchandises sous connaissement: causes d'exonération et limitation légales. Mémoire de Master, Option : droit des affaires, Faculté de Droit, Université de Montréal, décembre 2005, 157 p.

AUDEBAUD (Nicolas), La lutte internationale contre la piraterie somalienne : représentations et enjeux, Université Paris 1 Panthéon-Sorbonne, Mémoire de Master 2 de Recherche 2010, 313 p.

BOUDONG (Nathalie), La piraterie maritime moderne, UNIVERSITE PAUL CEZANNE III. Mémoire, Droit maritime et des transports, Année universitaire 2008/2009, 131 p.

BRONER (Romain), La répression de la piraterie maritime et ses enjeux juridiques, Mémoire de Master de Recherche, Sécurité et Défense, Université Panthéon-Assas-paris II, Année universitaire 2009/ 2010, 154 p.

DE BONTE POERI (Priscille), Les lacunes du droit relatif au mouvement transfrontière des déchets dangereux : illustration à l'aide de l'affaire Probo Koala en Côte d'Ivoire. Mémoire, Université de Montréal, juin 2015, $159 \mathrm{p}$.

DOUA (M), La contribution du droit pénal à la protection de l'environnement en Côte d'Ivoire, Mémoire de DEA, Droit privé fondamental, Université de Cocody, 1996-1997, 78 p.

FETZE KAMDEM (Innocent), La responsabilité du transporteur maritime au niveau international: un échec d'uniformisation juridique, Mémoire, Université Laval Québec, Canada, décembre 1999, 135 p.

NOËL (Benoît), Transport maritime : le développement de la conteneurisation, Mémoire, ECOLE SUPERIEURE DES TRANSPORTS, 2003, 62 p.

OUMAROU (Rachid Mahamane), Le respect des droits de l'homme dans la procédure d'extradition, Mémoire, Université catholique de l'Afrique de l'ouest UCAO. 2012, 65 p.

\section{V- REVUES ET QUDTIDIENS.}

Fondation Méditerranéenne d'Etudes Stratégiques (FMES), "Le golfe de Guinée, recrudescence de la piraterie et du brigandage maritime ", 29 Novembre 2019, in fmes-France.

Guide promotionnel du port de San Pedro, 1ère édition 2015.

Le Nouveau Réveil, 25 septembre 2012, TAKOUE (Sylvain), "Commerce maritime mondial : La Côte d'Ivoire doit-elle signer la convention de Rotterdam ?». 
Actualités juridiques $\mathrm{n}^{\circ}$ 57/2008, p. 154 et 155. Revue d'informations juridiques et judiciaires AIDD.

Revue international de droit pénal, $1^{\text {er }}$ et $2^{\text {ème }}$ trimestre 2008, p. 148.

Division des affaires maritimes et du droit de la mer, Nations Unies (2002), Bulletin $n^{\circ} 45$, pp. 61 à 85 .

Revue de la FAO, CERES, n c 112, volume 19, n², 1986.

Annuaire de la CNUDCI, 1972, vol. III, pp. 287-290.

Revue ivoirienne de droit RID 1970/3, p. 28.

\section{VI- CONVENTIONS, TRAITES, RESDLUTIONS, REGLEMENTS ET DIRECTIVES \\ * CONVENTIONS ONUSIENNES}

Traité des Nations Unies sur le commerce des armes de 2013. Ouvert à la signature à New York, en juin 2013.

Convention des Nations Unies sur le contrat de transport international de marchandises effectué entièrement ou partiellement par mer, du 23 septembre 2009 à Rotterdam (Pays-Bas).

Convention de Budapest relative au contrat de transport de marchandises en navigation intérieure (CMNI) du 22 juin 2001, entrée en vigueur le 1er avril 2005.

Protocole de 2005 relatif au Protocole pour la répression d'actes illicites contre la sécurité des plateformes fixes situées sur le plateau continental. Conclu à Londres le 14 octobre 2005.

Protocole de 2005 relatif à la Convention pour la répression d'actes illicites contre la sécurité de la navigation maritime. Conclu à Londres le 14 octobre 2005.

Code international pour la sûreté des navires et des installations portuaires. Code ISPS de 2002.

Protocole visant à prévenir, réprimer et punir la traite des personnes, en particulier des femmes et des enfants de Palerme (Italie) du 15 décembre 2000.

Protocole contre le trafic illicite de migrants par terre, mer et air, de Palerme (Italie) du 15 décembre 2000.

Convention des Nations Unies contre la criminalité transnationale organisée de Palerme (Italie) du 15 décembre 2000.

Convention internationale pour la répression du financement du terrorisme. New York, le 10 janvier 2000. 
Accord des Nations Unies relatif à la conservation et à la gestion des stocks de poissons chevauchants et des stocks de poissons grands migrateurs. New York, 4 août 1995.

Convention sur l'interdiction de la mise au point, de la fabrication, du stockage et de l'emploi des armes chimiques et sur leur destruction. Fait à Paris, le 13 janvier 1993.

Convention de Bâle sur le contrôle des mouvements transfrontières de déchets dangereux et de leur élimination. Conclue à Bâle le 22 mars 1989.

Protocole à la Convention pour la répression d'actes illicites contre la sécurité des plateformes fixes situées sur le plateau continental de Rome de 1988.

Convention pour la répression d'actes illicites contre la sécurité de la navigation maritime. Conclue à Rome le 10 mars 1988.

Protocole pour la répression d'actes illicites contre la sécurité des plates-formes fixes situées sur le plateau continental. Conclu à Rome le 10 mars 1988.

Convention des Nations Unies contre le trafic illicite de stupéfiants et de substances psychotropes. Adoptée le 19 décembre 1988 à Vienne.

Convention des Nations Unies sur le droit de la mer. Conclue à Montego Bay le 10 décembre 1982.

Convention internationale de 1978 sur les normes de formation des gens de mer, de délivrance des brevets et de veille Conclue à Londres le 7 juillet 1978 .

Convention des nations unies sur le transport de marchandises par mer de 1978. (Règles de Hambourg).

Amendements à l'annexe du protocole de 1978 relatif à la convention internationale de 1973 pour la prévention de la pollution par les navires (annexe révisée de MARPOL 73/78).

Convention internationale pour la sauvegarde de la vie humaine en mer. (SOLAS). Conclue à Londres le 1er novembre 1974.

Convention internationale de 1973 pour la prévention de la pollution par les navires. Fait à Londres, le 2 novembre 1973.

Convention internationale sur la sécurité des conteneurs (CSC) de Genève du 02 décembre 1972.

Convention douanière relative aux conteneurs, décembre 1972, Genève.

Traité sur la non-prolifération des armes nucléaires (TNP). Signé à Londres, Moscou et Washington, le 1er juillet 1968.

Convention sur la haute mer. Conclue à Genève le 29 avril 1958. 
Convention internationale sur la limitation de la responsabilité des propriétaires de navires de mer, du 10 octobre 1957 à Bruxelles.

Convention du 6 mars 1948 portant création de l'Organisation Maritime Consultative Internationale (OMCI) devenue aujourd'hui l'OMI (Organisation Maritime Internationale).

Convention de Bruxelles du 25 août 1924 pour l'unification de certaines règles en matière de connaissement "Règles de La Haye", Protocole du 23 février 1968 et Protocole du 21 décembre 1979.

\section{* CONVENTIONS AFRICAINES}

Résolution $\mathrm{n}^{\circ}$ 4/2004/CM/UEMOA du 28/03/2008 relative à la sécurité et à la sûreté maritime au sein de l'UEMOA.

Directive $\mathrm{n}^{\circ}$ 02/ 2008/CM/UEMOA relative à la recherche et au sauvetage en mer et à la protection de l'environnement marin au sein de l'UEMOA.

Acte uniforme relatif au transport de marchandises par route, du 22 mars 2003 à Yaoundé (Cameroun).

Convention d'extradition de la CEDEAO. Signée à Abuja le 6 août 1994.

Traité de Port-Louis relatif à l'Organisation pour l'harmonisation du droit des affaires en Afrique (OHADA), du 17 octobre 1993 modifié par le Traité de Québec du 17 octobre 2008.

Traité instituant la Conférence Interafricaine des Marchés d'Assurances (CIMA) du 10 juillet 1992 à Yaoundé.

Code des assurances des Etats membres de la CIMA du 10 juillet 1992 à Yaoundé.

Convention de Bamako sur l'interdiction d'importer en Afrique des déchets dangereux et sur le contrôle des mouvements transfrontières et la gestion des déchets dangereux produits en Afrique. Adopté à Bamako, Mali, le 30 janvier 1991.

Charte africaine des droits de l'homme et des peuples. Adoptée en juin 1981 à Nairobi, Kenya.

\section{* CONVENTIONS EUROPEENNES}

Règlement 1005/2008 du Conseil de l'Europe du 29 septembre 2008.

Règlement (CE) n 725/2004 du parlement Européen et du Conseil de l'Europe.

Traité de Maastricht sur l'Union européenne du 7 février 1992. 
Traité sur le fonctionnement de l'Union européenne. Fait à Rome, le 25 mars 1957.

\section{VII- LDIS, DECRETS ET ARRETES}

\section{* NATIONAUX}

Loi $n^{\circ} 2017-442$ du 30 juin 2017 portant Code maritime.

Loi n $2016-886$ du 8 novembre 2016 portant Constitution de la République de Côte d'Ivoire.

Loi n $97-019$ du 7 août 1997 relative au contrôle des stupéfiants, des substances psychotropes et des précurseurs et à l'extradition et à l'entraide judiciaire en matière de trafic des stupéfiants, des substances psychotropes et des précurseurs.

Loi n 96-766 du 3 octobre 1996 portant Code de l'Environnement.

Loi $n^{\circ}$ 88-686 DU 22 juillet 1988 portant répression du trafic et de l'usage illicites des stupéfiants, des substances psychotropes et des substances vénéneuses.

Loi n 62-254 du 31 juillet 1962 modifiant la Loi n 61-349 du 9 novembre 1961 relative à l'Institution d'un Code de la Marine marchande.

Loi n 61-211 du 12 juin 1961 autorisant le Président de la République à ratifier la Convention de Bruxelles de 1924.

Loi n $61-349$ du 9 novembre 1961 relative à l'Institution d'un Code de la marine marchande.

Décret $\mathrm{n}^{\circ}$ 2011-401 du 16 novembre 2011 portant organisation du Ministère des Transports art. 26 ; voir aussi l'arrêté n 46/MEMT/DGAMP du 14 mars 2005 portant organisation et attributions de la Direction Générale des Affaires Maritimes et Portuaires.

Décret n² 2011-401 du 16 novembre 2011 portant organisation du Ministère des Transports.

Décret $\mathrm{n}^{\circ}$ 2001-143 du 14 mars 2001 portant approbation des Statuts du Port autonome d'Abidjan (P.A.A.) et reclassification des immobilisations concédées, JORCI du 26 avril 2001.

Décret $\mathrm{n}^{\circ}$ 99-318 du 21 avril 1999 portant règlement de police du Port autonome d'Abidjan.

Décret $\mathrm{n}^{\circ}$ 95-818 du 29 septembre 1995 portant transformation du Port autonome de San-Pedro en société d'Etat. 
Arrêté interministériel $\mathrm{n}^{\circ} 013 \mathrm{MEF} / \mathrm{SEPMBPE}$ du 11 janvier 2018 portant modification de l'arrêté $n^{\circ}$ 849/MEF/DGTCP/DA du 10 novembre fixant le modèle de certificat pour l'assurance des biens et marchandises de toute nature à l'importation.

Arrêté $\mathrm{n}^{\circ}$ 46/MEMT/DGAMP du 14 mars 2005 portant organisation et attributions de la Direction Générale des Affaires Maritimes et Portuaires.

Arrêté 0082 du 5 mai 1999 définit les zones de pilotage obligatoire.

Arrêté $n^{\circ} 06 / \mathrm{MINIMAR/CAB/SGM/DNAMN} \mathrm{du} 04$ mai 1982 , relative à la sécurité des plates-formes de forage et autres installations off-shore.

\section{* ETRANGERS}

Loi française $n^{\circ}$ 66-420 du 18 juin 1966.

Loi belge d'avril 1936 relative aux transports de marchandises par mer.

Décret français du 10 mars 1893, portant création de la Colonie de Côte d'Ivoire.

\section{VIII- REFERENCES JURISPRUDENTIELLES}

\section{* JURISPRUDENCE IVOIRIENNE}

CSCJ, arrêt nº09 du 08 janvier 2009.

CSCJ, arrêt n 069/07 du 1er février 2007. Inédit.

CSCJ, arrêt nº 071/07 du 01 février 2007. Actualités juridiques n 57/2008, p.

154 et 155 .

CSCJ, arrêt n $301 / 06$ du 01 juin 2006.

CSCJ, arrêt $\mathrm{n}^{\circ}:$ 609/06 du 09 novembre 2006, inédit.

CSCJ, arrêt n 378 du 10 juin 2004. Inédit.

CSCJ, arrêt n²57 du 08 mai 2003. Inédit.

CSCJ, arrêt n 257 du 15 mai 2003.

CSCJ, arrêt n 155 du 14 février 2002.

CSCJ, arrêt n 406 du 16 mai 2002.

CSCJ, arrêt n 504 du 13 juin 2002.

CSCJ, arrêt n 449 du 13 juin 2002. Inédit.

CSCJ, arrêt n 504 du 13 juin 2002.

CSCJ, arrêt n 507 du 13 juin 2002.

CSCJ, arrêt n 270 du 10 mai 2001.

CSCJ, arrêt nº 52 du 19 déc. 1969, RID 1970 / 3, p. 28.

CAA, arrêt nº 929 du 30 Juillet 2004.

CAA, arrêt n 143 du 28 janvier 2000. 
CAA, arrêt n 595 du 12 mai 2000. Inédit.

CAA, arrêt nº 222 du 29 février 1999.

CAA, arrêt $\mathrm{n}^{\circ} 734 \mathrm{du} 08$ mai 1998. Inédit.

CAA, arrêt nº 1652 du 13 juillet 1990 .

\section{* JURISPRUDENCE FRANÇAISE}

Cass. Com, 3 févr. 1998, arrêt n 353 D, (1999) 34 Dr. europ. transp. 203).

Cass. Com., 24 avril 2007, n 06-12.508, DMF 2007, p. 825.

Cass. Com., 30 juin 2004, $\mathrm{n}^{\circ} 03-10.751$, Lamyline.

Cass. Com., 5 mars 2002, n 99-12.852, BTL 2002, p. 203.

Cass. Com. 17 septembre 2002, n 00-17.228, BTL 2002, p. 623.

Cass. Com., 27 octobre 1998, n 96-15.654, BTL 1998, p. 803.

Cass. Com., 25 mars 1996, n 94-14.627, lamyline ; Cour d'appel de Paris, 23.

Cass. Com. 17 janvier 1995, BTL 1995, p. 384.

Cass. Com., 17 novembre 1992, n 90-22.147, Bull. civ. IV, nº 203.

Cass. Com., 16 avril 1991, ${ }^{\circ}$ 89-17.956/G, BTL 1991, p. 591. Voir aussi Cour.

Cass. Com., 2 oct. 1990, DMF 1994, p. 504 ; BTL 1991, 340.

Cass. Com. 16 novembre 1983 n 79. 17. 031, BT. 1984, p. 385.

Cass. Com., 15 juillet 1987, $\mathrm{n}^{\circ}$ 86-10.409, Lamyline ; Cour d'appel de Paris, 9.

Cass. Com., 27 mars 1973 n $^{\circ} 2272$, BT 1973, p. 240.

Cass. Com., 12 octobre 1964, DMF, 1965 p. 18 ; BT.1965, p. 23.

Cass. Com., 13 juin 1935 n$^{\circ} 93-14861$.

CA Aix-en-Provence, 10 avril 2006, $n^{\circ}$ 206/246, Menorah insurance.

CA. Aix-en-en Provence, 13 avril 2006, nº 04/07013, CMA-c/Malfret, BTL 2006, p. 683.

CA. Paris 27 novembre 2006.

CA. Versailles 8 mars $2005, \mathrm{n}^{\circ} 03 / 02198$.

CA. 15 septembre 2005, $n^{\circ}$ 04/01943, Mutuelles du Mans et a. c/SA octobre 2002.

CA. Aix-en-Provence, 11 mars 2004, n 00/14533, Multiranda Tradingc/CMACGM.

CA. Aix-en-Provence, 6 mai 2004, $\mathrm{n}^{\circ}$ 0+0/19532, AGF et a. c/Cogema.

CA. Rouen, $2^{\text {ème }}$ chambre, 9 septembre 2004, n 02/01434, Hual As c/Axa et a. BTL 2004, p. 669.

CA. Rouen, 9 septembre 2004, $\mathrm{n}^{\circ}$ 02/02601, BTL 2005, p. 251, DMF.

CA. Versailles, 29 avril 2003, $\mathrm{n}^{\circ}$ 2001-644, VG Emballage c/Saga trans,

Lamyline ; 2005, p. 851.

CA. Paris, 6 novembre 2003, Axa et a. c/Golden Union Shipping et.

CA. Aix-en-Provence, 2 décembre 2003, ${ }^{\circ} 00 / 07505$, Navigation et.

CA. Rouen 28 février 2002, CP.SHIPSc/P\&O Nedllod, BTL 2002, p. 356.

CGMc/Gerling et a. BTL 2007, p. 287. 
CA. Paris, 27 novembre 2002, Palimar Shipping et a. c/Gan et a.

CA. Aix-en-Provence, 10 janvier 2001, Picc c/Cosco BTL 2001, p. 129.

CA. Versailles, 20 avril 2000, BTL 2000, p. 425, Lamyline.

CA., Rouen 8 décembre 1998, DMF 2000, p. 126. Groupama Transports Lmyline.

CA. Paris, 27 novembre 1996, Atlantic Container Line c/Réunion européenne, Lamyline. Transport et a. c/Damoskibsselskabet Af 1912 et a.

CA. Paris, 3 mars 1992, BTL 1992, p. 499.

CA. Paris 30 sept. $1992 . n^{\circ}$ 91/815 ;

CA. Aix-en-Provence, 31 octobre 1991, BTL 1992, p. 478.

CA. Aix-en-Provence, 31 mai 1990. BT. 1950, p. 663.

CA. Aix-en-Provence, 27 mai 1988 c/Beldjilali et CNAN, Lamyline.

CA. Rouen, 8 septembre 1988, DMF 1991, p. 360. Lamyline.

CA. Aix-en-Provence, 5 mai 1987, DMF 1988, p. 384.

CA Aix- en Provence, 19 février 1986, Caillaud et Cie et a., c/divers ass., Lamyline.

CA. Aix-en-Provence, 4 février 1982, DMF 1983, p. 531.

CA. Rouen 2 décembre 1982, BT. 1983 p. 210.

CA. Paris, 30 janvier 1979, BTL 1979, p. 172.

CA. Lyon, 11 mai 1978, BT. 1978 p. 317.

CA. Aix-en-Provence, 2 ème ch. 24 février 1994 inédit.

CA Lyon, 11 mai 1978, BT. 1978 p. 317.

Tribunal de commerce de Bordeaux, 18 août 1982, BT. 1982, p. 125.

Tribunal de commerce de Paris, 20 octobre 1977, DMF 1978, p. 352.

\section{* JURISPRUDENCE EUROPEENNE}

Cour de Justice de la Communauté Européenne (CJCE), arrêt du 3 juin 2008, Intertanko.

\section{IX- SITES WEB CONSULTES (décembre 2013 à Avril 2019).}

https://fr.wikipedia.org/wiki/Relations, consulté le 21 octobre 2018. www.ndu.edu/ctnsp/DefTech/DTP9\%20Container\%20 Security.pdf. www.logistiqueconseil. org/articles/transport-routier/type-transportmarchandises.htm.

http://unctad.org/fr/Pages/Statistics.aspx.

http://www.connectionivoirienne.net/82215/la-cote-divoire-face-a-la-piraterie-. http://www.affmar.ci/motdg.php.

http://www.un.org/fr/counterterrorism/legal-instruments.shtml.

https://www.diplomatie.gouv.fr/fr/. 
https://www.interpol.int/fr/crime-areas/trafficking-in-human-beings/.

https://www.universalis.fr/encyclopedie/abolition.

https://treaties.un.org/doc/traeties/1995/08/.

http://www.droit.univ-nantes.fr/labos/cdmo/centre-droit-maritime-

oceanique/cdmo/cdmo/cdmo.php.

https://books.openedition.org/ibeid 2153.

http://www.imf.org/external/np/tre/sdr/drates/0701.htm.

https://africacenter.org/fr/publication/lutte-contre-piraterie-golfe-guinee/.

http://www.grip.org/fr/node778.

http://lewebpedagogique.com/jmthouvenin/.

https://calenda.org/416048.

https://dyabukam.com/index.php/fr/savoir/histoire/item/, vu le 12 octobre 2014.

https://www.lgdj.fr/auteurs/langlais.peter.html.

https://www.adiac-congo.com/content/, consulté en mars 2015.

http://www.grip.org/fr/node778.

https://calenda.org/416048.

www.rta-atn.org, consulté en mai 2005.

http://www.emsa.europa.eu [archive.

https://africacenter.org/wp-content/uploads/2016/06/.

https://www.memoireonline.com/a/fr/cart/add/8554.

http://fr.wikipedia.org. (Vu en ligne le 20 décembre 2013).

https://slifoudabou@fratmat.info.

https://fr.slideshare. Net/rabahparadise2/protection-des marchandises-

transport-maritime.

https://www.connectionivoirienne.net/82215/.

http://www.smallarmssurvey.org/fileadmin/docs/C-Special-reports/SAS-SR14-

CoteIvoire.pdf. 17 mars 2018.

http://www.smallarmssurvey.org/fileadmin/docs/, consulté le 22 mars 2017.

http://www.smallarmssurvey.org/fileadmin/docs/C-Special-reports/SAS-SR14-

CoteIvoire. Consulté le 27 mai 2017.

https://metalaww.lead.org.tn. 


\section{CURRICULUM VITAE}

Yapo Firmin AKA est Juriste à l'Inspection Générale du Ministère de L'Education Nationale, de l'Enseignement technique et de la Formation professionnelle. Enseignant de formation, Yapo Firmin AKA est titulaire du Diplôme d'Etudes Approfondies (DEA), option Droit privé fondamental à l’Université Félix Houphouët Boigny d'Abidjan. 


\section{TABLE DES MATIERES}

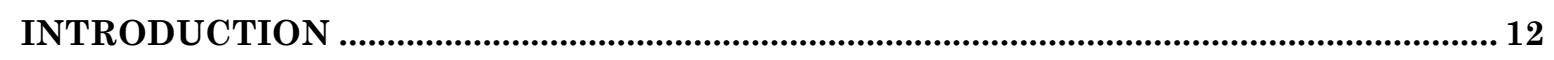

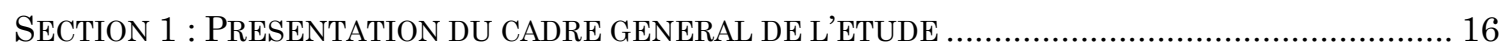

$\S 1$ : EVOLUTION DU TRAFIC DE MARCHANDISES EN COTE D'IVOIRE............................................. 16

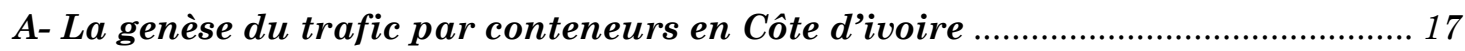

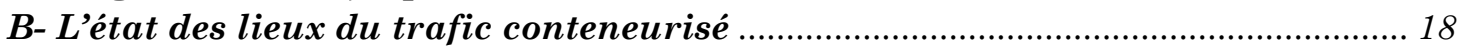

$\S 2$ : ENJEUX DU TRAFIC MARITIME ET APERÇU DE SON CADRE JURIDIQUE .................................. 20

A- Les enjeux socio-économiques du trafic conteneurisé et les problèmes de

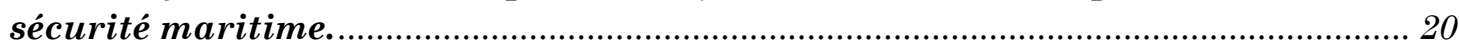

B- Un aperçu du cadre juridique applicable au transport maritime ..................... 22

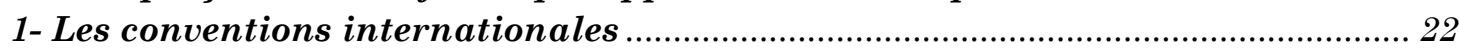

2- Les textes adoptés par le législateur ivoirien ....................................................... 23

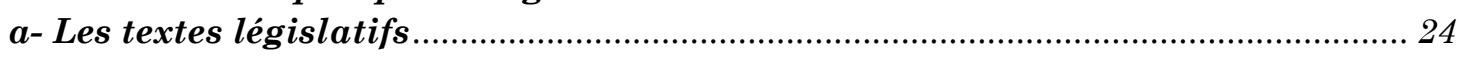

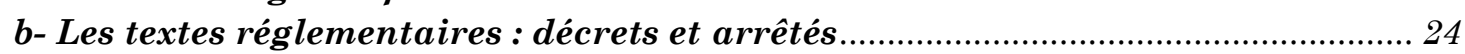

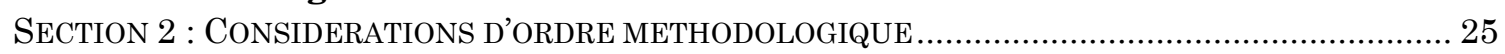

$\S 1$ : Approche définitionnelle des concepts clés du sujet .......................................2.

A- Le transport maritime et le contrat de transport maritime ................................ 26

$B$ - La protection des transports de marchandises : la sécurité et la sûreté

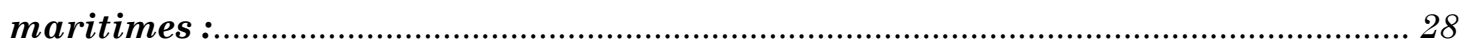

C- Les marchandises concernées par l'étude …….................................................... 29

$\S 2$ : DIFFICULTES DU TRANSPORT DE MARCHANDISES PAR MER ET HYPOTHESE DE TRAVAIL........ 32

A-Problèmes liés au trafic maritime, problème de recherche et intérêt de

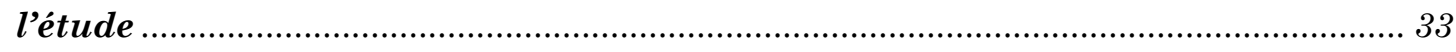

1 - Les problèmes liés au trafic maritime …….......................................................... 33

a- La fourniture du conteneur et sa nature juridique .......................................... 34

b-La vérification des déclarations du chargeur relatives à la marchandise

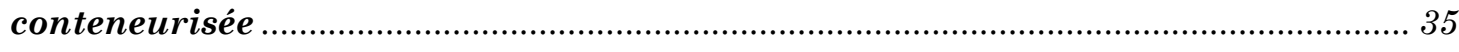

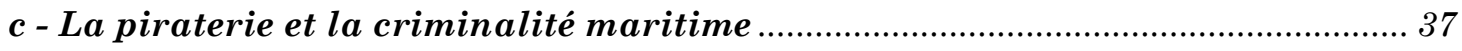

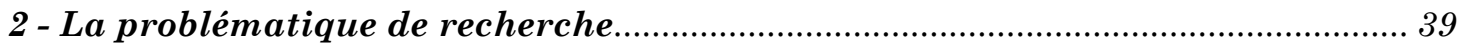

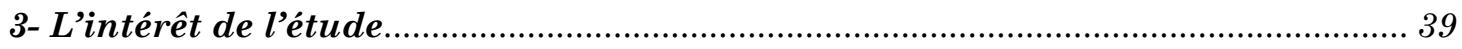

B- Hypothèse de travail, approche méthodologique et annonce du plan ............... 40

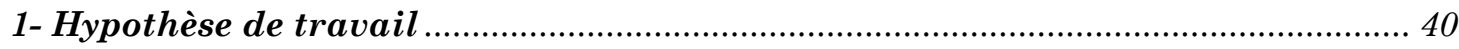

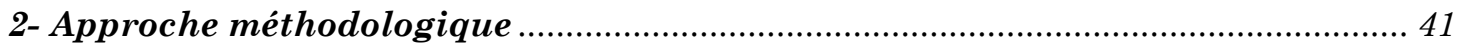

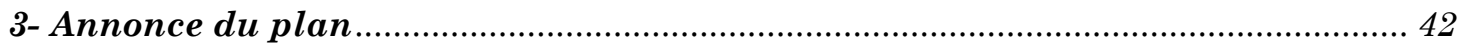

PREMIERE PARTIE : L'EXITENCE D'UNE LEGISLATION CENSEE PROTEGER

LES TRANSPORTS DE MARCHANDISES PAR MER EN DROIT IVOIRIEN ................ 43

TITRE 1 : UN CADRE LEGISLATIF CONSACRE AUX TRANSPORTS DE

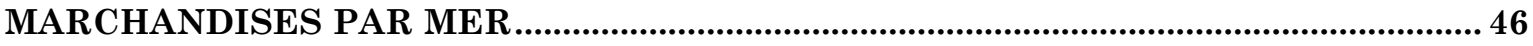

CHAPITRE 1 : LES NORMES INTERNATIONALES ET NATIONALES DE

PROTECTION DE LA MARCHANDISE .............................................................................. 49

SECTION 1 : LA PROTECTION DE LA MARCHANDISE SELON LES NORMES INTERNATIONALES......... 51

$\S 1$ : LES MESURES D'AVANT LA SURVENANCE DES PERILS MARITIMES ......................................52

A- Les normes prévues par la Convention de Montego Bay de 1982 et la

Convention sur les normes de formation du personnel naviguant,

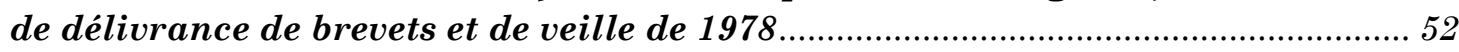

1- Les normes prévues par la Convention de Montego Bay de 1982 ........................ 52 
a- Les normes régissant la compétence de l'Etat côtier ...........................................5 54

b- Les normes régissant l'autorité de l'Etat du pavillon en haute mer .................. 56

2- La Convention sur les normes de formation du personnel naviguant, de délivrance de brevets et de veille STCW de 1978...................................................5

a- Les normes de sécurité prévues par la Convention STCW ..................................5 59

b- Les conditions de délivrance des Brevets aux membres de l'équipage................ 61

B- Les normes prévues par le Code international pour la sûreté des navires et des installations portuaires de 2002 et la Convention internationale sur la sécurité des conteneurs de 1972

1- Les normes prévues par le Code international pour la sûreté des navires et

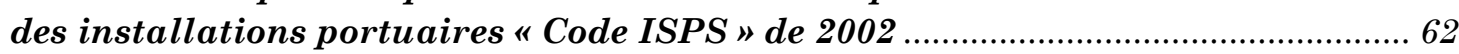

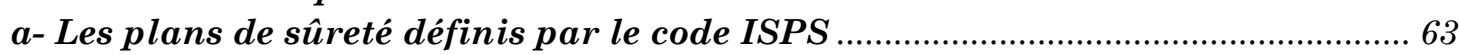

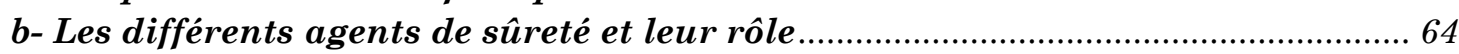

2- La Convention internationale sur la sécurité des conteneurs (CSC) de 1972 ... 65

$\S 2$ : LES SOLUTIONS SUITE A LA SURVENANCE DES PERILS MARITIMES ....................................... 67

A- Les normes prévues par la Convention de Bruxelles de 1924 et ses

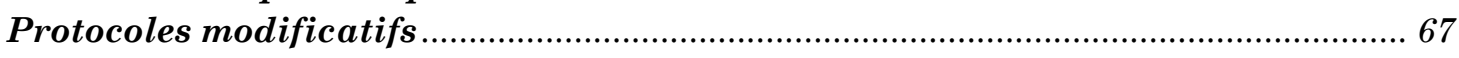

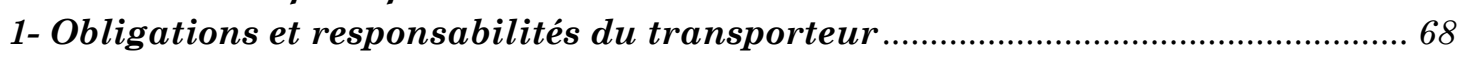

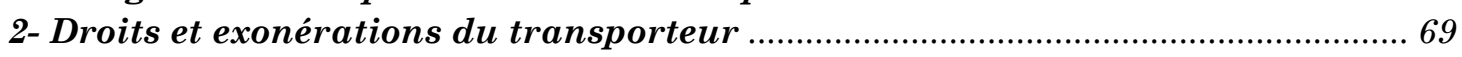

B- Les normes prescrites par les Règles de Hambourg de 1978 ............................... 72

1- La durée de la responsabilité du transporteur .................................................... 73

2- Le fondement de la responsabilité du transporteur............................................... 74

C- Les normes prévues par la Convention de Rotterdam de 2009 ........................... 75

1- Durée de la responsabilité du transporteur maritime ....................................... 76

2- Obligations et contenu de la responsabilité du transporteur.............................. 76

SECTION 2 : LA PROTECTION DE LA MARCHANDISE SELON LES NORMES MARITIMES

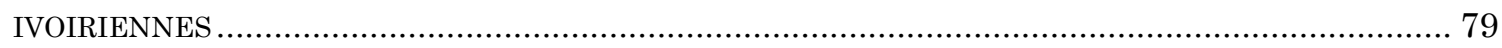

$\S 1$ : LES NORMES DE PREVENTION ET DE REPARATION DES DOMMAGES A LA MARCHANDISE....... 79

A- La prévention des dommages dans les ports ivoiriens ...................................... 79

1- Les normes prévues par le décret de 1999 portant règlement de police du

Port autonome d'Abidjan .......................................................................................... 79

2- Les normes prévues par l'arrêté $n^{\circ} 0082$ du 05 mai 1999 portant règlement

d'exploitation du port autonome d'Abidjan ............................................................... 81

3- La prévention des dommages au Port autonome de San Pedro.......................... 81

$B$ - Les normes prévues en cas de dommages à la marchandise ...............................8 81

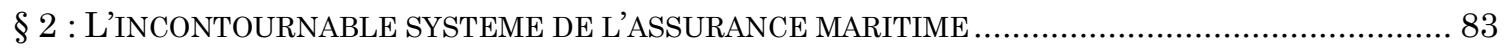

A- Domaine d'application et étendue de l'assurance sur facultés .......................... 85

1- Le domaine d'application de l'assurance sur facultés ........................................ 85

2- L'étendue de l'assurance sur facultés.................................................................... 86

B- Les caractéristiques de l'assurance sur facultés................................................. 87

1- Temps et lieu de la couverture d'assurance ........................................................ 87

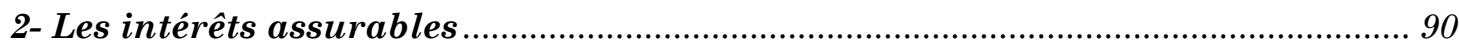

CHAPITRE 2 : LES NORMES LEGISLATIVES DE LUTTE CONTRE LES

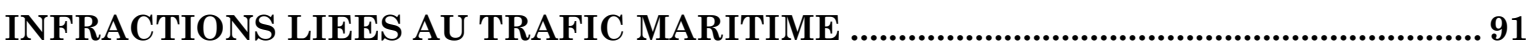

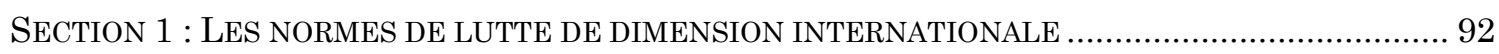

$\S 1$ : LA LUTTE CONTRE LES TRAFICS DE DROGUES ET LES TRAFICS D'ARMES ................................. 92

A- Les normes de la Convention des Nations Unies contre le trafic illicite de

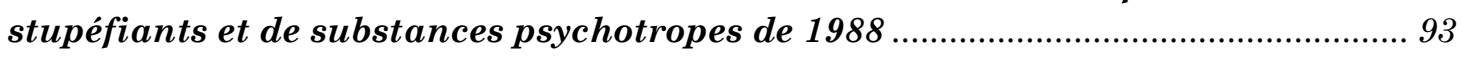

1- L'infraction et la compétence juridictionnelle ........................................................ 94

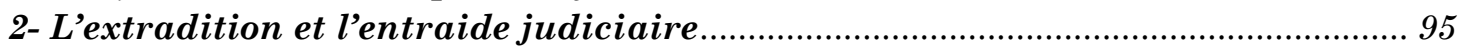

$B$ - Les normes prévues par le traité des Nations Unies sur le commerce des

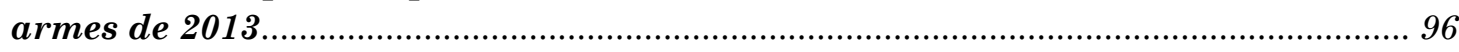

1- Le contexte de la lutte contre le trafic illicite d'armes......................................... 96 
2- Les normes juridiques de lutte contre le trafic illicite d'armes

$\S 2$ : LA LUTTE CONTRE LE TRANSPORT DES POLLUANTS, DE MARCHANDISES ET DE DECHETS

DANGEREUX ET LE TRAFIC D'ETRES HUMAINS.

A- Les normes prévues par la Convention MARPOL $73 / 78$ et les conventions

relatives à la conservation et à la gestion des stocks de poissons........................ 100

1- Les normes de la Convention MARPOL 73/78 pour la prévention de la

pollution par les navires ................................................................................................ 101

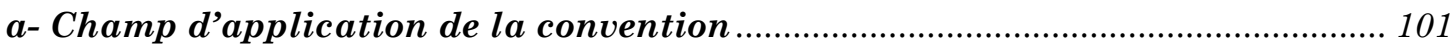

b-Inspections des navires, délivrance de certificats et apposition de visas ........ 102

c- Dispositions de lutte contre la pollution par hydrocarbures............................ 103

2- Les normes des Convention relatives à la conservation et à la gestion des

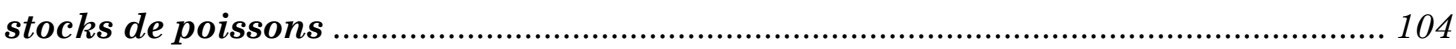

a-L'Accord des Nations Unies sur la conservation et la gestion des stocks de

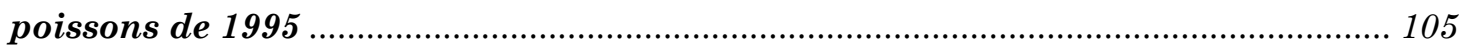

1)- Obligations et pouvoirs de police de l'Etat du pavillon ..................................... 105

2)- Les pouvoirs de police des Etats autres que celui du pavillon .......................... 106

b- Convention relative à la conservation et à la gestion des stocks de

poissons grands migrateurs dans le Pacifique occidental et central .................. 106

$B$ - Les normes de la Convention de Bâle sur les mouvements transfrontières

des déchets dangereux de 1989 et la Convention de Bamako de 1991 .................. 108

1- Les obligations générales des parties .............................................................. 109

2- Les mouvements transfrontières de déchets dangereux et d'autres déchets

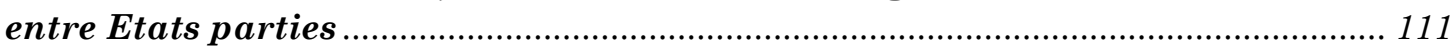

C-La lutte contre le trafic des êtres humains : le Protocole contre le trafic

illicite de migrants par terre, mer et air............................................................. 111

$\S 3$ : LA LUTTE CONTRE LA CRIMINALITE MARITIME ET LA PIRATERIE EN MER........................... 115

A- Les Conventions destinées à lutter contre la criminalité maritime.................. 116

1- La Convention des Nations Unies contre la criminalité transnationale

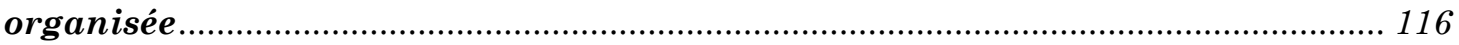

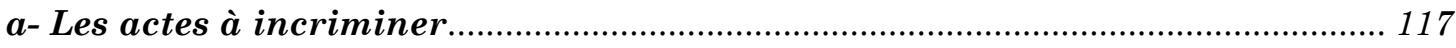

b- La répression : l'entraide judiciaire et l'extradition des suspects.................... 118

2- Le Protocole pour la répression d'actes illicites contre la sécurité des

plates-formes fixes situées sur le plateau continental ............................................ 119

B-Les normes issues de la Partie VII de la Convention de Montego Bay

(CMB) relative à la haute mer : la lutte contre la piraterie ................................... 121

SECTION 2 : LA PREVENTION ET LA REPRESSION DES INFRACTIONS A L'ECHELLE NATIONALE

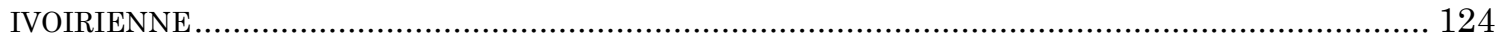

$\S 1$ : LA LUTTE CONTRE LA CRIMINALITE LIEE AU TRANSPORT MARITIME .................................. 124

A- Les normes issues du Code Pénal ivoirien …….............................................. 125

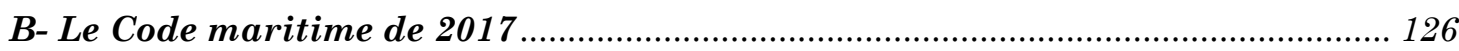

$\S 2$ : LA PROTECTION DE L'ENVIRONNEMENT MARIN : LES NORMES DE LA LOI N ${ }^{\circ}$ 96-766 DU 3

OCTOBRE 1996 PORTANT CODE DE L'ENVIRONNEMENT. ......................................................... 126

A- Les normes de prévention de la pollution de l'environnement marin .............. 127

B- Les normes de répression de la pollution de l'environnement marin............... 129

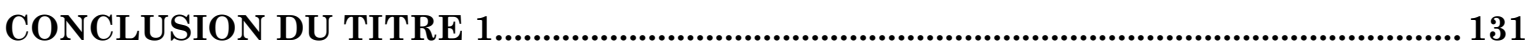

TITRE 2 : UNE ANALYSE CRITIQUE DU CADRE LEGISLATIF DES

TRANSPORTS DE MARCHANDISES PAR MER

CHAPITRE 1 : LES APPROXIMATIONS DES NORMES DE PROTECTION DE LA MARCHANDISE : GENESE ET LIMITES

SECTION 1 : LA GENESE DES REGLES DE PROTECTION DE LA MARCHANDISE EN DROIT IVOIRIEN 
$\S 1$ : L’ADMISSION DE LA CLAUSE DE PRISE EN CHARGE SOUS PALAN ANTERIEUREMENT AU CODE MARITIME.

A- La responsabilité de " palan à palan" du transporteur maritime ................... 139

B- La liberté contractuelle régissant les phases pré et post maritimes ............... 140

$\S 2$ : LA REGLE DE LA PRISE EN CHARGE DE LA MARCHANDISE PREVUE PAR LE CODE MARITIME

A- La responsabilité présumée du transporteur maritime.

1- La signification du principe de la responsabilité présumée du transporteur 145

2- La portée du principe de la responsabilité de plein droit .............................. 146

B- La durée de la présomption de la responsabilité du transporteur................. 147

SECTION 2 : LES LIMITES DECOULANT DES CONDITIONS D’APPLICATION DES NORMES DE REPARATION DES DOMMAGES.

$\S 1$ : LA LIMITATION DE LA RESPONSABILITE ET LES CONDITIONS DEFAVORABLES DE SA MISE

EN EUURE AU COURS DES PROCES

A- Le plafonnement de la responsabilité, défavorable à une réparation entière du préjudice

1- Le plafonnement de la responsabilité, signification du principe et perte du bénéfice ............................................................................................................. 151

a- La signification du principe du plafonnement de la responsabilité ............... 151

b- La perte du bénéfice du plafonnement de la responsabilité ........................... 154

2- Le plafonnement modéré de la responsabilité, une limite à la réparation complète $d u$ préjudice.............................................................................................. 155

B- La réclamation et l'action en responsabilité des dommages............................ 156

1- La réclamation de l'ayant droit à la marchandise .......................................... 157

2- Les règles relatives à l'action en responsabilité contre le transporteur.......... 159

$\S 2$ : LES CAS EXCEPTES JUSTIFIES, UN OBSTACLE A LA REPARATION DES DOMMAGES ............... 161

A- L'effet principal du cas excepté, l'exonération de la responsabilité du transporteur...

$B$ - Les cas exceptés, facteur d'incertitude de la réparation des dommages subis par la marchandise.

CHAPITRE 2 : LES INSUFFISANCES DE LA LUTTE CONTRE L'INSECURITE AU REGARD DE LA PERSISTANCE DES INFRACTIONS MARITIMES

SECTION 1 : LA PROBLEMATIQUE LIEE AUX INSTRUMENTS DE PREVENTION ET DE LUTTE CONTRE LES INFRACTIONS MARITIMES

$\S 1$ : CAS DES NORMES RELATIVES A LA SECURITE MARITIME A L'ECHELLE INTERNATIONALE.... 168

A-Méconnaissance des instruments juridiques internationaux faute de leur ratification en droit ivoirien.....

B-Mise en ouvre défaillante des normes internationales relatives à la répression des actes illicites.

$\S 2$ : CAS DES NORMES DE DIMENSION NATIONALE IVOIRIENNE RELATIVES A LA SECURITE MARITIME.

A- Les lacunes constatées dans la législation du transport avant le Code maritime

B- Des solutions décelables dans le Code maritime ivoirien de 2017.................. 174

SECTION 2 : CONSTAT DE L'INEFFICACITE DES NORMES NATIONALES ET SOUS REGIONALES DE LUTTE CONTRE LES INFRACTIONS MARITIMES .................................................... 177

$\S 1$ : CAS DES REGLES NATIONALES IVOIRIENNES RELATIVES A LA REPRESSION DES

INFRACTIONS MARITIMES...................................................................................... 177

A- Une application non effective des instruments internationaux...................... 178

B- Une inefficacité liée au sous équipement en matériels de surveillance maritime et de garde-côte .................................................................................... 180

$\S 2$ : CAS DES NORMES A CARACTERE SOUS REGIONAL ......................................................... 181

A- Les limites liées à la lutte opérationnelles de l'OMAOC. 182 
1- L'insuffisance des moyens d'actions de l'OMAOC

2- Les objectifs assignés à l'OMAOC

$B$ - Droit du pavillon et compétence universelle, face à la répression de la piraterie

1- Le principe de la compétence universelle en matière de piraterie

2- Compétence universelle et droit du pavillon : promotion et frein à la poursuite des pirates.

DEUXIEME PARTIE : LES PERSPECTIVES D'UNE AMELIORATION DE LA LEGISLATION EXISTANTE EN VUE DE SON EFFICACITE.

TITRE 1 : L'ANALYSE DU CADRE LEGISLATIF DES TRANSPORTS DE MARCHANDISES PAR MER EN DROIT COMPARE

CHAPITRE 1 : L'ANALYSE DES NORMES DE PROTECTION DE LA MARCHANDISE EN DROITS NATIONAUX ETRANGERS.

SECTION 1 : LES NORMES REGISSANT LA RESPONSABILITE DU TRANSPORTEUR MARITIME EN

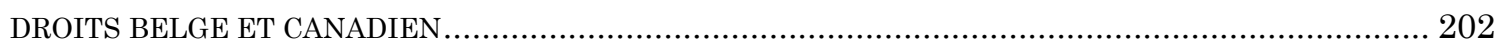
$\S 1$ : LE REGIME DE RESPONSABILITE APPLIQUE AU TRANSPORTEUR MARITIME EN DROIT

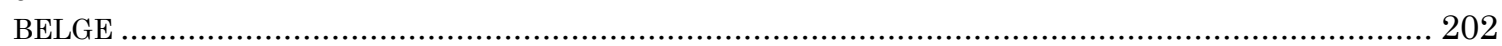

A- Le principe de responsabilité du transporteur maritime .................................. 203

B- La responsabilité du transporteur sur les phases non maritimes .................... 204

$\S 2$ : LE REGIME DE RESPONSABILITE APPLIQUE AU TRANSPORTEUR MARITIME EN DROIT

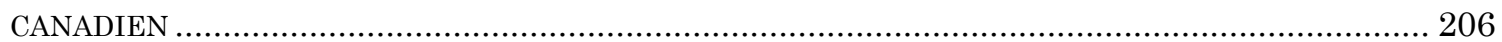

A- Le principe de la responsabilité du transporteur maritime............................. 206

$B$ - La responsabilité du transporteur avant le chargement et après le déchargement.

SECTION 2 : LES NORMES REGISSANT LA RESPONSABILITE DU TRANSPORTEUR MARITIME EN

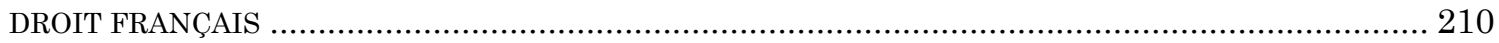

§ 1- LE PRINCIPE DE LA PRESOMPTION DE RESPONSABILITE DU TRANSPORTEUR ........................ 211

A- Le contenu du principe de la présomption de responsabilité.............................. 211

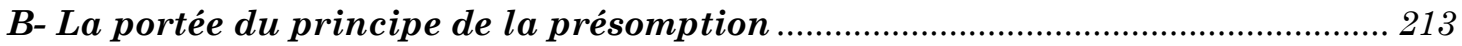

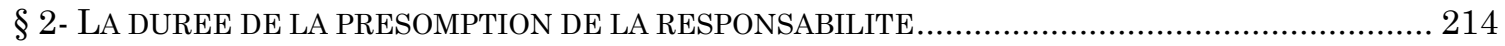

A- La présomption de responsabilité "de palan à palan" prévue par la

Convention de Bruxelles.

$B$ - La présomption de responsabilité "de la prise en charge à la livraison" prévue par la loi française de 1966

CHAPITRE 2 : L'ANALYSE DES NORMES DE LUTTE CONTRE L'INSECURITE MARITIME EN DROIT EUROPEEN

SECTION 1 : L'ADOPTION D'INSTRUMENTS REGIONAUX DE LUTTE CONTRE LES TRAFICS ET

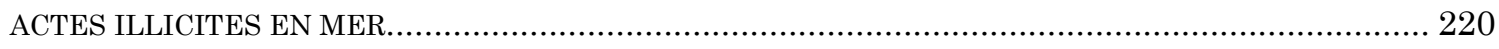

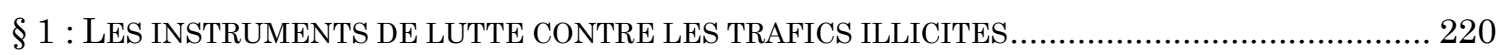

A- L'Accord de l'Union Européenne relatif aux trafics illicites par mer............... 221 $B$ - Le Règlement (CE) $n^{\circ}$ 1005/2008 du Conseil sur la pêche illicite, non

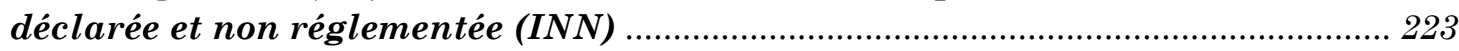

$\S 2$ : LES INSTRUMENTS DE LUTTE CONTRE LA CRIMINALITE ET LA PIRATERIE EN MER ................225 A- Au niveau de l'amélioration de la sûreté des navires et des installations portuaires

B- Au niveau de la lutte contre les actes illicites au large des côtes de la Somalie. 
SECTION 2 : DES EXEMPLES DE COOPERATION REGIONALE EN MATIERE DE LUTTE CONTRE

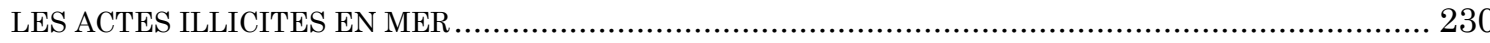

$\S 1$ : LA COOPERATION EN MATIERE DE LUTTE OPERATIONNELLE ............................................... 230

A- Cas de l'Agence européenne pour la sécurité maritime .................................... 231

B- Cas du Règlement 1625 de l'Union Européenne du 24 septembre 2016 ............ 232

$\S 2$ : LA COOPERATION EN MATIERE DE LUTTE REPRESSIVE CONTRE LA CRIMINALITE

MARITIME

A- L'observation d'une assistance mutuelle relative aux enquêtes, poursuites

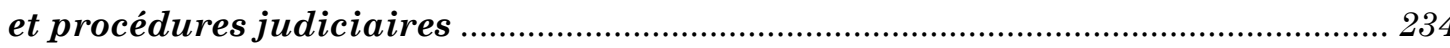

B- L'établissement de point focal dans chaque Etat pour émissions et

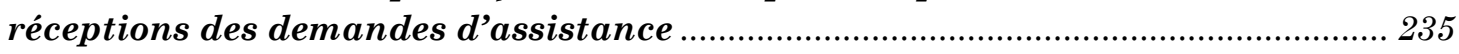

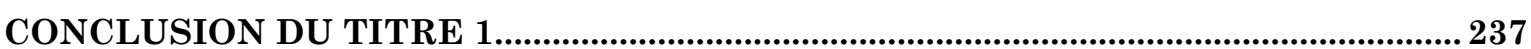

TITRE 2 :L'AMELIORATION DES NORMES DE PROTECTION DE LA

MARCHANDISE ET DE LUTTE CONTRE L'INSECURITE MARITIME A LA

LUMIERE DU DROIT ETRANGER

CHAPITRE 1 : L'AMELIORATION DES NORMES POUR LA PROTECTION DE LA MARCHANDISE ET LA SECURITE DE LA NAVIGATION MARITIME.

SECTION 1 : LA QUETE DES NORMES RELATIVES A L'AMELIORATION DE LA PROTECTION DE LA MARCHANDISE

$\S 1$ : POSSIBLE AMELIORATION DE LA PROTECTION DE LA MARCHANDISE PAR APPLICATION DE LA CONVENTION DE ROTTERDAM EN DROIT IVOIRIEN ...

A- Les avancées des dispositions de la Convention de Rotterdam.

1- Une prise en compte des opérations pré et post maritimes du transport et du retard de livraison.

2- Une extension de la durée de responsabilité du transporteur maritime.......... 245

B- Les Règles de Rotterdam, une Convention non ratifiée par la Côte d'Ivoire .. 246

$\S 2$ : DE LA PROTECTION CONVENTIONNELLE A LA PROTECTION LEGALE DE LA MARCHANDISE TRANSPORTEE

A-Aperçu des difficultés quant-à la protection de la marchandise avant

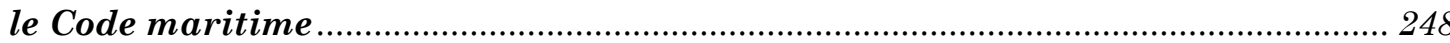

B- Les solutions issues de la réforme du Code maritime de 2017........................ 251

SECTION 2 : L'AMELIORATION DES NORMES DE SECURITE ET DE SURETE MARITIMES EN D

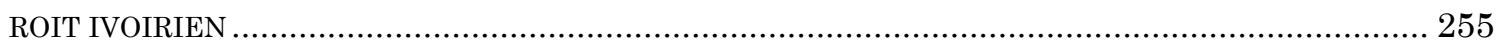

$\S 1$ : SELON LES REFORMES DECOULANT DU CODE MARITIME ................................................... 255

A- Les dispositions pertinentes du Code maritime relatives à la répression des atteintes à la sûreté de la navigation maritime............................................... 256

1- L'incrimination des actes de piraterie et de trafics illicites en mer par le

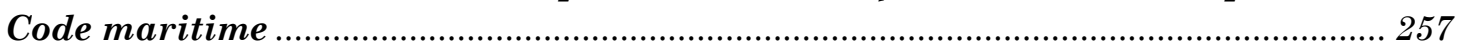

2- L'incrimination des actes de pollution maritime par la nouvelle

législation.

B-Les dispositions de lutte contre l'insécurité de la navigation maritime et le droit international

$\S 2$ : LA NECESSAIRE EXTENSION DE LA LUTTE CONTRE L'INSECURITE MARITIME AU PLAN SOUS REGIONAL

A- La nécessaire conclusion d'un Accord de lutte contre l'insécurité maritime

B-L'application de l'Accord de lutte contre l'insécurité maritime dans les législations nationales

CHAPITRE 2 : LE RENFORCEMENT DE LA LUTTE CONTRE L'INSECURITE ET DES RECOMMANDATIONS POUR SON AMELIORATION DANS LE GOLFE DE GUINEE. 
SECTION 1 : LA QUETE DE STRATEGIE DE LUTTE CONTRE L'INSECURITE DANS LE GOLFE DE GUINEE

$\S 1$ : LA COLLABORATION ENTRE LES STRUCTURES SOUS REGIONALES ET LES ORGANES

NATIONAUX DE LUTTE CONTRE L'INSECURITE MARITIME.

A- La restructuration de la coopération entre les Etats riverains du golfe de

Guinée

$B$ - Les opérations conjointes structurelles de redynamisation

$\S 2$ : DES RECOMMANDATIONS POUR UNE REPRESSION EFFICACE DES AUTEURS

D'INFRACTIONS MARITIMES A L'ECHELLE SOUS REGIONALE

A- Une uniformisation des peines, des procédures de poursuite, de

conservation et de transmission des preuves des actes illicites

B- Une simplification de la procédure d'extradition des présumés pirates dans les Etats riverains du golfe de Guinée

SECTION 2 : DES RECOMMANDATIONS EN VUE DE L'AMELIORATION DE LA LUTTE CONTRE

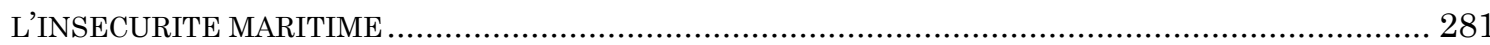

$\S 1$ : LE SUIVI DE L’APPLICATION DES INSTRUMENTS DE LUTTE CONTRE L’INSECURITE

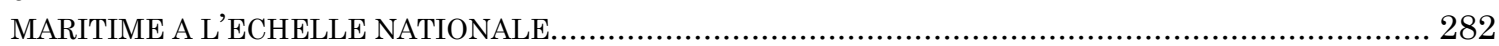

A- Un suivi de la lutte contre l'insécurité par la Direction générale des affaires maritimes et portuaires (DGAMP)

1- Mise en place d'une Coordination nationale de suivi de la législation de

lutte contre l'insécurité maritime

2- Coopération entre la Coordination nationale de suivi de la législation maritime et le CRESMAO

B- Un suivi de la lutte contre l'insécurité maritime par les organes

de répression

1- De l'opportunité ou non d'une juridiction spéciale pour connâ̂tre des

infractions maritimes en haute mer.

2- La coopération entre les tribunaux, la DGAMP et le CRESMAO pour

le suivi de la répression des actes illicites en mer

$\S 2$ : L'IMPLICATION NECESSAIRE DE CHAQUE ETAT RIVERAIN DU GOLFE DE GUINEE DANS

LA LUTTE CONTRE L'INSECURITE MARITIME 289

A- Les spécificités de la piraterie et de la criminalité maritimes dans le golfe de Guinée 289

B-Les instruments de lutte à adapter aux spécificités de la piraterie dans le golfe de Guinée

1- L'implication des organes des Nations Unies dans la recherche de solutions

2- Des mesures de lutte contre l'insécurité dans le golfe de Guinée, prises sous l'égide des Nations Unies et contraignantes pour les Etats riverains

CONCLUSION DU TITRE 2

CONCLUSION GENERALE.

RESUME .

SUMMARY

IMPACT DE LA THESE.

LISTE DES ANNEXES 308

INDICATION BIBLIOGRAPHIQUE 